3.1.

2.1.

in

(a)

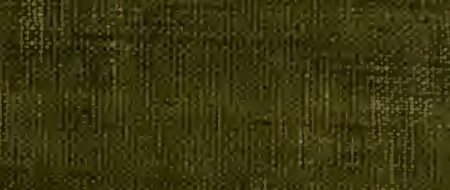

(5)

ofing

4.
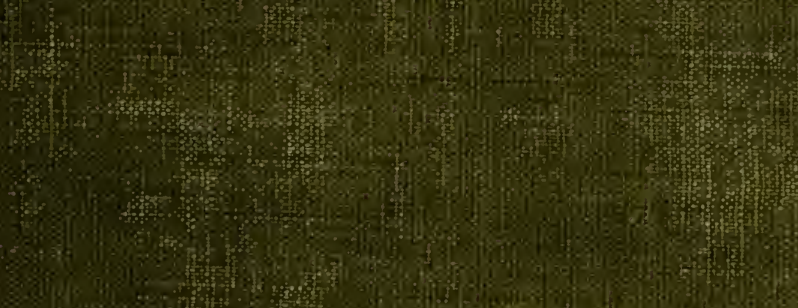

影
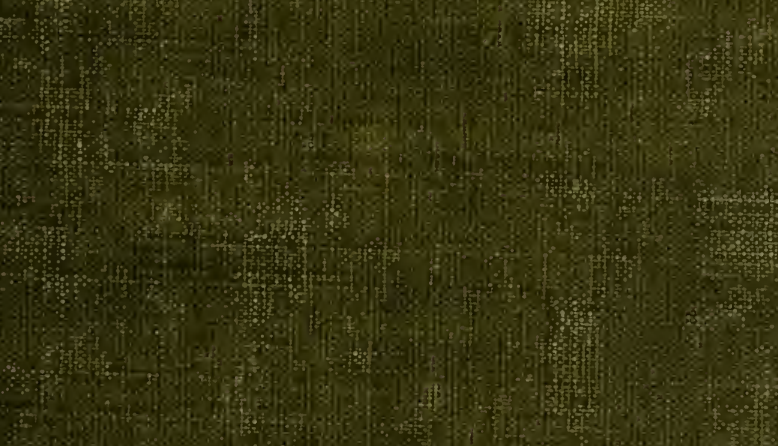

खा
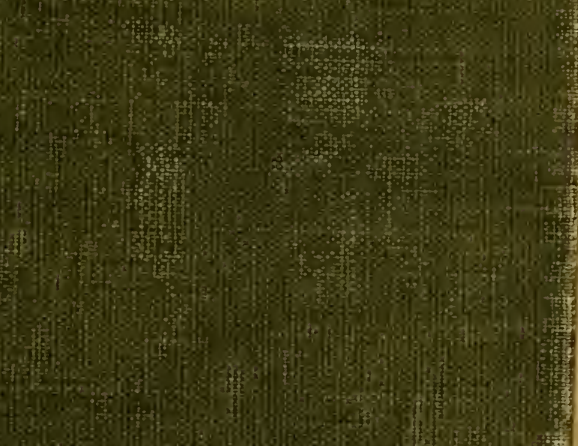

(x)

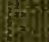

(3) 
Botannsib.

Illirillisthy

\section{doiltiaty at}

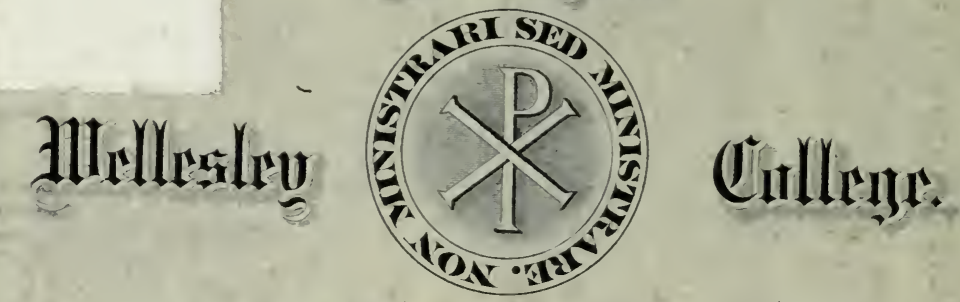

Hurliast from

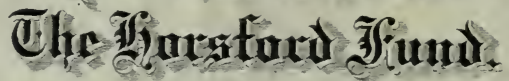

N! 68987 


\section{-}


Digitized by the Internet Archive in 2014 




\title{
LIGHT AND THE BEHAVIOR OF ORGANISMS
}

\author{
BY \\ S. O. MAST, Ph.D. \\ ASSOCIATB PROFESSOR OF BIOLOGY, GOUCHER COLLEGE, \\ JOHNSTON RESEARCH SCHOLAR, JOHNS \\ HOPKINS UNIVERSITY (1907-1908)
}

FIRST EDITION

FIRST THOUSAND

NEW YORK

JOHN WILEY \& SONS

LoNdoN: CHAPMAN \& HALL, Limited

I9I I 
Copyright, I9Io

BY

S. O. MAST

\section{7}

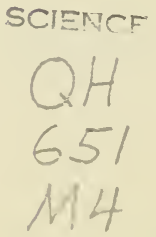

Stanbope Press

F. H. GILSON COMPANY BOSTON. U.SA 


\section{PREFACE}

PARTs I and II of this volume consist of an essay for which the Cartwright Prize was awarded by the College of Physicians and Surgeons of Columbia University in 1909. The entire volume is the outgrowth of an intensive and extensive study of the processes of orientation in plants and animals, especially those without eyes, i.e., a study of the perplexing and interesting question as to how these organisms regulate their activities so as to bend or move toward or from the source of stimulation. But while the book deals primarily with the question of orientation, it has a broader aspect and may be considered a treatise on the behavior of organisms based on their reactions to light. The generality of the treatment of the subject of actions in organisms, including plants as well as animals, it is hoped will make the work of value to all students of nature, especially to those interested in comparative psychology, zoology, botany and physiology.

Throughout the work it has been my aim first of all to state precisely what organisms do under different conditions of illumination, and then to consider the bearing of the observed reactions on the various theories that have been formulated regarding reactions in general. This aim has made it necessary to present somewhat lengthy and detailed descriptions of methods of stimulation and responses which, it is feared, may be rather tedious to those who are interested only in the general aspect of the problem. To such it will be of particular advantage to consult freely the table of contents and the summaries.

The historical chapters which are found in Part I deal with the origin and development of theories regarding the activities of organisms, especially those associated with light. No attempt has been made in these chapters to 
review all the literature on behavior. Only such works are here referred to as appear to have a theoretical bearing, but many others are considered elsewhere.

Part II is devoted largely to the description and discussion of experimental observations on orientation made by the author during the past five years. Only a few of these have been previously published. The remaining parts of the book are more general and contain relatively much less original matter.

A large part of the experimental work connected with this volume was done at Johns Hopkins University during my residence as Johnston Research Scholar. To this institution I am greatly indebted, not only for the scholarship, but also for exceptional facilities placed at my command by the late Professor W. K. Brooks, Director of the Zoological Laboratory during my residence, and for friendly courtesies extended on every hand by other members of the University. I am also under obligation to the Marine Biological Laboratory of Woods Hole, Massachusetts, for research facilities during the summer of 1907 , and to the United States Bureau of Fisheries for similar privileges during the following two summers, and especially to the Director of the Laboratory of the Bureau of Fisheries at Woods Hole, Massachusetts, Doctor F. B. Sumner, for generously supplying my needs. It is a pleasure to acknowledge my further indebtedness to Professor H. S. Jennings for his enthusiastic interest and support in the work at all times and for critically reading the manuscript; to Professors G. H. Parker and J. B. Watson for valuable suggestions after reading much of the work in manuscript; to Professor R. M. Yerkes for his thorough criticism regarding both composition and contents; and to my wife, Grace Tennent Mast, for invaluable literary aid and criticism. The author however must be held responsible for all of the subject-matter:

Baltimore, Maryland,

Samuel Ottmar Mast.

February 4, 1910. 


\title{
TABLE OF CONTENTŚ
}

\author{
PART I \\ INTRODUCTION AND HISTORICAL REVIEW \\ CHAPTER I \\ General Introduction
}

CHAPTER II

Historical Review Concerning the Origli and Development of Ideas and Theories Regarding Movements in Plants and ANimals with Special Reference to the Question of Tropisms

I. Early Investigations and Ideas concerning Movement in OrPAGE ganisms............................. 5

2. First Attempts at Mechanical Explanation of Life Phenomena — Galen, Harvey, Descartes, Borelli, Ray. . . . . . . . . . 6

3. Period of Vitalism........................ 8

4. Return to Mechanical Explanations - Johannes Müller, De

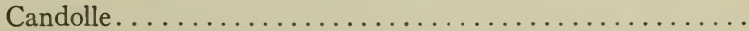

5. Evolution and its Effect on the Study of Behavior in Plants and Animals - Darwin, Bert, Graber, Romanes, Lubbock,

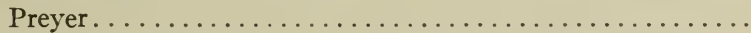

6. Introduction of the Term "Tropism" and Development of its Application to Difierent Reactions - De Candolle, Knight,

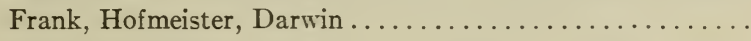

7. Further Analysis of Reactions in Plants to Light - Sachs, Strasburger, Engelmann, Darwin................... 8

\section{CHAPTER III}

Historical Review Concerning the Origin and Development of Ideas and Theories Regarding Movements in Playts and Antmals with Special Reference to the Question of Tropisus (continued)

I. The Application of the Underlying Principle of Tropisms in the Study of Animal Behavior as opposed to this Study from the Point of View of Comparative Psychology - Loeb, Verworn, Davenport, Rádl and Others................ 
2. More Thorough Experimental Analysis showing the Relative PAGE Importance of Internal and External Factors in Behavior Jennings, Holmes and Others............... 44

3. Summary of Historical Review. ............... 5 I

4. Various Definitions of Tropisms................ 53

5. Statement of Important Problems in the Study of Reactions

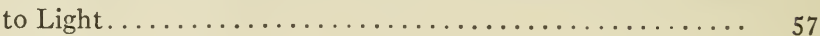

\section{PART II}

EXPERIMENTAL OBSERVATIONS AND DISCUSSIONS BEARING ON THE QUESTION AS TO HOW ORGANISMS (ESPECIALLY THOSE WITHOUT EYES) BEND OR TURN AND MOVE TOWARD OR FROM A SOURCE OF STIMULATION

\section{CHAPTER IV}

Processes Involved in the Bending of Different Parts of Higher Plants toward the Source of Light

I. Observations on Plumules of Indian Corn (Zea mays) and

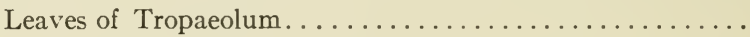

$a$. Introduction; $b$. Apparatus; $c$. Experiments; $d$. Re59 sults; e. Discussion.

\section{CHAPTER V}

Observations on Unicellular Forms in the Process of Attaining and Retainixg a Definite Axial Position with Reference to the SOURCE OF LIGHT

I. Myxomycetes and Rhizopods................. 74

2. Euglena ............................. 80

$a$. Description; b. Historical account; $c$. Orientation in light from two sources; $d$. Material; $e$. Method of locomotion; $f$. Accuracy of orientation; $g$. Mechanics of orientation in Euglena $x$ in the crawling state; $h$. Discussion; $i$. Orientation of Euglena in the swimming state; $j$. Threshold or sensitiveness when different surfaces are exposed to light; $k$. Function of the eye-spot.

3. Summary ........................ II 


\section{CHAPTER VI}

Observations on Unicellular foris in the Process of Attaintng and Retaining a Definite Axial Position with Reference to THE SOURCE OF LIGHT (continued)

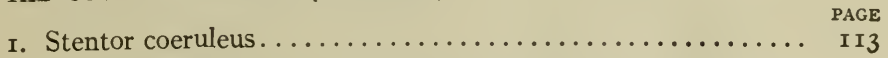

$a$. Introduction; $b$. Orienting reactions; $c$. Difference in sensitiveness with different surfaces illuminated; $d$. Localized stimulation; e. Summary.

2. Oed.gonium Swarm-spores.....................

$a$. Description; b. Material; c. Locomotion; $d$. Orientation in light.

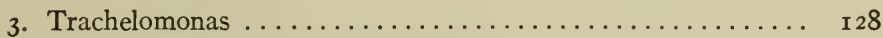

4. Chlamydomonas alboviridis (Stein) .............. I3I

5. Chlorogonium............................ ${ }_{334}$

6. Paramecium............................ I34

CHAPTER VII

The Factors Involved in the Process of Orientation in Colonal FORUS

I. Volvox globator and minor................... I36

2. Pandorina and Eudorina ...................... I46

a. Function of the eye-spots.

\section{CHAPTER VIII}

Observations on the Responses Involved in the Regulation of Movement toward the Source of Light in Coelenterates

I. Hydra viridis $\ldots \ldots \ldots \ldots \ldots \ldots \ldots \ldots \ldots \ldots \ldots \ldots \ldots \ldots \ldots \ldots \ldots$

$a$. Historical review; $b$. Effect of light intensity on activity; $c$. Orientation and locomotion; $d$. Reactions of negative specimens; $e$. General conclusions.

2. Eudendrium Planulae....................... I59

3. Eudendrium Hydranths. .................... I6

4. Reactions of Medusae...................... 164

\section{CHAPTER IX}

Regulation in the Direction of Movement with Reference to the Source of Light in Veries, Fly Larvae, and Echinoderus

I. Arenicola cristata - Larvae.................. I66

$a$. Description; b. Locomotion; $c$. Orientation; $d$. Mechanics of orientation; $e$. Discussion; $f$. Orienting stimulation; g. Summary. 
2. Blowfly Larvae - Musca sp. (?)

a. Introduction; $b$. Locomotion; $c$. Accuracy of orientation; $d$. Orientation in light from two sources; $e$. Orientation and movement - ( I) perpendicular to the direction of the rays - (2) toward a source of light; $f$. Sensitive region; g. Effect of light intensity on rate of locomotion; $h$. Method; $i$. Mechanics of orientation; $j$. Discussion; $k$. Summary.

3. Earthworms.......................... I98

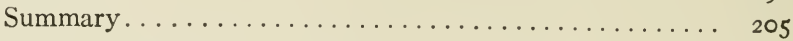

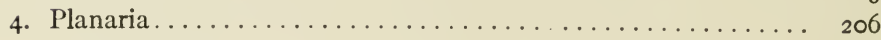

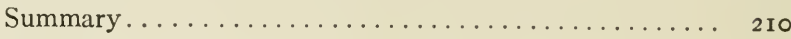

5. Echinoderms.......................... 2 II

\section{CHAPTER $\mathrm{X}$}

Concerning the Question of Orientation in Mollusks, Arthropods and Vertebrates, with Special Reference to Circus Movements AND THEIR BEARING ON THIS QUESTION

I. General Account of Orientation . . . . . . . . . . . . 2 I4

2. Circus Movements .................... 215

3. Frogs and Toads.................... 218

A. Bufo americanus.

$a$. Method; $b$. Orientation in light from two sources;

c. Orientation with one eye destroyed.

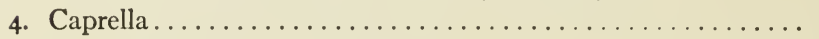

$a$. Orientation; $b$. Discussion.

5. General Summary and Conclusions of Part II ......... 228

\section{PART III}

GENERAL CONSIDERATION OF REACTIONS TO LIGHT

\section{CHAPTER XI}

Adaptation, Formation of Aggregations in Regions of a Given Light Intensity and Different Methods of Response in Attaining THIS REgion AND ReMaINING in IT.

I. Introduction showing that Reactions in general are Adaptive. 236

2. Different Reactions observed in the Process of Collecting in Regions having a given Condition of Illumination......... 
$a$. Random movements and avoiding reactions; $b$. OrientaPAGE tion, change in sense of orientation, and avoiding reactions; $c$. Orientation and extent of movement limited by environment; $d$. Orientation and movement directly toward the place where the organism comes to rest; $e$. Random movements and coming to rest in a given place.

\section{CHAPTER XII}

REACTIONS TO LIGHT WHICH DO NOT RESULT IN AggREgATION OR ORIENTATion

I. Reactions to Shadows - Protective.............. 247

2. Reactions to Shadows - Procuring Food............ 249

3. Reactions to Sudden Increase of Light Intensity.......... 250

4. Reactions to Light caused by the Effect of Continued Illumi-

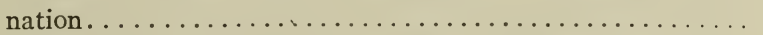

5. Classification of Reactions to Light-Phototropism, Photopathy. ............................ 253

6. Reclassification of Reactions to Light.............. ${ }_{25} 6$

(I) On the basis of the character of the stimulus.

$a$. Reactions to change of intensity; $b$. Reactions to constant illumination; $c$. Reactions of questionable cause.

(2) On the basis of the fundamental causes of the response.

$a$. Reactions caused by the direct effect of light on the reacting tissue; $b$. Reactions caused by an indirect effect of light; $c$. Reactions due, not to any effect of light in itself, but to what a given light condition or configuration may represent.

7. Evolution of the Reactions to Light

\section{CHAPTER XIII}

Factors Involved in Regulating Reactions to Light - Variability and Modifiability in Behavior

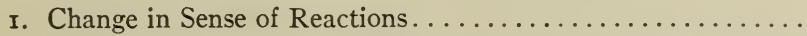

$a$. Effect of intensity of light; $b$. Effect of change in temperature - Original observations; $c$. Effect of chemicals - Original observations; $d$. Effect of concentration of the medium and mechanical stimuli; $e$. Effect of internal changes. 


\section{CHAPTER XIV}

Factors Involved in Regulating Reactions to Light - Variability and Modifiability in Behavior (continued)

I. Changes in Sensitiveness, in the Optimum, and in Various Other Features regarding Reactions................. 288

2. General Summary of Part III ................. 298

\section{PART IV}

REACTIONS IN LIGHT OF DIFFERENT WAVE-LENGTHS OR COLORS

\section{CHAPTER XV}

Energy, Photochemical Reactions, and Brightness

I. Energy Distribution in the Spectrum. ............. 304

2. Brightness Distribution in the Spectrum............ 305

3. Distribution of Actinic Effect in the Spectrum......... 308

\section{CHAPTER XVI}

Effect of Different Rays on the Reactions of Sessile Plants

I. Summary .................... 319

\section{CHAPTER XVII}

The Relative Effect of Different Rays on the Reactions of UNICELLULAR FORMS

I. Strasburger's Experiments

2. Engelmann's Experiments................... 322

a. Diatoms and Oscillaria with different species of Navicula and Pinnularia as types; $b$. Ciliates which have chlorophyll with Paramecium bursaria as a type; $c$. Flagellates with Euglena viridis as a type.

3. Verworn's Experiments..................... 326

4. Experiments of Harrington and Leaming on Amoeba...... 327

5. Original Observations on Amoeba................ 328

$a$. Experiments with color filters; $b$. Experiments with the solar spectrum. 


\section{CHAPTER XVIII}

Reactions of Multicellular Animals in Light Consisting of Waves DifFERING IN LENGTH

I. Experiments of Wilson on Hydra $\ldots \ldots \ldots \ldots \ldots \ldots \ldots \ldots . .333$

2. Bert's Experiments on Daphnia................. 336

3. Lubbock's Experiments on Daphnia.............. 337

4. Experiments of Yerkes on Simocephalus............. 34I

5. Experiments of Graber on Various Animals .......... 343

6. Loeb's Observations......................... 346

\section{CHAPTER XIX}

Brief Consideration of the Reactions of Multicellular Antmals With Well-developed Eyes in Light Differing in Color - With Special Reference to Color Vision.

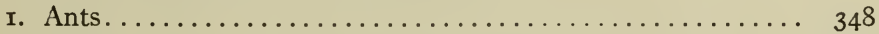

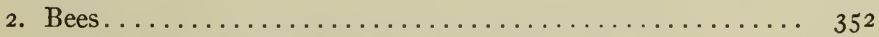

3. Higher Crustacea - Experiments of Minkiewicz....... 355

4. Fishes ............................... 358

5. General Summary and Conclusions of Part IV ......... 360

CHAPTER $\mathrm{XX}$

Theoretic Considerations ..................... 366

BIBLIOGRAPHY............................ 379

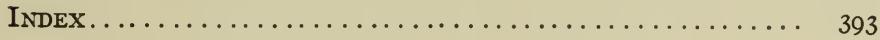





\title{
LIGHT AND THE BEHAVIOR OF ORGANISMS
}

\author{
PART I \\ INTRODUCTION AND HISTORICAL REVIEW
}

\section{CHAPTER I}

\section{GENERAL INTRODUCTION}

THAT plants and animals respond to stimulation by light is a matter of common information. It is also well known that many of the motile forms collect in regions of a given intensity of light; that many orient, some moving or turning toward a source of light, others away from it; and that many go toward a source of light under certain conditions and away from it under others. The distribution of the power to respond to stimulation by light in the plant and animal world has likewise been quite fully ascertained, ${ }^{1}$ and numerous accurate observations concerning the precise methods of response have been recorded. There is however still much contention as to the explanation of these phenomena, and it is this that concerns us chiefly in this work. In what manner and for what reasons do organisms collect in regions of certain light intensity? How do they

${ }^{1}$ See Wiesner, I879, I88I; Verworn, r889, pp. 35-6I; Nagel, I896; Davenport, I897, pp. I 82 , I95; Rádl, I903, pp. 64-67; Washburn, I 908 . pp. I20-I47; Congdon, I908.

The works of these authors referred to by means of the dates following each name, as well as those of all other authors similarly referred to in the text, will be found in the bibliography. 
behave in light of different colors? What are the factors involved in orientation, i.e., in attaining a definite axial position with reference to the source of stimulation? How do organisms regulate the direction of movement; how do they remain oriented? What is the cause of reversal in the sense of orientation? What controls variability and modifiability in reactions to light? Are the reactions adaptive? These are the principal problems before us, problems which cannot fail to be of interest to all who are in any way concerned with the activities of organisms.

Various solutions of these problems have been offered by different investigators. Some say that motile plants and animals orient and collect in light of a given intensity because the particular intensity in which they congregate pleases them more than any other, implying that there are psychic phenomena involved in the process and indicating that it is difference of light intensity in the field which controls the direction of movement. Others say the reactions are not fundamentally adaptive and can be explained mechanically; that the movements of organisms are, with few exceptions, regulated by the direction in which the rays of light penetrate the tissue or by the angle which the rays make with the sensitive surface or by the relative intensity on symmetrical opposite sides. Light is supposed by these investigators to act constantly as a directive stimulus. The organisms are automatically controlled by external factors. Still other authors claim that the reactions to light are in general useful to the organism, but that they can be accounted for mechanically and that the essential controlling factor is a change of intensity on the surface of the organism; that the other external factors mentioned are of importance only in so far as they make such a change possible; that light does not act constantly as an orienting stimulus, and that internal physiological processes have much to do with the reactions. Some maintain that only the more refrangible rays of the spectrum, those toward the violet end, are efficient in stimu- 
lating the organisms, others appear to be equally positive that all rays are active in this process, and still others say that the stimulating efficiency of different rays varies in different organisms and in the same organism under different conditions.

Many investigators have apparently not thoroughly analyzed the problems concerning reactions. To them the question regarding orientation, e.g., has been merely: Is it ray-direction or intensity difference that regulates this? And with regard to this question they have failed to see that there may be a vast difference in effect between direction of rays in the field and direction through the organism; between diversity in light intensity in the field and variation on different parts of the surface of the organism. Moreover they have failed to appreciate the importance of difference in sensitiveness of different parts of the reacting organism, and the consequent effect of change in position on stimulation.

An illustration will serve to emphasize the importance of distinguishing these characteristics. Suppose we have an elongated opaque organism the anterior end of which is more sensitive than the posterior, and suppose that this organism is in a field of direct sunlight without any other obstruction. Now it is evident that under such conditions the intensity in the field is uniform, but the intensity on the illuminated side of the organism may be almost infinitely higher than that on its shaded side, since no light can get through the organism, and if the organism changes its axial relation with reference to the ray direction, the intensity on the surface may change just as much as it would if the organism moved about in a field in which the intensity was not uniform. Moreover if the organism takes a position in which the sensitive anterior end is shaded by the rest of the body it is of course in a lower effective intensity of light than it would be if this end were illuminated. Here again we see that a change in axial position in a field uniformly illuminated may produce the same effect as 
movement from a region of one intensity to that of another. And all this is dependent upon the direction of the rays in the field whereas ray direction through the organism could have no such effect. It is evident then that the question "intensity difference or ray direction" may mean any one of several things. This loose way of stating the problems has led to much confusion.

Let us then, first of all, attempt to get a clear understanding of the questions involved in the reactions to light. With this in view we shall consider the origin and development of ideas concerning the movements in general of plants and animals, and those induced through stimulation by light in particular. 


\section{CHAPTER II}

HISTORICAL REVIEW CONCERNING THE ORIGIN AND DEVELOPMENT OF IDEAS AND THEORIES REGARDING

MOVEMENTS IN PLANTS AND ANIMALS WITH

SPECIAL REFERENCE TO THE QUESTION OF TROPISMS ${ }^{1}$

\section{Early Investigations and Ideas concerning Movement in Organisms}

To primitive man motion was the criterion of life. Everything that moved was alive, not only plants and animals but also various elements in nature,- -water, wind, fire, and the heavenly bodies. Motion was thought to be under the control of higher beings, or the result of the action of mind with which all living things were endowed. The philosophers of early civilized races abandoned the idea that all things which move are alive, but they still considered that all physiological processes are due to vital spirits. Aristotle (384-322 B.C.), thought that plants as well as animals had souls. The pith was supposed to be the seat of the soul in plants and all movements and other phenomena characteristic of living things were regarded as due to its activity. During this period, all but a few thinkers seemed to rest content that nothing more could be learned about the cause or sequence of physiological processes, and these few made only feeble attempts from a

1 The following works are the main sources of information regarding the earlier views on plant and animal activity: History of Botany, by Julius von Sachs (I875), translation revised by I. B. Balfour, Oxford (I89o); General Physiology, by Max Verworn (1894), translation second edition by F. S. Lee, New York (1899); Contemporary Psychology, by Guido Villa, translated by $\mathrm{H}$. Manacorda, London, 1903 . 
philosophical point of view at further analysis of causation. Not until the work of Galen (I3I-200 \pm A.D.), four hundred years later, was there anything approaching experimental analysis.

\section{First Attempts at Mechanical Explanation of Life Phenomena}

Galen studied the structure of animals by direct observation, even practicing vivisection on pigs and monkeys, and thus he sought to learn the functions of the various organs. But others did not continue the experimental work begun by him, and nearly thirteen centuries passed without any progress. It was not until early in the sixteenth century that interest in vital phenomena was again aroused, and it was a century later before Harvey made his important discovery on the circulatory system and presented mechanical explanations for many factors involved in the process of circulation, all of them based on experimental evidence.

A few years later, building on Descartes' idea " that the bodies of animals and men act wholly like machines and move in accordance with purely mechanical laws," Borelli undertook to reduce the movements of the organic motor apparatus to purely physical principles. The work of Borelli formed the foundation of the iatromechanical school, the members of which sought to explain all vital phenomena in animals by the application of physical principles. Other investigators of this period recognized the importance of chemical reactions in animal activity, and, under the leadership of Sylvius, founded the iatrochemical school, a school which admitted the importance of physical principles in explaining animal activity, but which strongly emphasized the influence of chemical phenomena in vital processes. The seventeenth century, and part of the eighteenth, formed a period in which mechanical explana- 
tions were offered for practically all reactions and other physiological phenomena in animals, and the same may be said with regard to plants, as will be shown in the following pages.

Toward the close of the seventeenth century, the striking movements of the sensitive plant, Mimosa, imported from America, attracted considerable attention. Ray described the movements of this plant in his "Historia Plantarum" (I693), and although an apparent believer in the soul of plants as defined by Aristotle, he tried to explain the movements mechanically. He thought that they were due not to sensations but to physical causes, - " Planta est corpus vivens non sentiens." The leaves remain erect, he said, because of the constant flow of sap into them. When touched, the tubes which carry the sap to them are partially closed, and thus the supply of sap is diminished to such an extent that the leaves are no longer held erect and consequently droop. He was of the opinion. that plants bend toward a window because of difference in rate of growth on opposite sides due to difference in temperature. It was known in a general way that an increase in temperature causes an increase in the rate of growth in plants; and Sharroc had found that the stem on which he was experimenting grew toward that part of a window where air entered through an opening. It was from these observations that Ray reached his conclusions.

At about the same time. Dodart came to the conclusion that physical contraction of the fibers on the moister side of roots and their expansion on the moister side of stems caused the former to turn down and the latter up.

Du Hamel, after studying the effect of light, temperature and moisture on the direction of growth, concluded that the "Richtung der Dämpfe" in the vessels and around the plant is of prime importance, and that if heat, light and moisture have any influence on the direction, it is through their effect on the gases. Ridiculous explanations, all of them, in the light of present knowledge! But, even 
so, their importance cannot readily be overestimated, for they formed the foundation of later work which led to most fruitful results.

\section{Period of Vitalism}

It was fully realized before the close of the eighteenth century that the mechanical explanations thus far presented were inadequate to account for many fundamental phenomena at which they were directed. Especially was this true with reference to movements of various kinds, in both plants and animals. It led to the postulation of a controlling principle in living beings, foreign to chemistry and physics, a hypermechanical principle known as vital force. Those who believed in this principle were called vitalists. Some vitalists considered the postulated force inscrutable, and consequently abandoned all hope of gaining an insight into vital processes through experimental means. Others, however, among the foremost of whom were the botanist, De Candolle, and the famous physiologist, Johannes Müller, held the opinion that this force was subject to further experimental analysis.

The prevalence of the former view was however undoubtedly the chief cause of stagnation in general physiology in its broadest sense, during this period, for there was no corresponding unproductive period in the development of physical sciences. As a matter of fact many who had been prominent investigators in both biological and physical sciences, now abandoned the former, and devoted their entire energies to the latter.

\section{Return to Mechanical Explanations}

Müller realized the weakness of the iatromechanical school as well as the inadequacy of pure philosophical speculation. On the one hand he recognized the importance 
of speculation in guiding and unifying experimental work; on the other he saw the necessity of founding philosophical speculation on experimental facts. This broad view resulted in much comparative work especially in physiology and psychology, work which had a direct bearing on the nature of psychic processes as well as on the nature of physiological activity. Müller worked on the higher animals almost exclusively. His aim was to analyze the phenomena of life as he found them in these organisms. His followers, Wöhler, Liebig, Helmholtz, du Bois-Reymond, Lotze, Weber, Fechner and others, perpetuated this aim, but they did not retain his breadth of spirit. Some confined their investigations to the chemical side of physiology, others to the physical side, and still others to pure psychology. The question as to the origin and evolution of vital phenomena, especially psychic phenomena, was not yet prominent, if indeed it had been at all considered. The behavior of lower animals had been studied to some extent, but the Cartesian doctrine that there is no resemblance between the mind of man and that of animals was still very generally accepted.

\section{Evolution and its Effect on the Study of Behavior of Plants and Animals}

With the establishment of the theory of evolution, there appeared a new incentive in the study of animal behavior. Darwin had demonstrated in a convincing manner the structural interrelationship between various animals, including man. It seemed clear that the complex anatomical structures found in the higher animals had their origin in the simpler structures found in the lower. Could the same be said with reference to behavior? Did the mental phenomena in man have their origin in the lower animals? If so, then there must be some evidence of mental activity in the lower animals, the psychic phenomena in these 
organisms must resemble those in man, and the Cartesian doctrine must be wrong.

The importance of this problem was at once recognized and a number of able investigators undertook its solution. Prominent among these may be mentioned Darwin, Paul Bert, Graber, Romanes, Lubbock and Preyer. It should be emphasized that these investigators were not primarily interested in explaining behavior either mechanically or otherwise. Their principal aim was to throw light on the origin of mental phenomena in man. Do the lower animals have sensations? Do they have memory? Do they reason? were questions which shaped their investigations. These questions they sought to answer by studying the behavior of animals under various conditions. Their results seemed to indicate that the psychic phenomena in animals differ from those in man in quantity rather than in quality.

With reference to reactions to light they used what is known as the preference method. Experimental conditions were so arranged that the animals could get into light of different intensities or different colors. The kind of light in which they collected was supposed to be the kind they preferred. The work was weak in that only end results of the experiments were considered; it was never ascertained precisely how the animals got into the region in which they finally remained. Variation in the color or in the intensity of light in the field was to these investigators the controlling factor in the movement of animals. They failed to consider the possible effects of the direction of the rays, of variation in light intensity on the surface of the animals, and of various internal factors. This led to many erroneous conclusions. Still it must be said that whatever one may think as to the point of view of these investigators and the validity of their conclusions in general, one cannot read with unprejudiced mind the account of their work, especially that of Darwin, Lubbock, and Romanes, without greatly admiring the keenness of their 
observations and the ingenuity of their experiments. The point of view of these men dominated the field of animal behavior from the middle of the nineteenth century until the appearance of Verworn and Loeb well on toward I 890. As has been stated, they studied the behavior of animals with the express purpose of demonstrating the evolution of psychic phenomena in man. These investigators were therefore not primarily interested in a physico-chemical explanation of animal behavior.

The study of behavior in plants during this period was however pursued with a very different aim. The question as to the origin of mental phenomena influenced this study but little, for it was generally conceded that plants were devoid of all traces of psychic activity. There was consequently nothing left but to attempt to account for their behavior by means of physico-chemical analysis. Even the vitalists realized that in the attempt of such analysis lay the only hope of progress.

\section{Introduction of the Term "Tropism" and Development of its Application to Different Reactions}

In 1806 De Candolle, a vitalist, succeeded in reversing the daily periodic sleep movements of leaves by exposing them to artificial light during the night and to darkness during the day. The same year Knight showed by attaching developing seedlings to a rapidly revolving wheel that the direction of growth of roots and stems is regulated by gravitation. He explained the directive action of gravitation by assuming "that the root, being of a semifluid consistence, is bent downwards by its own weight, while the nutrient sap in the stem moves to the underside and causes stronger growth there, until by means of the curvature so produced the stem assumes the upright position." In I828 Johnston found that roots in growing downward can overcome considerable resistance and that the direction of growth is therefore not due to their weight 
as Knight had assumed. About the same time Dutrochet applied endosmose and exosmose to explain the movement of plants mechanically. In I833 De Candolle proved that it is light which causes plants to grow toward a window and not difference in temperature on opposite sides as Ray had thought one hundred forty years earlier. De Candolle discovered that light retards growth in plants and concluded that they turn toward a source of light because growth is retarded on the more highly illuminated side. The reaction according to De Candolle is due to difference in intensity of light on opposite sides.

The turning toward the light was called heliotropism by De Candolle (I835, Vol. 2, p. 609), who was, according to Pfeffer (I906, pp. I54-I55), the first to use this term. He used it merely to indicate the exciting agency and not to express the physiological response involved. Hofmeister ( 1863 , p. 86) added the terms positive and negative heliotropism; Frank (I870), invented the term geotropism; and Darwin (I88I), Rothert (I896) and Massart (I902) introduced various special terms. While all these expressions were at first very generally used to designate the relation between the movement of the reacting organism and the source of stimulation, they soon came to be used to designate also the processes underlying the reactions. De Candolle's explanation of the reaction to light assumed a direct effect of the external agent on the tissue involved in the reaction; and the same was true with reference to Knight's explanation of the reactions to gravity. The cells in which the processes producing the curvatures took place were supposed to be stimulated directly. The idea of irritability, of transmission of stimuli, of a differentiation between sensitive and reacting tissue, in plants had not yet been promulgated. The term "tropism" then gradually came to signify not merely turning, but turning due to the direct effect of the stimulating agent on the tissue producing the movement, and this signification it has retained to some extent to the present time. 


\section{Further Analysis of Reactions in Plants to Light}

Sachs was the first to point out the inadequacy of the explanation brought forward by De Candolle. He and others found negative as well as positive plant structures in which the rate of growth was retarded by increase of intensity of light. The bending from the source of light in these structures could therefore not be due to difference in rate of growth on opposite sides induced by difference in illumination. Sachs was already of the opinion that gravitation does not control the direction of growth in plants by difference in the direct effect on the upper and lower surfaces of the reacting organ as Knight had assumed. He says (I887, p. 696)," "That in geotropic curvatures the important point is only as to the direction in which gravitation acts on the part of the plant, and that it is not in any way a matter of a stronger effect on the lower side and a feebler effect on the upper side, requires no proof." He was profoundly impressed by the similarity between the reactions to light and those to gravity. This together with the inadequacy of the explanations of De Candolle and Knight led him to the conclusion clearly expressed in these words (i 887, p. 695): "It necessarily followed from this that the standpoint assumed by De Candolle must be abandoned, and that the whole subject of heliotropism must be looked at in an entirely different way - a view which impressed me the more, since according to all the facts then known a striking agreement exists between heliotropic and geotropic effects, and at the same time I had even then come to see that geotropism and heliotropism are to be looked upon as phenomena of irritability. In addition to these reflections, also, I came to the conclusion that in heliotropic curvatures the important point is not at all that the one side of the part of the plant

1 The original German edition appeared in 1882 . Sachs first announced his views on reactions to light in the preface of a paper by $\mathrm{H}$. Müller in I 876 . 
is illuminated more strongly than the other, but that it is rather the direction in which the ray of light passes through the substance of the plant;" (I882, p. 85I) . . . "dass es sich bei den heliotropischen Krümmungen gar nicht darum handle, dass die eine Seite des Pflanzentheils stärker als die andere beleuchtet sei, dass es vielmehr nur auf die Richtung ankomme, in welcher der Lichtstrahl die Pflanzensubstanz durchsetzt."

It will thus clearly be seen that the term " ray direction," so frequently used to characterize Sachs' view in opposition to intensity difference, is confusing. It expresses the truth, but not the whole truth. Sachs did not refer to ray direction in general but to ray direction through the tissue, nor did he oppose intensity difference in general. He had nothing to do with the view of Bert and Graber that variation in illumination of the field regulates reaction to light. He opposed the view of De Candolle who states explicitly that it is difference of intensity on opposite sides of the reacting organ which causes heliotropic curvatures.

In the study of the reactions of sessile plants to light there is but one phenomenon to consider - the turning of the plant or some of its parts so as to assume a definite position with reference to the source of light, i.e., orientation. In motile forms we have not only to deal with the assumption of a definite axial position and movement but we have also to deal with the phenomenon of aggregation. How and why do certain unicellular organisms, for example, collect in dense masses in certain regions of their environment? How is it that so many swarm spores, for instance, collect on the side of the dish toward the source of light? It was generally assumed that this phenomenon is due to difference of intensity in the field, that these organisms in some way select the illumination adapted to their needs and remain there. But Nägeli had observed as early as I 860 that flagellates and swarm spores collect at the side of a porcelain dish nearest the window although the intensity of light at this place is lower than elsewhere owing to 
the shadow produced by the side of the dish. This fact led some authors to conclude that these organisms avoid the light, but this did not account for the fact that the swarm spores collect also at the window side of a dish which produces no shadow and in which this part is most highly illuminated. Cohn recognized this difficulty and concluded in I 865 , eleven years before Sachs announced his ray-direction theory, that it is not difference of intensity in the field but direction of the rays that regulates the direction of movement in these organisms. He does not, however, make it clear whether he means direction of the rays through the tissue or direction in the field.

Sachs answered the question as to the cause of aggregation in unicellular forms in a very simple way. He found (I876, p. 24I) that certain inanimate particles suspended in water collect in definite regions when exposed to light owing to currents caused by variation in temperature. He was of the opinion that the movement and aggregation of unicellular forms under similar conditions were largely if not entirely of the same nature.

For the express purpose of testing this opinion, Strasburger (1878, p. 552) studied the reactions of swarm spores to light. He repeated the experiments of Sachs and obtained confirmatory results, but concluded from detailed microscopic observations on the movements of these organisms that the aggregations formed in light under normal conditions are almost entirely due to active swimming of the swarm spores and not to currents in the water. Strasburger in this paper, however, incidentally supports the general theory of Sachs on heliotropism. He found in agreement with Nägeli's observation (I860) that positive swarm spores move toward a source of light even if in so doing they pass from regions of higher light intensity into regions of lower, and concluded just as Cohn (I 865) had, that this cannot be due to difference of intensity. He does not however consider the fact that under the conditions of his experiments the anterior ends of the spores were con- 
tinually more highly illuminated than the posterior, and that this difference of light intensity might determine the direction of movement; he merely states that this experiment shows that the reactions are due to ray direction without defining precisely what he means. Sachs, however, in referring to these experiments says (I887, p. 696), "Even in the case of the influence of light on the movement of swarm spores, the important point can only be as to the direction of the rays of light, not as to whether the given swarm spore is illuminated more strongly in front or behind."

The excellent observations of Engelmann (I882-I883) on the reactions of unicellular forms to light have a direct and important bearing on the question of aggregation. Strasburger (1878) had observed that a sudden reduction of light causes a definite reaction in swarm spores - "zitternde Bewegung " - and others had seen similar responses to sudden changes in the intensity of other stimulating agents. But Engelmann seems to have been the first to point out clearly the relation between such responses and aggregation. He made detailed observations on the movements of Paramecium bursaria, Euglena viridis, Bacterium photometricum and other similar unicellular forms, in a field on a slide containing a spot more highly illuminated than the surrounding region. The illuminated spot, he says, acts like a trap; the organisms in their random movements swim into it without response, but when they reach the boundary on the way out, they stop suddenly, turn back, and thus remain in the illuminated area, which soon becomes crowded with them. These cbservations are of such vital importance that it seems wise to emphasize them by quoting directly from the author. Regarding Paramecium bursaria Engelmann says (I882, p. 393), "Ueberschreiten sie z.B. zufällig die Gränze von Licht und Dunkel, oder tauchen sie auch nur mit der vorderen Hälfte ihres Leibes eine Strecke weit in das Dunkel ein, so kehren sie sofort um nach dem Licht, wie wenn das Dunkel ihnen unangenehm 
wäre." Referring to the reaction of Euglena in a drop partially illuminated he says (I882, p. 395), "Dieses wirkt wie eine Falle, denn einmal hineingekommen, gehen die Euglenen in der Regel nicht wieder heraus. Sie kehren an der Grenze des Dunkels immer so gleich wieder um ins Helle. Falls sie, was bei schnellem Vorwärtsschwimmen wohl einmal geschieht, gans ins Dunkel hineingekommen sind, sistiren sie doch sofort die weitere Vorwärtsbewegung, drehen um eine ihres kurzen Axen, probiren - oft unter bedeutenden Gestaltsänderungen - in verschiedenen Richtungen fortzukommen bis sie endlich wieder ins Licht gerathen." The effect of sudden reduction of light intensity on Bacterium photometricum is described in the following words (I883, p. I IO): "Schwächt man nun plötzlich das Licht . . so sieht man alle bis dahin im Gesichtsfeld schwimmenden Bakterien fast im nämlichen Moment eine Strecke weit zurück schiessen, einige, meist unter lebhaftesten Rotation um ihre Langsaxe, stillstehen und danach wieder die gewöhnliche Bewegung aufnehmen. Man erhält vollständig den Eindruck eines Erschreckens."

According to Engelmann none of the organisms mentioned above responds to an increase of intensity, nor do any of them respond to a decrease, if it is sufficiently gradual. The response is therefore dependent upon the time rate of change.

Engelmann's account of aggregation in these organisms, as far as it goes, has stood the test of time. He failed however to grasp the importance of orientation and direct movement toward the optimum. The reactions to sudden changes of intensity described in this account are in all essentials like those discovered by Jennings some fifteen years later in his study of Paramecium. They have been designated Schreckbewegungen by Pfeffer and motor reflex and avoiding reaction by Jennings. They have much in common with the reactions to shadows in many higher forms, which Loeb (I893) claims are due to Unterschiedsempfindlichkeit and Bohn (1908) says are due to "sensibi- 
lité différentielle." The valuable experiments of Engelmann on the behavior of unicellular organisms in microspectra will be considered later (see Part IV).

Several very important contributions to the knowledge of the reaction of plants, both in theory and in fact, were made by Charles Darwin and his son Francis, in their excellent work on "The Power of Movement in Plants" (I880). (I) They made detailed observations on the movement of different parts of plants in the absence of definite external stimulations, and found that practically all parts of plants-stems, leaves, roots, flowers, etc. - are constantly performing circumnutation movements. From this they concluded that tropic curvatures are brought about by modification of movements already present, i.e., that tropic stimuli are not the cause of movement but the cause of modification of movement. (2) They studied the reaction to light of plumules with the tips covered with small opaque caps; of radicles with the tips cauterized by the application of silver nitrate; and the reactions to gravity of radicles with the tips removed, and found that these structures responded normally after the tips were covered, removed or injured, provided that they had been previously stimulated, but that they did not respond if they were not stimulated until after the operation. From these results they concluded that plant-organs frequently have a sensitive part separated by some distance from a reacting part which is not sensitive, and that impulses originating in the former are transmitted to the latter. (3) They studied the reactions to light of certain plumules with one side covered with an opaque substance, and of others not covered but exposed at intervals, and concluded that the reactions are due to difference in intensity on opposite sides but that the principal factor in producing stimulation is a change of intensity rather than absolute difference of intensity.

These conclusions are of such fundamental importance that it seems advisable to insert the following quotations from the authors' work cited above. (p. 485): "All ob- 
servers apparently believe that light acts directly on the part which bends, but we have seen with the above described seedlings ${ }^{1}$ that this is not the case. Their lower halves were brightly illuminated for hours, and yet did not bend in the least towards the light, though this is the part which under ordinary circumstances bends the most." (p. 566), "We believe that this case [referring to an experiment of Wiesner], as well as our own, may be explained by the excitement from light being due not so much to its actual amount, as to the difference in amount from that previously received; and in our case there were repeated alternations from complete darkness to light. In this, and in several of the above specified respects, light seems to act on the tissues of plants, almost in the same manner as it does on the nervous system of animals." (p. 567), "It is an interesting experiment to place caps over the tips of the cotyledons of Phalaris, and to allow a very little light to enter through minute orifices on one side of the caps, for the lower part of the cotyledons will then bend to this side, and not to the side which has been brightly illuminated during the whole time." (pp. 568-569), " In the case of the radicles of several, probably of all seedling plants, sensitiveness to gravitation is confined to the tip, which transmits an influence to the adjoining upper part, causing it to bend towards the center of the earth. That there is transmission of this kind was proved in an interesting manner when horizontally extended radicles of the bean were exposed to the attraction of gravity for $\mathrm{I}$ or $\mathrm{I}^{\frac{1}{2}} \mathrm{~h}$., and their tips were then amputated. Within this time no trace of curvature was exhibited, and the radicles were now placed pointing vertically downwards, but an influence had already been transmitted from the tip to the adjoining part, for it soon became bent to one side, in the same manner as would have occurred had the radicle remained horizontal and been still acted on by geotropism. Radicles thus treated continued to grow out horizontally for two or three days, until

1 The tips of these were covered with opaque caps. 
a new tip was reformed; and this was then acted on by geotropism, and the radicle became curved perpendicularly downwards." I (pp. 572-573), "We believe that there is no structure in plants more wonderful, as far as its functions are concerned, than the tip of the radicle. If the tip be lightly pressed or burnt or cut, it transmits an influence to the upper adjoining part causing it to bend away from the affected side; and, what is more surprising, the tip can distinguish between a slightly harder and softer object, by which it is simultaneously pressed on opposite sides. If, however, the radicle is pressed by a similar object a little above the tip, the pressed part does not transmit any influence to the more distant parts, but bends abruptly towards the object. If the tip perceives the air to be moister on one side than on the other, it likewise transmits an influence to the upper adjoining part, which bends towards the source of moisture. When the tip is excited by light (though in the case of radicles this was ascertained in only a single instance), the adjoining part bends from the light; but when excited by gravitation the same part bends towards the center of gravity. In almost every case we can clearly perceive the final purpose or advantage of the several movements. Two, or perhaps more, of the exciting causes often act simultaneously on the tip, and one conquers the other, no doubt in accordance with its importance for the life of the plant. The course pursued by the radicle in penetrating the ground must be determined by the tip; hence it has acquired such diverse kinds of sensitiveness. It is hardly an exaggeration to say that the tip of the radicle thus endowed, and having the power of directing the movements of the adjoining parts, acts like the brain of one of the lower animals; the brain being seated within the anterior end of the body, receiving

1 This experiment was first performed by Ciesielski (1875). Darwin's interpretation of the results has been questioned. See Francis Darwin's interesting presentation of the controversy concerning this and related subjects (1907, pp. 35-42; 69-76). 
impressions from the sense-organs, and directing the several movements."

This work of Darwin seems to have been set aside by some of the most prominent investigators of the day and has even to this time not received recognition in accord with its importance. Loeb does not mention it at all. Sachs refers to it in the following terms (I887, p. 689): "In such experiments with roots not only is great precaution necessary, but also the experience of years and an extensive knowledge of vegetable physiology, to avoid falling into errors, as did Charles Darwin and his son Francis, who, on the basis of experiments which were unskilfully made and improperly explained, came to the conclusion, as wonderful as it was sensational, that the growing-point of the root, like the brain of an animal, dominates the various movements in the root." The very point which Sachs rejects has however been confirmed by Pfeffer (1894), Czapek (I895, p. 244), Rothert (I894, p. 3), and others. Czapek's experiment bearing on this point is ingenious and convincing. He forced the apex of radicles
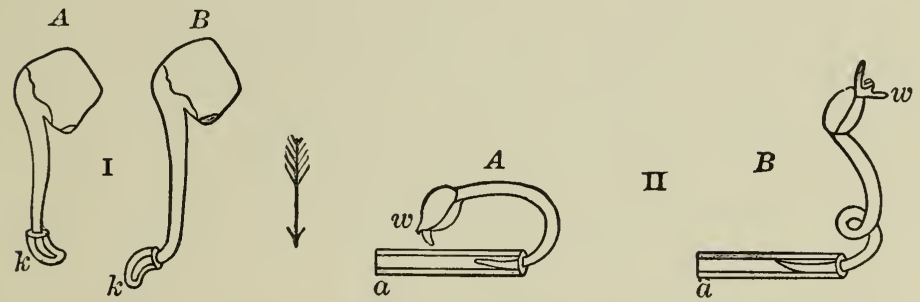

FIG. I. I. Seedlings of Lupinus albus (smaller size). The seedling $(A)$ has been removed from the klinostat after the apex is fixed in the glass cap $k$, and after twenty-four hours has curved so as to place itself parallel with the perpendicular line shown by the arrow. After Czapek, from Pfeffer (rgo6).

II. Seedlings of Setaria italica. The roots have been cut away down to the rudiments $w$, the cotyledon [plumule] fixed in the glass tube $a$, and the seedling is then placed horizontally. In $A$ the hypocotyl has curved through $180^{\circ}$, and at $B$ has formed a complete coil. (Twice enlarged). After Darwin, from Pfeffer (rgo6).

while being rotated on a clinostat to grow into small bent tubes of glass closed at one end. When the seedlings were 
permanently fastened so that the base of the radicle was horizontal and the tip vertical, there was no reaction, but when so fastened that the base was vertical and the tip horizontal, they responded by bending in the region above the glass tube until the tip became vertical. (See Fig. I.) 


\section{CHAPTER III}

\section{HISTORICAL REVIEW CONCERNING THE ORIGIN AND DEVEL- OPMENT OF IDEAS AND THEORIES REGARDING MOVE- MENTS IN PLANTS AND ANIMALS WITH SPECIAL REFERENCE TO THE QUESTION OF TROPISMS (continued)}

I. The Application of the Underlying Principle of Tropisms in the Study of Animal Behavior as opposed to this Study from the Point of View of Comparative Psychology

SEven years after the appearance of "The Power of Movement in Plants," by Darwin, Loeb began his work on behavior of animals, at Würzburg, in an atmosphere pervaded by the spirit of Sachs. His first paper on the subject, entitled "Die Orientierung der Thiere gegen das Licht (thierischer Heliotropismus)," appeared in January, I888. A far more important and extensive paper bearing the title "Der Heliotropismus der Thiere und seine Uebereinstimmung mit dem Heliotropismus der Pflanzen," was brought out in pamphlet form the following year. Other shorter papers followed from time to time. Most of these papers, originally published in German, were translated and published in English in Loeb's "Studies in General Physiology," Chicago, I905. These translations will be referred to almost exclusively in the following pages.

Loeb took up the work in animal reactions with the idea of explaining such reactions on chemical and physical bases in opposition to the so-called anthropomorphic explanations current at the time. His object was "to find the agencies which determine unequivocally the direction of motion in animals." He writes (I905, Preface), "I consider a complete knowledge and control of these agencies the biological solution of the metaphysical problem 
of animal instinct and will." The author assumed that these agencies had been fairly definitely ascertained with reference to plants, and it was generally conceded that their movements were not influenced by psychic phenomena. He therefore began his work by attempting to show that the reactions in plants and animals are controlled by the same agencies, with the express purpose of proving that the reactions of animals are not due to subjective (anthropomorphic) sensations as the work of Bert, Graber, Lubbock, Romanes and others might lead one to infer. "I consider it inadvisable," he says (I905, p. I6), "to represent the movements observed in animals as the expression of a 'color preference', or a 'color sensation', of a 'pleasurable' or 'unpleasurable sensation', as do most animal physiologists and zoologists who have studied the effects of light in the animal kingdom." (I906, p. I25), "It seemed to me that we had no right to see in this tendency of animals to fly into flame the expression of an emotion, but that this might be a purely mechanical or compulsory effect of the light, identical with the heliotropic curvature observed in plants. I believed that the essential effect of the light upon these animals might consist in a compulsory automatic turning of the head toward the source of light, corresponding to the turning of the head, or the tip, of a plant stem toward the light; and that the process of moving toward the source of light was only a secondary phenomenon. It seemed to me also that if the stem of the plant could suddenly acquire the power of locomotion, it would act exactly like the animals which fly into the flame."

In his first paper Loeb deals with the reactions of certain insect larvae. He found that positive larvae go toward the light even when conditions are so arranged that in so doing they must go into light of lower intensity. These results lead to the following conclusions (I888, p. 2): “Die Orientirung der Thiere gegen eine Lichtquelle wird bei den Pflanzen (J. v. Sachs) bedingt durch die Richtung, in welcher die Lichtstrahlen die thierischen Gewebe durchset- 
zen, und nicht durch die Unterschiede in der Lichtintensität auf den verschiedenen Seiten des Thieres." It is evident from this quotation that Loeb at this time held that the direction of the rays through the tissue is the controlling factor in orientation of animals; that is, that orientation in animals takes place just as Sachs had said it does in plants; that it is not due to difference of intensity on different parts of the organism, but to the direction in which the directive rays pass through the tissue.

The results recorded in the second paper, dated I889, are in all essentials like those found in the first. The principal points established are (I) that positive animals will proceed toward the window under conditions such that they continually get into weaker light; (2) that only the more refrangible rays are active in causing reactions. From these results Loeb concludes as follows (1905, p. 3; first edition, 1889): "The conditions which control the movements of animals toward light are identical, point for point, with those which have been shown to be of paramount influence in plants." Five conditions are considered: (I) ray direction; (2) wave length; (3) constancy of intensity; (4) limits of intensity; (5) temperature. Two of them, the first and the third, are of special interest to us at present. I shall therefore quote Loeb's words with reference to them (1905, p. 2), "So far as the light is concerned, the circumstance which controls the orientation of the animal and the direction of its movements is the direction of the rays falling upon the animal. The condition which is of importance on the part of the animal is the symmetrical shape of the body." It consequently appears that he, at this time, no longer considered the direction in which the rays pass through the tissue of the organism of special importance but that he still regarded the direction in which they fall upon it of importance. At the same time, however, he accepted Sachs' theory as giving an adequate explanation of orientation in plants and claimed that this theory also holds for animals, for he says (I905, p. 89), "I showed 
that the law put forward by Sachs for the heliotropism of plants, namely, that the direction of the rays of light determines the orientation, holds good also for animals." Elsewhere in the same paper he states this law explicitly as follows (1905, p. 5): "Sachs came to the conclusion that the direction in which the rays of light penetrate the plant tissue determines the orientation of the plant toward light." This statement of the law is correct, but it should be emphasized that Sachs also said "that in heliotropic curvatures the important point is not at all that the one side of the part of the plant is illuminated more strongly than the other." There is evidently much confusion here in the application of Sachs' theory.

Do Loeb's conclusions in this paper show "that the law put forward by Sachs for heliotropism of plants ... holds good also for animals"? He writes (I905, p. 28): "From what has been said, no one, I believe, will doubt that the direction of the progressive movements of the caterpillars of Porthesia chrysorrhoea is determined by the direction of the rays of light, and not by differences in the intensity of the light in different parts of space. Positively heliotropic animals are compelled to turn their oral pole toward the source of light and to move in the direction of the rays toward this source." And (1905, p. 53), "The direction of the rays, and not the distribution of the intensity of the light, in the test-tube, therefore, determines the direction of the progressive movements." From these quotations it is evident that Loeb means ray direction in general in opposition to difference in intensity in the field. He proved that under the conditions of his experiments the direction of motion is not governed by the difference of intensity in the field. But this has nothing to do with Sachs' theory, for this theory does not consider the effect of ray direction in the field or " distribution of the intensity in the testtube." Sachs, as stated above, says very definitely that it is the direction in which the rays pass through the tissue and not difference of light intensity on opposite sides of the 
organism which regulates the movement. Consequently if Loeb's explanation holds for animals and Sachs' for plants, it is clear that the orientation in animals is not necessarily regulated in the same way as in plants.

Sachs opposed the idea of De Candolle that difference of intensity on opposite sides of the reacting organism controls orienting reactions; while Loeb at this time opposed the idea of Bert and Graber that difference of intensity in the field determines the place of aggregation, and that animals are "unterschiedsempfindlich." Sachs argued in favor of ray direction through the tissue of the reacting organ, Loeb in favor of ray direction in general. Failure to recognize the difference between these views has led to much confusion. It is on this account that the problem has generally been so loosely stated in the terms "Is it ray direction or intensity difference?" - a question which evidently cannot be answered without an explicit statement of the sense in which these terms are used.

Do Loeb's experimental results prove the absence of sensations as factors in animal behavior as he assumes? The experiments on which he bases his conclusions are similar to those of Strasburger on swarm spores referred to on p. I5. Loeb found that positive animals very generally move toward a source of light even if in so doing they pass into regions of lower light intensity. He concluded from this result correctly that this cannot be due to variation in the intensity of light in the space, but incorrectly that this disproves the existence of sensation, for the animals with which he worked are more sensitive to light at the anterior than at the posterior end. If they enjoy light one would expect them to continue to face its source even if the general illumination is decreased, because, if they should turn, the sensitive anterior end would become shaded and this would cause a decrease in the pleasant effect of light. The experimental results just cited, therefore, do not prove the absence of sensation as a controlling factor in the behavior of animals; neither do 
they show that it is not difference in light intensity on the surface of the reacting organism which regulates orientation.

Let it be clearly understood that I am not arguing in favor of psychic phenomena as factors in orientation. Loeb's greatest service to the study of animal behavior was his strenuous opposition to this idea, in spite of his failure to demonstrate the absence of sensation as a factor in reactions.

Let us now turn more directly to Loeb's later views on orientation, or tropisms. These are clearly expressed and explicitly stated in the following quotations. Referring to the analogy between the effect of a constant electric current and light, Loeb says (I897, p. 440): "Wir finden hier erstens Wirkungen, die bei constanter Intensität des Lichtes unverändert andauern. Das sind die heliotropischen Wirkungen, die auf dem Einfluss des Lichtes auf die Spannung assoziirter Muskelgruppen beruhen ('das Licht wirkt bei constanter Intensität dauernd als heliotropische Reizursache auf die Thiere') . . . Ich glaube jetzt, dass hier eine iollkommene Analogie der Licht- und Stromwirkungen zu Tage tritt, derart, dass auch, wie beim Strom, die Licht-intensität dauernd die Spannung der Muskeln beeinflusst, dass aber die Steilheit der Intensitätsschwankung die Fortleitung der Spannungsänderung bestimmt.

"Aber die Analogie zwischen der Stromwirkung und der Lichtwirkung geht weiter. Als den für die heliotropische Orientirung der Thiere wesentlichen äusseren Umstand wies ich die Richtung der Lichtstrahlen nach, wie das Sachs bereits früher für die Pflanzen gethan hatte. Das Wesen der Orientirung fasste ich dahin auf, dass bei vollendeter Orientirung Symmetriepunkte der Oberfläche des Thieres unter gleichem Winkel ion den Lichtstrahlen getroffen werden."

An explanatory footnote (1905, p. 2), dated I903, reads as follows: "In these experiments it is presumed that the animals move under the influence of only one source of light. It is explicitly stated in this and the following papers 
that if there are several sources of light of unequal intensity, the light with the strongest intensity determines the orientation and direction of motion of the animal. Other possible complications are covered by the unequivocal statement, made and emphasized in this and the following papers on the same subject, that the main feature in all phenomena of heliotropism is the fact that symmetrical points of the photosensitive surface of the animal must be struck by the rays of light at the same angle. It is in full harmony with this fact that if two sources of light of equal intensity and distance act simultaneously upon a heliotropic animal, the animal puts its median plane at right angles to the line connecting the two sources of light. This fact was not only known to me, but had been demonstrated by me on the larvae of flies as early as I887, in Würzburg, and often enough since. These facts seem to have escaped several of my critics."

In these papers it is clear that the important factors in orientation to light are considered to be: (I) symmetry of the body; (2) the angle between the rays and the sensitive surface on opposite sides; and (3) constant intensity, functioning as it does in case of the electric current. Orientation in light is supposed to be controlled by the direct action of the external agent, on the locomotor tissue or through a direct reflex arc. It is controlled unequivocally by the external agent, which acts constantly as a directive stimulus similar to the action of a constant electric current.

At this time Loeb evidently still placed much dependence upon the assumed effect of the angle which the rays make with the sensitive surface (ray direction), for if he considered merely intensity difference on opposite sides it would be impossible for him to say as he does that when organisms are exposed to light from "several sources . . of unequal intensity, the light with the strongest intensity determines the orientation and direction of motion of the animal." In a more recent discussion however he uses the following expression (I906, p. I30): "We started with 
the assumption that the heliotropic reactions are caused by a chemical effect of light; in all such reactions time plays a rôle. We assume, furthermore, that if light strikes the two sides of a symmetrical organism with unequal intensity, the velocity or the character of the chemical reactions in the photosensitive elements of both sides of the body is different." This and the following quotation show that he now considers orientation to be controlled by difference of intensity on opposite sides, the very idea which Sachs in his theory opposed.

In the following quotation he also brings out his idea as to the direct effect of the agent on the reacting tissue with reference to plants. Orientation in animals is supposed to be just like this in principle; in animals, the agent is supposed to affect the locomotor organs directly or through a direct reflex arc (I906, p. I I8): " How can light bring about heliotropic curvatures? Let us suppose that light strikes a plant on one side only, or more strongly on one side than on the opposite side, and that it be absorbed in the superficial layers of tissue of that side. In this case we assume that on that side certain chemical reactions occur with greater velocity than on the opposite side. What these reactions are is unknown; we may think provisionally of oxidations. This change in the velocity of chemical reactions either produces a tendency of the soft elements on that side to contract a little more than on the opposite side, or creates otherwise a greater resistance to those forces which have a tendency to elongate or stretch the plant, e.g., hydrostatic pressure inside the cells, or imbibition of certain tissue elements. The outcome will be that one side of the stem will be stretched more than the opposite side, and this will bring about a curvature of the stem. Where the latter is soft at the tip, the bending will occur only, or chiefly, in that region; and as the degree of sof tness decreases rapidly from the tip downward, the result will be that the tip will bend toward the source of light. This result may possibly be aided by a greater photosensitive- 
ness of the extreme tip of the stem, although I am not aware that this is an established fact."

It is strange that such a theory should have been suggested to explain heliotropic curvatures in plants twentysix years after Darwin (see p. I8) proved that only the tips of certain radicles and plumules are sensitive to light and that the region where the curvature takes place is frequently not at all sensitive, and several years after Pollock (I900) had shown that traumatic stimuli are in many instances transmitted from the tip of radicles to the motory zone 5 to $8 \mathrm{~mm}$. distant and produce curvatures toward the uninjured side even if the cortex, the conducting tissue, is cut on the side between the point of stimulation and the motory zone. Moreover Loeb's theory fails utterly to account for curvatures in structures having but a single cell cavity as, for example, Vaucheria, the rhizoids of liverworts, and the hyphae of molds, all of which were known to respond to light long before his theory was formulated.

Loeb's idea that the movements in plants and animals are unequivocally controlled by external agents is emphasized in the following quotations: (I905, p. I07), "By the help of these causes it is possible to control the "voluntary' movements of a living animal just as securely and unequivocally as the engineer has been able to control the movements in inanimate nature"; (I906, p. I28), "It should be observed that the essential feature in these reactions is the compulsory turning of the head by the light, which leaves the animal no choice, making all the caterpillars of Porthesia or all the plant lice of the same culture behave exactly alike, just as in the case of a magnet all the pieces of iron are compelled to behave alike "; (I906, p. I24), "The light would turn them automatically until their axis of symmetry was in the direction of the rays of light, and theanimal could then move only in this direction."

Thus we have seen that in 1906 Loeb asserts that orientation in light is unequivocally controlled by the relative intensity on symmetrically located sensitive parts of the 
organism; that light stimulates the locomotor organs continuously and directly or through a direct reflex arc. When both sides are not equally illuminated one moves faster than the other, causing the organism to turn until the light intensity on the two sides is equal when they are both equally stimulated and consequently move at the same rate. This view he apparently still holds for he affirms it in unquestionable terms in a recent address (I909, pp. 9-I5): "Zwei Faktoren bestimmen die Progressivbewegung der Tiere unter diesen Bedingungen; der eine ist die symmetrische Strukturdes Tieres und der zweite die photochemische Wirkung des Lichtes (p. 9). . . . Wenn nun mehr Licht auf eine Retina fällt als auf die andere, so werden auch die chemischen Reaktionen, Beispielsweise die organischen Oxydationen, in einer Retina mehr beschleunigt als in der andern; und dementsprechend werden in dem einen optischen Nerven stärkere chemische Änderungen auftreten als in dem anderen (p. I I). . . . Diese Ungleichheit der chemischen Prozesse pflanzt sich von den sensiblen in die motorischen Nerven und schliesslich in die mit denselben verbundenen Muskeln fort. Wir schliessen daraus, dass bei gleicher Beleuchtung der beiden Retinae die symmetrische Muskelgruppe beider Körperhälften in gleicher Weiser chemisch beeinflusst werden und somit in den gleichen Kontractionszustand geraten; während wenn die Reaktionsgeschwindigkeit ungleich ist, die symmetrischen Muskeln auf einer Seite des Körpers in stärkere Tätigkeit geraten, als auf der andern Seite. Das Resultat einer solchen ungleichen Tätigkeit der symmetrischen Muskeln beider Körperhälften ist eine Änderung der Bewegungsrichtung des Tieres" (p. I2).

In his earlier work Loeb appears to have held that all reactions to light are due to constant intensity, but later (I893, p. 265) he recognizes that some are due to change in intensity. The former he calls heliotropic, the latter photokinetic (unterschiedsempfindlich). He characterizes the difference between the two thus (I906, p. I35): "Helio- 
tropism covers only those cases where the turning to the light is compulsory and irresistible, and is brought about automatically or mechanically by the light itself. On the other hand, there are compulsory and mechanical reactions to light which are not cases of heliotropism; namely, the reaction to sudden changes in the intensity of light." Orientation is therefore, according to Loeb, never due to change in light intensity. "At a constant intensity light acts as a continuous source of stimulation." When animals are not oriented both sides are continuously stimulated but one is stimulated more than the other. This causes one side to move faster than the other "until symmetrically situated points on the body of the animal are struck at the same angle by equally strong rays of light."

In a recent paper (1907) Loeb again emphasizes this difference between "heliotropism" and "Unterschiedsempfindlichkeit." It is therefore evident that he was well aware of the fact that certain animals respond to changes in light intensity. This, however, is an old idea. As a matter of fact it was the fundamental postulate of all who thought that reactions are controlled by psychic phenomena. And in his earlier work Loeb attempted to prove the absence of such phenomena, by showing that aggregation of animals in a given light intensity is not due to difference of intensity, i.e., that the animals are not "unterschiedsempfindlich." Later, however, he found that planarians collect in regions of lowest intensity because they are "unterschiedsempfindlich"; (1907), "Both forms of reaction may occur in the same animal (e.g., Spirographis), but this is neither necessary nor the rule."

Loeb did not study the reactions of unicellular organisms to light and it has been frequently stated that he did not apply his theory to their reactions. Such statements, however, are erroneous as the following quotations will show: (I905, p. 73), “Experiments on infusoria are already sufficiently complete to show that Sachs's laws of heliotropism also hold good for them. . . . Trembley's experiments on 
Hydra, however, show that in their case also the relation is the same; at least it seems to me that Trembley's experiments cannot be interpreted unless we assume that the progressive movements of Hydra are determined by the direction of the rays of light."

I have quoted Loeb rather freely in trying to present his views, mainly because he and others have repeatedly maintained that critics have failed to understand his work, particularly that referring to the cause of orientation and aggregation in regions of certain intensity. These quotations together with the discussion presented seem to warrant the following summary statements concerning his work on reactions to light.

(I) His object was to give a mechanical explanation of behavior in opposition to so-called anthropomorphic explanations of Bert, Graber and others.

(2) He proposed to do this by showing that the reactions in animals, especially those due to stimulation by light, are governed by the same law as those in plants.

(3) He accepted the explanation of orientation in plants given by Sachs and states his theory correctly. Loeb's conclusions however do not support this theory. He confuses ray direction through the tissue with ray direction in the field and difference of intensity on the surface of the organism with diversity of intensity in the field.

(4) Loeb failed to consider the effect of difference in sensitiveness to light between the posterior and anterior ends of animals and the effect of change in axial position on the relative illumination of these ends.

(5) His experimental evidence does not prove that the direction of light rays functions in orientation except in so far as it may produce difference of intensity on the surface of the organism; nor does it prove the absence of sensation in orientation.

(6) In I 888 Loeb held that orientation in animals is controlled by the direction in which the rays of light pass through the tissue. From I889 to I903 he advocated the 
idea that orientation is controlled by the direction in which the rays strike the surface, or the angle they make with the surface. His statements from 1906 to 1909 indicate that he thinks that orientation is regulated by the relative intensity of light on symmetrically located sensitive structures on opposite sides of the organism, a view which Sachs strenuously opposed.

(7) Loeb's theory of orientation with reference to plants implies that the external agent acts on the motor apparatus directly, and with reference to animals that it acts either on the motor apparatus directly or through a direct reflex arc.

(8) He thinks that movements in plants and animals are controlled unequivocally by external agents and that they are not fundamentally adaptive. "Eine 'Auswahl' einer passenden Beleuchtungsintensität habe ich nie beobachtet" (I909, p. 35).

(9) Reactions to light may be heliotropic or photokinetic. The former are never due to change in light intensity, they " are a function of the constant intensity; (the latter) a function of the quotient of the change of intensity over time," i.e., rate of change of intensity. There is a perfect analogy between the effect of light and the effect of a constant electric current.

(Io) Aggregation in some forms is due to photokinetic reactions.

(I I) Loeb considers his theory applicable to the reactions of the infusoria as well as to those of higher animals and plants.

(12) He stands for an objective explanation of the behavior of animals in all his work, but he cannot be considered as the originator of this idea. Nor was he the first to attempt to put it on an experimental basis.

Verworn was one of the first investigators in comparative physiology in its broadest sense. He was of the opinion that the fundamental physiological and psychological processes are common to all animals and that they can be solved in the simple forms more readily than in the more 
complex. In this connection we are interested primarily only in his investigations on the activities of the protozoa. These were taken up in I886, two years before Loeb's first preliminary note on the reactions of animals appeared. Verworn was probably the first to attempt an explanation of the behavior of animals from a purely objective point of view. In his papers many valuable observations are recorded on the collection of protozoa in given regions, and on the orientation of these creatures when subjected to stimuli of various sorts. Contrary to the idea of Loeb, he concluded that the reactions to light are fundamentally adaptive ( 1899, p. 60). His explanation of orientation is of particular interest to us since it has frequently been referred to in works on behavior. This he has presented in his General Physiology.1 (I 899, p. 499): "We will examine, first, the forms that possess one flagellum, such as many Bacteria and flagellate Infusoria, and will select as repre-

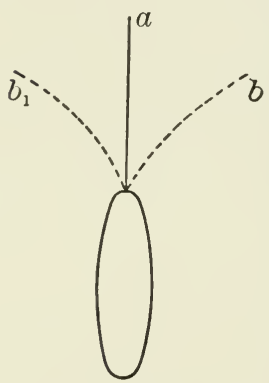

FIG. 2. Scheme of the contraction of the flagellum of a flagellate-infus- 1 orian cell. After Verworn (1899, p. 499). See text. sentative the delicate, green, flagellateinfusorian Euglena, which, in summer, by means of its countless numbers, changes the water of standing pools into a deep green. The flagellum of the Flagellata is upon the anterior pole of the body and moves through the water in a screw-like path. For the sake of simplicity its motion may be considered as taking place in a single plane. It is then seen that it oscillates about the straight middle position [Fig. 2] by means of alternate rhythmic contractions toward the right (b) and toward the left $\left(b_{1}\right)$; the swing out of the middle position (a) into one of the two extreme positions ( $b$ or $b_{1}$ ) represents the phase of contraction; the return from one

1 The first edition of this volume appeared in 1894 at a time when Loeb was emphasizing the importance of ray direction more strongly than he did later. 
of the extreme positions into the middle position, the phase of expansion. The flagellum works, therefore, like an oar that is moved alternately to the right and to the left at the bow of a boat. It is evident that, while undisturbed and having equal conditions upon all sides, the infusorian body must move forward in a straight line, if the flagellum beats equally strongly toward the right and toward the left, i.e., if contraction and expansion occur with equal rapidity toward the two sides. But if a contractile stimulus acts upon the flagellate suddenly from one side, and if the long axis of the body is not already turned in the direction of the stimulus with the posterior pole toward its source, such a position is assumed by means of a few strokes of the flagellum; for with every oblique or transverse position of the long axis the flagellum is stimulated to contract more strongly upon the side upon which the stimulus falls than upon the opposite side, it makes stronger strokes toward the former than toward the latter side, and the result is that the anterior part of the body is turned away from the source of the stimulus. Exactly the same relations exist here as in a boat moved by a single oar. The bow of the boat also turns toward the opposite side when the boat is propelled more strongly upon one side than the other. The unequal strength of the flagellar stroke in the two directions continues, and the anterior part of the body is turned constantly more away from the source of the stimulus, until the body has placed its long axis in the direction of the incident stimulus. Then both sides of the flagellum become equally stimulated and the protist swims in a straight line, so long as the stimulus continues. Thus, negative chemotaxis, phototaxis, etc., appear in uniflagellated Bacteria and Flagellata as a necessary result of a unilateral excitation of contraction in the flagellum."

Orientation in forms possessing two flagella and in forms possessing numerous cilia is similarly explained. When an organism of this sort is not oriented it is assumed that the flagella or the cilia are more strongly stimulated on one side 
than on the other and that this causes them to beat more or less effectively until the organism becomes directed toward or from the source of stimulation, a direction it must retain.

By careful reading of Verworn's theory, quoted above, one is led to infer that he considered the flagella or cilia to be stimulated directly. This, however, is not an essential part of the theory. The essential point is that there is a difference in the effect of the beat of the cilia on opposite sides when these sides are differently illuminated. It does not matter whether this is caused directly by the effect of the stimulating agent on the cilia or indirectly through impulses transmitted to the cilia from the body protoplasm. An organism once oriented in accord with this theory must remain oriented unless it is thrown out of orientation by some other agent than that which has caused the orientation. Orientation according to this theory is direct. Light acts constantly as a directive stimulus. Difference of intensity on opposite sides of the organism causes unequal action of the cilia on the two sides. Symmetrical location of organs is essential in the organism.

It will thus be seen that Verworn's theory of tropisms agrees with the theories of Loeb, especially the more recent, in all essential points. These two authors, however, opposed each other from the beginning. Loeb argued in favor of ray direction, Verworn in favor of intensity difference; neither seems to have known precisely what the other meant. Verworn gives the following statement (I899, p. 450): "From the preceding consideration and by analogy with the directive effects of other stimuli it is evident that only the difference in the intensity of the light upon different parts of the body can produce a directive effect; where the stimulus acts upon the surface of the body from all sides with equal intensity, the reason for a definite axial position disappears, as is to be observed most clearly in the action of chemical stimuli upon all sides. Although this is obvious, some investigators, such as Sachs and Loeb, have 
believed that the direction of the rays is more responsible for the manifestation of phototactic phenomena than are differences in intensity. It is difficult to conceive this, for, since the assumption of an axial direction is possible only when differences exist at two different points of the surface of the body, it is wholly mystical how the direction of the rays, which is the same upon all sides of the body, can produce such an effect." Loeb is here classified with Sachs where he claimed to belong. His experimental results and conclusions are, however, from the beginning, more nearly in harmony with the theory of Verworn than they are with that of Sachs.

Verworn considers his theory applicable to orienting reactions in unicellular forms induced by stimuli of various kinds. He says (I899, p. 503), "Thus the phenomena of positive and negative chemotaxis, barotaxis, thermotaxis, phototaxis and galvanotaxis which are so highly interesting and important in all organic life, follow with mechanical necessity as the simple results of differences in biotonus, which are produced by the action of stimuli at two different poles of the free-living cell."

In 1892 Oltmanns attempted to settle the dispute as to the relative effect of ray direction and intensity difference by studying the reactions of Volvox in an aquarium in which the light became more intense gradually from one end to the other. Such a distribution of light was produced by placing a hollow prism filled with a mixture of India ink and glycerine-gelatine between the source of light and the aquarium. The India-ink mixture of course absorbed only a little light at the thin end of the prism, but gradually more toward the thicker end. Under these conditions the Volvox colonies collected in light of a given intensity. Oltmanns says (I892, p. I95) that when the prism was put between the source of light and a vessel containing colonies which had a given direction of motion, they changed their direction of motion almost instantly and moved toward the region of optimum intensity. Olt- 
manns and others who used this method of producing light of graded intensity assumed that the light rays in the aquarium under such conditions were parallel with each other and perpendicular to the side through which they entered, and that the change in direction of motion when the prism was put into place was due not to the direction of the rays but to difference in light intensity. Oltmanns does not make it clear in what sense he uses these terms. He does not say whether he means difference of intensity in the field or difference on the surface of the organism, ray direction in the field or ray direction through the organism. No matter, however, in which sense these terms were used, the conclusion was not warranted, for it is clear from a theoretical as well as from a practical standpoint, that the rays of light in the aquarium were neither parallel with each other nor perpendicular to the side through which they entered. The India-ink mixture contains numerous solid particles of carbon in suspension, which, together with particles in suspension in the water in the aquarium, unquestionably diffuse the light in such a way that the rays in the aquarium coming from the more highly illuminated end are more numerous than those coming from the other end, and so if the direction of the rays were the controlling factor one might expect the organisms to go toward either end.

After reviewing the work of the preceding authors and presenting some original experiments similar in method to those of Strasburger, Davenport (I897) agrees with Loeb in assuming two dissimilar sorts of locomotor responses to light. These he designates phototaxis and photopathy. Phototaxis he defines " as migration in the direction of the light rays, and photopathy as migration toward a region of greater or less intensity of light." He accepts the theory of orientation as outlined by Sachs and formulates another which is in all essentials like that of Loeb. He says (p. 209): "Let us first think of the way in which light acts on the negatively phototactic (and photopathic?) earthworm. 
Represent the worm by an arrow whose head indicates the head end [Fig. 3,A]. Let solar rays $S S$ fall upon it horizontally and perpendicularly to its axis. Then the

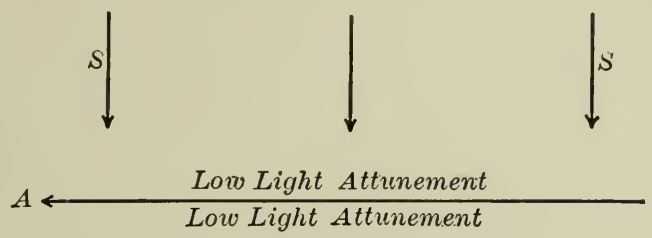

Fig. 3. Diagram representing sunlight $(S S)$ falling upon an elongated, bilateral organism (represented by the arrow) whose head is at $A$. After Davenport (I897, p. 209).

impinging ray strikes it laterally, or, in other words, it is illuminated on one side and not on the other. Since, now, the protoplasm of both sides is attuned to an equal intensity of light, that which is the less illuminated is nearer its optimum intensity. Its protoplasm is in a phototonic condition. That which is strongly illuminated has lost its phototonic condition. Only the darkened muscles, then, are capable of normal contraction; the brightly illuminated ones are relaxed. Under these conditions the organism curves towards the darker side; and since its head region is the most sensitive, response begins there. Owing to a continuance of the causes, the organism will continue to turn from the light until both sides are equally illuminated; i.e. until it is in the light ray. Subsequent locomotion will carry the organism in a straight line, since the muscles of the two sides now act similarly. Thus orientation of the organism is effected. The same explanation ... will account, mutatis mutandis, for positive phototaxis."

It is evident that this theory assumes a direct effect of the stimulating agent on the locomotor organs. Davenport thus claims that orientation may be brought about in two ways: "Light acts directly either through difference in intensity on the two sides of the organism, or by the 
course the rays take through the organism " (p. 2Io). He assumes that changes of light intensity do not result in orientation but that stimulation caused by such changes may determine the position of organisms in the field in some such way as described by Engelmann. He says (p. 2II), "Two kinds of effects are produced by light: one by the direction of its ray - phototactic; the other by the difference in illumination of parts of the organism photopathic."

Holt and Lee (I90I) studied the behavior of Stentor coeruleus in an aquarium receiving light through a prism similar to the one used by Oltmanns, and found that the animals collected at the darker end. In conclusion they support Verworn's theory; but from the preceding discussion of the effect of the prism on the direction of rays it is evident that the validity of this conclusion is questionable.

Rádl's work on reactions to light was almost entirely confined to the crustacea and insects. In I903 after a rather extensive review and criticism of the results and theories of others, and an exposition of his own work, he arrived at two conclusions which are of interest in this connection. One has reference to the mechanics of orientation, the other to the explanation of negative reactions.

His theory of orientation is based on the conception that change in the direction of motion is brought about by unequal stimulation of symmetrical points on the surface of the organism, a conception which lies at the foundation of all the theories thus far presented, excepting that of Sachs and the first one of Loeb. While all of these differ in some respects, they are alike in that they assume the external agent to act through the effect of chemical changes in the organism. Rádl proposes to explain orientation as the direct effect of light on the organism. He says (I903, p. I5I): "Alle Autoren, welche bisher dieses Thema berührt haben, haben an indirekte Wirkungen des Lichtes gedacht, dass nämlich durch dasselbe chemische Veränderungen 
hervorgerufen werden, welche erst die Reaktionen des Organismus direkt beeinflussen. . . Gegenüber diesen Anschauungen möchte ich das Problem des Phototropismus als direkte Wirkung des Lichtstrahls auf den Organismus auffassen. Wenn wir nämlich konsequent unsere Auffassung der Orientierungserscheinungen durchführen wollen, so müssen wir auch den Phototropismus als Folgeerscheinung aus dem Spiel zweier Kräfte, einer äusseren und einer inneren auffassen - ich bemühe mich wenigstens umsonst mir vorzustellen, dass die Sache anders sein könnte. Die äussere Kraft ist in diesem Falle der Lichtstrahl; derselbe muss eine Druckkraft auf den Organismus ausüben, ich glaube eine ähnliche Druckkraft, wie auf uns etwa der Luftstrom drückt. Diese Vorstellung scheint recht phantastisch $\mathrm{zu}$ sein, ich sehe jedoch keinen anderen Ausweg. Es ist nicht nötig, dass dieser Druck gross sei, er kann sehr fein sein, aber ein Druck, welcher eine Richtung hat, muss es sein, wenn überhaupt eine Orientierung, eine Drehung entstehen kann."

The maximum pressure of direct sunlight having an intensity of $5000 \pm$ candle meters is only $0.4 \mathrm{mg}$. on one square meter of black surface, and only twice as great on an equal area of reflecting surface. According to this theory then, an organism responding to o.I candle meter would have to be stimulated by light not to exceed 0.0000 I 6 mg. In view of this fact it is not likely that this theory will ever be seriously considered. It has been presented here merely as a matter of historical interest.

Rádl's view as to the difference between positive and negative reactions is equally untenable. He concludes his discussion on this subject with the following paragraph (I903, p. I03): "Ich glaube nun, dass der Unterschied zwischen positivem und negativem Phototropismus ähnlich wie beim Menschen nicht ein Unterschied in der Orientierung, sondern nur in der Lokomotion ist; dass das Tier in beiden Fällen gegen die Lichtquelle gleich orientiert ist, jedoch nicht gleiche Muskeln spannt." It is of course 
well known that contrary to Rádl's conclusion, most of the organisms which face the source of stimulation when positive, turn and face in the opposite direction when negative.

2. More thorough Experimental Analysis Showing the Relative Importance of Internal and External Factors in Behavior

None of the investigators thus far mentioned studied the behavior of lower organisms in sufficient detail to be able to tell from direct observation precisely what takes place in the reactions. It was well known from direct observation that many of these organisms form dense aggregations under certain conditions and that they frequently orient when subjected to certain stimuli; but just what takes place during the process of aggregation and orientation was with a few exceptions known only theoretically.

Jennings was the first to supply this deficiency in observation. He began his investigations on this subject in I 897 by working out in minutest detail precisely what movements are involved in the formation of the dense aggregations so frequently seen in cultures containing paramecia. His work differs from that of his predecessors in this line largely in that, while they, with the possible exception of Engelmann, studied mass movements and end results, he studied the individuals. He was interested not so much in the aggregations as in the process of their formation. How does each individual get there? and why does it stay there? were prominent questions in his mind.

The observations on the formation of aggregations of paramecia were followed by similar observations on the reactions of representative species of the various groups of protozoa and lower metazoa to various sorts of stimuli. All of this work is characterized by unity of purpose, keenness of observation and simplicity of method.

The results of all of Jennings' work, published in nu- 
merous papers, were brought together and systematized in the well known book on the "Behavior of Lower Organisms " (I906). I shall refer to this book almost exclusively in trying to present his views on the factors involved in the phenomena in which we are especially interested - aggregation in regions of given light intensity, orientation and change in sense of reaction.

Aggregation in a region having a given light intensity may be formed, according to Jennings, in either of two ways. (I) The organisms get into the region just as they would into any other region, merely by swimming about in an aimless manner, without orientation and without direct movement toward the region. When they get to the limit of the region and are about to pass out into light of a different intensity the sudden change to which they are subjected produces a stimulation which causes a definite reaction. This reaction consists chiefly in a sudden turn toward a given side, frequently after backing some distance, and procedure on a new course. They respond with this reaction every time they come to the edge of the region and therefore remain in this region. Other individuals behave in the same way and this results in an aggregation. "Motor reflex " was the first term applied to this method of reaction with its various modifications; later it was designated " motor reaction," and finally " avoiding reaction." The essential feature in the avoiding reaction is the fact that the organism always turns toward the same side regardless of the place of application of the stimulus. The side toward which it turns is determined by internal factors. Thus it is that the direction of turning bears no definite relation to the position of the source of stimulation. The organism may turn directly toward it or away from it or at any angle to it: The method of aggregation thus described by Jennings for Paramecium is in all essentials like that described by Engelmann in $\mathrm{I} 882$ and I 883 for Paramecium bursaria, Euglena, Bacterium photometricum and other organisms. 
(2) In place of getting into regions of a given light intensity by mere wandering movements, organisms may orient and move directly toward such regions, and the avoiding reaction may keep them in this region just as described above, or they may remain because it is illuminated by light of optimum intensity. If they get into light of lower intensity they become positive and return to the optimum directly after becoming oriented. If they get into light of higher intensity they become negative and orient in the opposite direction, which again causes them to return to the optimum intensity. The organism usually tries numerous positions before it becomes oriented. Many errors are made before the successful position is attained; many directions of motion are tried; one is selected. Jennings has designated this method of orientation as orientation by "trial and error," or more recently merely by "trial." Some seem to be of the opinion that the trial movements are haphazard movements, that they are not definitely determined. In answer to this Jennings says (I906a, p. 452): "The behavior may perhaps be most accurately characterized as 'selection from among the conditions produced by varied movements.' In general we find that many organisms are so constituted that internal conditions (permanent or temporary) will produce under stimulation movements that are varied in precisely such a way as to subject the creature to as varied environmental conditions as possible, and thus give it an opportunity to select what is nearest the optimum. Every one of these movements is, of course, as absolutely determined as the most orthodox tropism, only the determining factor is not the localization of the stimulus (or other external factor) alone.

"Certain recent writers have seemed to imply that there is a contrast between the 'trial and error' method, and behavior that is definitely determined by structural and other internal conditions. It needs to be emphasized, perhaps, that the behavior which I and others have char- 
acterized by this phrase is very precisely determined by structural and other internal conditions; indeed, its distinguishing feature is the fact that it is thus determined by such conditions, rather than exclusively by the external conditions."

Jennings places particular emphasis on the idea that " activity does not require present external stimulation." This is an idea of which Darwin made much in his work on movement in plants. To explain orientation, Darwin said, we do not need to account for movement; it is only necessary to account for change in the direction of movement. Jennings applies this idea to the orientation of animals. The animals are in motion; the question is, how is the direction of motion regulated so as to result in orientation? He says that in many of the infusoria it is regulated by means of the avoiding reaction. "This reaction" (1906, p. 79) "consists in successively 'trying' not only different directions of locomotion, but also different positions of the body axis. As soon therefore as a position is reached in which the disturbance causing the reaction no longer exists, the reaction of course stops; the animal therefore retains this axial position."

It will thus be seen that orientation in these forms is, according to Jennings, not brought about by a direct turning of the anterior end of the body toward or away from the source of stimulation. It is not due to unequal stimulation of points symmetrically situated on the body; the external agent does not act constantly as a directive stimulus. "The position of orientation is not one in which a median plane of symmetry takes up a definite position with reference to the external agent." Not all reactions resulting in orientation are however of this sort. Many organisms have the power of turning directly toward or away from the side stimulated; in these orientation may take place directly, as Jennings clearly states in the following words (1906, p. 27I), "In the symmetrical Metazoa we of course find many cases in which the animal turns 
directly toward or away from the source of stimulation, without anything in the nature of preliminary trial movements." Reactions which show a definite relation to the localization of the stimulus "include perhaps the greater number of the directed movements of the organisms."

It is evident, judging from these quotations, that Jennings does not hold that all organisms orient by means of avoiding reactions. He does not oppose the idea of direct orientation by means of differential response to localized stimulation. He opposes the view that this is the only method of orientation and the view that orientation is caused by the direct effect of the external agent on the locomotor organs. He holds that the power of differential response to localized stimulation is derived from other methods of reaction, as described in the following quotations and abstracts (I906, pp. 306-308): "First we have the simple phenomenon that when a portion of an organism is stimulated this portion may respond by contraction, extension, or other change of movement." Such local reponses to local stimulation we find in Amoeba, Hydra, Sagartia, flatworms and many other soft-bodied animals, and even in man when the electrode of a battery is applied directly over a muscle. "In many cases we find that the relation of the movement to the source of stimulation is brought about indirectly through selection from among varied movements. The organism tries moving in many directions, till it finds one in which there is no stimulus to further change. . . . In still other cases the reaction shows a definite relation to the localization of the stimulus, yet it is not due to local reaction of the part stimulated, nor is it brought about by trial. If an infusorian is stimulated at the anterior end it swims backward; stimulated at the posterior end it swims forward. Both these movements are reactions of the entire organisms, all the motor organs of the body concurring to produce them; they are not produced by local reactions of the organs at one end or the other.... Such behavior apparently represents 
not a primitive condition, but a product of development." "To a change leading away from the optimum (in either plus or minus direction)" the organism responds in such a way as to tend to return to the optimum. "Thus are produced the so-called positive and negative reactions."

The essential characteristics in behavior, as analyzed by Jennings, are clearly set forth in the following quotations (1906, pp. 283-292). Internal factors: "Activity does not require present external stimulation. . . . Activity may change without external cause.... Changes in activity depend on changes in physiological states. . . Reactions to external agents depend on physiological states. .. The physiological state may be changed by progressive internal processes, particularly those of metabolism. . . . The physiological state may be changed by the action of external agents. . . The physiological state may be changed by the activity of the organism.... External agents cause reaction by changing the physiological state of the organism. . . The behavior of the organism at any moment depends upon its physiological state at that moment. . . Physiological states change in accordance with certain laws. . . The resolution of one physiological state into another becomes easier and more rapid after it has taken place a number of times."

Different factors on which behavior depends : "We have seen that the behavior of the organism at a given moment depends on its physiological state, and that it therefore secondarily depends upon all the factors upon which the physiological state depends. Hence we cannot expect the behavior to be determined alone by the present external stimulus, as is sometimes maintained, for this is only one factor in determining the physiological state. The behavior at a given moment may depend on the following factors, since these all affect the physiological state of the organism:

"I. The present external stimulus.

"2. Former stimuli. 
"3. Former reactions of the organism.

"4. Progressive internal changes (due to metabolic processes, etc.).

" 5. The laws of the resolution of physiological states one into another.

"All these factors have been strictly demonstrated by observation and experiment, even in unicellular organisms. Any one of these alone, or any combination of these, may determine the activity at a given moment."

External factors (p. 299): "We may sum up the external factors that produce or determine reactions as follows: (I) The organism may react to a change, even though neither beneficial nor injurious. (2) Anything that tends to interfere with the normal current of life activities produces reactions of a certain sort ('negative'). (3) Any change that tends to restore or favor the normal life processes may produce reactions of a different sort ('positive'). Changes that in themselves neither interfere with nor assist the normal stream of life processes may produce negative or positive reactions, according as they are usually followed by changes that are injurious or beneficial. (5) Whether a given change shall produce reaction or not, often depends on the completeness or incompleteness of the performance of the metabolic processes of the organism under the existing conditions. This makes the behavior fundamentally regulatory."

Reactions and change in the sense of reactions are, therefore, according to Jennings, adaptive ; and if this be true, an explanation of them must be looked for along the same lines as an explanation of any other adaptive characteristic in organisms, functional as well as structural.

Finally we may refer to the "selection of random movements" as a factor in orientation, as put forward by Holmes (I905). He studied the reactions to light of earthworms and blow-fly larvae and found that when these animals are stimulated they turn in many directions, apparently feeling about until they become directed away 
from the source of stimulation. From these observations he concluded that "orientation is produced indirectly by following up these chance movements which bring respite from the stimulation."

This conclusion is in perfect harmony with that of Jennings regarding the orientation of protozoa. The only difference between the orienting reactions in the two classes of animals mentioned is that the unicellular forms studied by Jennings turn in different directions by means of the avoiding reaction, i.e., they always turn toward a structurally defined side, while the metazoa investigated by Holmes are not thus limited in their direction of turning. Not all protozoa however are limited in the direction of turning. Lacrymaria olar, for example, swings its long anterior proboscis-like appendage about in all directions and there appears to be no limitation set to the direction in which it may turn.

Holmes contrasts the random movements with forced reflexes, and characterizes the former as "elements of spontaneous, undirected activity." This statement naturally leads to the conclusion that the direction of motion in random movements is not definitely determined. It is however hardly probable that Holmes intends to convey such an idea, for it is undoubtedly true that the direction in random movements is as definitely and absolutely determined as it is in the avoiding reaction or in forced reflexes. The difference is merely that the factors involved are different in the different methods of reaction.

\section{Summary of Historical Review}

(I) During the early periods of civilized man all living things were held to be endowed with a soul which was responsible for all activity.

(2) Mechanical explanations of activity received but little attention until early in the seventeenth century, the period of Harvey, Descartes and Borelli. 
(3) This period resulted in the origin of the iatromechanical and iatrochemical schools. The object of these schools was to explain all vital phenomena on purely physical and chemical principles.

(4) The failure to accomplish this purpose led to the origin of the doctrine of vital force, during the first years of the eighteenth century. This resulted in a period of stagnation in research in this line which continued until the appearance of Johannes Müller, De Candolle and many others, early in the nineteenth century.

(5) The establishment of the doctrine of evolution by Darwin and the consequent interest in the origin of mental phenomena in man led to special activity in the study of behavior of animals from the psychological point of view, and numerous anthropomorphic explanations of their activity.

(6) In plants activity was studied from the physicochemical point of view during this period. This study resulted in the development of the idea that the actions are definitely controlled by external agents, e.g., the direction of growth in roots and stems by gravity, moisture, light, etc. The reactions thus definitely controlled were called tropisms. At first the term tropism was used merely to indicate the relation between the direction of bending and the position of the source of stimulation (De Candolle, I832). Tropisms were however in general regarded as reactions unequivocally controlled by external agents.

(7) The study of animal behavior from the physicochemical point of view was first taken up by Verworn and Loeb in I886 and I887. The activity of the different organs in animals had been studied from this point of view for nearly three centuries, but not the reactions of the animal as a whole. Loeb attempted to show that the behavior in plants and animals is essentially the same, and concluded that the behavior of animals is very largely unequivocally controlled by external agents. He and his followers therefore described reactions in animals in terms 
of tropisms in opposition to the anthropomorphic descriptions current at that time. Animals go toward a source of light neither because it is useful for them to do so nor because they enjoy light or can see, but because they are positively heliotropic. But what is the underlying cause of tropisms? What are the mechanics involved in the processes described by this term? Loeb applied the theories developed by botanists to answer these questions and developed others (see p. 25). Verworn and other investigators added new ones or suggested modifications. Thus it came about that the term tropism came to have a multiplicity of meanings.

(8) Some of the explanations of behavior offered under the name tropism were founded on the idea that the external agent acts directly or through a direct reflex mechanism on the locomotor organs. This idea together with others assuming unequivocal control of behavior by external factors, Jennings and his followers found to be untenable in their studies on the behavior of the lower organisms. The new features introduced by this school have been clearly set forth above; it will therefore not be necessary to emphasize them here.

\section{Various Definitions of Tropisms}

The term tropism was first used by De Candolle in I832. He called the bending of plants toward the light heliotropism, indicating merely the relation between the direction of bending and the source of stimulation. Later the term tropism came to signify not only the bending or orienting but also the explanation of the process. Thus for every new explanation the term received a new signification, and this has naturally led to much confusion. Let us point out some of the different meanings which have been applied to the term heliotropism.

(I) Sachs in I876 concluded, as stated above, that orientation of plants is due not to difference in light inten- 
sity on the surface as De Candolle held, but to the direction in which the rays pass through the tissue. Heliotropism, to some of those who agreed with Sachs, meant orientation due to direction of rays through the tissue, to others merely orientation due to ray direction in general.

(2) Darwin in I880 said orientation in plants is due to modification of circumnutation. It is regulated by difference of intensity on opposite surfaces, probably changes of intensity, and he used the term heliotropism to indicate this.

(3) In I 888 Loeb maintained that orientation in animals is controlled by the direction in which the rays pass through the tissue, that is, in the same way in which Sachs had said it was controlled in plants. In I 889 he still held that light reactions in plants and animals are governed by the same laws. But now he says symmetrically located points on the photosensitive surface must be struck by light at the same angle. "Light automatically puts the plant or the animal into such a position that the axis of symmetry of the body, or organ, falls into the direction of the rays of light." Heliotropism is however used not only to express this explanation of orientation, which differs materially from that of Sachs, but also to indicate movement toward or from the source of light. In his later work, he abandons the idea of the importance of the angle between the sensitive surface and the light rays and substitutes the idea that it is relative intensity on opposite sides which governs orientation. Thus heliotropism received a new signification. His most recent views are expressed in the following quotations (1906, pp. I35, I38): "Heliotropism covers only those cases where the turning to light is compulsory and irresistible, and is brought about automatically or mechanically by the light itself. . . . If the current curves of radiating energy, e.g., light rays, strike an animal on one side only, or on one side more strongly than on the symmetrical side, the velocity or the kind of chemical reactions in the symmetrical photosensitive points of both sides of 
the body will be different. The consequence will be in a positively heliotropic animal a stronger tension or tendency to contract in the muscles connected with the photosensitive points of the one side of the body than in those connected with the opposite side." This view is affirmed in a recent address (1909).

(4) It is ordinarily assumed that Verworn considers orientation in the lower forms to be due to the direct effect of the external agent on the locomotor appendages. If, e.g., one side is more highly illuminated than the other the cilia beat more or less effectively on that side and thus produce orientation. This process is termed heliotropism or phototaxis.

(5) "Two kinds of effects are produced by light " according to Davenport (1907, pp. 210, 21 I), " one by the direction of the rays . . . either through difference of intensity on the two sides of the organism, or by the course the rays take through the organism - phototactic; the other by the difference in illumination of parts of the organism photopathic."

(6) Yerkes says (I903, p. 36I), "All those reactions in which the direction of movement is determined by an orientation of the organism which is brought about by the light are phototactic; and all those reactions in which the movement, although due to the stimulation of light, is not definitely directed through the orientation of the organism are photopathic."

(7) To Rádl (1903) heliotropism means orientation due to difference in light pressure on unequally illuminated symmetrically located surfaces.

(8) Holmes (1905) calls orientation by selection of random movements phototaxis (heliotropism).

(9) Barrows (I907, p. 530) and Walter (I907, p. I49) suggest "asymmetrical response to asymmetrical stimulation" as a criterion of tropisms; and because the organisms worked on respond thus they conclude that their reactions are tropic. According to this criterion it is of course evident 
that every differential response to a localized stimulation even in a human being may be a tropic response.

(I0) To Bohn forced orientation constitutes a tropism; (I908, p. 78), “ L'orientation est directe; l'animal est attire sans qu'il puisse resister: il y a là un 'tropisme' au sens de Loeb "; (p. 80), “On n'a pas besoin de nier la 'volonte' de l'animal; on peut dire que ces impulsions sont plus fortes qu'elle. On ne peut nier les tropismes."

(II) Parker apparently considers any reaction which carries an animal toward or away from the source of stimulation as tropic; he says (I908, p. 426), "Since amphioxus swims away from a source of light, it is negatively phototropic." Minkiewicz (I907, p. 47), uses the term tropism in much the same sense, as does also Hadley, who defines it and photopathy as follows (I908, p. 20I): "A phototactic reaction [is] one in which the organism tends to place the longitudinal axis of the body parallel to the direction of the rays and to approach or recede from the source of those rays. . . A photopathic reaction is one in which an organism, without previous assumption of a body-orientation, 'selects' regions of optimal light-intensity.'

(I2) Washburn (I908, p. 57) refers to tropisms as "the direct motor response of an animal to an external stimulus," and Torrey defines the term similarly but somewhat more definitely. He says (I907, p. 319): "In heliotropism as well as in galvanotropism, the oriented organism is in a condition of physiological stimulation, and ... the response to stimulation is local." This definition is in all essentials like those of Verworn and Loeb.

(I3) Driesch (I908, p. II) says, "A tropism . . . is a directed movement of a growing part of a plant or hydroid determined by the direction of a directed agent."

(I4) Wheeler (I9IO, p. 5I5) considers reactions which "involve an adaptive orientation" as tropic.

(I5) Jennings (I909, p. I) suggests the following definition: "The tropism includes those reactions in which the organism takes and maintains a definite orientation - places 
the axis of its body in a definite position - with relation to some external source of stimulation."

It is evident from these statements that nearly every reaction in living organisms comes under one or another of the various definitions given to the term tropism. To say that an organism is tropic or not tropic means but little until the sense in which this term is used is defined. Failure to do this has led to serious misunderstanding. I have no objection whatever to the term tropism if used in its original sense, or in any other definite sense. At present, however, it conveys so many different meanings that it inevitably leads to confusion. I shall therefore avoid using it in the following analysis of reactions to light.

\section{Statement of Important Problems in the Study of Reactions to Light}

In this analysis we shall aim to keep in mind the variolis factors suggested as important in the different tropism theories and other explanations of behavior. We shall ask ourselves: is orientation direct, does the organism turn directly toward or away from the source of stimulation, or does it become oriented after a series of preliminary movements? How is the stimulus causing orientation produced: by direction of rays through the organism in accord with the theory of Sachs; by absolute difference of intensity on symmetrically located points on the sensitive surface in accord with the theories of Loeb and Verworn; or by changes of intensity on the surface in accord with the ideas of Engelmann, Darwin, and Jennings? Does light act constantly as a directive stimulation similar to the action of a constant current of electricity in accord with Loeb's theory of tropism, or does it act only when the organism turns out of its course so as to produce changes of intensity, as suggested by Jennings? Is orientation due to the direct effect of light on the locomotor appendages in accord with the theory of Verworn and the analysis of Torrey, to the indi- 
rect effect through a direct reflex arc as suggested by Loeb, or is the whole organism more or less involved in the reaction in accord with the ideas of Jennings and Holmes? If orientation is direct, precisely what movements are involved in the process? Are the avoiding reactions due to differential response to localized stimulation, as held by some, or is the direction of turning in such reactions absolutely determined by the structure and physiological state of the organism? Are the reactions to light in general adaptive and modifiable in accord with Jennings' analysis, or are they fixed and forced and unequivocally controlled by the external agent in accord with Loeb's ideas? Are the more refrangible rays most active in stimulating all organisms as claimed by Loeb and Davenport, or are some organisms stimulated more by waves of a certain length, and others by waves of a different length as claimed by Verworn and Nagel? These questions and others we shall attempt to answer in the following pages. 


\title{
PART II
}

\author{
EXPERIMENTAL OBSERVATIONS AND DISCUS- \\ SIONS BEARING ON THE QUESTION AS TO HOW \\ ORGANISMS (ESPECIALLY THOSE WITHOUT \\ EYES) BEND OR TURN AND MOVE TOWARD \\ OR FROM A SOURCE OF STIMULATION
}

\section{CHAPTER IV}

\section{PROCESSES INVOLVED IN THE BENDING OF DIFFERENT PARTS OF HIGHER PLANTS TOWARD THE SOURCE OF LIGHT}

I. Observations on Plumules of Indian Corn (Zea mays) and Leaves of Nasturtium (Tropaeolum)

a. Introduction. - It is well known that many plant structures have a sensitive zone which may be separated by some distance from the motory zone and that impulses are transmitted from the one to the other. Darwin (I880), Pfeffer (I 894), Czapek (I900), Pollock (I900), Haberlandt (1904) and others demonstrated this for leaves and plumules stimulated by light and for radicles stimulated by gravitation and injury (cauterization). Newcombe (1902, p. 346) also proved that impulses due to stimulation by water currents are transmitted in radicles. In radicles the distance of transmission of impulses is frequently over Io mm., while in leaves it is often several centimeters.

Just how the external agent produces the stimulus is not known, although it is generally supposed that it is by causing chemical changes. With regard to light it has been a question as to whether the orienting stimulation is depend- 
ent upon the direction in which the rays pass through the tissue or upon difference of intensity on opposite sides of the reacting organ. Sachs (see p. I3) originated the former view and Müller and others supported it, while Darwin, Wiesner and Oltmanns were prominent champions of the latter. Darwin also emphasized in particular the importance of change in intensity. Pfeffer (I906, p. 228) says that the experimental results and the arguments offered in support of either view are not conclusive.

Darwin exposed monocot plumules (stems of young seedlings) with one side covered with India ink in front of a window and found that they did not bend straight toward the window, but deflected toward the uncovered side. This result seems to indicate that the curvature is due to difference in light intensity on the surfaces. Pfeffer (1906, pp. 3, 229), however, considers it inconclusive, largely on account of the possible effect of the India ink on transpiration (evaporation). Oltmanns studied the curvature of plants grown behind a hollow prism containing India ink and glycerine gelatine so arranged that the light intensity decreased from right to left, and found that they deflected toward the brighter end of the field. He therefore concluded in favor of difference of intensity as the controlling factor in orientation. His results, however, are not conclusive, owing to the diffusion of light by the particles of India ink in suspension (see p. 40).

b. Apparatus. - In the following work the objections to the experiments of Darwin and Oltmanns were eliminated by the use of an apparatus known as the light grader modified to suit the conditions of the experiments. The important features in the construction of this apparatus will be understood readily by referring to Fig. 4. The walls of the apparatus are all light-proof and dead black inside, so as to prevent reflection. The outline of a cross section at any point is square. The upper portion of the front wall of the vertical part of the apparatus is hung on hinges forming a door. From the bottom of this door is 

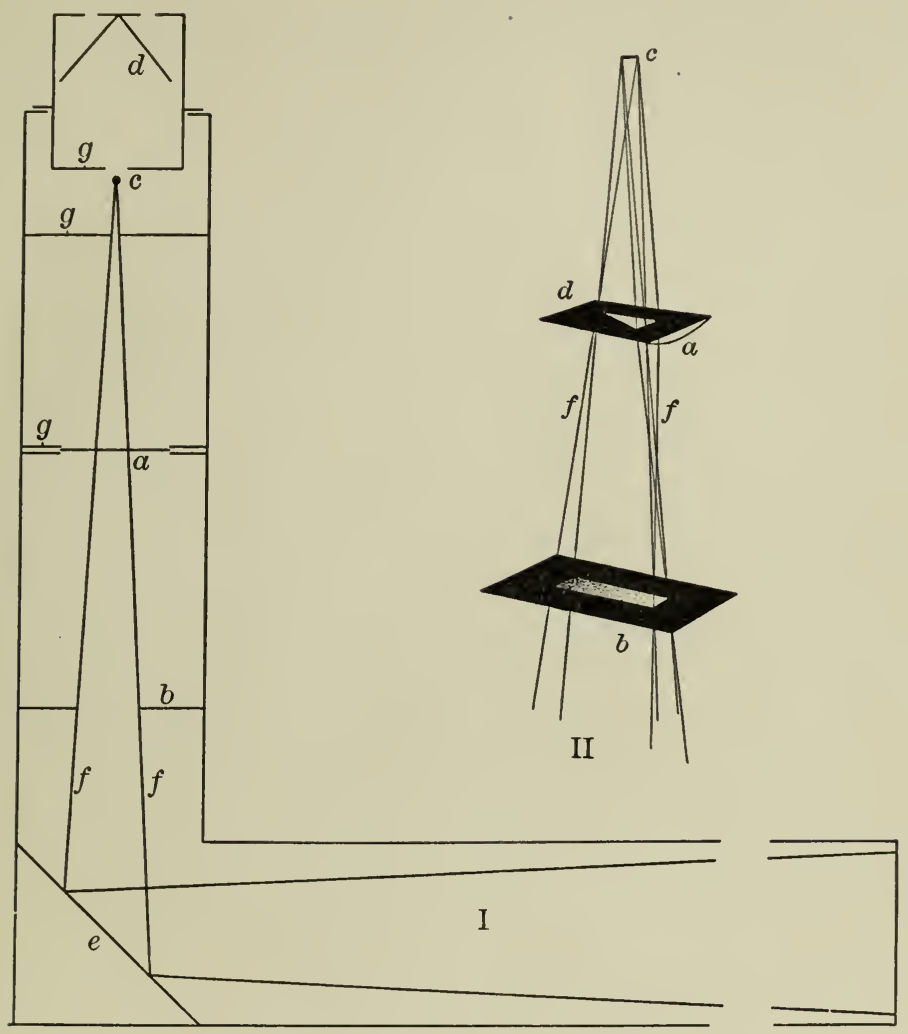

Fig. 4. I. A vertical section of the light grader. The lens (a), which is a segment of a cylinder, has its longitudinal axis lying in the plane of the section; $b$, stage; $c$, Nernst glower; $d$, non-reflecting background; $e$, mirror; $f$, light rays; $g$, opaque screens. Distance from glower of lamp to stage, one meter.

II. Stereographic view of light, lens, and image; $a$, lens; $b$, field of light produced by the image of the glower $(c) ; d$, opaque screen, which lies flat on lens and contains a triangular opening which causes a gradation in the light intensity of the field $(b)$.

hung a loose vertical curtain, which can be so opened that observations can be made without admitting light. The source of light is a Nernst glower, which is parallel with the minor axis of the lens. It is mounted in front of a small opening in a light-proof box painted dead black inside, which thus forms a non-reflecting background. The glower 
and stage are at the conjugate focal points of the lens, and therefore at equal distances $(50 \mathrm{~cm}$.) from it. The planoconvex cylindrical lens used is $25 \mathrm{~cm}$. long, $10 \mathrm{~cm}$. wide and has a radius of curvature of $12.5 \mathrm{~cm}$.

A cylindrical lens will not form a single definite image of an object, but rather a series of images, since by means of it light is focused only in reference to one plane. If, then, the object, e.g., a Nernst glower, is placed at one of the conjugate focal points so that the distance from the lens to the glower is equal to that from the lens to the image, and the glower is so arranged that it is perpendicular to the axis of the lens, the image will not consist of a narrow band of light as large as a glower, which would be true if the segment of a sphere were used as the lens, but it will consist of a comparatively large field of light, the length of which is proportional to the functional length of the lens, while the width is equal to the length of the glower, regardless of the functional width of the lens (see Fig. 4). But since the amount of light which passes through the lens is directly proportional to the functional width of the lens and the width of the field is constant, it is clear that the intensity of light in the field, if we disregard the amount of light absorbed by the lens, must also be theoretically proportional to its functional width. Direct measurements of the light intensity with different functional widths of the lens proved this to be true within the limits of error. If, then, the lens be covered with an opaque screen containing a triangular opening, the base of which is parallel with the minor axis of the lens as represented in Fig. 4, there will result a rectangular field of light in which the intensity gradually diminishes from the end produced by light which passes through the base of the triangular opening to the opposite end, where theoretically it fades into darkness. Practically, however, it was found to be impossible to cut the apex of the triangular opening so as to prevent an apparent line at the end of least intensity. Since the light intensity of the field is proportional to the functional width 
of the lens, it is evident that the rate of diminution in intensity depends upon the ratio of the altitude of the triangular opening to the length of its base; i.e., decreasing the altitude or increasing the base causes an increase in the rate of diminution, and vice versa. Yerkes (I903) was the first to make use of a cylindrical lens in studying reactions to light.

c. Experiments. - In these experiments the light grader was placed in a horizontal position in such a way that the glower was vertical. The lens was covered with an opaque screen containing two triangular openings with the apexes facing each other and only a millimeter apart. In this way two parallel horizontal beams of light were produced, the intensity of which gradually diminished from side to side (see Fig. 5). The object of having two beams was to neutralize any possible effect from diffusion of light by the lens.

A single plumule at a time was exposed in one of these beams of light. In some cases it was allowed to grow up into it from a small pot of sphagnum in which it was germinated; in others the seedlings were transferred to the light grader after the plumules were about one centimeter long.

In former experiments with this apparatus aquatic organisms were used; it was therefore necessary to expose them in an aquarium containing water. Under such conditions it is impossible to eliminate light reflected from the glass walls of the aquarium and from particles in suspension in the water. With the plumule growing in air, however, and with only one exposed in the beam of light at a time, it is evident that all such reflections are done away with. Thus the objections to Oltmanns' experiments with the hollow prism have been obviated, and likewise those brought forward against Darwin's work.

All the following experiments were performed in a large dark room. During the first part of the work the apparatus was situated several meters from a dead black wall upon 
which the beams of light fell and were absorbed. The altitude of the triangular openings in the screen over the lens was $7 \mathrm{~mm}$. and the base $50 \mathrm{~mm}$. The beams of light thus produced were $\mathrm{I} 4 \mathrm{~mm}$. wide and $20 \mathrm{~mm}$. high at the focal point in the light grader, the place where the plumules were exposed. At this point the light intensity in each beam decreased from side to side at the rate of $2 \mathrm{ca} . \mathrm{m} .{ }^{1}$ per $\mathrm{mm}$., it being Ioo ca. $\mathrm{m}$. at one side and zero at the other. From these data the intensity at any part could readily be calculated. In order to ascertain the intensity to which the plumules were exposed it was therefore necessary only to learn their position in the field; and to calculate the difference of intensity on opposite sides it was sufficient to know their diameter, the difference in all parts of the field being 2 ca. $\mathrm{m}$. per $\mathrm{mm}$. width.

During the first part of the work the movements of each plumule were recorded by tracing its shadow cast upon a sheet of paper held in a vertical position a few centimeters back of it. The shadow was thus traced at the beginning of the experiment and again at definite intervals. At first only a few tracings were made in twenty-four hours. It was however soon found that owing to marked circumnutating movements and to surprisingly indefinite lateral deflections it was necessary to locate the position of the plumules at 30 to 60 minute intervals (see Fig. 5).

By this method only the lateral and vertical movements of the plumule were recorded. There was no record of the movement toward the source of light; in some of the later experiments however this movement also was recorded. A fine pointer was fastened so that the sharp end was Io $\mathrm{cm}$. above the tip of the plumule. A glass plate was then fastened in a horizontal position one meter above the pointer. By proper illumination the sharp end of the pointer and the tip of the radicle could clearly be seen through the glass plate, and it was not difficult to fix a

${ }^{1}$ The abbreviation ca. $\mathrm{m}$. will be used for the term candle meters throughout this volume. 
dot of ink in line with these on the plate by sighting through a small circular hole in a piece of opaque paper. The horizontal movements of the tip of the radicle could thus be quite accurately recorded by making dots on the plate in line with the pointer and the tip of the radicle, at any
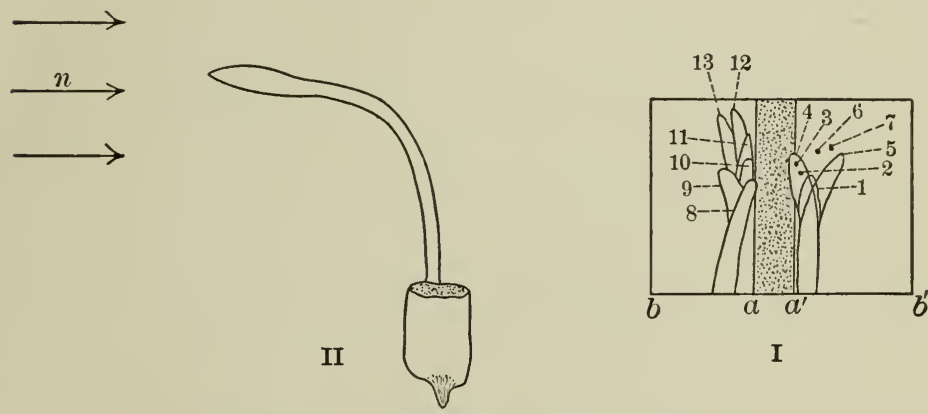

FIG. 5. Tracings of shadow of a plumule of corn showing its reaction in light of graded intensity, three-fourths natural size. I. Cross section of two beams of light as used in the experiment; intensity at $a$ and $a^{\prime}$, zero; at $b$ and $b^{\prime}$, roo ca. m.; $\mathrm{r}, 2,3,4,5,6,7$, successive positions of plumule at intervals of 60 minutes, right side more highly illuminated than left; 8,9 , I0, II, I2, I3, same with left side more highly illuminated than right. It will be seen that the plumules deflect slightly toward the more highly illuminated side under both conditions.

II. Side view of plumule showing amount of curvature toward source of light at close of experiment. $n$, direction of light.

desired intervals, and connecting them with a line. The records thus made represent the movement of the radicle magnified ten times. The direction of the rays was recorded by tracing the edge of a ruler placed on the glass plate in such a position that the edge was in line with the shadow of the plumule cast on a white surface temporarily arranged for the purpose (Fig. 6).

The intensity of light to which the plumules were exposed varied from about 2 to I4 ca. $\mathrm{m}$. In most of the experiments they were exposed to the lowest intensity, the edge of the plumule at the beginning of the experiment being in close contact with that side of the beam of light which had the lowest intensity (see Fig. 5). 


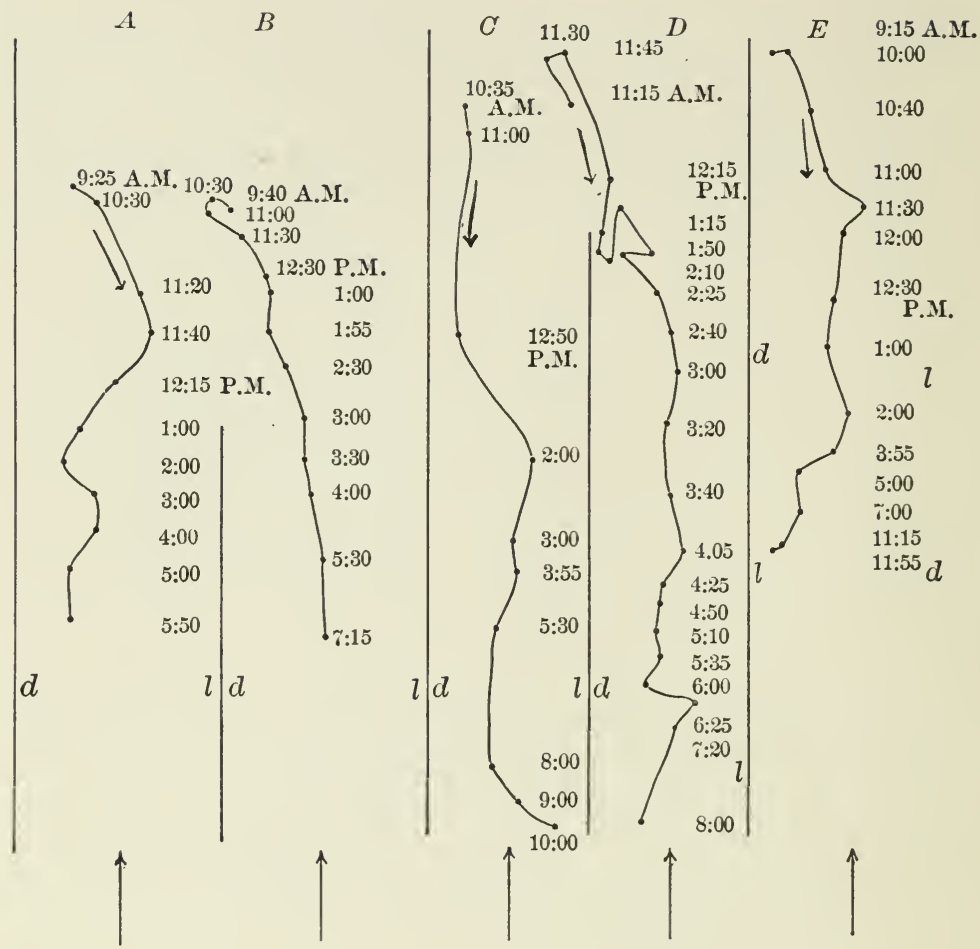

FIG. 6. $A-E$. Courses taken by tips of plumules in bending toward the glower in a graded beam of light; magnified five times. The dots represent the position at time indicated. The large arrows indicate direction of rays; the small ones the direction of movement of plumules; $d$, side of the beam having the lowest light intensity; $l$, side having highest intensity. In $E$ the beam was reversed between I.00 and 2.00 P.M. It will be seen that in every case except $A$ the plumules deflected slightly toward the more highly illuminated side. See text.

d. Results. - Under these conditions the reactions of 36 plumules, I4 of wheat (Triticum vulgare) and 22 of corn (Zea mays), were studied and recorded with the following results: of the I 4 wheat plumules studied 6 deflected toward the more highly illuminated side, 3 toward the less highly illuminated side, and 5 did not appreciably deflect in either direction. Of the $\mathbf{2} 2$ corn plumules 13 deflected toward the more highly illuminated side, 2 toward the less highly 
illuminated side, and 7 did not definitely deflect toward either side.

These results seem to indicate that it is difference in light intensity on the organism which regulates the direction of movement. The lateral deflections are, however, as indicated in Fig. 6, relatively small. The maximum is scarcely more than $2 \mathrm{~mm}$. in a movement of $10 \mathrm{~mm}$. toward the source of light. Considering the conditions of the experiments superficially one would expect a much greater deflection if the direction is regulated by the relation in light intensity on different parts of the surface. A corn plumule frequently has a diameter of over one millimeter at a point not more than one millimeter from the tip, well within the sensitive zone. In such a plumule placed in contact with the edge of the beam of light having the lowest intensity, the difference of intensity between the surface facing the glower and that facing in the opposite direction is apparently not as great as the difference of intensity between the two sides. Consequently one might conclude that if the movement is regulated by difference of intensity, the plumule should bend at least as far toward the highly illuminated edge of the beam as toward the glower.

There are however serious objections to such a conclusion. In the first place it is not known whether or not the sensitive tissue extends to the surface. It may be that it is restricted to the central portion of the plumule and that it is very narrow, so that the intensity difference on opposite sides of this tissue is relatively slight under the conditions of the experiment. In the second place it is evident that light can affect the tissue only by penetrating it, and since the rays strike the surface facing the glower nearly at right angles, and the more highly illuminated side at a very small angle, much more light will penetrate the former than the latter. And in the third place, under the conditions of the experiment, the illumination of the two sides will be equalized by the movement of the plumules much sooner than will that of the two surfaces. 
However this may be, it must be conceded that while the results of these experiments indicate that orientation is due to diversity of light intensity on the reacting organ, they do not definitely settle the question.

Much more convincing results were obtained toward the close of the work when it occurred to me that it would be possible to prevent the bending toward the glower entirely, without vitiating the results, by reflecting the beam of light and illuminating the surface directed away from the glower as well as that facing it. A small mirror of finest quality $5 \mathrm{~mm}$. $\times 2 \mathrm{~cm}$. was therefore supported in the beam of light in a vertical position $3 \mathrm{~cm}$. from the plumule. By careful manipulation and frequent adjustment it was possible to keep the intensity on the surface directed toward the glower and the one opposite nearly the same, while the difference of intensity on the right and left sides was nearly twice as great as it was when the beam was not reflected. The reactions of 4 plumules of Zea mays were studied under these conditions. All deflected definitely toward the more highly illuminated side, as represented in Fig. 7. These results seem to prove conclusively that orientation in plumules of the gramineae (grasses) is in some way regulated by difference in light intensity on opposite sides, and that the direction in which the rays enter the tissue influences the direction of motion only in so far as this may produce unequal illumination of different parts of the sensitive tissue.

A number of experiments were made with young nasturtium (Tropaeolum) leaves in graded light. Different parts of the leaf blades were thus subjected to different intensities. In some experiments one-half of the blade was entirely in the shadow. I was unable to detect any influence of the unequal illumination of the blade on orientation. The leaves turned toward the source of light just as they did when the blades were entirely illuminated by light of equal intensity throughout. The circumnutation movements in these leaves were so great, however, that it would 

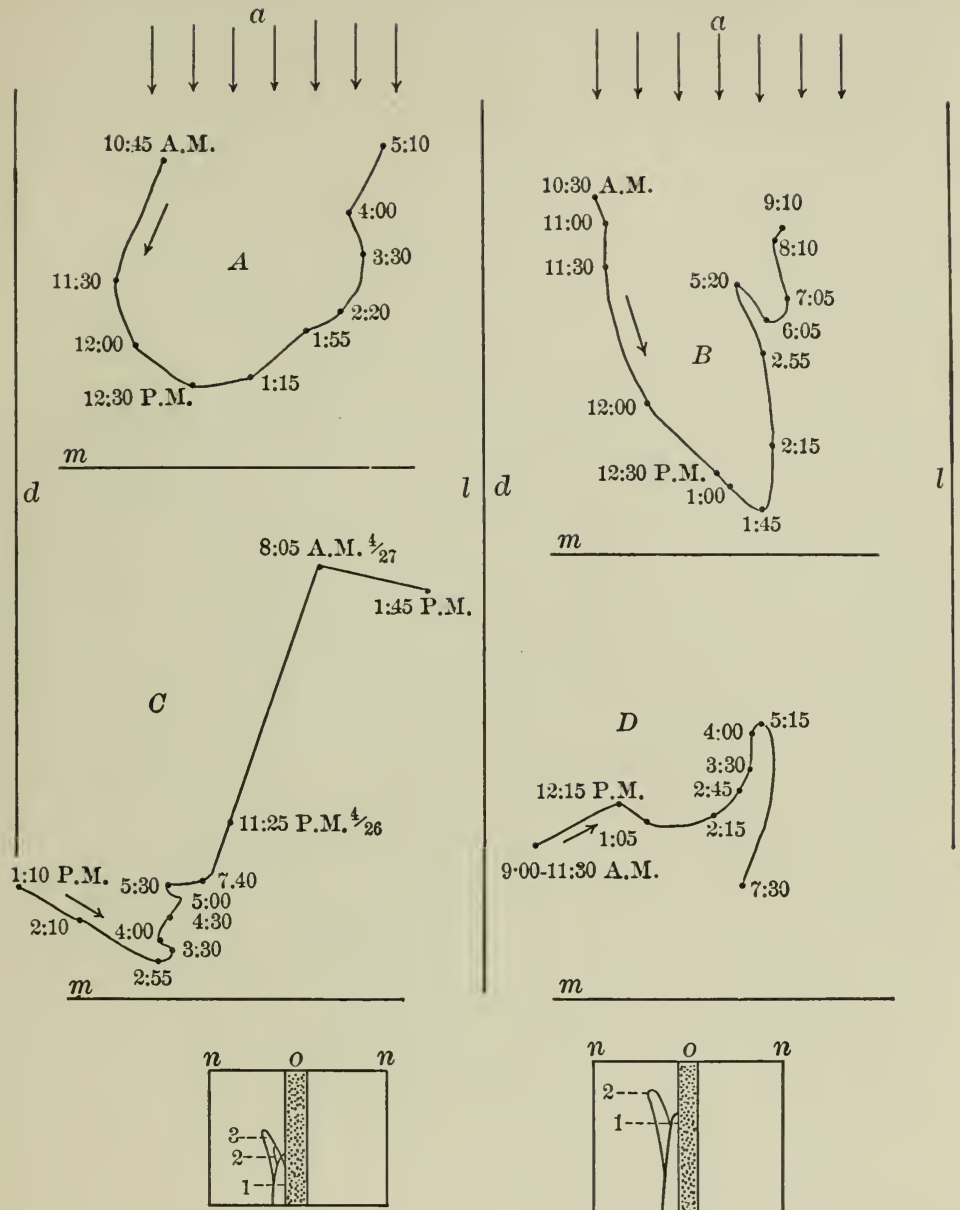

E

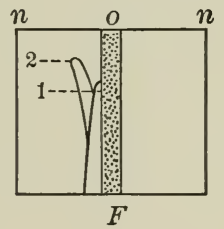

Fig. 7. $A-D$. Courses taken by tips of plumules of Indian corn (Zea mays) as viewed from above in a beam of graded light $(a)$ which was reflected from the mirror $m$ so as to illuminate the two surfaces equally. Magnified five times. The arrows $(a)$ indicate the direction of the rays from the glower, and the other arrows the direction of movement of plumules; $d$, side of beam of light having lowest intensity; $l$, side having highest intensity (see $F$ below). Movement in the direction of the rays of light was caused by imperfect adjustment of mirror producing unequal illumination from the glower and mirror.

$E$, Cross section of beams of light. I, outline of shadow of plumule at the beginning of Course $C$ above, I.IO P.M.; 2, shadow at 2.IO P.M.; 3, shadow at II.25 P.M.

$F, \mathrm{I}$, shadow of plumule at beginning of Course $D$ above, 9.00 A.M.; 2, same at 5.I5 P.M. The light intensity at $o$ was zero; at $n$, about $200 \mathrm{ca} . \mathrm{m}$. The increase of intensity in the field from side to side was about $\mathrm{I}_{4} \mathrm{ca} . \mathrm{m}$. per $\mathrm{mm}$. It will be seen that the plumules deflected strongly toward the side most highly illuminated. 
have been impossible to detect anything but rather decided effects. It is hoped that these experiments may be extended.

e. Discussion. - The conclusion arrived at above that orientation is regulated by the difference in light intensity on opposite sides of the plumules is in direct opposition to Sachs' theory (see p. I3) of orientation. It opposes that of Loeb in so far as he attaches importance to the idea that symmetrically situated points on the surface must be struck by light at the same angle when the organism is oriented (see p. 28). It neither confirms nor contradicts Loeb's and Verworn's idea (see pp. 29, 38) as to the direct effect of the external agent on the motory tissue. Nor does it bear on the question proposed by Darwin (p. I 8 ) that orientation is due exclusively to modification of circumnutations. It is entirely possible that the lateral illumination causes an increase as well as a change in the direction of the movement.

Superficially the evidence seems to indicate clearly that orientation is direct, that there is nothing corresponding to selection of random movements (see p. 50). However, it is impossible to say in how far even very slight circumnutating changes in position may affect diversity of light intensity within the individual cells in the sensitive zone, and in how far such changes in position may be interpreted as trial movements. Owing to the possibility of such variations in illumination within the cells, due to very slight changes in the position of the plumule, it is also impossible to decide whether the stimuli which cause orientation are due to constant intensity or to change of intensity.

These experiments have no bearing on the question as to how curvature resulting in orientation in the plumules is produced. The experiments of Darwin and others, however, showing that there is a distinct sensory and motory zone in these structures, demonstrate clearly that it is not due to the direct effect of the illumination on the tissues 
which produces the curvature, as Loeb's theory quoted above demands. The mechanism involved is undoubtedly far more complex than this theory indicates. It may be similar to that offered by Pollock to explain the curvatures in roots. He says (1900, p. 59): "The stimulus is transmitted from the sensitive root tip to the curving parts, in the cortical parenchyma. The effect of the stimulus is to increase the normal tension between cortical parenchyma and axial cylinder on the side that becomes convex, and to decrease or reverse the normal tension between the cortical parenchyma and the axial cylinder on the side that becomes concave. The change in tension also extends to the different layers of the cortical parenchyma on the concave side, the outer layers becoming negative with respect to the inner ones. So much has been demonstrated. The evidence is in favor of the view that the tensions on the concave side are changed by the protoplasm becoming more permeable to water, some of which passes out into intercellular spaces, possibly to be taken up by the convex cells, which later contain more water than the concave cells. The shortening of the concave side may be masked sometimes by a certain amount of growth." This theory does not account for curvature in structures having but a single cell cavity, like the hyphae of molds, rhizoids of liverworts, and some algae, all of which are known to respond to light by bending toward or from its source. That these reactions cannot be accounted for on the basis of osmotic changes was pointed out by Hofmeister as early as I867.

Very little is known concerning the fundamental factors involved in orientation in other plant structures than those mentioned, although much work has been done on them, especially on the leaves. Darwin (I88I) was the first to attempt to locate the sensitive structure in the leaf. He found that neither quality nor intensity of reaction is affected by shading the blade, and concluded that the petiole perceives the light. Voechting (I888) came to quite the opposite conclusion in experiments on malva 
and other plants. Krabbe (1889) supported Darwin in his conclusion, as did also Rothert (1894) and Czapek. Haberlandt (I904), on the other hand, maintains not only that the blade is functional in light perception, but also that the curved and thickened outer walls of the epidermal cells act as lenses and focus the light on the protoplasm within, and that orientation is regulated by responses due to the distribution of the intensity of light within the cells of the epidermis. Kneip (I907) covered the upper surface of the blades of Tropaeolum with a thin layer of paraffin oil whose index of refraction is about 0.I43 greater than the index of cell sap. The oil consequently inverted the lens effect of the curved walls of the epidermal cells and thus caused a dispersal of the rays within the cell. Kneip found however that the leaves treated thus responded to light much like those not treated, and concluded (p. I36), "that the lens action is of no importance in the leaves studied." Haberlandt (I909) however does not agree with this conclusion. He claims that the fact that leaves still respond to light after the epidermis is covered in such a way as to neutralize the focusing effect of the curvature of the outer cell walls, merely shows that the effect of these walls can be dispensed with and not that it is useless, and holds that after the lens effect of these walls is neutralized the light intensity is still unequal on the inner surface of the cells, when the light strikes the epidermis obliquely, and that this may cause orienting responses, but that the focusing effect of the curved outer walls of the cells enhances the promptness and precision of the orienting responses.

Various other experiments aside from those mentioned above have been carried out, but the results obtained lead to no definite conclusions concerning the function of the lens action of the epidermal cells, nor do they give any clear notion as to the mechanism of orientation in plants. About all that can be said is that leaves generally take a position such as to facilitate photosynthesis, and that the chloroplasts within the cells likewise assume what may be 
termed an optimum position. The reactions are adaptive. In some instances if the light is too intense the chloroplasts are found along the side walls which are more or less nearly parallel with the incident rays. In others the leaves turn so that the edge of the blade faces the light. In all probability both the petiole and the blade are sensitive to light, at least in some leaves, but the method of regulating the movements is still a mystery. 


\section{CHAPTER V}

\section{OBSERVATIONS ON UNICELLULAR FORMS IN THE PROCESS OF ATTAINING AND RETAINING A DEFINITE AXIAL POSITION WITH REFERENCE TO THE SOURCE OF LIGHT}

\section{Myxomycetes and Rhizopods}

AlL the Rhizopods and the plasmodia of Myxomycetes that are known to react to light are negative, as was shown by Baranetzsky (I876, pp. 328, 340), Stahl (I884, p. I67), Engelmann (1879, p. 3), Davenport (I897) and others. The contention of Hofmeister ( 1867, p. 20) that plasmodia are positive in light of very low intensity has not been confirmed.

Davenport (I897, p. I86) exposed specimens of Amoeba proteus under a compound microscope in a small horizontal beam of direct sunlight with all other light intercepted by means of opaque screens and found that they orient directly. They make no preliminary trial movements in this process. If the direction of the rays is changed they always turn from the source of light at once, never toward it. There is no evidence of selection of random movements in these animals. The same is probably true in case of other Rhizopods and Myxomycetes, although there are no investigations which bear directly on this point. Baranetzsky ( $18-6)$ found that even a slight increase in illumination causes a distinct retardation in streaming movements of Myxomycetes. Engelmann (I879) observed that light thrown upon a pseudopod of Pelomyxa palustris causes it to be withdrawn suddenly. Harrington and Leaming (I900) found that a sudden increase in light intensity causes a retardation in the movement of Amoeba. Ewart (1903, p. 69) says that protoplasmic streaming in cells in general is retarded by 
increase in light intensity, and Pringsheim (1879, pp. 334, 367) maintains that local retardations in streaming movement can be produced by local stimulation. Jennings (1904) has shown the same to be true for Amoeba when stimulated mechanically and chemically.

After completing this part of the manuscript I had the opportunity of observing the orienting reactions in Amoeba proteus in detail, and also the effect of different rays on the reactions. I shall insert a description of the former here; the latter will be discussed in Part IV.

In studying orientation numerous specimens were mounted under a large cover glass supported by a ring of vaseline so as to give them ample room for moving about and to prevent the solution from drying up. The specimens thus enclosed could be kept in excellent condition for several days. The observations were made under a compound microscope situated in diffuse daylight without any screen around it. Mirrors were so arranged that two horizontal beams of direct sunlight were reflected upon the stage at right angles to each other after passing through $8 \mathrm{~cm}$. of water to eliminate the heat. Specimens exposed in one of these beams without any light from the substage were found to direct their course in a general way from the source of light. In one instance, after a slide had been exposed for fifteen minutes, there were eleven specimens in one field of the low power, all but two of which were moving from the source of light. In another field there were twelve specimens; all but four of these were directed from the source of light. Of these four, two were proceeding at right angles to the rays and two were going toward the light. In still another field containing nine specimens, seven were negatively oriented, one positively and one at right angles to the rays. Orientation, however, was not very precise in any of the specimens. The amoebae usually took a sort of zigzag course. Pseudopods were frequently seen to extend toward one side for some distance, then stop as though they had been checked, after which new ones were 
ordinarily seen to extend on the opposite side for some distance, and stop, etc.

The details in the process of orientation were observed as follows: a specimen which had oriented in one beam of light was selected, after which the light in this beam was intercepted and that in the other simultaneously turned on. The reaction of numerous specimens to a change in the direction of the rays was thus observed and the movements in several were recorded by means of camera sketches made at short intervals. A typical record is presented in Fig. 8, although a majority of the specimens observed did not orient as precisely and definitely as did the one represented in this record. By referring to Fig. 8 it will be seen that the amoeba under observation gradually turned from the side most highly illuminated, sending out pseudopods only on the shaded side. What is the cause of this?

If direct sunlight is thrown upon an amoeba which is active in diffuse daylight, all movement stops instantly, but there is ordinarily no immediate contraction of any of the pseudopods. After a few moments of exposure new pseudopods usually appear at the posterior end, and not until these begin to form do the old ones begin to retract. In changing the direction of the rays so that the amoebae become strongly illuminated from the side, as described above, the distribution of the light intensity on the different pseudopods is changed since different surfaces become exposed. Judging from our preceding statement it might be expected that this change of light intensity would inhibit the protoplasmic streaming in the pseudopods on the illuminated side. I could, however, never be quite certain that it did, although it often appeared so. The difficulty in observation here lies in the fact that without any change of illumination the pseudopods form, extend a varying distance, then stop and retract while others form elsewhere. When a pseudopod stops after the direction of the rays is changed it is consequently impossible to be certain that it would not have stopped had the light not 

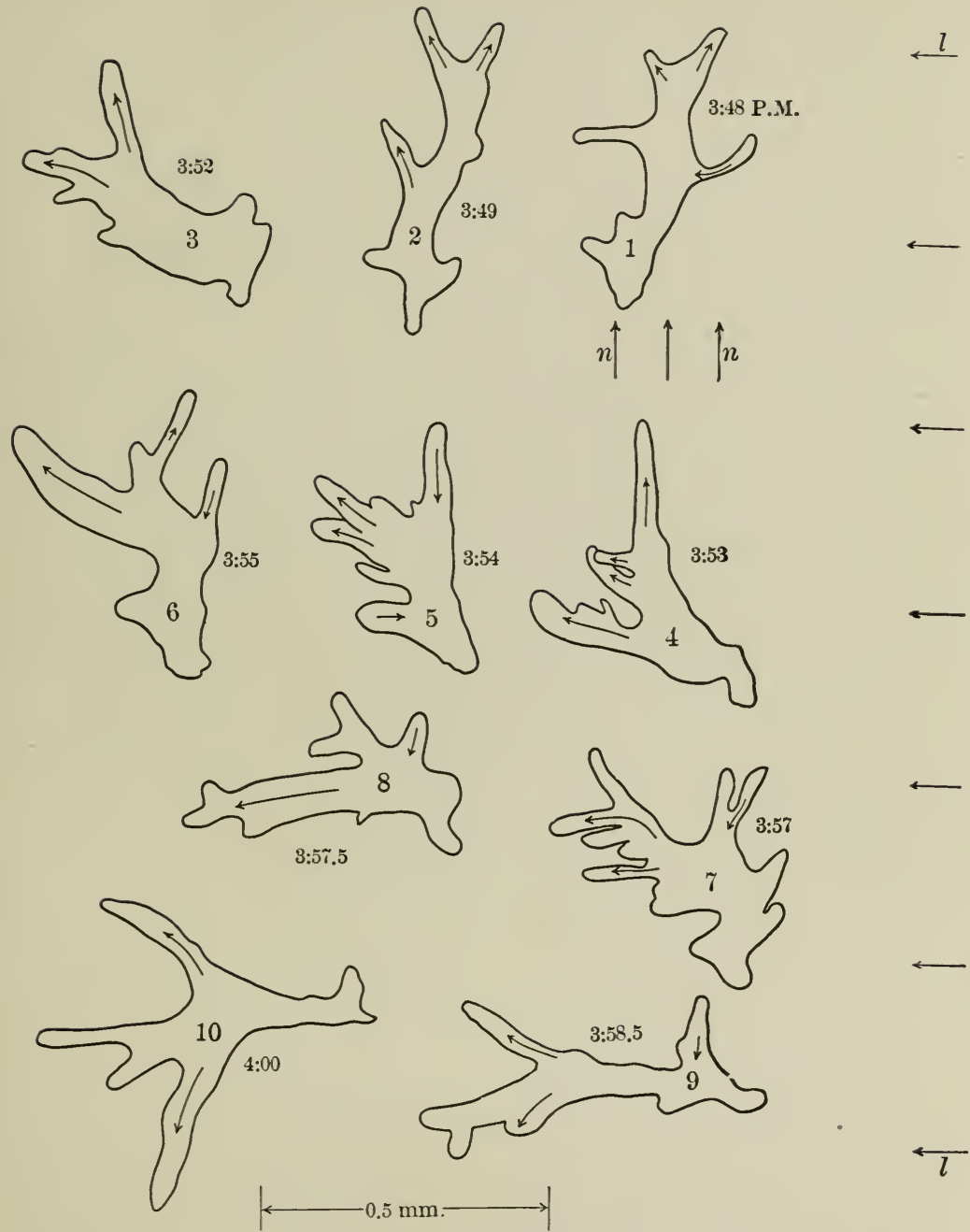

$0.5 \mathrm{~mm}$

Fig. 8. Camera drawing representing different stages in the process of orientation of Amoeba proteus. I, Amoeba oriented in light $n n$ before light $l l$ is turned on; $2-9$ successive positions at the time indicated on each after light $l l$ is turned on. Arrows represent the direction of streaming of protoplasm in pseudopods. In those which do not contain arrows there was no noticeable streaming at the time the sketch was made. $l l$ and $n n$, direction of light. 
been changed. If light acts directly on the protoplasm it might also be expected that in a pseudopod laterally illuminated, the flow on one side would be retarded, thus causing it to curve. But no evidence of this could be seen.

How then does orientation take place if the pseudopods which are present continue and do not turn from the source of light? There is but one way that I can see, and that is by the inhibition of the formation of new ones on the more highly illuminated side of the organism.

Since we know that an increase of intensity inhibits streaming in the pseudopods of Amoeba it seems strange that no one has thus far been able to see any reaction in an amoeba in passing from a region of one intensity to that of another. Davenport (I897, p. I86) studied their movements in a field "separated by a sharp line into a light and dark half," but could detect " no effect resulting from the change from light to dark or the reverse." I made observations much like those of Davenport, and found that when the amoebae came in contact with the light area they usually stopped and proceeded in a different direction, as represented in Fig. 9. The light area used in these experiments was about $0.5 \mathrm{~mm}$. square and had very definite edges and a high intensity. It was produced by focusing a limited area of a luminous Welsbach mantle on the slide by means of the mirror and an Abbe condenser. These observations were made in a dark room and no light except the small beam from the Welsbach mantle reached the microscope.

By referring to Fig. 9 it will be seen that after one pseudopod came in contact with the illumination and was stopped, the amoeba did not at once proceed in the opposite direction so as to avoid the light, but sent out other pseudopods at only a slight angle with the first, apparently trying to get around the obstacle in this way. The character of the response did not change after the first pseudopod came in contact with the light, or after the second and the third came in contact with it. But after the fourth became 
exposed the direction of motion was nearly reversed. This indicates that the reaction was modified, that the response to a given stimulus depends upon the preceding experience.
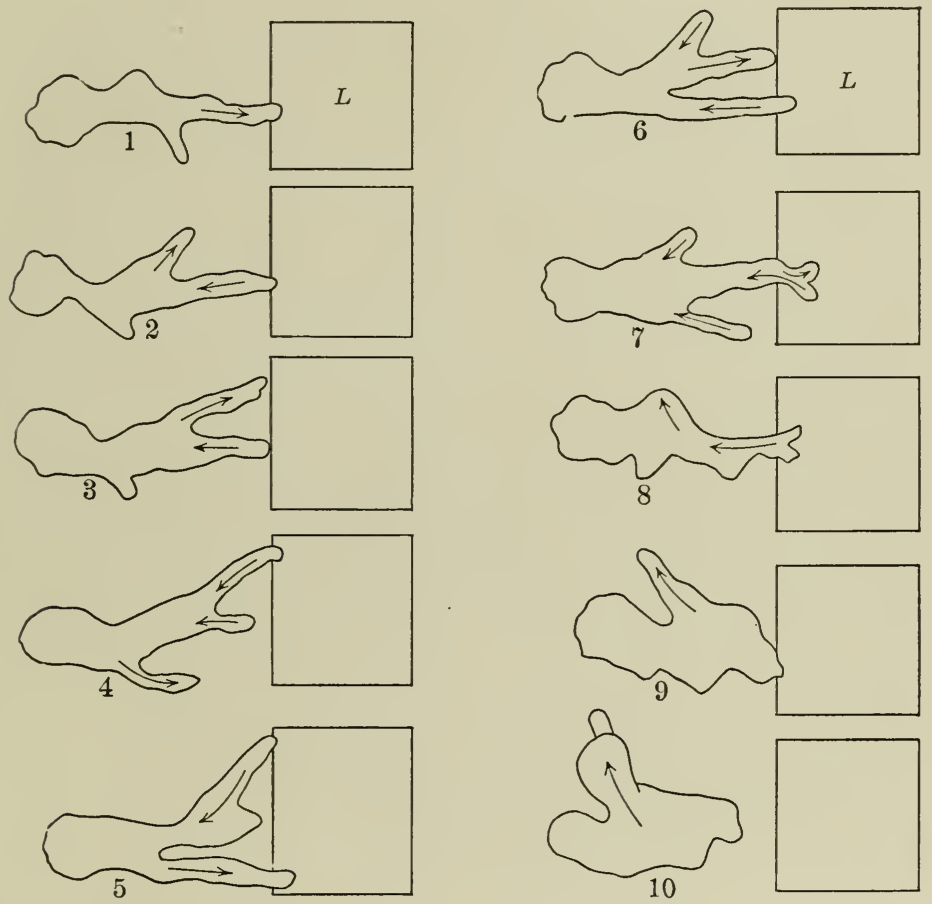

Fig. 9. Sketches representing the reactions of an amoeba proceeding toward an intense area of light the rays of which were perpendicular to the slide. $L$, field of light formed by focusing a section of a Welsbach mantle on the slide. I-10, successive positions of the amoeba a little less than one-half minute apart. Arrows indicate direction of streaming in pseudopods.

In view of these facts it is probably true that the orientation of all of the rhizopods in light is due to a local response to a local stimulation, a direct inhibition of the movement of the part most highly illuminated. This would of course result in the prevention of the formation of pseudopods on the more highly illuminated side, and the organism would 
turn until both sides are equally illuminated, and symmetrically located points on the body equally stimulated.

Such a method of orientation is in harmony with much in Verworn's theory and also with the essentials in Loeb's. It does not, however, support the idea connected with these theories, that a constant intensity produces a constant directive stimulation.

Jennings (I904) has shown that certain amoebae roll over and over in their movement. The protoplasm on the underside in relatively low light intensity is constantly coming to the surface into a greater intensity, and moreover the beginning of every laterally directed pseudopod in those forms which do not roll necessarily causes a change in the light intensity of the protoplasm in it. Thus it is clear that the protoplasm is being continuously subjected to changes of intensity. And while the rate of movement in the animal as a whole is no doubt influenced by constant light intensity, much as it is by temperature, it may be that orienting reactions are responses solely to changes in light intensity, - in negative organisms to a rather sudden increase of intensity.

This method of orientation is opposed to the idea of Sachs (see p. I4), that the direction in which the rays penetrate the tissue is of importance in orientation, and also to that of Loeb (see p. 28) with reference to the importance of the angle between the rays and the surface.

\section{Euglena}

a. Description. - Euglena is a minute elongated organism. The posterior extremity ends in a spinelike process; the anterior end is rounded off rather bluntly. The different species vary greatly in size; some are not over o.or mm. long and o.OoI mm. in diameter, while others are nearly fifty times as large. The forms most commonly met with average about $0.1 \mathrm{~mm}$. in length and $0.015 \mathrm{~mm}$. in diameter. Nearly all are green, having numerous chloro- 
plasts of various forms. They have a contractile vacuole which opens to the exterior at the anterior end, and a brown pigment spot known as the eye-spot, in close connection with the vacuole. They exist in three states, - free-swimming, crawling and encysted (Fig. IO). In the free-swimming
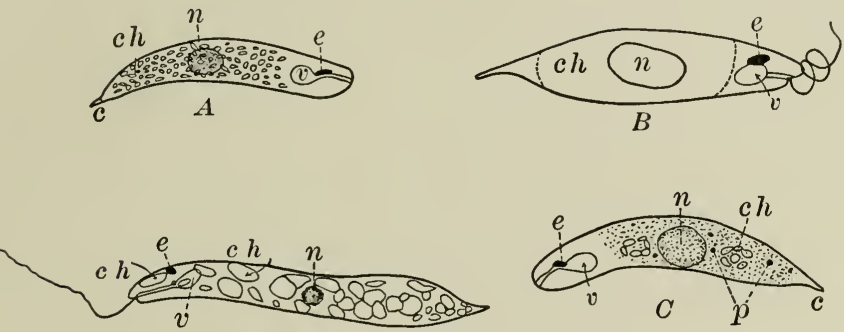

$D$

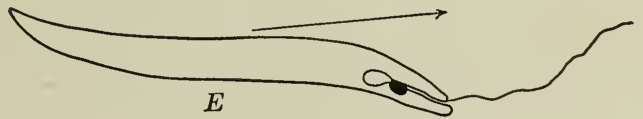

(5) $a$ a

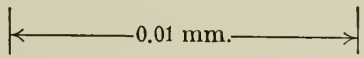

FIG. Io. Sketches of Euglena, showing general structure of different forms. $A$ and $C$, Euglena $x$ sp. (?) in crawling state; $B$, probably a form of E. viridis; $D$, $E$, E. deses; $e$, eye-spot; $v$, contractile vacuole; $c h$, chloroplasts; space in $B$ limited by dotted lines well filled with small chloroplasts; $n$, nucleus; $c$, caudal spine; $p$, pigment granules which appear to be composed of same substances as eye-spot, - these were found in only a few specimens. $E$, shows typical curvature toward dorsal surface while swimming in direction indicated by arrow. $F$, eye-spot highly magnified; $s$, surface view; $a$, view from anterior end. The convex surface is directed outward. mm., projected scale. All outlines were made with camera from specimens killed in iodine. Contractile vacuoles and nuclei were sketched free-hand from living specimens.

state they have a flagellum frequently nearly as long as the body. Wager (I900) found that in E. viridis it passes down through the opening of the contractile vacuole and divides into two branches, each of which is attached to the wall of the vacuole. One of these branches contains an enlargement which lies directly opposite the eye-spot, as 
represented in Fig. II. Under certain conditions some forms cast off the flagellum, sink to the bottom and crawl

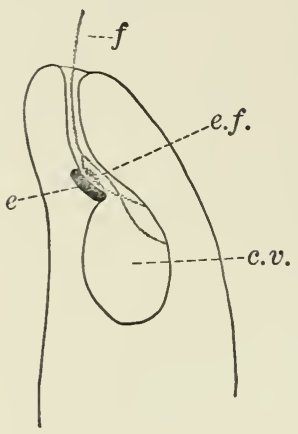

FIG. II. Side view of anterior end of Euglena viridis, after Wager; $e$, eyespot; $f$, flagellum; $e . f$., enlargement in flagellum; c.v., contractile vacuole.

ing a little $\mathrm{CO}_{2}$. They swim into it without any apparent reaction, but when they reach the boundary on the way out they stop suddenly, turn around, and thus remain in the illuminated area. Engelmann called this reaction Schreckbewegung, shock-movement, and Jennings, avoiding reaction. Engelmann also proved that the anterior end of $\mathrm{E}$. viridis is more sensitive than the posterior. Jennings (I904) however was the first to demonstrate the connection between the shock-movement, the sudden turning when subjected to a decrease in illumination, and orientation, although the idea expressed in the following words shows that Engelmann (I882, p. 395) was also very near the truth in this matter: "Falls sie, was bei schnellem Vorwärtsschwimmen wohl einmal geschieht, gans ins Dunkel hineingekommen sind, sistiren sie doch so fort die weitere Vorwärtsbewegung, drehen um eine ihrer kurzen Axen, probiren - oft unter bedeutenden Gestaltsänderungen - in verschiedenen Richtungen fortzukommen bis sie endlich wieder ins Licht gerathen." 
Jennings found that as Euglena swims on its spiral course it rotates on its long axis so as to keep the side containing the eye-spot constantly facing out, and that when it is stimulated it always turns toward this side, which is designated the dorsal side. The process of orientation is described as follows (I906, p. I38): "The Euglenae are swimming about at random in a diffuse light, when a stronger light is allowed to fall upon them from one side. Thereupon the forward movement becomes slower and the Euglenae begin to swerve farther than usual toward the dorsal side. Thus the spiral path becomes wider and the anterior end swings about in a larger circle and is pointed successively in many different directions. In some part of its swinging in a circle the anterior end of course becomes directed more nearly toward the light; thereupon the amount of swinging decreases, so that the Euglena tends to retain a certain position so reached. In other parts of the swinging in a circle the anterior end becomes less exposed to the light; thereupon the swaying increases, so that the organism does not retain this position, but swings to another. The result is that in its spiral course it successively swerves strongly toward the source of light, then slightly away from it, until by a continuation of this process the anterior end is directed toward the light. In this position it swims forward. The course of Euglena in becoming oriented is shown in "Fig. I2.

Orientation in Euglena is, therefore, according to Jennings, indirect. The stimulus resulting in orientation is due to changes in light intensity on the organism. The direction of the rays functions in orientation only in so far as it makes such changes possible. Changes of intensity on the organism may be due to movement from a region of one intensity to that of another, or to a change in the axial position of the organism with reference to the source of light. There is no evidence that orientation is due to a constantly acting directive stimulus in accord with Loeb's theory of tropisms. Jennings does not deny that the 
Euglenae are affected by light after they are oriented. $\mathrm{He}$ thinks, however, that whatever such effects may be, they are relatively unimportant in the process of orientation.

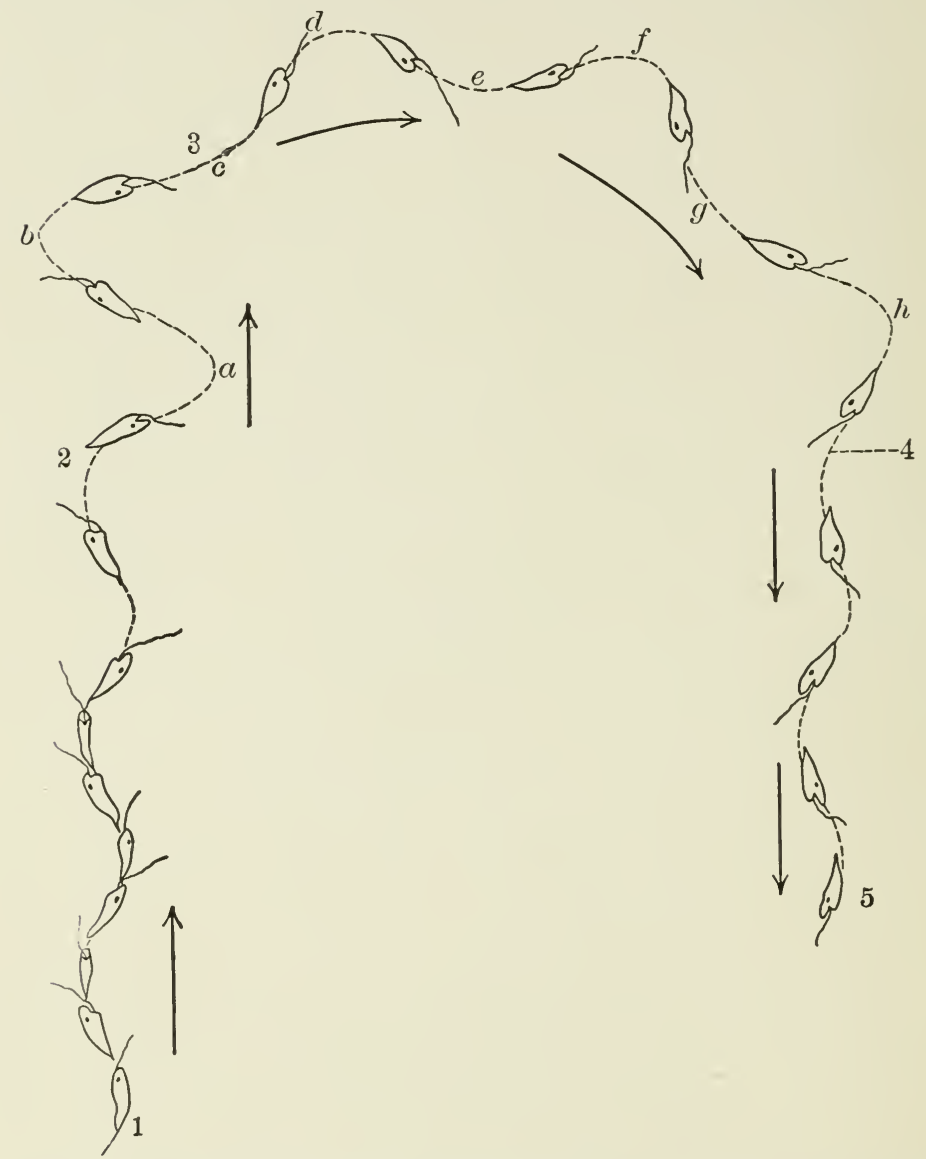

FIG. 12. Illustration of the devious path followed by Euglena in becoming oriented when the direction of the light is reversed. From $I$ to 2 the light comes from above; at 2 it is reversed. The amount of wandering $(a-h)$ varies in different cases. After Jennings (1906, p. 137).

Torrey (1907, pp. 317, 319) criticizes the analysis presented by Jennings in the following terms: "My analysis of their responses, based upon the figure which Jennings him- 
self has drawn, with text description, leads to quite a different conclusion from his. The figure indicates that Euglena is both unterschiedsempfindlich and heliotropic. At $a$ (Fig. I2) the reversal in the direction of the light, which has been coming from the direction in which the creature has been swimming, produces a sudden change in intensity of stimulation, a shock which results in the swerving from the previous course, as indicated between $a$ and $c$. The organism recovers rapidly, only to be subjected to the constant stimulus of a steady light from one direction to the end of the experiment. The result of the action of the constant stimulus is a path, from $c$ to 5 , so perfectly in harmony with the tropic schema, that, in spite of Jennings' descriptions and elucidations, I can only wonder at his running so boldly and so far into the enemy's camp. . . . In heliotropism . . . the oriented organism is in a condition of physiological stimulation, and . . . the response to stimulation is local; finally, ... the interpretation of the behavior of heliotropic organisms on the basis of general changes concerning the whole organism, not only does not accord with the main facts, but is rather psychical than physiological in character.'

It is thus evident that while Torrey recognizes that Euglena responds to change of light intensity, he considers that orientation is due to the local effect of unequal stimulation of symmetrically situated points on the body, and that after the organism is oriented it is held upon its course by constantly acting directive stimulation. He does not, however, explain where the symmetrically located points which are subject to local stimulation are situated in Euglena. They might be conceived to be in the flagellum or in the body. In the former case it would imply direct action of the point stimulated, in the latter a reaction in harmony with the location of the stimulus, i.e., if the stimulus is applied to the left side of the body the flagellum would strike toward the left; if applied to the right side, it would strike toward the right, etc. 
If Euglenae actually orient by local response to local stimulation, as Torrey assumes, or if light acts constantly as a directive stimulus in accord with Loeb's theory, one should be able to find evidence of it in these organisms in the crawling state. With this in mind, therefore, I took up the study of specimens in this state.

Before entering on the description of the reactions in Euglena bearing directly on the problem just stated, I shall however refer briefly to the question of orientation in light from several sources, since the experimental results obtained under these conditions throw some light on the idea of Sachs, that the direction of the rays through the organism regulates orientation, and on Loeb's idea that symmetrically located points on the sensitive surface must be struck by rays at the same angle when an organism is oriented.

c. Orientation in light from two sources. - In studying the movement of Euglenae in light from two sources, Nernst glowers in a dark room were so arranged and screened as to produce two small horizontal beams of light which crossed each other at right angles in the aquarium. One glower was stationary. The other was mounted on a horizontal track so that it could easily be pushed nearer to or farther away from the aquarium. Thus the relative intensity from the two glowers could be changed without any change in the direction of the rays. Several species of Euglena in the free swimming state, and two, Euglena deses and Euglena $x$ in the crawling state, were used in these experiments. The results were the same in all.

When the light from the two glowers was equal and the Euglenae positive they moved in a general way toward a point very nearly halfway between the glowers. But when it was unequal, they moved toward a point nearer the source from which the more intense light came. Negative specimens take the same general course but in the opposite direction. This experiment is particularly striking if the glower on the track is gradually moved from a position in 
which the light intensity from it is much lower than that from the stationary glower to a position in which it is much higher. Under such conditions one can clearly see these organisms, especially the free-swimming forms, gradually change their direction of motion through an angle of nearly $90^{\circ}$. (Just how this change is brought about will be demonstrated later.) By regulating the relative intensity of the light from the two sources, it is thus possible to cause Euglenae to move toward any point between the two sources of light without changing the direction of the rays. It is evident then that the direction of the rays does not absolutely control the direction of motion. These results are in harmony with those which I obtained in experiments on Volvox (1907, p. I34). Identical results were also obtained in light from two sources with Stentor coeruleus, Trachelomonas, Chlamydomonas, Oedogonium swarm-spores, Eudorina, Pandorina, Planulae of Eudendrium, Limulus polyphemus larvae, Musca larvae, Allolobophora foetida, medusae of Bougainvillea superciliaris, trochophores of Hydroides dianthus, Arenicola larvae, zoeae, several forms, and Leptoplana tremellaris. Judging from these results it is highly probable that all individuals without imageforming eyes orient in the same way under like conditions.

All of these forms can be induced to change their direction of motion by varying the relative light intensity on opposite sides of the body, or by changing the intensity on the same side, without changing the direction of the rays. It may therefore be concluded that difference in the intensity of light on opposite sides, or a change of intensity on the same side of the body of all these creatures, may determine orientation independently of the direction of the rays. The orientation of organisms without image-forming eyes can therefore not be explained by the application of Sachs' ray direction theory, nor are the orienting reactions in harmony with the statements of Loeb expressed in the following quotations: (1905, p. 2), "It is explicitly stated in this and the following papers that if there are 
several sources of light of unequal intensity, the light with the strongest intensity determines the orientation and direction of motion of the animal. Other possible complications are covered by the unequivocal statement, made and emphasized in this and the following papers on the same subject, that the main feature in all phenomena of heliotropism is the fact that symmetrical points of the photosensitive surface of the animal must be struck by the rays of light at the same angle. It is in full harmony with this fact that if two sources of light of equal intensity and distance act simultaneously upon a heliotropic animal, the animal puts its median plane at right angles to the line connecting the two sources of light. This fact was not only known to me but had been demonstrated by me on the larvae of flies as early as I887, in Würzburg, and often enough since. These facts seem to have escaped several of my critics;" (p. 6r), "When the diffuse daylight which struck the [Musca] larvae came from two windows, the planes of which were at an angle of $90^{\circ}$ with each other, the paths taken by the larvae lay diagonally between the two planes. . . . This experiment was recently published by an American physiologist as a new discovery to prove that I had overlooked the importance of the intensity of light!" (p. 82), "The direction of the median plane or the direction of the progressive movements of an animal coincides with the direction of the rays of light . . . if there is only a single source of light. If there are two sources of light of different intensities, the animal is oriented by the stronger of the two lights. If their intensities be equal, the animal is oriented in such a way as to have symmetrical points of its body struck by the rays at the same angle;" (p. 268), "Attention need scarcely be called to the fact that if rays of light strike the animal [larvae of Limulus polyphemus] simultaneously from various directions, and the animal is able to move freely in all directions, the more intense rays will determine the direction of the progressive movements." Note that this animal is in the list mentioned above (p. 87). 
Under the conditions of the experiment described above, the organisms mentioned do not move in a direction parallel with the rays, neither do they necessarily orient so " that symmetrical points of the photosensitive surface [are] struck by the rays of light at the same angle," nor does "the light with the strongest intensity determine the orientation and direction of motion."

Toads (Bufo americanus) were the only animals with image-forming eyes that were tested with reference to orientation in light from two sources (see p. 87). If the intensity from the two sources is unequal they usually hop directly toward the stronger light and pay no attention to the weaker. This is in accord with Loeb's explanation given above. But if the intensity from the two sources is equal, they go toward either one and not toward a point between the two, as Loeb's explanation demands. In none of the organisms studied are the orienting reactions such as are demanded by Loeb's explanation. These results will be referred to in connection with the discussion of the importance of equal stimulation of symmetrical points on the animal.

Let us now return to our study of the reactions of Euglena in the crawling state and to the problem suggested by Torrey's criticism of Jennings referred to above. Is orientation in Euglena due to light acting constantly as a directive stimulation similar to the effect of a constant electric current, or to an intermittent effect, a response to change of intensity only, in accord with Jennings' explanation?

d. Material. - During the months of November and December excellent material for this study was discovered in a puddle of water fed by a drain from a dwelling house at Windsor Hills, Baltimore. The bottom of the puddle was covered with a dense green layer composed almost entirely of two species of Euglena, - E. deses and another species which was somewhat like viridis but could not be positively identified. It will be referred to as Euglena $\mathrm{x}$. Most of the E. deses had flagella, but the E. $x$ with very 
few exceptions had none. The latter were considerably smaller than the former. They averaged nearly $0.08 \mathrm{~mm}$. in length and somewhat more than $0.015 \mathrm{~mm}$. in diameter. A fairly good idea of the form and structure may be obtained by referring to Fig. Io. It will be seen in this figure that the caudal end terminates in a spinelike process, and that the eye-spot, in close contact with the canal leading from the contractile vacuole, forms an angle of about $45^{\circ}$ with the long axis of the body. The eye-spot has the form of a flattened disk somewhat curved, so as to fit around the canal.

e. Method of locomotion. - It is frequently stated that Euglenae in this state progress by amoeboid movements, i.e., by streaming movements. I was, however, unable to detect anything resembling streaming movements in any of the several different species studied in the crawling state. Many do change their form very much by contracting in various ways, and some may move slightly by thrusting the anterior end forward and then drawing up the posterior end, but progression in this way is relatively unimportant.

The process of locomotion without flagella appears to be much the same in all forms observed. It was however studied in detail only in Euglena $x$. While in motion these organisms usually are considerably curved, being convex on the ventral surface, the side opposite the eye-spot. They rotate on the long axis either entirely over to the left, as seen from the posterior end, or only halfway, then back again, lying on the dorsal surface during this apparent rocking movement. During either of these rotating movements both ends appear to move back and forth. The posterior end however moves laterally much less than the anterior. In many instances it continues forward in nearly a straight path, while the anterior end progresses on a spiral course of considerable relative width.

While thus rotating the organisms appear to slide along, moving forward a little with each turn of the body. They progress at the rate of about $0.3 \mathrm{~mm}$. per minute. Pre- 
cisely what factors are involved in causing the forward movement I was not able to ascertain. Only very slight contractions can be seen at any time and no streaming movements at all.

The posterior end is in much closer contact with the substratum than the anterior. If currents of water are passed back and forth over the Euglenae it can be seen that the anterior end is free, for it moves with the current. Frequently specimens are found attached to the slide with only the tip of the caudal spine in contact with the surface. In such specimens the whole body swings about with the current. They are held fast by an adhesive substance which they secrete. The presence of such a substance can be detected by passing a small glass rod across the path of a crawling individual near its posterior end, or by pushing the rod about on a slide containing numerous Euglenae which have been crawling about for a short time. If this is done the end of the rod soon becomes covered with a substance to which cling numerous Euglenae attached usually only at the posterior end. It is however not likely that the extrusion of the secretion forces the Euglenae along, as is supposed to be true in the case of diatoms. The body appears to become alternately more and less curved as they rotate in such a way as to force them forward. The caudal spine appears to be used as a sort of lever in this movement. They can however move without the use of the spine, for moving specimens were repeatedly seen in which the point of the spine was not in contact with the slide at all. This was evident especially in specimens which rotated only partially over and then back again.

As these creatures crawl along, rotating on the long axis with the anterior end progressing on a spiral course, the dorsal surface, the surface containing the eye-spot, always faces the axis of the spiral. This is just the opposite of Jennings' observations on Euglena viridis in the freeswimming state. I found however that E. acus and a few other species swim with the dorsal side facing the axis 
of the spiral and that E. deses swims with one side facing the axis.

Euglenae in the crawling state, just as in the free-swimming state, may be either negative or positive in their light reactions. The crawling specimens worked on were however negative to light of surprisingly low intensity throughout the entire work. But very few were found which were positive even in diffuse sunlight during the middle of the day, unless the sky was covered with very dense clouds. The cause of reversal in the sense of orientation will be discussed elsewhere.

$f$. Accuracy of orientation. - In the study of their reactions to light, the Euglenae were exposed either to sunlight direct and diffused, or to light from a Nernst glower, a Welsbach burner or a carbon filament. When exposed to light from a single source, e.g., a Nernst glower so arranged that there is as little reflection as possible, Euglenae orient and move nearly straight toward or away from the light with little deviation, if they are strongly positive or negative; but if they are not, as is frequently the case, they deviate much. Even under the most favorable conditions there is however little similarity between Euglenae moving toward a source of light and iron filings moving toward a magnet, a comparison sometimes met with in the literature on reactions to light. In studying Euglenae one always finds specimens which do the unexpected thing. Their reactions are very much less dependent upon external conditions than are the reactions of iron filings. To come to a full realization of this, one need only consider the fact that these organisms may be negative or positive in almost any light intensity or they may not react at all. To predict with any degree of accuracy what these organisms are going to do under given conditions, it is necessary to know much about the history of their past reactions.

g. Mechanics of orientation in Euglena $x$ in the crawling state. - Nernst glowers mounted in front of a non-reflecting background (see Fig. 4) and properly screened in a large 
dark room were used in all quantitative work, and in all work in which it was desirable to regulate the direction of the rays. I have elsewhere pointed out the advantageous features of these glowers for such work (I906, p. 363 ).

The general movements of Euglenae could readily be followed under a Braus-Drüner binocular, but it was found necessary to use a compound microscope in working out the details in the reactions owing to the small size of the organisms. They progress so slowly however that every movement can easily be followed even under the highest magnification. They are consequently very favorable for the work in hand notwithstanding their minute size.

In studying the process of orientation the microscope was placed either in front of two windows in the laboratory so situated that the general direction of the light entering them was at right angles on the stage, or in the dark room in a similar relative position in front of two Nernst glowers (see Fig. I3). The two glowers were mounted so that the rays were practically parallel with the plane of the stage. One was stationary; the other was mounted on a track so that the distance between it and the aquarium could readily be varied, and thus the intensity of the light from it on the stage changed without any change in the direction of the rays. Both glowers were of the same kind and both were in the same circuit, so that any fluctuation in the current affected both alike. The relation in light intensity from the two sources could thus be regulated as desired. The glowers were so screened that only a small beam from each reached the stage, and this could readily be cut off from either or both.

The Euglenae were either mounted on a slide under a cover-glass or exposed in a rectangular glass aquarium made for the purpose by cementing slides together with balsam and linseed oil. After they had oriented in light from one of the two sources, the light from that source was cut off and that from the other turned on simultaneously. In 
this way their reactions during the process of reorientation could be studied in detail. The following description of this process refers to E. $x$ in the crawling state.

If the light in which positive organisms are oriented is decreased in intensity without a change in the direction of the rays, e.g., by pushing back the Nernst glower on the track, they respond in a characteristically definite way. If the decrease is relatively slight the anterior end is merely turned toward the ventral surface, the whole body becomes more curved and the spiral course of the anterior end becomes wider. If however the decrease is considerable, they frequently stop in their forward motion and turn the anterior end toward the ventral surface to such an extent that the two halves of the organism form a right angle. In this condition they continue to rotate, turning over and over in the same spot, and appear to be squirming and twisting about aimlessly. They soon however straighten again and continue on their way toward the source of light, having apparently become acclimatized to the change in light intensity. If the intensity is increased there is no response in positive Euglenae. Negative individuals, on the contrary, respond precisely as described above if the light intensity is increased, but not at all if it is decreased. If the specimens however are only slightly positive or negative they may be caused to respond with this twisting reaction either by increasing the intensity or by decreasing it. In order to induce this reaction it is necessary to change the intensity at a certain rate. If the glower is moved back very slowly and steadily, no reaction whatever is seen. A sudden decrease of intensity then without any change in the direction of the rays produces a definite reaction in positive individuals, and a sudden increase of intensity produces the same reaction in negative individuals. These reactions are in accord with the shock effects of Engelmann and Pfeffer and Unterschiedsempfindlichkeit of Loeb. They are not due to an absolute change of intensity but to the time rate of change of intensity. The amount of change 
necessary to induce a reaction will be discussed later (p. 105).

If the intensity from the two sources of light arranged as described above is equal and the beams which reach the stage of the microscope are alternately cut off with an opaque screen so as to change the direction of the rays suddenly without changing the intensity, it appears as though the Euglenae if positive always turn directly toward the source of light, never away from it no matter in what position they are or which surface becomes illuminated when the ray direction is changed. These results would seem to indicate that there is here a local response to a local stimulation, or at least differential response to localized stimulation. I was firmly convinced of the truth of this for several days, as were also other members of the laboratory who observed these reactions. Further work however demonstrated the fallacy of this conclusion.

By very careful observations under the high power it was found that if the ventral surface, the surface opposite the eye-spot, faces the source of light, after the direction of the rays is changed, there is no immediate reaction. The Euglenae continue on their course as though no change had taken place until the rotation on the long axis carries the dorsal surface over into a position in which it faces the light. As soon as this surface, the surface containing the eye-spot, faces the light there is a definite reaction. The Euglenae turn the anterior end toward the ventral surface more or less sharply, i.e., away from the source of light, but they continue to rotate so that the ventral surface soon faces the light again; but it is evident, owing to the curvature in the body, that the anterior end is now directed more nearly toward its source than it was when this surface faced the light during the preceding rotation. While in this position, the body is somewhat straightened, so that the anterior end is not carried back as far during the following rotation, and when the dorsal surface comes to face the light it is directed more nearly toward its source than it 
was when the organism was in this position before, as represented in Fig. I3. This reaction is repeated during each complete rotation. Every time the eye-spot becomes
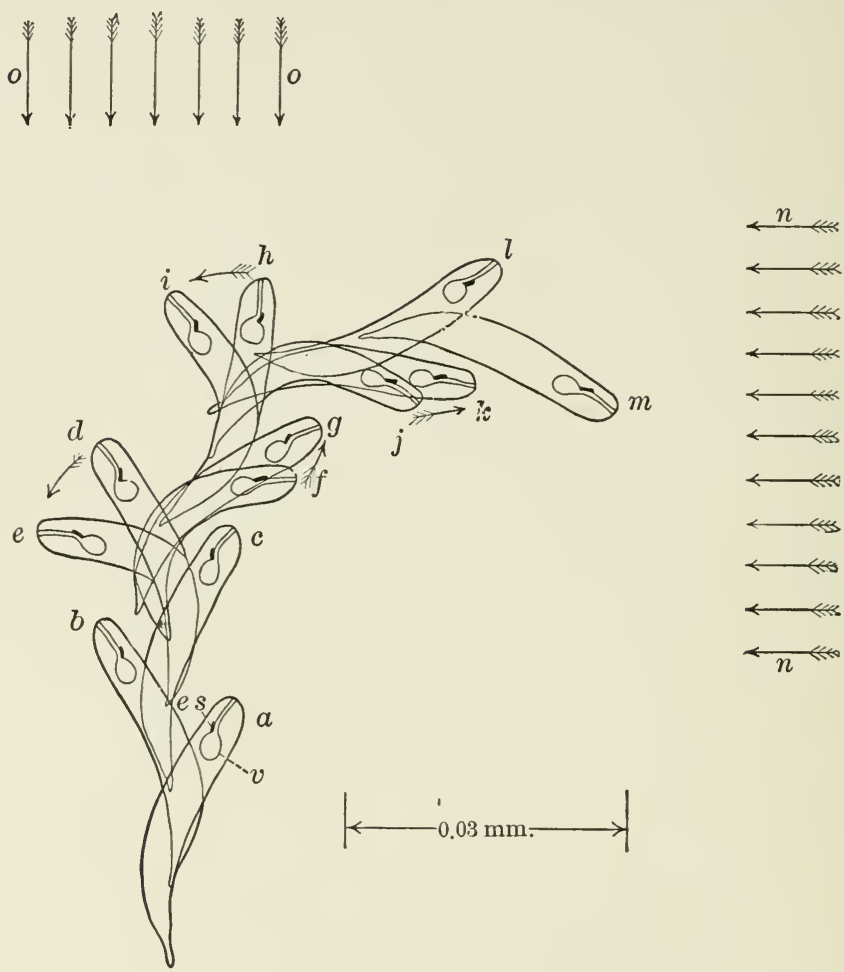

FIG. I3. Euglena sp. (?) in crawling state, showing details in process of orientation; $v$, contractile vacuole; es, eye-spot; $n, o$, direction of light; $a-c$, positions of Euglena with light from $n$ intercepted; $c-m$, positions after light from $n$ is turned on and that from $o$ cut off so as to change the direction of the rays. If the ray direction is changed when the Euglena is in position $c$ there is no reaction until it reaches $d$. Then it suddenly reacts by bending away from the source of light to $e$, after which it continues to rotate and reaches position $f$, where it gradually straightens to $g$, and rotates to $h$, when the eye-spot again faces the light and the organism is again stimulated and bends to $i$, from which it proceeds to $j$, etc., to $m$, where it is practically oriented. If the ray direction is changed when the Euglena is at $d$, it responds at once and orients as described above. If the intensity from $n$ is lower than that from $o$ the organism may respond at once when the ray direction is changed no matter in which position it is. (Compare with orientation in Stentor, Fig. I4.) 
more strongly illuminated the organism responds by bending, and when it becomes shaded the creature gradually straightens out and resumes its normal form again; thus the anterior end becomes directed more and more nearly toward the source of light until the organism reaches an axial position in which the eye-spot is no longer exposed to sufficient changes in illumination during the process of rotation to cause a bending reaction. The organism therefore continues in this direction, i.e., more or less nearly toward the source of light. Orientation is frequently brought about in two or three rotations. It is clear that during this process light does not act continuously as an orienting stimulus. Euglena responds with reactions leading to orientation only when the dorsal side is turned toward the source of illumination, not when the ventral side is exposed. And it should be emphasized that the first movement in the response is a bending away from the source of light, toward which it later becomes oriented.

It is evident from the above description that turning into such a position that the eye-spot faces the source of light produces a stimulation which results in a definite reaction. In this reaction the organism always bends the anterior end toward the ventral surface. It appears at first thought as though this reaction were due to the illumination of the eye-spot. It will however be demonstrated that this is not true.

If the light from the two sources arranged as described above is not equal, and the two beams which reach the aquarium are alternately intercepted, it is evident that the organism will be subjected simultaneously to a change in the direction of the light rays and a change of light intensity. If the stronger light is thrown upon the Euglenae after they are oriented in the weaker, they orient just as described above, but if the weaker is turned on after they are oriented in the stronger there is an immediate reaction, no matter which surface, the ventral or the dorsal, happens to be exposed at the time. If it is the dorsal and the 
difference of intensity between the light in the two beams is not too great, orientation takes place just as described above; but if it is the ventral surface which is exposed, it frequently happens that the organism first becomes directed away from the source of light and then toward it only after repeated reactions. The first step in all these reactions, regardless of how they are induced, is the same. It consists of a bending of the anterior end toward the ventral surface.

It has been demonstrated (I) that this reaction can be induced in positive Euglenae by reducing the light intensity of the field without changing the direction of the rays, no matter which surface is illuminated, and (2) that it can be induced without any variation in the light intensity of the field by changing the direction of the rays from one in which the anterior end is illuminated to one in which the dorsal surface is illuminated, or (3) it can be induced by the rotation of the organism on the long axis from a position in which the ventral surface is exposed to one in which the surface containing the eye-spot is exposed. Since the reaction under the first condition can be due only to a change of intensity on the whole or some part of the organism it is evident that the reaction under the second and third conditions is likewise due to a change of intensity. But since the light intensity of the field is constant under these conditions it is evident that the decrease of intensity must be restricted to a portion of the body and that it must be due to the shading of one part by another owing to the movement of the organisms. Our observations show that a change in the position of the organisms, from one in which the ventral surface is illuminated to one in which the dorsal surface is exposed, causes a reaction. Such a change in position must therefore produce a change of intensity on the sensitive parts of the organism. This may be conceived to be due to the eye-spot's acting as an opaque screen and casting a shadow when it faces the light on some highly sensitive protoplasmic structure located near it (see Fig. I I), or to the location of the more highly sensitive 
material in such a position that it is more strongly affected when the ventral surface is illuminated than it is when the dorsal surface is illuminated. The function of the eye-spot will be referred to again later.

Orientation in negative specimens takes place precisely as it does in positive specimens. The reactions resulting in orientation however are induced by an increase of intensity in place of a decrease, as in the case of positive specimens; and a change from a position in which the eye-spot faces the light to one in which the ventral surface is exposed induces the avoiding reaction, while in positive specimens it is a change from the latter to the former which causes this reaction.

After having thus worked out the details in the orienting reactions in Euglenae in the crawling state, I made observations on specimens in the free-swimming state and found the reactions to be essentially the same. A brief account of these observations will be found below (p. I02).

$h$. Discussion. - The orientation of Euglena in the crawling state confirms in general the description of the orientation in the free-swimming state given by Jennings (see p. 83). When the organism is not oriented every change from a position in which the light strikes the ventral surface to one in which it strikes the dorsal, and vice versa, due to rotation on the long axis, may be considered a "trial movement." If such a trial movement results in a decrease of light intensity on the sensitive protoplasm in the organism it responds with a definite reaction, after which it repeats the trial movements. Thus it continues until it becomes so directed in its course that rotation on the long axis no longer produces sufficient change of intensity on the sensitive part to induce a reaction. It is evident that this condition is fulfilled when the organism moves toward or away from the general source of light. Orientation can take place in an absolutely constant intensity of light in the field. It is however always induced by reactions which are due to changes of intensity on some part of the organism. 
This is of course due to the successive illuminating and shading of different parts of the organism owing to its movements. There is no evidence indicating that light, acting constantly as a directive stimulus similar to the action of the electric current, has any influence on orientation of Euglena in accordance with the idea of Loeb supported by Torrey. This however does not mean that light does not act constantly on the organism, for it is probable that it does, much in the manner of temperature. The evidence bearing on the point in question is however not conclusive. Euglena does become more active when the intensity is increased, but it is impossible to say whether this increase in activity is due to absolute intensity or to the change of intensity on certain structures caused by the rotation of the organism. The fact that the movement of the organism does cause changes of intensity on different structures in it makes the problem as to the effect of constant light intensity an exceedingly difficult one to reach experimentally.

Nägeli (I860, p. I02) concludes that in swarm spores the rate of movement is independent of the light intensity, and Strasburger (I878, p. 624) comes to the same conclusion. "Die Schnelligkeit der Bewegung wird durch das Licht nicht beeinflusst, doch bewegen sich die Schwärmer je grösser die Lichtintensität ist, in um so geraderen Bahnen." Pfeffer (I884, p. 375) also is of the opinion that chemical stimulation of fern spermatozoids causes no acceleration of movement. Holmes (I903, p. 323) however says: "It was found that, as the Volvox travelled towards the light, their movement was at first slow, their orientation not precise, and their course crooked. Gradually their path became straighter, the orientation to the light rays more exact and their speed more rapid. After travelling over a few spaces (centimeters), however, their speed became remarkably uniform until the end of the trough was reached." I came to the same conclusion in my study of Volvox (I907, p. I50), but was of the opinion that the increase in rate of movement 
is dependent more upon the time of exposure to light than upon the increase of intensity.

The experimental difficulty of course lies in the fact pointed out above, that the movement of the organism itself causes change of intensity on different structures in it. The fact however that Volvox, e.g., in swimming toward a source of light into regions of higher intensity without changing its orientation, swims more slowly as it approaches the region of optimum intensity and finally stops altogether, seems to show very clearly that the intensity affects the rate of movement. But the results of Holmes also show that the rate bears no definite relation to the absolute intensity. There is much need of more experimental data on this subject.

Does Euglena always turn toward or from the side stimulated? Is orientation due to differential response to localized stimulation? Or is the organism stimulated as a whole with a reaction dependent more or less upon the structure of the organism? If we are correct in our assumption that there is a highly sensitive protoplasmic structure located in the anterior end of Euglena, it is likely that it is always stimulated by light in the same place regardless of the portion of the surface exposed. Judging from this alone one might conclude that the stimulus acts as a local sign. But the fact that Euglena in the crawling state always bends toward the ventral surface when stimulated by light, while specimens in the free-swimming state always turn toward the dorsal surface when stimulated, contradicts this conclusion and supports the idea that the stimulus acts upon the organism as a whole. This is again in direct opposition to Torrey's statement (I907, p. 3I9), "The interpretation of the behavior of heliotropic organisms on the basis of general changes concerning the whole organism, not only does not accord with the known facts, but is rather psychical than physiological in character." It is difficult to see how the fact that an organism always turns in the same direction when it is stimulated as a whole can 
be considered a criterion of psychic activity. For all that is known to the contrary Euglena may be conscious. It may indeed have anthropomorphic sensations accompanying each reaction. But surely no one would consider the fact that it always turns toward the same side and does not respond in accordance with the theory of localized stimulation as indicating that it has such sensations.

$i$. Orientation of Euglena in the swimming state. Early in December two species, Euglena deses and a form much like viridis but somewhat larger, were found in the free-swimming state. They were however not very active; the specimens of $\mathrm{E}$. deses studied swam only at an average rate of approximately $0.25 \mathrm{~mm}$. per minute and rotated only about eleven times per minute; the other species moved somewhat faster. The reactions in both could readily be followed under a magnification of 150 diameters. Their orienting reactions were studied in the same manner as were those of Euglena in the crawling state, and they were found to be practically the same.

A decrease of the light intensity in the field without a change in the direction of the rays produces definite reactions. (I) There is a slight bending of the anterior end toward the dorsal surface. (2) The whole organism turns toward the dorsal surface by the action of the flagellum. (3) Their spiral course becomes wider. If the decrease is considerable they may be thrown out of orientation entirely and turn about several times before they become oriented again.

If the direction of the rays is changed without the light intensity's being changed, there is usually no reaction, just as in crawling specimens, until in the process of rotation the surface containing the eye-spot comes to face the light; then there is a sudden turning toward this surface, i.e., toward the source of light. In many instances the turning is so sharp immediately after the dorsal surface becomes illuminated that it may appropriately be designated as a jerk or a twitch. This reaction is repeated 
every time this surface is turned toward the light, each reaction resulting in directing the anterior end more nearly toward the source of light, until both surfaces are so nearly equally illuminated throughout the entire rotation that the change of intensity is no longer sufficient to cause a reaction.

If the light intensity is decreased at the same time that the ray direction is changed, the reaction described above always occurs immediately after the change is made, regardless of the surface illuminated. All however turn toward the dorsal surface. This results in movement in all directions and apparent confusion. When Euglenae are taken from the culture jars and first exposed in the aquarium they are more sensitive and respond to slighter changes than they do after they have been exposed for some little time. Among these one finds many specimens which always respond immediately after the ray direction is changed, even if the intensity remains the same, no matter which surface faces the light after the change is made. This indicates that a change in the direction of the rays from that in which the anterior end is illuminated to one in which the ventral surface is illuminated causes the same response as a decrease of intensity. It may therefore be concluded from this and preceding observations that the organism is most stable ${ }^{1}$ when the anterior end faces the source of light, less stable when the ventral surface faces it, still less stable when the dorsal surface is exposed, and least stable when the posterior end is directed toward the source of light. I was able to ascertain roughly the amount of reduction in light intensity required to induce the avoiding reaction with each of these different surfaces illuminated excepting that on the posterior end. The results of this work together with a description of methods will be found below.

The orienting reaction of free-swimming specimens is in all essentials like that of the crawling specimens. It

${ }^{1}$ It is meant by this that it requires a greater change of light intensity in the field to induce a reaction. 
takes place just as Jennings represents (Fig. I2), with the exception that if the direction of the rays is changed without any change of the intensity, orientation may take place without an increase in the diameter of the spiral course represented in Fig. I2, $a-c$. The organisms may orient by increasing the swerving only toward the source of light after its position is changed, not in the opposite direction.

The fact that these free-swimming specimens of Euglena in certain physiological states do not respond at all after the position of the source of light is changed from one in which the anterior end is illuminated to one in which the ventral surface is exposed, until the organism rotates so as to expose the dorsal surface; that as soon as this surface faces the light there is a sudden twitching turn toward the source of light; and that this reaction is repeated every time the surface containing the eye-spot comes to be illuminated in the course of the rotation on the axis, shows very clearly that orientation in the free-swimming state as well as in the crawling state is not due to a constantly acting stimulus, as Torrey assumes.

Unequal stimulation of symmetrically located points, as an important factor in causing orientation in accord with the theories of Verworn and Loeb, is of course out of the question in this form. If in heliotropism the results are a function of the constant intensity, as Loeb maintains (I906, p. I35), it must be admitted that there is no evidence indicating that Euglena is heliotropic.

$j$. Threshold or sensitiveness when different surfaces are exposed to light. - The difference in sensitiveness of the organism with different parts of the surface illuminated was measured in the following way: positive specimens were exposed in the small slide aquarium ${ }^{1}$ to light from the glower on the track. After they had oriented, the intensity was suddenly decreased without any change in the direction of the rays, by sliding the glower away until it could be

${ }^{1}$ An aquarium made of glass slides glued together with balsam boiled in linseed oil. 
clearly seen that a majority responded by definitely increasing the width of the spiral The point at which such response was given varied much with different individuals under different conditions and could therefore not be accurately ascertained. It was however discovered that if the organisms were oriented in $61 \mathrm{ca} . \mathrm{m}$. the intensity had to be decreased to $\mathbf{I} 7 \mathrm{ca}$. $\mathrm{m}$. before unquestionable response resulted. This shows that under the conditions of the experiment it requires a decrease of $44 \mathrm{ca}$. m., or over 66 per cent of the total intensity, to induce the avoiding reaction when the light strikes the anterior end.

By changing the position of the movable glower, the relation between the intensities of light from the two glowers, here arranged as in many of the preceding experiments, was so adjusted that when the Euglenae were suddenly exposed in the stronger light after they had oriented in the weaker, nearly all responded at once, regardless of the surface illuminated. Those in which the ventral surface was exposed turned away from the source of light; those with the dorsal surface illuminated turned toward it, and the rest turned in various other directions. The reaction is very striking under these conditions, although of course it was possible to ascertain only approximately the change of intensity necessary to produce it. It was found after many trials that the least reduction of light intensity with a simultaneous change in the direction of the rays, which caused this reaction in a majority of the specimens, was 32 ca. m., the intensity of the light from the stationary glower being $6 \mathrm{I} \mathrm{ca}$. $\mathrm{m}$. and that from the movable glower $29 \mathrm{ca} . \mathrm{m}$. It will of course be understood that individuals frequently respond to much smaller changes of intensity, depending upon their physiological state. With the anterior end exposed then, a reduction of $44 \mathrm{ca} . \mathrm{m}$. without a change in the direction of the rays is sufficient to cause the avoiding reaction. With the ventral surface exposed a reduction of $32 \mathrm{ca}$. $\mathrm{m}$. together with a simultaneous change in the direction of the rays causes the avoiding reaction, 
and with the dorsal surface exposed the same reaction is induced by a change in the direction of the rays without a decrease of intensity. These results lead to the conclusion that a change of the organism from a position in which the anterior end faces the source of light to one in which the dorsal surface faces it, results in a reduction of effective light intensity of approximately $44 \mathrm{ca}$. $\mathrm{m}$. in a total intensity of $6 \mathrm{I}$ ca. $\mathrm{m}$. Since the anterior end of Euglena is nearly transparent, such a relatively large reduction seems possible only if there is a highly sensitive bit of protoplasm so situated that the eye-spot casts a shadow on it when the light strikes the dorsal surface.

k. Function of the eye-spot. - Wager (I900, Pl. 32, Fig. 2) observed an enlargement in the flagellum, situated very near the concave surface of the eye-spot (see Fig. I I). It may be that this is highly sensitive to changes in light intensity and that the eye-spot functions as an opaque screen casting a shadow upon the enlargement whenever the dorsal surface is exposed. It may however also function in absorbing the rays when the ventral surface or the anterior end is exposed, much as the retinal pigment functions in the eye of higher forms, or it may function somewhat like the pigment cups in planarians, amphioxus, etc.

The only evidence we have with reference to the function of the eye-spot aside from that presented above is given by Engelmann (1882, p. 396). He says, in substance, referring to this structure in Euglena viridis, that if a sharp shadow is gradually brought from the posterior end of a swimming Euglena toward the anterior, there is no reaction until the shadow reaches the colorless anterior portion of the organism which contains the eye-spot. In the case of large individuals moving into a shadow, the reaction could be seen to be given before the eye-spot was in darkness. The colorless anterior end is therefore the primary light recipient region, but the eye-spot may still function secondarily, as do the pigment cells in the retina of higher animals. These observations of Engelmann have been 
widely quoted, and it is generally assumed that they prove that the sensitive portion of Euglena is located anteriorly from the eye-spot, and some hold that they even prove that the eye-spot does not function in light reactions at all. My observations on Euglena, however, seem to indicate that the portion most sensitive to light lies in close proximity with the inner surface of the eye-spot, not in front of it.

I repeated the experiment of Engelmann as follows: An opaque screen containing a rectangular opening $2 \times 3 \mathrm{~cm}$. was placed between the microscope and a Welsbach burner as near the globe of the burner as possible. A piece of tin was then hung inside the globe of the burner a few millimeters from the Welsbach mantle and so arranged that one of the straight edges could be seen through the opening in the screen. By means of the Abbe condenser that portion of the mantle exposed was focused on a slide under the microscope, containing Euglena deses and E. viridis (?), also E. triqueter and other species. The edge of the tin focused on the slide gave a strikingly sharp edge between the light area and the shadow. The reactions of the Euglenae were studied as they approached this edge. Both low and high power were used in the observations. The relation of intensity between light and shadow could be regulated by manipulating the iris diaphragm connected with the Abbe condenser, and the light area could easily be shifted by turning the mirror. In this way it was possible to move the shadow of the tin over any portion of the specimens while they were in motion. The Euglenae under observation swam about very slowly, $E$. deses at the rate of approximately $0.3 \mathrm{~mm}$. per minute and viridis (?) not much faster. Every movement and reaction could be distinctly seen. I was however able to confirm Engelmann's conclusions only in part. The Euglenae generally reacted before the entire body entered the shadow, and no response was observed when the posterior end was shaded until the shadow reached the anterior end, proving in accord with Engelmann's conclusion that the anterior end 
is undoubtedly more sensitive than the posterior. Specimens were also repeatedly seen to react as soon as the anterior end in front of the eye-spot came into the shadow, but many were seen to turn about before the anterior end reached the shadow at all, presumably owing to causes other than changes in light intensity. I was therefore at no time certain that those which reacted when only the tip of the anterior end touched the shadow would not have reacted had they not come in contact with the shadow.

But suppose that those which did react before the eyespot was shaded were stimulated by the shadow on the anterior end in front of the eye-spot, would this prove that the eye-spot is not a light recipient organ or that there is no highly sensitive structure back of the part stimulated? It evidently would not, for as soon as the anterior end touches the shadow, the light which is reflected from it onto the structures in the interior of the body before it reaches the shadow is cut off. The light intensity on structures which are not in the shadow at all is therefore reduced as well as that on those which are in the shadow, and it may be that the decrease of intensity on the former causes the reaction.

The possible effect on structures in Euglena near the eyespot, due to shading merely the tip of the anterior end, can readily be illustrated by noting the effect if one looks into the mouth of a test tube full of translucent jelly and throws a shadow on the closed end. The reduction of light will of course affect the eye at once, although it may be a considerable distance from the shadow.

If there were a differentiated bit of protoplasm highly sensitive to variation in light intensity, located in close proximity to the eye-spot on the side facing the interior of the body, one might even expect the organism to react before the anterior end reaches the shadow at all, for, since there is no light reflected from the shaded area, it is evident that merely turning the anterior end toward it would result in a decrease of light intensity on the postulated sensitive 
structure, and moving toward the shadow would decrease it still more.

There is consequently nothing in connection with the observations of Engelmann which contradicts the idea that the eye-spot in Euglena functions as an opaque screen, and that there is a bit of protoplasm which is highly sensitive to changes in light intensity in close contact with it. The hyaline protoplasm at the anterior end condenses the light so that it is most intense in the neighborhood of the eyespot. This can be seen in Euglena in direct sunlight. It is however much more marked in Chlamydomonas and the zooids of Eudorina and Pandorina (Figs. I7 and 2I). If the light is thus actually focused on the most sensitive structure of the organism it is easy to see how changes in the general direction of the rays could produce marked changes of intensity on this structure. Aside from acting as an opaque screen the eye-spot may, of course, as already stated, also function as an absorptive background.

In Trachelomonas hispida the eye-spot is situated very near the middle of the anterior end (see Fig. I6). If it functions by shading the sensitive portion or by absorbing the rays in this form it is highly probable that the sensitive portion consists of a minute structure situated very near it, perhaps in the hollow of the concave surface. In some of the forms however the location of this structure seems to show that it does not function as a screen. In Volvox, Pandorina and Eudorina the eye-spots are situated on the outer posterior surface of the zooids. It is difficult to see how they could function as screens in these forms (see Fig. $2 \mathrm{I}$ ). The same difficulty is encountered in some forms of Chlamydomonas in which this structure is situated near the posterior end (see Fig. I7). It does however not seem necessary to assume that the eye-spot functions precisely the same in all forms. While it may function both as an opaque screen and as an absorptive background in Euglena, it may possibly function only by absorbing light rays in Volvox and Chlamydomonas. 


\section{Summary}

(I) Some species of Euglena exist in three states, - freeswimming, crawling and encysted.

(2) While in the crawling state they push themselves along at the rate of about $0.3 \mathrm{~mm}$. per minute by alternately curving and straightening the body very slightly as they rotate on the long axis. There is no evidence of locomotion by means of amoeboid movement.

(3) In this state they orient fairly accurately in light. They may be either positive or negative.

(4) When exposed to light from two sources they may move toward or from a point located anywhere between the two sources. The location of this point depends upon the relation in amount of light from the two sources. If the light from one source is stronger than that from the other, this point will lie nearer the source from which the stronger light comes.

The orientation of sixteen other species in light from two sources was ascertained. All of those without image-forming eyes, fifteen in number, oriented just like Euglena. The one with image-forming eyes always moved directly toward one or the other of the sources of light, never toward a point between them. It is therefore evident that Loeb's statement regarding this point will not hold for any of these organisms.

(5) If the intensity is decreased without any change in the direction of the rays, positive Euglenae in the crawling state always respond by bending the anterior end toward the ventral surface. This may be termed a shock-movement, or avoiding reaction, or a bending reaction.

(6) A change from a position in which the ventral surface faces the source of light to one in which the dorsal, i.e., the surface containing the eye-spot, faces it, induces the bending reaction. Such a change in position therefore produces the same result as does a reduction in the light intensity. These reactions can consequently be induced either 
by changing the direction of the rays or by changing the light intensity of the field.

(7) The bending reactions are induced wherever the light strikes the dorsal side of Euglena owing to its rotation on the long axis. This reaction is repeated until the organism is oriented and rotation no longer causes a change of illumination on its dorsal and ventral surfaces. It remains oriented because, while it proceeds in this direction, there are no stimulations which induce the bending reaction.

(8) The intensity can be so gradually changed that there is no response. The bending reaction is therefore dependent upon a time rate of change, and orientation is consequently also due to a time rate of change in the light intensity.

(9) The results of these experiments support Jennings' conclusion that orientation in Euglena is brought about by selection from trial positions. This of course does not mean conscious selection.

(I0) It is probable that light has a constant effect on the activity of Euglena much as temperature does, but there is no evidence that such activity has anything to do with the process of orientation, as the explanations of Loeb, Verworn, and Torrey demand.

(I I) Orientation is not dependent upon the direction in which light rays pass through the tissue, in accordance with Sachs; nor is it dependent upon the angle between the rays and the sensitive surface, or the unequal stimulation of symmetrically located points on the surface, as Loeb assumes; nor upon the effect of the stimulating agent upon the locomotor organs directly, or through a direct reflex arc, as the theory of Verworn demands; nor upon light acting constantly as a directive stimulus, in accord with Loeb's idea supported by Torrey.

(I2) The most highly sensitive portion of Euglena is probably situated near the concave surface of the eye-spot, and the eye-spot probably functions in casting a shadow on the highly sensitive substance when the light strikes the 
dorsal surface. The eye-spot may also function in absorbing the rays.

(13) There is no evidence in these experiments bearing on the question of anthropomorphic sensation. The results do not exclude its presence. The reactions are due to changes in light intensity, and every change, for all that is known to the contrary, may cause a sensation. 


\section{CHAPTER VI}

\section{OBSERVATIONS ON UNICELLULAR FORMS IN THE PROCESS OF ATTAINING AND RETAINING A DEFINITE AXIAL POSITION WITH REFERENCE TO THE SOURCE OF LIGHT (continued)}

\section{Stentor coeruleus}

a. Introduction. - Davenport (I897) and Holt and Lee (I90I) worked out the general features in the light reactions of Stentor coeruleus. They found that these animals are negative and that they orient rather accurately. Holt and Lee concluded that orientation takes place in accord with Verworn's theory, that light acts constantly as a directive stimulation. If one side is more highly illuminated than the other the cilia beat more effectively on the illuminated side. This causes the animal to turn directly from the source of light until it is oriented and both sides are equally illuminated. Jennings (1904) found that an increase in the light intensity of the field causes a definite reaction in Stentor regardless of the direction of the rays or the surface exposed at the time the change is made. This reaction was designated the avoiding reaction. It consists of turning toward the right aboral side. The organisms may stop and turn very sharply or they may simply swerve farther towards this side as they proceed on their spiral course. By means of this turning the anterior end is directed toward various points in space. Sooner or later it becomes directed away from the source of light and the organism is oriented. This direction is retained because when the anterior end is turned from the light it is not subjected to changes in light intensity as the animal rotates on its axis and continues on its spiral course.

Orientation, therefore, according to Jennings, is brought 
about by reactions which are induced by a change in the effective intensity. This may be due to actual change of the intensity of the field, to a movement from a region of one intensity to that of another, or to a change of intensity on the surface of the organism caused by changing the surface turned toward the source of light. Direction of rays and difference of intensity in the field are functional in the process of orientation only in so far as they may influence change of intensity on the organism. Orientation is not induced by a constantly acting directive stimulus; it is the result of a response to a time rate of change of intensity, a shock-effect, Unterschiedsempfindlichkeit.

Working independently of Jennings I obtained (I906) results which were in all essentials in harmony with his. Jennings assumed that the anterior end of Stentor is more sensitive than the posterior. I proved that Stentors are more sensitive to light when the anterior end is exposed than they are when any other surface is exposed. The minimum threshold in animals stimulated by rays perpendicular to the long axis was found to be $\mathbf{I} .2 \mathrm{ca}$. m., and that in those stimulated by light striking the anterior end only $0.25 \mathrm{ca}$. $\mathrm{m}$.

$b$. Orienting reactions. - I was of the opinion that while the avoiding reactions no doubt play a large part in orientation of Stentor, a direct effect of light as a constantly acting stimulus in orientation might be discovered by a careful investigation with this in mind.

Three methods were used in this investigation: (I) Water was removed from under the cover glass until the space between it and the slide became so narrow that the Stentors could no longer rotate on their axes. They were then illuminated so that various surfaces were successively exposed. If light acts constantly as a directive stimulus one might expect the cilia on the illuminated side to strike back more vigorously than those on the shaded side regardless of the surface exposed. I was however unable to observe any relation between the rate of movement of the cilia and the 
surface illuminated as indicated by the currents in the water.

(2) A number of attached Stentors in a small rectangular glass aquarium were repeatedly suddenly exposed in light intensity of $8000 \mathrm{ca}$. m. produced by a Nernst lamp. When they were thus exposed they were directed toward various points of the compass, so that various parts of the surface faced the source of light in different individuals. A few always contracted immediately after each exposure, others began to swing about the point of attachment, some clockwise and others counter-clockwise, but all turned toward the ventral surface. The cilia must consequently beat the same in all individuals no matter which surface is exposed to the light. There is therefore no evidence in these results that light acts constantly as a directive stimulus.

(3) After Stentors had oriented in light from a single Nernst glower, the glower was slightly moved to one side so as to change the direction of the rays slightly, and the method of reorienting was observed. It was found that under such conditions the Stentors merely swerve farther away from the source of light each time after the oral side is directed toward it in the process of rotation. Thus they soon become oriented again. There is no definite avoiding reaction in this process of orientation. The organisms never increase the swerving toward the source of light; they always increase it in a direction which tends to turn the anterior end from the light. Does light act as a constantly directing stimulation in this process of orientation or does it act by causing repeated successive stimulations due to changes of intensity on some part of the surface of the organism as in Euglena? Is Stentor heliotropic according to Loeb's definition or is it unterschiedsempfindlich? The following experimental observations will furnish answers to these questions.

Two Nernst glowers were arranged and screened so as to produce two small beams of light which crossed at right angles in a small aquarium containing numerous Stentors. 
The light intensity from each of the two glowers was equal. The direction of the rays could therefore, without any altering of the intensity, be changed by alternately intercepting the light in each of the two beams. If the ray direction is thus changed after the Stentors are oriented in one of the beams of light, one side will of course be directed toward the light. If it chances to be the aboral side and the Stentors are not very strongly negative, they continue on their course just as though the direction of the rays had not been changed, until in the process of rotation the oral side comes to face the light; then the organism responds in one of two ways: it may stop suddenly and sometimes back a little and turn sharply toward the aboral side; that is, it may respond with the avoiding reaction, or it may merely swerve farther from the source of light on its spiral course as represented in Fig. I4. When the oral side again comes to face the light the organism is again stimulated and it again swerves farther from the source of light. This reaction is repeated once during each rotation until the oral side is nearly equally exposed to the light throughout the entire rotation. This is evidently true when the anterior end is directed away from the source of light. If the organism responds with the avoiding reaction it turns more directly from the source of light and thus becomes more rapidly oriented, as represented in Fig. I4.

Why does Stentor respond when the oral side faces the light and not when the aboral side faces it in the same intensity? If Stentors are oriented in light of a given intensity and the intensity is decreased without any change of ray direction there is no response; but if it is increased they respond in one of two different ways, depending upon the amount of increase. If the increase is relatively slight they merely swerve more strongly toward the oral side; and since this side always faces out when the organism swims on its spiral course, the result is that the course is made wider. If the intensity increase is greater the creature stops suddenly, turns toward the aboral side, sometimes 


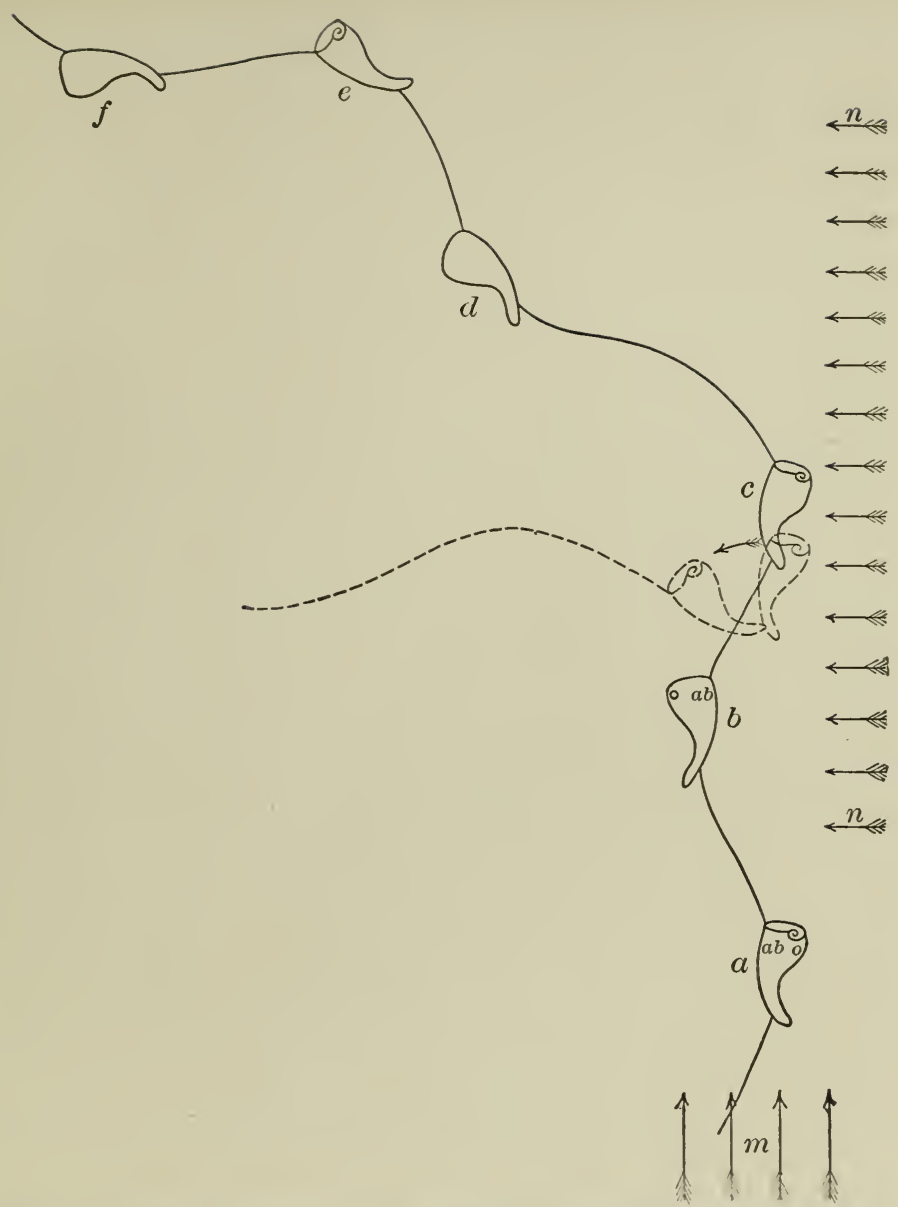

Fig. I4. Stentor coeruleus in the process of orientation. The curved line represents the spiral course; the arrows $m$ and $n$ the direction of light from two sources; $a-f$, different positions of Stentor on its course; $o$, the oral surface; $a b$, the aboral surface. At $a$ the Stentor is oriented in light from $m, n$ being shaded. If $n$ is exposed and $m$ shaded simultaneously when the Stentor is in position $b$, there is usually no reaction, if the intensity has not been changed, until it reaches $c$ and the oral side faces the light; then the organism may respond by suddenly stopping, backing and turning sharply toward the aboral side, as indicated by the dotted outline, and become oriented at once; or it may merely swerve more or less toward the aboral side without stopping. At $e$ the oral side is again exposed and the organism is again stimulated and it again swerves from the source of light. This process is continued until the oral side is approximately equally exposed to the light in all positions on the spiral course. If the Stentor is at $c$ when $n$ is exposed it responds at once and orients as described above. If the light from $n$ is more intense than that from $m$, or if the organism is very sensitive when $n$ is exposed and $m$ shaded, it responds at once no matter in which position it is. If it is at $b$ it turns toward the source of light, but now repeats the reaction, successively turning in various directions until it becomes oriented. 
backing slightly at the same time, and goes ahead swerving sharply toward the ventral surface and the oral side. This throws the animal out of orientation; the first method of response does not. This shows that the reaction is due to an increase of intensity on some part or on the whole of the body. It is evident that the intensity of light on the sides of Stentor changes, if it rotates while it is illuminated from the side, owing to its own shadow; and since it reacts only when the oral side is carried from a position in which it is shaded to one in which it is illuminated, it is clear that this side must be more sensitive than the aboral, or perhaps better, that the animal is more sensitive when the oral side is exposed than it is when the aboral side is exposed.

If the light intensity is increased at the same time that the direction of the rays is changed as described above, all the organisms respond with the avoiding reaction at once no matter which side faces the light, just as in the case of Euglena. In this response some may be seen to turn upward, some downward, and others to the right or left. They all turn toward the aboral side. The direction in which they turn therefore depends upon the position of this side when the change is made. Stentors frequently respond thus when the direction of the rays is changed without varying the intensity. This takes place when the organisms are highly sensitive.

It is clear from this description that the orienting reactions in Stentor and Euglena are the same in princible. Both organisms can orient in a field of uniform light of constant intensity. The stimuli causing orientation are however due to changes of intensity on the sensitive structures in the body. Such changes of intensity in a field of light of uniform and constant intensity are caused by the shadows produced by one part passing over other parts as the organisms rotate. There is no evidence that the direction of the rays functions in orientation excepting in so far as it may influence changes of intensity; nor is there 
any evidence that light acting constantly somewhat like a constant electric current, has any effect on orientation as Loeb's explanation of orientation demands.

\section{c. Difference in sensitiveness with different surfaces} illuminated. - The threshold of reaction in Stentors varies so much in different individuals and in the same individual in different conditions that quantitative results are of little value unless they can be correlated with causes of variation. A few measurements made may however be of interest in showing the relative stability of these organisms with different parts of the surface exposed.

On February I2, specimens fresh from the culture jar were put into the aquarium with the two Nernst glowers arranged as described above. The intensity from the two glowers was equal; it was $32 \mathrm{I} \mathrm{ca}$. $\mathrm{m}$. When the ray direction was changed by intercepting alternately the beams of light after the Stentors had become oriented, practically all of them responded immediately with the avoiding reaction regardless of their position when the change was made. Some turned toward the light, others away from it, and the remainder turned in various other directions. After these specimens had been experimented upon for about fifteen minutes only those responded immediately in which the oral side faced the light when the direction of the rays was changed. The rest did not respond until after they had rotated sufficiently to expose the oral side. In responding they gave either the avoiding reaction or merely swerved farther from the source of light as they continued on their spiral course. In both methods of reaction they always turned directly from the source of light, never toward it. In casually studying Stentors under these conditions only, one might readily conclude that orientation is always direct and that it is due to local response to a local stimulation. This however is not the case.

As soon as the observations described above were completed, I put the Stentors into darkness, left them for a short time and then exposed them to light from the 
movable glower in an intensity of I50 ca. m. After they had oriented the glower was suddenly pulled toward the aquarium until it could be clearly seen that many of the specimens responded with the avoiding reaction. By repeating this many times it was found that it required an increase from I5O ca. m. to 444 ca. m. (or 294 ca. m.) to throw them out of orientation. This may then be called the threshold with the posterior end illuminated.

Frequently during the progress of the preceding experiments the ray direction was changed and the light intensity increased simultaneously. It was found that when the intensity was thus increased from $\mathrm{I}_{50} \mathrm{ca}$. $\mathrm{m}$. to $32 \mathrm{I} \mathrm{ca.} \mathrm{m}$. (or I 7 I ca. m.), nearly all responded at once regardless of the surface turned toward the source of light after the change was made; and under these conditions they could be seen to turn toward the light as well as from it. But when the intensity was increased from $226 \mathrm{ca}$. $\mathrm{m}$. to $32 \mathrm{I}$ ca. m. (or $95 \mathrm{ca}$. m.), only those responded in which the oral side faced the light after the direction of the rays was changed, and these also responded when the ray direction was changed without an increase in light intensity, as represented in Fig. I4.

Judging from these results a change in the position of a Stentor from one in which the posterior end faces the source of light to one in which the oral side faces it, is equivalent to increasing the intensity nearly threefold; and a change from a position in which the aboral side is illuminated to one in which the oral side faces the light is equivalent to doubling the intensity. These considerations show clearly how a stimulation in a field of uniform and constant light intensity can be produced by change of intensity. The fact that Stentors are so much more sensitive when the oral surface is illuminated than when the aboral surface or the posterior end is exposed, points toward the presence of a highly sensitive region in the neighborhood of the oral opening in Stentors. The precise location of this region is a subject for future investigation. The following experiments however 
indicate that it is not in the membranellae or in the ridge from which they project.

On February 27, 3.30 P.M., a number of Stentors were put into a one-half-normal glycerine solution. In the course of about two minutes the entire ridge with the membranellae in nearly all the specimens was thrown off, after which the anterior end was rounded and the oral opening was tightly closed. They were then transferred to normal culture fluid, in which they swam about much like normal specimens. They rotated on the long axis, proceeded on a spiral course and responded with the avoiding reaction.when they were mechanically stimulated or when suddenly exposed to strong light. The threshold for light reactions was however much greater than normal. At 8.30 P.M. there was no indication that regeneration had begun, but on the following morning nearly all the specimens were normal again.

d. Localized stimulation. - Are the reactions in Stentor differential responses to localized stimulation? In Euglena, it will be remembered, we were obliged to answer this question in the negative. The results described above seem to show that there is a highly sensitive structure in Stentor at the anterior end near the oral side. It is therefore probable that whenever these animals are stimulated by light they are stimulated in this region regardless of which surface is exposed; and if this is true it is evident that the fact that these organisms may turn toward the illuminated side or toward the shaded side does not prove that they do not give a differential response to localized stimulation, nor does it prove that they do. We have therefore no conclusive evidence bearing on this question with reference to Stentor.

\section{Summary}

(I) Stentor coeruleus collects in shaded regions either by orienting and swimming directly toward such regions or by wandering into them aimlessly. They remain in the shaded region because whenever they come to the edge of it, the 
increase of intensity causes them to respond with the avoiding reaction.

(2) An increase in the intensity of light in which Stentors are oriented, without any variation in the direction of the rays, causes them to respond either with the avoiding reaction or by simply swerving farther toward the oral side, making the spiral course wider.

(3) Orientation in Stentor takes place essentially as it does in Euglena. It is caused by changes in light intensity on the sensitive tissue in the organisms. If, without a change in the intensity, the direction of the rays is changed so that the side of the organism instead of the end is exposed, there is no reaction, provided the Stentors are not highly sensitive, except when the oral side comes to face the light in the process of rotation on the long axis. Then the reaction may consist either of the avoiding reaction or merely of a greater swerving from the source of light. Both result in orientation. This shows that orientation is brought about by reactions due to changes of intensity and not to light acting constantly as a directive stimulus in accord with the theories of Loeb and Verworn.

(4) If the animals are highly sensitive or if the light intensity is increased when the direction of the rays is changed, they respond no matter which side is exposed after the change is made. In this response they turn in all directions, toward the light as well as away from it.

(5) Stentors may orient in a field of light which is uniform and constant in intensity; but the orientation even under such conditions is due to a change of intensity. This change is caused by the movement of the animal which results in alternately illuminating and shading different parts of the organism.

(6) Orientation may be said to be due to selection from trial movements, just as in Euglena, even in those cases where Stentor never errs by turning definitely toward the light, for during every rotation the relatively highly sensitive oral side is alternately shaded and illuminated until 
the organism becomes directed from the source of light. Thus it is that the rotation itself constitutes a trial movement.

(7) There is no evidence that light acting continuously has any influence on orientation. These organisms are not heliotropic in accord with Loeb's definition of this term.

(8) Stentors probably are more active in higher than in lower light intensity. But even here it is impossible to say whether the greater activity is due to stimulations produced by constant intensity or by changes of intensity, since even in a field of absolutely constant light intensity the movements of the organism cause the more sensitive parts to become alternately shaded and illuminated.

\section{Edogonium Swarm-spores}

The reactions of swarm-spores to light have been studied but little. Most observers have merely recorded the fact that they do respond to stimulation by light and that they may be negative or positive. Strasburger (I878, p. 59I) found that if exposed in glass jars they collect near the surface of the water at the side facing the window, but he says that they orient very indefinitely and that he therefore did not attempt to analyze the reactions.

These organisms are very nearly radially symmetrical. It is in such forms, rather than in asymmetrical forms like Euglena and Stentor, that one might expect to find a definite relation between the direction of turning and the side illuminated. In such forms one might also expect orientation to be the result of light acting constantly as a directive stimulation. I was therefore much interested in working out the details in the reactions of these creatures.

a. Description. - Edogonium swarm-spores are in general very much like an egg in form (Fig. I5). At the smaller end, the anterior, there is a colorless mound-shaped elevation. The rest of the body is green. At the base of this mound-shaped elevation there is a band of cilia. I was 
unable to find any indication of an eye-spot in living specimens although I spent much time in looking for it. Strasburger however claims to have observed a red pigment spot after treatment with acetic acid. There is great variation in the size of the spores; some of those used in these experiments were several times as large as others. I am not certain, however, that they were all of the same species. In general they are considerably smaller than Paramecia.

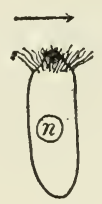

$A$

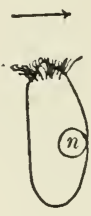

$B$

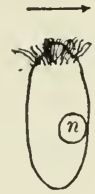

C

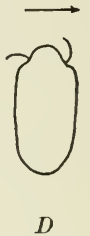

$D$

Frg. I5. Oedogonium swarm-spores. In responding with the avoiding reaction they always turn toward the same side. This side bears no definite relation to any visible asymmetry in their structure. A turned toward the more concave side, i.e., from the side near which the nucleus was located. $B$ turned toward the more convex side, near which the nucleus was found. $C$ was very nearly symmetrical in form. It turned toward the side containing the nucleus. $D$, diagram representing the direction of the stroke of the cilia during the process of turning. This can be very distinctly seen under high magnification.

b. Material. - Swarm-spores were obtained in great numbers in midwinter by adding fresh water to a jar which contained numerous Edogonium filaments, and letting it become slightly stale. In those jars which were in diffuse sunlight the swarm-spores collected near the surface of the water on the side facing the window. In those in direct sunlight they usually collected on the opposite side. They are quite strongly negative in their reactions to gravity; this accounts for the collection near the surface of the water.

c. Locomotion. - They swim on a spiral course of varying width and rotate on the long axis just as do Euglena and Stentor. The smaller end is usually ahead but they reverse freely, and under some conditions they swim with the larger end ahead almost constantly. They rotate clockwise when the smaller end is ahead, but in the opposite 
direction when the larger end is ahead. Early in the forenoon after the jars have been in darkness all night the spores usually all swim with the larger end ahead, but later in the day they proceed with the other end foremost. I was however unable to induce this change by keeping them in darkness during the day. The following quotation from my notebook serves to emphasize this peculiar reversal: On the morning of January Io all swam with the larger nonciliated end forward rotating counter-clockwise as seen from the posterior end. Most of them swam rather actively in closed curves circling toward the left. In the afternoon I was surprised to find all the spores swimming about with the smaller end, the end containing the cilia, ahead. They were very abundant in the jar and quite active. The jar was in strong light all day, part of the time in direct sunlight, and although they were most numerous on the wall of the jar facing the window, they gathered on the side under the cover-glass farthest from the window when exposed to the direct rays of the sun. On the morning of January I I there were but very few motile specimens, but all that were observed excepting one swam as those found on the preceding morning did, i.e., with the larger end ahead. At 2.30 P.M. they were slightly more numerous and nearly all swam with the smaller end ahead. I am, at present, unable to account for this reversal in locomotion.

These organisms are so small, move so rapidly, and are so nearly symmetrical that it was impossible to ascertain under normal conditions whether or not they always turn toward the same side in their orienting reactions. They were therefore mounted in a solution of quince-seed jelly. In this solution they swim about very slowly; they stop frequently, back some distance, turn toward one side and then proceed on a new course; that is, they respond with the avoiding reaction. If the solution contains considerable jelly they frequently swim with the posterior end ahead.

By focusing attention upon specimens in which the 
nucleus, ordinarily located near the surface, was visible, and upon others in which opposite sides had a slightly different curvature, it could be seen (I) that the same surface continually faces out as they proceed on the spiral course, precisely as in asymmetrical forms; and (2) that a given individual always turns toward the same side in giving the avoiding reaction. The side toward which they turn bears no definite relation to the location of the nucleus or to the curvature of the side. Some turn toward the more convex, others toward the more concave surface. These organisms then, although symmetrical, respond with the avoiding reaction, when mechanically stimulated, just like asymmetrical forms. They stop, usually back quite a distance, turn toward a given side, and then proceed on a new course (Fig. I5). Since there is no known asymmetric structure which bears any definite relation to the direction of turning, and since the organism always turns toward the same side no matter which point on the surface comes in contact with a solid, it is evident that as far as the facts are known they indicate that there is no differential response to a localized stimulation. The same is true in case of the symmetrical form Didinium nasutum. During the turning process it was clearly seen in both Didinium and the swarm-spores that the cilia strike forward on one side and backward on the opposite side, showing a remarkable differentiation in function.

d. Orientation in light. - The process of orientation was studied in negative forms in direct sunlight. In the quinceseed jelly solution the spores do not orient definitely enough to make it possible to work out their orientation reactions, and positive specimens under normal conditions orient very indefinitely. The method of procedure in this study was in general like that followed in the observations on Euglena and Stentor.

A small beam of light direct from the sun was allowed to fall on the stage of the microscope, and another beam was reflected at right angles to it with a mirror. The light in 
each of the two beams was then alternately intercepted, and thus the direction of the rays was changed. It was found that in the process of orientation under such conditions, the swarm-spores always turn away from the source of light, never toward it, but in this turning they merely swerve farther in their spiral path every time that the course in the spiral is directed away from the source of light, and not so far when it is directed toward it. Since the same side is always directed out in the spiral it is evident that they do not turn directly from the source of light. They turn from the source of light only when a given side faces the light, not when the opposite side faces it.

The orientation therefore takes place in these swarmspores just as it usually does in Euglena and Stentor when the ray direction is changed without a change of intensity of light. This shows that the organisms are more sensitive when one side is illuminated than they are when the opposite side is exposed, just as was shown to be true in asymmetrical forms. They are however not very readily stimulated by changes of intensity; it was impossible to induce the avoiding reaction in this way. If mounted on a slide containing a bright area in a dark field, the collection in the bright area is not definite, as it is in the case of Euglena under similar conditions; the swarm-spores usually pass out and in without any apparent response. If the light intensity is only moderately changed after they are oriented there is but a slight increase in the width of the spiral path. If it is changed much the spores immediately turn and swim up, since they are strongly negative in their reactions to gravity.

Orientation in these symmetrical forms is then governed by the same factors as it is in the asymmetrical forms. It is due to changes of light intensity on the organism. These changes are produced in a field of constant intensity by the rotation on the axis. There is no evidence that light acting constantly as a stimulus has any effect on orientation. The swarm-spores are more sensitive when one side is exposed 
than they are when the opposite side is exposed. They always turn toward a given side, which, as far as can be seen, is not structurally defined. There is no evidence indicating differential response to localized stimulation.

\section{Trachelomonas}

No detailed observations on the light reactions of Trachelomonas have been recorded. The reactions of this organism are of interest to us here chiefly because it is very nearly radially symmetrical and because it has a very prominent eye-spot located very near the middle of the anterior end, a location quite different from that in any other form of which I know.

Trachelomonas hispida, the species studied most carefully, is ellipsoidal in form, about $0.02 \mathrm{~mm}$. long and o.or 5 $\mathrm{mm}$. wide. It is surrounded by a dark brown rough brittle test of considerable relative thickness. A single large flagellum, frequently three times as long as the body, projects through a hole in this test at the anterior end. A relatively large contractile vacuole appears to communicate with the exterior through this hole. This suggests that the flagellum may possibly extend into the contractile vacuole as it does in Euglena viridis. The eye-spot is reddish brown in color and has the general form of a thin curved disk (Fig. I6). It is located between the contractile vacuole and the anterior end and appears partially to surround a canal leading from the former to the exterior. The eye-spot is very irregular in outline and appears under an oil immersion lens to consist of a number of small granules embedded in a homogeneous matrix. The granules project in the form of marked knob-like elevations on the convex surface, making it appear very rough. In most specimens similar granules were found lying about loose in the neighborhood of the eye-spot. The test is so nearly opaque in many specimens of hispida that little can be seen through it, while in some other species studied it is actually black, so that nothing 
can be seen of the structure inside. The tests can however be readily removed. If the cover-glass is allowed to press lightly on the organism it splits open and the cell within with its prominent eye-spot and bright green color escapes. All these forms react definitely to light; they are negative in strong light and positive in weak. They orient quite

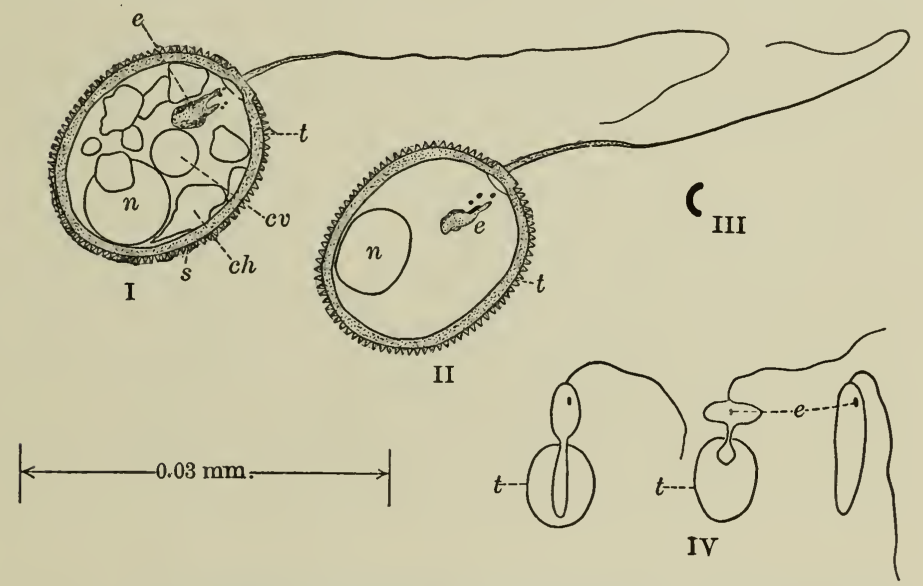

FIG. I6. I. Trachelomonas hispida showing structure; $c v$, contractile vacuole; $t$, dark brown test nearly opaque; $s$, spines on surface; $n$, nucleus; $c h$, chloroplast; $e$, eye-spot.

II. Different view of same specimen showing that the eye-spot is nearly centrally located. Note rough edges of eye-spot and loose granules composed of same material.

III. End view of eye-spot.

mm., projected scale. I and II drawn with camera as seen under oil immersion.

IV. Sketches of specimens seen in the process of leaving the test preparatory to fission. They frequently swim about in the naked elongated state for some time.

accurately and proceed on a spiral course much like Euglena. It is remarkable how sufficient light to cause a stimulation can get through the dense black tests of some specimens.

In the study of the reactions of these organisms they were mounted in water under a large cover-glass which was supported by a thin ring of vaseline. In this way evaporation was prevented. The specimens thus mounted lived 
for over a month and increased in numbers. When they are about to divide they crawl out through the opening in the test at the base of the flagellum and then they may swim about in the naked elongated state (Fig. I6) for some time before they divide and form new tests. When the test is new it is nearly transparent. It was in specimens in this condition and in those in the naked state that the reactions were observed.

The orienting reactions were studied just as they were in the forms already described. Trachelomonas was found to orient just like Euglena in the free-swimming state. If the light intensity is moderatelydecreased without changing the direction of the rays they swim in a wider spiral; if much decreased, they turn sharply in all directions. They always turn toward the convex surface of the eye-spot. If the ray direction is changed without a change of intensity only those with the convex surface of the eye-spot directed toward the light react immediately, the rest not until this surface becomes exposed in the process of rotation. The reaction consists in simply swerving farther toward the light each time that the eye-spot faces the source of light; thus they soon become oriented. If the ray direction is changed with a simultaneous decrease in the light intensity, all react at once. Under such conditions they turn from the light as well as toward it.

It is clearly evident that turning the convex surface of the eye-spot toward the source of light produces the same effect as a decrease in the light intensity of the field. There is practically the same amount of protoplasm on all sides around this structure, and as far as can be seen under the best oil immersion lens this protoplasm is the same on all sides. If this is true the shadow of the eye-spot should have the same effect whether illuminated from the concave or the convex surface. The fact that it does not indicates that there is a highly sensitive bit of protoplasm close to the eye-spot on the concave surface. 


\section{Chlamydomonas alboviridis (Stein)}

Chlamydomonas is a small green egg-shaped organism usually less than o.oI $\mathrm{mm}$. in length. It has two or four flagella, a contractile vacuole which appears to open to the exterior at the base of the flagella, and a distinct eye-spot located near the surface in various positions on the side of the body, sometimes nearer the posterior than the anterior end (Fig. I7). In Euglena and Trachelomonas the eyespot is situated near the contractile vacuole and the base
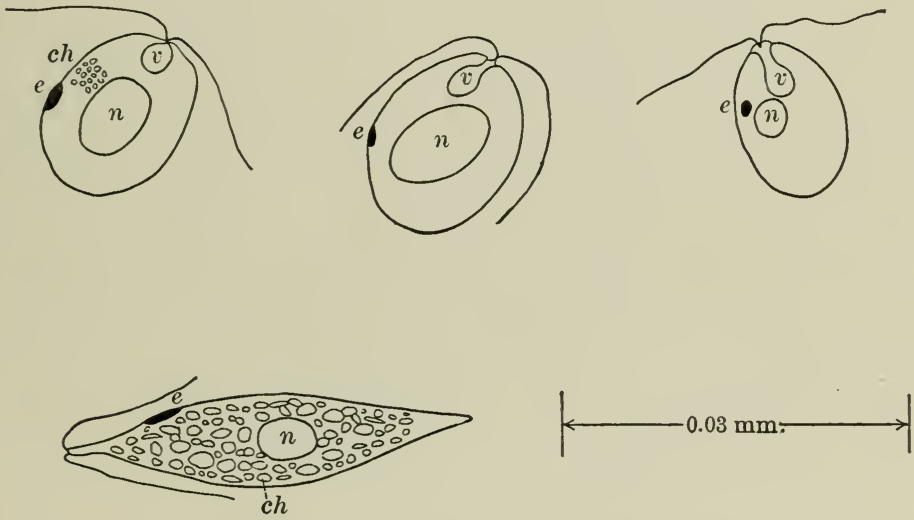

FIG. I7. I. Chlamydomonas alboviridis. II. Chlorogonium, showing structure and form. $v$, contractile vacuole; $n$, nucleus; $c h$, chloroplasts; $e$, eye-spot; $\mathrm{mm}$., projected scale.

of the flagellum; and it has been suggested that the eyespot is nothing more than a collection of waste material deposited by this vacuole. In Chlamydomonas it is, however, so far from the contractile vacuole that there does not appear to be any relation between the two structures. These organisms usually swim with the end containing the flagella ahead, but sometimes they swim for short distances with the opposite end foremost.

I was interested in this form chiefly because it appeared as though its reactions might have some bearing on the 
function of the eye-spot, since in this species it is located well toward the posterior end of the body.

These creatures react very definitely to light. They are positive in weak and negative in strong light, and swim on a spiral course. The intensity however in which they are positive or negative varies greatly in different individuals and in the same individual under different conditions. It is very difficult to follow their movements since they are so small and swim so rapidly. Jennings (I904, p. 64) found that they "react to a decrease in illumination by a sudden turn to one side, by an increase in the width of the spiral, and by a change in the course just as happens in Euglena and Cryptomonas." But he was "unable to determine the relation of its structure to the spiral path and to the direction of turning in the reaction." My observations confirm the conclusions of Jennings as stated above.

The orienting reactions in these organisms were studied just as they were in Euglena. They were alternately exposed in each of two beams of light which crossed on the stage of the microscope at right angles. If the light from the two beams is equal and the organisms are not very sensitive, all turn toward the source of light, none in the opposite direction, when the direction of the rays is suddenly changed. This they do by swerving farther in one direction than in the opposite as they proceed on their spiral course, just as do Euglenae and Stentors under similar conditions. But if the light from one source is more intense $^{1}$ than that from the other, and the intensity is increased at the same time that the direction of the rays is changed, many of them stop and turn sharply, some toward the light, others away from it. This reaction is very striking; there is apparent confusion for some time after the ray direction and the intensity are simultaneously changed, whereas if the ray direction is changed without a change

1 The light from one source was $100 \mathrm{ca} . \mathrm{m}$.; that from the other $\mathrm{I} 60 \mathrm{ca} . \mathrm{m}$. in these experiments. 
of intensity there appears to be perfect order, all the specimens turning gradually toward the light.

The fact that these organisms turn in various directions when the intensity is decreased regardless of the side illuminated indicates that they always turn toward a structurally defined side. I was however unable to follow the reactions under these conditions so as to see if there was a definite relation between the location of the eye-spot and the direction of turning. But by carefully studying specimens swimming about slowly in an optimum light intensity, I saw that with very few exceptions they turn toward the side on which the eye-spot is situated. A few specimens which were loosely entangled in débris were seen to turn in the opposite direction. This was probably due to some interference with the movement of the flagella. It may therefore be concluded that Chlamydomonas always turns toward the side containing the eye-spot.

The fact that positive specimens turn toward the source of light when the ray direction is changed without a change of intensity, and that they turn toward the side containing the eye-spot, indicates that they are most sensitive when the side without the eye-spot is illuminated, for it is a decrease of intensity which causes a reaction in these organisms when they are positive. It therefore follows that a change from a position in which the eye-spot is on the shaded side to one in which it is on the illuminated side has the same effect as a decrease of intensity. Is this decrease due to the shadow cast by the eye-spot? In Euglena it seems likely that it is. In some specimens of Chlamydomonas, however, this structure is situated so near the posterior end that it is difficult to see how it could function in this way. The long axis of one of the specimens represented in Fig. I7 would have to be at an angle of nearly $45^{\circ}$ with the direction of the light before the eye-spot would cast any shadow on structures in the body. 


\section{Chlorogonium}

Chlorogonium is a green spindle-shaped organism with two flagella and a very prominent bright reddish eye-spot located very near the surface, only a short distance from the anterior end (Fig. I7). This organism is frequently found in cultures containing Chlamydomonas.

The reactions in Chlorogonium are essentially like those in Chlamydomonas. They were studied in much the same way in both forms, but it was much easier to follow these reactions in the former than in the latter form.

The eye-spot in Chlorogonium is favorably situated to function by shading the interior.

\section{Paramecium}

The assumption held by some investigators that the power to react to light is common to all protoplasm is probably wrong. It is well known that Paramecia and many other protozoa do not respond to light of ordinary intensity. If all protoplasm can be stimulated by light, one would certainly expect these forms to show some evidence of response when suddenly subjected to powerful illumination.

At noon on a perfectly clear day in July I arranged a double convex lens Io $\mathrm{cm}$. in diameter so as to focus the direct rays from the sun on a slide under the mic oscope. The light was passed through distilled water in order to cut out the heat rays. The light at the focal point was at least $500,000 \mathrm{ca} . \mathrm{m}$. in intensity. This extremely intense light was repeatedly flashed upon the Paramecia as they swam about under the microscope, but there was no evidence of any response whatever. It is altogether probable then that the power to respond to light is not common to all protoplasm.

The fact that Paramecia do respond to ultra-violet rays as shown by Hertel (1904) has no bearing on this question. 
The wave length of the rays used in Hertel's experiment was only $280 \mu \mu$, while the length of the shortest wave of the visible spectrum is a little over $400 \mu \mu$. Paramecia continuously exposed to the ultra-violet rays are injured almost immediately; their movements become uncoördinated and they die in from 10 to 50 seconds. It seems probable, then, that these rays stimulate Paramecia because of their injurious effect. 


\section{CHAPTER VII}

\section{THE FACTORS INVOLVED IN THE PROCESS OF ORIEN- TATION IN COLONIAL FORMS}

\section{Volvox globator and minor}

MANy interesting observations have been made on the light reactions of Volvox since Leeuwenhoek discovered this organism over two hundred years ago. The details in the reactions have however only recently been worked out. In I907 I published an extensive paper on this subject, and the following account is based largely on this paper.

Volvox is an organism somewhat like a hollow sphere slightly elongated. The largest colonies are nearly i $\mathrm{mm}$. in diameter and the smallest can readily be seen with the naked eye. Each colony is composed of from 200 to 22,000 individuals and each individual consists of a single cell known as a zooid. The zooids, interconnected with protoplasmic strands, are arranged side by side so as to form a wall inclosing a cavity. They are very much like Chlamydomonas in structure and color. Each one contains two flagella and an eye-spot which is situated on the outer posterior surface. The eye-spots at the anterior end of the colonies are from eight to ten times as large as those at the posterior end much as in Pandorina represented in Fig. 2 I.

The colonies usually rotate counter-clockwise on the long axis, like Euglena, but they seldom swim on a spiral course. They orient and swim toward a source of light or away from it in a general way; they do not however orient very accurately. Colonies swimming horizontally toward a compact source of light usually deflect either to the right or to the left or up or down. The more strongly positive the 
colonies are the more nearly parallel with the rays they swim. If the position of the source of light is changed without a change of intensity, they change their direction of motion until the course bears to the light rays the same relation that it had before. In thus changing their direction of motion they always turn directly toward the source of light without any preliminary movement. No matter which surface is illuminated there is an apparent differential response to localized stimulation. There is no evidence of trial movements in the colonies taken as a whole. They never turn in the wrong direction as Euglena and Stentor frequently do, even if the intensity and the ray direction are changed simultaneously. There is no evidence that the sensitiveness of the colonies depends upon the surface exposed as was found to be true in many unicellular forms, nor is there any indication of an avoiding reaction when the intensity is changed. If the intensity is much decreased they merely stop forward progress and, because of the effect of gravity, the anterior end turns up. They do not aggregate extensively in highly illuminated areas in a dark field as Euglena and various other forms do. They pass from darkness into light and vice versa without any apparent reaction.

There is no evidence that the direction of rays through the organism, in accordance with Sachs' theory, or that the angle between the rays and the sensitive surface as suggested by Loeb controls orientation. This process is regulated by the relative intensity of light on opposite sides of the colony. The following facts prove this to be true: I. If exposed to light from two sources they swim toward any point between them. The location of this point depends upon the relative amount of light from the two sources as indicated in Fig. I8. 2. In the light grader (see Fig. 4) so arranged as to produce a field of light which consists of parallel rays, but in which the intensity gradually diminishes from side to side so that one side of a colony, swimming toward the source of light, is more strongly illuminated than the other, it deflects 
toward the more strongly illuminated side as represented in Fig. I9.

Difference in light intensity on opposite sides of the

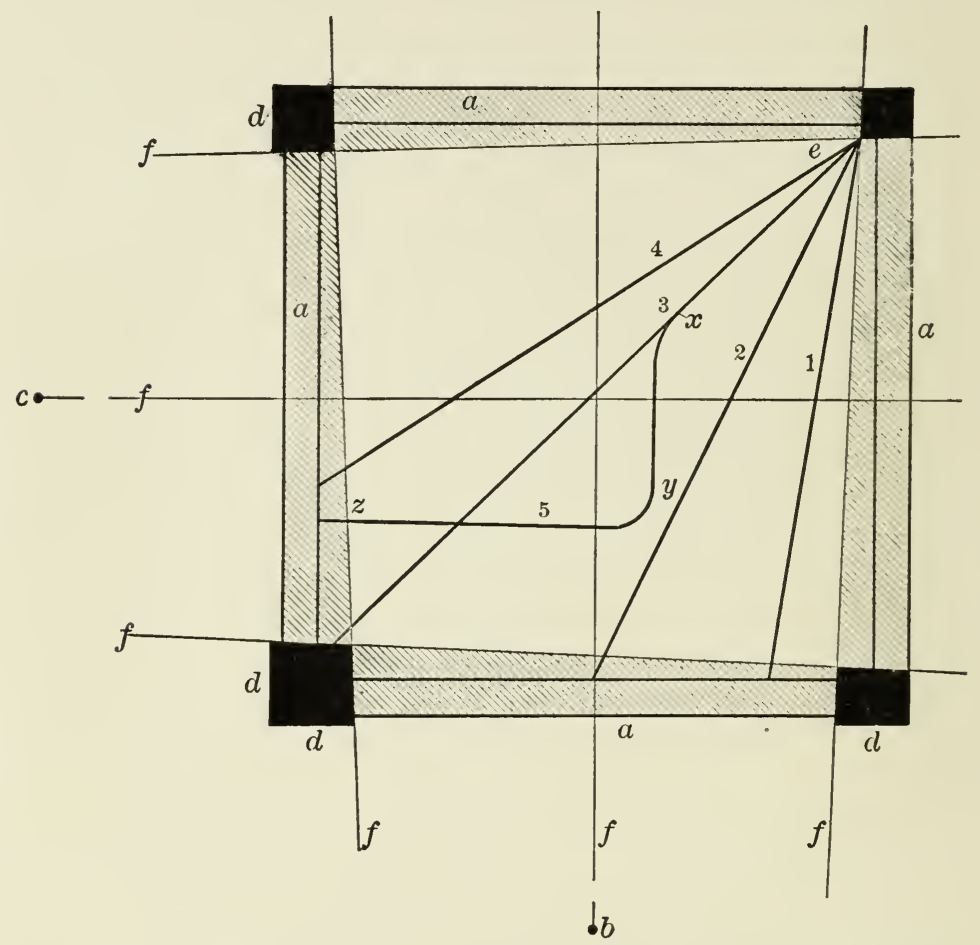

Fig. I8. Representation of the movement of Volvox when subjected to light from two sources. $a$, plate glass aquarium $8 \mathrm{~cm}$. long and $8 \mathrm{~cm}$. wide; $b, 22$-volt Nernst glower, $66 \mathrm{~cm}$. from aquarium (distance from aquarium constant); $c$, r rovolt glower (distance from aquarium variable); $d$, screen; $e$, point of introduction of Volvox; $f$, direction of light rays; $1,2,3,4$, courses of Volvox exposed to light from both glowers: I, with I Io-volt glower $199 \mathrm{~cm}$. from aquarium; 2, with I I0volt glower $99 \mathrm{~cm}$. from aquarium; 3 , with i ro-volt glower $49 \mathrm{~cm}$. from aquarium; 4, with I ro-volt glower $24 \mathrm{~cm}$. from aquarium; $x-y$, course of Volvox when exposed to light from glower $b$ only; $y-z$, course when exposed to light from glower $c$ only.

colonies, then, causes them to turn until the two sides are equally illuminated. "The turning ${ }^{1}$ may be conceived to be due to an increase in the backward phase of the stroke 
on the shaded side, or a decrease in the same phase on the illuminated side or a decrease in the forward phase on the shaded side, or an increase in this phase on the illuminated side. Can it be ascertained which of these is the cause of the difference between the effect of the stroke of the flagella on the shaded sides and that of those on the illuminated side of the colonies?

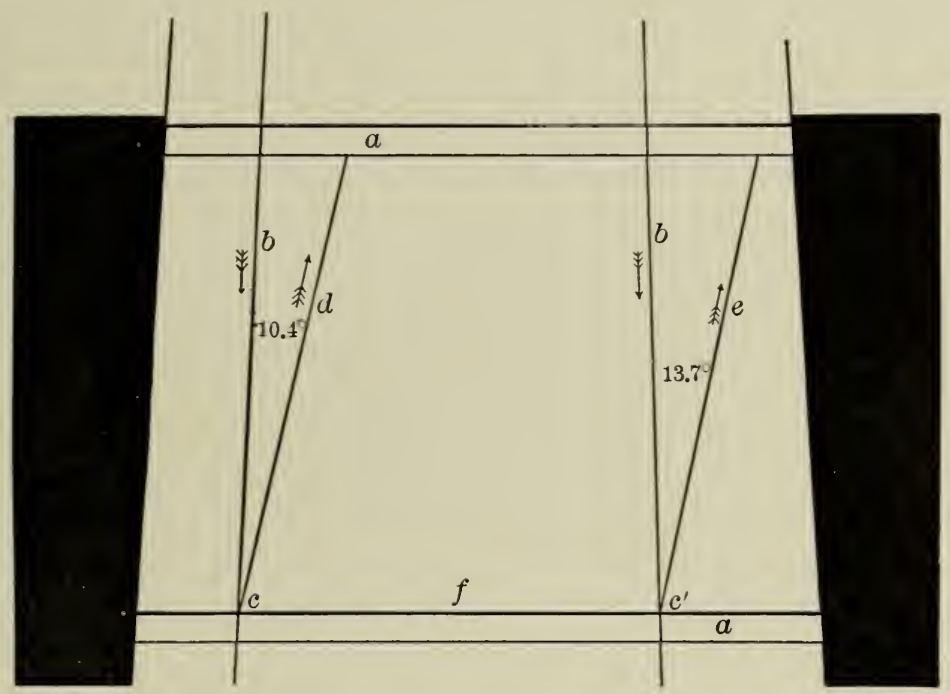

FIG. I9. Graphic representation of the total average difference in deflection due to difference in light intensity on opposite sides of Volvox colonies, compiled from numerous experimental records. $a$, plate-glass aquarium $8 \mathrm{~cm}$. wide and I $5 \mathrm{~cm}$. long; $b$, light rays; $c, c^{\prime}$, points where the colonies were introduced; $d$, average course with the region of highest light intensity to left; $e$, average course with strongest illumination to the right. Light intensity at $(f)$ the middle of field 57.I 2 candle meters. From the middle the intensity gradually increased toward either end where it was 442.68 candle meters. Intensity at $c, 327$ candle meters, at $c^{\prime}$, 263 candle meters.

"If the light intensity of the field is suddenly decreased while colonies of Volvox are swimming horizontally toward it, they stop forward motion, the longitudinal axes take a vertical position due to the effect of gravity, and then the colonies swim slowly upward. It is not at all difficult to find specimens in which this upward swimming is just suffi- 
cient to overcome the effect of gravity, and under such conditions they appear to be hanging in the water motionless. They are, however, rotating on their longitudinal axes. If now the light intensity, to which these apparently motionless organisms are exposed, is increased they soon begin to turn toward its source; but in so doing they swim upward, as represented in the accompanying diagram (Fig. 20).

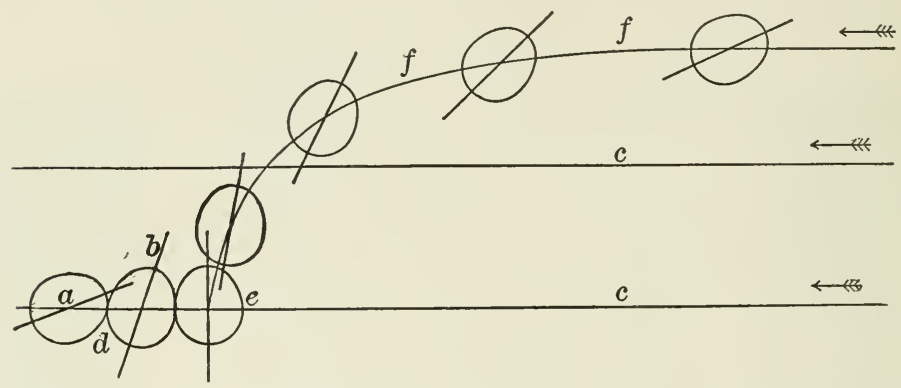

FIG. 20. Diagram representing the reaction of a Volvox colony when the light intensity is suddenly changed. $a$, outline of colony; $b$, longitudinal axis; $c$, light rays; $d$, point in the course where the light is suddenly decreased; $e$, point where it is suddenly increased; $f$, course taken by colony. In continuing from $e$, the side of the colony facing the source of light travels over a shorter distance than the shaded side. Consequently the backward stroke of the flagella on the latter side must be more effective than that of those on the former.

"In thus swimming upward and horizontally toward the source of light, it is clear that the effect of the backward stroke of the flagella increases both on the shaded side and on the illuminated side, for both sides move forward. But the shaded side moves farther than the illuminated side, consequently the increase in the effect of the backward stroke must be greater on the former than on the latter. The difference in the effect of the stroke of the flagella on opposite sides, which results in orientation of positive Volvox colonies, is, therefore, due to a greater increase in the backward stroke of the flagella on the shaded side than of those on the illuminated side.

"If the light thrown upon apparently motionless colonies is quite intense, they frequently may be seen to sink 4 or 
$5 \mathrm{~mm}$. immediately after the light is turned on, but while they are sinking this short distance, they apparently become acclimated and soon turn toward the light, and at the same time swim upward, just as described above. During the time in which these colonies sink they continue to rotate in the same direction as before. The sinking must then be due to a decrease in the effect of the backward stroke of the flagella on all sides, and this decrease is due to an increase in light intensity. But when the colonies turn toward the source of light, and at the same time swim upward, it is evident that the increase in light intensity must cause an increase in the backward phase of the stroke of the flagella on all sides, for if this were not true there could be no upward motion. The side nearest the source of light, however, passes over a shorter distance than the opposite side, as will readily be seen by referring to the diagram, and therefore the increase in the effect of the backward phase must be greater on the latter than on the former. But the light intensity is greater on the former than on the latter (a paradox). When the light intensity in the field is increased the effect of the backward phase of the stroke of the flagella may be increased or decreased on all sides. If it is increased the effect is most marked on the side in lowest light intensity. Furthermore, if the light is strong the colonies turn toward its source more rapidly and do not swim upward so far and thus make a sharper curve than when it is weak; but the stronger the light the greater the difference between the intensity on the shaded and that on the illuminated side. It therefore follows that the greater the difference in intensity on these sides, the greater the difference in effect of the backward phase of the stroke of the flagella, the effect being greatest on the side least illuminated. These considerations support the conclusion arrived at above, i.e., that the factors which regulate the activity of the colonies, as a whole, are different from those which regulate the direction of motion.

"We have thus demonstrated that while orientation is 
due to difference in light intensity on opposite sides of the colonies, it is brought about in positive specimens by the flagella striking backward with greater effect on the side in lowest light intensity than elsewhere. I suggest the following explanation of this:

"First, it must be remembered that the organism constantly rotates on its longitudinal axis. If then a colony is so situated that one side is more highly illuminated than the opposite, it is clear that the zooids will constantly be carried from a region of higher to a region of lower light intensity, and vice versa. They are thus subjected to constant changes in strength of illumination. As stated above, the flagella strike backward with greater vigor on the shaded side than on the opposite one and, therefore, it is evident that as the zooids reach the region of lower light intensity, in other words when the light intensity to which they are subjected decreases, they increase the effect of the backward stroke of the flagella, i.e., they attempt to turn toward a structurally defined side (the side facing the anterior end of the colony). This is precisely what Euglena does when it passes from a region of higher to one of lower light intensity, i.e., it turns toward a structurally defined side, the larger lip. The individuals in a colony then respond with a motor reaction induced by change in light intensity; they react on the same basis as do Euglena, Paramecium, Stentor and other unicellular forms, in their trial and error reactions, but owing to the way in which they are interrelated, and to the rotation of the colony on the longitudinal axis, this reaction of the zooids causes orientation in the colony as a whole, without error.

"This explanation of orientation in entire colonies holds also for orientation in segments. As previously stated, only those segments orient which have such a form that they can rotate. As they rotate the cut surface constantly faces the center of the spiral, so that if the axis of the spiral is not directed toward the source of light, the outer surface where the zooids are situated is alternately turned toward 
the light and away from it. Thus the zooids are carried from regions of higher to regions of lower light intensity and vice versa, and the motor reaction is induced just as it is in entire colonies.

"Orientation in negative colonies can be explained in precisely the same way as that in positive ones, assuming merely that in this condition the zooids respond with the motor reaction when they pass from lower to higher light intensity instead of when they pass from higher to lower (as is true when the organisms are positive). The backward stroke then becomes most effective on the side most highly illuminated."

It is altogether likely that the orientation in Volvox is not entirely due to the change of light intensity on the zooids caused by difference of intensity on the colonies as a whole and rotation on the long axis as described above; but that as in Euglena and other forms discussed above, the sensitiveness of the zooids depends upon the surface exposed. When the zooids are carried from the illuminated to the shaded side it is clear that they are not only transferred from a region of higher to a region of lower light intensity, but the surface turned toward the light is also changed. This change in itself may, as in various unicellular forms studied, cause a reduction of intensity on certain structures within the zooids by the movement of shadows of other structures, and consequently an orienting stimulus. The orientation of segments indicates that this factor plays a very important part in the orientation of the colonies.

Take for example a segment formed by cutting a colony in half lengthwise. The zooids in this segment lie side by side and are some distance apart, being connected by thin strands of protoplasm. Most of the substance in the cavity runs out when the colony is cut, and what remains is transparent. It is therefore evident that there is no more substance to shade the zooids when the inner surface of the segment faces the source of light than there is when the outer faces it. If the segments are in a field of uniform 
intensity the zooids are not carried from regions of higher to regions of lower light intensity and vice versa as described above. Under such conditions then the orienting reactions must be due entirely to the shading of certain structures within the zooids by other structures also within them, as the surfaces turned toward the source of light change.

Orientation in Volvox is, according to this account, due to changes in light intensity on the zooids as a whole together with changes of intensity on certain structures in the zooids, made possible by difference of intensity on the surface of the colony and rotation on the long axis. The change of intensity is caused by the movement of shadows of certain structures in the organism cast upon other structures. These shadows are present in a field of uniform intensity. There is no evidence that the direction of the rays in the field or through the body, or that the angle the rays make with the surface of the body, is of importance in orientation excepting in so far as it may affect difference of intensity in the individual zooids or the colony as a whole. Nor is the symmetry of the organism of prime importance, for, as was stated above, asymmetrical segments of various forms orient nearly as accurately as entire colonies. Orientation may take place in constant light intensity quite as well as in a field having various intensities. Difference of intensity in the field does however determine the distribution of the colonies. They are negative in light of high intensities, positive in that of low and neutral in that of optimum intensity. Orientation then, whether positive or negative, tends to direct the colonies to the area of optimum illumination. Light acts as a constant directive stimulus on the colonies as a whole, but there is no evidence that there is a directive stimulus without change of intensity, for the reacting elements, the zooids, and especially the structures within the zooids, are not subjected to constant intensity.

It is probable however that constant intensity affects the activity of these organisms somewhat as temperature does. 
They become negative in high intensity and appear to be more active in some intensities than in others, but since it is practically impossible to subject the different parts of the colonies to constant intensity owing to the shadow of one part on another and the movement of the organism, it is impossible to say whether or not they would become negative or more active if there were no such change of light intensity. This subject was dealt with more in detail under Euglena.

Bancroft (1907, p. I63) intimates that orientation of Volvox in light takes place in the same way as it does in a constant electric current; that it is not due to changes of intensity but to constant intensity; and that it is therefore a tropic reaction in accord with Loeb's definition. He says (p. 162): "It has been shown that the galvanotropic orientation of Volvox is brought about by a cessation or great diminution in the stroke of the flagella at one pole of the organism. This diminution in activity of the flagella appears to be the only way in which Volvox is capable of responding to stimuli. Nothing in the nature of a motor reflex has ever been observed in this organism so far as I know. The flagella always strike most strongly backward. We have then the simplest possible kind of a mechanism for bringing about galvanotropic orientation. The current diminishes the activity of the flagella at one pole of the colony and consequently the activity of the flagella at the other pole causes the organism to turn in that direction. We have here a tropism reduced to its lowest terms. There is nothing of the nature of trial and error present at all."

We have clearly demonstrated above that orientation of Volvox in light is not due to a "cessation or great diminution of the stroke of the flagella at one pole of the organism" as it is in a constant electric current. It is due to an acceleration in the backward stroke of the flagella on the shaded side. This is caused by a response to a decrease in the light intensity on the zooids as a whole together with a decrease in intensity on certain structures within the 
zooids, owing to the rotation of the colonies on the long axis and the consequent transfer of the zooids from the illuminated to the shaded side. This response is similar to the avoiding reaction in Euglena, Trachelomonas, Chlamydomonas and other unicellular forms.

If Bancroft is correct in his description it is evident that the factors involved in orientation in a galvanic current and in light are not the same, and that the orienting reactions in light are not tropic according to Loeb's definition.

\section{Pandorina and Eudorina}

These organisms are much like Volvox in structure. They are however very much smaller and contain only
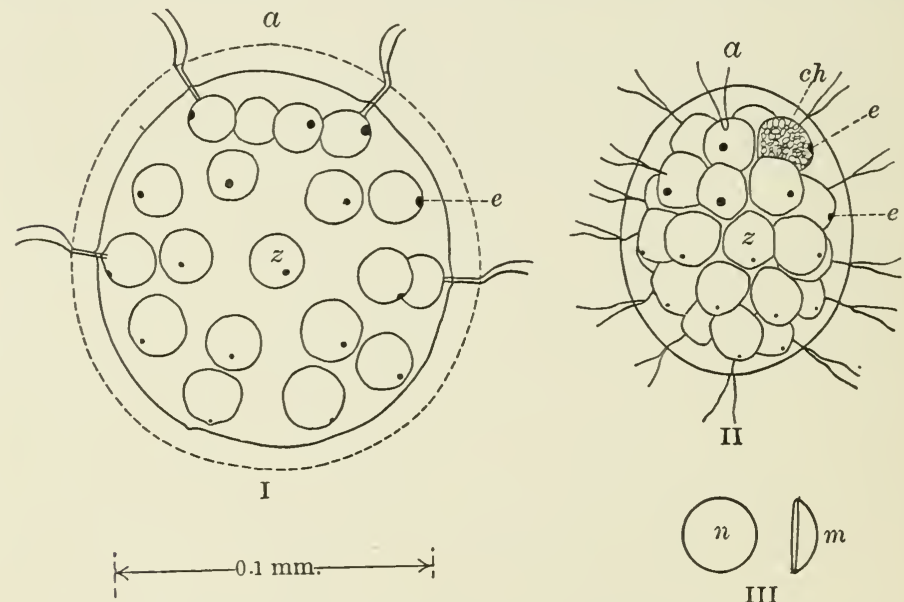

FIG. 21. I. Eudorina; II, Pandorina, showing structure and form; $a$, anterior end; $z$, zooids; $c h$., chloroplasts, all the zooids are well filled with them; $e$, eyespots - note difference in size at opposite poles, and location on outer posterior surface of zooids. Each zooid has two flagella, - only a few of them are represented. Eudorina is surrounded by a hyaline layer the outline of which is represented by a dotted line. Outlines made with camera; mm., projected scale.

III. Eye-spot greatly magnified; $n$, surface view; $m$, side view. The flat surface is directed outward and slightly posteriorly.

from 32 to 64 zooids (Fig. 2I). By means of methods similar to those used in studying Volvox it was found that 
the process of locomotion and the reactions in both Pandorina and Eudorina are in all essentials like those in Volvox. They are negative in strong and positive in weak illumination, but the degree of intensity in which they are positive or negative varies greatly. They always swim with the end containing the larger eye-spots ahead. They usually rotate counter-clockwise on the long axis and proceed on a straight path. Only a very few colonies were found to swim in a spiral course. If the light intensity is decreased or increased with or without a change in the direction of the rays there is no shock effect, nothing resembling an avoiding reaction. If the general direction of the rays is changed, positive specimens turn directly toward the source of light without any preliminary movements whatever, and negative specimens always turn in the opposite direction. If exposed to light from two sources so situated that the rays cross at right angles they swim toward or from a point situated between the two sources. The location of this point depends upon the relative intensity of light from these sources. Orientation in these forms takes place just as it does in Volvox.

a. Function of the eye-spots. - The eye-spots in both Eudorina and Pandorina are located on the outer posterior surface of the zooids just as in Volvox. They have the form of a segment of a sphere. The flat surface which is slightly concave faces out. Those at the anterior end of the colonies are much larger than those at the posterior, as represented in Fig. 2I. The former are nearly $2.5 \mu$ in surface diameter, and $0.9 \mu$ thick; the latter are only approximately $0.6 \mu$ in diameter, but relatively thicker than the former. They are reddish brown in color and stand out boldly in strong illumination from below, showing that they are comparatively opaque. In direct sunlight they become luminous, giving off a greenish blue light, and as the colonies rotate they sparkle and glitter, presenting a wonderfully beautiful spectacle. After having been in direct sunlight for some time they are also luminous in diffused sunlight, 
but not so in darkness. No evidence of this property was seen in the eye-spot of Euglena. It therefore appears that the eye-spots in these two forms differ in composition, and it may be that they function differently. At any rate, judging from their location I am unable to see how they could function in Volvox, Pandorina or Eudorina by shading structures in the interior, as they appear to in Euglena, unless they function only when the colonies are negative. The fact however that the eye-spots at the anterior are much larger than those at the posterior end is strong evidence in opposition to such a view. If these structures function in light reactions in these forms at all, they must function either as an absorptive background somewhat like the retinal pigment in the eye or as direct light recipient organs as I suggested (I907, p. I I2).

In our work on Euglena it was pointed out that the hyaline protoplasm at the anterior end condenses the light and brings it to a focus in the neighborhood of the eye-spot when the organism is oriented, possibly on the structure most sensitive to light. In Pandorina and Eudorina each zooid acts as a condensing lens. In direct sunlight a highly illuminated spot can be clearly seen at the surface directed away from the source of light in each zooid, even in those well filled with chloroplasts. The focusing of the light is much more definite in these forms than it is in Euglena. It is evident that every lateral movement of the organism causes a change in the location of the point on which the light is focused in the zooids, and this of course produces definite and marked changes in light intensity. It may be that the eye-spots, located near the posterior end of the zooids as they are, function in some way in connection with such changes of the focal point. 


\section{CHAPTER VIII}

\section{OBSERVATIONS ON THE RESPONSES INVOLVED IN THE REGULATION OF MOVEMENT TOWARD THE SOURCE OF LIGHT IN COELENTERATES}

ONLY a few of the animals belonging to this group orient in light. Many do not respond to light at all. In others the general activity depends upon the light intensity. Some get into regions of optimum light intensity by means of orientation, others by random wandering movements. In both cases they come to rest in this region. The former method is much more effective than the latter. If animals have the power to orient they can move directly toward the region of optimum intensity and consequently get there much more quickly than do those which reach such regions by random movements.

In this paper we shall consider only a few species, all of which show some evidence of orientation.

\section{Hydra viridis}

a. Historical review. - Trembley (1744) seems to have been the first to record experimental observations on the effect of light on the movements of Hydra. He exposed the animals in a glass jar covered with an opaque case containing an opening on one side, and found that they migrated toward the opening. He did not however record the details in the method of migration. Loeb (1905, p. 73) referring to these experiments says, "Trembley's experiments on Hydra, however, show that in their case also the relation is the same," i.e., "that Sachs's ${ }^{1}$ laws of heliotropism . . .

1 Sachs, it will be remembered, claimed that orientation is controlled by the direction in which the rays pass through the organism. 
hold good. . . . It seems to me that Trembley's experiments cannot be interpreted unless we assume that the progressive movements of Hydra are determined by the direction of the rays of light."

Wilson (I89I) found that while Hydra viridis usually collects on the bright side of the dish, it collects in shaded regions if the light is very intense; that it aggregates more freely in a blue field than in a yellow or white field; and that it collects more abundantly in the blue field even if it contains no more blue rays than the white field and is therefore of a much lower intensity. He found that a change from light to darkness or from blue or white light to light of other colors causes the animals to wander about more. When they pass into blue or white light they tend to come to rest. This explains their collection in blue and white light. Wilson thinks that the Hydras may also go toward the source of light directly; that the collection at the more highly illuminated side of the aquarium is not entirely due to random wandering. Washburn (1908, p. I23) however says, "Hydra shows no response to light other than a tendency to come to rest in the more illuminated parts of the vessel containing it."

The following experiments were undertaken with these questions in mind: I. Do Hydras wander about more in darkness than in light? 2. Do they move directly toward a source of light? 3. Do they orient? 4. What factors are involved in orientation?

b. Effect of light intensity on activity. - Experimental results recorded in literature show that Hydra is in general more active in sub and supra optimum intensities than in optimum intensity. The following observation shows, however, that total darkness seems to inhibit movement. On April I I at Io A.M. six green Hydras were taken from the culture which was in strong diffuse light, put into some water in a small rectangular aquarium and placed in total darkness without the temperature's being changed. They soon became attached to the bottom of the vessel in posi- 
tions represented by dots $(a)$ in the accompanying diagram (Fig. 22). At I2 M. all were still in the positions where

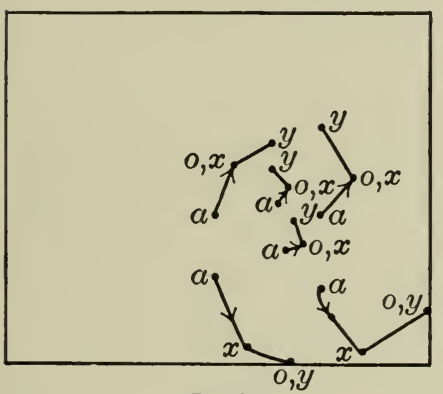

Fig. 22

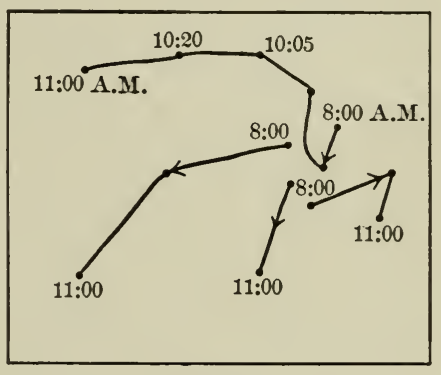

Fig. 23
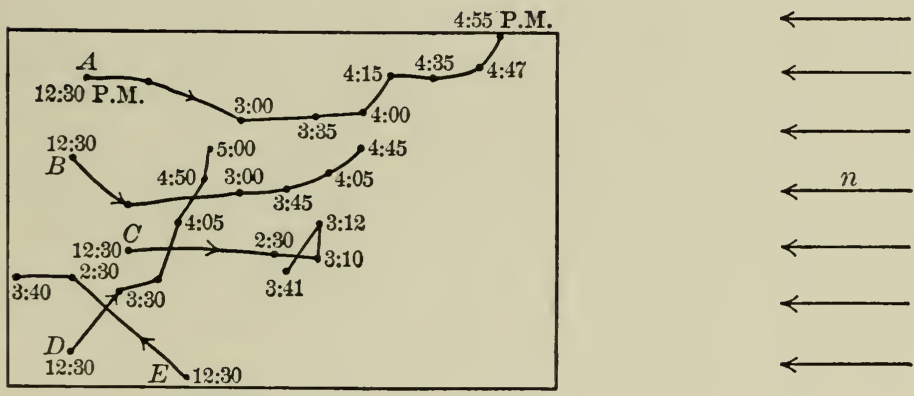

Fig. 24

FIG. 22. Movement of Hydra viridis in total darkness. $a$, position at beginning of course, 8 A.M., $\frac{4}{11} ; x$, position at 8 A.M., $\frac{4}{12} ; 0,9$ A.M., $\frac{4}{13} ; y, 8$ A.M., $\frac{4}{14}$.

FIG. 23. Movement of the same specimens after exposure to light. 8 to II A.M., $\frac{4}{14}$. Note that they have become much more active.

FIG. 24. Movement of $H$. viridis toward source of light, $n$; intensity I $2 \pm \mathrm{ca}$. $\mathrm{m}$. All the looping movements of each specimen are represented from three o'clock until the close of the experiment. The dots represent points of attachment. The animals extended in various directions from each point but usually traveled only toward source of light.

they first became attached. They were well expanded and the anterior ends were variously directed. At 2.I5 P.M. one had moved about $3 \mathrm{~mm}$., the rest not at all. At 8 A.M. the following morning four had moved to positions desig- 
nated $x$. At 9 A.M. the next morning two had taken positions represented by 0 . During the next 24 hours three moved to positions marked $y$; all were well contracted and motionless. They were now exposed to diffuse sunlight without being moved or jarred. They began to expand almost immediately and soon began to move about. The paths taken are indicated in Fig. 23. After I I A.M. they did not again change their positions until the close of the experiment 24 hours later.

This shows that darkness inhibits movement in Hydra viridis; that they become exceptionally active when exposed to light after having been in darkness for some time, and that they apparently become acclimatized readily, since they come to rest in the same intensity after having been exposed a few hours. The inhibition of movement by darkness may however not be due to absence of direct stimulation by light, but to the effect of darkness on photosynthesis.

c. Orientation and locomotion. - In the study of the movements of Hydras, they were put into water from the culture jar, I cm. deep, in a rectangular aquarium $2 \times 5 \times 8$ $\mathrm{cm}$. made by cementing slides together. The aquarium was exposed in the dark room to light from a 50-candlepower Nernst glower situated 2 meters from the end of it. The glower was so arranged that the rays were parallel with the bottom and sides of the aquarium. The end of the aquarium was covered with an opaque screen containing an opening such that the sides and surface of the water were in darkness, so that reflection from various surfaces might be reduced as much as possible. All the light except that in the beam which fell on the end of the aquarium was absorbed by screens.

At IO A.M., April I I, six green Hydras were put into the aquarium near the end opposite the glower. They became attached very soon and stretched out in various directions, some toward the source of light others away from it. Twenty-four hours later they were near the middle of the 
aquarium, and the following morning (April I3) they were all at or near the end facing the light. It therefore took them nearly 48 hours to move a distance of $8 \mathrm{~cm}$. There were now nine specimens; three buds had been set free. The aquarium was turned end for end so that the Hydras were again at the end farthest from the glower. During the following 24 hours several of the specimens traveled the entire length of the aquarium, $8 \mathrm{~cm}$. They therefore moved as far during the 24 hours as they had during the preceding 48 hours. This shows that they became much more active after they had been exposed in a given light intensity 48 hours than they were at first. There was at no time any indication of orientation. The specimens appeared to face in all directions equally, but they appeared to move quite directly toward the source of light.

In the following experiment more detailed observations on movement were made. Several specimens were put into the aquarium near the end farthest from the light at 9 A.M., April I6. They became attached almost at once. At I2.30 all were removed but the five which had been most active during the preceding hours. The courses taken by these five specimens are recorded in Fig. 24. Two of the specimens, $A$ and $B$, were attached to the surface film. One remained there during the entire experiment, but the other, $B$, went to the bottom after moving a short distance. The surface of the water was in darkness, but the Hydras hanging from it extended into the light. The animals moved from place to place by stretching out the body, attaching the tentacles to the substratum, and then pulling up the foot and fastening it again near the end bearing the tentacles, sometimes on the same side it had been and sometimes on the opposite side. They progress by what may be called the looping method. From 3 o'clock to the close of the experiment every progressive change in position of the specimens $A$ and $B$, and most of those of the other three specimens, were recorded. During the periods between the looping movements the specimens contracted and expanded from time 
to time and bent in various directions, remaining in any given position only a few minutes, so that during the periods in which the foot was fixed, the oral end was directed toward various points of the compass. But it will be seen by referring to the figure that the looping movements were in general directed toward the source of light. The only movements in the opposite direction occurred in specimens $C$ and $E$. The former moved in this direction but once, the last looping move it made during the experiment; the latter was not seen in the act of moving. It did however reach the end of the aquarium farthest from the source of light where it came to the surface and remained to the end of the experiment.

d. Reactions of negative specimens. - At I I.35 A.M., April I 7, two specimens were exposed in the small rectangular aquarium to direct sunlight. They became very active at once and bent from side to side, expanding and contracting frequently. One changed its position by looping five times in a little more than 15 minutes, the other by looping three times. Both proceeded from the source of light nearly as directly as the positive specimens studied moved toward it. There was no apparent relation between the direction of bending and the source of light, just as was found to be true in positive specimens. The anterior end appeared to be directed toward the source of light as much of the time as away from it, but locomotion occurred only when this end was directed from the light. After having been exposed a little over I 5 minutes they lost their attachment to the bottom and became perfectly quiet, apparently having been injured by the intense light.

As already stated the anterior end of Hydra is successively directed toward various points of the compass. After remaining in a given position a few minutes the animals usually contract, turn toward one side and expand again. Sometimes however they bend and turn so as to change their position without contracting. There is no definite relation between the direction of bending and the source of light. 
There is however in positive specimens a tendency to retain the position in which the oral end is most highly illuminated. This was demonstrated as follows:

Ten specimens were exposed in the rectangular aquarium in the dark room. As they traveled toward the light the direction in which they faced was recorded at intervals. These records appear in the table given below.

TABLE I.

\begin{tabular}{|c|c|c|c|}
\hline \multirow{2}{*}{$\begin{array}{c}\text { Time of } \\
\text { observation }\end{array}$} & \multicolumn{3}{|c|}{ Anterior end directed 1} \\
\hline & $\begin{array}{c}\text { Toward } \\
\text { source of light }\end{array}$ & $\begin{array}{l}\text { From source } \\
\text { of light }\end{array}$ & $\begin{array}{l}\text { Perpendicular } \\
\text { to direction } \\
\text { of light }\end{array}$ \\
\hline $3 \cdot 45$ & 7 & 3 & $\circ$ \\
\hline 4.10 & 5 & 2 & 3 \\
\hline $4 \cdot 20$ & 6 & 2 & 2 \\
\hline $4 \cdot 35$ & 4 & 2 & 4 \\
\hline 5.00 & 6 & 2 & 2 \\
\hline $5 \cdot 30$ & 3 & 2 & 5 \\
\hline 6.10 & 5 & 3 & 2 \\
\hline 6.30 & 8 & 0 & 2 \\
\hline $7 \cdot 15$ & 3 & 3 & 4 \\
\hline 8.00 & 4 & 2 & 4 \\
\hline 9.00 & 7 & I & 2 \\
\hline $9 \cdot 30$ & 5 & 3 & 2 \\
\hline 10.00 & 6 & I & 3 \\
\hline 10.30 & 5 & I & 4 \\
\hline Total & 74 & 27 & 39 \\
\hline
\end{tabular}

1 In making the table all those specimens in which the oral end was near a plane passing through the foot and perpendicular to the direction of the rays were recorded in column 4 ; all in which this end was definitely to the right, i.e., toward the light, in column 2; and those to the left, in column 3 .

The table shows very clearly that the oral end of the ten specimens studied was directed approximately toward the source of light nearly three times as much as from it. If the direction of locomotion depended merely upon the direction in which the oral end points, one would expect these organisms in the positive state to loop from the source of light more than one-third as often as toward it. This 
however is not true; movement from the source of light is ordinarily relatively rare. There must therefore be a greater tendency to travel when the oral end faces the light than when it faces in any other direction.

It may then be stated that Hydra tends to orient with the anterior end directed either toward or away from the source of light depending upon whether the specimens are positive or negative, and that it tends to travel in the direction in which it orients. There are evidently two apparently independent phenomena involved here, orientation and locomotion. How can these phenomena be explained? Let us first consider orientation.

Since Hydras tend to expose the anterior end to light when they are positive and to shade it when they are negative, it is probable that the oral end in this organism, as in Euglena and Stentor, is more sensitive to light than other parts of the body. If this is true it may be that orientation is, as Jennings suggests (1906, p. 213), "due to the fact that when it turns this end away, the change to relative obscurity at the anterior end causes further movement, till the light again falls on the anterior end." This explanation fits the facts, as far as they are known, fairly well. It is however difficult to see, since Hydra frequently retains a position in which the anterior end is shaded for more than two minutes, how "the change to relative obscurity at the anterior end could cause further movement." There is certainly no reaction in these animals comparable to the avoiding reaction or shock movements in the lower forms, for sudden changes of intensity even if extremely great produce no immediate reactions. If it is assumed that the organism tends to become oriented by random movements and tends to remain oriented because of inhibition due to the illumination of the anterior end, this difficulty is obviated.

As already pointed out, locomotion ordinarily occurs only when Hydra is approximately oriented. Positive specimens travel only when the oral end is illuminated, not when it is shaded. It is therefore evident that the light itself 
has something to do with this movement. It is not due entirely to internal changes. The organism must be affected differently when the anterior end is illuminated than it is when this end is shaded. A decrease in illumination ordinarily causes increase in activity, but this fact cannot be the cause of locomotion after orientation, for if it were, we should expect the greatest tendency to move when the anterior end is directed from the source of light in place of toward it.

One thing is clear from our results stated above, that is, that the light condition which tends to inhibit turning in various directions also tends to cause locomotion. From this it may be concluded that orientation and locomotion are phenomena which are regulated by different processes. It may be that the former is dependent largely on difference of intensity on opposite sides of the organism and the latter upon an action of light similar to that of heat.

e. General conclusions. - It can be definitely stated then that Hydra in the positive state reaches a position in which the anterior end faces the light by random movements; that it remains in this position longer than in any other, and that it ordinarily starts to travel only when it is in this position. The last two statements prove that light affects it differently when the oral end is exposed than when it is shaded.

It is impossible to say whether Hydra tends to retain the position in which the light strikes the oral end because of an inhibition due to an increase in effective light intensity, when the body is turned from a position in which the oral end is shaded to one in which it is illuminated; or whether it tends to remain oriented because of increase in motion due to a reduction in effective intensity when the anterior end is turned away from the light; or whether the tendency to retain the oriented position is due not to a change of intensity, but to the fact that in this position the anterior end is most highly illuminated and that the inhibition is due to the effect of constant intensity. 
While the tendency in Hydra to remain oriented may then be the result of stimulation by constant intensity, there is no evidence whatever that light acts constantly as a directive stimulus. Light may however affect locomotion by acting constantly, much as temperature does; but even in this case it is impossible to be certain that such effects are not due to changes of intensity, for the shadows of some parts of the body move almost constantly over other parts, owing to the fact that this animal is quiet only for short periods.
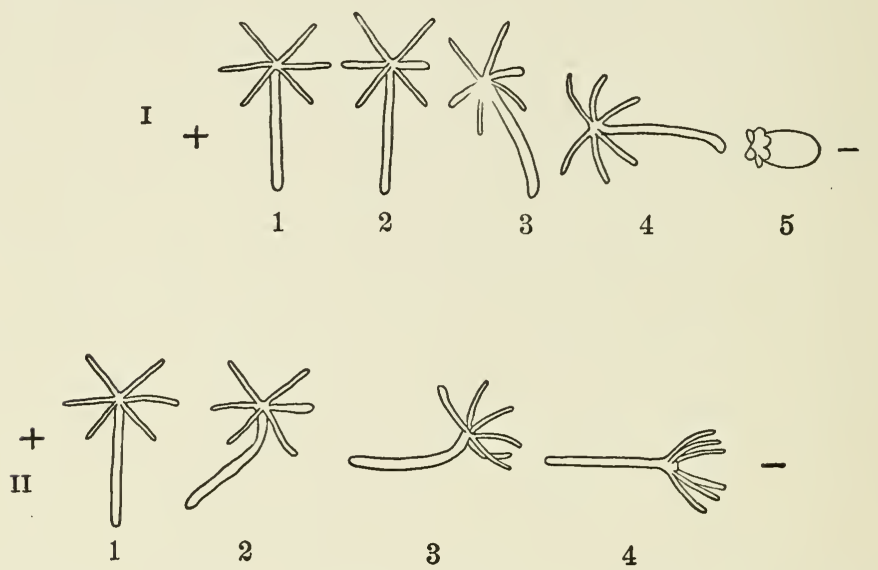

Fig. 25. I. Reaction of an attached Hydra to a constant electric current of moderate intensity. $\mathrm{I}-5$, successive stages in the reaction.

II. Successive stages in the reaction of a Hydra to the electric current when the foot is unattached. The foot becomes directed toward the anode. After Pearl (Igor).

The fact that there is no definite relation between the direction of turning and the side illuminated shows that neither the symmetry of the body, nor the angle the rays make with the surface, nor the direction of the rays through the body, nor local response to local stimulation, nor differential response to localized stimulation, can be of special importance in orientation in light.

The difference between the orienting reaction of Hydra in light and in a constant electric current is striking. As 
stated above, in light there is no evidence whatever of direct bending toward or from the source of stimulation. In a constant electric current however it bends directly until the long axis is in line with the direction of the current, as represented in Fig. 25. The electric current in the process of orientation acts constantly as a directive stimulation; the reaction is tropic, according to Loeb's definition. Light does not act constantly as a directive stimulation; orientation is the result of " selection of random movements; " the reactions are not in accord with Loeb's definition of tropism.

\section{Eudendrium Planulae}

The planulae of Eudendrium are set free during the latter part of July and the first part of August. In the laboratory they are usually liberated early in the forenoon, after which they immediately begin to travel toward the light. These organisms are cone-shaped, about $\mathrm{I} \mathrm{mm}$. in length and about $0.2 \mathrm{~mm}$. in diameter at the larger end when expanded; when contracted they are shorter and considerably wider at the larger end. They are light reddish in color and consist of numerous similar cells so arranged as to inclose a cavity. All the cells are well covered with comparatively short cilia on the outer surface.

Eudendrium planulae are always in contact with the substratum. They move along something like planaria. Locomotion seems to be due entirely to the action of the cilia, but the planulae are never found swimming freely through the water like infusoria. There is no evidence of constant rotation on the long axis. It may be, however, since all sides appear the same, that they move with different sides in contact with the substratum at different times. Locomotion is very slow, the average rate being only about $\mathrm{I} \mathrm{cm}$. in 15 minutes. Every movement of this creature can therefore be easily followed even under high magnification. The larger end is always ahead, and this end is constantly turned from side to side very slowly, and 
raised slightly from time to time during the process of locomotion. As the organism proceeds on its course it secretes a mucous substance in the form of a delicate fiber which can be readily detected by pushing a needle across the path a short distance from the posterior end. The planula and the needle usually adhere so firmly to the mucous fiber that the former can be lifted to the surface of the water.

Hargitt (I904, p. 272) referring to the reactions of Eudendrium planulae says, "At the height of the breeding season their numbers were large and they promptly swam directly toward the strongest light with great uniformity. By interposing a dark screen between this source of light and allowing another from the opposite side to operate upon the aquarium, there was an almost instantaneous response, the entire number almost without exception facing directly about, like a body of soldiers at command, and moving without deviation in the opposite direction, that is, toward the second source of light." When studied en masse in light from a window they do appear to orient very accurately; but if attention is focused on individuals it soon becomes evident that there is considerable variation in the direction of motion. This becomes still more evident if the reactions of individuals are studied in light from a single compact source. Thus several active specimens which appeared to be moving directly toward the window were selected and exposed one at a time in light of about the same intensity from a Nernst glower so arranged as to eliminate practically all refraction and reflection from the different substances in the aquarium, the glass walls, the surface of the water, and particles in suspension in the water. The angle between their direction of motion and the direction of the rays was frequently measured, and it was found that it varied all the way from $\mathrm{O}$ to $1 \mathrm{IO}^{\circ}$ and even more in a few individuals. If a number of specimens are put into the aquarium at the same time and at the same point, it is found that as they proceed toward the source 
of light, some deflect to the right, others to the left, so that the group gradually becomes wider and wider. When exposed to light from two sources they may travel toward any point between, as stated under Euglena.

They are positive in strong as well as in weak light, but if the intensity is very high, as, e.g., direct sunlight, or quite low, they do not orient so accurately as they do in light of moderate intensity, and the lateral movements of the anterior end are more pronounced. In general the more strongly positive the planulae are, the more accurately they orient and the less they swing the anterior end from side to side. From time to time the anterior end also becomes flatter and broader. The lateral movements of the anterior end, as well as the process of becoming broader, are due to internal contractions. If the ray direction is but slightly changed after the planulae are oriented, they do not turn directly toward the source of light in its new position, but merely swing the anterior end a little farther toward it each time. In the meantime the body gradually turns so as to become oriented again. If however the direction of the rays is changed to such an extent that the sides of the organism become fully exposed, they with very few exceptions appear to turn toward the light at once. In this process they swing the anterior end laterally until it nearly if not quite faces the source of light. It is thus frequently bent at right angles to the posterior end. The anterior end often swings back after turning but never so far as it was before. The lateral turning is a slow steady movement due, no doubt, to contraction of the tissue in the planulae and not to the action of the cilia, for it is much more rapid than the forward movement, which is entirely due to the action of the cilia, and moreover no currents indicating unequal ciliary action on opposite sides could be detected.

There is no definite reaction if the intensity is suddenly decreased or increased, nothing similar to an avoiding reaction or a shock movement. I have seen the planulae pass from darkness into strong light, consisting of rays perpen- 
dicular to the bottom of the aquarium, without any reaction excepting perhaps a very slight increase in the lateral movement of the anterior end.

The fact that these organisms turn directly toward the light when the side is illuminated apparently shows that they have the power of differential response to localized stimulation, that they can orient without preliminary trial movements. The fact that the anterior end is constantly being turned from side to side, and that orientation may take place if the ray direction is only slightly changed by merely swinging this end a little farther toward the source of light each time that it turns in that direction in the regular process of lateral movement, shows that under certain conditions orientation takes place by the trial method. The fact that the planulae can move toward any point between two sources of light shows that neither the direction of rays through the body nor the angle the rays make with the surface is of importance in orientation. If this be true, the orienting stimulus must be due to difference of intensity or a change of intensity on opposite sides of the body, especially on the anterior end. The lateral swinging movements serve to magnify the difference or change of intensity on this end, and thus make it possible for the animal to orient more accurately than it otherwise could.

The turning of the anterior end appears to serve in directing the course much as a cane serves a blind man in keeping him on the path. The man may go directly toward his goal without deviation and still it is evident that he orients and keeps on his course by the trial method. Every movement of the cane is a trial movement. Likewise every lateral movement of the anterior end in the planulae and many other organisms, as well as separate movements of the antennae, eyes, and other special organs in various forms may be trial movements. It is therefore clear that the mere fact that an organism moves directly toward a source of stimulation is not sufficient evidence to show that its orientation and direction of movement are not regulated 
by the trial method, as has been assumed by some investigators.

While the planulae of Eudendrium may undoubtedly orient by differential response to localized stimulation it is at present impossible to say whether such stimulation is due to changes of light intensity or to constant intensity. The question as to the importance of lateral movements of the anterior end in orientation, and the cause of stimulation will be referred to more in detail under the reactions of fly larvae and earthworms.

\section{Eudendrium Hydranths}

After the planulae are a few days old the anterior end becomes attached to the substratum and they soon develop into hydranths, which bend toward the source of light as they grow. In order to study this process of bending toward the light, I placed on the stage of the compound microscope, a small aquarium containing hydranths which had bent so that the distal end was nearly horizontal, and turned it so that one side of the organisms faced the light, and then projected a selected specimen with a camera lucida. This same individual was projected later from time to time, and in this way its movements were definitely recorded. It was found that the hydranths turn directly toward the source of light. There was no indication of circumnutation movements. The bending takes place only in the region of growth. All sides elongate but the shaded side elongates more than the illuminated side. The organisms bend toward the source of light very slowly. In all the individuals studied it required 48 hours or more to turn through $90^{\circ}$.

In the orientation of this organism it seems probable that light acts as a constant directive stimulation. But the knowledge we have concerning the process hardly warrants even a suggestion as to the probable mechanism involved. The bending may possibly be due to contraction as sug- 
gested by Loeb (I906, p. I2I): "The heliotropic curvature consists here in the stem undergoing a stronger contraction or shortening on the more strongly illuminated side of the polyp than on the opposite side." The fact however that the stem elongates on all sides does not favor this view, although growth might possibly mask shortening due to contraction. Unequal rate in growth may have something to do with the bending, since it takes place only in the region of elongation and is an exceedingly slow process.

Loeb thinks the orienting reactions in Eudendrium are the same as those in plants. He says (I906, p. I20), "The same phenomena of heliotropism which we find in plants we find also in sessile animals; and the identity of the heliotropic reactions in these two groups of organisms is so complete that it would be at any time possible to demonstrate the phenomena and laws of plant heliotropism in such animals, and vice versa." The identity Loeb maintains exists here is in all probability extremely superficial.

\section{Reactions of Medusae}

Many medusae do not react to light at all; others respond to changes of intensity by contracting; and still others become more active with change in the illumination. Only a few are known to orient. Both Yerkes and Morse have shown that Gonionemus murbachii orients under certain conditions, although very indefinitely. It apparently turns directly toward or away from the source of light without any preliminary movements. These organisms appear to have the power of differential response to localized stimulation. As to how light produces the orienting stimulation nothing is known. Many of the light reactions of this form are clearly due directly to change of intensity, while others appear to be due to the effect of constant light intensity.

The medusae of Bougainvillea superciliaris orient far more accurately than does Gonionemus or any other medusa of which I know, but even in these orientation is not accurate 
enough to warrant definite conclusions regarding the mechanics involved in this process.

These creatures are only about I $\mathrm{mm}$. in diameter. They have four prominent reddish brown spots symmetrically situated on the margin of the bell. From the tissue surrounding each of these spots there project three short tentacles which are much contracted when the medusae swim. The medusae are negative in their reactions to gravity, and positive to light of intensities ranging from weak diffused sunlight to intense direct sunlight. This causes them to collect at the surface of the water in the sea and to swim toward regions of highest light intensity.

In swimming toward the source of light they frequently turn to the right or left rather sharply so as to produce a zigzag course. The turning from side to side indicates that light does not act as a constant directive stimulation. If however the ray direction is changed through $90^{\circ}$ the medusae turn directly toward the source of light without any preliminary trial movements. It may be then that they are stimulated only when they turn a certain amount and that, owing to the power of differential response to localized stimulation, they always turn toward the light after such stimulation and consequently remain oriented, in a general way. If orientation is due to differential response to localized stimulation the stimulation may be caused by an increase of intensity on the illuminated side or a decrease on the shaded side. We have however no evidence bearing on this question.

If exposed to light from two sources they swim toward a point between them. The location of this point depends upon the relative intensity of light from the two sources. 


\section{CHAPTER IX}

\section{REGULATION IN THE DIRECTION OF MOVEMENT WITH REFERENCE TO THE SOURCE OF LIGHT IN VERMES, FLY LARVAE, AND ECHINODERMS}

MANY of the organisms belonging to these groups respond very definitely to stimulation by light. In some, the response results in orientation, in others it consists merely of an increase or decrease in rate of movement, and in still others it consists chiefly of a sudden contraction. We shall concern ourselves here primarily with forms which orient, emphasizing particularly the orienting reactions. The reactions of the blowfly larvae will be discussed in this section owing to their worm-like structure and method of locomotion.

\section{Arenicola cristata - Larvae}

a. Description. - Arenicola deposits its eggs in great numbers in masses of jelly-like substance. In the course of a few days the eggs develop into finger-shaped free-swimming larvae about $0.3 \mathrm{~mm}$. long. These organisms are strongly positive in their reactions to light and negative in their reactions to gravity. They contain two ciliary rings, one near the anterior and the other near the posterior end; these are connected by a median ventral band of cilia. On either side near the anterior end is an eye-spot. Lillie (I903, p. 345) says, "Each [eye-spot] consists of a compact clump of pigment or excretory granules on the surface of the brain." I studied the eye-spots in living specimens slightly flattened with the cover-glass, under an oil immersion lens and found that they consist of a brownish granular cup-shaped portion which partially surrounds an ellipsoidal 
hyaline portion and that this is directed dorso-anterio-laterally. The hyaline structure in the eye-spot is probably highly sensitive to light, while the pigmented portion appears to serve in shading the inner surface so as to admit light only from in front and from the side on which the eye-spot is located.

b. Locomotion. - The larvae have two methods of locomotion. They swim by means of the cilia for a few days then settle to the bottom and crawl. The crawling movement is brought about by means of muscular contraction much as in many other annelids. During this method of progression they are slightly negative and there is scarcely any indication of orientation. In the free-swimming positive state however they orient quite accurately. Both methods of reaction are adaptive. The positive reaction in the free-swimming state serves to keep the larvae at the surface of the water and causes them to scatter widely. The negative reaction serves to keep them at the bottom and to guide them into the mud where most of their future days are to be spent.

In swimming they proceed much like the ciliates. They rotate counter-clockwise on the long axis and travel on a spiral course. The ventral surface, the surface containing the median band of cilia, constantly faces out in the spiral, contrary to what might be expected if these cilia are functional. The organism is slightly curved, the ventral surface being concave. It may be that this causes the constant swerving toward this surface, which together with rotation on the long axis results in the spiral course.

c. Orientation. - Orientation is not so accurate as is generally assumed. If casually observed it is true that the larvae do appear to move directly toward the source of light, but if the course of a given individual exposed to light from a single compact source is carefully followed it is found that there are frequent deviations. As the organisms proceed they frequently turn the anterior end slightly but suddenly toward either side by means of muscular contrac- 
tion. This causes the spiral course to become very irregular and makes it appear as though they were constantly being thrown out of orientation and reorienting. Their general course is toward the source of light but it is a very irregular course.

d. Mechanics of orientation. - If the direction of the rays of light is changed after the larvae are oriented they all appear to turn directly toward the source of light in its new position without preliminary trial movements. What is the mechanism involved in this apparent direct orientation? If one edge of a cover-glass is supported so that it is a little higher than the other, and if the larvae mounted in water on the slide are forced to travel toward the lower edge, they soon reach a place where the cover-glass is so near the slide that they no longer rotate. Under such conditions the animals lie usually on the ventral surface, but some specimens are found on either side or on the dorsal surface. No definite movement is seen in those on either side, excepting occasionally a slight forward motion. But in those on either surface, the anterior end is constantly seen to move from side to side with a slight jerky motion. This lateral movement of the anterior end is undoubtedly due to muscular contraction. If one of the specimens with the dorsal surface up is selected and light thrown upon it from such a direction that the rays strike its side at right angles, the lateral movement toward the side illuminated is at once much increased and the organism turns in that direction. By using two sources of light so situated that the rays cross at right angles in the region where the specimen is located, and then alternately intercepting the light from each of the two sources, it can be seen clearly that the larva, by muscular movement, turns the anterior end toward the source of light directly. There is no trial reaction in this process. It is an asymmetrical response to an asymmetrical stimulation. This does not however mean that both sides of the organism are stimulated in accord with the theories of orientation of Loeb and Verworn. The reac- 
tion may be due to an increase in illumination on one side or a decrease on the other. The stimulation may be local and the reaction a differential response. We shall refer to this problem again later.

The larvae are so small and move so rapidly in the freeswimming state that it is exceedingly difficult to follow their movements in detail during the process of orientation. By carefully observing this process, however, in a low temperature by means of which the rate of movement is much reduced, it was found that it takes place somewhat as follows: If the source of light is changed in its position after a free-swimming specimen is oriented, reactions occur immediately only if either eye-spot is fully exposed after the change is made. If the ventral or the dorsal surface is directed toward the source of light after the ray direction is changed, there is no reaction until the organism has rotated through $90^{\circ}$ as it proceeds on its spiral course, and one of the sides comes to be illuminated. Then the anterior end is turned sharply toward the source of light, frequently to such an extent as to form a right angle with the posterior end. This causes rapid swerving on the spiral toward the light and speedy orientation (see Fig. 26). I was unable to detect any change in the course due to ciliary action.

$e$. Discussion. - The method of orientation in Arenicola larvae has some features in common with that of Euglena in the free-swimming state. In both forms there is a definite reaction whenever an eye-spot comes to face the source of light as they proceed on their spiral courses. This reaction consists of a turning toward the side containing the eye-spot and a swerving on the spiral course in the same direction, and this results in orientation. The larvae however, having two eye-spots, can turn toward the source of light in two positions in the spiral, whereas the Euglenae can turn toward it in only one. If one were to imagine two Euglenae united so as to form an organism with two eyespots facing in opposite directions, it would not be difficult to conceive the organism thus formed capable of turning 


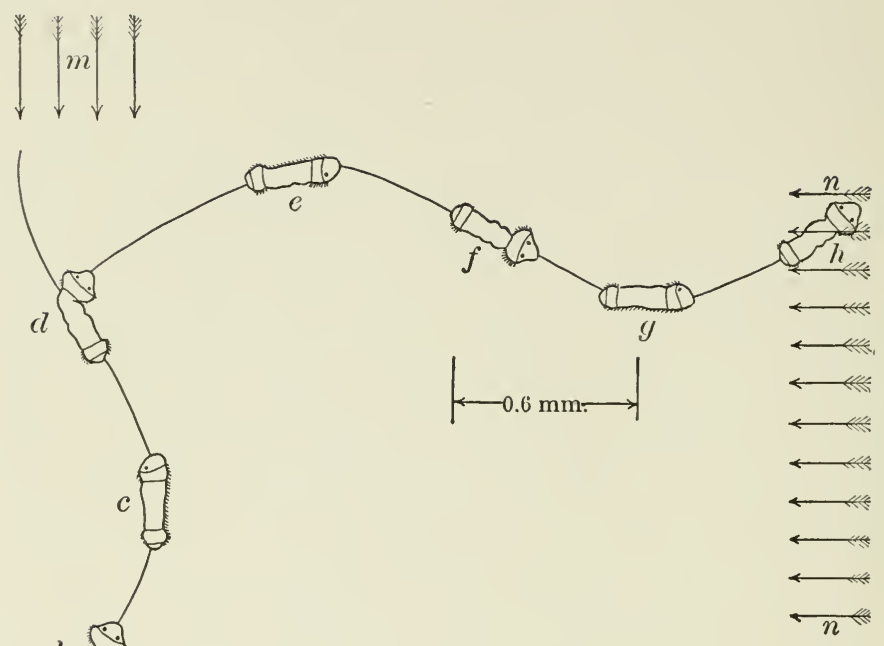

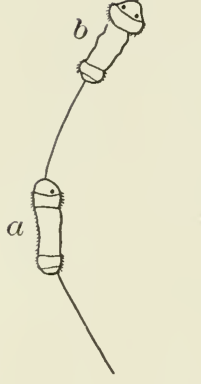

I

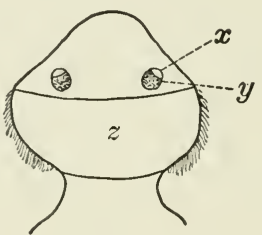

II

FIG. 26. I. Arenicola larva in the free-swimming state, proceeding on a spiral course. $m, n$, directions of light; $a$ - $h$, different positions on the spiral; $b$, dorsal surface up, right eye-spot toward $n ; d$, ventral surface up, left eye-spot toward $n$. If the ray direction is changed by simultaneously exposing $n$ and shading $m$ when the larva is in position $a$ or $c$, no reaction takes place until it reaches $b$ or $d$, then it bends the head sharply toward the source of light and turns in its course. In the former position it turns toward the right side of the body, in the latter toward the left. This indicates that the larvae have the power of differential response to localized stimulation, and that the orienting stimulus may be due to a change of light intensity.

II. Much enlarged sketch showing the general structure and position of the eye-spots as seen under an oil immersion objective. The eye-spots are composed of a dark brownish caplike portion, $y$, which partially surrounds a colorless portion, $x$, directed slightly dorso-laterally; $z$, band of cilia. 
toward the source of light in two positions on the spiral course just as Arenicola larvae do. If in place of a union of two individuals we should have a union of three, it would result in an organism that could turn toward the source of light in three positions on the spiral. And if a sufficient number were united it is clear that the organism could turn toward the source of light in all positions on its course. Such organisms we have in the colonial forms Volvox, Eudorina, and Pandorina. All of these consist of numerous individuals united, and all can turn toward the source of light directly no matter which side is illuminated. It is however probable that this analogy is, with reference to Arenicola larvae, merely superficial.

$f$. Orienting stimulation. - In positive Euglenae it was found that orientation is due to a reaction caused by a reduction in effective light intensity due either to a change in the intensity of the field or to rotation of the organism owing to the fact that it is more sensitive when the ventral surface is illuminated than when the dorsal surface is. In Volvox the orienting stimulus is likewise due to a reduction of effective intensity. To what is it due in Arenicola larvae? Is it due to a decrease of intensity caused by the shadow of the pigment on the hyaline portion of the eyespot on the side turned from the light, or to an increase of intensity on this structure in the eye-spot turned toward the light, or to an absolute difference of intensity on the two sides in accord with the theories of Verworn and Loeb?

Two methods were used in attempting to answer these questions. In both the larvae were mounted under a large cover-glass supported by means of a ring of vaseline. The cover was then pressed down until the space became so narrow that the larvae could not rotate. (I) A piece of sheet metal containing an opening I $\mathrm{cm}$. square was hung about $3 \mathrm{~mm}$. from a Welsbach mantle. From the middle of one side of the opening there projected nearly to the center a spinelike process. The incandescent mantle was focused on the slide by means of the plane mirror and Abbe 
condenser where it produced a sharply defined rectangular area of intense light with a narrow triangular shadow projecting from one side. By manipulating the mirror I was able to change the position of this area of light so as to illuminate or shade any part of a larva fairly accurately in spite of its microscopic size. All light except that from the opening in front of the mantle was thoroughly eliminated by means of suitable screens. Without going into detail regarding the numerous observations made at different times, the reactions may be summarized as follows: (a) If the anterior end is suddenly illuminated the larva bends from side to side vigorously. (b) If the light intensity on one eye-spot is increased without changing that on the other, it bends both ends rather sharply toward the illuminated side. (c) If the intensity on either eye-spot is decreased it also bends toward the illu minated side. (d) If any portion back of the eye-spots is shaded or illuminated there are no definite reactions. This shows that the anterior end (probably the eye-spots) is the most sensitive part of the larvae if it is not the only sensitive part, and that if the light intensity is increased or decreased on either side regardless of the direction of the rays, the larvae turn toward the more highly illu ninated side.

(2) Two sources of light were so arranged and screened as to produce small horizontal bea ns which crossed at right angles on the stage. The larvae exposed in the light from these two beams oriented toward a point approximately halfway between the two sources. If the light from one source was now intercepted they turned directly toward the other, and when it was again exposed they returned to their former position. These reactions do not occur in all instances nor is the orientation always precise and definite, especially if the larvae are not in prime condition. They were however seen in so many cases that there can be no doubt concerning the conclusions stated above.

What bearing have these conclusions on the problem in hand? It is evident that when the light in one beam is 
intercepted after the larvae are directed toward a point between the two, the intensity on the side facing this beam is decreased more than that on the opposite side, and when this light is turned on again after the larvae are directed toward the other, the intensity on the same side is increased more than it is on the opposite side. Under both conditions however we find that the larvae turn toward the side most highly illuminated. Under one therefore they turn toward the side on which the intensity is increased, under the other from the side on which it is decreased. It is evident then that if the orienting stimulus is due to change of intensity, it may be due to an increase as well as to a decrease of intensity. And if this is true the organism must in some way perceive the difference between a stimulus due to an increase and one due to a decrease of illumination, for in response to the former it turns toward the point of stimulation whereas in response to the latter it turns from this point.

It can be definitely stated then that orientation in Arenicola larvae is due to difference of intensity on opposite sides. Whether it is the result of light acting constantly as a directive stimulation like a constant electric current, or whether it is the result of reactions due to changes of intensity on the sensitive structures in the organisms brought about largely by its movements, is a question concerning which our evidence does not warrant a definite conclusion. The facts that the organisms are frequently thrown out of orientation as they proceed toward the source of light, and that the anterior end is almost constantly turned from side to side speak in favor of the latter. The organism is not held definitely on its course as one would expect in case of light acting constantly as a directive stimulation in accord with the definitions of tropisms of Loeb and Verworn. It must however be remembered that even if the organism is under the influence of a constantly acting directive stimulus it might turn from side to side frequently owing to the effect of internal processes or other external stimuli. 


\section{Summary}

(I) Arenicola larvae are positive to light in their freeswimming state. They rotate on the long axis and swim on an irregular spiral course owing to frequent sharp lateral movements of the head.

(2) If held under a cover-glass so that they cannot rotate, it is found that the head is suddenly turned directly toward the source of light when either of the two sides is illuminated, frequently to such an extent that the anterior end of the body is at right angles to the posterior end.

(3) The larvae have two prominent eye-spots, which consist of a hyaline portion partly surrounded by an opaque caplike structure. The hyaline portion, which is probably sensitive to light, is directed dorso-anterio-laterally. In the free-swimming state orientation takes place by a greater swerving toward the source of light on the spiral course every time an eye-spot faces the light just as in Euglena. In Arenicola, since it has two eye-spots, the increase in swerving takes place in two different positions on the spiral, i.e., twice during a complete rotation on the long axis. In Euglena, since there is but one eye-spot, it takes place only in one position on the spiral, or once during a complete rotation. Euglena however responds when the eye-spot faces the source of light because when it is in this position the eye-spot shades the tissue. It responds only to a decrease of intensity while it is positive. Arenicola larvae, on the contrary, respond to either an increase or a decrease of intensity on the sensitive tissue on either side, but they always turn toward the more highly illuminated side.

(4) The stimulus causing this reaction, a reaction by means of which the organism orients, is probably due either to a decrease or to an increase of intensity on either side. The orienting reaction is probably a differential response to a localized stimulus. Our evidence however does not 
warrant a definite conclusion on this point. Orientation may be the result of a response regulated by the absolute difference of intensity on opposite sides, that is, it may be due to the action of light owing to continued intensity rather than to its action owing to change of intensity.

\section{Blowfly Lariae - Musca sp.(?)}

a. Introduction. - The reactions of the blowfly larvac to light were described by Loeb in I890. He exposed the larvae in front of a window in diffused and direct sunlight and found them to be negative and to orient very accurately. He says (1905, p. 57), " They crept with mathematical precision in the direction of the rays. When a shadow was thrown on the board by a penholder, it could be noticed that the animals moved away from the light in a direction exactly parallel to the edge of the shadow. . . . They acted as though they were impaled on the ray of light which passed through their median plane. When I turned the board around, the animals immediately turned about also, and again placed their median planes in the direction of the rays." Loeb, assuming that the method of orientation in this form is the same as it is in others, concluded that it is controlled by the same factors. In this form as in others light acts constantly as a directive stimulus and " the main feature... is the fact that symmetrical points of the photosensitive surface of the animal must be struck by the rays of light at the same angle." (I897, p. 440), "Ich glaube jetzt, dass hier eine vollkommene Analogie der Lichtund Stromwirkungen zu Tage tritt, derart, dass auch, wie beim Strom, die Lichtintensität dauernd die Spannung der Muskeln beeinflusst, dass aber die Steilheit der Intensitätsschwankung die Fortleitung der Spannungsänderung bestimmt. . . . . Das IVesen der Orientirung fasste ich dahin auf, dass bei vollendeter Orientirung Symmetriepunkte der Oberfläche des Thieres unter gleichem Winkel von den Lichtstrahlen getroffen werden." According to Loeb then, if the position of the 
source of light is changed, the larvae turn immediately and directly from the light in its new position until both sides are again struck by the rays at the same angle.

Holmes' observations of the orienting reactions of fly larvae do not support Loeb's theory. He found among other things (1905, p. I05), "If a strong light is thrown upon a larva from one side it may swing the head either towards or away from the light . . . In the animals here described there is, so far as I can discover, no forced orientation brought about by the unequal stimulation of the two sides of the body, but an orientation is produced indirectly by following up those chance movements which bring respite from the stimulus. I do not deny that there may be an orienting tendency of the usual kind, but if there is it plays only a subordinate rôle in directing the movements of the animal. The orientation of these forms is essentially a selection of favorable chance variations of action and following them up."

b. Locomotion. - The blowfly larvae move from place to place entirely by means of muscular contraction. They proceed somewhat as follows: the anterior end is raised, thrust forward toward one side, fastened to the substratum, and then the posterior end is pulled forward, after which the anterior end is again raised and thrust forward, now toward the opposite side, fastened, and the posterior end again drawn up. The anterior end is thus turned alternately toward the right and left quite regularly during the process of locomotion. The extent of this lateral movement varies much, but it is usually great enough so that the extremity of the anterior end is nearly at right angles to the direction of locomotion (see Fig. 3I).

In drawing forward the posterior end the whole body contracts, but the contraction is greater on the ventral than on the dorsal surface, forming an arch, in which the extreme anterior end is nearly vertical and the sensitive tip (Fig. 30) well drawn under so as to be hidden from view. Thus the tip of the anterior end becomes alternately thrust out and 
exposed, retracted and concealed. This is of importance in the orienting reactions as will be seen later (Fig. 3I).

c. Accuracy of orientation. - The orientation of organisms is generally supposed to be far more accurate than it really is. This is no doubt due to the fact that many of the observations on light reactions have been made in light which is more or less diffused and the direction of which is not thoroughly under control. In testing the accuracy of orientation in the blowfly larvae they were exposed on a piece of smooth moist black paper on a glass plate in a small horizontal beam of light from a Nernst glower. The course taken by the larvae was traced on the paper in white ink with a small pen held about $\mathrm{I} \mathrm{cm}$. in front of the end of the larvae. In this way the movements could be quite accurately traced. Neither the presence of the pen nor the ink on the paper made any appreciable difference in the course taken. The courses of four different individuals are given in Fig. 27. All of the specimens tested deviated considerably; those used in Fig. 27, $B$ and $C$, deviated toward the left in all the trials; the one used in Fig. 27, $A$, to the right, and that in Fig. 27, $D$, to the right in some trials and to the left in others. In Fig. 27, $A$, the head movements are represented more in detail than they are in the others. It will be seen that the lateral movements to the right and the left alternate quite regularly. The posterior end takes a much more regular course than the anterior. In direct sunlight orientation is somewhat more accurate and the lateral movements are not so pronounced. But I failed to find any specimens which " crept with mathematical precision in the direction of the rays, . . . exactly parallel to the edge of a shadow," or which " acted as though they were impaled on the ray of light which passed through their median plane," as Loeb states.

$d$. Orientation in light from two sources. - In the study of orientation in light from two sources the larvae were exposed on moist black paper just as in the preceding experiment, in a field of light composed of two small horizontal 
beams, one from each of two Nernst glowers so situated that the beams crossed at right angles. One of the glowers was stationary and the light from it constant. The other was mounted on a track so that the light from it could be

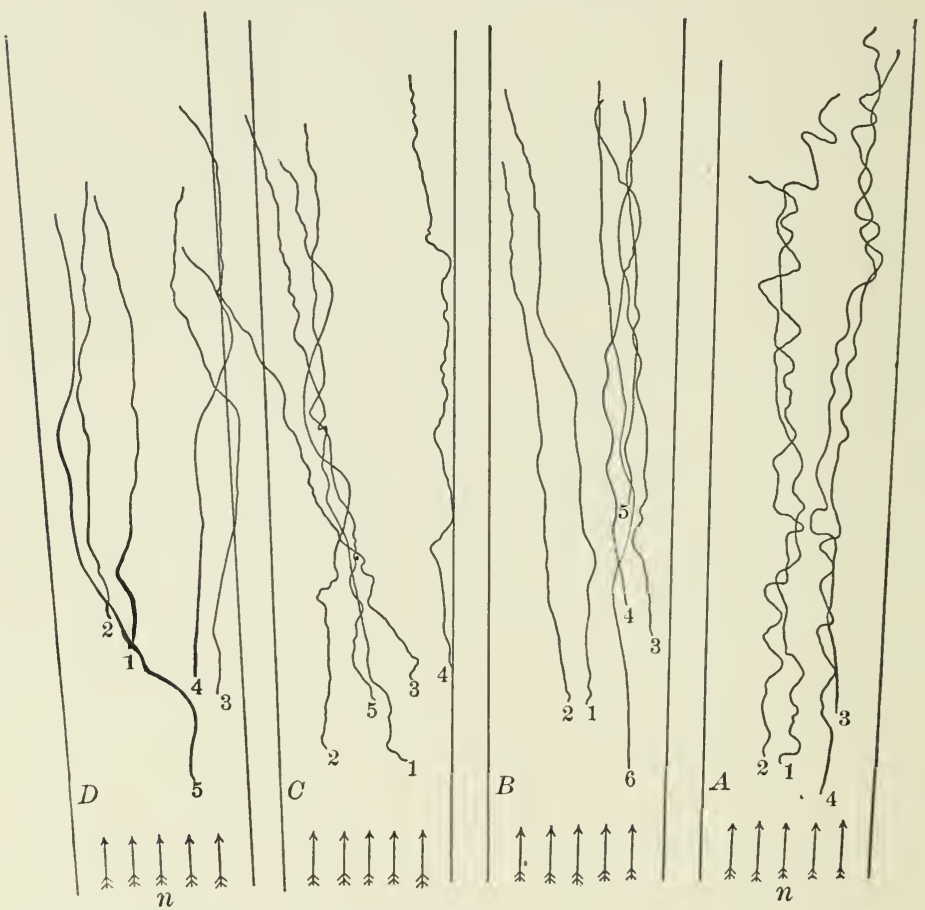

Fig. 27. The lines I, 2, etc., in $A, B, C, D$, represent courses taken by four different blow-fly larvae in light of $78 \mathrm{ca}$. m. intensity. n, direction of horizontal rays from single Nernst glower. Orientation is not as accurate as one would expect if light acts constantly as an orienting stimulus in accord with the theories of Sachs, Loeb, and Verworn. See text.

varied. The paths taken by the larvae under the different conditions are represented in Fig. 28.

It will be seen by referring to the figure that the larvae can move in a direction leading from any point between the two sources of light just like all the other lower organisms tested under these conditions. Loeb says (I905, p. 6I), 
"When the diffuse daylight which struck the [fly] larvæ came from two windows the planes of which were at an angle of $90^{\circ}$ with each other, the paths taken by the larvæ

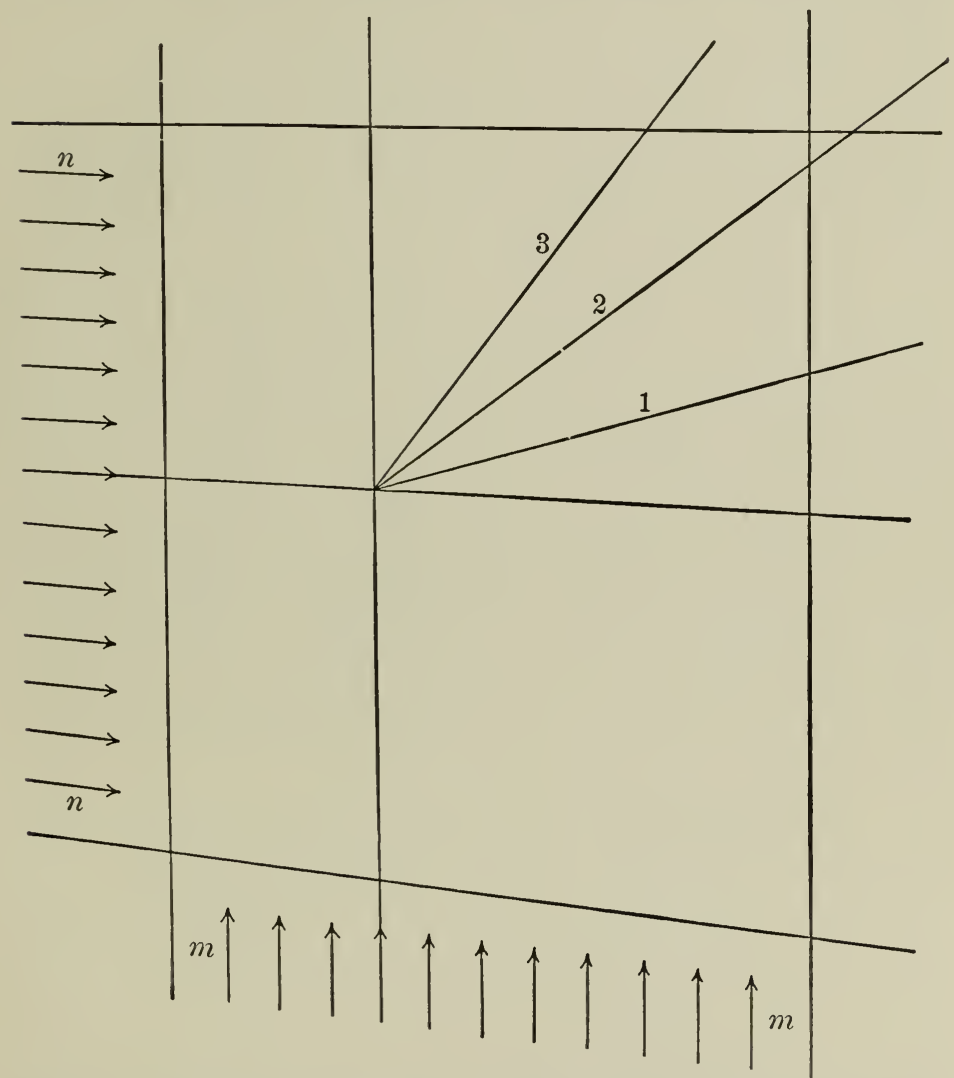

FIG. 28. Direction of movement of fly larvae in light from two sources; $n, m$, direction of rays; $\mathrm{I}$, course in light from $n$ and $m 50$ and $5.5 \mathrm{ca} . \mathrm{m}$. respectively; 2, course in light from $n$ and $m$, 50 and I5 ca. m. respectively; 3 , course in light from $n$ and $m, 50$ and $60 \mathrm{ca} . \mathrm{m}$. respectively. Lines $\mathrm{I}, 2$, and 3 represent the average direction of several courses taken by each of three larvae.

lay diagonally between the two planes; " and (p. 2), "It is explicitly stated in this and the following papers that if there are several sources of light of unequal intensity, the light with the strongest intensity determines the orientation 
and direction of motion of the animal. Other possible complications are covered by the unequivocal statement, made and emphasized in this and the following papers on the same subject, that the main feature in all phenomena of heliotropism is the fact that symmetrical points of the photosensitive surface of the animal must be struck by the rays of light at the same angle. It is in full harmony with this fact that if two sources of light of equal intensity and distance act simultaneously upon a heliotropic animal, the animal puts its median plane at right angles to the line connecting the two sources of light. This fact was not only known to me, but had been demonstrated by me on the larvæ of flies as early as I887 in Würzburg, and often enough since. These facts seem to have escaped several of my critics."

It is evident without further discussion that the reactions of fly larvae in light from two sources are not in accord with Loeb's conclusions. When exposed in light from two sources of different intensity the stronger does not determine the orientation and direction of motion, nor are symmetrical points on the photosensitive surface struck by the rays of light at the same angle.

e. Orientation and movement - (I) perpendicular to the direction of the rays - (2) toward a source of light. - The following experiments bring out clearly the importance of intensity in the orientation of fly larvae. A small horizontal beam of light from a single Nernst glower was thrown on the black paper used in the preceding experiments. In this beam a small vertical post was erected so as to produce a well-defined narrow shadow. By means of a mirror this shadow was illuminated with rays of light either perpendicular to or parallel with its edges, as represented in Fig. 29. The intensity of light in the shadow could be regulated by changing the position of the mirror. It was always considerably lower than that in the field on either side.

If a specimen taken from darkness is placed on the plate in the shadow with its anterior end directed toward the 
mirror, i.e., toward the source of light, it soon begins to crawl and turn so as to direct the anterior end away from the mirror, but in attempting this the anterior end extends into the direct light owing to the narrowness of the shadow. This produces a stimulus which causes it to withdraw and swing in the opposite direction, where it soon comes into the intense direct sunlight again. It continues this swinging and crawling from one side of the shadow to the other

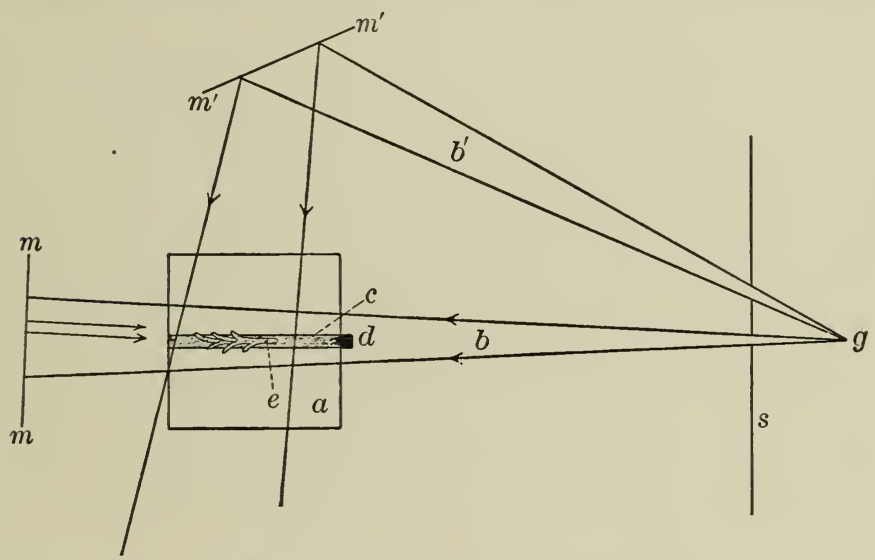

Fig. 29. Representation of arrangement of apparatus used to produce light conditions in which negative fly larvae crawl toward the source of light or perpendicular to the rays. $a$, glass plate; $b, b^{\prime}$, beams of light; $c$, shadow cast by the opaque standard $d$; $e$, fly larva; $g$, Nernst glower; $s$, opaque screen; $m, m^{\prime}$, mirrors, relatively much farther from the glass plate than represented. The larva is placed in the shadow, $c$, which is illuminated by light reflected from either the mirror $m^{\prime}$ or $m$. The intense illumination on the anterior end whenever it projects beyond the shadow prevents the larva from turning around and shows that under the conditions of the experiment it is the change of light intensity on the anterior end, and not the direction of the rays or the relation of intensity on symmetrically located sensitive points, which regulates the direction of movement.

for a short time, but soon comes to travel more nearly parallel with the edges of the shadow and consequently extends into the light much less frequently. If the rays from the mirror are perpendicular to the edges the larva also remains in the shadow, but usually it crawls along near the edge farthest from the mirror. The negative larvae can 
thus be forced to move toward a source of light or at any angle with the rays.

If exposed in a narrow shadow in a field of light consisting of rays perpendicular to the substratum they crawl along in the shadow. If the anterior end chances to project out into the light it is stimulated and turned in the opposite direction. The direction of the rays here is however perpendicular to the substratum; under the preceding conditions it was parallel with the substratum, yet the reaction is the same under both conditions. It is of course due to a change of intensity and is not primarily dependent upon the ray direction. In a narrow shadow in the field consisting of vertical rays the larvae can also be made to move toward or perpendicular to light rays in the shadow just as under the conditions described above. Cole (1907) obtained similar results in experiments on Bipalium kewense.

These results indicate that in their movements the larvae attempt to keep the sensitive anterior end in the lowest possible light intensity regardless of the direction of the rays or the angle between them and the sensitive surface. Loeb claims that the larvae follow the direction of the rays even if in so doing they go from regions of lower into regions of higher light intensity. He says (I905, p. 58), "I put the almost fully grown larvae into a test-tube and placed it horizontally on the table, with its longitudinal axis perpendicular to the plane of the window. The sun's rays made a small angle with the window. By means of a screen I arranged the test-tube so that only diffuse light fell through the window upon the half turned toward the window, while direct sunlight fell on the half turned toward the room. At the beginning of the experiment the animals were all on the window side of the test-tube. They immediately moved from the shaded part into the direct sunlight on the room side, and remained there." Do these results prove Loeb's conclusions? Can the reactions described in the quotation be explained on the assumption that orientation reactions are due to difference of intensity? 
Loeb says (p. 58), "When the animals crossed the boundary from diffuse light into direct sunlight, the reaction caused by the increase in the intensity of the light did not take place until a half or a third of the body was in the sunlight (because in all phenomena of stimulation some time elapses between the application of the stimulus and the reaction to it). The animal checked its movement and turned its head through an angle of $90^{\circ}-130^{\circ}$ from side to side. If in so doing the head again came into the shade the animal returned into the shade; but if this did not happen, as was more usually the case, the animal continued its movement into the sunlight." Under the conditions of the experiment quoted above there was therefore no cause for turning until one-half or one-third of the body was in direct sunlight. It is evident that after the anterior end is in the sunlight, it is in lowest light intensity when it is directed from the source of light. Consequently if the larvae did start to turn around so as to get back into the shaded region, the effective intensity would be increased and this would at once cause them to turn the head back again to the position in which it is shaded. Moreover Loeb says, as quoted above, that if the head came into the shadow in turning, the animal returned into the shade. It is therefore evident that there is nothing in the observations of Loeb inconsistent with the idea that the orienting reactions are due to difference or change of intensity on the surface of the organism. Nor do these observations show that these reactions are not accompanied by anthropomorphic sensations as Loeb intimates, since every reaction shows that the larvae assume positions such that there is a minimum exposure of the sensitive anterior end.

$f$. Sensitive region. - Both Loeb and Holmes assume the anterior end to be the most sensitive part of the fly larvae with reference to stimulation by light. The following experiments on the effect of intensity on the rate of locomotion indicate that this is not only the most sensitive region, but that it is the only region sensitive to light. At 
the anterior end there are two minute cone-shaped protuberances not over $0.5 \mathrm{~mm}$. apart (Fig. 30). These protuberances can barely be seen with the naked eye when the anterior end is extended, and not at all when it is contracted. Judging from their connection with the nervous system, I am inclined to believe that they are light recipient organs.
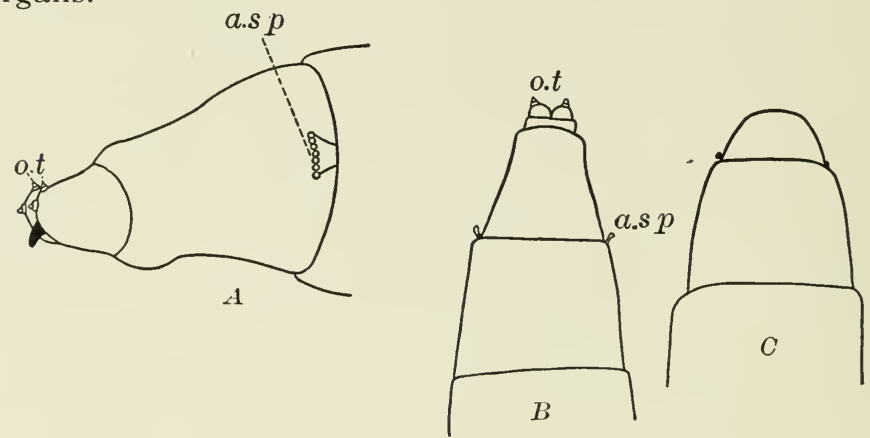

o.t

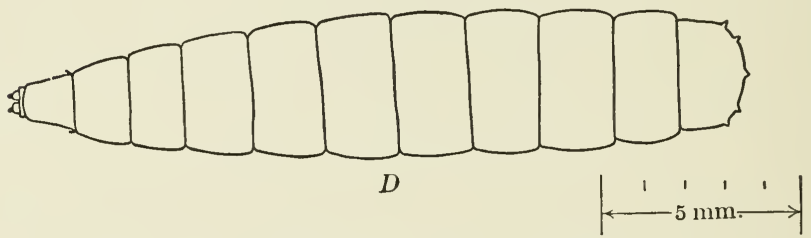

Fig. 30. Musca larva. A, side view anterior end expanded; a.sp., anterior spiracular process showing seven spiracular papillae; o.t, optic tubercle. After Hewitt (I908, Pl. 30, Fig. 9). B, camera outline, dorsal view showing anterior end expanded. $C$, same showing anterior end contracted, and optic tubercle withdrawn and turned under as it is during the process of looping. $D$, dorsal view of entire animal.

g. Effect of light intensity on rate of locomotion. - The effect of light intensity on the rate of locomotion in fly larvae was tested under three conditions: (I) with the entire larva exposed; (2) with the posterior third exposed; and (3) with the posterior three-fourths exposed.

$h$. Method. - A glass plate $25 \mathrm{~cm}$. square was covered with two sheets of filter paper over which was placed a sheet of smooth black paper. This was then thoroughly 
soaked in water and the plate so arranged that the edges of the filter paper which projected over the edge of the glass plate extended into water kept in a vessel below. In this way a smooth surface containing a constant amount of moisture was produced. It was found that such conditions are very essential in quantitative work with the larvae, especially that of constant moisture, since their rate of locomotion depends much upon the amount of moisture in the surface upon which they crawl; either too much or too little causes marked retardation. Two fine white threads were placed parallel with each other on the paper $15 \mathrm{~cm} .{ }^{1}$ apart, so as to form a definitely limited course upon which to try the speed of the larvae under different light conditions. A horizontal beam of light $4 \mathrm{~cm}$. wide was projected from a Nernst glower upon the glass plate perpendicular to the threads. The light in this beam halfway between the threads was $7 \mathrm{ca}$. $\mathrm{m}$. in intensity. The time it required a given larva taken from the culture jar kept in total darkness to travel the distance between the threads was accurately ascertained by means of a stop watch. At the end of the course the larva was allowed to crawl onto a piece of black paper supported on a section lifter and then transferred to the starting point without changing its orientation, and allowed to continue on its course with the least disturbance possible. After having ascertained the time required to crawl $\mathrm{I}_{5} \mathrm{~cm}$. in the beam of $7 \mathrm{ca}$. $\mathrm{m}$. intensity, the plate was turned through an angle of $90^{\circ}$ so as to expose the larva in a similar beam of light but one of a much higher intensity. The intensity of this second beam of light in the middle of the course was $3888 \mathrm{ca}$. m. It was produced by a group of three Nernst glowers so arranged that a cross section formed a small triangle. When the current was on, the three glowers appeared much like a highly illuminated

1 Through some oversight I failed to record the distance between the threads. I am not quite positive whether it was $15 \mathrm{~cm}$. or $10 \mathrm{~cm}$. This however does not invalidate the results recorded in the following table since they are comparative in every case. 
solid rod several times as large as a single glower. It therefore cast a sharp shadow, a point of importance in the following experiments. The time required to travel the distance was recorded just as under the preceding conditions. The rate of movement was now obtained alternately under the two conditions. The results appear in Table II. This table shows that it required on an average 46.4 seconds to

TABLE II

\begin{tabular}{|c|c|c|}
\hline \multirow{2}{*}{ Distance } & \multicolumn{2}{|c|}{ Time in seconds } \\
\hline & $\begin{array}{l}\text { Light intensity, } \\
3888 \mathrm{ca} . \mathrm{m} \text {. }\end{array}$ & $\begin{array}{l}\text { Light intensity, } \\
7 \text { ca. m. }\end{array}$ \\
\hline $\begin{array}{l}\text { I } 5 \\
66 \\
\text { c } \\
\text { "6 } \\
\text { "6 } \\
\text { "6 }\end{array}$ & $\begin{array}{l}44 \cdot 4 \\
43 \cdot 2 \\
42 \cdot 4 \\
44 \cdot 8 \\
42 .\end{array}$ & $\begin{array}{l}47.2 \\
46.8 \\
44 . \\
46.6 \\
47.4\end{array}$ \\
\hline Total Average & $43 \cdot 3^{6}$ & 46.4 \\
\hline
\end{tabular}

travel $15 \mathrm{~cm}$. in an intensity of $7 \mathrm{ca}$. m., and 43.36 seconds to travel the same distance in an intensity of $3888 \mathrm{ca} . \mathrm{m}$. Under the former conditions the larvae therefore crawled at the rate of $0.32 \mathrm{I} \mathrm{cm}$. per second, and under the latter at the rate of $0.345 \mathrm{~cm}$. per second, a difference of only $0.024 \mathrm{~cm}$. per second, due to a difference of $388 \mathrm{I} \mathrm{ca.} \mathrm{m}$. of light.

In studying the effect on the rate of locomotion of exposing the posterior third and three-fourths of the larvae, the apparatus was arranged just as described above. The time required to travel $15 \mathrm{~cm}$. in $7 \mathrm{ca}$. $\mathrm{m}$. intensity was first ascertained with a given larva, then the larva was transferred to the starting point, and after it had crossed the thread a small beam of light $3888 \mathrm{ca}$. m. in intensity from the three glowers was thrown on the posterior end and held there by means of moving along by the side of the larva a screen containing a small rectangular opening. The time 
required to complete the course was thus alternately obtained under each of the two conditions. The results obtained with one-third exposed are recorded in Table III;

TABLE III

\begin{tabular}{|c|c|c|c|}
\hline \multirow[b]{2}{*}{ Date } & \multirow[b]{2}{*}{ Distance } & \multicolumn{2}{|c|}{ Time in seconds } \\
\hline & & $\begin{array}{l}\text { Posterior } \frac{1}{3} \text { in } \\
3888 \mathrm{ca} . \mathrm{m} \text {. }\end{array}$ & $\begin{array}{l}\text { Entire larva } \\
\text { in } 7 \mathrm{ca} . \mathrm{m} .\end{array}$ \\
\hline Jan. 29 & I $5 \mathrm{~cm}$. & 36.95 & $37 \cdot 35$ \\
\hline " 30 & " 6 & 50.64 & $5 \mathrm{I} .40$ \\
\hline "6 6 & "6 6 & 36.77 & 36.67 \\
\hline " $" ~$ & "6 6 & $35 \cdot 3^{8}$ & $35 \cdot 18$ \\
\hline 6 6 6 & " " & 41.10 & $41 \cdot 75$ \\
\hline " 6 & " " " & 43.66 & $43 \cdot 5^{8}$ \\
\hline " $3 I$ & "6 6 & 69.45 & $71 \cdot 5$ \\
\hline 64 & " " & $4^{2} .64$ & 42.64 \\
\hline " "6 & "6 6 & 42.01 & 41.96 \\
\hline Feb. I & " " & $40 \cdot 3$ & 40.4 \\
\hline Total average & & 43.89 & 44.24 \\
\hline
\end{tabular}

those with three-fourths exposed in Table IV. Each figure in columns three and four in the tables represents the aver-

TABLE IV

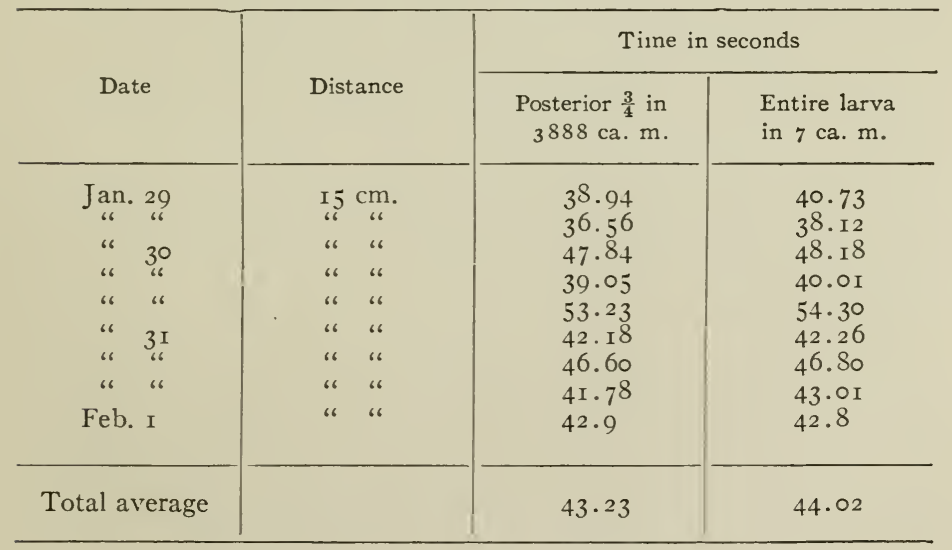


age of ten trips across the course made by different individuals. The total average as seen in Table III, with the entire larva exposed in $7 \mathrm{ca}$. $\mathrm{m}$. light intensity, is 44.24 seconds, and that in $7 \mathrm{ca} . \mathrm{m}$. intensity with the posterior third of the body in $3888 \mathrm{ca}$. m. intensity, is 43.89 seconds, a difference of only 0.35 seconds in traveling $15 \mathrm{~cm}$. In Table IV the total average in $7 \mathrm{ca}$. $\mathrm{m}$. intensity is 44.02 seconds; and in $7 \mathrm{ca}$. $\mathrm{m}$. with $\frac{3}{4}$ of the body exposed in 3888 ca. $\mathrm{m}$. intensity, it is 43.23 seconds, a difference of 0.79 seconds in traveling $15 \mathrm{~cm}$. By comparing these results with those recorded in Table II it will be seen that there is very little difference in rate of locomotion under the different conditions of illumination, i.e. larvae entirely exposed in 3888 or $7 \mathrm{ca}$. $\mathrm{m}$. or the posterior one-third or three-fourths exposed in $3888 \mathrm{ca}$. $\mathrm{m}$. This seems to indicate that the tissue sensitive to light is restricted to the anterior tip of the body. The difference in rate of locomotion under the different conditions can be accounted for by assuming it to be caused by the light reflected from the highly illuminated posterior end of the body upon the sensitive anterior end.

The exposure of the side of the body to the very intense light from the three glowers has apparently no effect whatever on orientation. The larvae continue as directly on their course as though they were exposed only to light of $7 \mathrm{ca} . \mathrm{m}$. intensity from the single glower. As a matter of fact all but the very tip of the anterior end can be illuminated by this intense lateral light without causing any noticeable deviation in the direction of motion. If however the tip is exposed there is a sudden sharp turning of the anterior end either toward or from the source of light.

The results recorded in the last two tables indicate either that the tissue sensitive to light in fly larvae is confined to the extreme anterior end, or that light of constant intensity has no effect on the rate of locomotion, the increase in rate due to increase in light intensity when the entire organism 
is exposed being due to change of intensity caused by the extension and contraction of the anterior end.

$i$. Mechanics of orientation. - Holmes (1905, p. 105) says, "If a strong light is thrown upon a larva from one side it may swing the head either towards or away from the light," intimating that it is turned in one direction as often as in the other. I exposed various individuals to sudden lateral illumination by direct sunlight, or light of nearly equal intensity from the three glowers, at different times and recorded the direction in which the anterior end turned. The results appear in Table V. It will be seen by referring

TABLE V

Number of times anterior end is turned

\begin{tabular}{|c|c|}
\hline $\begin{array}{c}\text { From source of } \\
\text { light }\end{array}$ & $\begin{array}{c}\text { Toward source of } \\
\text { light }\end{array}$ \\
\hline 6 & 6 \\
I3 & 9 \\
8 & 8 \\
I3 & 7 \\
26 & 26 \\
26 & 24 \\
I9 & $3 \mathrm{I}$ \\
28 & 22 \\
3 & 3 \\
8 & 8 \\
27 & $2 \mathrm{I}$ \\
\hline Total & I6 65 \\
\hline
\end{tabular}

to this table that in all there were $\mathbf{I} 77$ turns from the light to 165 toward it, i.e., nearly the same number in both directions. Later however I obtained results very different from these. They are recorded in Table VI. The results recorded in Table VI show that when a larva is first exposed to intense unilateral illumination, it turns toward the source of light practically as frequently as from it, and orientation is indirect, but that after being exposed for some time it turns considerably more of ten from the source of light than 
toward it, and if then exposed to lateral illumination of a lower intensity it seldom turns toward the source of light at all, and orientation is direct. ${ }^{1}$

\section{TABLE VI}

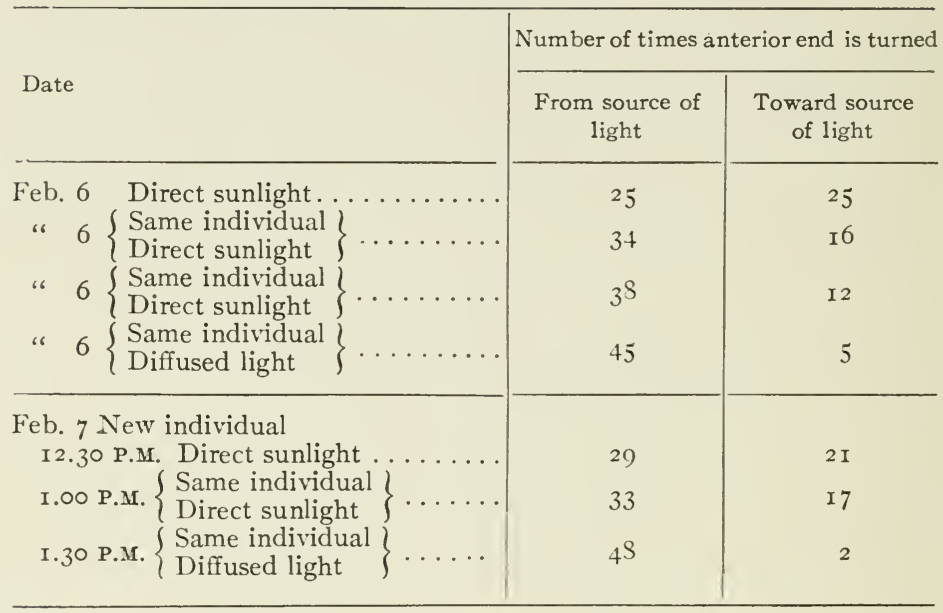

How are these results to be explained? It is ordinarily supposed that the higher the illumination the more direct the orientation in such organisms as fly larvae. The results above indicate the opposite to be true. Have these creatures the power of differential response to localized stimulation, as the final results recorded in the table seem to indicate?

During the normal process of locomotion, as already stated, the larvae alternately swing the anterior end slightly to the right and left at the same time that they thrust this

1 The variable results recorded in Table VI show very clearly the importance of studying reactions under different conditions, and also that statistical results in the study of reactions may be very misleading. This is particularly true in case of organisms which readily become acclimatized, as the blowfly larvae do. If the larvae are exposed to direct sunlight half an hour or so they frequently lose all power of response to lower intensities and sometimes respond no longer even in direct sunlight. 
end forward. When the anterior end is thus extended the two cone-shaped elevations at the very tip (Fig. 30) become fully exposed; and these, owing to the lateral movements of the anterior end, face alternately to the right and the left. When the animal fastens the anterior end to the substratum and pulls up the posterior end, the cone-shaped structures cannot be seen. They appear to be drawn in, and the whole anterior end is turned under somewhat as the arch is formed in the looping process. This causes the tip to be thoroughly concealed and shaded.

When the larvae are first exposed to sudden lateral illumination in direct sunlight, they respond immediately by throwing the anterior end toward one side violently, no matter in what position this end chances to be. If it happens to be directed from the source of light when the sunlight is flashed upon the organism, it turns toward the source of light, and if the sunlight is immediately intercepted after the larva turns, it will continue in the direction toward which the anterior end points; if it is not intercepted, the anterior end is thrown in the opposite direction, and then the larva may follow this turn and become oriented immediately, or it may swing the end back and forth a few times before becoming oriented. If the anterior end faces the light when it is exposed to the sun it is first thrown in the opposite direction and orientation takes place just as described above. The anterior end is thus turned in the direction opposite to that in which it is when the exposure is made. It is therefore evident that under these conditions the larvae will turn toward a strong unilateral illumination about as often as from it.

According to the tables, however, turning toward the source of light becomes less frequent after the organism is exposed for a time and much less frequent if the intensity is decreased. What is the cause of this? If the larvae are carefully observed when they are suddenly exposed to lateral illumination by diffuse light, it is found that they respond immediately only if the anterior end is turned 
toward the source of light when the exposure is made (Fig. $3 \mathrm{I})$. If this end is in any other position, there is no reaction whatever until the organism, in its normal process of locomotion, extends it toward the source of light. Then it is at once turned from the light to such an extent that it frequently makes a right angle with the posterior end. Later it is swung back, but only part way. The tip is however exposed and so the animal may be stimulated again, after which it again turns sharply from the source of light. This process is repeated until the organism has turned to such an extent that the anterior end is practically as much exposed when it turns in one direction as it is when it turns in the other. The great preponderance of lateral movements from the source of light and direct orientation in diffuse light therefore do not indicate that fly larvae have the power of differential response to localized stimulation.

But why does the organism turn toward the light if the lateral illumination is very intense? Whenever the larva is stimulated, it turns the anterior end in a direction opposite to that in which this end is when it receives the stimulus. The tip of the anterior end is relatively very sensitive; in diffuse light the larvae are stimulated only when this end is extended and fully exposed, but in rery intense light, owing to the translucency of the surrounding tissue, it is stimulated no matter in what position the anterior end is; consequently if this end is turned from the source of light when the organism is exposed it is at once turned sharply in the opposite direction, i.e., toward the light.

j. Discussion. - It has already been demonstrated that neither the direction of the rays through the organism, in accord with Sachs' theory, nor the angle between the rays and the sensitive surface, in accord with Loeb's explanation, is of importance in explaining the orienting reactions of the fly larvae. Nor is the direction of the rays in the field of importance except in so far as it may produce difference of intensity on the body. How then are the orienting stimulations produced? Are they due to light 


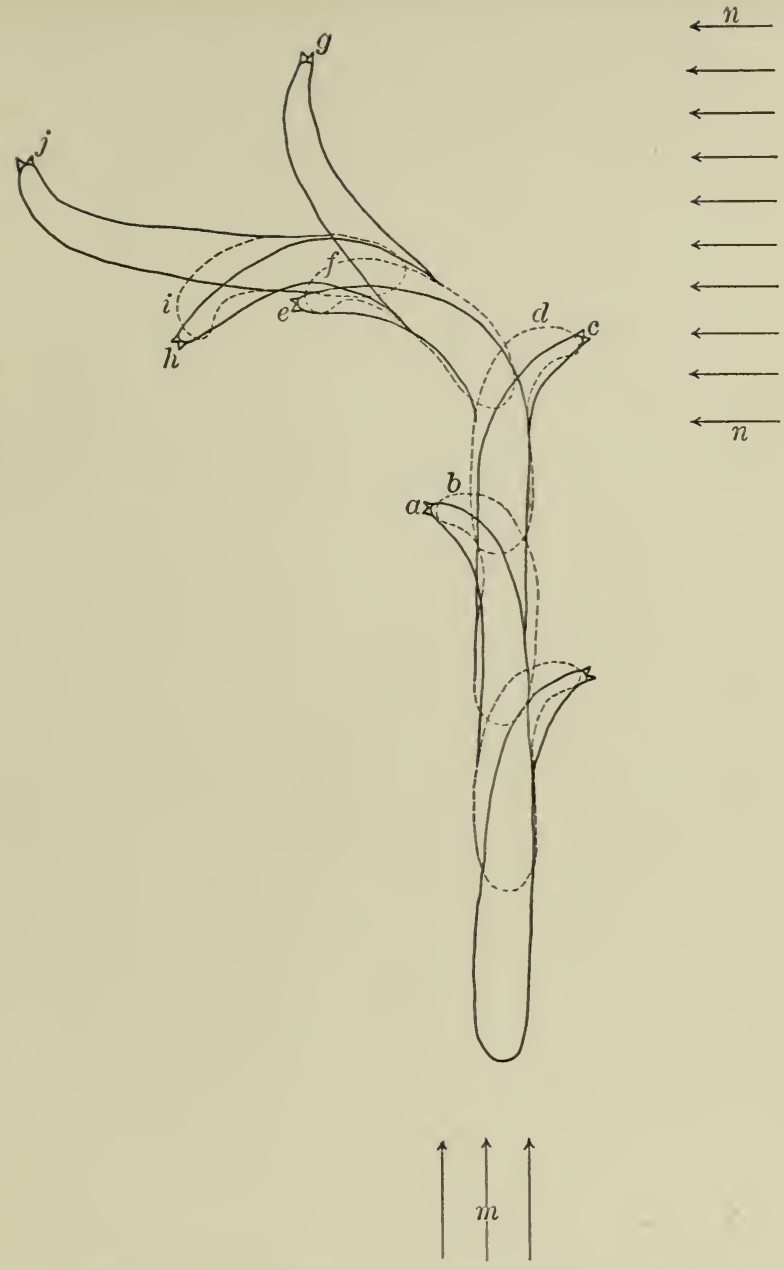

FIG. 31. The process of locomotion and orientation in blow-fly larvae. $a-j$, different positions taken during the process; $m, n$, direction of light rays. The anterior end of the larvae is quite regularly turned from right to left during the process of locomotion. If $n$ is exposed and $m$ shaded simultaneously when a larva is at $d$, it turns sharply to $e$, then loops to $f$, turns and expands to $g$, where the sensitive anterior end becomes fully exposed and consequently stimulated. This causes the larva to turn sharply at once to $h$, where it becomes attached and loops to $i$, expands and turns to $j$ and is again stimulated, after which it repeats its former response, etc., until it is oriented and the oral end is no longer subjected to marked changes of intensity, as it swings back and forth in the process of locomotion. If $n$ is exposed when the larva is in position $b$, no reaction takes place until it expands and turns to $c$, then it responds as described above. If the light from $n$ is much more intense than that from $m$, or if the larva is in a very sensitive state it responds at once when $n$ is exposed no matter in which position it is. If it is at $a$ or $b$ it throws the anterior end sharply toward $n$, then in the opposite direction, after which it orients as described above. It may however wave the anterior end back and forth several times before it orients. 
acting constantly as a directive stimulus similar to stimulation by a constant electric current, or to absolute difference of intensity on symmetrically located points in the sensitive surface, or to changes of intensity?

According to the idea of Loeb that light acts constantly as a directive stimulation, the organism is continuously stimulated by light on both sides. When one side is more highly illuminated than the other, that side becomes stimulated more than the other and causes a more rapid movement of the locomotor organs connected with the sense organs of that side. This of course causes the organism to turn until both sides are equally stimulated. We have demonstrated that in a light intensity of $3888 \mathrm{ca}$. m. the rate of locomotion is only $0.02+\mathrm{mm}$. per second greater than in an intensity of $7 \mathrm{ca} . \mathrm{m}$. (Table II). If then the rate of motion of the two sides of the organism under discussion is due to the absolute intensity on the two sides in accord with Loeb's theory, and if one side were exposed to an intensity of $3888 \mathrm{ca}$. m., while the other is exposed to an intensity of $7 \mathrm{ca}$. $\mathrm{m}$., the former would move only $0.024 \mathrm{~mm}$. per second faster than the latter. It would therefore require several seconds for a fly larva to become oriented even with a difference of intensity on opposite sides amounting to nearly $4000 \mathrm{ca}$. $\mathrm{m}$.; whereas it actually requires only a fraction of a second for the larvae to orient under conditions in which the greatest difference of intensity could not possibly be more than $5^{-10} \mathrm{ca} . \mathrm{m}$. The theory that orientation is due to light acting constantly as a directive stimulation is therefore inadequate to account for the orientation of fly larvae. Moreover the fact that the larvae, when exposed to moderate light intensity, respond only when the anterior end comes to be fully exposed to the light in the process of locomotion, shows clearly that the orienting stimulation is not acting constantly.

The symmetry of the body with reference to the location of the sensitive surface seems to be of no special importance as far as orientation is concerned in this organism. I was 
unable to obtain any evidence of the power of differential response to localized stimulation. The orienting reactions could readily be explained by assuming the area sensitive to light to be restricted to a small mass of substance located in the middle of the very tip of the anterior end.

The idea that the stimulations leading to orientation are due to changes of intensity (in fly larvae an increase only) on the sensitive surface seems to fit the facts as far as known. Stimulations thus produced cause an increase in the lateral head movements somewhat similar to the avoiding reactions and shock movements in the lower forms. Owing to the difference in exposure of the anterior end, the movements from the source of light are increased more than those toward the light. This continues until the organism is directed away from the source of light and the change of intensity on the anterior end is no longer sufficient to cause a response.

The process of orientation in the fly larva is strikingly similar in principle to that in Euglena and Stentor. Stentor, e.g., is most sensitive when the oral side is exposed; the fly larvae when the anterior end is exposed. When Stentor is not oriented the highly sensitive oral side is alternately fully illuminated and shaded by means of rotation on the long axis. In the fly larvae the alternate illuminating and shading of the sensitive anterior end is brought about by the swinging of the head from side to side. If the intensity is not high, Stentor never turns toward the light; it responds only after the oral side is turned toward the light. This response consists in a rapid swerving from the source of light and eventually results in orientation. Likewise the fly larva under similar conditions responds only after the anterior end is exposed, and the response consists in sharp turning from the source of light, which on repetition results in orientation. Stentor makes no mistakes in the process of orientation under these conditions. It never turns toward the source of light, but still there are constant trial movements during the process of orientation. The same 
is true with regard to the fly larvae. In Stentor every rotation on the spiral course may be considered a trial movement. If the organism is not oriented it swerves a little farther from the source of light in each rotation after the oral side is turned toward the light, until this side is equally exposed throughout the entire rotation. Just so every lateral movement of the fly larvae may be considered a trial movement. If the organism is not oriented the anterior end becomes much more fully exposed when it is turned toward the light than when it faces in the opposite direction. This produces a stimulation and causes it to be turned farther than usual in the opposite direction, but it is swung back again, receives another stimulation, and is turned still farther from the light. Thus the organism may be considered to try different positions by swinging the anterior end back and forth. This trial process does not cease after the organism is oriented; the anterior end continues to swing from side to side. If it is subjected to but little difference of light intensity as it swings from side to side, there is no response and the organism continues as it is directed, but if it is subjected to considerable difference of intensity it responds and turns as described above.

The fly larva presents an excellent example of an organism guided fairly directly on its course by successive trial movements, and shows again that the mere fact of accurate orientation is not a satisfactory criterion of direct orientation. Of course it is not necessary to assume that this organism consciously tries different positions in the process of orientation.

In how far do the reactions of the fly larvae agree with the explanation Holmes presented with reference to them ? Is " orientation in these forms . . . essentially a selection of favorable chance variations of action and following them up"? The answer to this question depends entirely upon what is meant by chance variations. It is therefore evident that a statement with reference to it would add little or nothing to our analysis. 


\section{Summary}

(I) Fly larvae are negative in their light reactions in all intensities to which they respond. They become acclimatized very readily so that after they have been exposed in a given intensity for about half an hour they fail to respond unless the intensity is increased.

(2) The tip of the anterior end is the only sensitive region on the larvae. On this tip there are two cone-shaped structures which probably are light recipient organs.

(3) In locomotion the larvae turn the anterior end slightly from side to side with considerable regularity; but if suddenly exposed to high intensity they throw the anterior end from side to side violently.

(4) Absolute difference in light intensity has but little effect on the rate of movement. In $7 \mathrm{ca}$. $\mathrm{m}$. it was found to be $0.32 \mathrm{I} \mathrm{cm}$. per second; in $3888 \mathrm{ca} . \mathrm{m}$., $0.345 \mathrm{~cm}$. per second.

(5) Unilateral illumination of the posterior third or threefourths of the body has practically no effect on the rate of locomotion.

(6) The process of orientation in the fly larva is similar in principle to that in Euglena and Stentor. It is brought about by reactions which are similar to the avoiding reactions or shock movements of the lower organisms. These reactions are due to changes of light intensity on the sensitive anterior end; and the changes of intensity are due largely to the lateral movements of this end.

(7) Orientation is the result of trial movements, but it is doubtful whether it could be considered as the result of selection of random movements as defined by Holmes (I905).

(8) In light from two sources they may take a path extending from any point between them. The location of this point depends upon the relation in intensity of light from the two sources.

(9) There is no evidence indicating differential response to localized stimulation. If the fly larva has the power of 
such response at all, it is but little developed and is of very little importance in the general reactions to light.

(Io) Neither the direction of the rays through the organism, nor the angle with the surface, nor the symmetry of the sensitive surface, nor absolute difference of intensity on the body, is of importance in orientation excepting in so far as they may influence change of intensity on the anterior end.

(I I) There is no evidence indicating that the orienting reactions in fly larvae are tropic in accord with Loeb's definition of this term.

\section{Earthworms}

The light reactions of various earthworms have been studied by a number of investigators, several of whom directed special attention to the process of orientation. Parker and Arkin (I90I), Miss Smith (I902), and Adams (1903) made observations on the direction of movement of the anterior end when illuminated from one side, and found that it turned from the light more of ten than toward it, indicating, since these organisms are ordinarily negative, that orientation is direct. Holmes, however (I905), is of the opinion that the animals actually start to turn toward the light just as often as from it, but that the movements toward the light are inhibited owing to the greater exposure as the end expands. This causes marked movements only in the direction from the source of light. He believes that Parker and Arkin and others may have failed to take into consideration the slight preliminary movement which occurs before the actual extension takes place, and that this may account for the preponderance of negative turning recorded by these investigators. Holmes, taking account of all the minute preliminary movements, says (p. Ior): "In the two specimens employed the first detectable turn was away from the light 27 times and towards the light 23 times. After a few extensions the worm in nearly all cases soon turned and crawled away from the light. The first detectable 
movement of the earthworm seems, therefore, to be nearly as likely to be towards the light as away from it. The slight preponderance of negative turns may be due to the fact that some of the smaller trial movements were overlooked, to a slight direct orienting effect of the rays, or merely to chance."

Harper (1905), working on Perichaeta bermudensis and a species of Lumbricus in various light intensities, concluded that in light of comparatively low intensity orientation is indirect and that there are numerous random movements, but in direct sunlight, especially if the worms have previously been kept in darkness, orientation is direct and random movements are almost entirely eliminated.

I undertook the study of the reactions of Allolobophora foetida with the express purpose of ascertaining the effect of constant light intensity on the rate of movement with different portions of the animal highly illuminated, thinking that it might be possible thus to demonstrate the difference between the action of light as an orienting stimulus, and a stimulus affecting the general activity of the organism. The rate of movement in this form however is so irregular that I found it impossible to obtain results worthy of consideration. I therefore turned my attention to direct observation of the process of orientation.

In locomotion the earthworm usually swings its anterior end from side to side, but not nearly so regularly as do blowfly larvae. If after a specimen is oriented in a beam of light, the ray direction is suddenly changed so as to illuminate the side, one of four different kinds of movements may result: (I) a contraction of the anterior end; (2) an extension of the anterior end; (3) sudden raising of the anterior end frequently accompanied by swinging from side to side, or (4) direct turning either toward or from the source of light in the plane of the substratum. If the animal is active, the lateral movements of the anterior end are more pronounced and regular during its locomotion than if it is sluggish. When exposed to unilateral illumination in such 
a condition the anterior end is simply turned sharply in the direction opposite to that in which it is when it receives the stimulus, just as in the case of blowfly larvae. Thus it is turned toward the source of light about as often as from it, regardless of the light intensity. I found this to be true in direct sunlight, contrary to Harper's conclusion, as well as in light of lower intensities.

If the animal however is rather sluggish so that there is little lateral movement of the anterior end it turns from the source of light with very few exceptions. The direction in which the anterior end started to move after exposure to lateral illumination in six such specimens is recorded in Table VII. These specimens were allowed to orient in light of I $5 \mathrm{ca}$. m. intensity, after which they were suddenly exposed to a horizontal beam of light, ordinarily of higher intensity, from one side. There was but little lateral movement of the anterior end after the specimens were oriented in the lower intensity, and they moved so slowly that the direction in which the anterior end started to turn after one side was illuminated could be clearly seen.

TABLE VII

\begin{tabular}{|c|c|c|c|c|}
\hline \multirow{2}{*}{$\begin{array}{l}\text { Intensity of } \\
\text { Lateral Illumi- } \\
\text { nation }\end{array}$} & \multicolumn{2}{|c|}{$\begin{array}{c}\text { Number of times anterior end } \\
\text { turned }\end{array}$} & \multirow{2}{*}{$\begin{array}{l}\text { Condition of } \\
\text { specimens used }\end{array}$} & \multirow[b]{2}{*}{ Time } \\
\hline & $\begin{array}{l}\text { From source } \\
\text { of light }\end{array}$ & $\begin{array}{c}\text { Toward source } \\
\text { of light }\end{array}$ & & \\
\hline $200 \mathrm{ca} . \mathrm{m}$. & $2 \mathrm{I}$ & 4 & $\begin{array}{c}\text { Fresh specimen } \\
\text { taken from } \\
\text { darkness }\end{array}$ & ? \\
\hline $200 \mathrm{ca} . \mathrm{m}$. & 22 & 3 & Same specimen & ? \\
\hline $200 \mathrm{ca}$. & 25 & 0 & Same " & I2. I 5 \\
\hline I2 ca. m. & 24 & I & " & 12.55 \\
\hline $200 \mathrm{ca} . \mathrm{m}$. & 25 & 0 & “ & $3 \cdot 5^{\circ}$ \\
\hline
\end{tabular}

In a few other sluggish specimens the exposure to unilateral illumination was not made until after they had come to rest in the light of $\mathrm{I}_{5} \mathrm{ca} . \mathrm{m}$. Under such conditions the animals did not react at all until a few moments after 
the exposure, then they very slowly extended and turned the anterior end from the source of light every time. The movements were so slow that they could be readily followed in detail under a hand lens. There was no evidence of even the slightest preliminary turning toward the source of light. It must therefore be concluded that these animals have the power of differential response to localized stimulation by light. This conclusion is in harmony with the results of Parker and Arkin, Miss Smith, Adams, and Harper.

Parker and Arkin also found that if only the middle or the posterior third of the body is exposed there are more negative head movements than positive. I was unable to confirm these results. Specimens were repeatedly allowed to orient in a horizontal beam of light of $\mathrm{I} 5 \mathrm{ca}$. $\mathrm{m}$. intensity on smooth moist black paper supported by a glass plate as described above; and after they had started to crawl away from this source of light a portion of the body was exposed in an intensity of $200 \mathrm{ca}$. m. to lateral illumination from a Nernst glower. The glower was mounted vertically so that it cast a well-defined sharp shadow. By means of an opaque screen containing a rectangular opening a beam of light could be thrown upon any portion of the body and held there by moving the screen in harmony with the movement of the animal. The orientation of specimens was thus frequently studied and the direction of movement carefully noted while they crawled across the field, a distance of $20 \mathrm{~cm}$., alternately with and without some portion of the body exposed to unilateral illumination. The exposure of any portion back of the sixth segment had no appreciable effect on the direction of motion. If however the screen was at any time brought forward so that the relatively intense lateral rays fell on the anterior end there was always an immediate response if the specimens were active. If the anterior end chanced to be directed from the source of light in its swinging movements when the exposure was made, it was at once thrown sharply toward the light; if it chanced 
to be directed toward the source of light, it was thrown equally strongly in the opposite direction. These results, together with some statistical tabulations of direction of head movements with different portions of the body back of the sixth segment exposed to unilateral illumination, indicate that, while these portions are no doubt sensitive to light, only the anterior end is immediately functional in regulating orientation. Jennings (I906a, p. 442) arrived at practically the same conclusion with reference to other stimuli.

Parker and Arkin in their experiments used a Welsbach gas burner as a source of light. Owing to the width of the luminous part of the burner it is evident that a shadow of an object in light from such a source will not have sharp edges; and likewise a beam produced by means of a screen containing an opening will not have well-defined edges. In such a beam there is a region of uniform highest intensity in the middle and a region of graded intensity on either side. By calculations based on the data furnished by Parker and Arkin it was found that in the beam of light at the place where they exposed the earthworms the region of uniform highest intensity was ro $\mathrm{mm}$. wide and the region of graded intensity on either side was $16 \mathrm{~mm}$. wide. Outside of this on either side there was another region I5 mm. wide faintly illuminated by light reflected from the water screen. It is evident that when the middle or posterior end of a specimen of Allolobophora foetida, usually only about $4 \mathrm{~cm}$. long, is exposed in the region of greatest intensity in such a field, the anterior end will be exposed to the weaker light in the adjoining region. It may be then that the preponderance of negative head movements found by Parker and Arkin with the posterior portion of Allolobophora exposed to relatively strong lateral illumination, was due to the effect of the weak illumination on the anterior end. Since the light in the beam becomes gradually weaker as one proceeds outward, it is clear that the anterior end of the worm will be in higher light intensity when the 
middle is in the region of strongest illumination, than when the posterior end is there. One would therefore expect a greater proportion of negative head movements under the former conditions than under the latter, which is just what Parker and Arkin found.

The tabulated conclusions of these authors are formulated with the supposition that all positive head movements in Allolobophora exposed to lateral illumination are "due to other stimuli than light" (1. c., p. I53). My observations do not confirm this conclusion. As already stated, it was found that if the anterior end is bent toward either side when the exposure is made, it simply turns toward the opposite side regardless of the direction of the rays. Orientation in these forms is by no means entirely due to differential response to localized stimulation. Selection of random movements or trial movements, as Holmes, Harper and Jennings pointed out, undoubtedly plays a very large part in the process of orientation in the earthworm under ordinary conditions.

The swinging movements of the anterior end are in the nature of trial movements. They may be induced by external conditions, but their character and direction are determined by the structure of the organism and various physiological processes. They make it possible for the organism to orient much more accurately than it otherwise could. When the anterior end is directed straight ahead and the organisms are oriented, this end is more or less shaded and not in a position to be readily stimulated by changes in the direction of the greatest illumination. If it were immovably fixed to the rest of the body in this position the entire organism might turn toward either side considerably without receiving an orienting stimulation. In place of turning the entire body it raises the anterior end so as to magnify the difference of intensity on opposite surfaces, extends it so that it becomes more sensitive, and swings it from side to side so that the different surfaces become alternately shaded and illuminated, thus producing changes of inten- 
sity. If the change of intensity is greater when the oral end is turned toward the right than when it is turned toward the left, it is stimulated and bends farther toward the left. The direction of bending is generally independent of the direction of the rays, but the extent of bending usually is not.

Holmes and Harper both pointed out that swinging movements toward the source of light are checked because the animal becomes more and more sensitive as the anterior end extends toward it. This end is however not only checked under such conditions, it is also stimulated and swings farther in the opposite direction. This is an important factor in the process of orientation, that can hardly be said to be included in the explanation of orientation by selection of random movements, as described by Holmes.

It may now be asked: Is the orienting stimulus in this form due to a change of light intensity or to the effect of light acting constantly as a directive stimulus?

There is no doubt that a change of intensity causes definite reactions in the earthworm, and that reactions thus produced may result in orientation either by the selection of random or trial movements, or by inducing more definitely prescribed movements, as in the blowfly larvae. But this does not indicate that constant light cannot also produce orienting stimulations. There is however no evidence showing that it does. Even in case a worm lies perfectly quiet and very gradually starts to turn from the light when laterally illuminated, as can be readily demonstrated, it is impossible to say whether the stimulus causing the reaction is due to the effect of constant intensity or to change of intensity. And when the worm is in motion, ever extending and contracting the anterior end and changing its position so that the effective intensity is continually changing, it is of course impossible to predict what would take place if the sensitive elements could be exposed to light having a constant intensity. If light is thrown upon a specimen which is perfectly quiet it begins to move, but in this case 
also it is impossible to say whether the activity is caused by a change of intensity or by constant intensity.

The idea of Verworn, Holt and Lee, Loeb, and Torrey that when an organism is oriented both sides are equally stimulated and consequently move at equal rates, and that when it is not oriented the two sides are unequally stimulated and therefore move at unequal rates, thus causing orientation, has no experimental support in the reactions of the earthworms.

\section{Summary}

(I) All the earthworms that react to light are ordinarily negative. There is, however, some evidence that some at least are positive in very low light intensity.

(2) They orient fairly accurately under some conditions and move away from the source of illumination.

(3) The entire surface of the earthworms is probably sensitive to light, but the anterior end is much more sensitive to light than any other part of the body. Our evidence indicates that in Allolobophora orientation is entirely controlled by the sensory elements in the first five or six segments. The anterior end is most sensitive when extended, as shown by Harper.

(4) These animals have the power of differential response to localized stimulation. Under certain conditions, if one side is illuminated, they always turn toward the shaded side without preliminary movements and therefore orient directly.

(5) They frequently swing the anterior end from side to side continuously during the process of locomotion. If light is thrown on one side under such conditions they turn the oral end sharply in the direction opposite that in which it chances to be when it receives the stimulation. They may therefore turn toward the source of light first and become oriented only after several more preliminary movements. Or they may be in such a state that they are only stimulated when the anterior end is extended toward the 
source of light, not when it is turned in the opposite direction. Under such conditions they will of course never turn sharply toward the source of light. The swinging of the anterior end may however be considered as a trial movement and orientation consequently indirect.

(6) The swinging movements of the anterior end increase the possible accuracy of orientation in case of direct as well as indirect orientation. By means of them the animal takes its bearing, if this anthropomorphic term may be permitted.

(7) The stimulations which lead to orientation are ordinarily unquestionably due to change of intensity on the sensitive surface.

(8) Light may possibly have some effect on orientation by acting constantly as a directive stimulus, but there is no evidence indicating that it has. There is no evidence showing that these animals are tropic in accord with Loeb's definition.

\section{Planaria}

It is well known that nearly all the planarians respond to stimulation by light, but it is frequently assumed that they orient only very indefinitely and that the effect of light consists largely in making them more or less active. Loeb (I906, p. I36) says, "If fresh-water Planarians are put into such a circular glass dish, they show very little or no tendency to move in the direction of the rays of light, creeping along in an irregular manner and gathering not at the negative or positive side of the jar, but on both sides . . where, on account of the refraction of light, the intensity is a relative minimum."

More recent investigations have however shown that many of these forms orient fairly accurately, and it is primarily these investigations that concern us at present.

In the planarians the power of differential response to localized stimulation seems to be more highly developed than in the earthworms, and orientation in light seems to be brought about largely by such responses. There are how- 
ever also numerous head movements which bear no definite relation to the location of the stimulus.

Cole, studying the reactions of Bipalium kewense to sources of light of different size, refers to the process of orientation as follows (1907, p. 365): "Like most planarians, it creeps with an even, gliding motion, the head being slightly raised and waved to right and left apparently in searching movements, as the worm crawls forward. . . . Bipalium kewense is exceedingly sensitive to light, of even a very low intensity, falling upon it from the side, and responds immediately by turning away from the light."

Walter (I907) made an extensive study of the light reactions of the following species: Planaria maculata; Planaria gonocephala; Phagocata gracilis; Dendrocoelum lacteum; and Bdelloura candida. He found that all of these species orient more or less accurately under certain conditions and concluded that orientation "is primarily due to asymmetrical response resulting from asymmetrical stimulation." $\mathrm{He}$ also found that these animals frequently respond by raising the anterior end and throwing it from side to side, and noticed that such movements are caused either by sudden increase or by sudden decrease of intensity. These movements, however, he thinks are functional in orientation only " by assisting an organism to secure asymmetrical stimulation". (1. c., p. 153).

I made some observations on the orienting reactions of Leptoplana tremellaris and several other polyclads, all of which were positive in their light reactions, and found that all of these forms orient directly. There is no evidence of preliminary trial movements in the process. The lateral head movements are always slight and frequently apparently absent. When exposed to light from two sources all of these forms crawl toward a point between the lights. The location of the point toward which they move, however, depends upon the relative intensity of light from the two sources. It is always nearer the source from which the more intense light comes. This indicates that orientation 
is regulated by the relative intensity of light on opposite sides.

It may now be asked: What is the cause of the orienting stimulus? Is it a change of intensity or constant intensity? There is direct evidence showing that the organism responds both to changes of intensity and to constant intensity. If a planarian passes suddenly from a region of a given intensity into a region of a higher or lower intensity, it responds by suddenly turning the head from side to side; and when subjected to constant light of different intensities it may become more or less active. In working with fresh-water planarians I frequently observed that if they were exposed to constant illumination after they had been at rest for some time, they did not respond for several minutes; when they did respond they first moved very slowly and very gradually became more active. Walter ( 1907, p. 63) records similar observations. It may of course be argued that even in this case it is the change of intensity due to turning on the light that arouses the animals. It is however hardly probable that it is, since the response is frequently not apparent until after the animals have been exposed for several minutes. It appears that a difference in constant light intensity not only causes the planaria to become active or to come to rest, but that it also affects the rate of movement after they are active.

In experiments on Planaria gonocephala in constant illumination of different intensities from directly above, Walter $(1907$, p. 57) found an average rateof locomotion of $0.57 \mathrm{~mm}$. per second in darkness, $0.63 \mathrm{~mm}$. per second in $43 \mathrm{I} \mathrm{ca} . \mathrm{m}$. The highest rate, $0.75 \mathrm{~mm}$. per second, was in $39 \mathrm{ca} . \mathrm{m}$. It will thus be seen that the greatest increase due to a difference in constant intensity is $0.18 \mathrm{~mm}$. per second.

It is therefore clear that a change of intensity causes a comparatively rapid response, and difference in absolute or constant intensity a comparatively slow response. This leads to a conclusion arrived at previously several times in these chapters, that while an organism may be stimulated both 
by a sudden change of light intensity and by constant intensity, the processes involved are different. A sudden change of intensity acts much like mechanical contact or a change in an electric current. Constant intensity on the other hand acts like constant temperature.

Our original questions still remain: Is orientation due to light acting through change of intensity? Or is it due to constant intensity, both sides of the organism being stimulated constantly, but unequally when one side is more highly illuminated than the other, thus causing difference in rate of movement of the two sides? The maximum difference in rate due to absolute difference of intensity, as we have seen, is only $0.18 \mathrm{~mm}$. per second. It is evident then that the greatest difference in rate of locomotion on the two sides due to absolute difference of intensity could not be more than $0.18 \mathrm{~mm}$. per second; and if orientation is due to this it is clear that the orienting process would be exceedingly slow, very much more so than it actually is.

Our evidence then indicates that orientation in these forms is due not to light acting constantly as a directive stimulus similar to the action of a constant electric current in accord with Loeb's theory, but to reactions caused by intermittent action of light through changes of intensity on some part of the sensitive surface. These changes may of course be due to the movements of the organism or to changes in the direction of illumination.

It is evident that if the anterior end turns from side to side, or if the ray direction is changed, the intensity on one side becomes higher while that on the other becomes lower. Is the orientation due to the former or to the latter? In Euglena it was demonstrated that if the specimens are positive the orienting stimulus is due to a decrease of effective intensity; if negative, to an increase of effective intensity. In Planaria there appear to have been no observations bearing directly on this point. I frequently observed, however, that when positive polyclads crawling toward a source of light come into contact with a sharp shadow at either edge 
of the beam in which they are exposed, so as to shade one side, they turn directly from the shaded side, indicating that the orienting stimulus in positive Planaria, as in Euglena, is due to a decrease in effective intensity on some part of the sensitive surface and that orientation is brought about directly by differential response to localized stimuli.

\section{Summary}

(I) Planaria may collect in regions of optimum light intensity either by wandering into such regions and coming to rest or by orienting and crawling directly toward such reg ons and coming to rest. The latter method is of course more effective than the former.

(2) In some forms orientation is very indefinite; in others it is fairly accurate.

(3) In locomotion there are frequent lateral head movements. These may be accelerated either by sudden increase or by sudden decrease in light intensity. They appear to be independent of the location of the stimulus.

(4) Orientation at least in some forms is due largely to differential response to localized stimulation. The lateral head movements no doubt function by increasing localized stimulations, and thus make it possible for the organism to direct its course more efficiently than it otherwise could.

(5) Light acts on Planaria by virtue of both changes of intensity and constant intensity. Responses to changes of intensity are comparatively rapid; responses to constant intensity comparatively slow. The effect of constant light is similar to the effect of constant temperature.

(6) The orienting stimulus appears to be due to changes of effective intensity on some part of the sensitive surface. In positive specimens it is, as in Euglena, probably due to a decrease, in negative specimens to an increase of intensity on one side.

(7) There is no evidence indicating that light owing to constant intensity is functional in the process of orientation. 


\section{Echinoderms}

The Echinoderms are peculiar in that they can move with any side ahead. In reversing the direction of movement they ordinarily do not turn around but merely move with the opposite side ahead. Some appear to be permanently positive and others permanently negative, while still others may be either positive or negative, depending upon circumstances.

Washburn (I908, p. I3I) says that the starfish and sea urchins depend for their response to light upon pigment or eye-spots on the arms. This conclusion is based largely upon the observations of Romanes, who obtained no reactions after the tips of the arms bearing these structures were amputated. In some species however the response appears to be independent of the eye-spots, for Cowles found that in Echinaster crassispina the reactions to light were normal three hours after one centimeter had been cut from the tip of each arm.

Jennings (1907), working on Asterias forreri, a negative starfish, found that it moves toward the shaded side no matter whether the side is shaded by the substance in the starfish itself or by some other object, showing that the direction of motion is regulated by difference of intensity on the surface regardless of the direction of the rays. If illuminated from one side it therefore moves from the source of light because the side opposite the light is shaded. If the position of the source of light is changed it alters its direction of motion at once, ordinarily by simply proceeding with the side ahead which has become shaded. Bohn (I908), however, working on several different species, found that there is some tendency to turn after the direction of the light is changed so that a given ray will be ahead.

The lack of orientation in moving from a source of light is much more striking in the holothurians, which are superficially at least much more definitely bilaterally symmetrical. Pearse (1908, p. 278) describes the process in the holothu- 
rian Thyone briareus as follows: "In a series of twenty-four reactions the locomotion in every case carried the animal away from the light to the end of the dish, but there was no definite orientation of the body in relation to the light. In ten of these negative responses the anterior end was ahead as the individual moved; in nine instances the posterior end preceded the anterior; and in five the locomotion was straight toward the right or left. Not one of the eight individuals [used in this experiment] moved in every case with the anterior or posterior end in front."

Very little is known about the actual mechanism involved in these reactions. It seems clear however that it is the shading of part of the body that produces the stimuli which regulate the direction of motion, for if a shadow is thrown on one side of a specimen of Asterias forreri, e.g., in such a way as not to produce any change of intensity on the exposed side, it moves toward the shaded side; and the continued movement toward the shaded side seems to be due to a constant difference in absolute light intensity on opposite sides. If this is true the direction of movement is regulated by light acting constantly as a directive stimulus. It must however be borne in mind that there is no orientation in these organisms. They move with any side ahead much like an amoeba. In Amoeba, it will be remembered that the formation of pseudopods on the illuminated side is probably checked by the action of the light, and that this results in movement toward the shaded side of the organism. It may be that in the echinoderms light has a similar effect on the extension of the tube feet. If it has, direction of movement is of course regulated by changes of intensity on these structures. This idea is supported by the fact discovered by von Uexküll (I897) that a single spine or pedicellaria connected with a piece of shell responds to stimuli practically as it does in the entire animal, showing that the parts of this organism are capable of independent action, and the same is probably true of other organs in this form and also in the other echinoderms. 
After I had completed this part of the work, Cowles reported to me personally that he found that positive starfish, when placed on the dorsal surface, always extend the tube feet toward the shaded side of the body and turn from the source of light, whereas in the normal position they extend the tube feet toward the light. This seems to show clearly that the direction of locomotion is not regulated by the direct effect of light on these structures, as suggested above. 


\section{CHAPTER $\mathrm{X}$}

\section{CONCERNING THE QUESTION OF ORIENTATION IN MOL- LUSKS, ARTHROPODS AND VERTEBRATES WITH SPECIAL REFERENCE TO CIRCUS MOVEMENTS AND THEIR BEARING ON THIS QUESTION}

\section{General Account of Orientation}

WE have found in our work on the lower metazoa that as the organisms become more complex and the structures more highly differentiated, the power of differential response to localized stimulation by light becomes more highly developed and plays an increasingly more important part in orientation; and trial and random movements become of relatively less importance. In the mollusks, arthropods and vertebrates, there is little evidence of preliminary trial movements in the process of orientation in light. If the ray direction is changed these forms turn directly until their direction of motion bears the same relation to the source of light it previously had. I found this method of orientation to hold in the following forms: Limnea columella, Cypris sp. (?), Daphnia sp. (?), Scapholeberis armata, zoeae, several species belonging to the Anomura and Brachyura, Caprella sp. (?) and Bufo americanus. The work of Cole, Bohn, Parker, Holmes, Yerkes, Harper, Hadley, Torelle Rádl and others shows the same to be true for numerous other species belonging to these groups.

The fact that these forms orient in light without preliminary movements does not however indicate the absence of trial movements when subjected to other stimuli and is no argument against the "trial and error " hypothesis in general as Bohn (I908, pp. 77, 82) seems to imply; nor does it show how light acts as a stimulus. It probably means that with reference to stimulation by light the power of differen- 
tial response to localized stimulation has become so highly developed that trial movements are largely eliminated. Jennings (I906a, p. 453) makes the following characteristically clear statement regarding this question: "It is, of course, very true, as Harper ('05) remarks, that definitely localized reaction methods are developed as we rise higher in the scale, yet it appears to be equally true that if we mean by ' trial and error' the performance of varied movements, subjecting the organism to varied conditions, certain of which are selected, then this also becomes more highly developed and more used by organisms as we ascend the scale. We must not forget that this expression 'trial and error' was originally based on the behavior of such highly developed organisms as the cat, dog and monkey; and doubtless there is no organism which uses this method to any such extent as does man. Whenever the external conditions do not furnish a precise determining factor for the movements yet some sort of reaction is required, any organism is forced to have recourse to this style of behavior, performing varied movements till a condition is reached that relieves theorganism of the necessity of continuing these movements. In its highest form we call this experimentation."

\section{Circus Movements}

In Euglena, Stentor and some of the other lower forms it was demonstrated that the orienting stimulus is due to a change of light intensity. Is there any evidence as to how the local stimulus which leads to orientation in the higher forms is produced?

It has been found by a number of investigators working on different forms that if one of two symmetrically located sense organs is in any way prevented from functioning, the organism no longer orients but continually turns toward one side when stimulated. Loeb and others found this to be the case in several different animals with one-half of the brain destroyed. Holmes (I90I, p. 220) found that the 
positive terrestrial amphipods and several different flies with one eye blackened turn continuously toward the functional eye. Parker (I903, p. 463) working on Vanessa antiopa, and Rádl (I903, p. 6I) on the flies Dexia carinifrons and Musca domestica, obtained similar results. The fact that these organisms, all of which are positive, thus turn continuously toward the functional eye seems to show that the orienting stimulus is not necessarily and exclusively due to a decrease of intensity in these forms, as it is in positive Euglena and many other organisms. It may be due to the continued action of light on the eye. A change of light intensity does however undoubtedly produce a stimulus which may result in orientation.

The performance of circus movements has frequently been brought forward in support of Loeb's theory of orientation stated in the following quotation (I906, p. I39): "It seems that in animals the region at the oral pole is, as a rule, more sensitive than the rest of the body. Consequently the tension of the muscles determining the position of the head or oral pole is more intensely affected by differences in the intensity of light than that of the muscles of the rest of the body. The head is consequently bent until its symmetrical photosensitive points are again struck at the same angle by the rays of light. The tension of the symmetrical muscles of the head then again becomes equal, and the head must remain in this position unless other forces disturb its orientation. The rest of the body follows the orientation of the head."

The precision with which some organisms with but one functional eye perform circus movements does indeed appear to add support to this explanation of orientation. Recent investigations have however thrown considerable doubt on the earlier interpretation of these movements. It has been found that they are not so regular and constant as was formerly supposed. Carpenter (I908, p. 486), experimenting on Drosophila with one eye blackened, observed that they " crept in a fairly direct path toward the light, 
although a tendency to deviate toward the side of the normal eye regularly occurred." Rádl (1903, p. 62) says, "Die Calliphora vomitoria bewegt sich fast ebenso gerade mit einem geschwärzten Auge, wie wenn sie auf beiden sieht, und es ist mir nicht leicht, diese Erscheinung zu erklären." Holmes (1905) discovered that Ranatra with one eye blackened at first deviates strongly toward the functional eye in going toward a source of light, but that this deviation decreases and that the path becomes much more nearly direct after repeated trials, indicating that the animal learns to adjust itself to the new conditions and that its reaction mechanism is not so simple as Loeb's theory demands. This is still more clearly demonstrated by the interesting observations of Holmes on the fiddler crab, Uca pugnax. I cannot do better than to quote his conclusions based on these observations (1908, p. 496): "The point of principal interest in the phototaxis of the fiddler crabs is the relation of their lateral orientation to the theories of tropisms. Can we regard orientation as a direct response in which the animal is involuntarily forced into line, or is it rather to be considered as coming under the pleasure-pain type of behavior, and as therefore related to the voluntary seeking of a certain end which is exhibited in the behavior of higher forms? In order to explain the orientation of a highly organized form like an insect or crustacean in which, in most cases, response to light takes place through the eyes, we may assume that light falling more strongly on one eye sets up impulses which are transmitted more or less directly to the leg musculature. We may assume that the extensors of the opposite side are stimulated, or the flexors on the same side, or both, and that in consequence of this distribution of impulses the animal moves until its body is in line with the rays. In such a case the movements involved in orientation are the same as those employed in ordinary locomotion, only the activity of the legs on one or the other side is accentuated according to the position of the body in relation to the direction of the rays. 
"In the fiddler crab, however, the case is different, and we cannot explain the phenomenon in this way. The legs of the fiddler move in a plane approximately at right angles to the sagittal plane of the body, but they are capable of a certain amount of forward and backward motion which may be employed to change the direction of locomotion. The movements involved in orientation are different from those employed in ordinary running. They are special movements employed to check deviations from a certain course, a circumstance which would greatly complicate any attempt to explain orientation as a comparatively direct response. The results of observations on fiddler crabs tend to confirm the conclusion reached in studies made on the phototaxis of Ranatra, namely, that light is followed much as an animal pursues any other object of interest, such as prey, or its mate, and until we can give a physiological explanation of these phenomena we are not, I believe, in a position to give a satisfactory explanation of orientation to the direction of the rays of light."

A similar idea regarding reactions to light was expressed by Graber much earlier. He says (I 884, p. 248), "Um ein analoges Beispiel aus einer andern Sinnessphäre anzuführen, so benimmt sich hier [exposed to light differing in color or intensity] die Raupe offenbar ganz ähnlich wie in dem Fall, wenn ihr als Futter einerseits Nesselkraut und andererseits irgend eine andere Pflanze vorgesetzt wird, indem sie constant das letztere verschmäht und das erstere ergreift, und in dem Sinne können wir also auch ganz gut von einem Farbengeschmacke reden."

\section{Frogs and Toads}

The conclusions of Holmes as far as they refer to orientation in animals with image-forming eyes are strongly supported by the observations of Miss Torelle on the response of the frog to light and by the orienting reactions of the American toad Bufo americanus described below. Miss 
Torelle says (1903, p. 47I): "Tests were made at midday on a level tract of ground about two acres in extent which contained neither trees nor any object that could cast a shadow. Six frogs were tried. When freed, each moved indifferently toward any point of the compass, but usually kept on moving in the direction in which it began to move. In several trials no movement resulted; the frog crouched low between short bunches of grass, its head held close to the ground. When dark black or dark brown screens were placed in the middle of this area and the frogs placed within five yards of them, the movement was toward and into the shadow of the screen, where they usually remained indefinitely." In various other experiments it was found that frogs exposed in direct sunlight hopped toward shadows in the neighborhood, no matter if this required movement perpendicular to the rays of light. When first exposed the frogs turned toward the light, but after being in this position a few moments they turned and hopped toward the shadows. After they are in the shade they usually turn so as to face the light. These reactions seem to show that the frogs go toward the shadow because they see and perceive it. The following reactions of toads lead to the same conclusion.

\section{A. Bufo americanus}

a. Method. - Two horizontal Nernst glowers were so arranged in a large dark room that the rays crossed at right angles above a black table one meter square. The two beams of light, $20 \mathrm{~cm}$. wide at the place of intersection, were parallel with the plane of the table, and the lower edge of the beams was just high enough to clear the table, which was therefore not illuminated. Both beams were absorbed by the dead black walls of the room, which were several meters from the table. The light intensity in the middle of the field from one glower was $12.5 \mathrm{ca}$. m., and that from the other was $25 \mathrm{ca} . \mathrm{m}$.

b. Orientation in light from two sources. - On July 7 , at 7 P.M., seven toads, two large ones and five small ones, 
were collected and brought to the laboratory. These specimens were exposed one at a time in light from a single source; they all oriented directly and fairly accurately. If placed on the table in the beam of light so that one side faced the glower they turned slowly but directly until they faced the light and then hopped or walked toward its source, stopping frequently for a few moments at intervals on the way. The light from both glowers was now turned on and the specimens were exposed, one at a time, in the beam having the lower intensity, in such a position that after they oriented and moved toward the source of light they soon reached the more intense lateral light from the second glower, which of course illuminated one side. I was somewhat surprised to find that ordinarily there was no apparent reaction whatever when the specimens reached the beam of lateral light, although the intensity of this was twice as high as that in which they were oriented. The toads continued on their way just as though there had been no lateral illumination. All the other organisms studied in light from two sources proceeded toward or from a point between the sources of light. The toads always went directly toward one or the other of the two sources.

Each of the seven specimens under observation was studied while it crossed the field six times, and all but one continued toward the glower which produced the beam in which they were first oriented, without any perceptible deviation on account of the lateral light from the second glower. Only one specimen turned when it reached the lateral illumination. It did not however go toward a point between the two glowers as might have been expected, judging from results of previous experiments on other forms. It proceeded directly toward the glower which produced the lateral illumination. In no instance was there any evidence of movement toward a point between the two sources.

These results do not support Loeb's recent statement regarding orientation in light from two sources. He says 
(1909, p. I3), "Sind zwei gleich starke Lichtquellen in gleichem Abstand vom Tier vorhanden, so bewegt sich dasselbe senkrecht zur Verbindungslinie der beiden Lichtquellen weil dann beide Augen in gleicher Weise vom Licht beeinflusst werden Darin untersche det sich, wie Bohn richtig bemerkt, die maschinenmässige heliotropische Reaktion der Tiere von der nicht durch Heliotropismus bedingten Bewegung eines Menschen zu einer von zwei Lichtquellen." Toads, exposed to light from two sources, as stated above, do not proceed toward a point between them. Judged by the criterion of Loeb and Bohn, their reactions under these conditions are therefore like those of a human being under similar conditions and not like those of other animals (Tiere).

c. Orientation with one eye destroyed. - Toads with the lenses ${ }^{1}$ removed from the eyes so that the power of forming images is destroyed, frequently orient fairly accurately and hop or walk toward a source of light. When exposed to light from two sources they move toward a point between them, contrary to what occurs in specimens that can see.

In specimens with one eye destroyed there is a slight tendency to deflect toward the injured eye. The head in such specimens is inclined toward the blind side as though

1 No special precaution was taken to destroy the retina in the eyes from which the lens was removed. This seemed unnecessary since I was not primarily interested in the question of distribution of sensitive elements. Parker (1903 and 1905) demonstrated very clearly that the skin of some frogs and fishes is sensitive to light, and Pearse (rgro) showed the same for various amphibia. Many of these creatures can orient fairly accurately with the retina of both eyes entirely destroyed. My aim was to test the effect on orientation of unequal stimulation on opposite sides. In the toad with the lens removed, the eye fills with a substance which, while it may not be absolutely opaque, certainly intercepts nearly all the light, so that even if the retina is functional in both eyes, one receives much more light than the other. The important point here is that when the toads with the lens of one eye removed as described in the text are oriented and move toward the light they are not equally stimulated on symmetrically located sensitive points. 
the animals were trying fully to expose the intact eye and still travel toward the light. Hadley (I908, p. I87) observed somewhat similar reactions in positive lobster larvae with one eye removed, as did also Miss Torelle (1903) in frogs with one eye covered. Thus it will be seen that the toads and frogs and lobster larvae tend to deflect toward the blind eye, while butterflies, amphipods and flies tend to deflect toward the functional eye.

On June 27 several toads were exposed to light from one glower, and from these the three which oriented most accurately were selected. The lens was then removed from one eye in each toad. The following day they were exposed $250 \mathrm{~cm}$. from a 50 candle power Nernst glower in a beam of light $45 \mathrm{~cm}$. wide. The beam of course became narrower as the source of light was approached. If set down so that one side was illuminated all of these specimens turned directly so as to face the source of light, but in all the head was turned toward the blind side so that there was a distinct curve in the spine, and after turning thus they hopped or walked toward the glower, deflecting slightly toward the injured side. They almost always reached the edge of the beam of light before getting to its source and one passed out into the shadow a few times.

On July I4 the lens was removed from one of the eyes of a large active toad which had oriented rather accurately. The toad was then immediately exposed in the beam of light. It hopped toward the glower apparently as accurately as it did before the operation, but there was a tendency to turn the intact eye toward the light whenever it came to rest after each leap. The light intensity was much reduced but still the specimen went directly toward the glower. The following day this toad was again exposed; it now went toward the source of light even more nearly directly than on the preceding day. There was no longer any appreciable tendency whatever to turn toward the blind side.

These results show that in this form and in all the other 
forms which orient after one eye is destroyed difference of effective intensity on opposite sides does not regulate orientation. "The head is ... [not necessarily] bent until its symmetrical photosensitive points are . . struck at the same angle by the rays of light," nor is it necessary that both eyes be influenced alike, as Loeb's theory demands. It appears that these organisms, as Holmes says, referring to the fiddler crab, follow light "much as an animal pursues any other object of interest, such as prey, or its mate."

Graber (I884, p. 226) found that Rana esculenta tends to collect in light of relatively low intensity and we have seen that Miss Torelle found that the frogs she studied tended to collect in shaded places, but Parker (1903) and Cole (I907) found that when frogs are exposed to light in a dark room they are positive, apparently regardless of the intensity of the light. I found the same true with reference to Bufo. How can these contradictory phenomena be accounted for? In a dark room containing but a single compact source of light such as was used by Parker, Cole and myself in these experiments, it is not likely that an animal can see anything but the source of light. If then the frogs and toads are guided by sight in their movements, as their reactions indicate, it is evident that they must go toward the source of light if they go at all. In these reactions light no doubt acts continuously as an orienting stimulus, and the direction of the rays must necessarily, if they go toward an object because they see it, guide them on their way. This of course does not imply that the reactions are controlled by psychic phenomena. The process of orientation is however, without doubt, far more complicated than the theory of Loeb demands.

\section{Caprella}

What can be said with regard to orientation in the higher forms with eyes incapable of forming images ? Such animals are of course not able to see. They cannot follow 
an object because of its size or orm. The eyes function merely in distinguishing different degrees of intensity or movement perhaps. Caprella seems to possess eyes of this kind. At any rate when exposed to light from two sources it swims toward any point between them, depending upon

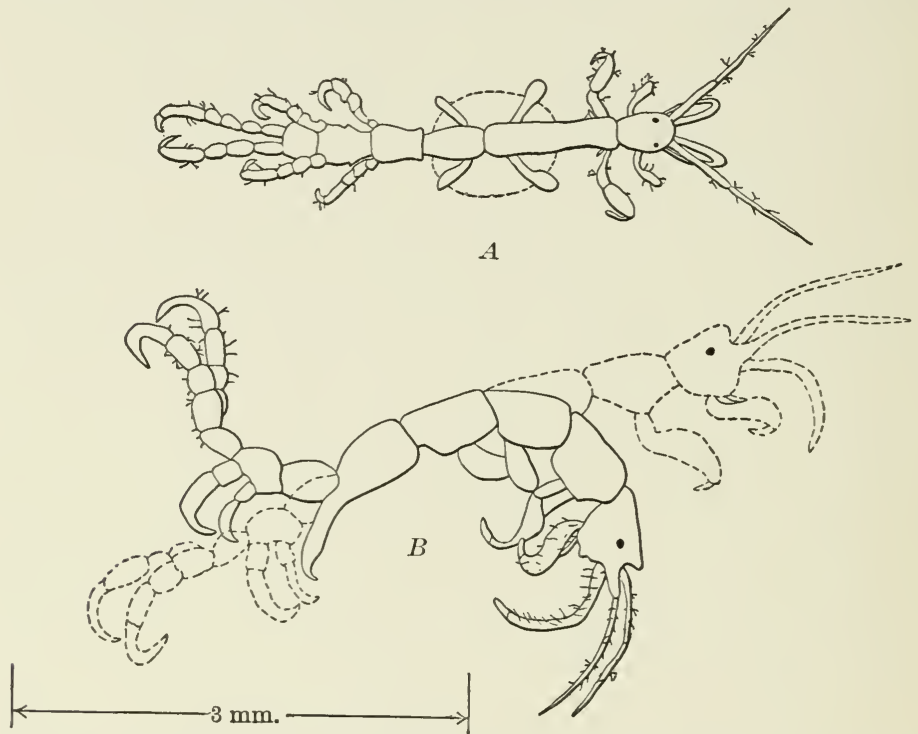

Fig. 32. Camera outline of Caprella sp. (?). $A$, dorsal view; $B$, side view, showing the extent of bending during locomotion. See text.

their relative intensity, indicating that orientation is not regulated by the same factors as in the toad.

An idea of the general form and structure of the form on which the following observations were made can be gained by referring to Fig. 32. This creature is found in abundance attached to Eudendrium colonies. I did not ascertain the species.

a. Orientation. - While attached this form shows no indication of orientation, but when free it usually swims toward a source of light fairly accurately. When it swims slowly the anterior end, with its appendages spread out, is thrown toward the ventral surface until it is nearly at right 
angles with the rest of the body, after which it returns more slowly with the appendages partially folded. When it swims rapidly the posterior end strikes backward at the same time that the anterior end straightens, and moves forward when the anterior end strikes backward. Thus the creature alternately bends and straightens in rapid succession and forces itself through the water. Ordinarily it swims on either the right or the left side. When it changes its direction of motion it always turns toward the dorsal surface. If the ray direction is changed it turns directly toward the source of light if the dorsal surface is illuminated, but if the ventral surface faces the light it first rotates on its long axis through $180^{\circ}$ and then turns.

Orientation is not brought about by unequal action of symmetrically located sensory and locomotor organs. When the organism turns, either the entire anterior end alone or both ends must strike differently than when it swims straight ahead. The appendages on opposite sides of the body act the same. The organism as a whole must be involved in the process of orientation. This cannot be due to a " compulsory automatic turning of the head " toward the source of light, in accord with Loeb's explanation of orientation. In some way or another these creatures do keep the anterior end directed toward the general source of illumination. Just how this is done I am unable to say. It may be that the organism receives a localized stimulation when it turns so that the anterior end is no longer directed toward the light, and orients by means of a differential response to such a stimulation. There certainly is no evidence indicating that light acts constantly as a directive stimulation, nor is there any indicating that "the head is . . . bent until its symmetrical photosensitive points are . . . struck at the same angle by the rays of light." The process of orientation is by no means as simple as these explanatory quotations from Loeb demand.

$b$. Discussion. - Orientation in Corethra larvae, which, according to the work of Harper (1907) bend sharply alter- 
nately to the right and left in the process of locomotion, supports the conclusion reached in the study of Caprella, as do also the orienting reactions of zoeae and lobster larvae. Lobster larvae in the earlier stages always orient with the posterior end toward the source of light. When they are positive they swim toward the light with this end ahead. When they are negative they swim in the opposite direction with the anterior end ahead. Hadley (I908, pp. 264-276) showed that if the direction of the rays is changed in any way after the larvae are oriented, they immediately and directly turn until the anterior end is shaded again. If the position of the source of light is so changed that the dorsal or the ventral surface is exposed, it is evident that the sides may still be equally illuminated. If the dorsal surface, for example, becomes illuminated when the ray direction is changed they turn toward the ventral surface. This shows very clearly that orientation in these forms is not regulated solely by relative intensity of light on symmetrically located structures, for the illumination on opposite sides throughout this whole reaction may have been equal. I observed similar reactions in the zoeae of several different species of the Brachyura and Caridea. In some of these animals the eyes extend laterally beyond the surface of the body so far that both are illuminated no matter whether the anterior or posterior end is directed toward its source.

In all these forms it is evident that the turning toward the dorsal or the ventral surface, when the source of light is lowered or raised, must be due to the fact that different portions of the eyes become illuminated, unless it is regulated by vision. If it is, the former orientation appears to be a differential response to a localized stimulation. The observations of Holmes and others indicate that orientation in a number of other arthropods also depends upon the surface of the eyes exposed. Holmes (1905) covered different parts of the eyes of Ranatra with an opaque substance and found that it responds just as though the environment in the direction of the blackened portion of the eyes were dark. 
The fact that many animals with image-forming eyes respond to size of the luminous area rather than to intensity difference as shown by Parker (1903) and Cole (1907), is not at all opposed to the idea of Holmes stated above. In this fact we have an answer to the much-discussed and perplexing question as to why moths fly toward a candle at night and not toward the moon. The reason clearly is that in moonlight there are large illuminated areas all about, while in candle light the objects about are so faintly illuminated that the moths do not react to light reflected from them. But this answer is clearly superficial. The question is: Why do the Mourning-cloak butterflies, e.g., fly toward large illuminated patches rather than toward the sun, which is much brighter? Parker ( 1903, p. 465) says it is because the larger area makes a larger "spot on the retina." "I therefore believe that Vanessa antiopa stays near the ground on bright sunny days because its flight is directed by large bright retinal spots rather than by small ones, even though the latter are of vastly greater intensity." These answers are no doubt correct, but they are not fundamental. The reactions referred to above are in general adaptive, and an explanation of them must be sought along the same general lines as an explanation for any other question involving adaptation. It is frequently said that organisms in water are limited in their movements toward the sun by the surface of the water, but that insects flying in air are not thus limited. Referring to Labidocera Parker says (p. 462): "Their positive phototropism is held in check by their inability to pass above the surface of the water. No such barrier holds the butterfly to the earth." It is evident that this is true only in a restricted sense. Insects flying up in the air soon find their limit, and of course no one knows how many have tried this very thing during the process of fixing the adaptive habit of reacting positively to large luminous areas rather than to small ones of much higher intensity. Thus it may be that they have learned to go toward the larger luminous areas in preference to smaller ones much 
as they have learned to follow their mates or other objects of interest.

The fact that an insect flies into a candle flame at night or a bird against a lighthouse tower and loses its life does not indicate that its light reactions are not in general adaptive, as many assume. One might as well say, if a creature in a room flies toward a window and is injured by striking the glass, that its behavior is not adaptive. The environment in both cases contains artificial factors which animals rarely experience. It remains for future investigators to demonstrate whether or not insects and birds can learn to avoid such pitfalls as candles and lighthouses.

Whether or not the flight of birds against a lighthouse is tropic, as Cole suggests in the following quotation, depends upon the sense in which the term tropism is used: (I907, p. 4IO) "The way in which migrating birds often, on stormy nights, gather about lighthouses and dash into the glass only to be killed, recalls strongly the flying of moths into a flame, and it seems possible that this is an expression of phototropism in birds which is ordinarily inhibited by other responses." It seems probable that all creatures which fly are guided on their course by sight at least with reference to their immediate environment. It is well known that birds seldom fly against the lighthouse windows unless the night is dark and stormy. Under such conditions the light intensity all about is very low, so that when the birds get near the lighthouse they can see nothing but the light in it, and if they are to fly toward something they can see, they must evidently fly toward this light. If this is true the factors involved in this phenomenon are similar to those involved in regulating their flight toward any other object.

\section{General Summary and Conclusions}

The several summaries at the close of the different sections in this part and the table of contents should be referred to for a general idea of the subjects treated and the 
results and conclusions reached. Here we aim only to bring together the more important factors involved in the process of orientation in different organisms.

(I) The plumules of Zea mays and probably of all the other gramineae bend toward the more highly illuminated side of the sensitive region regardless of the direction of the rays. Our experimental results do not bear on the question as to whether or not orientation is due to a modification of circumnutating movements as maintained by Darwin. Nor do they warrant a conclusion as to whether the stimulation causing bending is due to a change of intensity on some part of the sensitive region in accord with Darwin's suggestion, or to constant intensity, all sides being continuously stimulated in proportion to the intensity to which they are exposed, in accord with the theories of De Candolle, Loeb, Verworn and others. The bending may be due to a differential response to a localized stimulation.

(2) In the myxomycetes and rhizopods orientation is in all probability due to a local response to a local stimulation. Light retards the activity of the protoplasm and thus prevents the formation of pseudopods on the more highly illuminated side. It is impossible to say whether light acts constantly as a directive stimulation, all parts of the organism being continuously stimulated in proportion to the absolute intensity to which they are exposed (Loeb, Verworn, etc.), or whether it acts only through changes of intensity, the prevention of formation of pseudopods on the illuminated side being due to the increase in light intensity on the protoplasm as the pseudopods are thrust out.

(3) In Euglena, Stentor, Trachelomonas, Chlamydomonas, Chlorogonium, Oedogonium swarm spores and probably in all other ciliates and flagellates which orient in light, orientation is due to definite responses to changes of light intensity on the sensitive part of the organism. The changes of intensity are ordinarily due to the movement of shadows of one part of the body over another part. This is caused largely by the rotation on the long axis. In 
Euglena and Trachelomonas the most highly sensitive part is probably restricted to a relatively small mass of protoplasm in close proximity with the concave surface of the eye-spot. The eye-spot probably functions in shading this structure when its convex surface faces the light. The eye-spot may also function by absorbing light in a manner similar to that in the choroid coat in the eye. In Chlamydomonas and the volvocineae, judging from its location, the eye-spot cannot function by shading the sensitive part of the organism, as it appears to in Euglena. In these forms it can only function by absorbing light, if it functions in light reactions at all.

The difference in sensitiveness with different surfaces exposed is surprisingly great in Euglena and Stentor, and probably in all the other ciliates and flagellates. In Stentor, under the conditions of the experiment it requires an increase in intensity from I5O ca. m. to $444 \mathrm{ca}$. $\mathrm{m}$. to induce a reaction when the posterior end faces the light, while a change from a position in which the aboral to one in which the oral surface is exposed causes a reaction without any change of intensity in the field, showing the marked effect of the shadow of the former surface on the latter. There is no evidence that the direction of the rays functions except in so far as it may affect change of intensity. Nor is there any evidence that light acts constantly as a directive stimulus similar to the effect of the constant current in accord with Loeb's theory of tropisms.

In Euglena the avoiding reaction is not a differential response to a local stimulus, for in the crawling state it bends toward the ventral surface, while in the free-swimming state it bends toward the dorsal surface. The direction of bending is governed by internal factors. The reactions caused by changes of intensity result in directing the organisms toward various points of the compass. As soon as they reach a position in which the rotation on the long axis no longer causes a change of intensity on the sensitive region there is no longer any cause for turning; they there- 
fore continue in this direction. Orientation in these forms takes place in principle precisely as Jennings' description demands.

(4) The same factors are involved in the process of orientation in the colonial forms, Volvox, Eudorina and Pandorina, as are involved in the orientation of the ciliates and flagellates. The orienting stimulus is due to a change of intensity on some part of the zooids. This is due (I) to the change in the surface of the zooids exposed as the colonies rotate, and (2) to the transfer of the zooids from the illuminated side of the colony to the shaded side and vice versa. The change of intensity causes a definite response in the zooids, a shock movement or avoiding reaction, which consists in an effort to turn toward the side facing the anterior end of the colony. Owing to the way in which the zooids are united there are no errors in the process of orientation in the colonies as a whole. They never turn in the wrong direction as many of the protozoa frequently do. The reaction of Volvox in light is not like the reaction of this form in a constant electric current, as Bancroft assumes.

(5) Hydra viridis moves fairly accurately toward or from a source of light. When attached it does however not take a definite axial position with reference to the direction of the rays. It may bend toward any point of the compass. There is no definite relation between the direction of bending and the side illuminated. But the anterior end is directed toward the source of light a greater part of the time, and the animal usually travels only in this direction. When the anterior end is shaded the animal tends to turn, but when this end is illuminated it tends to travel. This indicates that the tendency to become oriented and the tendency to travel are not the result of the same factors. The former may be due to the stimulation by light owing to a change of intensity, the latter to the action of light owing to its constant intensity. There is no evidence indicating that the reaction in light is the same as the reaction in a constant electric current. 
All the other coelenterates studied orient directly. We are however unable to say how light produces the orienting stimulus. Orientation probably is due to a differential response to a localized stimulation.

(6) In Arenicola larvae orientation takes place much as it does in the flagellates and ciliates; but the larvae can turn directly toward the right or the left side. They appear to have the power of differential response to localized stimulation; the stimulation is probably due either to a reduction of light intensity on the shaded side, or to an increase of intensity on the illuminated side.

In the blowfly larvae only the very tip of the anterior end is sensitive to light. They turn this tip to the right and left alternately during the process of locomotion. If it becomes more highly illuminated as it turns toward either side it is turned farther in the opposite direction. The larvae apparently continually test their position with reference to the light. The lateral head movements make it possible for these creatures to orient much more accurately than they otherwise could. The orienting stimulus is undoubtedly due to an increase of intensity.

The earthworms can turn directly from the light. They probably have the power of differential response to localized stimulation by light. The random movements of the anterior end may serve to localize the stimulation. The direction of movement is, however, not entirely determined by localized stimulation. It is largely influenced by internal factors. The worms frequently turn toward the source of light when stimulated. The "selection of random movements," essentially as described by Holmes, is an important factor in orientation.

The anterior end of the earthworm is much more sensitive to light than the rest of the body. Lateral illumination of any portion of Allolobophora back of the sixth segment does not appreciably affect orientation, although this part of the animal is undoubtedly sensitive to light.

The planarians orient directly. A sudden change of 
intensity causes definite lateral head movements. In positive specimens, where one side is shaded, they turn toward the side which is not shaded, indicating that it is a decrease of intensity on the shaded side that causes orientation.

There is no evidence indicating that the direction of the rays or the angle between the rays and the sensitive surface functions in orientation in any of the forms referred to under vermes, except in so far as it may cause change of intensity; nor is there any evidence that light acts constantly as an orienting stimulus.

The echinoderms do not orient; they can move with any part of the body ahead. When the direction of the light is changed they change the direction of motion by moving with another part of the body ahead. Precisely how the direction of motion is regulated is unknown.

(7) The mollusks, arthropods and vertebrates all orient directly. There is little evidence of preliminary trial movements in this process in these forms. Orientation is probably due to differential response to localized stimulation. In some of the positive mollusks the orienting stimulus appears to be due to a decrease of intensity on the shaded side. With reference to the way in which light produces the stimulation in the other forms in these groups our evidence does not warrant a conclusion.

The animals with image-forming eyes no doubt orient and go toward a source of light much as they go toward any other object of interest to them.

(8) Orientation may then be due $(a)$ to local response to local stimulation, as in the rhizopods and myxomycetes; (b) to shock movements, avoiding reactions, as in the ciliates, flagellates, colonial forms, vermes and larvae of various kinds; $(c)$ to differential response to localized stimulation, as in some of the coelenterates, the vermes and all the higher forms; $(d)$ to sight, as in many animals with imageforming eyes.

(9) No evidence was found indicating that the direction of light in the field or through the tissue (Sachs) functions 
in orientation of any organisms without image-forming eyes except in so far as it may produce difference of intensity on different parts of the organism. Those organisms which orient by sight are of course guided by the direction of the rays reflected from the object toward which they go.

(Io) There is no evidence indicating that symmetrically located points on the surface must be struck by light at the same angle when organisms are oriented, as Loeb maintains (I905). The only organisms which do not travel toward or from a point located anywhere between two sources of light are those with highly developed image-forming eyes. Such forms, as far as experimental evidence indicates, always go toward one or the other of the two sources of light. With but one functional eye these animals still orient fairly accurately, although under such conditions symmetrically located points are unequally stimulated.

(I I) There is no conclusive evidence, except perhaps in animals with image-forming eyes, showing that light acts continuously as a directive stimulus, that symmetrically located sides are continuously stimulated, - equally when the light intensity on them is equal, unequally when it is not, and that this regulates orientation by regulating the rate of motion of the locomotor apparatus on the two sides as is demanded by the theories of De Candolle, Loeb, Verworn, Davenport and Rádl.

(I2) There is no conclusive evidence showing that orientation in light is ever due to tropic reactions in any organisms, if the definitions of tropisms given by Loeb, Verworn, or Rádl are used as criteria.

(I3) All organisms that respond to light at all respond to changes of intensity. In some the response to such changes results in orientation, in others it does not. They are all unterschiedsempfindlich, in accord with Loeb's definition of this term. They all respond to time rate of change in light intensity. The idea of reactions to change of intensity is however not original with Loeb, as is sometimes assumed. The explanations of reactions to light 
given by Engelmann, Bert, Graber, Lubbock, Romanes, Darwin and others, all of whom preceded Loeb, were largely founded on this idea.

(I4) Light no doubt acts on organisms without a change of intensity much as constant temperature does, making them more or less active and inducing changes in the sense of orientation; but there is no conclusive evidence showing that light acting thus ever functions in the process of orientation. 


\section{PART III}

\section{GENERAL CONSIDERATION OF REACTIONS TO LIGHT}

\section{CHAPTER XI}

\section{ADAPTATION, FORMATION OF AGGREGATION IN REGIONS OF A GIVEN LIGHT INTENSITY AND DIFFERENT METHODS OF RESPONSE IN ATTAINING THIS REGION AND REMAINING IN IT}

\section{Introduction Showing that Reactions in General are Adaptive}

THus far we have dealt almost exclusively with the mechanism of orientation. In this and the following chapters we shall deal with reactions to light from a much broader point of view. We shall consider not only the various different methods of response leading to a general classification, but also the various factors which control the different responses, leading to a discussion of the nature of stimulation and the cause of reactions.

Under natural environmenta conditions organisms are usually found in places well suited for the continuance of their life processes. Sometimes they crowd together and form dense aggregations in such regions. This is especially true in case of unicellular organisms. Euglena, Chlamydomonas, Volvox and other similar forms collect in the more highly illuminated regions of their environment during dark, cloudy days, early in the morning and late in the evening, and in shaded places when the sunlight is very intense. A certain amount of light is necessary for the well-being of these organisms since they depend upon photosynthesis in 
the process of feeding, but too much is fatal. Stentor coeruleus, Amoeba and myxomycetes thrive in total darkness. They are always found in regions of comparatively low light intensity. The same is true of fly larvae. Negative response to light tends to keep these creatures buried in cadavers where they find food. It is ordinarily only under artificial conditions that the reactions of organisms to light prove fatal. Positive reactions to candle, lamp and lighthouse destroy untold numbers of moths and flies and bees and beetles and birds, but who has seen such fatalities under natural conditions! Under such conditions the responses to light direct these animals to the advantage of their wellbeing. When an insect or a bird in a room, a bee in a flower or a pomace fly in a wormhole of a decaying apple is excited it flies directly toward the light and ordinarily escapes. It could not be expected to react differently in the presence of a candle surrounded by darkness, since it receives the same general stimulation and has had no experience with the consequences. Many water-inhabiting larvae are strongly positive even in light so intense that it is injurious. They do not become negative and escape danger. Under natural conditions the strong positive response serves to scatter them far and wide, and under such conditions there is no need for a negative response. The surface of the water limits the distance they can proceed toward the light and in their natural environment they experience none of sufficient intensity to be injurious. As they grow older many of them lose their positiveness and become negative, and now their reactions guide them to the bottom into dark places, where they spend most of their adult life.

Sand fleas are usually found in dark places under masses of seaweed on the beach. If they are disturbed they become strongly positive. This response directs them toward the water, from which the stronger light usually comes. After they are in the water they become negative. This response directs them to the bottom and into dark crevices. Under natural conditions their reactions to light 
are adaptive, but if they are confined in a glass jar with a bunch of seaweeds at one end and an intense light at the other they collect at the illuminated side and remain there and die, whereas if they had become negative they would have been saved by the shelter of the seaweeds. But could they, even from a rational point of view, be expected to react otherwise under conditions which neither they nor their ancestors have experienced?

If the positive reaction which guides a moth into a candle is a non-adaptive reaction, then the positive reaction which guides the wolf searching for food into a baited pitfall must also be considered non-adaptive. But what would happen to the wolf if he did not react positively to food; does not the trapper expect him to get into the pitfall ? Is not the flight of the moth into the flame, after all, precisely what one would expect if its reactions to light in general are adaptive?

Even in case of positive reactions of animals which live in darkness, as e.g. the caterpillar of the willow borer and the mud-inhabiting crustacean Cuma rathkii, referred to by Loeb (I906, p. I59), or the cave-dwelling fishes mentioned by Eigenmann (I899), it is probable that the reactions were inherited from ancestors in which they were adaptive. Reactions to light which are non-adaptive, except under artificial conditions, are certainly rare. And whatever the fundamental cause may be, it is evident that organisms in general in their natural habitats tend to aggregate in regions which have conditions adapted to the needs of their life processes. We shall have occasion to emphasize this in the following paragraphs. These conditions may differ for different species and different individuals and for the same individual from t'me to time.

Of course the fact that reactions are adaptive does not explain their origin. Natural selection may tell us why organisms are as they are. It shows why adaptive characteristics continue to exist while the non-adaptive ones do not, but it does not tell us how they originated or why they 
are at all. It may be, for all that is known to the contrary, that Loeb is correct in his assumption that the reactions of organisms have their origin in fortuitous chemical combinations (see Chapter $\mathrm{XX}$ ), and that those organisms which live in high light intensity do so because they are positive in their reactions to light, while those which live in low intensity do so because they are negative. It must however be conceded that we have as yet but very few, if any, acts which bear directly on this question.

\section{Different Reactions Observed in the Process of Collecting in Regions having a given Condition of Illumination}

Let us now proceed to ascertain precisely how the different organisms respond so as to get into and remain in favorable light conditions. This has been thoroughly investigated for a number of different forms. It is by no means the same in all. We shall consequently consider the different methods under several different headings:- $a$. Random movements and avoiding reactions; $b$. Orientation, change in sense of orientation, and avoiding reactions; $c$. Orientation and extent of movement limited by environmental conditions; $d$. Orientation and movement directly toward the place where the organism comes to rest; $e$. Random movements and coming to rest in a given place It should be emphasized here that our aim in this section is not merely to discuss methods of aggregation but also to set forth all different methods of reactions with the view of classifying them.

a. Random movements and avoiding reactions. - Quite a number of the unicellular organisms get into the region of optimum intensity by random movements. They swim about aimlessly hither and thither, testing conditions in many different places. Thus they sooner or later get into an optimum intensity, where they remain, not by coming to rest, but because whenever they reach the boundary of the optimum region they are stimulated and consequently 
return. Engelmann (1882) was the first to observe and record this method of aggregation in detail. He says (I882, p. 393), referring to the aggregation in light of Paramecium bursaria, Stentor viridis and other chlorophyll-bearing ciliates: "Ueberschreiten sie $z$. B. zufällig die Gränze von Licht und Dunkel, oder tauchen sie auch nur mit der vorderen Hälfte ihres Leibes eine Strecke weit in das Dunkel ein, so kehren sie sofort um nach dem Licht, wie wenn das Dunkel ihnen unangenehm wäre." The collection of Euglena in an illuminated area is described as follows (p. 395): "Dieses wirkt wie eine Falle, denn einmal hineingekommen, gehen die Euglenen in der Regel nicht wieder heraus. Sie kehren an der Grenze des Dunkels immer so gleich wieder um ins Helle. Falls sie, was bei schnellem Vorwärtsschwimmen wohl einmal geschieht, ganz ins Dunkel hineingekommen sind, sistiren sie doch so fort die weitere Vorwärtsbewegung, drehen um eine ihres kurzen Axen, probiren - oft unter bedeutenden Gestaltsänderung - in verschiedenen Richtungen fortzukommen bis sie endlich wieder ins Licht gerathen." In the last sentence we have an intimation of orientation by trial, a method so thoroughly worked out and clearly stated by Jennings later. The clearest statement however which Engelmann made with reference to aggregation by the method under consideration is found in his article on Bacterium photometricum (I883, p. IIO): "Schwächt mann nun plötzlich das Licht . . so sieht mann alle bis dahin im Gesichtsfeld schwimmenden Bakterien fast im nämlichen Moment eine Strecke weit zurückschiessen, einige, meist unter lebhaftester Rotation um ihr Langsaxe stillstehen und danach wieder die gewöhnliche Bewegung aufnehmen. Man erhält vollständig den Eindruch eines Erschreckens." The reactions to sudden change of intensity in Bacterium photometricum has since been designated "Schreckbewegung." It is in all essentials like the reaction of Paramecium to changes in chemical concentration which Jennings has designated "motor reflex " or " avoiding reaction," and somewhat similar to the 
reaction of serpulids to sudden changes of light intensity. Loeb designated the power in serpulids to respond thus "Unterschiedsempfindlichkeit."

Besides those already mentioned various other organisms have been found to aggregate by this method, notably Stentor coeruleus, Trachelomonas, Chlamydomonas, Chlorogonium, Phacus and some swarm-spores, but so far as known Bacterium photometricum is the only form which is entirely dependent upon random movements to get into the region of optimum illumination. All the others are only partly dependent upon random movements in this. Under certain conditions they orient and proceed directly toward the region of most favorable illumination. Many forms however which make use of orientation at times in reaching the optimum light are entirely dependent upon random movements and avoiding reactions in case of other sources of stimulation, notably chemicals.

Reactions of the sort described above have usually been referred to as photopathic. They are supposed by some to be fundamentally different from orienting reactions, which are often called tropic. The former are supposed to be due to the action of light owing to difference or change of intensity, the latter to the action of light owing to constant intensity or direction of rays. This distinction however will not hold, for we have clearly demonstrated that orientation in many organisms is due to changes of light intensity on the sensitive tissue.

$b$. Orientation, change in sense of orientation, and avoiding reactions. - Many organisms, as stated above, have the power of orienting and moving directly toward the region of favorable illumination. In relatively low light intensities they are positive; in relatively high they are negative; in favorable intensity they do not react to light; consequently they tend to remain, but they do not come to rest. ${ }^{1}$ The rate of movement is apparently not decreased.

${ }^{1}$ Loeb has recently impugned these statements. We shall refer to this matter in detail later (see footnote, p. 266). 
The organisms simply do not orient but swim about in an apparently aimless way. If in their wandering they get out of the optimum they orient and return. Under certain conditions the avoiding reaction serves to prevent them from leaving the optimum, just as described under (I) above, but this reaction functions mainly in the process of orientation, as set forth in detail for many different forms in the part of this volume devoted to that subject.

Practically all the lower motile forms which react to light at all make use of this method of getting into the optimum and remaining there. In this group we may put a few rhizopods, numerous flagellates, some ciliates, several colonial forms, a few rotifers, at least one coelenterate, a number of vermes, and some insect larvae.

The advantage of orientation over random movement in getting to the optimum is evident, for it usually guides the organisms directly there. Conditions can however be so arranged that the greatest amount of light does not come from the portion of the field most highly illuminated. On the floor in front of a window for instance the region of highest illumination is some distance from the window. From this region toward the window the intensity decreases, but the window is still the source of strongest illumination. Under such conditions the organisms may be led astray. If they are positive they. proceed in the direction from which the strongest light comes and may thus be carried directly from the optimum. This was the case in a number of Loeb's experiments. It led him and others to the erroneous conclusion that difference of intensity is of no importance in regulating reaçtions to light in many forms. They failed to realize that the process of orientation is in itself an attempt on the part of the organism to attain optimum environmental conditions. Its purpose is essentially the same in all organisms without eyes, plants as well as animals, sessile organisms as well as motile. When an organism is oriented it is in its most favorable light conditions as far as the immediate surrounding is concerned, for in 
positive individuals the most sensitive part is then fully exposed to the light, whereas in negative individuals it is shaded. In sessile forms nothing more can be accomplished, but in motile forms still more favorable conditions are ordinarily attained by locomotion after orientation, that is, movement toward or from the source of greatest illumination, depending upon whether the organism is positive or negative.

The fundamental principle involved in orientation, as shown in Part II, is the same in all organisms without image-forming eyes, although the process differs much. Orientation is the result directly or indirectly of the effect of illumination on life processes. Movement toward unfavorable conditions generally induces orienting reactions. The reaction leading to orientation is however frequently not a response to an immediate unfavorable condition. It may be a response to a sign quite as much as the sudden contraction which closes the valves of a mussel when a shadow passes over it. The shadow in itself is of no particular consequence to the mollusk, but what follows may be. Just so the change of intensity has no particular influence on the life processes of Euglena, e.g., but what follows may have. Thus it is evident that orientation in the lower forms is dependent upon the power of discrimination between different degrees of intensity - "Unterschiedsempfindlichkeit " (Loeb), " sensibilité différentielle " (Bohn). In many of these forms orientation is undoubtedly, and in all it is probably, a response to change of light intensity on some part of the organism. At any rate it has in no instance been demonstrated that it is, as Loeb states, " a function of the constant intensity," that orientation in light is like orientation in an electric current.

c. Orientation and extent of movement limited by environment. - Many organisms orient and proceed toward or from the source of light as far as the physical conditions of the environment will permit and collect there. Arenicola and Eudendrium larvae, zoeae and many other aquatic 
forms, particularly in the earlystages of development, aggregate at the surface of the water in this way. They do not have a response similar to the avoiding reaction in many unicellular forms, nor do they become negative even if the light intensity is increased to such an extent that it is undoubtedly injurious. Conditions can readily be so arranged that they will go toward the light into chemical solutions, temperatures and concentrations where they are killed. Still their reactions under natural conditions are highly adaptive. Owing to their strong positive reaction they are brought to the surface of the water and scattered far and wide. Under natural conditions they apparently never or at least seldom experience light of such an intensity that it is injurious, or a combination of other environmental conditions such that their positive reactions to light prove fatal. The power to become negative in excessively high light intensity would consequently be of no special benefit to these organisms.

$d$. Orientation and movement directly toward the place where the organism comes to rest. - Most of the organisms with well-developed eyes, together with some few without, may be placed under this head. They go directly to a given place and remain because they come to rest there. Thus we find according to Bohn (I908) that Littorina and some starfishes under certain conditions go directly toward rocks and other objects and come to rest in their shadows. Butterflies and various other forms, according to Parker (1903) and Cole (1907), go directly toward large luminous areas and come to rest there. And frogs in direct sunlight were found by Torelle (1903) to go directly toward shadows, even if in so doing they had to move perpendicular to the direction of the light rays. But after they were in the shadow they turned so as to face the light, an adaptive reaction throughout; for under the conditions of the experiment it was probably advantageous for the frogs to be protected by the shade and to face the light when in it, since thus they were most likely to see both food and enemies. 
$e$. Random movements and coming to rest in a given place. - Probably all organisms that react to light at all are affected in their movements by the action of light owing to the absolute intensity. Such effects are not dependent upon the time rate of change of intensity but upon the actual amount of light energy present and the time of exposure. Light tends to inhibit the movements of plasmodia, and some bacteria, while total darkness has the same effect on purple bacteria, Volvox, Euglena, Chlamydomonas, Hydra, some planaria, earthworms and a number of other organisms. In most of these organisms this action of light is either insufficient to have any apparent effect on aggregation or it is masked by other stronger reactions. In planaria however the influence of relatively low light intensity has a marked effect on the process of aggregation. Some of these animals, as Loeb points out (I906, p. I36), do not orient. When exposed in a dish in front of a window they wander about aimlessly until they get into the darker regions, where they come to rest and consequently remain. Thus it is that they collect in the region of lower light intensity. Loeb considers this reaction of planaria "a function of the quotient of the change of intensity over time," i.e. time rate of change. I am however of the opinion that it is a function of the absolute intensity, that the action of light in these reactions is similar to the action of heat, for active planarians respond by raising the head and throwing it from side to side, both when the light is suddenly decreased and when it is suddenly increased. There is no indication of an immediate.decrease in locomotion under such conditions (Walter, I907, p. 7I), as would be expected if the aggregation were due to a change of intensity. And moreover, if the intensity is suddenly increased after the planarians have come to rest, they do not become active at once. Walter says (1907, p. 63) that the interval between sudden increase in illumination and response under such conditions "was often several minutes." 


\section{CHAPTER XII}

\section{REACTIONS TO LIGHT WHICH DO NOT RESULT IN AGGREGATION OR ORIENTATION}

WE have demonstrated in the preceding pages that reactions to sudden changes of light intensity may result in orientation followed by aggregation, or in aggregation without orientation. In either case the immediate response to the change of intensity is an abrupt change in direction of motion called Schreckbewegung, or avoiding reaction. Most of the organisms considered respond thus to an increase of intensity under some conditions and to a decrease under others. The immediate response under the two conditions is precisely the same; but in case of orientation the former leads to locomotion away from the source of light, the latter to locomotion toward it; and in case of aggregation, the former results in collections in regions of relatively low light intensity, the latter in regions of relatively high intensity.

There are many organisms which respond to sudden changes of light intensity much like those referred to above. They contract suddenly or change their direction of locomotion abruptly, but these reactions ordinarily result neither in orientation nor in aggregation. Most of these reactions are responses to shadows, i.e. to a sudden decrease in light intensity. These organisms do not all however react in the same way, and may consequently be divided into several groups as follows:- I. Reactions to shadows - protective; 2. Reactions to shadows - procuring food; 3. Reactions to sudden increase of light intensity; 4. Reactions to light caused by the effect of continued illumination. 


\section{Reactions to Shadows - Protective}

Many animals respond only to shadows, i.e., to a sudden decrease in light intensity, not to a gradual decrease or to an increase, no matter how sudden or how great. Such reactions to shadows are widely distributed. They are highly protective in all instances, and consequently vary somewhat in accord with the different habits of the different animals. The holothurian Thyone briareus contracts when the light intensity is suddenly reduced, frequently to such an extent that any portion protruding above the sand and mud in which the animal lives is entirely withdrawn (Pearse, I908, p. 277). Several different sea urchins, according to von Uexküll (I 897), turn the spines toward the shaded part, apparently to ward off an approaching enemy. Various tubicolous annelids have been observed to contract violently and jerk back into their tubes when an object passes between them and the source of light, e.g., Amphitrite bombyx (Dalyell, I853), Branchiomma köllikeri (Claparède, I868), Serpula (Ryder, I883), Hydroides dianthus (Andrews, I89I, pp. 285, 296), Serpula uncinata (Loeb, I893, p. I03), Spirographis spallanzani (Nagel, I896, p. 76), Potamilla oculifera, Sabella microphthalmia and Protula intestimum (Hargitt, 1906, p. 310), and Bispira voluticornis (Hesse, 1899). Shadows cause Pecten (Rawitz, I 888), Avicula, Arca, and Cardium (Patten, I886) to close their valves rapidly. Nagel (1896, pp. I8-77) observed similar reactions in 23 species of lamellibranchs without eyes, 4 species of gastropods with the eyes removed, and several blind arthropods. I have also frequently seen the short-neck clam Maya aranaria close its siphon and contract, and Littorina littorea retract rapidly into its shell. The hermit crab Pagurus also darts back into its stolen home when a shadow is cast on it. Mosquito larvae, ordinarily found at the surface of the water, scurry to the bottom at the approach of a shadow, and the killifish Fundulus responds much in the same way. Barnacles, according to the observation of Pouchet and 
Joubert (I875), stop their respiratory movements and contract if they are attached to objects some distance beneath the surface where a shadow might indicate the approach of an enemy, but they do not respond to decrease in light intensity if attached to objects floating on the surface, where shadows can have no such signification. All of these reactions are very much like the involuntary closing of the eyelids caused by shadows in higher forms.

All of the organisms in this class are readily acclimated to changes of intensity, and in all, the reduction can be made so gradual that they do not respond, showing that the response is dependent upon the time rate of change. Those organisms which react by contracting expand again very soon, even if the intensity remains constant at the lowest point reached during the application of the stimulus. This shows that the response is due to the process of changing the intensity and not to the absolute difference in the amount of light (at different times) before and after the change takes place. Von Uexküll says that the response in sea urchins usually fails after three or four trials. Nagel found the same with regard to mollusks. He says (I 896 , p. 29), "Das auffallendste an den Beschattungsreaktionen ist nun aber die Art, wie sich die Tiere an öfter wiederholte Reize gewöhnen.

"Ich lasse beispielsweise den Schatten eines Bleistiftes über die ausgestreckten Siphonen einer Herzmuschel hinstreifen. - Sie schliesst blitzschnell die Siphonen.

"Ich warte einige Minuten und wiederhole den Versuch. - Jetzt schliesst die Muschel ihre Siphonen nicht mehr, sondern es zucken nur die Ränder derselben ein wenig zusammen.

"Ich warte wieder einige Minuten, und wiederhole den Versuch zum drittenmale, und jetzt bleibt jede Reaktion aus. Nun kann ich aber auch den Grad der Verdunklung um das hundertfache steigern, indem ich als schattenwerfenden Körper statt des Bleistiftes ein Buch oder ein grosses Stück Karton verwende: Trotzdem bleibt die 
Muschel regungslos, der Schatten geniert sie in keiner Weise.

"Noch auffallender ist die Erscheinung bei der Auster und unserer Malermuschel. Wenn diese einmal durch einen Schatten erschreckt worden sind, dann bleibt jede weitere Beschattung ohne Erfolg. Erst wenn eine Stunde oder mehr seit dem ersten Versuche ohne Störung verflossen ist, sind die Muscheln wieder für den Schattenreiz empfänglich." I have frequently noticed that the hermit crab (Pagurus), mosquito larvae and tubicolous worms. especially Hydroides, soon fail to respond to ordinary shadows if they are kept in a place where the shadows frequently occur, but under such conditions they still respond to reduction of intensity greater than they ordinarily experience. The experimental results of Mrs. Yerkes (1906) and Hargitt (1906, I909) on Hydroides dianthus lead to the same conclusion. Hargitt's observations (1909, p. 158) are of especial interest in showing the relation between the reaction and the habitat. He found that specimens taken from a depth of about twenty fathoms did not respond to shadows which caused very definite reactions in specimens taken in shallow water. Whatever the immediate physiological cause of all these reactions may be, it is evident that they are admirably adapted to protect the organism against the attack of enemies. There are however animals in which similar reactions are found which serve quite a different purpose. These are included in the following group.

\section{Reactions to Shadows - Procuring Food}

Whitman observed that even a very faint shadow causes the leech, Clepsine, to become restless and stretch up and sway from side to side, apparently in search of something to seize. Bateson records similar reactions in shrimps and prawns. When a shadow passes near these animals they raise their antennae and swing them about. The primary cause of reaction in these animals is probably the same as 
it is in the preceding group. In both, the reaction has to do with the well-being of the individuals responding. But in the one it has to do with protection against mechanical injury, while in the other it has to do with the process of procuring food. The important point is that the shadow in itself is of no particular importance in either case, but what follows may be. It is a response to a sign just as truly as is the reaction of a dog to which Brooks refers in the following characteristically convincing words (1907, p. 53), "The kick is a sign of something which may follow, and the actions which do follow are not the effect of the kick, for they are directed or adjusted, either consciously or unconsciously, to an event of which it is only the forerunner."

\section{Reactions to Sudden Increase of Light Intensity}

There are reactions to changes of intensity which appear to be more directly concerned with the effect of light than are those just referred to. They are mostly responses to an increase of intensity and may be due to the effect of the change of intensity or to the effect of the absolute illumination. An earthworm, e.g., jerks back into its burrow when light is flashed upon it, as definitely as Hydroides does when it is suddenly shaded. If however the intensity is gradually increased it may not react at all. This is therefore evidently a reaction which is primarily dependent upon the time rate of change of light intensity. A sudden decrease of intensity produces no such reaction. I have frequently observed similar reactions in Stentor coeruleus, as did also Bronn in the actinia, Edwardsia and Cerianthus; Nagel (I896) in the sea squirt, Ciona, and in several different mollusks, and Parker (1908, p. 419) in Amphioxus. Parker says: "In all the tests I carried out, I never observed a reaction to a rapid diminution of light, and the reactions to light that did occur were always the result of a rapid increase of intensity. When an animal was resting quietly 
on its side in a shaded aquarium and a beam of sunlight was suddenly thrown upon it, it would usually respond by one or two vigorous locomotor leaps, after which it might come to rest even in the sunlight. If now the sunlight was suddenly cut off, no response followed. That this failure to respond was not due to exhaustion from over-exposure to light was easily shown by quickly throwing on the sunlight a second time, whereupon a reaction much like the first one usually followed immediately."

The jellyfish Sarsia contracts, according to Romanes ( 1885 , p. 4I), if suddenly illuminated while it is at rest, and Yerkes (1902) observed similar reactions in Gonionemus. A decrease in illumination produces no response in either of these forms if they are at rest, but in case of Gonionemus in the active state the movements are immediately checked either by an increase or by a decrease of intensity, after which the medusae turn over and sink to the bottom. While a sudden decrease of intensity does not call forth a response in Gonionemus when at rest, prolonged exposure to light of low intensity causes it to become active. Thus its light reactions are such as to keep it in moderately illuminated regions. In Sarsia in the active state, on the other hand, increase in illumination tends to cause increase in activity. It does not inhibit movement as it does in Gonionemus. A number of animals respond to both a decrease and an increase of light intensity. Most of these respond more definitely to the former than to the latter, but there are some which appear to respond to both in the same way and equally definitely. Nagel says (1896, p. 74), e.g., that Helix hortensis draws into its shell when suddenly illuminated, much as it does when suddenly shaded. Such reactions are of considerable theoretic importance: they will be referred to again later. 


\section{Reactions to Light Caused by the Effect of Con- tinued Illumination}

In all of the animals referred to above, the reaction is clearly a response to change of intensity, except in the case where Gonionemus becomes active after having been subjected to low light intensity for some time. In the actinians Aiptasia, Cerianthus and Eloactis the response appears to be due primarily to the action of light owing to its absolute intensity.

"Aiptasia annulata," Jennings says (I905, p. 459), " is very sensitive to light, expanding in darkness, but contracting after a few seconds when exposed to strong light. In ordinary daylight the animal remains contracted for some hours, but after such a period most specimens extend in spite of the light. In comparative darkness the animals direct the disk toward the source of light, through a contraction on the side of the column exposed to the light. After remaining undisturbed for a long time in an aquarium that is fairly well lighted, the animals give up their orientation with respect to the strongest source of light; with less light they retain it."

Regarding Eloactis, Hargitt says (1907, p. 277) that they begin to retract almost immediatelyafter exposure to diffuse daylight. "This reaction is not sudden or general at once, as in such creatures as the earthworm, but begins in a somewhat indefinite movement of the body, accompanied by similar movements of the tentacles, followed very soon by a slow but definite retraction of the entire body within the tube, often including likewise the tentacles as well." In direct sunlight the reaction is more striking. "In some cases the reaction was so definite and prompt as to leave the impression on the observer that the creature was possessed of something akin to visual sensation."

While, as stated above, these reactions appear to be produced by the action of light owing to constant intensity, it may even here be due to the effect of the changes of inten- 
sity. The principal reason for thinking it is due to the effect of constant intensity is the fact that there is no immediate response when the intensity is changed. But this retardation and slowness in reaction may be due to the general character of the animals. As a matter of fact we have as yet presented no conclusive experimental evidence showing that reactions are dependent upon any action of light other than that due to changes of intensity, although we have several times intimated that in all probability the activity of many organisms is affected by constant intensity. The strongest evidence we have in support of this is found in connection with observations on the change in sense of reaction.

However this may be, there is in this group no evidence of a reaction to a sign. The reaction is undoubtedly a direct response to the light itself.

In organisms with image-forming eyes the reactions are preëminently responses to signs, at least in so far as the eyes function in the responses. These animals are not primarily interested in light as light, but in what may follow a given light condition, e.g., an image on the retina. At first thought it seems as though here were a clear case of stimulation due to the action of light through constant intensity, for objects can be seen for some time without changing the light configuration on the retina. No new image is however formed on the retina without change of intensity, and it is consequently evident that here, too, the stimulation may be due to changes of intensity rather than to constant intensity.

\section{Classification of Reactions to Light-Phototropism, Photopathy}

Reactions to light have ordinarily been classified as phototropic (phototropism) or phototactic (phototaxis) and photopathic (photopathy). In some instances "helio" has been substituted for "photo." Organisms which orient and 
move toward or from a source of light are usually termed phototactic, those which orient but do not move as phototropic, and those which do not orient but still react have been termed photopathic. The adjectives positive and negative are ordinarily used in connection with these terms to signify whether the organisms go or bend toward the source of light or in the opposite direction; or whether they collect in regions of higher intensity or in those of lower intensity. The terms mentioned above have however been used not only to signify direction of movement, but also to designate the nature of the stimulation and the response as set forth in Part I, under definitions of tropisms.

Loeb says (I906, p. I35): “Heliotropism covers only those cases where the turning to the light is compulsory and irresistible, and is brought about automatically or mechanically by the light itself. On the other hand, there are compulsory and mechanical reactions to light which are not cases of heliotropism; namely, the reaction to sudden changes in the intensity of light. . . In the former case the results are a function of the constant intensity, in the latter a function of the quotient of the change of intensity over time." All cases of orientation are considered by him to be due to heliotropism, i.e., to the effect of light by virtue of its " constant intensity." All other reactions to light are due to changes of intensity. In this class Loeb puts the contraction of the tubicolous annelids Serpula and Spirographis and the collection of Planaria in regions of low light intensity. These reactions, he says, are due to Unterschiedsempfindlichkeit - sensibility to difference of intensity; those resulting in orientation are not.

Davenport (I897, pp. 2I0, 2II) maintains that "Two kinds of effects are produced by light: one by the direction of its ray - phototactic; the other by the difference in illumination of parts of the organism - photopathic.... Light acts directly either through difference in intensity on the two sides of the organism, or by the course the rays take through the organism." Here again we have two 
classes, - phototropism and photopathy. All cases of orientation belong to the former, and all cases where organisms aggregate without orientation, to the latter. Davenport mentions Planaria torva, Daphnia and Volvox as examples of organisms which are photopathic. Both he and Loeb affirm that there are some organisms which are both phototropic and photopathic. The one mentions Daphnia as an example, the other Spirographis.

Yerkes (1903, p. 36r) refers to this problem as follows: "The motor reactions of organisms to light, so far as known at present, are of two kinds: phototactic and photopathic. In both intensity of the light, not the direction of the rays, is the determining factor. All those reactions in which the direction of movement is determined by an orientation of the organism which is brought about by the light are phototactic; and all those reactions in which the movement, although due to the stimulation of light, is not definitely directed through the orientation of the organism, are photopathic.... An organism which selects a particular intensity of light and confines its movements to the region illuminated with that intensity is photopathic." Thus it is seen that Yerkes, like Loeb and Davenport, divides reactions into two classes and ascribes both kinds of reactions to a given individual in certain cases. All three authors agree in designating orienting reactions as photopathic or phototropic, but they do not agree in their explanation of the process of orientation. Loeb claims it is due to the effect of constant intensity; Davenport thinks in some cases it is due to the direction in which the rays pass through the organism, and in others to the effect of difference of intensity on opposite sides; and Yerkes maintains that it is due to difference of intensity in all cases. But if the light intensity on the surface of an organism is not uniform almost every movement of the organism produces changes of intensity on some part of it. It is therefore evident that orientation (phototropism), according to Loeb, Davenport and Yerkes, may be due respectively to the effect of con- 
stant intensity, direction through the tissue, or change of intensity. We have however clearly demonstrated in Part II of this volume that there is no experimental evidence proving that direction of the rays through the tissue or difference of light intensity on different parts of the body is functional in the orientation of any organism, excepting in so far as it may cause changes of intensity on the organism.

Photopathy, or Unterschiedsempfindlichkeit, as Loeb calls it, is due to change of intensity according to Loeb, to difference of intensity on the organism according to Davenport, and to difference of intensity in the field according to Yerkes. It is at once evident however that there may be agreement in these apparently different statements. If an organism is so illuminated that the light intensity on different parts of the body differs, every moment is almost certain to cause changes of intensity on some part of the organism, and if the intensity is not uniform in the field an organism, of course, cannot more about without causing changes of intensity on its surface. It may be, then, that the fundamental factor involved in photopathy, according to all of these authors, is change of intensity.

It is thus evident that the reactions grouped under phototropism and photopathy by the authors mentioned may all depend upon changes of intensity, and that the two phenomena may be fundamentally the same. If this be true, then the classification of reactions to light as photopathic and phototropic is without a foundation. Are there, then, no differences in these reactions which will serve as a basis for a classification?

\section{Reclassification of Reactions to Light}

Reactions to light may conveniently be classified (I) on the basis of the character of the stimulus, and (2) on the basis of the fundamental causes of the response.

(I) On the basis of the character of the stimulus we 
obtain the following groups: $a$. Reaction to change of intensity; $b$. Reactions to constant illumination; $c$. Reactions of questionable cause.

$a$. Reaction to change of intensity. - Response to change of intensity on the surface of the organism may result in orientation or merely in a change in position or direction of motion. (a) Orientation: Examples - Euglena, Chlamydomonas, Trachelomonas, Chlorogonium, swarm-spores, Volvox, Stentor, Planaria, earth worms and fly larvae. Changes in direction of motion: Examples - Shock reactions, or avoiding reactions which do not result in orientation, in all the forms mentioned above. (c) Changes in position: Examples - Sudden contraction in the tubicolous worms, Gonionemus, a few actinians, various mollusks and arthropods, and Amphioxus. (d) To these a fourth division may be added consisting of reactions to shadows in Clepsine, shrimps, prawns, mosquito larvae and Fundulus.

$b$. Reactions to constant illumination. - Constant or continuous illumination affects the sense of the reaction of organisms and their general activity, and it may possibly produce orientation in some forms. Whenever a positive organism becomes negative in light or vice versa, it is in all probability due to the action of light owing to its continued intensity, the absolute amount of light energy received, the product of the intensity and time of exposure. Reversal in the sense of reaction is not common to all organisms which respond to light, but the general activity of all probably depends upon the absolute amount of light energy received, much as the activity depends upon the temperature or heat energy received. The aggregation of Planaria in regions of low light intensity is no doubt in part due to this effect of light, since they come to rest even in a field uniformly illuminated from above in such a way that there is no perceptible change of intensity on any part of the organism. The time of exposure is an important element in this response. This is contrary to Loeb's conclusions regarding the cause of aggregation of Planaria. He claims the aggre- 
gation of Planaria to be due to Unterschiedsempfindlichkeit, sensibility to changes of intensity, and classifies the reactions with those of Serpula and Spirographis to shadows. I can however see no similarity between the responses of these organisms.

c. Reactions of questionable cause. - There are many responses in which it is as yet impossible to be certain as to what characteristic of light causes them. The orientation of Amoeba for example is probably due to the direct effect of the increase in light intensity on the protoplasm, but for all that is known to the contrary it may be due to continued illumination rather than to change in illumination. With regard to the orientation of the sessile plants and animals, as well as all animals with well-developed eyes, and many of the lower forms (entomostraca, Hydras sea anemones, and the larvae of Arenicola, Limulus and various crabs), experimental results do not as yet warrant a definite conclusion as to whether the reaction is due to the effect of change of intensity or continued illumination. It should however be emphasized again that in no case has it been demonstrated that orientation is " a function of the constant intensity " as maintained by Loeb. Nor is there any evidence indicating that the direction of the rays through the tissue has any direct effect on this process.

(2) On the basis of the fundamental cause of response, the reactions to light may be classified as follows: $a$. Reactions caused by the direct effect of light on the reacting tissue; $b$. Reactions caused by an indirect effect of light; c. Reactions due, not to any effect of light in itself, but to what a given light condition or configuration may represent.

$a$. Reactions caused by the direct effect of light on the reacting tissue. - Examples: Inhibition of protoplasmic streaming in the rhizopods and plasmodia and in numerous different plant cells, probably reversal in the sense of reaction and the change in sensitiveness, and the general activity of some organisms at least.

b. Reactions caused by an indirect effect of light. - 
Examples: Shock-movements and orientation in Euglena, Chlamydomonas, Trachelomonas, Chlorogonium, swarmspores, Volvox and Stentor; orientation in all higher plants, especially those in which the sensory zone is separated from the motory zone, as in the plumules of grasses; and the shock-movements in Edwardsia, Cerianthus, Gonionemus, various mollusks, fly larvae, earthworms, and Amphioxus. Light may have a marked effect on the life processes of all these organisms, but there is no evidence indicating that the slight changes of intensity required to induce reactions affect these processes. The organisms mentioned above are interested, not in the light condition which causes the reaction, but in that which ordinarily follows such a condition if the position or the direction of movement is not changed. Euglena for example may respond when the intensity on the colorless anterior end is reduced by a small fraction of a candle-meter. It cannot be of any special importance to the organism to keep this colorless end illuminated, but it is of the greatest importance to keep the green portion back of it illuminated, for light is necessary in the process of photosynthesis. Likewise the slight increase of intensity necessary to cause an earthworm to withdraw into its burrow, or to cause a negative Euglena to give the avoiding reaction, cannot be injurious to either of these organisms, for both thrive in light much stronger than that required to produce these reactions. I have kept earthworms continuously exposed to strong diffuse daylight ( $150 \cdot \mathrm{ca} . \mathrm{m}$.$) in excellent condition for weeks, whereas at$ night a candle-meter of light flashed on them is often sufficient to cause violent contraction. The light condition which causes this response in earthworms is not injurious, but the illumination that usually follows if they do not respond may be. Then, too, there is another factor involved here. Exposure ordinarily puts the worms at the mercy of the birds which prey upon them. Thus the light may be a sign of an enemy to the worms and in this regard they belong in the following group, for this phase of the response 
is not a reaction to light at all, but a reaction to what light represents.

The distinguishing characteristic which differentiates the responses in the organisms in this and the following group is however superficial. The fundamental principle involved in the reactions of the organisms in both is the same, for the reactions in the former as well as those in the latter are responses to signs. To those in this group the stimulating light condition is a sign of another condition of light either more or less intense than the one to which they respond; to those in the next group it is a sign of an object. And it is this more or less intense light, or the object represented, that is of vital importance to these organisms, not the condition of light to which they respond.

c. Reactions due, not to any effect of light in itself, but to what a given light condition or configuration may represent. - (a) Reactions caused by shadows or a sudden decrease in light intensity, representing either enemies or food: Examples - the sudden contraction or movement of tubicolous annelids, numerous echinoderms, mollusks and arthropods, and the response of Clepsine, shrimps, prawns, mosquito larvae and Fundulus. In case of Clepsine the shadows undoubtedly represent food; in the rest, with the probable exception of shrimps and prawns, it represents enemies. (b) Reactions to sudden exposure to light or increase of intensity probably representing enemies, especially in case of earthworms: Examples - Arenicola and fly larvae, earthworms and a few mollusks. (c) Reactions caused by the size of the luminous area in connection with intensity: Examples - Butterflies (Vanessa), Water scorpion (Ranatra) and frogs (Rana and Acris). In some of these organisms the positive reaction to a large area in preference to a small one of the same intensity prevents flight toward the sun, and it probably has something to do with mating. (d) Reactions caused by size, form, variation in shadow and color of luminous area: Example The higher animals, especially man. In these organisms 
the reactions are associated with objects which have some vital relation to their existence as food or a source of danger. In the higher animals, man in particular, pleasure and other emotions enter in as factors in the response, and the objects represented by the condition of light which causes the response may consequently have additional significations. I do not however wish to be understood as advocating the exclusion of such factors in the reactions of lower organisms, for, while they have not been demonstrated in these organisms, they may exist for all that is known to the contrary.

In the organisms in Group $a$ all the tissue appears to be equally sensitive to light. In many of those in Group $b$, Euglena, Stentor and Planaria, for example, some parts of the body are undoubtedly more sensitive than others, and it may be that the sensitive tissue is confined to a small area definitely located, as for instance in Euglena near the eye-spot. This tissue serves to distinguish changes of intensity, but owing to its positional relation to non-sensitive tissue (see Fig. II) which intercepts the light from one side, and the movement of the organism, especially the rotation on the long axis, it serves also to locate the direction from which the strongest light comes. Thus we have in these organisms structures which may be termed direction eyes. In Planaria and Arenicola larvae the highly sensitive tissue is nearly surrounded by opaque tissue which admits light only from one side (see Fig. 26), and consequently serves to locate more accurately the direction from which the light comes. In these organisms the lateral head movements are also of importance in locating the direction of the light. While the photosensitive tissue may be confined to limited regions in some of these forms, we are certain that it is not in others. Planaria and earthworms e.g. are known to respond after the more highly sensitive anterior end has been removed. Histological investigations in the latter seem to indicate that the photosensitive elements are fairly well distributed over the entire body surface. 
Most of the organisms in Group $c$ have image-forming eyes. The simplest of these appear to serve merely to distinguish between difference in size and location of illuminated areas, while the more complex serve to distinguish form, distance, and color as well. In many of these organisms the tissue which is sensitive to light is not confined to the eyes. Many of the fishes and amphibia respond to light at ter the eyes, including the retina, have been removed, and there are also a number of blind species which respond to light.

Nearly all of the reactions classified above are probably responses to changes of intensity. They are no doubt associated with chemical changes caused by changes of light intensity, and affected by other chemical changes dependent upon the effect of continued illumination, the absolute intensity, and the time of exposure. We shall refer to this matter again in the final chapter.

\section{Evolution of Reactions to Light}

It is not my purpose to discuss the problem of the evolution of the reactions to light. Nothing of importance could at present be added, in such a discussion, to the ideas of Jennings on this question expressed in his treatment of the development of behavior (1906, pp. 314-327). I shall therefore merely suggest, without argument, the order in which the reactions to light seem to have appeared.

The most primitive responses to light are probably due to the effect of continued illumination on synthetic and growth processes in green plants. Responses of this nature we may assume to have been the basis for the origin of all others, which probably appeared somewhat in the order following:

(I) Change in the rate of locomotion dependent upon the absolute amount of light energy received. No orientation, but probably aggregation at the optimum intensity Bacteria. 
(2) Contraction of naked protoplasm due to sudden changes in the light intensity, i.e., changes in the amount of light energy received, resulting in orientation in some instances - Amoeba.

(3) Fixed responses (avoiding reactions) caused by sudden changes of intensity, the nature of the response dependent upon the structure of the organism. No orientation, but aggregation at the optimum - Bacteria.

(4) Reactions similar to those under (3), but more definitely circumscribed by the structure of the body, especially the localization of tissue sensitive to light. Definite orientation and movement directly toward the optimum - Stentor, etc.

(5) Reactions to a sign. The change in illumination which causes the response is of no consequence to the organnism, but the illumination which would follow if it did not respond may be - Euglena, Volvox, etc.

(6) Reactions to a sign. The change of intensity (shadow) which causes the response represents objects which may be beneficial or injurious, food or enemies Clepsine Hydroides, etc.

(7) Reactions to a sign. The light condition or configuration which causes the response represents objects, not by means of shadows cast by them, but by means of the light reflected from them expressing size, form or color Animals with image-forming eyes. 


\section{CHAPTER XIII}

\section{FACTORS INVOLVED IN REGULATING REACTIONS TO LIGHT — VARIABILITY AND MODIFIABILITY IN BEHAVIOR}

Everyone who has ever attempted observations on the behavior of organisms with precise methods, knows that variability even in the lower forms under constant external conditions is one of the striking characteristics in reactions. There are internal as well as external factors involved in determining what the organism is to do. Just what these are and how they influence reactions is a question of primary importance.

Many organisms turn or move toward a source of light under certain conditions and away from it under other conditions. They may be either positive or negative; that is, the sense of orientation and response, in general, may be reversed. Nearly all organisms turn through $180^{\circ}$ when the sense of orientation changes so that they always move with the same end ahead. There are however some exceptions. Rádl (1903, p. 9I) claims that Daphnia may swim about in various directions with the back constantly facing the source of light. Bohn (1905, p. 8) found that young European lobster larvae always swim with the posterior end directed toward the source of light, so that when they are positive this end is ahead, and when negative it is behind. Hadley (I908, p. 260) observed the same in the larvae of the American lobster, as did also Lyon (I906) in several larval stages of Palaemon. I observed similar methods of locomotion in the larvae of several other decapod crustacea. In many of the lower forms orientation results from responses to changes in light intensity. When these forms are negative they respond only to an increase of intensity, and when they are positive only to a decrease. It will be our 
primary aim in this chapter to consider the factors involved in producing these changes.

\section{Change in Sense of Reactions}

a. Effect of intensity of light. - Famintzin (I867, p. 20) appears to have been the first to observe and record, although not very definitely, that the sense of reaction in organisms depends upon the intensity of the light. He placed a shallow dish containing Chlamydomonas and Euglena in diffuse daylight and a similar one in direct sunlight, and covered about three-fourths of each at the room side with an opaque screen. In the diffuse light the organisms collected at the window side of the dish; in the direct sunlight they collected in the shadow of the screen at the opposite side. In I 872 Müller recorded the observation that seedlings of Lapidium, which bend toward the source of light if it is moderately strong, turn and bend in the opposite direction if it is very intense, e.g. direct sunlight. Strasburger (I878, p. 572) was perhaps the first to actually see motile organisms turn about when the light intensity was changed and swim in the opposite direction. He found that various swarm-spores, which were strongly negative in a given light intensity, became positive when the microscope was moved farther from the window, but that they turned about and swam in the opposite direction when the microscope was again brought to the window. "Falls die Schwärmer nicht zu grosse Neigung haben sich niederzusetzen, kann dies Spiel beliebig wiederholt werden."

Reactions similar to those mentioned above were seen by Stahl (I880, p. 4I2) in Vaucheria, by Berthold (I882) in marine algae, by Verworn (1889, p. 50) in diatoms, by Wiesner (I880, p. 38) in tendrils of Ampelopsis and Vitis, by Oltmanns ( 1897 , p. I) in Volvox, Phycomyces and various seedlings, by Lubbock (1884) and Ostwald (1907) in Daphnia, by Wilson (I89I) in Hydra, by Frandsen (I90I) in Limax, by Rádl (1901, p. 83) in Simocephalus sima, by 


\section{Adams (1903) in Allolobophora foetida, by Parker (I902, p. II9) in Labidocera, by Yerkes (I902) in Gonionemus, by Groom and Loeb (I890, p. I69) in nauplii of Balanus, by Loeb (I 905, p. 276) in Polygordius larvae, ${ }^{1}$ by Hadley (I908)}

${ }^{1}$ In an address published after this part of the manuscript was finished Loeb says (1909, p. 34) that if organisms are positive in a given light intensity they are positive in every intensity to which they respond at all, and that forced suggestions in connection with the theory of natural selection are responsible for the idea that they aggregate in the intensity of light best suited for their general welfare. "Man hat nun auch versucht, zu zeigen, dass die Organismen eine 'Lichtstimmung' besitzen und ihren Heliotropismus so regulieren, dass sie stets in diejenige Lichtintensität kommen, welche für ihr Gedeihen am besten geeignet ist. Ich glaube, dass es sich hier ebenfalls um eine den Forschern durch die extreme Zuchtwahltheorie aufgezwungene Suggestion handelt. Ich habe an einer grossen Zahl von Organismen Versuche angestellt, aber ich habe bei klarer Anordnung der physikalischen Versuchsbedingungen auch niemals eine einzige Erscheinung gefunden, welche für eine derartige Anpassung spricht. Es hat sich stets herausgestellt, dass positiv heliotropische Tiere gegen Licht jeder Intensität, sobald nur die Reizschwelle überstiegen wird, positiv heliotropisch sind. . . . Eine 'Auswahl' einer passenden Beleuchtungsintensität habe ich nie beobachtet."

I am unable to understand how anyone can accept the statements quoted above in the face of the numerous records to the contrary; nor can I reconcile these statements with those of Loeb in earlier publications. He says (1905, p. 272 ), "Groom and I described some observations at Naples on the behavior of the nauplii of Balanus perforatus, and certain other marine animals, which were at times negatively heliotropic, and at other times positively heliotropic. We found that the intensity of the light determines the sense of heliotropism in these animals. Above a certain intensity light makes these animals negatively heliotropic, and this the more quickly the greater the intensity of the light. By lamplight the animals were always positively heliotropic." (p. 276), "The heliotropism of Polygordius larvae can also be influenced by light. This influence consists chiefly in the fact that direct sunlight makes positively heliotropic animals negative. I did not succeed in making negatively heliotropic larvae positive by exposing them to weak light." The idea that these larvae do not become positive in weak light is however not supported by Loeb's observations as recorded in the same paper a few paragraphs farther on. Referring to Polygordius larvae which had become negative in direct sunlight he says (p. 277), "When later I carried the animals back into the north room and kept the temperature constant at $15^{\circ}-16^{\circ} \mathrm{C}$., they again became positively heliotropic in the course 
in lobster larvae, and by various investigators in a number of other organisms.

It will thus be seen that reversal in the sense of orientation caused by the effect of light is widely distributed among living organisms. Is this effect of light due to stimulation caused by the process of changing the intensity, as in case of orientation in Euglena, for example, or the contraction of Hydroides? Or is it due to continuous illumination, as in case of the activity of many organisms? In other words, is it due to the time rate of change, or to constant intensity? I have frequently observed that Chlamydomonas, Euglena, Volvox, and other similar forms do not become negative at once if the light intensity is suddenly increased above the optimum. These organisms must be exposed to the higher intensity for some little time before the sense of reaction is

of twenty minutes"; and on the following page he says, "I again took some animals which had become positively heliotropic in the north room, and convinced myself first of all that at a constant temperature of $20^{\circ} \mathrm{C}$. they would become negatively heliotropic in direct sunlight in a few minutes. I then returned them to the north room, and here the animals again became positively heliotropic at the same temperature in the course of fifteen minutes."

It would be difficult to state in more explicit terms that the nauplii of Balanus and the larvae of Polygordius are negative in strong light and positive in weak than Loeb has done in the passages quoted from his publication of 1905 , and it would be equally difficult to state more explicitly that they are not negative in strong and positive in weak light than he has stated in his address of 1909 .

If these organisms are negative in strong and positive in weak light, as Loeb's experiments indicate, it is evident that their reactions tend to keep them in light of moderate intensity, an idea quite in harmony with those Loeb rejects in his recent address. As a matter of fact it is not at all difficult to find Chlamydomonas, Euglena, Volvox, or any other similar organisms in such a state that they are neutral in a given light intensity, positive in a lower intensity, and negative in a higher. I have repeatedly observed this in all of these forms as well as in several others; and in case of Volvox I have many times observed, as stated elsewhere, that the colonies collect in great numbers in the open spaces between pond-lily leaves and other water plants on dark, cloudy days, but that they collect in shaded places when the sun is bright. 
reversed. This is clearly shown in the following observations on Volvox, graphically represented in Fig. 33. By referring to path $A$ it will be seen that the colony introduced at $n$ was positive to light from the three glowers as well as

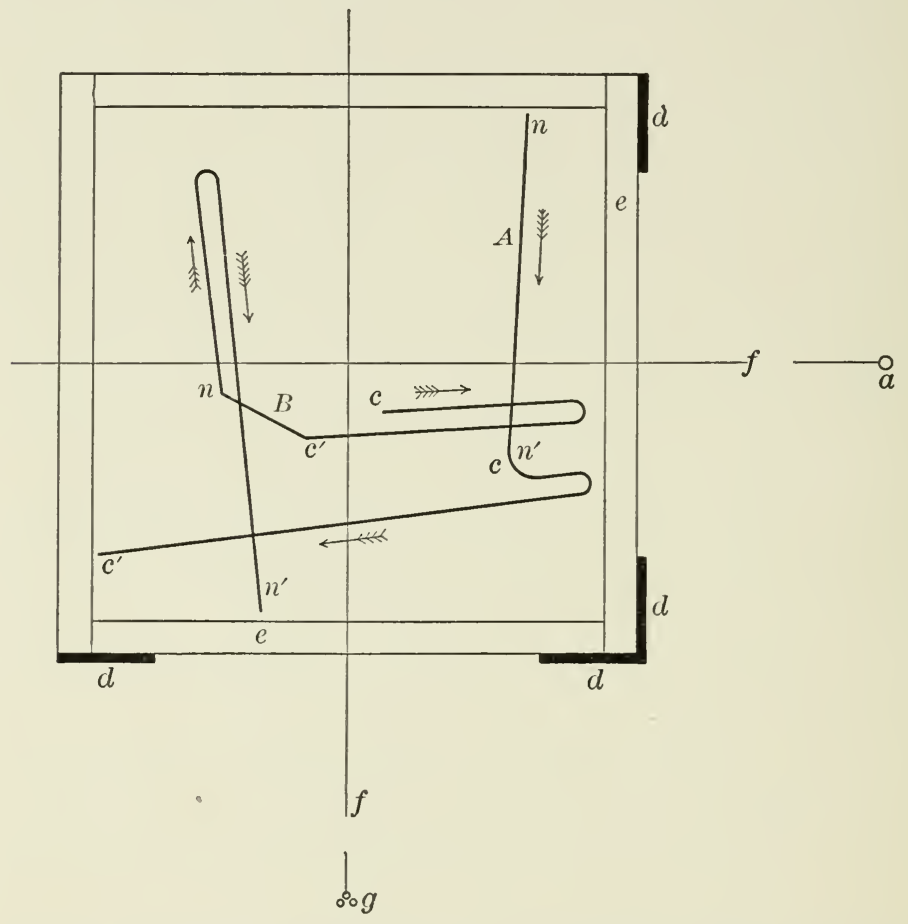

Fig. 33. The lines $A$ and $B$ represent the courses taken by single Volvox colonies as seen in water $2 \mathrm{~cm}$. deep in a plate-glass aquarium $e$. (The paths are represented in approximately accurate proportions); $g$, a group of three 222-volt Nernst glowers in a vertical position; $a$, carbon arc; $f$, direction of light rays; $d$, opaque screens; $n n^{\prime}$, path with glowers exposed and arc shaded; $c c^{\prime}$, path with arc exposed and glower shaded; $c^{\prime} n$, path with both glowers and arc exposed.

to that from the arc, but that it became negative after swimming toward the arc for a short distance from $c$, turned about and moved across the aquarium to $c^{\prime}$. That is, at the end of the experiment the colony was negative to a much lower light intensity than at the beginning. The arc was approximately 250 candle power. It was $15 \mathrm{~cm}$. 
from the point where the organism became negative. The light intensity at this point was therefore I I, I I I $\pm \mathrm{ca}$. $\mathrm{m}$. But the colony was still negative after having crossed the aquarium, a distance of nearly $8 \mathrm{~cm}$., or nearly $23 \mathrm{~cm}$. from the arc, i.e., in an intensity of $4726 \pm$ ca. m., which is $6385 \pm \mathrm{ca}$. $\mathrm{m}$. less than the intensity in which it first became negative. Similar results are represented in path $B$, but unfortunately the distances between the sources of light and the aquarium, in this exposure, were not recorded.

The colony which produced path $B$ was positive to the light from the arc when first put in to the aquarium at $c$, but after moving toward the source of light a few centimeters it became negative, turned about and moved in the opposite direction. When it reached $c^{\prime}$ the glowers were exposed and the colony promptly changed its direction of motion and proceeded on a course directed from a point between the two sources of light. This point, however, was much nearer the arc than the glowers, the light from the former being much more intense than that from the latter. When the light from the arc was cut off at $n$, the colony was found to be negative to the comparatively weak light from the glowers. It consequently changed its course and moved from this source; but after continuing about $3 \mathrm{~cm}$. it became positive, turned about and moved toward the glowers to $n^{\prime}$, and probably would have continued farther had it not been prevented from doing so by the wall of the aquarium. It will be noticed that the point $n^{\prime}$, where the colony was still positive at the end of its course, was about $3 \mathrm{~cm}$. nearer the glowers than $n$, where it proved to be negative, and nearly $7 \mathrm{~cm}$. nearer than the point where it changed its course from negative to positive. That is, the organism was positive at $n^{\prime}$ in a much higher light intensity than that in which it was negative at $n$ and at the point where it changed from negative to positive.

This shows that there were very striking changes in the optimum in these colonies. It also shows that the reversal in sense of reaction was not due to an effect produced by 
the processes of changing the intensity; for if it had been the colony on path $A$ would have turned from the source of light at $c$ in place of toward it, and then from it after having been exposed to the high intensity for some little time. The fact that the colony moved toward the arc light some little distance after turning at $c$, and that it was negative in a much lower light intensity a little later, shows clearly that there is some time required to bring about the changes in the organism which determine whether it shall be negative or positive. Reversal in the sense of reaction is not merely dependent upon the intensity but also upon the time of exposure. It is probably a function of the product of intensity and time. It is therefore evident that the change in sense of orientation in these lower forms is due to continued illumination, while orientation is due to change in the intensity of illumination. If all reactions are regulated by chemical changes, there must be at least two different sets of chemicals involved, one which is influenced by changes of intensity, another by constant intensity. I have discussed the possible nature of the chemical changes associated with reversal in reactions in a former paper (1907, pp. I57-I6I), and shall refer to it in this volume under theoretic considerations, Chapter XX.

Reversal in the sense of reaction is of the greatest importance to the well-being of organisms, for, as shown in the preceding chapters, it tends to keep them in the optimum illumination. This is true whether the change of intensity causes reversal in orientation or merely a change in the avoiding reactions, shock-movements, for both of these methods tend to produce aggregations at the optimum. A change in light intensity does not however induce reversal in all organisms which respond to light. I was unable to obtain positive reactions in Stentor coeruleus, Amoeba, and fly larvae; and the same is true for many of the planarians, including the land planarian Bipalium kewense, and some other worms, especially in certain stages of their development. 
There are also many organisms which never become negative in their responses. This is true of the great majority of higher plants and various animals. I exposed the entomostracan Scapholeberis armata, and Caprella, Leptoplana tremellaris and the early stages of Eudendrium, Arenicola, Limulus, and many other forms in light of $15,000 \pm \mathrm{ca} . \mathrm{m}$. intensity, and found that they remained positive although many were soon injured by the intense light. Carpenter (1908) was unable to make Drosophila negative to light, although he exposed specimens in over 480,000 ca. m., an intensity which produced convulsive reflexes and was undoubtedly injurious. Those organisms mentioned above which do not become positive thrive in darkness. There is, as stated in the preceding chapters, consequently no need for a positive reaction to light. Those which do not become negative thrive in strong light. Under natural environmental conditions they rarely meet with intensities so high as to be injurious. In these animals there is, then, no need for negative reactions.

Holmes says (I90I, p. 233), " Talorchestia longicornis is strongly and permanently positive both in weak and strong light." These animals however come to rest in shaded spots and are usually found under drifts of seaweeds. Orchestia agilis, which is found in similar places, is negative when first exposed, but it soon becomes positive, " the more quickly the stronger the light." After it is positive it "remains so even in the strongest light, but it may be rendered temporarily negative to exposure to light of lower intensity." Similarly Holmes (1905) found that Ranatras are negative when first taken from darkness and later positive, after which they remain positive as long as they are in the light, no matter how intense the light may be or how long they may be exposed. In general, exposure to light tends to make them positive, whereas darkness tends to quiet them and make them negative. It should be emphasized here that not only the intensity but also the time of exposure has to do with these reactions. Holmes says that 
after seventeen Ranatras, negative in a given light intensity, had been exposed for an hour and forty minutes, all became positive.

The positive reactions in all of the animals just referred to prove fatal under certain conditions, and Loeb (1905, pp. 42,74 ) claims that the caterpillar of the willow borer and the mud-inhabiting crustacean Cuma Rathkii are positive, although in their natural environment they are never exposed to light. Here, then, we have a number of reactions which do not lead the organisms to their optimum, reactions which under certain conditions are clearly not adaptive. But, as already shown, these reactions are non-adaptive only under artificial conditions. It was however reactions of this character that led Loeb (I906, p. I59) to conclude "that the tropisms could not have been acquired by the way of natural selection," and to formulate an explanation of their origin which we shall consider later, Chapter XX.

b. Effect of change in temperature. - It is well known that temperature affects the activity of organisms. If it is increased above normal, organisms ordinarily become more active and more sensitive to other stimuli until the optimum is reached, when their activity and their response to other stimuli decrease, as they usually do when the temperature is decreased below normal. Changes in temperature may however have quite a different effect on some organisms.

Strasburger (1878, p. 606) found that haematococcus swarm-spores, which were positive in a given light intensity at $16^{\circ}$ to $18^{\circ} \mathrm{C}$., became negative when the temperature was decreased to $4^{\circ} \mathrm{C}$., and more strongly positive when increased to $35^{\circ} \mathrm{C}$. He obtained similar though somewhat less striking results with other swarm-spores. The degree of change of temperature required to cause a reversal in reaction to light was found to vary with the different organisms and with the same organism under different conditions. Strasburger says (p. 6ro), "Sind die photometrischen Schwärmer, mit denen experimentirt werden soll, auf sehr hohe Lichtintensität gestimmt, so wird es, um sie auf den negativen Rand 
des Tropfens herüberzubringen, niederer Temperatur bedürfen, als wenn sie auf geringere Helligkeitsgrade gestimmt wären. Im ersten Falle wirken Licht und Temperatur sich so zu sagen entgegen, im letzteren so $\mathrm{zu}$ sagen gleichsinnig."

The experimental results of Massart (I89I, p. I64) on the flagellate Chromulina confirm those of Strasburger in that a decrease in temperature causes these organisms to become negative to light. Loeb (1905, p. 274) however observed that an increase in place of a decrease in temperature causes a change in the sense of reaction. He says that Polygordius larvae which were strongly negative in a given light intensity at $\mathrm{II}^{\circ}$ became strongly positive when the temperature was lowered to $6^{\circ}$, and negative again when it was raised; that others which were positive at $24^{\circ}$ became negative at $29^{\circ}$; and that still others positive at $17^{\circ}$ became negative at $24^{\circ}$. Loeb claims to have found similar reactions in marine copepods. And Miss Torelle discovered a reversal in reactions in the frog Rana clamata, but here it is again a decrease of intensity that causes negative reactions. She says (1903, p. 487), "A rise in the temperature to $30^{\circ} \mathrm{C}$. accelerates the rate of the positive response. A lowering of the temperature to $10^{\circ} \mathrm{C}$. produces movements away from the light." Holmes (I905, p. 323) observed similar reactions in Ranatra. He says, "Raising the temperature tends to accentuate the positive phototaxis in Ranatra and lowering it tends to produce the negative reaction. In several experiments two dishes containing Ranatras were set before a window so as to receive the same amount of light. As the specimens had been previously kept in the dark, they showed a negative reaction. Into one dish warm water was poured raising the temperature from about $20^{\circ} \mathrm{C}$. to nearly $30^{\circ} \mathrm{C}$. In a few minutes the specimens in the warmer dish became positive, the ones in the cool water still showing a negative phototaxis. Ranatras transferred to the cooler dish soon became negative, while those which were picked up in the same way and dropped back into the 
warm water from which they were taken soon resumed their positive reaction."

Change in temperature does not however cause reversal in reactions to light in all organisms. Strasburger (p. 6o8) discovered that while the swarm-spores of Ulothrix, Ulva lactua, Chaetomorpha aerea, and Chytridium vorax respond much like those of haematococcus, those of Scystosiphon lomentarium, Chilomonas curvata, Botrydium and Bryopsis could not be induced to reverse by changing the temperature; and the same is true for the copepod Labidocera, and for Daphnia pulex and Cypris, according to the work of Parker (I902, p. I I 7) and Yerkes (I900, p. 4I 7). I have observed the same in a number of organisms referred to below. It must be admitted that the above statement with reference to the copepods is somewhat too broad, since Parker tested the reactions only in $10^{\circ}, 30^{\circ}$, and $35^{\circ}$, and Yerkes studied only the effect of increase in temperature above the normal.

Original observations. - Observations on the effect of changes in temperature on reactions to light in microscopic forms were made by mounting them on a Pfeffer warmingstage under a large cover-glass sealed and supported by means of a ring of vaseline. The Pfeffer warming-stage consists of a glass cell $\mathrm{I} \times 6 \times 8 \mathrm{~cm}$. with three holes in the ends, one for a thermometer, the other two for water inlet and outlet. It is fastened on the stage of a compound microscope and admits of observation under either low or high power. The temperature is regulated by passing hot or cold water through the openings, and recorded by means of the thermometer. It was thus possible to subject the organisms to gradual or sudden changes in temperature ranging from a little above zero to nearly $100^{\circ}$.

May I I, I908, at 9 A.M. a few drops of solution were taken from some collected the preceding day and mounted on the warming-stage. The solution contained numerous specimens of Euglena viridis, Euglena deses, Phacus triqueter, and a few specimens of Euglena spiragyra and Phacus 
longicaudus. A large majority of all of these species were strongly negative at $22^{\circ}$, in light of $250 \mathrm{ca}$. m., when first mounted, but after they had been exposed from two to three minutes they became strongly positive without any change in temperature or light intensity. The temperature was now gradually lowered, and as this proceeded the organisms became less and less active. At about $12^{\circ}$ nearly all of them came to rest and the Euglenae contracted and became nearly spherical as if about to encyst. Thus the organisms lay motionless as the temperature decreased to $8^{\circ}$ and finally to $5^{\circ}$. But after having been in this low temperature for nearly five minutes, they gradually became active again and swam about, first in an apparently aimless fashion, but later as definitely and rapidly from the source of light as they had been swimming toward it at $22^{\circ}$. They thus became negative in the low temperature without any change in the intensity of the light. Is this reversal in the sense of reaction due to the effect of changing the temperature, or is it due to the absolute difference in temperature? The following has reference only to Euglena viridis, although the reaction of the other species mentioned above is similar to that in this form. After the Euglenae used in the observations referred to above had been subjected to $5^{\circ}$ for some minutes, the temperature was gradually raised and it was found that they were still negative at $8^{\circ}$, but positive at $\mathrm{I} 2^{\circ}$. After having been at $\mathrm{I} 2^{\circ}$ for six minutes, the temperature was again decreased, and now it was found that the organisms remained active and positive at a temperature even below $5^{\circ}$. They did not come to rest at $8^{\circ}$ as they had when first exposed to decrease in temperature. The temperature was now allowed to rise gradually to about $22^{\circ}$ in $250 \mathrm{ca} . \mathrm{m}$. About half of the Euglenae collected on the side toward the light and the rest on the opposite side. When the slide was turned end for end, the two groups immediately began to swim in opposite directions in two columns which met and passed near the middle of the field, the positive column above, near the cover-slip, the negative 
below, near the slide, owing no doubt to the fact that the source of light was somewhat above the level of the stage. About half of the Euglenae were now evidently negative and the rest positive, but half an hour later nearly all were negative, although there had been no change in light intensity or temperature. When the temperature was reduced they became still more strongly negative. After keeping the temperature between $5^{\circ}$ and $8^{\circ}$ for three minutes, it was rapidly raised to $22^{\circ}$; the Euglenae were now very strongly positive. They fairly streamed toward the source of light. The temperature was now again reduced and held at $5^{\circ}$ for a few minutes, during which the organisms were negative. It was then slowly raised, and many became positive at I $2^{\circ}$, after which it was once more reduced and held at $5^{\circ}$ for five minutes, during which the organisms were negative, and then again slowly increased. Many of the Euglenae now became positive at $8^{\circ}$.

We have thus seen the same individuals within the course of a few minutes in constant light intensity reverse in the sense of reaction several times. IVe have seen them come to rest as the temperature decreased and become active again as it decreased still farther. We have seen them change from a condition in which they were negative at $22^{\circ}$ and positive at higher temperature to one in which they were positive at $8^{\circ}$ and negative at lower temperature. These observations were repeated many times under different conditions with the same general results. Similar changes in reactions to light were also repeatedly produced by changes in temperature in different species of Chlamydomonas, Trachelomonas, Chlorogonium and Volvox.

These results show: (I) That a decrease in heat energy tends to cause a change in the sense of reaction to light from positive to negative and an increase tends to cause a change from negative to positive. A decrease in heat energy, therefore, produces the same changes in the reactions to light as an increase in light energy. (2) That the reactions to light of a given intensity depend not only 
upon the absolute temperature at the time of the observation, but also upon the preceding temperature, the time rate of change in temperature, and the time of exposure at a given temperature. (3) That reversal in the sense of reaction may take place without any change in temperature or light intensity. Reversal in the sense of reaction, therefore, seems to be due to the effect of constant temperature and time of exposure rather than to the effect of change in temperature.

In some of the forms mentioned above the changes are very indefinite, but in Chlamydomonas alboviridis they are even more pronounced and striking than in Euglena. In studying Chlamydomonas it was also found that only under certain conditions will changes in temperature cause reversal in the sense of reaction to light. Thus, for example, it could not be reversed in specimens which had been in total darkness for twenty-four hours. These specimens were negative at $22^{\circ}$ in light having an intensity as low as $\mathrm{I}_{5} \mathrm{O}$ ca. m., and they remained negative when the temperature was raised until they died at a little over $40^{\circ}$.

No change in the sense of reaction to light could be induced by varying the temperature in either direction between zero and the maximum in the following forms: Stentor, various species of zoeae, Scapholeberis armata, Daphnia, Cyclops, Cypris and a small water spider. Change in temperature, however, has certain effects on the reactions in Daphnia, Cyclops, Cypris and the water spider which are similar to those observed in Euglena. On May I6 several specimens of each of these species were exposed in light having an intensity of $\mathrm{I} 60 \mathrm{ca} . \mathrm{m}$. They were neutral at room temperature $\left(22^{\circ}\right)$, and swam about slowly without orienting or aggregating. When the temperature was decreased they gradually became more and more quiet, and finally sank to the bottom motionless, but when the temperature reached $8^{\circ}$ they became active again, and soon collected at the side of the dish nearest the 
source of light. When the temperature was decreased still more they became strongly positive. This experiment was repeated several times with similar results. Increase in temperature above normal ordinarily causes these organisms to become more strongly positive until a maximum is reached, when the movements become irregular and reaction to light ceases. In no instance was it found that any of these organisms became negative owing to changes in temperature. The interesting point in these observations is the fact that they become quiet as the temperature decreases and then active again when it decreases still further, just as in case of Euglena, but the former become only more strongly positive, whereas the latter change from positive to negative.

Not all entomostraca can be made positive by decreasing the temperature. On June I, Alona gracilis was found in great abundance in a paramecium culture jar. A few specimens of Cypris were also found in the same jar. They were strongly negative at room temperature $\left(25^{\circ}\right)$ in light of $250 \mathrm{ca} . \mathrm{m}$. The temperature was lowered to freezing, but the organisms were continuously negative whenever they responded at all.

It is thus evident that in some organisms a decrease in temperature causes negative responses to light, whereas in others it causes positive responses. How this is brought about is very difficult to see from a physico-chemical point of view, although there are chemical compounds in which decrease in temperature facilitates reactions caused by light, as shown in Part IV of this volume. The fact that the organisms become quiet as the temperature decreases, and then active again as it decreases still more, is particularly puzzling. In some organisms the change in the sense of reaction caused by change in temperature is clearly adaptive, and from this point of view we get some light on the causes of the change in reaction, but of course only a superficial explanation for adaptation is itself a problem. In Euglena and frogs, for instance, the negative reaction 
to light in low temperature takes them from the surface and prevents their freezing, while in Polygordius larvae and those entomostraca which become negative when the temperature increases the reactions take them out of the warm surface water. I am however not positive that the surface water becomes warm enough to injure these creatures. If it does not, then those reactions are apparently not adaptive.

c. Effect of chemicals. - That the reactions to light in some organisms are closely associated with the chemical constituents of the environment was clearly shown by the experiments of Englemann referred to elsewhere. In these experiments, Englemann found that the green ciliates, Paramecium bursaria and Stentor viridis, respond to light only when the oxygen pressure is below normal, but he did not note any actual reversal in reaction due to changes in the chemical condition of the medium. Loeb (1904, p. 2) however states that Gammarus pulex, which is " naturally negatively heliotropic" can be made positive by adding small quantities of any of the following substances to the water: carbon dioxid, hydrochloric, oxalic or acetic acid, various narcotics, "such as ether, chloroform, paraldehyde, alcohol or esters" and "all the ammonium salts, ammonium hydrate included." The alkalis, excepting $\mathrm{NH}_{4} \mathrm{OH}$, urea, oxygen and hydrogen, on the other hand, only excite these creatures; they do not cause reversal in the reaction. Similar results were obtained in experiments on Cyclops and Daphnia. The former however can also be made negative, if it is in the positive state, by the addition of $\mathrm{NaOH}$. "Attempts to make sea-water Gammarus positively heliotropic by $\mathrm{CO}_{2}$ have failed." Holmes (I90I) observed that the amphipod Jassa becomes positive when placed into foul sea water.

The fact that chemicals so very different in their general properties as acids, alkalis and narcotics may have the same effect on the sense of the reactions of these organisms seems to show that the effect of the different chemicals is not 
specific. The chemicals appear to produce changes in the general state of the organism as a whole or a unit. This idea is strongly supported by the observations on Arenicola larvae to be presented later, and by the work of Holmes (1905, p. 3I 7 ) on Ranatra. He found that any condition which causes an increase in activity accentuates the positive reactions to light, while any condition which quiets the organisms tends to make them negative. "The causes that produce the negative reaction are, as a rule, those which lead to diminished activity and excitement. Cold, exposure to darkness, and the quieting effect of contact stimuli lead to a condition of lessened excitability and, perhaps as a result of this, to a negative reaction to light." The same is probably true of many other insects. When a moth becomes quiet it is likely to crawl into dark crevices, but when it is disturbed it flies toward the light, and the more it is stimulated the more energetically positive it becomes. The pomace fly Drosophila is often found in dark cavities in decaying fruit. If it is disturbed it immediately flies out and escapes. Carpenter showed that the stronger it is stimulated the more strongly positive it becomes. Many similar instances could be cited. The strong positive reactions to light in these forms may lead them into fatal surroundings, but ordinarily they are of the greatest importance, for they guide them to places of safety.

Original observations. - On May 29, I908, a solution containing numerous specimens of Daphnia, Cypris, $\mathrm{Cy}$ clops, a small water spider about $0.5 \mathrm{~mm}$. in diameter, and various insect larvae, all taken from a shallow pond the preceding day, were exposed in light of $200 \pm \mathrm{ca}$. $\mathrm{m}$. Some of the individuals of the different species were negative but most of them were neutral. In these there was no apparent response to light. They remained equally scattered throughout the aquarium and swam slowly about. Pure $\mathrm{CO}_{2}$ was now allowed to bubble through the water very slowly. Nearly all of the organisms except the water 
spiders soon became more active and began to swim toward the light side of the aquarium, where in the course of a very few moments they formed a dense aggregation. Those which had been negative as well as those which were neutral had become positive. They remained at the more highly illuminated side of the aquarium only four to five minutes, then gradually scattered about again. A little more $\mathrm{CO}_{2}$ was then added to the water and the organisms became positive again. This process was repeated several times. When air was forced through the water they scattered almost immediately, and became indifferent to light, or sometimes slightly negative. It is consequently not the agitation which makes them positive when $\mathrm{CO}_{2}$ is allowed to bubble through the water. These results seem to indicate that the change in reaction to light is dependent upon the change in amount of $\mathrm{CO}_{2}$ as well as upon the absolute amount.

In these experiments the water spiders became quiet when the $\mathrm{CO}_{2}$ was added and sank to the bottom, but in some later experiments they also became strongly positive. In Stentor, Chlamydomonas, Volvox and Scapholeberis no change in sense of reaction could be induced by means of adding $\mathrm{CO}_{2}$. They become quiet and sink to the bottom after the $\mathrm{CO}_{2}$ reaches a certain concentration. I was unable to change the sense of reaction to light in several different zoeae and in the larvae of Hydroides dianthus by means of hydrochloric-acid solutions. The hydroides larvae were exposed in sea-water solutions of $\mathrm{HCl}$ varying in strength from $n / 250$, in which they were immediately killed, to $n / 7250$, in which their response was nurmal in every respect, both in light intensities so low that they were positive and so high that they were negative.

In Arenicola larvae however the sense of reaction to light can be reversed by means of various chemical solutions. These larvae are strongly positive during the first few days, even in very intense light. They swim freely through the water near the surface. Later they settle to 
the bottom and become slightly negative to light. On August 6, I909, a considerable number of larvae, a few hours after they had emerged from the egg-strings, were put into each of several small glass aquaria containing sea water. The larvae were strongly positive in the light intensity in which they were exposed. To one of the aquaria distilled water was added drop by drop, until the larvae no longer responded to light; to another concentrated sea water was added, and to each of the others a weak solution of one of the following chemical compounds: chloroform, adrenalin, atropin, carbonic acid, hydrochloric acid, acetic acid, magnesium sulfate, magnesium chlorid, ammonia and sodium hydrate.

After the larvae became neutral in each solution, they were left undisturbed. If they became positive in the course of a few minutes, as frequently happened, the solution was made stronger until they became neutral again. In the solutions containing carbon dioxid, caffeine, distilled water or concentrated sea water, the larvae became negative in the course of a few minutes and collected at the side of the aquaria farthest from the source of light, but in no instance was the negative reaction as marked and precise as the positive had been. There was no very definite orientation in the negative specimens, no such streaming from the source of light as there is toward it under normal conditions. Many of the larvae in each solution settled to the bottom of the aquaria and remained there, having apparently lost all power to respond to light. The larvae in the solution containing magnesium sulfate, magnesium chlorid, hydrochloric acid, acetic acid, ammonia, sodium hydrate or atropin, also became negative, but it required a much longer time. In some of these solutions the larvae did not become negative until several hours after the compounds had been added.

After becoming negative the larvae usually remain so permanently, or at least for several hours. For example, those which became negative in the afternoon of August 6 
were still negative the following morning. Many of those in diluted sea water and in sea water containing $\mathrm{CO}_{2}$ were, however, positive after being in over night. In these aquaria there were two collections, one at the end toward the light and one at the opposite end. In those solutions containing ammonia, sodium hydrate or magnesium sulfate the aggregation at the negative side of the aquarium was much more pronounced the following morning than it had been the preceding evening. Larvae taken from any of these solutions and put into normal sea water became positive in the same light intensity almost immediately in every instance. I did not succeed in producing reversal in reactions with chloroform or adrenalin, nor did I succeed by changing the temperature. The experiments under these conditions were, however, not very extensive.

It is at once evident that there is a striking difference between the reversal in reaction in such forms as Chlamydomonas and Arenicola larvae. In the former the change is comparatively sudden, sharp and definite, and the negative orientation is as accurate and precise as the positive orientation. In the latter the change is comparatively slow and indefinite, and negative orientation is much less precise than positive orientation. In Arenicola larvae it appears that any condition which acts as a depressant tends to cause the young positive larvae to become negative. These larvae become negative under normal conditions as they grow older. Depressants apparently hasten the appearance of this state, and under their influence larvae become negative earlier than they otherwise would.

d. Effect of concentration of the medium and mechanical stimuli. - We have already stated the fact that Arenicola larvae become negative both in concentrated and in diluted sea water. Loeb (1893, pp. 94, 96) was able to make negative Polygordius larvae positive by adding I to I.3 per cent. $\mathrm{NaCl}$ to the sea water and positive individuals negative by diluting the sea water with 40 to 60 per cent. fresh water. Similar results were obtained with cope- 
pods. Minkiewicz (I907, p. 50) says that Lineus ruber, which is ordinarily negative in the regions of the spectrum toward the violet end and positive in those toward the red end, becomes positive in the former and negative in the latter if subjected to a solution consisting of 25 to 80 c.c. of distilled water and Ioo c.c. of sea water, but that the reactions to white light remain negative. There may then be, according to Minkiewicz, a reversal in the sense of reaction to light of given wave lengths without a reversal in the sense of reaction to white light.

In working on the light reactions of Temora longicornis, a copepod, Loeb (I905, p. 282) noticed that the animals, ordinarily negative, were frequently positive immediately after being caught. This change in the sense of reaction was due probably to mechanical agitation. Miss Towle (I906, p. 345) obtained similar results. She found that the light reaction of Cypridopsis could be temporarily changed from negative to positive by taking the animals up in a pipette or by making them pass through a maze constructed with needles, but that they could not be changed in the opposite direction. In certain organisms however precisely the opposite change takes place. Holmes (1905, p. 319) observed that Ranatra becomes negative if it is handled under water or taken from the water and dropped in again. He also (I90I) thinks that the fact that Orchestia gracilis is positive in air and negative in water may be due to the contact stimulus of the water. It is of interest to note that while these animals are permanently negative in sea water they become positive in fresh water shortly before they die. The copepod Labidocera, which is ordinarily positive to light, can, according to Parker (I902, p. I I 7), be made temporarily negative by vigorously ejecting it from a pipette into sea water several times.

e. Effect of internal changes. - There are many organisms which respond to light in one way during part of their existence and in a different way, or perhaps not at all, 
during another. Thus we find the plumules of many of the grasses (gramineae) very sensitive to light during the early stages of development and not at all later. Fly larvae are strongly negative, but the imagos are positive. Loeb (I906, p. I34) found that the nauplii of Balanus are positive when they leave the egg, but that they become negative soon afterward. I have observed similar changes in reactions in the larvae of Arenicola, Limulus, and Hydroides dianthus, in various larvae of crabs and in the medusae of Bougainvillea. There is a striking peculiarity connected with the change in the sense or reaction of Limulus larvae. When these animals proceed toward the source of light they always swim, but when they proceed from it they always crawl. They usually swim most of the time when they are young and are positive, but when they get older they nearly always crawl on the bottom and are negative. If specimens which are crawling from the source of light are agitated until they swim they proceed toward the light, but as soon as they touch the bottom and begin to crawl they go away from the light. I have repeatedly seen specimens in a glass dish swim toward the source of light against the side of the dish, sink to the bottom and crawl from the light several centimeters, then start up again and swim toward the light, and so on, repeating the process many times. Contact seems to have something to do with the sense of reaction here, but the fundamental causes of the changes are no doubt rooted in the developmental changes in the organism associated with its habits. In nearly all of the species mentioned above the changes in the sense of the reactions are undoubtedly adaptive. When the larvae first leave the egg they are strongly positive, and swim out in various directions from the site of their birth so as to become widely scattered. Later, when the developmental processes prepare them for sedentary life, they become negative and consequently go to the bottom, where they become attached or burrow in the mud. It is not probable that the 
different conditions of light are of vital importance to these creatures. The reactions are in reality responses not to light, but to what light represents. They appear to have learned to use light as a guide in directing their course in accord with the demands of their state of development and general habits.

Hadley (1908) made a very thorough study of the changes in the photic reactions of lobster larvae. He found that they are positive for about two days after hatching, after which they become negative and remain so until shortly before molting, when they again become positive. Both the early second-stage, and the thirdstage larvae are negative but as in the first stage they become positive before molting. The fifth and later stages are persistently negative.

It has long been known that changes in light cause daily periodic movements in plants, the so-called sleep movements of leaves and flowers, and that these movements continue for some time if the plant is kept in continuous illumination. Pfeffer (1906, p. I08) says, "The periodic movements are at first pronounced, both in constant light and in darkness, in the case of the leaves of Acacia lophantha, Mimosa pudica, Impatiens noli-metangere, and Sigesbeckia orientalis, and they continue to be perceptible until after the lapse of four to eight days."

Similar after effects have been noted in certain animals. Mitsukuri (I9OI) observed that the mollusk Littorina is negative when under water during high tide and positive when it is exposed to the air at low tide. Bohn (I905 and I907) made similar observations on Littorina, Hedista diversicolor, and Actinia equina, and claims for them that these periodic changes in the sense of reactions to light continue in harmony with the tide for some days in specimens confined in aquaria where they are not directly affected by the tides. I was unable to confirm the results recorded by Bohn in observations on Littorina littorea at 
Woods Hole. Nor was I able to confirm them in observations on several related species at the Tortugas.

We have thus presented various instances in which an organism is positive under given external conditions at one time and negative under precisely the same conditions at another time. In some cases this change in reaction requires a long time, in others only a few moments, as e.g., in the reaction of Volvox represented in Fig. 33. It is evident that such changes must be regulated by internal factors, that they must be due to alterations within the organism itself. As a matter of fact, all reactions are directly controlled by internal factors which are in turn influenced by external factors. The interesting point here is however the fact that we may have movements and change in movements without any immediate changes in the environment. Many instances of this have been cited by Jennings (1906), especially in Chapter XVI.

The facts (I) that the reactions may be affected in the same way in a given organism by so many contrasting conditions, including concentration and dilution of medium, high and low temperature, acids, alkalis, narcotics and salts; (2) that the same change in external conditions may cause opposite reactions in different organisms, e.g., a rise in temperature causes some to become negative and others positive; and (3) that the sense of reaction may change without any immediate external change, - indicate that these responses are due not to a direct and specific effect of the environment on some definite chemical compound within the organism, but rather to the effect on the organism as a whole. 


\section{CHAPTER XIV}

\section{FACTORS INVOLVED IN REGULATING REACTIONS TO LIGHT - VARIABILITY AND MODIFIABILITY IN BEHAVIOR (continued)}

I. Changes in Sensitiveness, in the Optimum, and in Various Other Features Regarding Reactions

THE sensitiveness and the optimum vary greatly in different organisms and in the same organism under different conditions. In some the optimum is nearly total darkness, in others it is direct sunlight, $5000 \pm \mathrm{ca} . \mathrm{m}$. Some are negative in extremely low intensities, others are positive in equally low intensities. The flatworm Bipalium kewense, e.g., avoids light so weak that it barely affects the human eye, and responds to the slightest changes in illumination; and the plants Lepidium sativum, Amaranthus melancholicus ruber, Papaver paeoniflorum, and Lunularia biennis bend toward the source of light in an intensity as low as $0.00033 \mathrm{ca}$. m. (Figdor, I893). Some organisms are usually negative in direct sunlight, and the intensity may be changed thousands of candle meters without a response. Other organisms are positive in equally high light intensity. What interests us here chiefly is not the difference in response in different species, but variability in response, and the changes in sensitiveness and in the optimum in given individuals and the regulation of such changes.

Strasburger (I878) found that if swarm-spores are kept in light of relatively high intensity their optimum is much higher than if they are kept in weak illumination. These organisms, then, adapt themselves in some way to the 
environmental conditions. They tend to become attuned, as Strasburger puts it, to the light intensity of their environment; they become acclimated. The sensitiveness and the optimum, as well as the reactions in general, at any given time, depend upon the preceding exposure of the organism. This is well illustrated by the behavior of Volvox as observed by the writer.

On July 30, I904, at 5 P.M., it was found that Volvox, which had been collected at 6 A.M. and kept in the dark all day, responded definitely to light of 0.I6 ca. m. intensity, and quite definitely to light of 0.14 ca. $m$. This is the lowest intensity to which any response was obtained at any time. Specimens collected shortly after I2 M., July I4 and 15 respectively, and tested as soon as brought into the laboratory, responded to light of 0.50 to $0.83 \mathrm{ca} . \mathrm{m}$. The sky was clear on both of these days, but the organisms were found among the water plants in more or less shaded places.

It was found at different times that after being exposed to direct sunlight a few moments the colonies did not respond even to an intensity as high as $500 \mathrm{ca}$. m. We have thus observed the threshold to vary from 0.I4 to 500 ca. m., and this variation seems to have been due largely to preceding exposure to light. The threshold is higher in colonies previously exposed to strong light than in those exposed to weak light.

The optimum light intensity for practically all Volvox colonies is somewhat lower than that of direct sunlight, $5000 \pm$ ca. m., but sometimes it is very much lower; it varies greatly. This variation is clearly shown in the following observation:

After a few very cloudy days the sun came out at II A.M., July 24, 1904, and the sky became exceptionally clear and remained so the remainder of the day. At 2 P.M. Volvox colonies were found in abundance freely exposed to the sunlight. Some of the colonies were collected and taken to the laboratory, where it was accidentally discovered that 
they were negative in light intensities in which this organism had formerly always been found to be strongly positive. I then tested the colonies for the optimum and was greatly surprised to find that they were negative to all light intensities above $0.57 \mathrm{ca}$. $\mathrm{m}$. In light from 0.57 to $0.29 \mathrm{ca}$. m., the lowest intensity to which they were exposed, their reactions were indefinite. There was no indication of any positive reaction whatever.

At different times a number of colonies were taken from a given jar and half of them put into each of two similar vessels containing equal amounts of water. One of the vessels was then exposed to direct sunlight and the other covered so as to exclude all light. After having been in this condition a short time the reactions of the colonies in the two ressels were compared by exposing both to the same light intensity. In such cases it was always found that the specimens which had been in direct sunlight were negative to light of lower intensity than those which had been in darkness. These results indicate that the colonies had not become acclimated to the high light intensity. But they do become acclimated under certain conditions, judging from the observations of Oltmanns, who says (I892, p. I90), that he covered two lots of Volvox with the same kind of prisms, July $3 \mathrm{I}$, in the evening. One of these lots with its prism was kept in darkness until 9 A.M., August I, the other was exposed to light. During the following three days it was found that those which were in darkness until 9 A.M. collected in regions of lower light intensity than the others. Strasburger found the same to be true with reference to the reactions of swarm spores. It seems strange that the effect upon the optimum in colonies exposed for so short a time could, as Oltmanns states, be still observed after three days.

There are some indications that when Volvox is negative to light of low intensity it becomes positive when exposed to a much higher intensity. This is shown by the following observations: 
August 23, I904, was a bright, clear day. At 4 P.M. specimens were collected in a place which had been well exposed to the sun much of the afternoon. Soon after reaching the laboratory, these specimens were found to be positive in light intensities varying from 230 to $1400 \mathrm{ca} . \mathrm{m}$. The colonies not'used in these tests were put into a liter jar and placed in strong diffuse sunlight in a west window. Here many of the colonies soon aggregated on the side of the jar farthest from the source of light. At 5.45 P.M., after having been in the window about an hour, they were found to be negative to an intensity of $230 \mathrm{ca}$. m. and at 6.45 P.M. to an intensity as low as $3 \mathrm{ca}$. $\mathrm{m}$. They seemed to become more strongly negative the longer they were left in the window, although the light from 6.30 P.M. on was quite dim. At the close of the experiment, 7 P.M., certain colonies which had been strongly negative to an intensity of $230 \mathrm{ca}$. $\mathrm{m}$. were found to be positive to an intensity of $400 \mathrm{ca} . \mathrm{m}$. The following day these organisms were exposed again to light of $\mathrm{I} 400 \mathrm{ca}$. $\mathrm{m}$. and to various lower intensities, but there were no indications of negative reactions.

In certain cultures of attached specimens of Stentor coeruleus kept in low light intensity I have seen some specimens respond definitely by violent contraction to a sudden increase of illumination of even less than $120 \mathrm{ca} . \mathrm{m}$., while other specimens in the same culture did not respond at all, even to a much greater increase. In other cultures under the same environmental conditions none of the specimens could be made to respond even by flashing the most intense direct sunlight $(5000 \pm$ ca. m.) upon them.

Free-swimming individuals at times avoid even the faintest illumination, while at other times they are found in strong, diffuse daylight. These creatures apparently become accustomed to light very readily. They were often observed to give very definite responses in diffuse light when first taken from a culture jar, and none at all 
after they had been exposed five minutes. Many similar instances have been cited in the preceding pages, notably those with reference to reactions to shadows.

It will thus be seen that there is a tendency in organisms toward adaptation to environmental conditions. Exposure to low intensity tends to lower the optimum and increase the sensitiveness, while exposure to high intensity tends to produce the opposite effect. But momentary exposure to high intensity, as we have seen in Volvox, may actually lower the optimum. The reaction of an organism depends not only upon the rate of change in illumination and the intensity, but also upon the time it is exposed.

Among the most interesting and conclusive observations on variation and modification in reactions to light are those of Mrs. Yerkes (1906) and Professor Hargitt (1906) on the annelid, Hydroides dianthus. Hydroides, as previously stated, ordinarily jerks rapidly back into its tube when the light intensity is suddenly decreased, but it does not respond when the intensity is increased. This is clearly a reaction to a sign. The decrease of intensity, the shadow, is of no direct consequence to these creatures, but what ordinarily follows the shadow, an attack of an enemy, may be.

Mrs. Yerkes was primarily interested in modification of behavior. She selected two specimens, one of which did not respond at all to a given reduction of light intensity and the other responded only once. Both however reacted definitely when lightly touched. For ten days these two specimens were subjected to a series of stimulations consisting of shadows followed by light tactile stimuli. The first day one responded to the shadow, alone, three times in forty trials, and the other only once. In the former there was a great increase in the number of responses to shadow from the fourth to the eighth day, then a slight falling off. In the latter the increase was not so great, but still it was definite, especially from the second to the fifth day. It thus appears that these creatures 
learned to react to the shadow, the sign of the tactile stimulus that regularly followed it.

Hydroides becomes acclimated to a given stimulus with surprising rapidity. Mrs. Yerkes (I906, p. 442) found that in sixteen tests out of twenty-seven with different specimens the animals responded to shadows passed over them at regular intervals only from one to three times, after which the decrease of intensity did not appear to affect them at all.

Hargitt records similar results in a paper published a few months earlier than that of Mrs. Yerkes, and again in a later paper. He observed (I909, p. I79) that specimens taken at a depth of from eight to fifteen fathoms react to shadows only in an indefinite way, and that many do not respond at all, indicating clearly that the response depends upon past experience as well as upon present conditions. Jennings (I906) and others have observed similar effects of other stimuli on numerous different species.

One of the most interesting features in the behavior of Hydroides, and one that has been most accurately recorded, is the variation in the time that these animals remain in the tubes after responding to a given reduction in light intensity. In a series of ten trials Mrs. Yerkes (I906) found the time to vary from 15 to 240 seconds, and in another series of sixty trials from Io to 7 IO seconds. There is no apparent regularity in this variation. The author says, referring to the last series mentioned above (p. 447): "The period of retraction is short the first three times - I9 to $34^{\prime \prime}$ - but the fourth time it is nearly four minutes. For the next thirteen times it ranges from eighteen to ninety-three seconds; then comes another period of nearly four minutes followed by nineteen contractions which last from twelve to eighty-five seconds each and then a contraction of nearly twelve minutes' duration. Thus after the fourth, eighteenth, thirtyeighth and sixtieth trials the animal remained contracted for a relatively long period, varying from four to twelve 
minutes, whereas the intervening contractions seldom lasted more than one and a half minutes and are usually less than thirty seconds."

Hargitt (I909) extended these observations on the variability in reactions of the tubicolous annelids. Of especial interest are his results with experiments on specimens taken in deep water where shadows are very faint as compared with specimens taken from shallow water where changes of light intensity are striking. The following tables illustrate the character of these reactions (pp. I70, I 73) :

\section{TABLE VIII}

Showing reactions of specimens from deep waters ${ }^{1}$

August 9, I I A.M.

Temperature, $22^{\circ} \mathrm{C}$.
August 9, 2 P.M.

Temperature, $22.5^{\circ} \mathrm{C}$.

\begin{tabular}{|c|c|c|c|c|c|c|c|c|c|c|}
\hline & A & B & $\mathrm{C}$ & $\mathrm{D}$ & $\mathrm{E}$ & A & B & $\mathrm{C}$ & $\mathrm{D}$ & $\mathrm{E}$ \\
\hline I $\ldots \ldots$. & - & - & - & - & - & - & - & - & - & 一 \\
\hline $2 \ldots \ldots$ & - & - & - & - & - & - & - & - & - & - \\
\hline $3 \ldots \ldots$ & - & + Io & - & - & - & - & $+\mathrm{I} 8$ & - & +30 & +20 \\
\hline $4 \ldots \ldots$ & - & 0 & - & - & - & - & - & + & - & - \\
\hline $5 \ldots \ldots$ & - & $\circ$ & + & + & - & - & - & 0 & - & - \\
\hline $6 . \ldots \ldots$ & - & - & $\circ$ & $\circ$ & - & - & - & $\circ$ & - & - \\
\hline $7 \ldots \ldots$ & $+\mathrm{I} 2$ & +10 & ० & $\circ$ & - & - & - & ० & - & 一 \\
\hline $8 \ldots \ldots$. & - & - & ० & - & - & - & - & $\circ$ & - & - \\
\hline $9 \ldots \ldots$ & - & - & $\circ$ & - & - & - & - & $\circ$ & - & - \\
\hline Io....... & - & + & ० & - & - & - & - & $\circ$ & - & - \\
\hline II $\ldots \ldots$. & - & $\circ$ & $\circ$ & - & - & - & +35 & ० & - & - \\
\hline I $2 \ldots \ldots \ldots$ & - & - & 0 & - & - & - & - & $\circ$ & - & - \\
\hline I $3 \ldots \ldots \ldots$ & - & - & ० & - & - & - & - & $\circ$ & - & - \\
\hline $14 \ldots \ldots \ldots$ & - & - & - & - & - & - & - & $\circ$ & - & - \\
\hline $1_{5} \ldots \ldots \ldots$ & - & - & - & - & - & - & - & $\circ$ & - & - \\
\hline I6........ & - & - & - & - & 一 & - & - & $\circ$ & - & - \\
\hline I $7 \ldots \ldots$ & - & - & - & - & - & - & - & $\circ$ & - & - \\
\hline I $8 \ldots \ldots$ & - & - & 一 & 一 & - & - & - & $\circ$ & - & - \\
\hline I $9 \ldots \ldots$ & - & - & 一 & 一 & - & - & - & $\circ$ & - & - \\
\hline $20 \ldots . .$. & - & - & 一 & - & - & 一 & - & $\circ$ & - & - \\
\hline
\end{tabular}

${ }_{1}^{1}$ The numbers preceded by + represent time in seconds animals remained in tubes after stimulation. Minus sign indicates failure to respond; zero indicates that animal was in tube when stimulus was applied. The stimulus consisted in turning off a I6-candle-power electric lamp. The intensity is not recorded. Interval between successive stimuli, usually 5 minutes. (Hargitt, I909, Pp. I59 and I70.) 


\section{TABLE IX}

Showing reactions of two specimens $\mathrm{F}$ and $\mathrm{G}$, from shallow water.

Legend same as for Table VIII. See footnote.

\begin{tabular}{|c|c|c|c|c|}
\hline & \multicolumn{2}{|c|}{$\begin{array}{l}\text { IO A.M. } \\
22^{\circ}\end{array}$} & \multicolumn{2}{|c|}{$\begin{array}{l}2 \text { P.M. } \\
23^{\circ}\end{array}$} \\
\hline & $\mathrm{F}$ & G & $\mathrm{F}$ & G \\
\hline I $\ldots \ldots \ldots \ldots \ldots \ldots \ldots$ & 40 & 360 & I 5 & 20 \\
\hline $2 \ldots \ldots \ldots \ldots \ldots \ldots \ldots \ldots \ldots \ldots$ & 30 & 60 & I0 & 30 \\
\hline $3 \ldots \ldots \ldots \ldots \ldots \ldots \ldots \ldots \ldots \ldots$ & 30 & I80 & I 2 & 45 \\
\hline $4 \ldots \ldots \ldots \ldots \ldots \ldots \ldots \ldots \ldots \ldots \ldots \ldots \ldots \ldots$ & 33 & 60 & IO & 30 \\
\hline $5 \ldots \ldots \ldots \ldots \ldots \ldots \ldots \ldots \ldots \ldots \ldots$ & 60 & 50 & I 8 & 45 \\
\hline $6 \ldots \ldots \ldots \ldots \ldots \ldots \ldots \ldots \ldots \ldots \ldots \ldots$ & 45 & 50 & I 5 & 50 \\
\hline 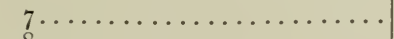 & 100 & 90 & I 2 & 35 \\
\hline 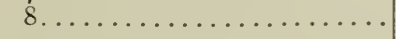 & - & 60 & I3 & So \\
\hline 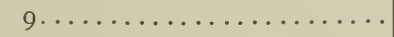 & 300 & 35 & - & 100 \\
\hline 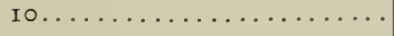 & 40 & I 20 & I5 & 40 \\
\hline II $\ldots \ldots \ldots \ldots \ldots \ldots \ldots$ & 30 & 300 & I 2 & I IO \\
\hline I $2 \ldots \ldots \ldots \ldots \ldots \ldots \ldots \ldots$ & I 80 & 60 & 45 & 90 \\
\hline I $3 \ldots \ldots \ldots \ldots \ldots \ldots \ldots$ & 43 & 90 & 75 & I5 \\
\hline I $4 \ldots \ldots \ldots \ldots \ldots \ldots \ldots$ & I 80 & 105 & 20 & 90 \\
\hline I $5 \ldots \ldots \ldots \ldots \ldots \ldots \ldots \ldots$ & 75 & 90 & 20 & 90 \\
\hline I $6 \ldots \ldots \ldots \ldots \ldots \ldots \ldots \ldots \ldots \ldots$ & 75 & I 30 & I2 & IO5 \\
\hline I $7 \ldots \ldots \ldots \ldots \ldots \ldots \ldots \ldots \ldots \ldots$ & 470 & 150 & - & 80 \\
\hline I $8 \ldots \ldots \ldots \ldots \ldots \ldots \ldots \ldots$ & 50 & I50 & I5 & 85 \\
\hline I $9 \ldots \ldots \ldots \ldots \ldots \ldots \ldots \ldots$ & 60 & 225 & II & 45 \\
\hline $20 \ldots \ldots \ldots \ldots \ldots \ldots \ldots \ldots$ & I 50 & 90 & I8 & - \\
\hline
\end{tabular}

The fact that there is no "definite law in relational sequence" in the reactions of Hydroides, especially the fact that the time that a given specimen remains in the tube varies so much without any observable regularity or relation with environmental changes, has led Hargitt to conclude that behavior of organisms cannot be explained by the application of purely physical principles and to sympathize "with a tendency to postulate the presence of certain psychic factors."

However one may regard Hargitt's conclusion, his results seem to show clearly that the immediate environment at any given time will not account for the reactions of Hydroides at that time, that they are. dependent upon 
internal as well as external factors, and that if the internal processes, physiological changes, do account for the variability in the reactions these processes cannot be running their course with any degree of regularity.

Among the crustaceans and the higher forms variability and modifiability in reactions to light are common. Holmes (I905) found that Ranatra with the left eye blackened tends to turn to the right in going toward a source of light, but after several trials it goes nearly directly toward it. "In the first trial the insect veered over constantly to the left, passed by the lamp and went off from the table before it turned around. In the following trials a marked tendency to turn to the left is also shown; frequently the insect makes one or more complete circus movements to the left before reaching the light. At the eleventh trial its course is corrected for the first time by a turn to the right side, but, instead of going straight up to the light, it performed a complete circus movement to the left before reaching it. The next time the course was corrected by a sharp turn to the right and the circus movement was dispensed with. At the next trial the course was corrected in the same way, and at the fourteenth attempt the insect deviated only slightly to the left side and then turned to the right to reach the lamp. In the following ten trials it reached the light by a nearly straight path. Whenever it began to turn away from the light to the left it corrected its course by a direct turn in the opposite direction instead of going around in a complete circle as at first."

Spaulding (I904) observed that hermit crabs are ordinarily positive. They usually collect in the more highly illuminated regions of an aquarium. But he found that after shading the part of the aquarium in which the crabs were fed every time that food was introduced, they soon came to the part shaded even before food was put in, quite contrary to their ordinary reaction to light.

In even casually studying the behavior of bees, wasps, 
ants and various insects in their natural environment, one can hardly fail to see that their reactions to light are anything but fixed. Ants, for example, ordinarily avoid the light. They are said to be negative. But they are not always found in the dark recesses of their nests. Does this mean that the sense of reaction changes? Light undoubtedly guides them at times, and the sense of reaction changes frequently, but sight no doubt plays a part in the reactions. If a nest containing pupae or larvae is opened, a given ant may often be seen, in caring for the young, to travel back and forth repeatedly from the brightest sunlight to the dark cavities of the nest. Here it is evident that the ordinary negative response to light has been modified. Again, the flight of bees from the extreme darkness of the hive out into the brightest sunlight, through shadow and sunshine, into and out of the cavities of flowers and back into the darkness of the hive again, offers another striking example of variability in response to light, for it is no doubt light that guides these organisms in many of their movements, although that in which they are primarily interested is not light, but the objects represented by different conditions or configurations of light.

We have thus seen that the reactions to light depend upon various agents, and that they are modifiable and variable to a certain degree in all organisms from the lowest to the highest, i.e., that they are in general adaptive and regulatory. But in none of the lower forms have such striking adaptive changes in reaction to light been observed as Jennings records with reference to other stimuli in his interesting description of the behavior of Stentor and some other organisms (I906, pp. I70-I79). There is at present no greater need in the study of the behavior of lower organisms than a comprehensive and thorough quantitative study of the relative activity of the different factors involved in regulation. 


\section{General Summary of Part III}

(I) Reactions to light are in general adaptive. There are, however, certain reactions which are clearly injurious and often fatal; as, for example, the flying of insects into a flame and the positive reactions of organisms which live in darkness. But the positive reactions of insects are ordinarily advantageous. It is only under artificial conditions that they prove fatal, and the ancestors of many animals which now live in darkness lived in the light. Positive reactions were probably advantageous to them. and the power to respond thus was probably inherited by the offspring, in which it is useless.

(2) Organisms ordinarily collect in light conditions which facilitate life processes. They get into an optimum light condition either by orienting and moring directly toward it or by random movements: and they remain either because they come to rest there or because theyrespond with the avoiding reaction when they reach the limit of the region of optimum light. All of the reactions involved in aggregation are responses to changes of intensity, with the probable exception of those in which the organisms come to rest at the optimum. In these. aggregation is no doubt due to the effect of continued illumination or constant intensity.

(3) Many organisms react to light without orienting or aggregating. In nearly all cases these reactions are sudden contractions or changes in direction of morement caused by sudden changes in light intensity. as, for example, the jerking into its tube of Hydroides when a shadow passes orer it. Most of these reactions are highly protective against the attack of enemies, but some serve to indicate the presence of food, as in the case of Clepsine. These are clearly reactions to signs. It is not the shadow in which these organisms are interested. but what ordinarily follows. There are, however, organisms which respond to the effect of light more directly; as, for example, 
the contraction of the sea anemone Edwardsia when light is flashed on it. It is the change of intensity that causes the response, but there is no evidence of a reaction to a sign here. These creatures are directly interested in the effect of the light which produces the response. Continued illumination probably affects the activity of all organisms that respond to light, and change in the sense of reaction when due to the action of light is in all probability due to the effect of continued intensity rather than to change of intensity.

(4) The actions of organisms may change without any change whatever in external conditions. They may, for example, be positive to light of a given intensity under given conditions at one time and negative to the same intensity under precisely the same external conditions at another. This change in reaction must be due to internal factors. It may take place in course of a few moments, as in Volvox, or it may require weeks, as in the case of the development of the fly, the larva of which is negative while the imago is positive. Then, again, it may be periodic, as in the sleep movements of many of the plants.

(5) High light intensity ordinarily causes organisms in the positive state to become negative. There are, however, organisms which do not become negative no matter how high the intensity is, e.g., many plant structures and numerous aquatic larvae. Under natural conditions they do not experience illumination so strong that it is injurious; there is, therefore, no need for a negative response. The positive reactions of insects and other forms which frequently prove fatal under artificial conditions are adaptive under natural conditions.

Reversal in the sense of reaction is not a response to a change of intensity. It does not take place until some time after the change is made. There is a time element involved here. It is due to changes occurring within the organisms, caused by continued light conditions, not by changes in such conditions. 
(6) Decrease in temperature causes swarm-spores, Euglena, Chlamydomonas, Volvox and other similar organisms in the positive state to become negative. Increase of intensity causes the opposite change. Decrease in heat energy, therefore, causes the same change in reaction in these forms as increase in light energy. In other forms however this is not true. Polygordius larvae, for example, become negative when the temperature is increased. In many organisms changes in temperature do not cause reversal in the sense of reaction.

(7) In Gammarus pulex, Cyclops, Daphnia, Cypris, a small water spider, and various insect larvae, addition of $\mathrm{CO}_{2}$ causes the reactions to light to become strongly positive. In Gammarus various acids and narcotics and all the ammonium salts also cause strong positive reactions. In Cyclops sodium hydrate causes positive specimens to become negative. In Stentor, Chlamydomonas, Volvox, and Scapholeberis carbon dioxid does not cause a change in the reaction. In Arenicola larvae various narcotics, acids, alkalis and neutral salts - in general, apparently any substance which acts as a depressant - cause a change from positive to negative reactions. In Ranatra any condition which tends to make the animal quiet produces negative reactions, while any condition which excites it tends to produce positive reactions.

(8) The sense of reaction in most organisms is only temporarily affected by concentration of the medium or mechanical stimulation. Arenicola larvae become negative in both concentrated and diluted sea water, while Polygordius larvae become positive in the former and negative in the latter.

Mechanical stimulation appears to cause Temora and Cypris to become positive, while it causes Ranatra, Orchestia and Labidocera to become negative.

(9) The fact that change in sense of reaction can be produced by such a variety of different means seems to show very clearly that this change is not due to a specific 
interaction between external and internal chemical constituents, as, for example, a relation between acids and alkalis, but to an effect on the general state of the organism as a whole.

(Io) Variability and modifiability in response to a given external condition are striking characteristics in the behavior of all living beings. The optimum and sensitiveness in swarm-spores, diatoms, Euglena, Stentor, Volvox and other similar organisms have been found to change in accordance with the environment. If they are exposed to strong illumination for some time the optimum intensity increases and the sensitiveness decreases. If exposed to low intensity the opposite change takes place. Not only the light intensity, but also the time of exposure, is active in these changes. Momentary exposure may produce results just the opposite from those due to continued exposure. Changes in response frequently occur without any immediate changes in the environment. These changes are regulated by internal factors, physiological processes. Many of the responses to a given light condition are extremely variable. This is due to the fact that numerous factors, both internal and external, are involved in these responses. Concerning the internal factors little is as yet known. 


\section{PART IV}

\section{REACTIONS IN LIGHT OF DIFFERENT WAVE- LENGTHS OR COLORS}

\section{CHAPTER XV}

\section{ENERGY, PHOTOCHEMICAL REACTIONS AND BRIGHTNESS}

IT is assumed by some investigators that the reactions to light in lower forms, plants as well as animals, are all induced by waves of approximately the same length, and that these waves are the more refrangible in the spectrum, the so-called actinic rays, the rays which are generally supposed to have the greatest effect on chemical reactions.

Davenport (I897, p. 202) closes a brief review of the literature on this subject with the following words: "Thus, without multiplying cases, the results of experiments may be summed up as follows: positively phototactic or positively photopathic organisms are such only in the presence of the blue rays." Referring to experiments with numerous different animals, Loeb says (I905, p. 294), " “ [I] found a universal confirmation of the fact .. . that the more strongly refrangible rays of the visible spectrum are the most active heliotropically, as in the case of plants."

Other investigators have, however, arrived at different conclusions. They claim that all the rays in the visible spectrum and some in the ultra-violet may be active in stimulating organisms and that not all organisms are equally stimulated by the different rays. After disagreeing with Loeb's statement that the shorter waves are the more efficient in all plants and animals, Nagel adds (I90I, p. 294), "Es ist sehr wahrscheinlich dass für sehr viele

1 Original in Pflüger's Arch., Vol. 54, I893. 
lichtempfindliche Thiere das Maximum der Reizwirkung im Gelbgrün liegt, dass sie mit anderen Worten lichtempfindliche Substanzen besitzen die dem Sehpurpur der Wirbelthieraugen ähnlich sind." Pfeffer (I906, p. I75) maintains that " the relative efficiency of the different rays is not the same in all plants," and Verworn says (I889, p. 60), "Es hat sich herausgestellt, dass die meisten Protisten nur auf bestimmte Farben, d. h. Strahlen von bestimmten Wellenlängen reagiren, welche durchaus nicht für alle die gleichen sind." It is therefore evident that with reference to the reactions of the lower forms there are contradictory opinions as to the efficiency of the different rays of light. The same may be said in regard to animals with image-forming eyes.

Let us review the more important of the experiments which have led to these contradictory opinions and try to formulate the conclusions to which they lead.

In this review we shall first attempt to ascertain the efficiency of different parts of the spectrum in producing reactions in various plants and animals, then we shall compare this with the distribution of energy in the spectrum, with the distribution of brightness as judged by the human eye, and with the distribution of actinic or photochemical effect.

Sunlight, as is well known, consists of ethereal vibrations composed of waves varying in length from approximately $390^{\mu \prime \prime}$ to $760^{\mu \mu}$. Aside from varying in length, light waves may also vary in amplitude, and then there may be innumerable combinations of waves of different lengths. These three different physical characteristics of light are said to produce different specific subjective sensations in man, known respectively as color-tone or hue, brightness or shade, tint or saturation. The subjective sensations are in all probability in some way associated with the effects of light on chemical changes in the retina.

Monochromatic light, or light having a fixed color-tone, consists of waves which are equal in length. In accord 
with the above supposition there are, therefore, theoretically as many different color-tones in the visible solar spectrum as there are different wave lengths. Practically, however, these numerous theoretical hues are divided, usually into six classes, - violet, blue, green, yellow, orange and red. Authorities differ but little as to the point of division in the spectrum between the different colors. Selecting the classification most commonly found we shall refer to wave lengths 390 to $430^{\mu \mu}$ as violet, 430 to $490^{\mu \mu}$ as blue, 490 to $560^{\mu \mu}$ as green, 560 to $590^{\mu \mu}$ as yellow, 590 to $630^{\mu \mu}$ as orange, and 630 to $760^{\mu !}$ as red.

\section{Energy Distribution in the Spectrum}

The distribution of energy in the solar spectrum as well as that in various artificial spectra has been thoroughly investigated, as has also that of the effect of different rays on a number of different chemical reactions and the distribution of brightness as judged by the human eye. In a recent paper Nichols (1905) has summarized much of the work on the energy in the visible spectrum. He gives the curves of distribution for the normal or grating spectrum of the following sources of light: Hefner lamp, acetylene lamp, petroleum lamp, illuminating gas with different burners, Welsbach mantle, various electric incandescent carbon filaments, magnesium flame, direct and diffuse sunlight and a few others. While the distribution of energy in the spectrum differs considerably with the different sources of light, it corresponds in that the energy toward the red end is much greater than that toward the violet (Fig. 34). There is only one exception to this: in case of magnesium oxide the energy is "greater in the violet than in the yellow and green" (l.c., p. 159).

In the normal gas spectrum the energy increases very gradually from the beginning of the violet to the beginning of the green at about $5 \mathrm{Oo}^{\mu \mu}$, then it increases very rapidly and reaches its maximum at the end of the red. 
At $450^{\mu \prime \prime}$ (with a bat's wing burner) the energy is represented by $0.1 \mathrm{I}$; at $50 \mathrm{O}^{\mu \mu}$ by 0.52 ; at $700^{\mu \mu}$ by 12.70 . In the red, then, the energy is 100 times as great as in the violet and about 20 times as great as in the green. In case of direct sunlight the maximum energy in the normal spectrum is between the yellow and the orange. From this point there is a gradual decrease toward the red end and a somewhat more rapid decrease toward the violet. The difference in energy in different parts of the normal sunlight spectrum is not nearly so great as in the normal gas spectrum. In the prismatic spectrum of both gas and sunlight it is, however, much greater than in the normal spectrum, owing to the relatively greater condensation of the rays toward the red end. Whereas the maximum in the normal sunlight spectrum is between the yellow and the orange at about $60 \mathrm{o}^{\mu \mu}$, in the prismatic spectrum it is, according to Langley (I884), at the end of the red or perhaps even in the infra-red. (Fig. 34.)

\section{Brightness Distribution in the Spectrum}

The determination of relative brightness of different parts of the spectrum is a matter of considerable complexity, owing largely to the difficulty of comparing different colors with reference to brightness and to the fact that the relative brightness of the different colors varies with the absolute intensity, a characteristic known as Purkinje's phenomenon. In spite of these difficulties the results obtained by eight or more different methods, all refined in every detail, are in close agreement, indicating that the conclusions stated below are in all probability reliable.

The method most widely employed is the direct comparison of the different colors with white light of known intensity. By means of this method Fraunhofer in 1817 located the maximum brightness in the prismatic solar spectrum in the neighborhood of the line $D$. In I87I Vierordt 
obtained results which agree fairly well with those of Fraunhofer, by means of finding the amount of white light required to make a given color imperceptible when added to it. The results of Vierordt are graphically given in Fig. 34.

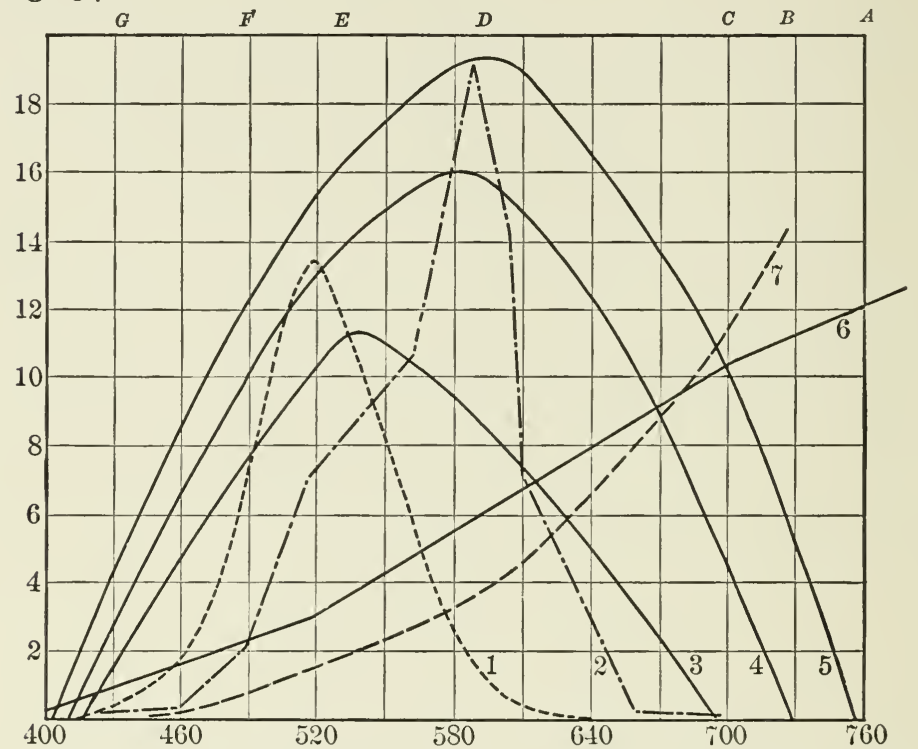

FIG. 34. Curves representing the relative distribution of brightness and energy in the spectrum. I, brightness curve for color-blind persons showing that the red end is considerably shortened (after König, I89I); 2, brightness curve for normal eye in prismatic solar spectrum (from Davenport, I897, p. 159, after Vierordt, 1873 , p. 17); 3, 4, and 5, brightness curves for normal eye in normal gaslight spectrum of low, medium, and high intensities respectively (after Haycraft, I897, p. I4I); 6, energy curve for solar prismatic spectrum (after Langley, I884, p. 233); 7 , energy curve for normal gas-light spectrum constructed from data given by Nichols, I905, p. I5I. The value of the ordinates in most of these curves is arbitrary. $A-G$, approximate positions of Fraunhofer lines in spectrum.

These curves show clearly that the distribution of brightness in the spectrum is not proportional to the energy of the different parts and that consequently brightness must depend upon the length of the waves as well as upon their amplitude.

Haycraft (I897, p. I40) ascertained the brightness distribution in a normal gas spectrum produced with Hilgar's large spectroscope and diffraction grating, by means of the so-called flicker method. The results obtained by this method, graphically recorded in Fig. 34, agree very well 
with those Haycraft obtained by measuring the size of the pupil in different parts of the spectrum and by determining the distance at which small areas differing in color become invisible. It will be seen by referring to Fig. 34 that the maximum brightness obtained in these experiments in light of high intensity is very near the Fraunhofer line $D$, that is, between the yellow and the orange, which agrees with the maximum in the solar spectrum obtained by Fraunhofer and Vierordt. It is interesting to note that in low light intensity the maximum is in the green, and that this corresponds fairly well with the maximum for color-blind individuals.

In case of color-blind individuals the difficulty of comparing intensity of different colors is of course obviated. The brightness distribution in the spectrum has been ascertained in several cases, all of which are in approximate agreement, the maximum being in the green near the Fraunhofer line $E$ (Fig 34), in fairly close agreement with the maximum for the normal eye in the spectrum of low light intensity.

By comparing the curves in Fig. 34 it is at once evident that the brightness distribution in the spectrum is not proportional to the energy. The distribution of brightness in the normal solar spectrum, the prismatic solar spectrum and the normal gas spectrum agrees fairly well in certain respects, while the distribution of energy in these spectra is very different. Brightness sensation is therefore associated with some specific effect of the length of light waves, as well as with the amplitude of the wave. Color sensation, on the other hand, is associated with the specific effect of the length of the waves and with the effect of combination of waves of different lengths. The specific effect of waves of a given length and amplitude is no doubt due to chemical changes in the retina. Visual purple is most rapidly bleached by the rays in the spectrum between the lines $D$ and $E$, the region containing the rays which are absorbed most readily, and the region which contains the 
maximum brightness. There is probably some interrelation between these phenomena. It is however not our purpose to discuss theories of vision. We wish merely to emphasize that experimental results appear to show that brightness is not proportional to the energy in light, that it is a function of wave length as well as of amplitude.

\section{Distribution of Actinic Effect in the Spectrum}

That light causes profound changes in chemical compounds is a matter of common information to all familiar with the process of photography. The fact that the shorter waves of the spectrum, the ultra-violet, violet and blue are chiefly active in causing changes in the halogen salts of silver and various other metals used in this process, is at least in part responsible for the idea that photochemical changes in general are largely if not entirely brought about by the action of the shorter waves, which are usually referred to as the actinic rays.

Photochemical reactions are far more numerous in both the inorganic and the organic realms than is generally supposed. Davenport (I897, pp. I6I-I65) brought together many instances under the following heads: synthetic, analytic, substitutional, isomeric, polymerismic, fermentative effects of light. Recent investigations have made known others which are of especial interest to us. Most important among these are numerous reversible reactions, reactions which take place in one direction in daylight or in light of a given wave length, and in the opposite direction in darkness or in light of a different wave length.

The following reversible equations are referred to in a recent paper by Stobbe (1908) on photochemical reactions. The first five are quoted by Stobbe, the rest were discovered by him. In these equations the arrows indicate the direction in which the reaction takes place in the different conditions of light with which they are labeled. 
In the first equation, for example, the reaction proceeds toward the right in the light and toward the left in darkness.
I. $2 \mathrm{AgCl} \underset{\text { dark }}{\stackrel{\text { light }}{\rightleftarrows}} \mathrm{Ag}_{2} \mathrm{Cl}+\mathrm{Cl}$.
2. $2 \mathrm{C}_{14} \mathrm{H}_{10} \underset{\text { dark }}{\stackrel{\text { light }}{\rightleftarrows}} \mathrm{C}_{28} \mathrm{H}_{20}$.

3. $5 \mathrm{AgI} \underset{\text { dark }}{\stackrel{\text { light }}{\rightleftarrows}} \mathrm{AgI}_{3}+2 \mathrm{Ag}_{2} \mathrm{I}$.

4. Tetraphenyldihydrotriazin.

$$
\text { White } \underset{\text { dark }}{\stackrel{\text { light }}{\rightleftarrows}} \text { rose red. }
$$

5. Dimethyloxalessigesterphenylhydrazon.

$$
\text { White } \underset{\text { dark }}{\stackrel{\text { light }}{\rightleftarrows}} \text { citron yellow. }
$$

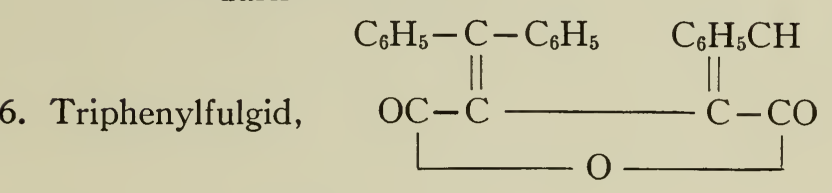

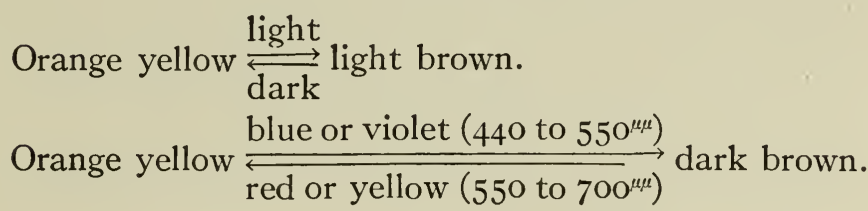

7. $\beta$-Tetrachlor- $\alpha$-ketonaphtalion, $\stackrel{\mathrm{HC}}{\mathrm{I}}$ II

White $\underset{\text { yellow green }}{\stackrel{\text { ultra-violet }}{\rightleftarrows}}$ violet.

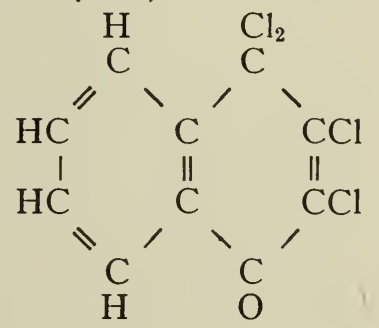


In the last two equations it is clearly shown that the longer waves as well as the shorter are actinic. Stobbe investigated the reactions of numerous so-called fulgides in the different rays of the spectrum ("Steinheilschen Spectrographen") and found seventeen which behave much like triphenylfulgid. There is however considerable variation as to the specific effect of the rays in the different forms. In general the shorter waves cause the fulgides to become darker in color, while the longer ones cause them to become lighter. But in some it is the violet which produces the dark shades, while in others it is the ultra-violet or the blue. "Je mehr sich die Farbe eines Fulgides vertieft, je weiter sich die Absorption eines Fulgides nach dem rothen Ende des Spectrums erstreckt, um so weiter rückt auch die Erregungszone nach derselben Richtung vor" (I908, p. 3I).

In white light the fulgides turn dark, just as in monochromatic light, but strange as it may appear the reaction is much less pronounced, even if the white light has more of the effective rays than the monochromatic light of any given region in the spectum. The relatively feeble effect of white light must be due to the presence of the longer waves, which, as represented in the equation above, tend to produce the lighter shades and consequently retard the production of the darker. It may be well to call attention to the fact in passing that the investigations of Lubbock on Daphnia, of Wilson on Hydra and of Wiesner on some of the higher plants show that as in the fulgides, monochromatic light consisting of certain rays is more effective in causing reactions than the same light in combination with other rays.

It is evident from the last two equations that the longer rays as well as the shorter may have a specific photochemical effect. Triphenylfulgid, e.g., is changed from dark brown to orange yellow by the longer waves and not by the shorter. There are many other reactions which are induced only by the longer waves. Among the most 
important of these the process of photosynthesis in plants furnishes an excellent example. The maximum for this process lies in the red very near the Fraunhofer line $C$. This is not solely due to the fact that the rays in this region are more readily absorbed than those in the adjoining regions, for the violet rays are also absorbed, and here there is no appreciable effect on photosynthesis. In solutions which contain ferrocyanide or certain other coloring matter the longer waves are also more effective than the shorter, and pure ozone, which is changed to oxygen only in the ultra-violet, is similarly acted upon by the visible rays if chlorine be added. These various examples inevitably lead to the conclusions that while the shorter rays may induce chemical changes in more substances than the longer, they cannot be considered as the only actinic rays. The relative efficiency of the different rays depends first of all upon one or more of the compounds between which the photochemical reaction is taking place, but it also, at least in certain cases, depends upon the presence of substance in which no apparent change is taking place.

Many of the photochemical reactions are exothermal. For example, the light conditions which induce the fulgides to become dark are much more effective in lower temperature than in higher. According to Stobbe it requires nearly ten times as much light energy to produce a given change at $100^{\circ}$ as it does to produce the same change at $87^{\circ}$. A decrease in heat energy, therefore, produces the same effect as an increase in light energy, a statement which at first thought appears self-contradictory. As a matter of fact, however, it merely demonstrates the independence of these two forms of energy in producing chemical reactions.

It is evident from what has thus far been presented that the actinic distribution in the spectrum is not proportional to distribution of energy. There are many well-known photochemical reactions which occur only in 
ultra-violet, the region of the spectrum which contains least energy.

Precisely how light produces chemical changes is unknown, but it is clear that only those rays which are absorbed can be effective. The efficiency is however not proportional to the absorption. According to the excellent researches of Luther and Forbes (1909), the reaction between quinine and chromic acid is only affected by the rays absorbed by the quinine, and not at all by those absorbed by the chromic acid. Only about 4 per cent of the light absorbed by the quinine is changed to chemical energy. The ultra-violet and violet are most readily absorbed, but the green is most efficient, i.e., a greater amount of chemical action is caused by a given amount of light energy absorbed in the green than by the same amount absorbed in the violet and ultra-violet, showing clearly that the efficiency is not proportional to the absorption. The same is true in case of photosynthesis, which is supposed to be due to the action of light absorbed by the chlorophyll. Chlorophyll dissolved in alcohol has, according to Reinke ( 1884 ), a prominent absorption band in the red, a weak band in the orange, the yellow and the green, while from $50^{\mu \mu}$ on, i.e., in the blue and violet, practically all light is absorbed. The maximum rate of photosynthesis however takes place in the red, from which it decreases rapidly in either direction, so that beyond the green in the region of maximum absorption there is scarcely any photosynthesis.

The specific effect of the different rays on chemical reactions as well as on brightness sensation is evidently a function of the length of the waves and the rate of vibration. The effect of the different rays is not proportional to the energy in these rays, but the effect of light of a given wave length is of course dependent upon the amplitude of the waves, their intensity, as well as upon their length. 


\section{CHAPTER XVI}

\section{EFFECT OF DIFFERENT RAYS ON THE REACTIONS OF SESSILE PLANTS}

IT is evident that as in inorganic and organic compounds and in man, so in the lower organisms, the reactions to light may be due to or at least associated with a specific action of the length of the light waves, or with the amplitude of the waves, or with a combination of waves of different lengths. In experiments on the effect of colored light on organisms it is therefore essential to know what sort of light is being used as a stimulating agent; many results are unreliable because this was not known, or at least is not recorded. The colors used were frequently produced by means of solutions or colored glass which transmit waves varying much in length. In case of red glass, e.g., there is usually some orange and yellow and frequently a little blue, violet or ultra-violet transmitted as well as the red. A reaction in such light, apparently due to the longer waves may actually be due to the shorter, or to the specific effect of the combination. Then, too, the relative intensity of the different colors was often not considered. There was then the possibility that the reactions were due to intensity rather than to color.

The bearing of this discussion becomes evident when we consider the fact that some organisms are sensitive to light of extraordinarily low intensity; e.g., Figdor (I893) found the plants Lepidium sativum, Amaranthus melancholicus ruber, Papaver paeoniflorum, and Lunularia biennis to respond to light as weak as $0.00033 \mathrm{ca}$. m. In organisms so extremely sensitive it is evidently impossible to be certain as to what causes a reaction if they are not subjected to monochromatic light of known intensity. In 
organisms which are not very sensitive it is, however, unlikely that a few stray foreign rays mixed with a given color will alter the reactions. In reviewing the work on reactions in colored light and formulating conclusions it will consequently be necessary to consider carefully the methods used in such work.

Poggioli (I8I7) was the first to study the relative effect of light waves of different lengths on the reactions of plants. He exposed seedlings of Brassica and Raphanus in different parts of the spectrum and found that they turn toward the source of light in the red as well as in the violet, but that the reaction in the latter occurs much more rapidly than in the former. He does not mention the reaction in other parts of the spectrum. These results seem to have remained unchallenged for twentyfive years, when Payer ( 1842 ), after studying the reactions of different seedlings in a solar prismatic spectrum and behind different color media, came to the conclusion that red, orange, yellow and green act like darkness, and that blue is more active than violet. This conclusion, however, although supported by Sachs, is not in harmony with the experimental results of Gardner, Dutrochet and Pouillet, Guillemin, Wiesner and others. Gardner (I844) found that all the seedlings in a trough which extended beyond the solar prismatic spectrum into the ultra-violet and the infra-red bent toward the sources of light, but that they deflected slightly toward the indigo. The deflection toward the indigo was no doubt due to light reflected by the seedlings in this region of the spectrum. Dutrochet and Pouillet (I 844) obtained similar results in their experiments with the roots of white and black mustard in a strong solar prismatic spectrum. They concluded that all the rays, including ultra-violet and infra-red, cause the roots to bend from the source of the light, but that the blue is most active.

Guillemin (1858) made a more detailed study of this subject than had previously been made. His methods 
were excellent. He studied the reactions of white mustard and cress seedlings in three different solar prismatic spectra produced respectively by means of flint glass, rock salt, and quartz. All diffuse light was eliminated by means of suitable screens, and twenty-five different tests were made. In all three spectra there were two regions of maximum effect. The primary maximum lay in the violet or ultra-violet in all cases, and the secondary maximum between the infra-red and the green. The minimum effect in all cases was in the blue near the Fraunhofer line $F$.

These conclusions were in the main confirmed by the thorough work of Wiesner (I879). Wiesner studied the reactions of stems and roots of several different seedlings behind thoroughly tested absorbing media and in different parts of a direct sunlight spectrum produced by means of the "Soleil'sche apparat mit Flintglasprisma." The spectrum "showed the Fraunhofer lines clearly" and was consequently relatively pure. I shall mention but one of the numerous experiments the results of all of which agree in general. In this experiment numerous pots of Vicia sativa were distributed in the spectrum from infra-red to ultra-violet. The seedlings between the violet and the ultraviolet began to bend first, then those to the right and left, and later those in the red. In the yellow and orange there was no reaction. Wiesner states the results in the following words (I879, p. I90): "Schon nach $I \frac{1}{4}$ Stunde waren die an der Grenze zwischen Violett und Ultraviolett $(\mathrm{H}-\mathrm{J})$ befindlichen Pflänzchen nach vorn geneigt. Nach Ablauf von etwa $\frac{1}{2}$ Stunde folgten die im mittleren Violett und Ultraviolett aufgestellten; eine Viertelstunde später neigten sich die im Indigo stehenden, Io Minuten hierauf die im Blau, nach weiteren 20 Minuten die im Grün und Ultraroth stehenden, sodann, nach einer Viertelstunde die im äussersten Roth, und nach einer weiteren Viertelstunde die im Roth von B-C. Die Keimlinge in Gelb und Orange standen jetzt, d. i. nach vollen 3 Stunden, 
noch völlig aufrecht. Eine Stunde später hatten die vom Indigo bis ins Ultraviolett reichenden Keimlinge sich stark hankenförmig gegen die Lichtquelle hingewendet, gleichzeitig neigte sich das im Orange stehende Pflänzchen schwach vor. Der im Gelb befindliche Keimling blieb aber bis ans Ende des Versuches vollkommen aufrecht." The roots of Sinapis alba (white mustard) were found to respond in the spectrum in all essentials like the stems of Vicia sativa, except that they turned from the light in place of toward it.

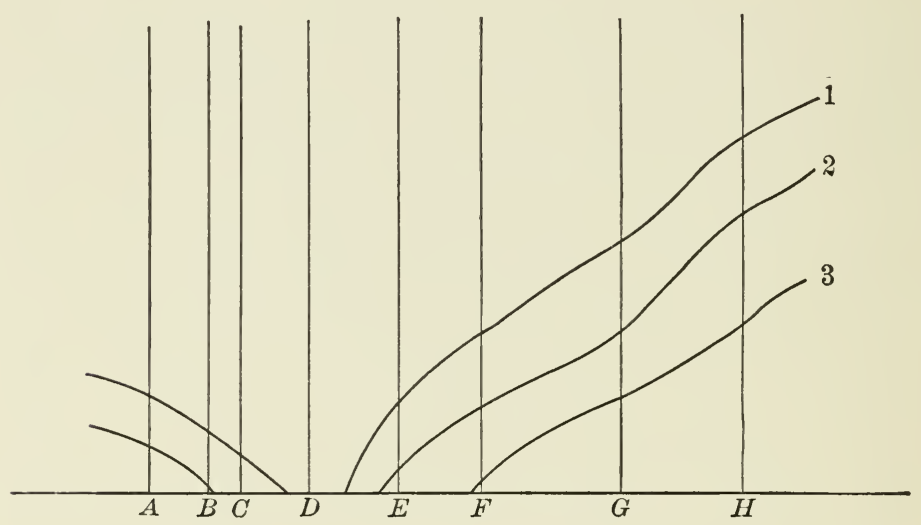

Fig. 35. Graphic representation of the reaction of several plants in light differing in wave-length. $A-H$ represent Fraunhofer lines in the spectrum. The curves $\mathrm{I}, 2$, and 3 were constructed by tabulating as ordinates the reciprocals of the time required to induce a response under the different light conditions: $\mathrm{I}$, stem of Vicia seedling; 2, stem of cress seedling; 3, etiolated willow shoot. After Wiesner (I879, p. I9I).

The results of numerous observations on the reactions of different seedlings behind different absorbing media all of which were spectroscopically tested are graphically represented in Fig. 35. It is interesting to note that these results agree fairly well with those obtained in the spectrum, although the different colors were in no instance monochromatic. Wiesner claims that yellow is not merely 
neutral, but that it actually causes a retardation in reaction when mixed with other active rays.

Müller (I872) obtained varying results in his study of the reactions of seedlings in the solar prismatic spectrum. He found the region of maximum effect for cress to be in the blue at line $F$, and that for Sinapis alba in the yellow and upper part of the green between lines $D$ and $E$. He claims that this difference is due to the difference of absorption of light under different conditions and in different plants. The farther a plant is from the prism the farther the maximum extends toward the red end of the spectrum. It may even extend into the infra-red. In case of cress seedlings, e.g., set in a row extending from the prism, it was found that those farthest away were neutral in violet and blue but still reacted in green and yellow, whereas those nearer the prism responded most strongly in the violet and blue. Müller thinks this is due to difference in absorption of different rays under different conditions.

The worl of Sachs in I 864 and later, as already stated, led to conolusions similar to those of Payer. Sachs studied the reaotions of various seedlings under doublewalled bell jars, some of which were filled with ammoniacal solution of copper hydrate and others with potassium bichromate. The former transmitted violet to green inclusive, the latter yellow to red. The seedlings under the copper solution curved strongly, while those under the chromate remained straight. Similar results were obtained behind cobalt and ruby glass. These results are not in accord with those of Guillemin, Wiesner and others, who found that seedlings responded in the longer wave lengths. The fact that Sachs could get no reaction in red produced by sunlight passed through a solution of potassium bichromate was probably, as Pfeffer points out (p. I76), "the result of feeble intensity of the light used, or of the special properties of the experimental material." The experiments of Kraus (I876) with colored screens show that the stalks of the perithecial heads of the fungus 
Claviceps microcephala turn toward the source of light nearly as rapidly in the red as in the blue, and Brefeld obtained similar results for Pilobolus microsporus and Pilobolus crystallinus.

Some of the contradictory results mentioned above are evidently due to the fact that the authors did not take into account the effect of the time of exposure and the intensity of the light. If the blue, for instance, is more active than the red, the maximum curvature will take place in the blue in weak illumination, while a minimum curvature will take place in this region in very strong illumination; for plants either become negative in high light intensity or fail to respond. Recently Blaauw (I909) made a thorough investigation of the reactions of plants in different regions of the spectrum with these facts in mind. He calculated the relative efficiency of different rays in terms of energy contents and time of exposure of the reacting organ, and found for oats seedlings, Avena sativa, that in medium light intensity and time of exposure there is a slight reaction from the red end of the spectrum to the green, $500^{\mu \mu}$, then a rapid increase to a maximum in the indigo $465^{\mu \mu}$, and a decrease to zero well in the ultra-violet. For equal energy and time of exposure the reaction is 2600 times greater in the region of maximum efficiency than in the red, yellow and green, twice as great as between the violet and the ultra-violet, $390^{\mu \mu}$, and only four times as great as in the ultra-violet at $365^{\mu \mu}$.

In case of the fungus Phycomyces, Blaauw found the effect of red and yellow relatively much greater than in Avena. In other respects the distribution of efficiency in the spectrum was found to be similar in the two forms.

In spectra of very high intensity produced by means of a grating it was found that the minimum rate of curvature for Phycomyces is in the indigo, and that there are two regions of maximum rate of curvature, one in the red, the other in the violet. This, the author maintains, is due to the fact that Phycomyces is positive in weak light (roo- 
I50 ca. $\mathrm{m}$. seconds), neutral in strong light (I00,000200,000 ca. m. sec.), ${ }^{1}$ and negative in very strong light (2,000,000-I $2,000,000$ ca. m. sec.). However, the red and yellow rays are, under all conditions, relatively more efficient in the molds than in green plants. The difference in the distribution in the spectrum of the stimulating efficiency in different intensities of light may possibly account for the discrepancies in the results of former investigation in this field.

\section{Summary}

(I) According to Gardner all visible rays are active in producing curvature in plants; according to Dutrochet and Pouillet, Guillemin and Müller, plants respond to all visible rays and some ultra-violet and infra-red as well; according to Wiesner they respond to all rays in the visible spectrum except some yellow and orange, and possibly some beyond at either end; according to Kraus and Brefeld the red is nearly as active as the blue in causing reactions in the molds; according to Blaauw all the visible rays of the spectrum and some ultra-violet produce curvature in oats seedlings and molds, but the longer waves are relatively more active in the latter than in the former; according to Sachs and Payer only the shorter waves are active. Thus it is seen that all but Sachs and Payer obtained reactions to the longer as well as to the shorter waves of the spectrum, and since nearly all of these investigators used relatively pure prismatic colors and efficient methods in other respects, it is evident that the great bulk of evidence goes against Sachs' conclusion that only the shorter waves are active in light reactions in plants.

(2) The experimental results of all the investigators

1 "Candle-meter seconds" indicates the product of the time of exposure and the intensity of the light. This, Blaauw maintains, is a constant for the threshold of a given plant, that is, the higher the intensity, the shorter the time of exposure required to produce a reaction. 
mentioned above agree in that they indicate that the region of maximum effect for all the plants tested is located somewhere toward the violet end of the spectrum. It may therefore be definitely concluded that the distribution in the spectrum of stimulating efficiency for plants is not primarily dependent upon energy or brightness as judged by the human eye, since the maximum for these is located in the yellow.

(3) The reactions to light in plants are in all probability associated with photochemical changes induced by the light. We have seen that photochemical changes are specific. If, e.g., one chemical reaction takes place only in blue and another only in green, other conditions being the same, it may be concluded that the chemical constituents taking part in the two reactions are not the same. The experimental results presented above show that the effect of the different rays on reactions is not the same for all plants. It is therefore probable that the photochemical changes associated with the reactions to light are not the same in all plants. I do not consider this point definitely established, owing to the possible effect of difference in selective absorption of light in the different plants. It is however more strongly supported by the observed reactions in unicellular forms than by those in sessile plants. 


\section{CHAPTER XVII}

\section{THE RELATIVE EFFECT OF DIFFERENT RAYS ON THE REACTIONS OF UNICELLULAR FORMS}

THE first observations on the effect of different colors on the movement of unicellular forms were made by Cohn in I865, nearly fifty years after similar observations had been made on sessile plants by Poggioli (I8I7). Cohn's account of his observations is very brief. He studied the movements of swarm spores in colors differentiated by means of colored glass and concluded that the blue rays are the most effective and that the red act like total darkness. He says (I865, p. 222), "Die Organismen werden von den blauen Strahlen am stärksten angezogen, während sich die rothen wie totale Finsterniss verhalten."

\section{Strasburger's Experiments}

Much more extensive and conclusive results were obtained by Strasburger (1878), who also studied swarmspores of various kinds, but principally Botrydium. Strasburger exercised the utmost precaution in his experiments. Many of the observations were made in a dark room in light of different colors produced by a quartz prism in a horizontal beam of direct sunlight. The slit in the opaque screen over the prism was only $0.4 \mathrm{~mm}$. wide and the spectrum at the point of exposure $55 \mathrm{~mm}$. long. The Fraunhofer lines could be clearly seen. It is therefore evident that there was but little intermingling of rays of different lengths in the spectrum. In addition to the spectrum, colored glass and various solutions were used. The results led Strasburger to conclude that the blue, indigo and violet light alone cause orienting reactions, but that yellow, red and green cause a quivering movement 
("zitternde Bewegung") in some swarm-spores. "Die blauen indigofarbigen und violetten Strahlen sind allein auf die phototaktischen Schwärmer von Einfluss und liegt das Maximum der Wirkung im Indigo" (p. 623). These conclusions in general support those of Cohn, but it appears quite probable that in higher light intensity the swarmspores would have been found positive in the longer waves as well as the shorter, since, as Strasburger states, the red and yellow produced indefinite reactions in the low intensity in which they were exposed. It is worthy of note that Strasburger and IViesner both obtained practically the same effect on reactions with slightly impure colored light produced by means of filter screens as they did with monochromatic light produced by means of prisms. And the same appears to be true in all other experiments on organisms without eyes, in which such a comparison has been made, as, e.g., in the observations of Harrington and Leaming on Amoeba and in my own work on the same organism referred to in detail later. This indicates that the reactions of these organisms in waves of a given length are not appreciably affected by the presence of waves of a different length and that extreme precautions to eliminate all foreign rays are not necessary in studying their reactions to different colors. In more sensitive forms, however, especially in those with well-developed eyes, monochromatic light is indispensable.

\section{Engelmann's Experiments}

Engelmann's experiments on unicellular forms in spectral colors are of the highest character and the greatest interest. He exposed the organisms in monochromatic light of solar, gas, and electric microspectra thrown on the slide by means of a prism attached to a microscope, and noted not only the regions in which they aggregated, but also the reactions during the process of aggregating. $\mathrm{He}$ divides these creatures into three classes based upon their different reactions, as follows: 
a. Diatoms and oscillaria with different species of $\mathrm{Na}$ vicula and Pinnularia as types (I882, p. 390). - These organisms are active in daylight or in the yellow, orange and red of the spectrum, but become quiet if the light intensity is decreased or if they are transferred to the green, blue or violet regions. In these colors they may however become active again if the intensity is sufficiently increased. It is evident that owing to these reactions they would tend to collect in the spectrum toward the violet end, or at least leave the opposite end, since they become quiet whenever they chance to get out of the yellow, orange or red. This region however has the greatest stimulating efficiency. Engelmann thinks that the reactions of these organisms are dependent upon the liberation of oxygen, and that they react primarily to the longer light waves because of the liberation of oxygen when they are exposed to them. This conclusion is based upon the fact that a reduction of oxygen pressure without a change of light intensity or color causes cessation of movement. It appears then that these organisms do not respond to sudden changes in light intensity and that the reaction to light is dependent upon the absolute intensity rather than upon change of intensity.

b. Ciliates which have chlorophyll with Paramecium bursaria as a type (I882, p. 393). - Engelmann found that these organisms do not react to light at all, unless the oxygen pressure is reduced below the normal. If the air surrounding the preparation is replaced with hydrogen they become very active ("sehr unruhig ") and aggregate in the region of highest light intensity. Under such conditions they also collect in the red of the gas or solar microspectrum between the lines $B$ and $C$ at $650-700^{\mu \mu}$. Engelmann describes the process of aggregation as follows: "Ueberschreiten sie z. B. zufällig die Gränze von Licht und Dunkel, oder tauchen sie auch nur mit der vorderen Hälfte ihres Leibes eine Strecke weit in das Dunkel ein, so kehren sie sofort um nach dem Licht, wie wenn das 
Dunkel ihnen unangenehm wäre." The process of collecting in regions of given light conditions in these forms is therefore precisely the same as that which Jennings found some fifteen years later with reference to the collection of Paramecium caudatum and aurelia in regions containing carbon dioxide.

It is evident that in Paramecium bursaria a reduction of light intensity or a change from regions illuminated by the longer waves to one illuminated by the shorter causes a definite response. Whether or not this response would under certain conditions result in orientation in these organisms as it does in Euglena was unfortunately not ascertained. Nor was it ascertained whether or not they ever become negative, i.e., respond to an increase of intensity or to a change from the shorter waves to the longer.

Engelmann thinks that the reactions of these organisms to light is regulated by the oxygen liberated, that it is a change in the oxygen pressure that produces a stimulation. The response which results in aggregation in these organisms is however, undoubtedly, at least indirectly dependent upon the time rate of change of light intensity rather than upon the absolute intensity, and their reaction system and method of collection in a given region are evidently quite different from those in diatoms.

c. Flagellates with Euglena viridis as a type (I882, p. 395). ${ }^{1}$ - The light reactions of the organisms in this class are not primarily dependent upon oxygen pressure. They respond to light in the same way whether the oxygen pressure is normal or above or below normal, unless it is carried to such extremes that all activity ceases.

These organisms were found to form dense aggregations in the more highly illuminated regions, just as Paramecium bursaria does when the oxygen pressure is below normal, but in the microspectrum they collect in the blue near the Fraunhofer line $F, 470-490^{\mu \mu}$, not in the red where

1 Bacterium photometricum ( 1883 , pp. 95-124), a form on which Engelmann worked later, might also be included here. 
P. bursaria collects. The method of collection of Euglena is described as being the same as that of P. bursaria. The region in which they aggregate "wirkt wie eine Falle, denn einmal hineingekommen, gehen die Euglenen in der Regel nicht wieder aus. Sie kehren an der Grenze des Dunkels immer sogleich wieder nur ins Helle." Engelmann does not mention the fact that these forms orient and that they may become negative, and of course did not realize that owing to these reactions they can move directly toward the optimum, so that the aggregation is not entirely due to random movements. According to the work of Engelmann, then, a reduction of light intensity or a change from blue in the region of the Fraunhofer line $F$ to any other color of the spectrum stimulates Euglena and causes it to turn and proceed in a different direction.

Like Euglena, so specimens of Bacterium photometricum collect in the more highly illuminated regions of their environment, but in the microspectrum, unlike Euglena, most of them collect in the infra-red between 800 and $900^{\mu \prime \prime}$, some in the orange between 580 and $6 \mathrm{IO}^{\mu \mu}$ and a few elsewhere. In general they collect in those regions where the absorption bands for the coloring matter they contain are found. Their reactions to light are independent of oxygen pressure. The method of collection is described as being similar to that of Euglena. A reduction of intensity or a change in color from that in which they collect to any other causes the bacteria to swim suddenly backward ("zurück schiessen ") Io to 20 times their length, after which they proceed in the ordinary way again. This reaction has been designated "Schreckbewegung." An increase of intensity or movement into the regions of the spectrum where they collect does not produce the "Schreckbewegung," neither does a gradual decrease of intensity. Engelmann found but little evidence indicating that these organisms orient, and did not ascertain whether or not they become negative in very high intensity. 


\section{Verworn's Experiments}

The experiments of Verworn (I889) yielded results which led him to conclude that the diatom Navicula brevis reacts only to the shorter waves, while Oscillaria reacts to all the waves in the visible spectrum. "Als die allein wirksamen Lichtstrahlen erwiesen sich auch bei den Diatomeen die kurzwelligen" (p. 49); "Die Versuche, welche sich auf die Ermittelung der wirksamen Strahlen bezogen, hatten das ganz unvermuthete Ergebniss, dass Strahlen von allen Wellenlängen ungefähr von der Linie a bis über $\mathrm{G}$ hinaus die Bewegungen der Oscillarien beeinflussen. .... Die Ansammlungen der Oscillarien war nach Einschaltung von Rubinglas oder Kalibichromatlösung, auch im Halbdunkel, ebenso vollkommen, wie bei Anwendung von grünem Glas, Kobaltglas, Kupferoxydammoniaklösung oder reinem Sonnenlicht" (p. 5I). In these experiments Verworn mounted the organisms on a slide and studied the movements under a microscope, surrounded by a tight case which was black inside. The case contained an opening I5 $\times 20 \mathrm{~mm}$. in one side to admit light. Colored glass plates or flat flasks containing different solutions could be so adjusted as to admit only light which passed through them. The colored media used were thoroughly tested spectroscopically ("genau spektroskopisch untersucht"). Five different media were used. The red glass transmitted red and orange $\left(600-740^{\prime \prime \prime}\right)$; the cobalt glass, blue and violet $\left(4 \mathrm{IO}^{-5} \mathrm{IO}^{\mathrm{mu}}\right)$ and a little infra-red; the green glass, yellow and green, and a little orange and blue $\left(480-600^{\mu \mu}\right)$; the potassium bichromate solution, red, orange, yellow, and a little green $\left(55^{0}-740^{\mu \prime \prime}\right)$; and the ammoniacal solution of copper hydrate, blue and considerable green $\left(430-520^{\mu !}\right)$.

The Oscillaria were positive; they collected at the side nearest the light, even if it was of very low intensity ("Halbdunkel"), no matter which one of the media was in the opening. The diatoms, on the other hand, moved toward the light only in the shorter waves; they did not 
respond behind the ruby glass or the potassium bichromate solution, and only indefinitely behind the green glass even in direct sunlight. It is therefore evident that the distribution in the spectrum of stimulating efficiency is not the same in these two forms, for the diatoms react only to the shorter waves, while Oscillaria reacts to the longer as well as to the shorter. Whether or not the reaction of Oscillaria to the different rays is proportional to the energy can however not be definitely ascertained from the data at hand.

\section{Experiments of Harrington and Leaming on Amoeba}

One of the most interesting of the investigations on the effect of different colors on the reactions of protozoa is that of Harrington and Leaming (I900). These authors projected amoebae on a screen with a Zeiss photomicrographic apparatus, and studied the effect of sudden changes in color and intensity on the movements. The light rays were differentiated by means of Bierstadt's colored celloidin plates. The results of numerous observations, all recorded in detail, are summarized in the following table, which has been slightly modified (p. I6). The table shows clearly that the violet is more effective than any other color tested, except white, in causing retardation in movement, and since orientation is the result of such reta.dations in movement the violet must also be more effective in regulating this phenomenon.

TABLE X

\begin{tabular}{|c|c|c|c|c|c|}
\hline & White & Violet & Green & Yellow & Red \\
\hline White following & o & $-5 ?$ & $-I$ & $-I$ & - I sec. \\
\hline Violet " & +5 & 0 & -20 & -24 & $-9 "$ \\
\hline Green " & +5 & $+\mathrm{I} 2$ & 0 & $?+12$ & 0 " \\
\hline Yellow “ & $+I$ & +3 & 0 & 0 & $0 "$ \\
\hline Red “ & $+\mathrm{I}$ & +2 & $\circ$ & $\circ$ & $0 "$ \\
\hline
\end{tabular}

Zero indicates that there was no change in movement when the light conditions were changed as indicated; the numbers preceded by - indicate the average time in seconds before streaming stopped or decreased; and the numbers preceded by + indicate the average time before streaming started or increased. 
It is claimed that a sudden increase of intensity causes an immediate cessation of movement either in white light or in light containing only the shorter waves, but that " after a few minutes [exposure] streaming will commence under any light if the amoeba be a fairly active individual" (p. I6). The authors appear to think that some colors actually cause an increase in the rate of movement in the amoebae: "That red is the most powerful excitant to flow is indicated by the shorter latent period after quiescence in white light." There is however little evidence supporting this conclusion.

Harrington and Leaming did not ascertain the intensity of light transmitted by the different filters, and the light was not spectroscopically examined, so that the purity of the colors used remains unknown. Similar results were however obtained in spectral colors, but the authors unfortunately have not described how the spectrum was produced or what kind of light was used as a source. Their results have occasionally been seriously questioned.

\section{Original Observations on Amoeba}

Owing to the questionable character of some of the results of Harrington and Leaming and to the fact that the region in the spectrum of maximum effect on the movement could not be definitely located from their data, it seemed desirable to have the experiments repeated.

a. Experiments with color filters. - Early in June, I909, Dr. H. S. Jennings put at my disposal an excellent culture of Amoeba proteus, which had come up in hay infusion used in rearing Paramecia. Specimens of this culture were studied both in a solar prismatic spectrum and in different colors produced by means of filters which were kindly furnished by Dr. R. P. Cowles. The filters were prepared and spectroscopically tested in the physical laboratory of Johns Hopkins University. The red was transparent from $620^{\mu \mu}$ out, opaque from 450 to $590^{\mu \mu}$ and 
faintly transparent from 380 to $45 \mathrm{o}^{\mu \mu}$. The blue was transparent from 430 to $490^{\mu \mu}$ and from $69 \mathrm{o}^{\mu \mu}$ out, and opaque from 590 to $670^{\mu \mu}$. The green was transparent from 380 to $400^{\mu \mu}$, from 450 to $550^{\mu \mu}$ and from $68 \mathrm{o}^{\mu \mu}$ out. It was opaque between 580 and $660^{\mu \mu}$ and faintly transparent between 400 and $450^{\mu \mu}$.

Several amoebae were mounted under a large coverglass surrounded by a thin ring of vaseline so as to prevent evaporation, and give ample space for free movement. In this inclosure they were found to remain active and in excellent condition for several days. The observations were made on the stage of a compound microscope under a magnification of about I50 diameters with very faint illumination from the mirror. A beam of direct sunlight which passed through $8 \mathrm{~cm}$. of water was thrown on the slide at an angle of about $45^{\circ}$ with the stage.

The organisms were exposed to light of different colors by intercepting the beam with the colored filters. It was found that amoebae which moved actively in weak diffuse light ceased moving shortly after being suddenly exposed to strong red light, but soon began again. If they were now exposed to green the movement again ceased; the same was true for blue after green and for direct sunlight after blue. A change from direct sunlight to blue, blue to green, or green to red, produced no apparent effect. After being exposed to any color or any combination of colors for a short time the movement was resumed. In direct sunlight or in blue light it required longer than in green or red. As a matter of fact, in these two colors, in the red in particular, there was no cessation of movement in some specimens, and only a slight decrease in others, while in still others the movement stopped entirely. In case of direct sunlight or blue, on the other hand, the movement stopped abruptly in nearly every specimen almost as soon as exposed. Similar but somewhat more detailed results were obtained in the spectrum.

$b$. Experiments with solar spectrum. - In these experi- 
ments a horizontal beam of direct sunlight was passed through a vertical prism and thrown on the mirror below the stage of the microscope, from which it was reflected to the slide. By manipulating the mirror the amoebae on the slide could be suddenly subjected to light in any part of the spectrum, and the color to which they were exposed could be instantaneously changed.

The vertical slit in the opaque screen over the face of the lens was $2 \mathrm{~mm}$. wide and the spectrum on the slide nearly $3 \mathrm{~cm}$. long. There was consequently some overlapping of rays in adjacent parts of the spectrum, but there was no intermingling of rays in distant parts. For example, in the red there was some orange, but no rays of shorter wave lengths.

The amoebae were examined in daylight so faint that they could scarcely be seen. After a specimen active in this light had been selected, it was suddenly exposed to any desired part of the spectrum and the reaction noted.

Many observations were made on numerous individuals between Io A.M. and I P.M., June I6 and I8. The sky was clear, and the intensity of light consequently at a maximum, approximately $5000 \mathrm{ca} . \mathrm{m}$. Without going into details with reference to reactions of individual specimens it may be stated that the effect of sudden exposure to red, ${ }^{1}$ yellow or violet after very faint diffuse sunlight was essentially the same. There was in many specimens a slight decrease in rate of movement, in some a momentary cessation, and in others no apparent reaction whatever. In the green the effect was similar to that in red, yellow and violet, only somewhat more marked. To obtain the

1 The wave lengths are designated in terms of color.

$$
\begin{aligned}
\text { Red } & =630-760^{\mu \mu} \\
\text { Orange } & =590-630^{\mu \mu} \\
\text { Yellow } & =560-590^{\mu \mu} \\
\text { Green } & =490-560^{\mu \mu} \\
\text { Blue } & =430-490^{\mu \mu} \\
\text { Violet } & =395-430^{\mu \mu} \\
\text { Ultra-violet } & =340-395^{\mu \mu}
\end{aligned}
$$


effect described above it is necessary (I) to have amoebae in a certain condition, (2) to keep them in as low light intensity as possible before exposing, and (3) to use very intense light. When exposed in blue after having become active in any other color or in diffuse sunlight, all movement stopped instantly in nearly all specimens observed. But there was no apparent contraction; the animals retained almost the exact form they had before the exposure. After remaining quiet a few seconds, the streaming of the protoplasm in the anterior pseudopods slowly began again, but now it nearly always proceeded in the same direction. Gradually new pseudopods were formed, usually at the posterior end, and as these developed the old ones were slowly withdrawn. The rate of movement ordinarily increased at such a rate that after 30 to 60 seconds it was again normal. If any other part of the spectrum was flashed on an amoeba which had become active in the blue there was no apparent reaction, but when such a specimen was exposed to direct sunlight it was clearly seen, in some instances, that the streaming ceased again.

The results obtained in these experiments lend support to the general conclusions of Harrington and Leaming. They differ from their results only in a few details. I found red and yellow to have a slight effect on the movement of Amoeba. Harrington and Leaming did not, probably owing to deficiency in light intensity or to exposure in too great an intensity preceding the exposure to red or yellow. I found only a very slight stimulation in the violet, whereas they recorded no difference between the effect of blue and violet.

It may then be definitely concluded that the blue rays, 430 to $490^{\mu \mu}$, have a very marked effect on the rate of movement of Amoeba, while the violet, green, yellow, orange and red rays have only a slight effect; and since the direction of movement is in all probability regulated by changes in the rate, it is evident that the blue rays are also of primary importance in this process. 
It will be seen at once that the effect of different parts of the prismatic solar spectrum on the movement of Amoeba is not proportional to the energy contents, for the energy gradually increases as one proceeds from the violet toward the red end, whereas the region of maximum stimulation for this animal is in the blue, from which it decreases toward both ends. Nor is it proportional to the brightness as judged by the human eye, for the yellow is much brighter than any other part of the spectrum. In fact, under the conditions of the experiment, one could hardly bear to look through the microscope when the yellow was reflected, while in the case of blue, the region of maximum stimulation for Amoeba, there was no unpleasant stimulation whatever to the eye.

One of the most interesting characteristics in the reactions of unicellular forms is the variation in the location of the region of maximum stimulating efficiency in the spectrum. The experimental results presented above indicate that for the swarm-spores it is in the indigo, for Amoeba it is in the blue, while Oscillaria appears to be stimulated equally by all the visible rays. This indicates that, as in plants so in unicellular forms, the chemical changes associated with the reactions to light are not the same in all of the different species (see p. 320). 


\section{CHAPTER XVIII}

\section{REACTIONS OF MULTICELLULAR ANIMALS IN LIGHT CONSISTING OF WAVES DIFFERING IN LENGTH}

\section{Experiments of Wilson on Hydra}

Among the most thorough and reliable experiments on the reactions to light of different wave lengths are those of Wilson (I89I) on Hydra. Wilson had "a fraternity of Hydras five hundred to a thousand strong all of which had arisen in [a large] aquarium [in a north room] from a group of three or four progenitors" (Footnote, p. 4I5). The window side of the aquarium was divided into equal areas which were covered with strips of red, yellow, green, blue or colorless glass. In some instances there were two areas of each color, one with a single thickness of glass, the other with two, producing two fields of the same color but of different intensity.

The activities of the animals and the changes in position were studied and recorded for a week, during which the glass strips were frequently rearranged. It was found that the Hydras tend to collect in the colorless region and in the more intensely illuminated regions of each color, i.e., back of the areas covered with only one thickness of glass, but that with reference to the different colors they tend to aggregate in the blue even if the intensity in it is much lower than that in any other region. The tabulated results of two series of observations will serve to emphasize this. These results were obtained after rearranging the plates so as to change the color of the different regions. 
TABLE XI. (After Wilson, I89I, p. 424.)

Yellow decrease [in number of Hydras] . . 5 $5_{66}^{6}$ per cent.

Red

Green

Blue increase

" $\ldots \ldots 55$ " $\ldots 70$ "

TABLE XII. (After Wilson, p. 427.)

Total increase [in number of individuals during period of observation] $42 \mathrm{I}$ to 674 , i.e., 60 per cent.

Blue, increase. . . . . . . . . . . . .

Yellow, decrease...................................

Dark screen, decrease. . . . . . . . . . . . . . . . . . .

Daylight, increase.................

Wilson says that hydras are positive in blue, that they go fairly directly toward the source of light, and that the other colors are inactive, but he does not show definitely how the aggregations in the blue are formed. We shall discuss the movement in different colors more in detail later.

The colors produced by the plates of glass used were not monochromatic. Thorough spectroscopic examination showed that the red transmitted a little orange, the yellow some green, orange and red, the green some yellow and a trace of red, and the blue some indigo and violet and a trace of green and red. It is not at all likely that such slight transmission of foreign colors as represented above modifies the reactions of organisms that have not well-developed eyes and are no more sensitive to light than Hydra, although much has been said regarding this and many results have been branded worthless owing to the use of slightly impure colors. Wilson fortunately confirmed the results obtained with colored glasses by critical tests in a spectrum produced by focusing light from an Argand gas burner on a narrow slit in an opaque screen in front of a large carbon bisulphide prism. "The apparatus was placed in a perfectly dark underground room and every pains was taken, by the use of suitable screens, etc., 
to exclude from the aquarium all light excepting that proceeding from the prism" (Footnote, p. 430). In the spectrum, which was about three inches long, the hydras showed a very marked tendency to collect in the lower blue, from line $G$ to line $F$, and for a slight distance in the green. They were wholly indifferent to the lower rays, the violet and ultra-violet, as well as to all those above the lower green, including the infra-red. It should be emphasized that they are not negative in these colors. This was shown both by their reactions in the spectrum and by those under colored glass.

The observations of Wilson seem to prove conclusively that the blue is most active in stimulating both Hydra viridis and Hydra fusca. This stimulating activity of the blue is specific; it bears no definite relation to the distribution of energy or of brightness, both of which are fairly definitely located for the gas-light spectrum, the region of maximum energy and brightness being well toward the red end.

One of the striking peculiarities in the results obtained by Wilson is the fact that whereas hydras collected most abundantly in the regions of highest intensity under given color conditions, more were regularly found in the blue than in daylight, when they were given a choice between these two conditions of light (see Table XII), although the latter contained at least as much blue as the former and was of course more intense owing to the presence of other rays. This result is similar to that obtained by Lubbock (I 888) on daphnias, which were found to collect more freely in yellow and green light than in daylight.

Loeb appears to doubt the accuracy of these results. Referring to those of Lubbock he says (I905, p. Io): "One half of a dish was covered by a yellow screen; the other half was left uncovered. In the uncovered half, I,904 animals collected, while 3,096 gathered under the yellow screen. From this Lubbock concludes that Daphnia has a 'preference' for 'yellow.' But one would suppose that 
in the uncovered part of the dish there was at least as much yellow light as under the yellow screen; or did the majority 'hate' the blue light?" Referring to observations on Porthesia chrysorrhoea he says (I905, p. 29), "This experiment shows that the more refrangible rays have the same effect as mixed rays."

The methods of both Lubbock and Wilson were however such as to leave little room for doubt regarding their results. It is interesting to note that the recent work of Stobbe (1908) on the photochemical changes in the organic compounds known as fulgides demonstrates reactions which proceed more rapidly in monochromatic light of a given intensity than in the same light in combination with other rays. These experiments have been referred to under the section on photochemical reactions, p. 3IO. It is likely that the chemical changes in Hydra and Daphnia associated with their light reactions are of the nature of certain fulgides.

\section{Bert's Experiments on Daphnia}

The first experiments dealing with the effect of different colors on the reactions of multicellular animals were made by Paul Bert in I868. Bert was interested in color vision. He attempted to answer the question as to whether the specific effect on the different rays in the spectrum is the same in the inferior animals as it is in man. He attacked the problem from a purely psychological point of view, as the title of his paper published in I 869 indicates: "Sur la question de savoir si tous les animaux voient les mêmes rayons que nous."

An electric-light spectrum was thrown on the flat side of an aquarium covered with an opaque screen containing a narrow vertical slit. Daphnias were exposed to the different colors of the spectrum, and it was found that they collected at the side of the aquarium nearest the light, no matter which part of the spectrum was allowed 
to enter the slit. The organisms were therefore positive in all colors; the reactions however were more rapid in the yellow and green than in other parts of the spectrum. Bert says (I869), “Il fut facile de remarquer, qu'elles accouraient beaucoup plus rapidement au jaune ou au vert qu'a toute autre couleur."' 1

When the opaque screen was removed so as to expose the daphnias to the entire spectrum at once, most of them collected in the yellow and green. Bert was of the opinion that the distribution of effect in the spectrum is the same in Daphnia as it is in man, and he concluded that the collection of Daphnia in the yellow and green part of the spectrum and the great activity in these colors is not due to color vision, but to the fact that the light intensity in this part of the spectrum is higher than elsewhere. He was of the opinion that light affects these animals much as it does the human being, with reference to brightness, that the yellow for them as for man is the brightest and consequently the most effective part of the spectrum.

Results similar to those recorded by Bert were obtained by Merejkowsky (I88I) on Dias longiremis and larvae of Balanus, by Lubbock (I88I) on Daphnia, and by Yerkes (I900) on Simocephalus.

Merejkowsky states that he exposed Dias longiremis and Balanus larvae in light of different colors but of equal brightness and found no evidence of preference. The validity of these results is, however, questionable, since it is by no means certain that the brightness of the different colors used in these experiments was actually equal.

\section{Lubbock's Experiments on Daphnia}

Lubbock's experimental methods and results are far more convincing than those of Merejkowsky. He published his interesting observations on Daphnia in the

1 Taken from Loeb (1905, p. 9). Page in original not given by Loeb. 
Journal of the Linnean Society in I88I. The following account is however taken from a later publication (I882, pp. 2I2-23I).

In these experiments Lubbock projected a prismatic solar spectrum arranged by Professor Dewar at the Royal Institute, vertically downward on a wooden trough I4 inches long and 4 inches wide. In this trough he put 50 specimens of Daphnia pulex, scattered them equally through the water, and after ten minutes inserted glass partitions so as to divide the trough into compartments corresponding in size with the five principal colors of the spectrum. He then recorded the number of individuals in each, after which he repeated the process. The total for ten trials follows: 5 in the violet, 32 in the blue, 298 in the green, 74 in the yellow, 90 in the red and one in the dark part of the spectrum.

In comparing these results it is necessary to consider the fact that in a prismatic spectrum the red and green are each much more than twice as wide as the yellow; and the blue and violet are each wider than the green. Lubbock allowed three-fourths of an inch for the yellow and two inches for the green. Correcting for this difference in width the calculated number in the yellow would have been I96. Lubbock concludes (p. 2I4), "It will be observed ... [that] there were more Daphnias in proportion, as well as absolutely, in the green, although the yellow is the brightest portion of the spectrum."

It was also found that when daphnias were exposed in the green, yellow and red of a normal spectrum, they collected in the green rather than in the red. In these experiments the region of highest intensity in the middle of the field was shaded. After ten minutes' exposure 4IO specimens were found in the green end, I 4 in the shaded area and 76 in the red. These results indicate clearly that if brightness alone controls the reactions of Daphnia, it must be different for them than it is for the human eye. Numerous convincing experimental results showing that 
this animal is positive in ultra-violet indicate the same thing.

Lubbock's primary object in this work, however, was to test the color vision of Daphnia. I can do no better than to quote at length the experiments which bear on this question:

"I placed (March 26) fifty Daphnias in a trough (I), covering over one half of it with a pale green, and another fifty in a trough (2) half of which was covered with yellow (aurine). On one side was a similar trough (3), one end of which was shaded by a porcelain plate; and on the other side a fourth trough (4), one end of which had a little, though but little, extra light thrown on it by means of a mirror. As before, I counted the Daphnias from time to time, and turned the troughs round. All four were in a light room, but not actually in direct sunshine. Thus, then, in one trough I had half the water in somewhat green light; in the second trough, half the water in yellow light; in the third, one half was exposed and the other somewhat darkened; while the fourth, on the contrary, gave me a contrast with somewhat more vivid light. If, then, the Daphnias went under the green and yellow glass, not on account of the color, but for the sake of shade, then in trough 3 a majority of them would have gone under the porcelain plate. On the other hand, if the porcelain plate darkened the water too much, and yet the open water was rather too light for the Daphnias, then in the fourth trough they would, of course, have avoided the illuminated half. The results show that the third trough was unnecessary, still I may as well give the figures; the fourth proves that the Daphnias preferred a light somewhat brighter than the ordinary diffused light of the room. Of course it does not follow that the effect of color is the same as with us" (p. 226).

The results of twenty trials are recorded, but since all are essentially the same I shall quote only the following five (p. 227): 
TABLE XIII. (After Lubbock, p. 227.)

\begin{tabular}{|c|c|c|c|c|c|c|c|c|}
\hline & \multicolumn{2}{|c|}{ Trough I } & \multicolumn{2}{|c|}{ Trough 2} & \multicolumn{2}{|c|}{ Trough 3} & \multicolumn{2}{|c|}{ Trough 4} \\
\hline & $\begin{array}{l}\text { Green } \\
\text { light }\end{array}$ & $\begin{array}{l}\text { White } \\
\text { light }\end{array}$ & $\begin{array}{l}\text { Yellow } \\
\text { light }\end{array}$ & $\begin{array}{l}\text { White } \\
\text { light }\end{array}$ & $\begin{array}{c}\text { Ex- } \\
\text { posed } \\
\text { half } \\
\end{array}$ & $\begin{array}{l}\text { Dark- } \\
\text { ened } \\
\text { half } \\
\end{array}$ & $\begin{array}{c}\text { Illumi- } \\
\text { nated } \\
\text { half }\end{array}$ & $\begin{array}{c}\text { Unillumi- } \\
\text { nated } \\
\text { half }\end{array}$ \\
\hline \multicolumn{9}{|l|}{ March 28} \\
\hline $7 \cdot 30$ & 33 & I 7 & 34 & I 6 & 35 & I 5 & 30 & 20 \\
\hline $7 \cdot 50$ & 32 & I 8 & 37 & I 3 & 27 & 23 & $3^{2}$ & I8 \\
\hline 8.10 & 34 & I 6 & 33 & I 7 & 29 & $2 \mathrm{I}$ & 30 & 20 \\
\hline 8.35 & 36 & I4 & 35 & I5 & 26 & 24 & 33 & I 7 \\
\hline \multirow[t]{2}{*}{9.05} & 26 & 24 & 27 & 23 & 33 & I 7 & 35 & I 5 \\
\hline & I6I & 89 & I 66 & 84 & I 50 & 100 & 160 & 90 \\
\hline
\end{tabular}

In another series of experiments in which one half of one dish was covered with a ruby glass and that of another dish with blue glass, the majority of the animals collected in the uncovered portion of both dishes. It is evident from the results in troughs 3 and 4 above that the daphnias were positive to the highest light intensity used in these experiments. It may then be assumed that they were positive to the light conditions in which the majority collected in troughs I and 2, and in the experiments with red and blue. In the former however they collected in the part of the trough having the lower intensity, i.e., in the green and yellow respectively, in preference to white, whereas under all the other conditions they collected in that portion of the trough having the higher light intensity.

While these results do not demonstrate subjective color sensation, I am unable to see how they can be explained without assuming a specific effect depending upon the length of the waves or the color independent of intensity or brightness.

Lubbock's conclusions are very cautiously summed up in the following paragraphs (p. 23I):

"My experiments, I think, show that while the Daphnias prefer light to darkness, there is a certain maximum of brilliancy beyond which the light becomes inconven- 
iently bright to them, and that they can distinguish between light of different wave-lengths. I suppose it would be impossible to prove that they actually perceive colors; but to suggest that the rays of various wave-lengths produce on their eyes a different impression from that of color, is to propose an entirely novel hypothesis.

"At any rate, I think I have shown that they do distinguish between rays of different wave-lengths, and prefer those which to our eyes appear green and yellow."

The striking positive reaction to yellow and green in preference to white light of a higher intensity seems to indicate that Daphnia is negative to the other rays of the spectrum. This question has been discussed elsewhere.

\section{Experiments of Yerkes on Simocephalus}

Yerkes (I899) made a very thorough study of the reactions of Simocephalus vetulus, a form similar to Daphnia, both in gas and sunlight spectra. Every reasonable precaution was taken in the manipulation of the apparatus. The method employed was like that used by Lubbock on Daphnia. The following table shows the relative numbers which collected in the different regions of the two spectra:

TABLE XIV. (After Yerkes, I899.)

\begin{tabular}{|c|c|c|}
\hline & Gas spectrum & Sunlight spectrum \\
\hline Red.......... & 24.7 per cent & $9 \cdot 7$ per cent \\
\hline Yellow............. & $23 \cdot 3 "$ " " & $35.2 " 6$ \\
\hline Green................. & 6.2 " " & $14.6 " 6 "$ \\
\hline 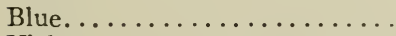 & $5 \cdot 3$ " " & 25.5 " " \\
\hline Violet............... & 0.8 " " & 0.8 " \\
\hline
\end{tabular}

Since Simocephalus is positive even in direct sunlight, it is safe to say that it is positive to the light conditions of that part of the spectrum in which it aggregates. The table above shows clearly that in the gas spectrum most of 
the specimens collected in the red and yellow, whereas in the sunlight spectrum most of them collected in the yellow, green and blue. In the former, then, they collected nearer the red end than in the latter, and since the brightest part of the gas spectrum is somewhat nearer the red end than it is in the sunlight spectrum, Yerkes concluded that the reactions of Simocephalus are dependent upon intensity rather than upon color.

The results appear to me to demonstrate that intensity is undoubtedly a factor in the reactions of Simocephalus, but they do not appear to demonstrate that the reactions are independent of the length of the waves of light. The distribution in the spectrum of the power to stimulate Simocephalus agrees roughly with that of brightness for the human eye. If corrections are made for the difference in width between yellow and blue in the sun spectrum, then the 25 per cent for the blue, which is fully twice as wide as the yellow, will be reduced to about twelve per cent, and the percentage in the green will also be reduced somewhat, showing that the yellow is the most active by far. This however is not in opposition to the conclusions reached from Lubbock's results, that the reactions depend upon the length of the waves as well as upon the amplitude. On the contrary, the fact that the distribution in the spectrum of stimulating efficiency in these forms does not correspond with the distribution of energy, indicates that the reactions are dependent upon the wave length, possibly in some such way as brightness is dependent upon the wave length. This does not mean that the chemical changes and the mechanism in general is the same in these forms as that associated with brightness sensations in man; and of course it does not demonstrate the presence of brightness sensations in these crustacea, as the conclusions of Bert and Lubbock might lead one to suspect.

Considering the results of all the experiments on the daphnias referred to above, it may be concluded: (I) that 
these organisms, contrary to the hypothesis of Loeb and Davenport, are most strongly affected by the green and yellow rays; (2) that this effect is dependent primarily upon the length of the waves and secondarily upon the amplitude or energy; (3) that these organisms can be stimulated by the ultra-violet and by all the rays in the visible spectrum, except perhaps those near the infra-red; (4) that the stimulating efficiency is not proportional to the energy contents; and (5) that the distribution in the spectrum of stimulating efficiency in these organisms differs from that in a majority of the lower forms, in which it has been clearly demonstrated that the blue or violet rays are the most active. This indicates that the chemical changes associated with the reactions are not the same in all organisms.

\section{Experiments of Graber on Various Animals}

The experiments of Graber on the reactions of animals to colored light are the most extensive of any yet made in this line. He tested 54 different species, - 5 mammals, 7 birds, 2 reptiles, 3 amphibia, 2 fishes, 3 mollusks, 27 insects, 2 spiders, and 3 worms. Nearly all of these species have well-developed eyes. Besides these in the normal state a blinded amphibia and a blinded insect were tested.

Following the work of Bert and Lubbock, Graber attacked the problem from the psychological point of view. The foremost question with him appears to have been: Do the animals perceive color? In nearly all the experiments he studied the change of distribution of the animals in suitable boxes or troughs, the two halves of which were illuminated with light of different colors or different intensities, and recorded the number which collected in each half of the inclosure. He does not state how the animals reacted so as to aggregate in one or the other of the light conditions. The aggregations may have been due to 
positive orientation to the light conditions in which the animals collected, or to negative orientation to the other condition; or the organisms may have wandered into the light in which they collected by random movements and have remained because of a definite reaction when the border of this area was reached, somewhat similar to the reactions of Paramecium on reaching the limit of an area containing carbon dioxide; or they may have remained because they came to rest somewhat as planarians come to rest in a given light condition under some circumstances. It is therefore impossible to be certain as to the interpretation of many of the results. Moreover only a limited number of different colors was used, so that the maximum effect in the spectrum cannot be located. We shall consequently consider only a few of Graber's observations.

Colored glass and solutions were used almost exclusively to differentiate the rays. These were all, however, thoroughly examined spectroscopically, and the relative intensity of the light transmitted was also fairly accurately ascertained. In this work Graber had the assistance of the physicist Professor Mach. The lower forms only are of interest to us here.

Lumbricus is well known to be negative in its light reactions. Graber's results are in harmony with this. In a trough one half of which was shaded he found over five times as many in the shaded region as in the illuminated region. When one half of the trough was red and the other blue there were nearly five times as many in the former as in the latter, and in the case of red and green, and green and blue, the majority collected in the light having the longer wave lengths. In all these experiments the worms were undoubtedly negative to the light conditions they avoided.

The red in these experiments contained rays between $6 \mathrm{IO}$ and $7 \mathrm{IO}^{\mu \mu}$; the blue rays between 550 and $570^{\mu \mu}$, those between 700 and $720^{\mu \mu}$, and those below $540^{\mu \mu}$; the 
green rays between 450 and $600^{\mu \mu}$. In the red-blue and green-blue tests the intensity of the red and green was twice as high as that of the blue. In the red-green test it was a little more than twice as high in the red as in the green. In these tests, however, the worms consistently collected in the light having the higher intensity, whereas in white light the opposite was true. However, when white light containing ultra-violet was contrasted with white light without, but of decidedly higher intensity, the great majority collected in the light having the higher intensity.

Considering the conditions of these experiments I do not hesitate to conclude that blue, violet and ultra-violet are more efficient in causing reactions in Lumbricus than green or red. Similar conclusions are strongly supported by the reactions of various other species, notably the snail Limnaeus stagnalis and several insect larvae as well as imagos. In numerous other instances, however, as already intimated, the results are not conclusive; in these it is questionable whether the quality of light has any specific functions and it is impossible to say to what the change in distribution is due.

The following conclusion of Graber is undoubtedly not warranted ( 1884 , p. 245): "Als eines der allerwichtigsten und interessantesten Ergebnisse meiner vergleichenden Lichtgefühl-Studien betrachte ich die Tatsache, dass die leukophilen oder weissholden Tiere mit geringen Ausnahmen alle blauliebend, die leukophoben oder dunkelholden hingegen rotliebend sind."

The results of these experiments appear to indicate that in general animals which are positive in white light are also positive in blue, whereas those which are negative in white are negative in blue, not positive to red, as Graber's conclusions would suggest. This is however not universally true, as the experiments on Daphnia clearly show.

The ideas in Graber's conclusions expressed in the quotations above and elsewhere, that animals actually perceive 
color and that the reactions are controlled by subjective sensation, are evidently without experimental foundation. They are reached purely through human analogies.

\section{Loeb's Observations}

The accounts of Loeb's experiments on the effect of different colors on reactions are found in two papers, published in $\mathrm{I} 890$ and $\mathrm{I} 893$ respectively. Of the two colors, red and blue, used in these experiments, the former was produced by means of a solution of potassium bichromate or ruby glass, and the latter by means of " cobalt glass or an ammoniacal solution of copper." In each of these two colors the reactions of the following animals were studied: Musca larvae, plant lice, caterpillars of Porthesia chrysorrhoea, moths of Sphinx euphorbia and Geometra piniaria, various copepods, the meal worm Tenebrio molitor, and larvae of the June bug Melolontha vulgaris, Limulus polyphemus, and Polygordius.

Loeb maintains that these forms react in blue light essentially as they do in white; that the negative forms are negative in the blue light and the positive forms positive; and that the red rays have a slight effect on the movement of some of the animals but none on that of others. He concludes that in all of these animals "the more strongly refrangible rays of the visible spectrum are the most active heliotropically, as in the case of plants " (I905, p. 294). He also says (I905, p. 73), “I have confirmed the identity of animal with plant heliotropism on crabs (Gammarus locusta, Cuma Rathkii), naked snails and worms (leeches, planarians, earth-worms and others)," but he does not state definitely that he studied the reactions of these forms in colored light.

In harmony with the results of Graber's experiments, as well as with those of various other investigators, Loeb's results show fairly clearly that blue is more efficient than red in stimulating the organisms he tested, but they do 
not show that it is more efficient than yellow or green or any other rays in the spectrum. It is difficult to understand how he could conclude that in animals "the more strongly refrangible rays of the visible spectrum are the most active heliotropically, as in the case of plants," and "that the more refrangible rays have the same effect as mixed rays" (r905, p. 29), after studying reactions in but two different colors. 


\section{CHAPTER XIX}

\section{BRIEF CONSIDERATION OF THE REACTIONS OF MULTI- CELLULAR ANIMALS WITH WELL-DEVELOPED EYES IN LIGHT DIFFERING IN COLOR - WITH SPECIAL REFERENCE TO COLOR VISION}

IN the lower animals with image-forming eyes the reactions to colors are very much more complicated than in those without them. In these there is but little evidence that any one color is much more efficient than another. They may be positive to or may select a given color at one time and a very different one at another. Investigations in this line are still few and methods inadequate. We shall present only a few of the more conclusive. Foremost among these may be mentioned those of Lubbock on ants, bees and wasps. Of these we shall devote special attention to the work on ants and bees.

\section{Ants}

In his earlier experiments with ants Lubbock (I 895, p. I86) placed strips of glass differing in color, or glass jars containing colored solutions, side by side over an artificial nest. ${ }^{1}$ After leaving them for a few minutes he recorded the number in each of the different colors, then rearranged the color media and repeated the process. In twelve different observations there was a total of 890 ants under the red, 544 under the green, 495 under the yellow and only 5 under the violet. The results of numerous other observations under similar conditions were in all essentials like them.

1 These color media were spectroscopically tested by Professor Dewar. 
In later experiments Lubbock used more refined methods: He had a prismatic electric-light spectrum thrown upon a nest especially prepared for the purpose. Ten different experiments were made with this, the results of which were similar. I shall quote one in full:

"Professor Dewar kindly prepared for me a condensed pure spectrum (showing the metallic lines) with a Siemens' machine, using glass lenses and a mirror to give a perpendicular incidence when thrown on the nest. . . . I arranged the light and the ants as before, placing the pupae in the ultra-violet, some being distinctly beyond the bright. thalline band. The ants began at once to remove them. At first many were deposited in the violet, some, however, being at once carried into the dark beyond the red. When all had been removed from the ultra-violet, they directed their attention to those in the violet, some being carried, as before, into the dark, some into the red and yellow. Again, when those in the violet had all been removed, they began on the pupae in the red and yellow, and carried them also into the dark. This took nearly half an hour. As I had arranged the pupae so that it might be said that they were awkwardly placed, we then turned the nest round, leaving the pupae otherwise as they had been arranged by the ants; but the result of moving the nest was to bring some of them into the violet, though most were in the ultra-violet. They were, as before, all carried into the dark space beyond the red in about half an hour.

"We then turned the glass round again, this time arranging the end about the length of the spectrum beyond the end of the violet visible to our eyes. They began clearing the thalline band, carrying some into the violet, but the majority away further from the spectrum. In a quarter of an hour the thalline band had been quite cleared; and in half an hour a band beyond, and equal to the thalline band, those in the violet being left untouched. After the pupae in the ultra-violet portion had all been moved, those in the violet were also carried away and deposited 
about twice as far from the edge of the violet as the further edge of the bright thalline band" (I895, pp. 203-205).

Considering the results of all these different experiments, Lubbock concluded (p. I99) " that: (I) ants have the power of distinguishing colours; (2) that they are very sensitive to violet; and it would also seem (3) that their sensations of colour must be very different from those produced upon us." We shall discuss these conclusions later.

Many experiments with various color and intensity conditions were performed, in which the light in one part of the nest was passed through carbon bisulphide so as to eliminate the ultra-violet. It was found in general that, other conditions being equal, the ants avoid the light containing ultra-violet rays. These rays, although invisible to man, appear therefore to stimulate the ants somewhat like the rays which are visible. These results agree with those of Lubbock on Daphnia and those of Graber on the earthworm, and ten different species of insects as well as a few other forms. It is also well known that paramecia and various bacteria can be stimulated by ultraviolet. Stimulation by these rays therefore appears to be fairly common among animals.

Lubbock assumes that ultra-violet as well as the visible rays in the spectrum produces color sensation in ants. He says (1895, p. 220): "These experiments seem to me very interesting. They appear to prove that ants perceive the ultra-violet rays. Now, as every ray of homogeneous light which we can perceive at all appears to us as a distinct colour, it becomes probable that these ultra-violet rays must make themselves apparent to the ants as a distinct and separate colour (of which we can form no idea), but as unlike the rest as red is from yellow, or green from violet."

Very few will agree with Lubbock in assuming that he has demonstrated color vision - subjective sensation in ants. His results however are reliable. There can be no 
question but that these creatures while in their nests avoid white light, and particularly rays of the shorter wave lengths, and that red is much less efficient in stimulating them than any other color. The effect of the different rays is at least to some degree specific. The distribution of efficiency in stimulating ants in the prismatic solar spectrum is certainly not proportional to the distribution of energy or brightness as judged by the human eye. But why this is true and what mechanism is involved in the process of avoiding the shorter waves are questions upon which Lubbock's results have no definite bearing.

Can the reactions of ants to colors be explained by assuming that they are negative to rays of the shorter wave lengths, and that they are oriented by the light in the sense of Loeb's definition of heliotropism, or in any other definite way? In the absence of larvae or pupae there is some evidence indicating that ants orient and move from light containing the shorter waves, and that their movements are fairly definitely controlled by external conditions, but in the presence of these organisms there is no evidence showing that their reactions are thus definitely controlled. Under such conditions internal factors must have much to do with the reactions. In transferring larvae and pupae, as in the experiment of Lubbock quoted above, a given individual may pass back and forth many times from the red end of the spectrum to the violet and ultra-violet before all the young are deposited in the red or beyond. It cannot be maintained that they become negative to violet light when they are carrying their young and positive when they are not; for this opposes the fact that in the absence of larvae and pupae they avoid the violet. During the process of transferring their young the ants cannot therefore be considered either negative or positive to the violet or to any other color or condition of illumination. These reactions must be regulated primarily by internal factors. What these factors are is a question concerning which there is yet very little knowledge. That the 
reactions are adaptive, that it is to the advantage of the larvae and pupae, as well as to the adults, to be in darkness or in rays of longer wave lengths while in their nests, rather than in those of shorter, can scarcely be questioned. And Lubbock's suggestion that " ants do not like light in their nests, probably because they do not deem it safe," if liberally interpreted, may not be so far from the truth as some investigators assume (see Loeb, I905, p. I3).

\section{Bees}

In the study of the effect of different colors on the behavior of bees Lubbock showed the same characteristic thoroughness and ingenuity manifested in his work on ants. Several pieces of paper which differed in color were pasted to glass slips, upon each of which a drop of honey was placed. A bee was then taken from a hive, marked and placed near the honey on one of the glass slips. After the bee had taken honey to the hive and returned several times the glass slip was removed to a distance of from one to three feet, and one of a different color was put in its place. When the bee now returned it seldom went to the honey over the new color in the old position; it usually returned to that over which it had been accustomed to collect honey, although it was now in a new position. The reactions to various different colors were tested in this way. In case of blue being the original color visited by the bee, it returned 3 I times to the blue, two times to the green and not at all to the yellow, orange, red and white, one of which was substituted for the blue between each visit. In case of green being the original color the bee returned to the green 20 times, to the blue twice, to the yellow once and not at all to the other colors. In case of orange it returned 20 times to the orange, and but twice to other colors which were not recorded. These experiments extended over several days and a number of different bees were used. 
In a second set of experiments Lubbock trained a bee to come to a lawn for honey placed on a piece of colorless glass. He then procured several similar pieces of glass of different colors, arranged them on the lawn so that they were all about one foot apart, and put a drop of honey on each. After the bee returned it was frequently disturbed, so that it was compelled to sip honey several times, either over the same color or over different ones, before it left for the hive. The order in which it visited the different colors was recorded, and every time the bee left for the hive the relative position of all the glass plates was changed.

Many different series of observations were made in this way under various conditions; the results in all are however essentially the same. I shall therefore present only a portion of one series. In this series (I895, p. 307) the bee came first to the blue $3 \mathrm{I}$ times, to the green IO, to the orange II, colorless 5, red I4, white I9, and to the yellow 9 times. This shows that the blue is visited much oftener than any other color, although the bee was trained to get honey from the colorless piece of glass.

Graber (I 884, pp. I67-I74) obtained similar results in comparing the effect of red with that of blue by means of a different method. He inclosed the bees in a box one half of which was illuminated with red, the other half with blue light. In some experiments the blue was much brighter than the red, in others the red was brighter than the blue. In every test a majority of the individuals inclosed collected in the blue.

The first set of experiments led Lubbock to conclude "that bees possess the power to distinguish colours" (p. 302); and the second, that they prefer blue.

Perhaps the most interesting of Lubbock's results is the demonstration that honey bees can be trained to select any given color. This shows that they can in some way distinguish color and that the different rays and combinations of rays must have a specific effect on them; but it does not prove that they have color vision, for color-blind 
persons can also distinguish different colors if they differ in brightness as did those in Lubbock's experiments. It does, however, demonstrate that internal factors are of primary importance in these reactions. The selection of a given color now and a different one some other time, flight into the pitch darkness of their home at one moment and out into the brightest sunlight the next, is surely not the result of orientation unequivocally controlled by the immediate environment. These reactions can be explained only upon the assumption that some internal condition regulates the change in reaction.

Concerning the second conclusion of Lubbock, that bees "prefer blue," it must be said that if this is anthropomorphically interpreted there is no solid foundation for the conclusion, but if it is merely intended to indicate that shorter waves having a given amount of energy stimulate bees more strongly than longer waves having the same amount of energy, there can be no doubt as to its validity, unless the bees used in the experiments of Lubbock and in those of Graber had been accustomed to collect honey from blue flowers before the tests were made.

Aside from those already mentioned there are numerous other references to the reactions to color in ants, bees and other arthropods in the literature on these subjects. Among these may be mentioned those of Minkiewicz (1907), Keeble and Gamble (I900), and Bell (I906) on decapod crustacea, those of the Peckhams and McCook on spiders, and those of Graber, Forel, Plateau, Buttel-Reepen, Bethe, Bulman, Miss Fielde, Darwin, Müller and Bonnier on ants, bees, wasps and other insects. Much of the work of the investigators in the last group was directed toward the question as to the influence of the color of flowers on the visits of insects with its bearing on their evolution. Most of the results of this work favor the negative of this question, but nearly all of these investigators agree that insects have color vision, although their evidence is far from conclusive. With reference to reaction to color, none of the work of any 
of the authors mentioned above is as thorough as that of Lubbock. And since it leads to no essentially new or contradictory conclusions, with the exception of that of Bethe, it would be of but little value to review it here. That of Minkiewicz is nevertheless somewhat out of the ordinary, and it may consequently not be out of place to devote a few paragraphs to it.

\section{Higher Crustacea - Experiments of Minkiewicz}

Before presenting the work of Minkiewicz on the crustacea, it will be necessary to refer briefly to his earlier observations on the nemertean Lineus ruber, since these form the basis of his later work.

Minkiewicz exposed these worms in horizontal beams of light of different colors produced by means of a prism, colored glass or tissue paper. Under normal conditions they were found to be negative in blue or green and positive in red or yellow. But if left for several hours in Ioo c.c. of sea water diluted with 25 to 80 c.c. of distilled water, they became positive to the more refrangible rays of the spectrum. The striking peculiarity of these reactions is that in colorless light the organisms were negative under all conditions. He says ( 1907, p. 48): "I have not as yet found, in spite of long continued researches, a single means of transforming the negative phototropism of Lineus into positive phototropism by agents either chemical, osmotic or thermic. Thus, for example, the animal remains negative until its death in the presence of white light whatever the concentration of the sea water."

The author concludes that all the chromatic rays have a specific action independent of each other and of white light.

Among the crustacea, Minkiewicz experimented with spider crabs and hermit crabs. His studies on the former were devoted primarily to Maja verrucosa and Maja squinado, but he claims to have made analogous observations on different species of Pisa, Inachus and Stenorynchus. 
It is well known that many of the spider crabs fasten seaweeds and other objects to the carapace. Minkiewicz placed the crabs into aquaria with the sides and bottom uniformly colored and added bits of colored paper, some corresponding to the walls of the aquarium and others not. He claims that the animals selected those pieces which harmonized with their environment in color, and fastened them to the surface of the body and legs so that they became inconspicuous. "Les resultats sont . . vraiment frappants, la couleur du costume correspondant toujours precisement a celle du milieu" (I907, p. 4I). In a black aquarium however there was no evidence of selection, and it appears that the animals were unable to distinguish between green and yellow.

The author also says that if the crabs are left on a given color for some time and then transferred to an aquarium which is variegated in color, they come to rest in that part which corresponds in color with that from which they were taken.

In the experiments on the hermit crabs Minkiewicz illuminated the two halves of an aquarium with light of different colors, placed the animals so that the two eyes were exposed to light of different colors, and found that the creatures turned toward the color indicated by the arrows below; i.e., in case of black and red in the aquarium they went toward the red, in case of red and yellow, toward the yellow, etc., as indicated:

$$
\text { black } \rightarrow \text { red } \rightarrow \text { yellow } \rightarrow \text { blue } \rightarrow \text { violet } \rightarrow \text { green } \rightarrow \text { white. }
$$

If the crabs are kept in a jar and exposed to their own excreta for some time their reactions to colors gradually change as follows:

Normal: red $\rightarrow$ blue $\rightarrow$ green.

red $\rightarrow$ green $\rightarrow$ blue.

green $\rightarrow$ red $\rightarrow$ blue.

green $\rightarrow$ blue $\rightarrow$ red. 
Minkiewicz maintains that these reactions cannot be due to intensity difference, since the light in the yellow and green under the conditions of the experiments was more intense than that in any other color, and the organisms were positive to blue in the presence of yellow, but positive to green in the presence of violet.

The most interesting of the results obtained by Minkiewicz refer to the change in reaction to different colors. The spider crabs apparently become positive to the color which is dominant in the environment. Lineus and Pagurus, positive to a given color under certain conditions, become negative to that color under different conditions, or positive to some other color, while they remain continuously positive to white light. These reactions have much in common with those of the honey bee to different colors. They show that the creatures, especially the spider crabs, can distinguish colors. This of course does not demonstrate the power of subjective color sensations. It does however indicate that the different rays cause different changes in the organisms; in other words, that they have specific effects which are in some way related to the wave lengths. There is, however, no evidence bearing on the question as to whether or not these effects are analogous to those associated with brightness sensation or with color sensation in man or with neither.

The results of Minkiewicz must unfortunately be accepted with reserve, since he does not describe his methods in sufficient detail to warrant definite conclusions as to their validity, and they have as yet not been confirmed, although similar experiments have been made on other forms.

Pearse has recently (1909) repeated the experiments of Minkiewicz at Woods Hole, Mass., using Libinia emarginata in place of Maja. He obtained no evidence whatever of decoration in harmony with the environment. I have observed many of Pearse's experiments and repeated some myself, and feel justified in saying without going into details, that there was no evidence of color selec- 
tion. Bateson ( $\mathrm{I} 887$ ) records similar results in work on Stenorynchus. Recently I have again tested crabs for selection of color. At the Tortugas Islands numerous specimens of each of three species, not yet definitely identified, were used in these tests. A large proportion of all of the animals observed decorated profusely in the colored aquaria used; but I found no evidence whatever of harmony between the color of the substance selected and that predominating in the environment, although the methods used by Minkiewicz were closely imitated.

\section{Fishes}

I shall refer to but two other experiments on the subject of reactions to colors, one by Washburn and Bentley on the creek chub Semotilus atromaculatus, the other by Reighard on the marine gray snapper, Lutianus griseus.

Washburn (1908, p. 140) gives the following description of their experiment: "Two dissecting forceps were used, alike except that to the legs of one were fastened, with rubber bands, small sticks painted red, while to those of the other similar green sticks were attached. The forceps were fastened to a wooden bar projecting from a wooden screen, which divided the circular tank into two compartments, and hung down into the water. Food was always placed in the red pair of forceps, which were made frequently to change places with the green ones; and the fish was caused to enter the compartment half of the time on one side and half of the time on the other. This was to prevent identification of the food fork by its position or the direction in which the fish had to turn. The animal quickly learned to single out the red fork as the one important to its welfare, and in forty experiments, mingled with others so that the association might not be weakened, where there was no food in either fork, and where the forceps and rubber bands were changed so that no odor of food could linger, it never failed to bite first at the red. 
Moreover, the probability that its discrimination was based upon brightness was greatly lessened by using, when we experimented without food, a different red much lighter than that in the food tests. The fish successfully discriminated red from blue paints in the same way, and it was afterwards trained, by putting food in the green fork, to break the earlier association and bite first at the green."

Reighard made his experiments on a school of gray snappers, a form which usually inhabits the water under a dock at one of the Dry Tortugas Islands. The gray snappers feed on atherina, a small fish found in abundance near the shore. They take these fish, even if they have been killed in formalin and stained any color, but if Cassiopea tentacles are fastened to the atherinas they soon learn to avoid them. After the gray snappers had learned to reject red atherinas with tentacles it was found that they also rejected red ones without, but that they still took those stained any other color. For example, when blue and red atherinas were thrown in together they took only the blue, and this was true even if some of the red ones were of a much brighter shade and others of a much darker shade than the blue ones.

This seems to prove that the selection could not have been due to difference in brightness, such as a color-blind person can perceive in the different colors, and it led the author to conclude that gray snappers have color vision.

It will be seen that the conclusion that fishes have color vision, both in the work of Washburn and Bentley and in that of Reighard, rests primarily upon the fact that the animals discriminated between red of different shades and blue or green, and upon the assumption that the brightness of the different parts of the spectrum is practically the same for fishes as it is for man-that their eyes are stimulated by all the rays from the infra-red to the ultra-violet somewhat as ours are. While this may be true, it has not been positively demonstrated. As a matter of fact, there are reasons for believing that the red end of the spectrum for fishes 
and some other vertebrates, e.g., the dancing mouse and color-blind persons, is much darker than it is normally for man, and that the visible spectrum for these forms is somewhat shortened at this end. It is evident that the red, which appeared brighter than the blue to the human eye, may have actually appeared darker to the fishes, and if this be true the discrimination may have been made on the basis of brightness. There consequently remains some doubt as to the validity of the conclusion stated above.

Even in the birds and mammals the question of color vision is not settled, although these animals can undoubtedly distinguish different regions in the spectrum. But since it is not our object to discuss this subject we shall refer the reader to the excellent researches of Porter (I904, I906) on the birds, Yerkes (1907) on the dancing mouse, Kinnaman (I902) and Watson (I909) on the monkey, and Cole (I907) on the raccoon.

\section{General Summary and Conclusions of Part IV}

(I) The energy curve in both normal and prismatic spectra is much the same for nearly all sources of light. Beginning with the violet end it rises more or less gradually to a maximum at the red end, $760^{\mu \mu}$. In the normal or grating spectrum for sunlight, however, the maximum is in the orange at $6 \mathrm{Io}^{\mu \mu}$. From this point the energy decreases slightly toward the red end.

(2) The location in the spectrum of the maximum effect on photochemical reactions depends primarily upon the wave length and the chemical substances which take part in the reaction; and secondarily upon the absorption of light, the distribution of energy and the presence of substances which apparently do not take part directly in the reaction. The reaction between quinine and chromic acid, e.g., takes place most rapidly in the ultra-violet, whereas Triphenylfulgid is changed from the black form to the yellow most rapidly in 
the presence of red, orange and yellow rays, and photosynthesis in plants proceeds most rapidly in the red and orange. The photochemical reaction in a given substance is therefore primarily dependent upon the length of the light waves. The reaction between quinine and chromic acid is affected only by the light absorbed by the quinine, but the effect is not proportional to the absorption. The maximum absorption takes place in the ultra-violet, but the maximum efficiency is in the green. This shows that the location of the maximum effect is dependent upon the power of absorption and upon the distribution of energy as well as upon wave length. Ozone in the presence of chlorine is changed to oxygen by the visible light rays, while pure ozone is not, showing that photochemical reaction in a given substance may depend upon the presence of other substances.

(3) The distribution of brightness as judged by the human eye is approximately the same for both normal and prismatic spectra of sunlight and gaslight. But the distribution of energy in these spectra differs considerably. It is therefore evident that brightness must be primarily a function of the length of the waves and secondarily a function of the amplitude or energy contents. In lower intensity the maximum is near the green, in higher it is in the orange. In color-blind persons it is usually in the green.

(4) In the higher plants the maximum rate of curvature in the spectrum takes place at the lower limit of the violet, but there is a secondary maximum in the red. In some fungi, however, the rate of curvature takes place under potassium bichromate as rapidly as it does under an ammoniacal solution of copper hydrate. That is, it takes place as rapidly in the longer waves of the spectrum as it does in the shorter. In the swarm-spore the region of maximum stimulation in the solar prismatic spectrum is in the indigo near the Fraunhofer line $G$. In Amoeba, Euglena and Hydra it is in the blue, in Paramecium in the ultra- 
violet, in Daphnia and Simocephalus in the yellow or green, in Bacterium photometricum probably in the infra-red with a secondary maximum in the orange, while in Oscillaria all rays appear to be equally efficient. In plasmodia, protoplasmic streaming in cells, earthworms, some mollusks, and number of insects and spiders, the region of maximum stimulation is probably somewhere toward the violet end of the spectrum, although it has not been definitely located. In nearly all organisms without image-forming eyes $^{1}$ the relative stimulating efficiency of the different rays is apparently constant under different conditions, but in the forms with eyes there is evidence that it varies. Some of the spider and hermit crabs, a number of insects and spiders and many higher forms may be positive to certain rays under certain conditions and to others under other conditions. Bees and fishes can undoubtedly distinguish different regions in the spectrum. They can be trained to select any of the primary colors of the spectrum by associating these colors with food. That is, they are positive to (or select) one color at one time and another at a different time. Just what mechanism is involved in this power of selection is unknown. Whether it is on the basis of brightness or on the basis of color vision or neither is a matter concerning which experimental evidence does not warrant a definite conclusion. Many organisms react to ultra-violet much as they do to visible rays. This is in harmony with the following quotation from Schäfer referring to man (I898, p. I055): "The invisibility of the infra-red rays is probably due to insensitiveness of the retina, while the ultraviolet rays fail to be seen, partly, at any rate, owing to absorption by the ocular media."

(5) The presence of certain rays retards the reaction to others in a number of organisms. According to Wiesner, some plants react to red more strongly than to red mixed with yellow. And according to Lubbock and Wilson

${ }^{1}$ Euglena appears to be an exception to this. According to the researches of Engelmann it becomes positive to red in low oxygen pressure. 
Daphnia reacts more strongly to green or yellow and Hydra to blue than to white light. These reactions have much in common with the reversible photochemical reactions of certain chemical compounds, particularly the fulgides, in which the reaction in one direction proceeds most rapidly in the shorter wave lengths and in the opposite direction in the longer, while in a mixture of rays the reaction proceeds more slowly in one or the other direction, depending upon the relative amount of the different rays.

(6) Considering the results set forth above it is evident (a) that, contrary to the hypothesis of Sachs, Loeb and Davenport, the shorter waves are not the more active in all plants and animals; the different rays do not have the same relative stimulating efficiency in all organisms; and $(b)$ that the stimulating efficiency of the different rays, probably in all organisms, is not proportional to the energy they contain, but that for a given ray or color there is a definite relation between the energy and the stimulation which is probably in accord with Weber's law.

(7) Light, as we have seen, causes reactions between many different chemical compounds. In these reactions the different rays have a specific effect. That is, certain reactions are produced only by waves of a given length and others only by waves of a different length. If reactions in a given chemical solution take place in light waves of a given length, and those in another solution in waves of a different length, we may be fairly certain that the reacting compounds in the two solutions differ. The reactions of organisms are caused by, or at least associated with, chemical changes in the organisms. The organisms probably do not react to the external agents directly, but to the chemical changes within produced by these agents. Since the reaction to the different rays is not the same in different organisms, it is clear that the chemical changes associated with the reactions in the different organisms are not the same. For example, in Amoeba the maximum power of stimulation is in the blue; this must be associated with 
certain chemical changes which are produced by the blue. In Daphnia the maximum is in the yellow and green, and in many of the plants it is in the violet. These reactions, too, are associated with chemical changes, but since these chemical changes are caused by rays differing in wave length from those which are most efficient in Amoeba, the chemical compounds must also be different unless the difference in the effect of the different rays can be accounted for by assuming the presence of certain inactive substances which influence the chemical reaction, or by assuming selective absorption on the part of the organism. It is however not likely that the difference in reaction to different rays can be explained thus. We may then conclude that the chemical changes associated with reactions are not the same in all organisms. While we do not at present know what these changes are, there are prospects that future investigations along this line may demonstrate the nature of some of them at least, especially after the photochemical reactions in organic and inorganic substances have been more thoroughly investigated.

(8). In plants and the lower organisms on which the relative stimulating efficiency of the different rays is fairly constant the chemical changes accompanying the reactions may be relatively simple, but in the higher forms in which the relative stimulating efficiency of the different rays varies it seems evident that the chemical changes must be very complicated. If this is true, it contradicts Loeb's general conclusion that the reaction mechanism associated with photic responses in plants is the same as that in animals, that "the dependence of animal movements on light is in every point the same as the dependence of plant movements on the same source of stimulation" (I905, p. $8 \mathrm{I}$ ).

(9) Honey bees, some fishes, birds and mammals, and probably some of the decapod crustacea and spiders, can unquestionably, and many of the lower forms with welldeveloped eyes can probably, distinguish the different 
regions of a spectrum. Whether the mechanical processes associated with this discrimination are analogous to those associated with brightness or color vision in the human being or neither is not known, but the processes in these forms are undoubtedly very different from those associated with the reactions in simpler forms, e.g., in Amoeba or plants. 


\section{CHAPTER XX}

\section{THEORETIC CONSIDERATIONS}

THE following points have been established in the preceding pages:

(I) Movement and change in movement, both in rate and direction, may take place without any immediate external change.

(2) Sudden changes in light intensity on any sensitive structure in an organism may cause reactions; ${ }^{1}$ for example, the orientation of Euglena and the retraction of the tubicolous annelids.

(3) Continued illumination without any variation of intensity probably affects the rate of locomotion in all organisms which respond to light, and it may cause changes in direction of movement by inducing a reversal in the sense of reaction. The time of exposure, as well as the absolute intensity, is functional in this. In fact the product of the time of exposure and the intensity is probably, within certain limits, constant in producing a given stimulus, no matter what the relative value of the two factors is.

(4) A sudden increase and a sudden decrease of light intensity may under certain conditions produce the same reaction, e.g., the contraction of Helix hortensis, the avoiding reaction in Euglena and the raising and throwing of the anterior end from side to side in planarians. Such responses are more striking in some cases of stimulation by temperature than in case of stimulation by light. Paramecium, for instance, gives the avoiding reaction to de-

1 In this discussion we shall consider anything which causes a change of movement a stimulus, and any response to a stimulus a reaction. A reaction, then, is either a change in rate of movement or in direction of movement. 
crease as well as to increase of temperature, even if the change is only slight.

(5) A given condition of illumination may inhibit one kind of movement in an organism and cause movement of another kind. When the oral end of Hydra viridis is fully illuminated the swinging about the point of attachment is inhibited and locomotion is produced. (See Chapter VIII).

(6) An increase in the general illumination of an organism may cause an increase in activity, while a sudden decrease of intensity causes a still greater increase in activity in the same organism at the same time. If the light intensity on a Volvox colony under certain conditions is increased, all of the zooids in the colony become more active, but those on the shaded side of the colony become most active. The rotation of the colony on the longitudinal axis causes a sudden decrease of intensity on the sensitive part of the zooids as they are carried to the shaded side of the colony (see Chapter VII), and the greater increase in activity of the zooids on the shaded side is no doubt due to this sudden decrease of intensity, while the activity of all the zooids is probably augmented by the effect of the continued illumination.

(7) An increase in light energy may produce the same effect on reactions as a decrease in heat energy. Chlamydomonas, for example, becomes negative in constant temperature if the light intensity is increased or in constant illumination if the temperature is decreased. (See Chapter XIII).

(8) Acids, certain narcotics and salts, and at least one alkali, may cause a change in the sense of reaction from negative to positive in Gammarus pulex. Any condition which acts as a depressant may cause Ranatra or Arenicola larvae to become negative.

(9) The stimulating effect of the different rays in the spectrum is specific. But it is not the same in all organisms. With a given amount of energy some are most strongly 
stimulated by blue, others by violet or ultra-violet, others by green and yellow, and still others by red and infra-red (see Summary to Part IV, Chapter XIX).

(Io) Reactions to light are variable, modifiable, and in general adaptive. (a) An attached specimen of Stentor coeruleus, for example, may contract suddenly when light of a given intensity is flashed upon it, or it may merely swing about its point of attachment or it may not respond at all. Hydroides may remain in its tube after stimulation by a given decrease of intensity only a few seconds, or it may remain for several minutes. This difference in response to the same external conditions must be due to internal factors. (b) Wherever there is a reaction to a sign, it is probable that the response to a given external condition has been modified. For example, Euglena under certain conditions responds to a very slight decrease in light intensity on the colorless anterior end, which is in itself of no consequence to the organism, but this slight decrease in illumination is usually followed by a greater decrease on the entire body if there is no change in the direction of locomotion, and it is of course for the welfare of the organism to prevent this. It is probable that originally no response was given until the injurious condition was realized. Many similar illustrations are found in organisms that respond to shadows which announce the approach of an enemy. (c) Adaptation and regulation are striking characteristics in nearly all reactions to light. The reactions are adaptive not only under constant conditions, but also under varying conditions, for if the environment is changed the reactions change to meet the demands of the new circumstances. Jennings has well said (I906, p. 338): "Regulation constitutes perhaps the greatest problem of life. How can the organism thus provide for its own needs? To put the question in the popular form, How does it know what to do when a difficulty arises? It seems to work toward a definite purpose. In other words, the final result of its action seems to be present in 
some way at the beginning, determining what the action shall be. In this the action of living things appears to contrast with that of things inorganic."

Let us now see in how far the various theories concerning behavior account for the phenomena set forth above. The more prominent of these are those of Loeb, Jennings and Driesch. We have already referred to some theories elaborated to account for the reactions of plants to light (see Chapter IV). These we shall not consider again here.

Loeb's theories refer to two features in behavior: (I) the direct cause and regulation of any given reaction and (2) the origin of adaptive reactions. (I) He says (I906, p. I30) that the reactions "are caused by a chemical effect of light" and then continues as follows, showing how the reactions are regulated: "We assume . . . that if light strikes the two sides of a symmetrical organism with unequal intensity, the velocity or the character of the chemical reactions in the photosensitive elements of both sides of the body is different; that in consequence of this difference the muscles, or contractile elements, on one side of the organism are in a higher state of tension than their antagonists." He claims (p. I3I) that "it [is] possible by the use of chemicals to control the precision and sense of the heliotropic reactions " and that this and other facts prove that reactions to light are caused by the chemical changes produced by the light. Very few will agree that Loeb has proved his point here. But practically every one assumes that light does cause chemical changes in organisms and that these changes affect the reactions. Many, however, do not agree with Loeb in the idea that they are the direct and immediate cause of the reactions to light, as his elucidation indicates. The fact that acids, narcotics, salts, alkalis or any condition which acts as a depressant may produce the same effect on the reactions of certain organisms to light seems to indicate that the reactions are, at least in some instances, due to a general effect on the organism as a whole. 
There are however photochemical reactions which are suggestively similar to some of the photic reactions in organisms. We have shown in Part IV that in some compounds the reactions proceed in one direction in one light condition and in the opposite in another; that the action of the different rays of light is specific, and that in some of these chemical reactions heat and light tend to produce opposite effects. The first two of these reactions are somewhat similar to the change in the sense of reactions produced by changes in light intensity in many organisms and to the specific reactions to different rays. The last is similar to the effect of heat and light on the sense of reaction in Chlamydomonas and various other organisms referred to under (7) above. If then these organisms contain chemical compounds which are affected by light like those referred to above, we can account for the reactions mentioned by assuming that they are due to the effect of the light on the chemical changes in the organism. In case of Volvox I was also able to account for a number of peculiarities in the process of reversal in the sense of response by the assumption of reversible photochemical reactions within the organism (Mast, I907, pp. I57-I6I). And we might account for the fact that an increase in illumination produces the same effect as a sudden decrease, as in the case of the zooids of Volvox (see (6) above), by assuming two photochemical reactions, one dependent upon the time rate of change of intensity, the other upon the absolute intensity and the time of exposure. In this same way the inhibition of one sort of movement and the augmentation of another in the same organism (Hydra) might be accounted for. So we might continue and account for modifiability, variability, adaptation, etc., by various other assumptions. But all of these assumptions regarding chemical changes are so extremely hypothetical that speculation based on them has at present but little value. And it is important to realize that the common belief that light in some way influences the activity 
of organisms by chemical changes which it causes within them, is as yet founded almost entirely on such hypothetical assumptions - assumptions which are problems, not solutions.

(2) Loeb's explanations of the origin of adaptive reactions to light is found in the following quotation (1906, p. I60): "The fact that cases of tropism occur even where they are of no use, shows how the play of the blind forces of nature can result in purposeful mechanisms. There is only one way by which such purposeful mechanisms can originate in nature; namely, by the existence in excess of the elements that must meet in order to bring them about. In green plants and in some animals the positive heliotropism is useful; yet there exists probably an endless number of heliotropic animals for which their heliotropism is about as useless as is galvanotropism. The prerequisites for heliotropism are a symmetrical body form, which seems to be present in almost all organisms - although some asymmetries exist - and the presence of photosensitive substances, which is not quite so common, but certainly not infrequent. Some of the regular substances found in protoplasm seem to turn readily into a photosensitive form. As the two conditions mentioned above are quite common, the laws of probability make it necessary that in a certain number of cases both conditions will be fulfilled, and then we may expect heliotropic actions. If it now occurs that in an organism the turning to the light helps it to find its food, as is the case with certain caterpillars, e.g., Porthesia chrysorrhoea, or the stems of green plants whose starch is manufactured by light, we have a "purposeful mechanism.' Again, according to the laws of probability, the number of animals in which the three groups of conditions meet is much smaller than where only two meet. The tropisms thus furnish an insight into the origin of purposeful reactions by the blind forces of nature." The difficulty with this hypothesis is that it does not fit the facts. It rests primarily upon the assumption that there 
exists an endless number of organisms whose reactions to light are useless. Indeed, according to this theory, there must be more organisms in which the reactions to light are or have been useless than there are in which they are purposeful, for the author states, as quoted above, that "the number of animals in which the three groups of conditions [purposeful mechanism] meet is much smaller than where only two meet [useless reactions]." We have demonstrated that, while there are isolated instances, mostly under artificial conditions, in which orientation and subsequent locomotion (heliotropism) lead to fatal results, the orienting reactions are in general useful to the organism in its life processes, and the same may be said regarding all other reactions to light. Thus, it is evident that Loeb's theory of the origin of purposeful reactions is not in harmony with the observed facts.

Jennings' theory of behavior is founded upon the idea that the reactions are fundamentally " purposeful." $\mathrm{He}$ admits that light and other external agents cause chemical changes in the organism, and that all reactions are determined by chemical changes or states; but that the chemical change or state which causes a given reaction is not directly and entirely the result of the external condition which precedes the reaction; that what an organism does under a given condition depends upon what it and its ancestors have done and experienced in the past as well as upon the present external conditions. The reactions are above all things regulatory. External conditions are not the direct cause of reactions.

Reactions are defined as changes in the activity of organisms. Such changes may occur under constant external conditions. They are therefore due primarily to internal changes. External factors cause reactions not directly, but indirectly, by altering internal processes (physiological states). Variability in reaction to given external conditions is due to changes in physiological states. If an organism responds to light of a given inten- 
sity in a given way now, and to the same intensity in another way later, it is because the physiological state of the organism has changed. When external changes persistently follow each other, as, for example, shadow and contact in case of the attack of an enemy on Hydroides, the shadow produces a certain physiological state. This state is resolved into another by contact, and this results in a reaction. Repetition tends to cause the resolution of the first physiological state into the second, without contact, and consequently a reaction to the shadow which was formerly given only to a contact stimulus. Thus we have the origin of a reaction to a sign, response to a representative stimulus, as Jennings terms it. The shadow in the case mentioned above represents the contact; it is a sign of the approach of danger. All of this the author has elaborated in a most masterful way in his book "Behavior of the Lower Organisms" (1906). Every step in the development of the theory is supported by numerous experimental facts and all seems to fit what is known concerning the reactions of organisms. Reactions, according to this theory, are, as stated above, primarily due to physiological states. External agents ordinarily produce reactions through the effect they have on these states. By the application of this idea all the different phenomena connected with reactions to light as summarized at the beginning of this chapter can be accounted for.

But what are these physiological states and of what do they consist? That there are such states in organisms cannot reasonably be doubted, and that the reactions are dependent upon them much as Jennings assumes, seems to me to have been well established in his work. But what regulates the physiological states is a question concerning which we have as yet but little knowledge. Jennings assumes that they are regulated entirely objectively, i.e., by the interaction of external and internal physicochemical processes. This is of course a legitimate assumption, an assumption which indeed has some experimental 
support, especially in the fact that changes in metabolism cause changes in reaction. "Hungry animals react positively to possible food while satiated ones react negatively to the same stimuli." Paramecium bursaria is positive to light in solutions deficient in oxygen, whereas it does not react under normal conditions. After Volvox has been resting in darkness for some time it responds to light in a manner very different from the response given when it is active. Jennings (I906, pp. 25I-253 and elsewhere) cites several other similar instances indicating that reactions depend upon physiological states, but he frankly admits that "it is rarely possible to observe them [physiological states] directly," especially in the lower organisms, in which "the real data of observation are the actions; if we considered these alone, we could only state that a given organism reacts under the same external conditions sometimes in one way, sometimes in another. This would give us nothing definite on which to base a formulation and analysis of behavior, so that we are compelled to assume the existence of changing internal states. This assumption, besides being logically necessary, is, of course, supported by much positive evidence drawn from diverse fields, and there is reason to believe that in time we shall be able to study these states directly. Before we can come to a full understanding of behavior, we shall have to subject the physiological states of organisms to a detailed study and analysis, as to their objective nature, causes, and effects" (p. 25I).

And again, after giving a most excellent description of the reactions of Stentor, in which he shows that these creatures sometimes respond in at least five different ways to the same stimulus, Jennings says (p. I77): "Since in each of these cases the external conditions remain throughout the same, the change in reaction must be due to a change in the organism. The organism which reacts to the carmine grains by contracting or by leaving its tube must be different in some way from the organism which reacted to the 
same stimulus by bending to one side. No structural change is evident, so that all we can say is that the physiological state of the organism has changed. The same organism in different physiological states reacts differently to the same stimuli. It is evident that the anatomical structure of the organism and the different physical or chemical action of the stimulating agents are not sufficient to account for the reactions. The varying physiological states of the animal are equally important factors. In Stentor we are compelled to assume at least five different physiological states to account for the five different reactions given under the same conditions." It is thus evident, without further argument, that while there is some evidence bearing on physiological states, we know but little about their nature and regulation. Even in those cases where it appears evident that they are dependent upon metabolic processes, it must be said that we know practically nothing about their regulation, since we know almost nothing concerning the fundamentals in metabolism. It is evident, then, that for all that is known to the contrary, subjective factors, entelechies, or psychoids, factors foreign to inorganics, may have a hand in controlling physiological changes and consequently the reactions. Such factors have been postulated by the vitalists and neovitalists, notably by Hans Driesch.

Driesch postulated a non-energetic factor to account for form regulation and regulation in behavior. He claims that if certain organisms, starfish eggs, for instance, are divided into halves in any direction, each half will produce a new individual. Such organisms, he says, form harmonious equipotential systems. Every part has the same potency (future possibilities) as every other part, no matter how the whole is divided. No machine ${ }^{1}$ (using the term in its broadest sense), he holds, could account for

1 "A machine is a typical configuration of physical and of chemical constituents, by the acting of which a typical effect is attained." (Driesch, Vol. I, pp. I38, I39.) 
this. Referring to genesis, Driesch asserts that an egg must be considered as a whole, a unit, an entity, an individual, but during every step in the process of development it is still a whole, an individual, although it may have been divided many thousands of times. Now he asks (Vol. I, p. 225), "Can you imagine a very complicated machine, differing in the three dimensions of space, to be divided hundreds and hundreds of times and in spite of that to remain always the same whole?" and adds (p. 226), "We say it is a mere absurdity to assume that a complicated machine, typically different in the three dimensions of space, could be divided many many times, and in spite of that always be the whole: therefore there cannot exist any sort of machine as the starting-point and basis of development." Acting, too, he affirms, cannot be explained by the application of physico-chemical principles alone; and it is this part of his analysis which concerns us in particular. "In acting," he says (Vol. II, p. 69), " there may be no change in the specificity of the reaction when the stimulus is altered fundamentally, and again, there may be the most fundamental difference in the reaction when there is almost no change in the stimulus." In other words, each constituent of the effect does not depend upon each constituent of the stimulus, "but one whole depends on the other whole, both 'wholes' being conceivable in a logical sense exclusively" (p. 8I). The author supports his contention still further by referring to the historical basis of acting. He says (p. 8I), "Firstly, the effects that are given off in acting occur in a field of natural events very different from that of the stimuli received historically: sensations belong to one, movements to another field. Secondly, the historical basis serves only as a general reservoir of faculties, the specific combinations of the stimuli received historically being preserved by no means in their specificity, but being resolvable into elements; these elements then - transferred, however, to another sphere of happening - are rearranged into other specificities 
according to the individuality of the actual stimulus in question."

Thus it is maintained that acting or behavior cannot be accounted for on the basis of physics and chemistry. There must be a factor involved here which is not active in the inorganic realm. This factor is postulated as a nonenergetic regulatory factor. It is supposed to prevent reactions - activity or becoming - by compensating potentials, i.e., by transferring kinetic into potential energy, and to regulate reactions and becoming by setting "free into actuality what it has itself prevented from actuality, what it has suspended hitherto" (p. I80). Thus it is that this non-energetic factor, entelechy, psychoid, is supposed to regulate development, becoming and action in organisms. It requires the same amount of energy under certain conditions to fire a gun to-morrow at IO A.M. as it does at I I A.M., and just as much to fire it east as it does to fire it west. In some such way, I understand the author to assume that psychoid can regulate behavior without energy. It does not create reactions, but it regulates them with regard to time and direction.

Admitting the operation of a factor of this sort it is a simple matter to explain the regulation of physiological states and all of the puzzling phenomena in behavior previously referred to, but in such an explanation we still have an unknown factor to account for, the psychoid; and concerning this some maintain nothing can be learned, for it is evident that if there is such a factor at work in behavior different things can happen under precisely the same physicochemical conditions. And if this be true, how can we hope to progress experimentally? According to Driesch's theory every act is definitely and absolutely determined, although not mechanically. With a given physico-chemical constellation and a psychoid in a given state, precisely the same things will always occur. If there is a psychoid of this sort, a factor which has different states but which always acts the same in any given state, it seems to me that by 
experimental investigation it will be possible to learn something concerning its nature, just as we have learned, at least in part, the character and manifestation of electricity, gravity and other similar concepts.

It is however highly essential in all investigation and discussion bearing on such concepts to differentiate clearly the two points of view from which they may be considered, the scientific and the metaphysical. From a scientific point of view entelechy and psychoid, like gravity, electricity and chemical affinity, can be used only to indicate the facts observed, not the cause of the phenomena. From this point of view gravity indicates merely the fact that bodies tend to approach each other, not the cause of this tendency. It is only in the realm of metaphysics that all of these concepts, psychoid and entelechy, as well as gravity, electricity and chemical affinity, are looked upon as causal agents.

Entelechy, then, from a scientific point of view, merely indicates certain facts concerning regulation which apparently do not fit into any of our physical or chemical concepts. It has no more to do with the cause of these acts than chemical affinity has with the cause of chemical reactions. It is a name for certain phenomena just as is electricity. Whether or not there are any such phenomena is the question at issue, and our only hope of agreement in an answer lies in further investigations. But until this question is settled it must be said that those who maintain that there are no factors functional, no phenomena, in living matter that are not also found in irorganic matter, that there are no entelechies, are certainly no more scientific than those who maintain the opposite, for the fundamental phenomena, the distinguishing characteristics of living matter, have not as yet been accounted for mechanically. To say that they can be is prejudging the future quite as much as to say that they cannot be. Convictions are valuable, but dogmatic statements as to what can or cannot be done in the future have no place in science, as has been repeatedly demonstrated. 


\section{BIBLIOGRAPHY}

The following bibliography contains all of the essential references consulted in the preparation of this book. It is hoped that all of the important works which have a bearing on reactions to light in both animals and plants will be found in it. Those referring to vision are, however, not included.

Adass, G. P., I903. On the Negative and Positive Phototropism of the Earthworm Allolobophora foetida (Sav.) as Determined by Light of Different Intensitiess. Amer. Jour. Physiol., Vol. 9, pp. 26-34.

Albrecht, G., I908. UỦber die Perzeption der Lichtrichtung in den Laubblättern. Ber. d. deutsch. bot. Ges., Vol. 26, pp. I82-19I.

ANDREws, E. A., I89r. Compound Eyes of Annelids. Jour. Morph., Vol. 5, pp. 27 I-299.

Axenfeld, D., I899. Quelques observations sur la vue des arthropodes. Arch. ital. biol., t. 3I, pp. 370-376.

Bancroft, F. IV., I907. The Mechanism of the Galvanotropic Orientation in Volvox. Jour. Exp. Zoöl., Vol. 4, pp. $1_{57-163 .}$

Baranetzski, J., I876. Influence de la lumière sur les plasmodia des Myxomycètes. Mém. Soc. Sc. nat. Cherbourg, Vol. I9, pp. $321-360$.

Barrows, W. M., Ig07. The Reactions of the Pomace Fly, Drosophila ampelophila Loew, to Odorous Substances. Jour. Exp. Zoöl., Vol. 4, pp. $515-537$.

Bateson, W., I887. Notes on the Senses and Habits of Some Crustacea. Jour. Mar. Biol. Assoc. United Kingdom, Vol. I, p. 2 I I.

, I887a. On the Sense-organs and Perceptions of Fishes. Ibid., Vol. I, p. 225 .

BEer, TH., I893. Studien über die Accommodation des Vogelauges. Arch. f. d. ges. Physiol., Bd. 53, pp. I $75^{-237}$.

, I894. Die Accommodation des Fischauges. Ibid., Bd. 58, pp. $523-650$.

, I897. Die Accommodation des Kephalopodenauges. Ibid., Bd. 67, pp. $54 \mathrm{I}-586$.

, r898. Die Accommodation des Auges bei den Reptilien. Ibid., Bd. 69, pp. $507-568$.

, I898a. Die Accommodation des Auges bei den Amphibien. Ibid., Bd. 73, pp...5०I-534.

, Ig0I. Über primitive Sehorgane. Wiener klin. Wochenschr., Jahrg., I90I, Nr. I I-I3.

BeER, TH., Bethe, A., u. Uexküll., J. v., I899. Vorschläge z. einer objectivirender Nomenclatur in der Physiologie des Nervensystems. Biol. Cent., Bd. I9, pp. $5^{\text {I } 7-5^{2 I} \text {. }}$

Bell, J. C., I906. The Reactions of the Crayfish. Harvard Pysch. Studies, Vol. 2, pp. 615-644. 
Bert, P., r869. Sur la question de savior si tous les animaux voient les mêmes rayons que nous. Arch. de physiol., t. 2, p. 547 .

, I870. Influence de la lumière verte sur la sensitive. Compt. Rend., Vol. 70, pp. 338-340.

, I878. Influence de la lumière sur les êtres vivants. Revue Scient., Vol. $2 \mathrm{I}$, pp. 98I-990.

Berthold, G., I882. Beiträge zur Morphologie und Physiologie der Meeresalgen. Jahrb. f. wiss. Bot., Bd. I3, pp. 569-7 I 7 .

Bethe, A., I898. Dürfen wir den Ameisen und Bienen psychische Qualitäten zuschreiben? Arch f. d. ges. Physiol., Bd. 70, pp. I5-100.

, I902. Die Heimkehrfähigkeit der Ameisen und Bienen. Biol. Cent., Bd. 22, pp. 193-238.

Binet, A., I894. The Psychic Life of Micro-organisms. Authorized Translation. Chicago. I $20 \mathrm{pp}$.

BlaAuw, A. H., Igo8. The Intensity of Light and the Length of Illumination in the Phototropic Curvature in Seedlings of Avena sativa (Oats). Kon. Ak. Wet. Amsterdam. Proc. Meeth., Sept. 26, I908. Review in Bot. Cent., I9o9, Vol. I Io, p. 655 .

, I909. Die Perzeption des Lichtes. Rec. d. Trav. bot. Néerl. V. Review in Bot. Cent., I9Io, Vol. I I3, pp. 353-356.

BoHn, G., I902. Contributions à la psychologie des annélides. Bull. Mus. d'hist. nat., t. 9, p. 62 .

, 1903. Sur les mouvements oscillatoires des Convoluta roscoffensis.

C. r. Acad. Sci., Paris, t. I37, pp. 576-578.

-, I903a. Actions tropiques de la lumière. C. r. Soc. Biol., Paris, t. 55, Pp. I440-I 442 .

, I903b. Sur le phototropism des artiozoaires supérieurs. C. r. Acad. Sci., Paris, t. I37, pp. I 292-1 294.

, I904. Périodicité vitale des animaux soumis aux oscillations du niveau des hautes mer. Ibid., t. I39, pp. 610-6II.

- I904a. Oscillations des animaux littoraux synchromes des mouvements de la marée. Ibid., t. I39, pp. 646-648.

- I I 4 b. Mouvements de manège en rapport avec les mouvements de la marée. C. r. Soc. Biol., Paris, t. 57, pp. 297-298.

, I904c. Théorie nouvelle du phototropisme. C. r. Acad. Sci., Paris, t. I39, pp. 890-89 I.

, I905. Attractions et oscillations des animaux marins sous l'influence de la lumière. Mémoires Inst. gén. psych., Paris, Vol. I, I $10 \mathrm{pp}$.

, I906. Sur les mouvements de roulement influencés par la lumière. C. r. Soc. Biol., Paris, t. 6I, p. 468.

t. 62, p. 473 .

- I 1908 . Introduction à la psychologie des Animaux a symétrie rayonnée, II. Les Essais et Erreurs chez les Étoiles de mer et les Ophiures. Paris, 86 pp.

, I909. Les Tropismes. Rapport au VIme Congrès International de Psychologie. Genève. I5 pp.

Bonnier, G., I879. Les Nectaires. Ann. des. sc. nat. Bot., 6 ser., Vol. 8, pp. 46-48.

Bosch, F., I907. Über die Perzeption beim tropistischen Reizprozess der Pflanzen. Doctorate Dissertation. Bonn, Germany.

Brooks, W. K., I907. The Foundations of Zoölogy. New York. 339 pp. Bulman, G. W., I89o. On the Supposed Selective Action of Bees on Flowers. The Zoölogist, Vol. I4, 3 ser., p. 422. 
1899. Bees and the Origin of Flowers. Nat. Sci., Vol. I4, pp. I28I30.

Bunsen, R., and Roscoe, H. E., I859. Photochemischer Untersuchungen, V. Die Sonne. Poggendorff's Annalen, Vol. 108, pp. I93-273.

Buttel-Reepen, H. v., I907. Are Bees Reflex Machines? Experimental Contribution to the Natural History of the Honey-bee. Translated by Mary H. Geisler. Published by A. I. Root Co., Medina, O. 48 pp. Original in Biol. Cent., I 900, Vol. 20.

Byк, A. v., Igo8. Die Fortschritte der Photochemie im Jahre 1908. Zeitschrift f. Elektrochemie, Bd. 15, pp. 331-338.

Candolle, A. P. de, $183^{2}$. Physiologie végétal. A German trans. by Röper, pub. in 1835 .

Carpenter, F. W., I905. Reactions of the Pomace Fly Drosophila ampelophila Loew to Light, Gravity, and Mechanical Stimulation. Amer. Nat., Vol. 39, pp. I57-I7 I.

, rgo8. Some Reactions of Drosophila, with Special Reference to Convulsive Reflexes. Jour. Comp. Neur. and Psych., Vol. I8, pp. 48349I.

Ciesielski, T., I875. Untersuchungen über die Abwärtskrümmung der Wurzel. Cohn's Beiträge z. Biol., Vol. I, pp. I-30.

Clapark̀de, E., i86. Annélides Chétopodes du Golfes de Naples.

CoHN, F., I865. Über die Gesetze der Bewegung mikroscopischer Thiere und Pflanzen unter Einfluss des Lichtes. Jahresber. d. Schles. Ges. f. Vaterl. Cult., Vol. 42, pp. $35^{-3} 3$.

Cole, L. J., I9or. Notes on the Habits of Pycnogonids. Biol. Bull., Vol. 2, pp. $195^{-207}$.

, I907. Influence of Direction vs. Intensity of Light in Determining the Phototropic Responses of Organisms. Abstract in Jour. Comp. Neur. and Psych., Vol. I7, p. I93.

, Ig07a. An Experimental Study of the Image-forming Power of Various Types of Eyes. Proc. Amer. Acad. Arts and Sci., Vol. 42, pp. $335-417$.

Cole, L. W., I907. Concerning the Intelligence of Raccoons. Jour. Comp. Neur. and Psych., Vol. 17, pp. 2 I I-26I.

Congdon, E. D., I908. Recent Studies upon the Locomotor Responses of Animals to White Light. Jour. Comp. Neur. and Psych., Vol. I8, pp. 309-328.

Cowles, R. P. Reaction to Light and Other Points in the Behavior of the Starfish. To appear in Publication of the Carnegie Institution of Washington.

- Stimuli Produced by Light and by Contact with Solid Walls as Factors in the Behavior of Ophiuroids. To appear in Jour. Exp. Zoöl., Brooks Memorial Volume.

CzAPEK, F., 1895. Über den Nachweis der geotropischen Sensibilität der Wurzelspitze. Jahrb. f. wiss. Bot., Bd. 27, pp. 31 I- 366 .

$\longrightarrow$, I898. Weitere Beiträge zur Kenntniss der geotropischen Reizbewegungen. Ibid., Bd. 32, pp. I75-308.

, 1900. Untersuchungen über Geotropismus. Ibid., Bd. 35, pp. 243-339.

Dalyell, Sir J. G., I853. The Powers of the Creator Revealed. London.

Darwin, C., I876. The Effect of Cross- and Self-fertilization in the Vegetable Kingdom. London. $482 \mathrm{pp}$.

, I88I. The Formation of Vegetable Mold through the Action of Worms, with Observations on their Habits. New York. 326 pp. 
Daritin, Charles AND Francis, i88o. Power of Movement in Plants. London. $592 \mathrm{pp}$.

DARWIN, FrancIS, 1907. Lectures on the Physiology of Movement in

Plants. New Phytologist, Vol. 6, pp. Io, 35, 69, 120.

Davenport, C. B., I897. Experimental Morphology. Vol. ı. New York. $280 \mathrm{pp}$.

- I899. The Same. Vol. 2. pp. 28I-509.

Davenport, C. B., and Cannon, W. B., I897. On the Determination of the Direction and Rate of Movement of Organisms by Light. Jour. Physiol., Vol. 21, pp. 22-32.

Davenport, C. B. and Lewis, F. T., I899. Phototaxis of Daphnia. Science, N. S., Vol. 9, p. 368.

Driesch, H., I890. Heliotropismus bei Hydroïdpolypen. Zoöl. Jahrb. Abth. f. Syst., Vol. 5, pp. 147-156.

- I907. The Science and Philosophy of the Organism. London. Vol. I, 329 pp.

- , I908. The Same. Vol. 2, 381 pp.

Dubors, R., I89o. Sur la perception des radiations lumineuses par la peau, chez les protées aveugles des grottes de la Carniole. C. r. Acad. Sci., Paris, t. I Io, pp. $35^{8-36}$ I.

Dutrochet, M. De l'inflexion des tiges végétales vers la lumière colorée. Ann. des. sc. nat., 2 ser., t. 20, pp. 329-339.

Dutrochet, M., and Pouillet, I844. Ann. des. sc. nat., 3 ser., t. 2, pp. 96II 3 .

Eigenmann, C. H., I899. The Blind Fishes. Biol. Lectures, Marine Biol. Lab., Woods Hole, I 899, pp. I I 3 - I 26.

Engelmann, T. W., I879. Über Reizung contraktilen Protoplasmus durch plötzliche Beleuchtung. Arch. f. d. ges. Physiol., Bd. 19, pp. $\mathbf{I}-7$.

— , I881. Zur Biologie der Schizomyceten. Ibid., Bd. 26, pp.537-545. -, I882. U̇ber Sauerstoffausscheidung von Pflanzenzellen in Microspectrum. Ibid., Bd. 27 , pp. $485-489$.

, I882a. Über Licht- und Farbenperception niederster Organismen. Ibid., Bd. 29 , pp. $387-400$.

- 1883 . Farbe und Assimilation. Bot. Ztg., Vol. 41, pp. I-I3, I 7-29.

- , I883a. Bacterium Photometricum. Arch. f. d. ges. Physiol., Bd. 30, pp. $95^{-1} 24$.

- I884. Untersuchungen über die quantitativen Beziehungen zwischen Absorption des Lichtes und Assimilation in Pflanzenzellen. Bot. Ztg., Vol. 42, pp. 8r-106.

- 1885 . UỦber Bewegungen der Zapfen und Pigmentzellen der Netzbaut unter dem Einfluss des Lichtes und des Nervensystems. Arch. f. d. ges. Physiol., Bd. 35 , pp. 498-508.

, I888. Die Purpurbacterien und ihre Beziehungen zum Lichte. Bot. Ztg., Vol. 46, pp. 66I-669; 677-689; 693-70I; 709-720.

Esterly, C. O., I907. Reactions of Cyclops to Light and to Gravity. Amer. Jour. Physiol., Iol. 18, pp. 47-57.

Ewald, W. F., I9Io. Über Orientierung, Lokomotion und Lichtreaktionen einiger Cladoceren und deren Bedeutung für die Theorie der Tropismen. Erlangen. $34 \mathrm{pp}$.

Ewart, A. J., I903. On the Physics and Physiology of Protoplasmic Streaming in Plants. Oxford Press. London. I3 I pp.

Fammtzin, A., I867. Die Wirkung des Lichtes auf Algen und einige andere nahe verwandte Organismen. Jahrb. f. wiss. Bot., Bd. 6, pp. I-44. 
Fielde, Adele M., I902. Notes on Ants. Proc. Acad. Nat. Sci., Philadelphia, Vol. 54, pp. 599-625.

FigdoR, W., I893. Versuche über die heliotropische Empfindlichkeit der Pflanzen. Sb. d. Akad. Wiss., Wien, Bd. IO2, pp. 45-59.

, I908. Experimentelle Studien über die heliotropische Empfindlichkeit der Pflanzen. Wiesner Festschr., pp. 287-307.

Fitring, H., 1907. Die Leitung tropistischer Reize in parallelotropen Pflanzenteilen. Jahrb. f. wiss. Bot., Vol. 44, pp. I $77-253$.

- I908. Lichtperzeption und phototropische Empfindlichkeit, zugleich ein Beitrag zur Lehre vom Etiolement. Ibid., Bd. 45, pp. 83-136.

Fleure, H. J., and Walton, C. L., I907. Notes on the Habits of Some Sea-anemones. Zool. Anz., Bd. 3I, pp. 21 2-220.

Forel, A., I886-I888. Expériences et remarques critiques sur les sensations des insectes. 2 parties avec appendices. Rec. Zool. Suisse, Vols. 2 and 4 , pp. I-50; $145^{-240}$; 515-523.

, I900-I90I. Sensations des insectes. Rivista di biologia generale. Vol. 2, pp. 56I, 64I; Vol. 3, pp. 7, 24I, 40I.

, I904. Ants and Some Other Insects. Trans. by W. M. Wheeler. Chicago.

Forel, A., and Dufour, H., I902. Über die Empfindlichkeit der Ameisen für ultraviolett und Röntgensche Strahlen. Zool. Jahrb. Abth. f. Syst., Bd. I 7, pp. 335-338.

Frandsen, P., Igor. Studies on the Reactions of Limax maximus to Directive Stimuli. Proc. Amer. Acad. Arts and Sci., Vol. 37, pp. 185-227.

Frank, A. B., I870. Die natürliche wagerechte Richtung von Pflanzenteilen, u. s. w. Leipzig.

Franzé, R., I893. Zur Morphologie und Physiologie der Stigmata der Mastigophoren. Zeitschr. f. wiss. Zool., Bd. 56, pp. I38-164.

Gardner, D. P., I844. Sur l'action de la lumière jaune dans la production de la couleur verte des plantes et sur celle de la lumière indigo dans la production de leurs mouvements. Bibliothéque universelle de Genève. Feor. I844.

Gaulhofer, K., 1908. Die Perzeption der Lichtrichtung im Laubblatte mit Hilfe der Randtüpfel, Randspalten und der windschiefen Radialwände. Sb. d. Akad. Wiss., Wien, Bd. II7, pp. I53-19o.

Gius, L., I907. Über den Einfluss submerser Kultur auf Heliotropismus und fixe Lichtlage. Sb. d. Akad. Wiss., Wien, Bd. I I6, pp. I593-165I.

Graber, V., I883. Fundamentalversuche über die Helligkeits- und Farbenempfindlichkeit augenloser und geblendeter Thiere. Sb. d. Akad. Wiss., Wien, Bd. 87, pp. 20I-236.

I sinnes der Thiere. Prag u. Leipzig. 322 pp.

, I885. Über die Helligkeits- und Farbenempfindlichkeit einiger Meerthiere. Sb. d. Akad. Wiss., Wien, Vol. 9I, pp. I29-150.

Grant, R. E., I829. On the Influence of Light on the Motions of Infusoria. Edinb. Jour. of Sci., Vol. Io, pp. 346-349.

Groos, T. T., and LoEB, J., I89o. Der Heliotropismus der Nauplien von Balanus perforatus und die periodischen Tiefenwanderungen pelagischer Tiere. Biol. Cent., Vol. Io, pp. I60-177.

Guillemin, 1858. Production de la chlorophyll et direction des tiges sous l'influence des rayons ultraviolette, calorifiques et lumineux du spectra solaire. Ann. des sc. nat., 4 ser., t. 7, pp. I54-I 72.

Haberlandt, G., I904. Die Perzeption des Lichtreizes durch das Laubblatt. Ber. der deutsch. bot. Ges., Bd. 22, pp. I05-II9. 
- I905. Die Lichtsinnesorgane der Laubblätter. Leipzig. I38 pp.

- I906. Ein experimentaler Beweis für die Bedeutung der papillösen Laubblattepidermis als Lichtsinnesorgan. Ber. d. deutsch. bot. Ges., Vol. 24 , pp. $36 \mathrm{I}-366$.

, I907. Die Bedeutung der papillösen Laubblattepidermis für die Lichtperzeption. Biol. Centr., Bd. 27, pp. 289-301.

, I 908 . Über die Verbreitung der Lichtsinnesorgane der Laubblätter.

Sb. d. Akad. IViss., Wien, math.- naturw. Klasse, Bd. I I 7 .

, I908a. Über Reizbarkeit und Sinnesleben der Pflanzen. (Vortrag.)

Wien, A. Hölder. 27 pp.

- I909. Zur Physiologie der Lichtsinnesorgane der Laubblätter. Jahrb. f. wiss. Bot., Vol. 46 , pp. 377-4I 7 .

Hadley, P. B., I906. The Relation of Optical Stimuli to Rheotaxis in the American Lobster (Homarus Americanus). Amer. Jour. Physiol., Vol. I7. pp. 326-342.

- Igos. The Reaction of Blinded Lobsters to Light. Ibid., Vol. 2I, pp. I 80-I99.

- I908a. The Behavior of the Larval and Adolescent Stages of the American Lobster (Homarus Americanus). Jour. Comp. Neur. and Psych., Vol. I8, pp. I99-301.

HAxd , A., I88\%. Über d. Farbensinns der Thiere u. die Vertheilung der Energie im Spektrum. Sb. d. Akad. Wiss., Wien, math.-naturw. Klasse, Bd. 94. p. 935 .

Haxssex, O., Igo8. Recherches expérimentales sur la sensibilisation optique du protoplasma. Bull. Ac. roy. Sc. et Lettr. Danemark, Vol. 3. pp. II $3^{-1} 3^{2}, 4$ pls.

Hargitr, C. W., I904. The Early Development of Eudendrium. Zool. Jahrb., Bd. 20, Heft 2, pp. 257-276.

- I906. Experiments on the Behavior of Tubicolous Annelids. Jour. Exp. Zool., Vol. 3, pp. 295-320.

I907. Notes on the Behavior of Sea-anemones. Biol. Bull., Vol. I 2, pp. $274^{-284}$.

- I I99. Further Observations on the Behavior of Tubicolous Annelids. Jour. Exp. Zool., Vol. 7, pp. I57-187.

Harper, E. H., I905. Reactions to Light and Mechanical Stimuli in the Earthworm, Perichaeta bermudensis (Beddard). Biol. Bull., Vol. Io, pp. $17-34$.

- 1907 . The Behavior of the Phantom Larvae of Corethra plumicornis Fabricius. Jour. Comp. Neur. and Psych., Vol. I8, pp. $435^{-456}$.

Harrixgton, N. R., and LeAMing, E., I goo. The Reactions of Amoeba to Light of Different Colors. Amer. Jour. Physiol., Vol. 3, pp. 9-I6.

Harcraft, J. B., I897. Luminosity and Photometry. Jour. Phys., Vol. 21, pp. I $26-146$.

Herrick, F. H., I896. The American Lobster: A Study of its Habits and Development. Bull. U. S. Fish Commission, for I 895 , pp. I-252.

Hertel, E., Ig04. Über Beeinflussung des Organismus durch Licht, speziell durch die chemisch wirksamen Strahlen. Zeitschr. f. allg. Physiol., Vol. 4. pp. I-43.

Hesse, R., ISg6. Untersuchungen über die Organe der Lichtempfindungen bei niederen Thieren, I. Die Organe der Lichtempfindungen bei den Lumbriciden. Zeit. f. wiss. Zool., Bd. 61, pp. 393-4I9.

- I897. Untersuchungen u. s. W., II. Die Augen der Platyhelminthen, insonderheit der tricladen Turbellarien. Ibid., Bd. 62, pp. 527-582.

- I I87a. Untersuchungen u. s. w., III. Die Sehorgane der Hirudineen. Ibid., Bd. 62, pp. 671-707. 
, 1898. Die Lichtempfindung des Amphioxus. Anat. Anz., Bd. I4, pp. $55^{6-557 .}$

, I898a. Untersuchungen u. s. w., IV. Die Sehorgane des Amphioxus. Zeit. f. wiss. Zool., Bd. 63 , pp. $456-464$.

, I899. Untersuchungen u. s. w., V. Die Augen der polychaeten Anneliden. Ibid., Bd. 65, pp. 446-5I6.

, I900. Untersuchungen u. s. w., VI. Die Augen einiger Mollusken. Ibid., Bd. 68, pp. 379-477.

I90I. Untersuchungen u. s. w., VII. Von den Arthropodenaugen. Ibid., Bd. 7o, pp. 347-473.

I902. Untersuchungen u.s.w., VIII. Weitere Thatsachen. Allgemeines. Ibid., Bd. 72, pp. 565-656.

Hewits, C. G., Igo8. The Structure, Development and Bionomics of the Housefly, Musca domestica (Linn.). Quar. Jour. Micr. Sci., Vol. 52, pp. $495^{-545}$.

Hofmeister, W., I863. Über das Eindringung der Wurzeln in den Boden. Jahrb. f. wiss. Bot., Bd. 3, pp. 77-I 4 .

, I867. Die Lehre v. d. Pflanzenzelle. Leipzig. 664 pp.

Holmes, S. J., Igor. Phototaxis in the Amphipoda. Amer. Jour. Physiol., Vol. 5, pp. 2I I-234.

- I902. Observations on the Habits of Hyallella dentata. Science, N. S., Vol. I5, p. 529.

- 1903. Phototaxis in Volvox. Biol. Bull., Vol. 4, pp. 319-326.

- I905. The Selection of Random Movements as a Factor in Phototaxis. Jour. Comp. Neur. and Psych., Vol. I5, pp. 98-I I 2.

- I905a. The Reactions of Ranatra to Light. Ibid., Vol. I5, pp. 305-349.

I908. Phototaxis in Fiddler Crabs and its Relation to Theories of Orientation. Ibid., Vol. I8, pp. 493-497.

Holt, E. B., and Lee, F. S., I9or. The Theory of Phototactic Response. Amer. Jour. Physiol., Vol. 4, pp. 460-48I.

Jennings, H. S., I904. Contributions to the Study of the Behavior of Lower Organisms. Carnegie Inst. of Washington, Pub. No. I6, 256 pp., 8I figures.

- I905. Modifiability in Behavior, I. Behavior of Sea-anemones. Jour. Exp. Zoöl., Vol. 2, pp. 447-472.

, I905a. The Basis for Taxis and Certain Other Terms in the Behavior of Infusoria. Jour. Comp. Neur. and Psych., Vol. I5, pp. I38I43.

—, rgo6. Behavior of the Lower Organisms. New York. 366 pp. , I906a. Modifiability in Behavior, II. Factors Determining Direction and Character of Movement in the Earthworm. Jour. Exp. Zoöl., Vol. 3, pp. 435-455.

Zoöl., Vol. 3, pp. $435-455$. Cal. Pub. in Zoöl., Vol. 4, pp. 53-185.

- I909. Tropisms. Rapport au VIme Congrès International de Psychologie. Genève. $20 \mathrm{pp}$.

Keeble, F., and Gamble, F. W., I904. The Colour Physiology of the Higher Crustacea. Phil. Trans. Roy. Soc., London, Vol. I96 B, pp. $295-388$.

Kinnaman, A. J., I902. Mental Life of two Macacus rhesus Monkeys in Captivity. Amer. Jour. Psych., Vol. I3, pp. 98-I48; I 73-218.

KNIEP, H., I907. Über die Lichtperzeption der Laubblätter. Biol. Centr., Vol. 27, pp. 97-I06; I29-I42.

Köntg, G., I89I. Beitr. z. Psych. u. Phys. d. Sinn., p. 3I I. 
KrabBE, G., I889. Zur Kenntniss der fixen Lichtlage der Laubblätter. Jahrb. f. wiss. Bot., Bd. 20, pp. $21 \mathrm{I}-260$.

KraUS, G., I876. Versuche mit Pflanzen im farbigen Licht. Ber. Sitzungs d. Naturf. Ges. Halle. Jahre I876, pp. 4-8.

Krause, IV., r897. Die Farbenempfindungen der Amphioxus. Z ool. Anz., Bd. 20 , pp. $5^{I} 3^{-5} 5^{I}$.

Langley, S. P., I884. Researches on Solar Heat and its Absorption by the Earth's Atmosphere. Profess. Papers Sig. Serv. XVI, Washington, Gov't Print. Office, $242 \mathrm{pp}$.

Lillie, R. S., I903. Structure and Development of the Nephridia. Mit. a. d. zool. Sta. z. Neapel, Bd. I 7, pp. 34I-405.

Loeb, J., I888. Die Orientirung der Thiere gegen das Licht. (Thierischer Heliotropismus). Sb. d. phys. med. Ges., Würzburg, pp. I-5.

- I888a. Die Orientirung der Thiere gegen die Schwerkraft der Erde. Ibid., Würzburg, I888, p. 5.

- I889. Der Heliotropismus der Thiere und seine Übereinstimmung mit dem Heliotropismus der Pflanzen. Würzburg. I I8 pp.

—_, 1893. Über künstliche Umwandlung positiv heliotropischer Thiere in negativ heliotropische und umgekehrt. Arch. f. d. ges. Physiol., Bd. 54, pp. $8 \mathrm{I}-107$.

- I897. Zur Theorie der physiologischen Licht- und Schwerkraftwirkungen. Ibid., Bd. 66, pp. 439-466.

- 1900. Comparative Physiology of the Brain and Comparative Psychology. New York. 309 pp.

- I904. The Control of Heliotropic Reactions in Fresh-water Crustaceans by Chemicals. Univ. of Cal. Pub. in Physiol., Vol. 2, pp. I-3.

- I905. Studies in General Physiology. Chicago. Vol. I, 423 pp.

-, I906. The Dynamics of Living Matter. New York. 233 pp.

, I906a. Über die Erregung von positiven Heliotropismus durch Säure, insbesondere Kohlensäure, und von negativen Heliotropismus durch ultraviolette Strahlen. Arch. f. d. ges. Physiol., Bd. II5, pp. $564-58$ I.

- 1907 . Concerning the Theory of Tropisms. Jour. Exp. Zoöl., Vol. 4, pp. I $_{5} \mathrm{I}^{-1} 56$.

- Igog. Die Bedeutung der Tropismen für die Psychologie. Leipzig, 5 I pp.

Lovell, J. K., I909. The Color Sense in the Honey-bee; is Conspicuousness an Advantage to Flowers? Amer. Nat., Vol. 43, pp. 338-349.

Lubbock, Sir J., I88I. On the Sense of Color among Some of the Lower Animals, Part I. Jour. Linn. Soc. (Zoöl.), Vol. I6, pp. I 2 I-I 27.

$\longrightarrow$, I882. On the Sense of Color, etc., Part II. Ibid, Vol. I 7, pp. 205214.

- 1888 . On the Senses, Instincts, and Intelligence of Animals, with Special Reference to Insects. New York. 292 pp.

- I I 895 . Ants, Bees and Wasps. New York. 448 pp. Preface to original edition dated I88I.

Luther, R., and Forbes, G. S., I9o9. A Quantitative Study of the Photochemical Reaction between Quinine and Chromic Acid. Jour Amer. Chem. Soc., Vol. 31, No. 7, pp. 770-783:

Lyon, E. P., I9o6. Note on the Heliotropism of Palaemonetes larvae. Biol. Bull., Vol. I 2, pp. 23-25.

Massart, J., I888. Recherches sur les organismes inférieurs, I. La loi de Weber vérifiée pour l'héliotropisme du champignon. Bull. Belg. Acad., ser. 3, t. I6, pp. 590-597. 
I89I. Rechercnes, etc. La sensibilité à la concentration chez les êtres unicellulaires marins. Ibid., ser. 3, t. 22, pp. I48-I67.

Mast, S. O., I903. Reactions to Temperature Changes in Spirillum, Hydra, and Fresh-water Planarians. Amer. Jour. Physiol., Vol. Io, pp. 165Igo.

- I906. Light Reactions in Lower Organisms. I. Stentor coeruleus. Jour. Exp. Zoöl., Vol. 3, pp. 359-399.

, 1907. Light Reactions in Lower Organisms. II. Volvox. Jour. Comp. Neur. and Psych., Vol. I7, pp. 99-180.

- I9o9. The Reactions of Didinium nasutum (Stein), with Special Reference to the Feeding Habits and the Function of Trichocysts. Biol. Bull., Vol. I6, pp. 9I-1 i8.

McСook, H. C., I889-I893. American Spiders and their Spinning Work. 3 vols.

Merejkowsky, M. C., I88r. Les Crustacés inférieurs distinguent-ils les couleurs? C. r. Acad. Sci., Paris, t. 93, pp. I $160-$ I 16 I.

Minkrewicz, R., I907. Analyse expérimentale de l'instinct de déguisement chez les Brachyures oxyrhynques. Arch. d. Zool. Expér. et Gén., t. 7, pp. 37-67.

, r9o7a. Chromotropism and Phototropism. Trans. in Jour. Comp. Neur. and Psych., Vol. I 7, p. 89.

, Igo8. Sur le chlorotropisme normal des Pagures. Compt. rend., Nov. I908. 3 pp.

Mrtsukuri, K., Igor. Negative Phototaxis and Other Properties of Littorina as Factors in Determining its Habitat. Annot. Zool. japonenses, Vol. 4, pp. I-I9.

MoorE, S. LEM., I887. Studies in Vegetable Biology. III. The Influence of Light upon Protoplasmic Movement, Part I. Jour. Linn. Soc. (Bot.), Vol. 24, pp. 200-25 I, Pl. V.

Morgan, C. L., Ig0o. Animal Behavior. London. 344 pp.

Morse, M., I907. The Behavior of Gonionemus. Amer. Nat., Vol. 4I, pp. $683-688$.

Müller, N. J. C., I872. Über die Krümmung der Pflanzen gegen das Sonnenlicht. Bot. Ztg., Vol. 30, p. 446.

Müller, H., I873. Die Befruchtung der Blumen durch Insekten und die gegenseitigen Anpassungen beider. Leipzig.

- I876. Ửber Heliotropismus. Flora, Vol. 59, pp. 65-70; 88-95.

, I882. Versuche über d. Farbenliebhaberei der Honigbiene. Kosmos, Bd. I 2, pp. 273-299.

MURBACH, L., I909. Some Light Reactions of the Medusa Gonionemus. Biol. Bull., Vol. I 7, pp. 354-368.

NÄGELI, C., I860. Ortsbewegungen der Pflanzenzellen und ihren Theile (Strömungen). Beitr. z. wiss. Bot., Heft 2, pp. 59-Io8.

NAGEL, W. A., I894. Beobachtungen über den Lichtsinn augenloser Muscheln. Biol. Cent., Bd. I4, pp. 385-390.

, I894a. Experimentelle sinnesphysiologische Untersuchungen an Coelenteräten. Arch. f. d. ges. Physiol., Bd. 57, pp. 495-552.

- I896. Der Lichtsinn augenloser Thiere. Jena. Fischer. I 20 pp. , I901. Phototaxis, Photokinesis, und Unterschiedsempfindlichkeit. Kritische Betrachtungen. Bot. Ztg., Vol. 59, pp. 289-299.

-, I9ora. Der Farbensinn der Thiere. Ein Vortrag. Wiesbaden. Nathansohn, A., and Pringshenr, E., I908. Über Summation intermittierender Lichtreize. Jahrb. f. wiss. Bot., Bd. 45, pp. I37-I90.

Newcombe, F. C., I902. The Rheotropism of Roots. Bot. Gaz., Vol. 33, pp. I77-I98; $263-283 ; 34 I-362$. 
Nichols, E. L., I905. On the Distribution of Energy in the Visible Spectrum. Phys. Rev., Vol. 2I, pp. I47-I65.

Nicolai, G. F. (and Dr. Baudouin), Igo8. Das Lernen der Tiere (auf Grund von Versuchen mit Pawlowscher Speichelfistel). Centr. f. Physiol., Bd. 22, pp. 36.2-364.

Nordhausen, M., I907. Über die Bedeutung der papillösen Epidermis als Organ fur die Lichtperzeption des Laubblattes. Ber. d. deutsch. bot. Ges., Vol. 25, pp. 398-410.

Nuel, J. P., I904. La vision. Paris, $376 \mathrm{pp}$.

Oelzelt-Newin, A., I906. Beobachtungen über das Leben der Protozoen. Zeit. f. Psych. und Physiol. der Sinnesorgane, Bd. 4I, pp. 349-382.

Oltmanns, F., I892. Über die photometrischen Bewegungen der Pflanzen. Flora, Vol. .75, pp. I83-266.

I I 197 . Über positiven und negativen Heliotropismus. Ibid., Vol. 83 , pp. I-32.

Orbeli, L. A., I908. Conditioned Reflexes resulting from Optical Stimulation of the Dog. Dissertation. St. Petersburg, I908. (Russian.)

Ostwald, W., I907. Zur Theorie der Richtungsbewegungen niederer schwimmender Organismen, III. Über die Abhängigkeit gewisser heliotropischer Reaktionen von der inneren Reibung des Mediums, sowie u. d. Wirkung "mechanischer Sensibilatoren." Arch. f. d. ges. Physiol., Bd. II7, pp. 384-408.

PARker, G. H., I9oI. Reactions of Copepods to Various Stimuli and the Bearing of this on Daily Depth Migrations. Bull. U. S. Fish Com. for I9oI, Pp. I03-I 23 .

, I903. The Phototropism of the Mourning-cloak Butterfly. Mark Anniversary Volume, pp. 453-469.

- I903a. The Skin and the Eyes as Receptive Organs in the Reactions of Frogs to Light. Amer. Jour. Physiol., Vol. Io, pp. $28-36$.

- I905. On the Stimulation of the Integumentary Nerves of Fishes by Light. Ibid., Vol. I4, pp. 4I $3-420$.

- I908. The Sensory Reactions of Amphioxus. Proc. Amer. Acad. Arts and Sci., Vol. 43, pp. 4I5-455.

PArker, G. H., and Arkin, L., I IoI. The Directive Influence of Light on the Earthworm Allolobophora foetida (Sav.). Amer. Jour. Physiol., Vol. 4, pp. I5I-I 57 .

Parker, G. H., and Burnett, F. L., Igor. The Reactions of Planarians with and without Eyes to Light. Ibid., Vol. 4, pp. 373-385.

Patten, IV., I886. Eyes of Molluscs and Arthropods. Mit. a. d. Zool. Sta. z. Neapel, Bd. 6, pp. $542-756$.

PAyer, J., I842. Memoire sur la tendance des tiges vers la lumière. Compt. rend., t. I5, pp. II94-II96.

Pearl, R. J., Igor. Studies on the Effects of Electricity on Organisms. II. The Reactions of Hydra to the Constant Current. Amer. Jour. Physiol., Vol. 5, pp. 30I-320.

, I903. The Movements and Reactions of Fresh-water Planarians. Quar. Jour. Micr. Sci., Vol. 46, pp. 509-7 I4.

- I904. On the Behavior and Reactions of Limulus in Early Stages of its Development. Jour. Comp. Neur. and Pysch., Vol. I4, pp. I38I64.

Pearl, R. J., and Cole, L. J., Igor. The Effect of Very Intense Light on Or.ranisms. Report Mich. Acad. Sci., I90I, pp. 77-78.

Pearse, A. S., igo6. Reactions of Tubularia crocea. Amer. Nat., Vol. 40, pp. $401-407$. 
, I908. Observations on the Behavior of the Holothurian, Thyone briareus (Leseur). Biol. Bull., Vol. I5, pp. 259-288.

-, I9 10. The Reactions of Amphibians to Light. Proc. Amer. Acad. Arts and Sci., Vol. 45, pp. 16 $1-208$.

Peckham, G. W., and E. G., I887. Some Observations on the Mental Powers of Spiders. Jour. Morph., Vol. I, pp. 383-4I9.

, I887a. Some Observations on the Special Senses of IVasps. Proc. Nat. Hist. Soc. Wisconsin, I887, p. 105.

- I894. The Sense of Sight in Spiders, with Some Observations on the Color Sense. Trans. Wis. Acad. Sci., Arts and Letters, Vol. Io, p. $23 \mathrm{I}$.

, I905. Wasps, Social and Solitary. Boston. $306 \mathrm{pp.}$

Pfeffer, IV., I884. Locomotorische Richtungsbewegungen durch chemische Reize. Unters. a.d. bot. Inst. Tübingen, Vol. I, pp. 364-482.

, I894. Geotropic Sensitiveness of the Root-tip. Ann. of Bot., Vol. 8, pp. 31 7-320.

, I906. The Physiology of Plants. Trans. by A. J. Ewart. Oxford. Vol. III. 45 I pp.

Plateau, F., r885. Recherches expérimentelles sur la vision chez les arthropodes. Les insectes distinguent-ils la forme des objects? Bull. Acad. roy. Belgique, 3 ser. t. Io, pp. $23 \mathrm{I}-350$.

- 1886 . Recherches sur la perception de la lumiére par les myriapodes aveugles. Jour. de l'anat. et de la physiol., t. 22, pp. 43 I-457.

, I897. Comment les fleurs attirent les insectes. Troisième partie. Bull. Acad. roy. Belgique, 3 ser., t. 33 , pp. I 7-4I.

- I I89. La choix des couleurs par les insectes. Mémoires Soc. zool. France, t. I2, pp. 336-370.

- I899a. La vision chez l'Anthidium manicatum. Ann. Soc. ent. Belgique, t. 43 , pp. $45^{2-456}$.

- I902. Observations sur les erreurs commises par les hymenoptères visitant les fleurs. Ibid., t. 46, pp. II 3 - I 29.

Poggioli, S., I8I7. Opuscoli scientifici. Bologna.

Pollock, J. B., Igoo. The Mechanism of Root Curvature. Bot. Gaz., Vol. 29 , pp. I-63.

Porter, J. P., I904. A Preliminary Study of the Psychology of the English Sparrow. Amer. Jour. Psych., Vol. I 5, p. 313-346.

, I906. Further Study of the English Sparrow and Other Birds. Ibid., Vol. I7, pp. 248-357.

Pouchet, G., I872. Sur de l'influence de la lumière sur les larves des diptères privées d'organes extérieurs de la vision. Rev. et Mag. de Zool., 2 ser., t. 23, pp. I IO-I I 7; I 29-I38; I83-I 86; 225-23I; 26I-264; 3 I 2-3I6.

Pouchet and Joubert, I875. La vision chez les Cirrhipedes. C. r. et Mémoires Soc. Biol., 6 ser., t. 2, pp. $245^{-247}$.

Poulton, E. B., I887. Notes in 1886 upon Lepidopterous Larvae, etc., Trans. Ent. Soc. Iond. for I887, pp. 28I-32I.

Preyer, W., I886. Über die Bewegungen der Seesterne. Mit. a. d. zool. Sta. z. Neapel, Bd. 7,..pp. 27-127, I9I-233.

Pringsheim, N., I879. 'Uber Lichtwirkung und Chlorophyllfunction in der Pflanze. .Jahrb. f. wiss. Bot., Bd. I2, pp. 288-437.

RÁDl, E., I901. Über d. Phototropismus einiger Arthropoden. Biol. Cent., Bd. 2 I, pp. $75^{-86}$.

- I90Ia. Untersuchungen über die Lichtreactionen der Arthropoden. Arch. f. d. ges Physiol., Bd. 87, pp. 418-466.

, I903. Untersuchungen über den Phototropismus der Tiere. Leipzig. I $88 \mathrm{pp}$. 
I 906. Einige Bemerkungen und Beobachtungen über den Phototropismus der Tiere. Biol. Cent., Bd. 26, pp. 677-69o.

Rawitz, B., I888. Der Mantelrand der Acephalen. Jena.Zeitsch., Bd. 22, pp. $415-556$.

Reinke, J., I883. Untersuchungen über die Einwirkung des Lichtes auf die Sauerstoffausscheidung der Pflanzen, I. Mitt. Bot. Ztg., Vol. 16, pp. 697-707; 713-723;732-738.

- I884. The Same, II. Ibid., Vol. 42, pp. I-10; 1 7-29; 33-46; 46-59. Romanes, G. J., I883. Animal Intelligence. New York. 520 pp.

-, I885. Jellyfish, Starfish and Sea-urchins. New York. 323 pp.

Rothert, IV., r894. Ủber Heliotropismus. Cohn's Beiträge z. Biol., Vol. 7, pp. I-2I 2 .

- I90I. Beobachtungen und Betrachtungen über taktische Reizerscheinungen. Flora, Bd. 88, pp. 37I-421.

Ryder, J. A., I883. Primitive Visual Organs. Science, N. S., Vol. 2, p. 739.

S.AcHs, J. v., I 864. Wirkungen farbigen Lichtes auf Pflanzen. Bot. Ztg., Bd. 22, pp. 353-358; 36I-367; 369-372. (Also in his Gesammelte Abh. über Pflanzenphysiologie, pp. 26I-292.)

_, I876. Über Emulsionsfiguren und Gruppirung der Schwärmsporen im Wasser. Flora, Vol. 59, pp. 24I-248; 257-264; 273-28I.

- 1887 . The Physiology of Plants. Transl. by H. M. Ward. Oxford. $836 \mathrm{pp}$. Original edition, I882.

- I890. History of Botany. Transl. revised by I. B. Balfour. Oxford. 568 pp. Original Edition, I875.

Schäfer, E. A., I 898 . Textbook of Physiology. Edited by E. A. Schäfer. New York. Vol. 2, 1 365 pp.

SEefried, F., I g07. Über die Lichtsinnesorgane der Laubblätter einheimischer Schattenpflanzen. Sb. d. Akad. Wiss., Wien, Bd. I I6, pp. I3I II357. 4 Taf.

Sevi, G., I908. Die Gestalts- und Lagenveränderung der PflanzenChromatophoren. Leipzig.

SharP, B., I884. On the Visual Organs in Lamellibranchiata. Mit. a. d. zool. Sta. z. Neapel, Bd. 5, pp. $447-469$.

Sinth, Amelia C., Ig02. The Influence of Temperature, Odors, Light, and Contact on the Movements of the Earthworm. Amer. Jour. Physiol., Vol. 6, pp. 459-486.

Spaulding, E. G., I904. An Establishment of Association in Hermit Crabs, Eupagurus longicarpus. Jour. Comp. Neur. and Psych., Vol. I4, pp. 49-6r.

Stahl, E., I 878 . Über d. Einfluss des Lichtes auf die Bewegungserscheinungen der Schwärmsporen. Bot. Ztg., Vol. 36, p. 7 I5.

- I879. Über den Einfluss des Lichtes auf die Bewegung der Desmidien nebst einigen Bemerkungen über den richtenden Einfluss des Lichtes auf Schwärmsporen. Verh. phys.-med. Ges. Würzburg, Vol. I4,

pp. $24-34 \cdot$ Über den Einfluss von Richtung und Stärke der Beleuchtung auf einige Bewegungserscheinungen im Pflanzenreiche. Bot. Ztg., Vol. 38 , pp. 298-4I3.

- , r884. Zur Biologie der Myxomyceten. Ibid, Vol. 40, pp. I46I55; I62-I75; I87-I9I.

StoввE, H., I908. Phototropieerscheinungen bei Fulgiden und anderen Stoffen. Liebig's Annalen der Chemie, Bd. 359, pp. I-48.

Stockard, C. R., Igo8. II. Habits, Reactions, and Mating Instincts of the "Walking Stick," Aplopus Mayeri. Publication I03, Carnegie Institution of Washington, pp. 43-59. 
Strasburger, E., I878. Wirkung des Lichtes und der IVärme auf Schwärmsporen. Jena. Zeitschr., N. F., Bd. I2, pp. 55I-625.

Torelle, Ellen, I903. The Response of the Frog to Light. Amer. Jour. Physiol., Vol. 9, pp. 466-488.

Torrey, H. B., I907. The Method of Trial and the Tropism Hypothesis. Science, N. S., Vol. 26, pp. 3I3-323.

Towle, Elizabeth IV., I900. A Study in the Heliotropism of Cypridopsis. Amer. Jour. Physiol., Vol. 3, pp. 345-365.

Trembley, A., I744. Mémoires pour servir à l'histoire d'un genre de polypes d'eau douce à bras en forme de cornes. Leyden. 324 pp.

UexkÜLL, J. v., I897. Über Reflexe bei den Seeigeln. Zeitschr. f. Eiol., Bd. 34 , pp. $298-318$.

___ I897a. Der Schatten als Reiz für Centrostephanus longispinus. Ibid., Bd. 34, pp. 319-339.

__ - I930. Die Wirkung von Licht und Schatten auf die Seeigeln. Ibid., Bd. 40, pp. $447-476$.

Verivorn, M., I889. Psycho-physiologische Protisten studien. Jena: Fischer. 2 I 8 pp. 6 pls.

-—_, I899. General Physiology, Trans. by F. S. Lee. New York. 6r5 pp. Original Edition, I894.

VierordT, K., I87 I. Die Anwendung des Spektralapparats zur Messung d. Stärke des farbigen Lichts. Tübingen.

-_ I873. Die Anwendung des Spektralapparats zur Photometrie der Absorptionspectren und zur quantitativen chemischen Analyse. Tübingen. Laupp. I69 pp. 6 Taf.

Vilisa, Guido, I903. Contemporary Psychology. Trans. by H. Manacorda. London. 396. pp.

Vöchtisg, H., I888. "Über Lichtstellung der Laubblätter. Bot. Ztg., Vol. 46, pp. 50I-559.

WWager, H., rgoo. On the Eye-spot and Flagellum of Euglena viridis. Jour. Linn. Soc. (Zoöl.), London, Vol. 27, pp. 463-481.

IVAlter, H. E., I907. The Reactions of Planarians to Light. Jour. Exp. Zoöl., Vol. 5, pp. $35^{-162 .}$

IWashburn, Margaret F., I908. The Animal Mind. New York. 333 pp.

Washburn, M. F., and Bentley, I. M., Igo6. The Establishment of an Association involving Color Discrimination in the Creek Chub, Semotilus atromaculatus. Jour. Comp. Neur. and Psych., Vol. I6, pp. I I 3-I 25.

Watson, J. B., I909. Some Experiments Bearing upon Color-vision in Monkeys. Jour. Comp. Neur. and Psych., Vol. I9, pp. I-28.

Wheeler, W. M., I9io. Ants. New York. 663 pp.

Whitman, C. O., r898. Animal Behavior. Biol. Lectures, Marine Biol. Lab., Wood's Hole, I898, pp. 285-338.

IVIEsner, J., I879. Die heliotropische Erscheinungen im Pflanzenreiche. Eine physiologische Monographie. Theil I. Denkschr. Wien Akad., Bd. 39, pp. I $43^{-209}$.

_- I88I. Die heliotropischen Erscheinungen u. s. w., Theil II. Ibid., Bd. 43, pp. I-92.

- - I893. Photometrische Untersuchungen auf pflanzenphysiologischen Gebiete. Erste Abhandlung. Orientirende Versuche über den Einfluss der sogenannten chemischen Lichtintensität auf den Gestaltungsprocess der Pflanzenorgane. Sb. d. Akad. Wiss., Wien., Bd. IO2, pp. $29 \mathrm{I}-350$.

WilleM, V., I892. De la vision chez les mollusques gastéropodes pulmonés. Arch. de biol., t. I2, pp. 57-147. 
Wilson, E. B., I89I. The Heliotropism of Hydra. Amer. Nat., Vol. 25, pp. 4I $3-433$.

Winogradsky, S., I887. Über Schwefelbacterien. Bot. Ztg., Bd. 45, pp. 489-6 го.

YERKES, ADA W., Igo6. Modifiability of Behavior in Hydroides Dianthus. V. Jour. Comp. Neur. and Psych., Vol. I6, pp. 44I-449.

YERKES, R. M., I899. Reactions of Entomostraca to Stimulation by Light. Amer. Jour. Physiol., Vol. 3, pp. 157-182.

-, I900. Reactions of Entomostraca, etc., II. Reactions of Daphnia and Cypris. Ibid., Vol. 4, pp. 405-422.

- 1902. A Contribution to the Physiology of the Nervous System in the Medusa Gonionemus murbachii, I. The Sensory Reactions of Gonionemus. Ibid., Vol. 6, pp. 434-449.

- , 1903. Reactions of Daphnia pulex to Light and Heat. Mark Anniversary Volume, pp. 36I-377.

- I904. The Reaction Time of Gonionemus murbachii to Electric and Photic Stimuli. Biol. Bull., Vol. 6, pp. 84-95.

Yerkes, R. M., and Ayer, J. B., Jr., I903. A Study of the Reactions and Reaction Time of the Medusa Gonionema murbachii to Photic Stimuli. Amer. Jour. Physiol., Vol. 9, pp. 279-307.

Yung, E., I878. Contributions ̀̀ l'histoire de l'influence des milieux physiques sur les êtres vivants. Arch. de Zool., Bd. 7, pp. 25 I-282.

- I892. La fonction dermatoptique chez le ver de terre. C. r. des Trav. Soc. Helv. Sci. nat., I892, pp. I $27-\mathrm{I} 28$.

—_, I893. La psychologie de l'escargot. Ibid., I893, pp. I28-I3I. 


\section{INDEX}

Acacia, 286.

Acclimatization, Euglena, I03; Volvox, I4I; Hydra, I52; Stentor, I I9; Musca larvae, I89, I90, I97; to change of intensity, 248,249 ; 288-297.

Acids, effect of, on reversal of reactions, $279-283,300$.

Acris, 260.

Actinia, reaction to sudden increase of intensity, 250 ; reaction to continued illumination, $252 ; 257$.

Actinia equina, 286.

Adams, orientation in earthworms, I98; $201 ; 266$.

Adaptation, Verworn on, 36 ; in reactions in plants, 72 ; in Arenicola larvae, $\mathrm{I} 67$; in reactions of butterflies, 227; in Euglena, Chlamydomonas, Volvox, Stentor, Amoeba, etc., 236-239; natural selection, 238, 239; 285; 292; 297; 298; in ants, $35 \mathrm{I} ; 368$; chemical regulation of, 370 .

Aggregation, method of in: Euglena (Engelmann), I6, Paramecium (Jennings), 45, Volvox, I44, coelenterates, I49, Planaria, 206, frogs, 2I 1 , general, 239-245; cause of, $242,243$.

Aiptasia annulata, reactions of (Jennings), 252.

Algae, 265.

Alkalis, effect of, on reversal of reactions, 279-283, 300 .

Allolobophora foetida, I99; 266. See Earthworm.
Alona, 278.

Amaranthus, 288; 313 .

Amoeba, 48; reactions to light, $74^{-}$ 80 ; process of orientation, $76^{-} 79$; effect of change of light intensity on movement of, 76-79; adaptation, $237 ; 257 ; 263 ; 270 ; 322$; reactions of, in spectrum, 327-332, $36 \mathrm{I}$; effect of change of intensity and color on movement of, 328 , 330,$331 ; 363 ; 365$.

Ampelopsis, 265.

Amphibia, function of skin in response, 262; 343. See Bufo.

Amphioxus, reaction to sudden increase of intensity, 250; 257; 259 .

Amphipods, 2 I 6.

Amphitrite bombyx, 247 .

Andrews, 247.

Animal behavior, effect of theory of evolution on, 9, Io; relation to psychic phenomena, see Psychic phenomena; summary of Loeb's ideas on, 34, 35; analysis of (Jennings), 49,50 ; Driesch on, 374-378. Annelids, tubicolous, reactions to shadows, 247. See Hydroides.

Anomura, 2 I4.

Ants, modification in reactions of, 296, 297; reactions to colors, $348-352$; effect of ultra-violet rays on, 349; sensation in, $35^{\circ}$; change in reactions of, $35 \mathrm{I}$.

Arca, 247.

Arenicola larvae, orientation in light from two sources, 87 ; description of, 166, I67; locomotion, 167 ; 
accuracy of orientation, 167 ; mechanics of orientation, I68-I7I, I 74, 232; orientation compared with that in Euglena and Volvox, I69, I7I; distribution of sensitive tissue, 172; aggregation of, 243; 258 ; 260; reversal in reactions, $27 \mathrm{I}, 280-283,285 ; 367$.

Aristotle, regulation of behavior, $5 ; 7$.

Arkin, orientation in earthworms, I98; $201 ; 202$.

Arthropods, 233; 257; 260 .

Asterias forreri, 2I I ; 2 I 2.

Atherina, 359 .

Avena, reactions in spectrum, 318 .

Avicula, 247; 323; 326 .

Avoiding reaction, 17 ; defined, 45; compared with "Schreckbewegung," 82, I10; in Euglena, $82-86,92-106$; in Stentor, II3I 21 ; in swarm-spores, I 25, I26; I37; in Volvox, I42; in Pandorina and Eudorina, I47; in Eudendrium, I6I; 233; effect of, on aggregation, 239-243; 246; 257 .

Bacteria, 36; 37; 350; 362 .

Bacterium photometricum, I6; 17 ; 45 ; aggregation of, $240,24 \mathrm{I} ; 263$; 324 ; reactions of, in spectrum, 325 .

Balanus, nauplii of, 266; change in reactions, $285 ; 337$.

Bancroft, reaction to electricity in Volvox, I45, I46; 23I.

Baranetzsky, movements of myxomycetes, 74 .

Barnacles, reactions to shadows, 247.

Barrows, definition of tropism, 55 . Bateson, 249; decoration in crabs, 357.

Bdelloura candida, 207.
Bees, adaptation, 237; modification in reactions of, 296, 297; reactions to colors, $35^{2-355}$; change in reactions, $35^{2-}-354 ; 364$.

Bell, 354 .

Bentley, $35^{8}$.

Bert, I0; I4; $24 ; 27 ; 34 ; 235$; reactions of Daphnia in spectrum, 336,$337 ; 342 ; 343$.

Berthold, 265 .

Bethe, 354 .

Bierstadt, 327 .

Bipalium kewense, I82; reactions to light, 207; 270; sensitiveness of, 288.

Birds, flight of, into lighthouse, 228 ; adaptation, 237; color vision in, $343,360,364$.

Bispira voluticornis, 247 .

Blauuw, reactions of plants in spectrum, 318, 319.

Blowfly larvae. See Musca larvae. Bohn, I7; definition of tropism, 56 ; 2II；2I4；22I；243；244；264； periodic movements, 286. See Criticism.

Bonnier, 354 .

Borelli, founder of iatromechanical school, 6; 5 r.

Botrydium, 274; 32 I.

Bougainvillea superciliaris, medusae of, orientation in light from two sources, 87,165 ; orientation, 164 , I65; description of, $165 ; 285$.

Brachyura, $2 \mathrm{I} 4$; orientation in zoeae of, 226 .

Branchiomma köllikeri, 247.

Brassica, 314.

Brefeld, 318; 319.

Brightness, distribution in spectrum: normal, 305-308, 36I, in colorblind individuals, 307 ; cause of, 307; distribution of, in spectrum

' compared with that of energy, 36r. 
Bronn, 250.

Brooks, response to a sign, 250.

Bryopsis, 274.

Bufo americanus, orientation in light from two sources, 89, 21922I; 2I 4; orientation with one eye destroyed, 22I, 222.

Bulman, 354 .

Buttel-Reepen, 354 .

Butterfly, Mourning-clock. See Vanessa antiopa.

Calliphora vomitoria, 217 .

Caprella, 2I4; structure and locomotion, 224; $27 \mathrm{I}$.

Carbon dioxid, effect of, on reversal of reactions, $279^{-283}, 300$.

Cardium, 247 .

Caridea, orientation in zoeae of, 226.

Carpenter, on circus movements, 216; reactions of Drosophila, 27I, 280.

Cartesian doctrine, 9 .

Cassiopea, 359.

Cerianthus, $250 ; 252 ; 254$.

Change of intensity, I 7; orientation by, in Euglena, 99. See Light.

Chaetomorpha aerea, 274.

Chemicals, changes in, related to reactions, 270, 278, 308-312, 320, $363,364,370$; effect of, on reversal in reactions, $279^{-28}, 300$, 367 ; extent of effect of, on reversal in reactions, 280; reactions of, reversible in light (Stobbe), 308312; effect of different rays on reactions of, and cause of, 312, 360, . 363; effect of mixed rays of light on reactions of, 310,363 ; same compared with effect of mixed rays on organisms, 335,336 ; effect of, on reactions of organisms in spectrum, 323-325, 332, 343 .

Chilomonas curvata, 274 .
Chlamydomonas, orientation in light from two sources, 87; function of eye-spot, I09, I33; structure of, $\mathrm{I} 3 \mathrm{I}$; mechanics of orientation, I32, I33; I34; I36; I46; 229; 230; adaptation, 236; aggregation of, 24I; 257; 259; reversal in reactions and effect of temperature on, $265,267,277,280,300$; reversal in reactions compared with same in Arenicola, $283 ; 367$; 370.

Chlorogonium, structure of, I34; function of eye-spot in, I34; aggregation of, 24I; 257; 259 .

Chromulina, 273.

Chytridium vorax, 274 .

Ciesielski, 20.

Ciliates, 229; 230; 232; 233; 240; aggregation of, 242 ; reactions in spectrum, 323,324 .

Ciona, 250.

Circus movements, in various species, 215-218.

Claparède, 247.

Classification, of reactions to light, 253-262.

Claviceps, 3 I8.

Clepsine, reactions to shadows, 249 ; $257 ; 260 ; 263 ; 298$.

Cohn, ray-direction and movement of organisms, I5; effect of different rays (unicellular forms), 321, 322 .

Cole, L. J., I82; reactions of $\mathrm{Bi}$ palium to light, 207; 214; 223; effect of size of light area on reactions, $227 ; 228 ; 244$.

Cole, L. W., 360.

Color, wave-length of, 304; energy in, 304, 305; brightness of, 305308; effect of, on reactions: chemical, 308-31 2, Daphnia, 310, 336-34I, Hydra, 310, 333-336, plants, 310, 3I3-320, unicellular 
forms, 321-332, Simocephalus, $34 \mathrm{I}-343$, higher animals, 343-346, ants, 348-352, bees, 352-355, higher crustacea, $355^{-} 35^{8}$, fishes, $35^{8-360}$, birds and mammals, 360 ; effect of impurity of, on reactions, $310,313,322,335,340,362$; selection of, in crabs, 356-358. See Spectrum.

Concentration of medium (mechanical stimuli). See Reactions.

Copepods, 273; 274 .

Corethra larvae, orientation in (Harper), 225 .

Cowles, 2Ir; direction of righting reactions in starfishes, $2 \mathrm{I}_{3} ; 328$.

Crab, fiddler: reactions to light, 2 I 7 , 218; Hermit, see Pagurus; 258; effect of color on reaction (decoration), 355-358.

Criticism, of Darwin by Sachs, 2I; of Loeb's theories of orientation, 26, 27, 31, 70, 80, 83,87-89, ro4, I Io, III, I I9, I22, I 37, I44, I64, I68, I 7I, I73, I 77-I80, I 82, I83, I88, I92-I95, I98, 205, 206, 209, $220,22 \mathrm{I}, 223,225,229,230,233^{-}$ $235,242,258,351,363,364$; of Loeb and Sachs by Verworn, 38; of Sachs' ray-direction theory, 70, 80,87 , I I I, I37, I44, I 58 , I 82 , I92, I98, 233; of Pollock's theory of curvature in roots, $7 \mathrm{I}$; of Jennings by Torrey, 84,85 ; of Torrey on orientation in Euglena, 85,86 , IOI, I04, III, 205; of Rádl's theory of orientation, 43, 234; of Bancroft on orientation, I45; of Verworn's theory of orientation, I04, I 22, I68, I 7 I, I 73, 205, 229, 234; of Parker and Arkin on orientation in earthworms, 202, 203; of Holt and Lee on orientation, 205; of Bohn on orientation, 220,
$22 \mathrm{I}$; of Davenport on orientation, 234 ; of Loeb on cause of aggregation in Planaria, 245; of classification, 255, 256; of Loeb on regulation and adaptation, 266, 267, 272, 369, 371, 372; of Loeb on cause of change in reactions, 287, 301; by Loeb on Lubbock's experiments on Daphnia, 335, 336; of Loeb on reactions in spectrum, $336,346,347,363,364$; of Sachs' hypothesis on effect of different rays, 363 ; of Davenport on reaction in spectrum, 363 ; of Jennings on regulation, 377 ; of Driesch on regulations, 378 .

Crustacea, $42 ; 238$; reactions to shadows, 249; decapod, 264; 272; 354 ; modifiability in reactions, $355-35^{8} ; 364$.

Cryptomonas, 132 .

Cuma rathkii, adaptation, $238 ; 272$; 346.

Cyclops, 277; 279; 280-283; 300 .

Cypridopsis, 284 .

Cypris, 214; 274; 277; 278; 280-283; 300.

Czapek, curvature of roots controlled by root-tip, $21 ; 59 ; 72$.

Dalyell, 247 .

Daphnia, 214; 255; orientation of, $264 ; 265 ; 274 ; 277 ; 279 ; 280-283$; 300 ; effect of different wavelengths on reactions of, 310 ; reactions in spectrum, 335-34I, 362; $345 ; 350 ; 364$.

Darkness, effect of, on movement: in Hydra, $5_{52}$; in Hydra, etc., 245.

Darwin, 9; 10; I 2; theory of orientation in plants, $18-2 \mathrm{I}$; transmission of stimuli in plants, $19 ; 23$; $31 ; 47 ; 52$; definition of tropism, 
$54 ; 57 ; 59 ; 60 ; 63 ; 70$; location of sensitive structure in leaves, $7 \mathrm{I}$; 229; 235; 354 .

Davenport, theory of orientation, 40-42; definition of tropism, 55; 58; reactions of Amoeba to light, 74 ; movement in Amoeba affected by change in light intensity, 78 ; reactions of Stentor, II $3 ; 234$; phototaxis and photopathy compared, 254-256; effect of different rays on reactions: 302 , criticism of, 343,363 ; photochemical reactions, 308 .

De Candolle, vitalism, 8; sleep movements of leaves, II; theory of orientation in plants (heliotropism), $12 ; 13$; $14 ; 27 ; 52$; definition of tropism, 53; 54; 229; 234 .

Decoration, in crabs, $356-358$.

Dendrocoelum lacteum, 207.

Descartes, philosophy of movement, $6 ; 51$.

Dewar, 338; 349 .

Dexia carinifrons, 216.

Dias longiremis, 337 .

Diatoms, 265; reactions of, in spectrum, $323,326$.

Didinium nasutum, I 26.

Dodart, curvature of roots, 7 .

Driesch, definition of tropism, 56; 369; theory of vitalism, $374-378$.

Drosophila ampelophila, 2I6; effect of intense light on, $27 \mathrm{I}$; change in reaction of, 280.

Du Bois-Reymond, 9.

Du Hamel, cause of curvature in plants, 7 .

Dutrochet, osmosis and movement of plants, I 2 .

Dutrochet and Pouillet, 3I4; 3I9.

Earthworms, orientation of (Davenport), 40, 4I; 50; locomotion, I99; trial in orientation, 200-206, 232; distribution of sensitive tissue in, 201-205; accuracy of orientation, 205; reaction to sudden increase of light intensity, 250; 257; 259; $260 ; 343 ; 346$.

Echinaster crassispina, 2 II.

Echinoderms, method of locomotion, $2 \mathrm{II}$; orientation of, $2 \mathrm{II}_{-}-2 \mathrm{I} 3$; 233; aggregation of starfishes, 244; reactions of sea urchins to shadows, $247 ; 260$.

Edwardsia, 250; 259; 299.

Eigenmann, 238.

Eloactis, reactions of (Hargitt), 252.

Energy, distribution in spectrum, 304-308, 360; distribution in spectrum compared with stimulating efficiency, 332, 343 .

Engelmann, reactions of unicellular forms to light, I6, I $7 ; 42 ; 44 ; 57$; stimulation of pseudopods, 74 ; method of aggregation in Euglena, etc., 82 ; 94; function of eye-spot, I06-I09; 235; methods of aggregation compared with ideas of Jennings, 240, 323, 324; 279; reactions of unicellular forms in spectrum, 322-325.

Entelechy, as a factor in regulation, 377 .

Entomostraca, 258; 271; 278 .

Eudendrium, hydranths, mechanics of orientation, I63, I64.

Eudendrium, planulae of, orientation in light from two sources, 87 ; description and locomotion, I59; accuracy of orientation, I60; mechanics of orientation, $161-163$; aggregation of, 243; $27 \mathrm{I}$.

Eudorina, orientation in light from two sources, 87,147 ; function of eye-spot, I09, I47; structure of, 
I46; locomotion of, I47; orientation and change in sense of, I 47 , 23I; I7I; aggregation of, 242.

Euglena, viridis, I6; method of aggregation (Engelmann), I7; 36; 45 ; description of, $80-82$; aggregation of (Engelmann), 82 ; orientation of (Jennings) $, 8_{3}, 8_{4}$, (Torrey), $8_{4}, 8_{5}$; orientation in light from two sources, 86,87 , I Io; different species and collection of, 89,90 ; locomotion of, 90, II0; accuracy of orientation, 92; mechanics of orientation, 92-99, I02-IO4, IIO; discussion of orientation, 99-IO2; distribution of sensitive tissue, I04-I06, III; function of eyespot, 98, 99, I02, I06-I09, III; sensation in, I I 2 ; I I5; I I8; I 22I37; I42-I48; I56; I6I; I74; orientation compared with that in Arenicola larvae and Musca larvae, I69, I7 I, I95; 209; 210; 2I5; 2I6; 229; 230; adaptation, 236; 243; 257 ; $259 ; 26 \mathrm{I} ; 263$; reversal in reaction and effect of temperature, 265, 267, 274-279; deses, viridis, spiragyra, 274; 30I; reactions in spectrum, $324,325,36 \mathrm{I}$; $366 ; 368$.

Evolution, effect of theory of, on behavior, 9, I0; 52 ; natural selection, 238, 239; of reactions to light, 262,263 .

Ewart, protoplasmic streaming, 74 . Eyes, function of, in reactions: flies, $2 I 6,217$, fiddler crab, 217 , Ranatra, 2I8, toads and frogs, 2I9223, arthropods, 226,227 , birds, 228,233 ; function of, in aggregation, 244 .

Eye-spot, in Euglena: structure of, 8I, 82, function of, 98, 99, IO2, I06-I09. III; in Trachelomonas: structure of, I28, I29, function of, Io9, I30; in Chlamydomonas: function of, Io9, I33; in Chlorogonium, function of, I34; in Eudorina and Pandorina, structure and function of, I47, I48; luminosity of, in direct sunlight, I4 7 ; in Arenicola larvae: 166 , function of, $I 7 I, I 72, I 74$; function of, in starfish, 2 II; summary of function of, 230 .

Famintzin, change in sense of reaction, 265.

Fechner, 9.

Fielde, 354.

Figdor, sensitiveness of plants, 288, 3 I3.

Fishes, adaptation in blind, 238 ; function of skin in response, 262 ; 343; color vision in, $358-360$, 364 .

Flagellata, 36; 37; 229; 230; 232; 233; aggregation of, 242 ; reactions in spectrum, 324,325 .

Flies, circus movements in, 2I6, 217 ; function of eyes in reactions, 2I6, 2I\%; adaptation, 237. See Musca.

Forbes, 312.

Forel, 354.

Frandsen, 265.

Frank. geotropism, I 2.

Fraunhofer, brightness in spectrum, $305-30 \%$.

Frogs, aggregation of, 244; 260; reversal in reactions, $273 ; 278$; See Bufo.

Fulgides, reversible in light, 3083 IO.

Fundulus, reactions to shadows, 247; $257 ; 260$.

Fungi, reactions of, in spectrum, 3I7-3I9. 
Galen, experiments on animals, 6 .

Galvanotropism, compared with heliotropism, 28, 29; 56; II9; in Volvox, I45, I46.

Gamble, 354 .

Gammarus, 279; 300; 346; 367 .

Gardner, reactions of seedlings in spectrum, 3I4, 3I9.

Geometra, 346.

Geotropism, I3.

Gonionemus murbachii, orientation in, $164 ; 251 ; 252 ; 257 ; 259 ; 266$.

Graber, preference method, I0; I4; $24 ; 27 ; 34$; theory of reactions, $218 ; 223 ; 235$; effect of color on reactions of higher animals, 343$346 ; 35 \circ ; 353 ; 354$.

Gramineae, 68; 229; 259; change in reactions, 285 .

Groom, 266.

Guillemin, reactions of seedlings in spectrum, 3I4, 3I7, 3I9.

Haberlandt, 59; function of epidermal cells in reactions to light, 72 . Hadley, definition of tropism, 56; $214 ; 222$; orientation in lobster larvae, 226; reversal in reactions of lobster larvae, 264, 266, 286.

Haematococcus, $272 ; 274$.

Hargitt, $160 ; 247$; reactions of $\mathrm{Hy}-$ droides, 249; reactions of Eloactis, 252 ; variation and modification of reactions of Hydroides, 292295.

Harper, orientation in earthworms, 199; 200-205; 214; 215; orientation in Corethra larvae, 225.

Harrington and Leaming, movement of Amoeba, $74 ; 322$; reactions of Amoeba in spectrum, 327 , 328,33 I.

Harvey, experiments of, on the circulatory system, 6; 5 I.
Haycraft, brightness in spectrum, 306, 307 .

Hedista, 286.

Heliotropism, origin of term, I2; Sachs' theory of, I3-I6; compared with galvanotropism, $25-31$; Loeb's theory of, 28-33; compared with Unterschiedsempfindlichkeit, 32 , $33,254-256$; Verworn's theory of, 36-38; defined, 53-56, 253-256; of Euglena, 85, ro4; compared with galvanotropism in Volvox, I 45 , I46; I64; 227 ; in birds (Cole), 228; 266; in plants and animals compared, 346. See Orientation.

Helix hortensis, 25I; 366.

Helmholtz, 9 .

Hertel, response to ultra-violet in Paramecium, I34.

Hesse, 247.

Hewitt, I84.

Hofmeister, heliotropism, I 2; curvature in single-celled structures, 7I; plasmodia, 74 .

Holmes, orientation: selection of random movements as a factor in, 50, 5 I, I96, I97; definition of tropism, 55 ; 58 ; effect of light intensity on rate of movement, Ioo, Ior; orientation in Musca larvae, I 76; I83; I89; trial movements in earthworms, I98; 203; 204; 214; on circus movements, 2I5, 2I 7 ; on orientation, 218; 223; 226; 227; 232; reversal in reactions, $27 \mathrm{I}$, $273,279,280$; effect of contact on reactions, 284 ; modification in reactions of Ranatra, 296.

Holothuriar, orientation of, 2 II.

Holt and Lee, 42 ; reactions of Stentor, II $3 ; 205$.

Hydra, $34 ; 48$; effect of light intensity on activity, $150-152$; orientation and locomotion, I5I-I57, 


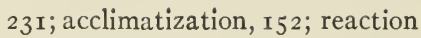
of negative specimens, I54 $_{5}$ distribution of sensitive tissue in, I56; reaction to electric current compared with reaction to light, I $_{5} 8 ; 258 ; 26_{5}$; effect of different wave-lengths on reactions of, 310 ; reactions in spectrum, 333-335; $36 \mathrm{r}, 363 ; 367 ; 370$.

Hydroides dianthus, orientation in light from two sources, 87 ; reactions to shadows and acclimatization, 247, 249; 250; $263 ; 280 ; 285$; variation and modification in reactions of, 292-295, 368; 298; $366 ; 373$.

Impatiens, 286.

Inachus, 355 .

Indian corn. See Zea mays.

Infra-red, effect of : on seedlings, 314319 , on bacteria, 325 , on Daphnia, 343 ; cause of invisibility, $362 ; 368$.

Infusoria; 36 .

Insects, 42, 343 .

Intensity-difference, 3, 4; effect of, on movement of organisms, I5 $_{5}$. See Light.

Jassa, 279.

Jellyfishes. See Sarsia, Gonionemus and Bougainvillea.

Jennings, I7; work compared with that of predecessors, 44; method of aggregation of lower organisms, 45, 46; motor reaction, motor reflex, avoiding reaction defined, 45 ; theory of orientation (trial and error), 46-49; external stimulus not necessary for activity in organisms, 47; direct orientation, 48; analysis of behavior, 49,50 , $372-375$; on regulation in behavior, 50, 368, 372; 51; 53; definition of tropism, $56 ; 57 ; 58$; stimulation of Amoeba, 75 ; movement of Amoeba, 80; 82 ; orientation in Euglena, 83, 84; 89; 91; 99; I04; II 2; orientation of Stentor, II3; II4; reactions in Chlamydomonas, 132 ; orientation in Hydra, I56; 202; 203; orientation in Asterias, 2II; "trial and error" defined, 2 I 5 ; 23I ; theory of orientation compared with that of Engelmann, 240, 323, 324; reactions of Aiptasia, $252 ; 262 ; 287$; 293; 297; 328; 369 .

Johnston, II.

Joubert, 248 .

Keeble and Gamble, 354.

Kinnaman, 360.

Kneip, function of epidermal cells in orientation of leaves, 72 .

Knight, effect of gravitation on curvature of roots, I I, I $2 ; 13$.

Krabbe, 7 I.

Kraus, reactions of fungi in spectrum, 3I7, 3I9.

Labidocera, 227; 266; reversal in reactions, $274,284,300$.

Lacrymaria olar, $5 \mathrm{I}$.

Langley, 305 .

Lapidium, 265, 288, 3I3.

Larvae, Limulus, 87; Musca, 87; Arenicola, 87; lobster, 226 ; adaptation, 237; aggregation of, 242; mosquito, 247; Pala emonetes, 264; Polygordius, 266.

Leaves, orientation of, $7 \mathbf{1}-73$.

Leeches, 346. See Clepsine.

Leeuwenhoek, 136 .

Leptoplana tremellaris, orientation, in light from two sources, $87 ; 207$; orientation of, $207 ; 271$.

Liebig, 9.

Life, primitive ideas of, $5,5 \mathrm{I}$. 
Light, change of intensity on plants (Darwin), I9; graded by means of prism, 39, 60; pressure of, and supposed effect on orientation, 43 ; graded by means of lens, $60,6 \mathrm{r}$; effect of constant, and change of intensity of, on reactions of: Euglena, I6, 83, 85, 98, 99, 100II 2, Stentor, II3-II5, II8-I23, Swarm-spores, I27, Trachelomonas, I30, Chlamydomonas, I32, I33, Volvox, I39, I43-145, Eudorina and Pandorina, I47, Hydra, I57, Eudendrium, I6I, I63, Medusae, I65, Arenicola larvae, I72I75, Fly larvae, I9I-I97, earthworms, 204, Planaria, 208, 210 , general, 229-235, 24I, 245, 253$258,299,366,367$; effect of, on movement, 245 ; reactions to sudden decrease of, 247-250; reactions to sudden increase of, $25^{\circ}$, $25 \mathrm{I}$; reactions to continued illumination, 252, 253; effect of, on reversal in reactions, $265-272$, 299; characteristics of, 303 ; effect of, on chemical reactions, 308-312.

Light grader, 60-62.

Lillie, 166.

Limax, 265 .

Limnaeus stagnalis, 345 .

Limnea columella, 2 I 4 .

Limulus polyphemus, larvae of, orientation in light from two sources, $87 ; 88 ; 258 ; 27$ I reversal in reactions, $285 ; 346$.

Lineus ruber, 284 ; effect of color on reactions, 355 .

Littorina, aggregation of, $244 ; 247$; periodic movements caused by tides, 286.

Lobster larvae, orientation and change in sense of orientation, 226,$264 ; 267$.
Loeb, II; I 7; 2I; object of observations on reactions of animals, 23 , 24, 34; control of movement in animals and plants identical, 25, $26,164,346$; on relation between sensations and animal behavior, 27,28 ; first theory of orientation (ray direction), 24, 25, 34; second theory of orientation (angle of rays), 28, 29, 35; third theory of orientation (intensity difference), 29-3I, 35, 22I; effect of constant intensity compared with change of intensity, 32, 33; extent of application of theories, 33,34 ; ideas on animal behavior summarized, 34-36; theory of orientation (tropism) compared with Verworn's, 39; 40; 42; 52; 53; definition of tropism, $54-58 ; 70$; $80 ; 83 ; 86$; theories criticized. See Criticism; theories of orientation applied to: Volvox, I37, I44, I46, Hydra, I49, I50, I59, Arenicola larvae, I73, earthworms, 205, Planaria, 209, Caprella, 225, ants, $35 \mathrm{I} ; 363 ; 364$; on orientation in Eudendrium, I64; 168 ; 171 ; orientation in Musca larvae, I $75, \mathrm{I} 76$, I82, I83; I77; I78; I80; I92; I94; I98; reactions of planarians to light, 206; on circus movements, 215; 216; 220; 223; 229; 230; $234 ; 238$; on origin of reactions, 239-243; cause of aggregation in Planaria, 245; 247; heliotropism compared with Unterschiedsempfindlichkeit, $254^{-257} ; 258$; on adaptation and change in sense of reaction, 266, 267, 272, 273, 285 ; effect of chemicals on reactions, 279; effect of concentration of medium on reactions, $283 ; 284$; effect of different colors on reac- 
tions: $302,346,347$, criticism of, $335,336,343,346,347$; on cause and regulation of reactions, 369 ; on origin of adaptive reactions, $37 \mathrm{I}$.

Lotze, 9 .

Lubbock, 10; $24 ; 235 ; 265$; on effect of different colors on reactions of: Daphnia, 3 10, 335-343, 362, ants, 348-352, bees, $35^{2-355}$.

Lumbricus, I99; reactions in colors, 344. See Earthworms.

Lunularia, 288; 3 I3.

Lupinus albus, $2 \mathrm{I}$.

Luther and Forbes, photochemical reactions, 3 I 2 .

Lutianus griseus, 358 .

Lyon, 264 .

Mach, 344 .

Machine, defined (Driesch), 375 .

Maja, verrucosa and squinado, 355; 357.

Mammals, 343 ; 360 ; color vision in, 364.

Massart, 12; reversalin reactions 273.

Maya aranaria, 247.

McCook, 354 .

Medusae, reactions to light, $164, \mathbf{1} 65$.

Melolontha, 346.

Merejkowsky, 337 .

Metazoa, 47.

Mimosa, 7; 286 .

Minkiewicz, definition of tropism, 56 ; effect of concentration of medium on reactions, $284 ; 354$; reactions of Crustacea to color, $355^{-}$ $35^{8}$.

Mitsukuri, reversal in reactions, 286.

Modifiability, in behavior, 264-30I; 368; chemical regulation of, 370 . See Acclimatization.

Mollusks, 233; 243; reactions to shadows, 247; acclimatization, $248 ; 257 ; 259 ; 260 ; 343$.
Monkey, color vision, 360 .

Morse, reactions of Gonionemus, 164 .

Mosquito larvae, reactions to shadows, $247 ; 249 ; 257 ; 260$.

Moths, flight of, into flame, 227, 228; adaptation, 237; change in reactions, $280 ; 346$.

Motor reaction, defined, 45 .

Motor reflex, I 7 ; defined, $45 ; 240$.

Mouse, dancing, color vision, 360 .

Movement, random, as a factor in orientation, 50, 5I, 157; rate of, in: swarm-spores and Volvox, roo, IоI, Euglena, Iо2, Iто, Hydra, I5I, Musca larvae, I84-I89, earthworms, 199, Planaria, 208; random, in Musca larvae, I89-192, I 96 ; random, as a factor in orientation of earthworms, 203, 232; effect of random, on aggregation, 239-24I, 245; periodic, in plants, 286; periodic, in Littorina, etc., 286; cause of change in, 366 .

Müller, H., I3; 354 .

Müller, J., vitalism, general physiology, 8, 9; $5^{2}$.

Müller, N. J. C., 6o; change in sense of reactions (seedlings), 265; reactions of seedlings in spectrum, 317, 319 .

Musca larvae, 50; orientation in light from two sources, $87, \mathrm{I} 77$, 197; 88; orientation according to Loeb, I75; locomotion, 176 ; accuracy of orientation, I77; orientation perpendicular to the rays, 180-183; distribution of sensitive tissue, I83, I84, I88; effect of light intensity on rate of locomotion, 184-189, I97; random movements, I89-192, I96; acclimatization of, I89, 190, 197; mechanics of orientation, $189-197,232$; orientation compared with that in Euglena 
and Stentor, 195, 197; trial and error, I96, 197; circus movements, 216 ; $257-260 ; 270$; change in reactions, $285 ; 346$.

Mustard. See Sinapis.

Myxomycetes, 74; 229; 233; adaptation, 237.

Nägeli, early observations on movement of flagellates and swarmspores, $1_{4} ; 1_{5}$; effect of light intensity on rate of movement, Ioo.

Nagel, 58; 247; on reactions to shadows and acclimatization, 248; 250 ; $25 \mathrm{I}$; effect of different rays on reactions, 302 .

Narcotics, effect of, on reversal of reactions, $279-283,300$.

Natural selection and adaptation, 238, 239, 272.

Nemertean, 355 .

Nernst glower, 6r; 86; 92.

Newcombe, transmission of stimuli, 59.

Nichols, distribution of energy in spectrum, 304, 305 .

Oats. See Avena.

Oedogonium swarm-spores, orientation in light from two sources, 87 ; description of, I23, I24; collection of material, I24; locomotion of, I 24; reversal in sense of orientation, I25; mechanics of orientation, I 26- I 28; aggregation of, I 27 , 24I; 229.

Oltmanns, experiments on ray direction and intensity difference, 39 , $40 ; 42 ; 60 ; 63 ; 265 ; 290$.

Optimum intensity, effect of, on aggregation, 242; variation in, 288-297, 301.

Orchestia, reversal in reactions, $27 \mathrm{I}$, 284,300 .
Orientation in light, in plants and animals compared (Loeb), 24, 25; plumules of Zea mays: $63^{-69}$, discussion of, $70-7 \mathrm{I}$; in leaves, $7 \mathrm{I}-73$; in Amoeba: $76-79$, discussion of, 80; in Euglena (Jennings), $8_{3}, 84$; from two sources (Euglena, etc.), 86-89, 219-22I, 224; accuracy of, in Euglena, 92; mechanics of, in Euglena crasting, 92-99; discussion of, in Euglena, 99-102; in negative Euglena, 99; mechanics of, in Euglena swimming, IO2-104; mechanics of, in Oedogonium swarm-spores, I $26-\mathrm{r} 28$; in Trachelomonas: accuracy of, I29, mechanics of, I29, I30; mechanics of, in Chlamydomonas, 132 , 133 ; mechanics of, in Volvox, I37-I 44 , 23I; in Volvox compared with that in Euglena and Stentor, I42; in Eudorina and Pandorina, 147 , $23 \mathrm{I}$; in Hydra, $157,23 \mathrm{I}$; in Eudendrium planulae, I6I-163; in Eudendrium hydranths, I63, I64; in Arenicola larvae, $167-171,232$; in Musca larvae, I89-197, 232; in earthworms, $198-205,232$; in Echinoderms, 2II-2I3; in Bufo, 219-223; in Caprella, 224, 225; in Corethra larvae, 225 ; in lobster larvae, 226; in zoeae of Brachyura and Caridea, 226; mechanics of (general), 233-235; effect of, on aggregation, 24I-244; fundamental cause of, 243; in Daphnia, 264.

Oscillaria, reactions of, in spectrum, $323,326,327,362$; distribution of stimulating efficiency in spectrum, 332.

Ostwald, 265 .

Oxygen, effect of, on reactions, 279 , $323-325,362,374$. 
Pagurus, reactions to shadows, 247; 249; modification in reactions of, 296.

Palaemon, 264.

Pandorina, orientation in light from two sources, 87, r47; function of eye-spot, I09, I47; 136; structure of, $\mathrm{r} 46$; locomotion of, $\mathrm{r} 47$; orientation and change in sense of, I47, 23I; I 7 ; aggregation of, 242.

Papaver, 288; 313.

Paramecium, $17 ; 45 ; 82$; reactions to light, I34, I35, 36r; I42; 324 ; $344 ; 350 ; 366$.

Paramecium bursaria, method of aggregation (Engelmann), I6; 45; aggregation of, 240; effect of oxygen on reactions of, 279; reactions in spectrum, 323,$324 ; 374$.

Parker, definition of tropism, 56; orientation in earthworms, 198; 201 ; 202 ; 214 ; on circus movements, 216; 221; 223; effect of size of illuminated area on reactions, $227 ; 244 ; 250 ; 265 ; 274$; effect of contact on reactions, 284.

Patten, 247.

Payer, reactions of seedlings in spectrum, 314, 317, 3I9.

Pearse, orientation in holothurians, $21 \mathrm{I} ; 22 \mathrm{I} ; 247$; decoration in crabs, 357.

Peckham, 354 .

Pecten, 247.

Pelomyxa palustris, 74 .

Perichaeta bermudensis, I 99.

Pfeffer, I2; 17；21; 59;60; 94; 100; warming-stage, 274 ; sleep movements in plants, 286; effect of different rays on reactions, $303 ; 317$.

Phacus, aggregation of, 24I; 274.

Phagocata gracilis, 207.

Phalaris, I9.
Photokinesis, defined, 35. See Unterschiedsempfindlichkeit.

Photopathy, defined by Davenport, $40,4 \mathrm{I}$; 55 ; 56 ; 24I ; defined, $253-$ 256 ; compared with phototaxis, $254 ; 302$.

Photosynthesis, 31 r, 312, 36r.

Phototaxis, defined by Davenport, 40; 55 ; defined by Hadley, 56; 217; defined, 253-256; compared with photopathy, 254; 302. See Heliotropism.

Phototropism. See Heliotropism.

Phycomyces, 265; 318.

Physiological states, dependence of reactions upon, 49; effect of, on reversal in reactions, 284-287; Jennings on, $372-375$.

Pilobolus, 318.

Pinnularia, 323 .

Pisa, 355 .

Planaria, accuracy of orientation, 206; locomotion and rate of locomotion, 207-2 I0; method of aggregation, 210; 254；257；26I；270; 346 ; 366; maculata, 207 ; gonocephala, 207; torva, 255 .

Plants, theory of orientation in: (Darwin), I8-21, (Loeb), 30; reactions of, in light, 59-73; sensitiveness of, 288, 3I 3 , 319; effect of different wave-lengths on reactions of, $310,313-320,36 \mathrm{r}$; effect of mixed rays on reactions of, 362. See Table of Contents.

Planulae of Eudendrium, 87. See Eudendrium.

Plateau, 354.

Plumules, orientation of, 63-69.

Poggioli, effect of different rays on reactions of plants, $3 \mathrm{I} 4,32 \mathrm{I}$.

Pollock, transmission of stimuli in roots, 31 , 59 ; theory of root curvature, $7 \mathrm{I}$. 
Polygordius larvae, 266; reversal in sense of reaction, $273,279,283$, $300 ; 346$.

Porter, 360.

Porthesia chrysorrhoea, 3I ; 336; 346; 371.

Potamilla oculifera, 247.

Pouchet, 247.

Pouillet. See Dutrochet.

Prawns, 249; 257; 260.

Preference method, Io; 343.

Preyer, Io.

Pringsheim, protoplasmic streaming, 75.

Problems, in reactions to light, statement of, I, 2, 3, 57, 58 .

Protozoa, 5I. See Table of Contents.

Protula intestimum, 247.

Psychic phenomena, in organisms, 9, 10, 27; in Euglena, I02; in frogs and toads, 223 , in ants, 350 , in bees, 353 .

Psychoid, defined, 377.

Purkinje's phenomenon, 305 .

Raccoon, color vision, 360.

Rádl, theory of orientation (pressure of light), 42, 43; cause of change in sense of orientation, 43; definition of tropism, 55; 214; on circus movements, 216,217 ; $234 ; 264 ; 265$.

Rana, 260; 273.

Ranatra, 21 7; 218; 226; 260; reversal in reactions, $27 \mathrm{I}, 273,280,284$, 300 ; modification in reactions of, $296 ; 367$.

Raphanus, 3I4.

Rawitz, 247.

Ray, explanation of movement in plants, 7; orientation in plants, $\mathrm{I} 2$.

Ray direction, as used by Sachs, I4; effect of, on orientation in animals (Loeb), 24-26; compared with dif- ference of intensity, 27; Oltmanns on, 39,40 ; function of, in orientation: plumules, 68, 69, Euglena, 83,87 , IIO, III, Stentor, II4, II8, Hydra, I50, Musca larvae, I80I82; I37; I44; 24I; Davenport on, $254-256$.

Reactions to light, distribution of, I; preference method,10; problems in, $\mathrm{I}-3,57,58$; in various organisms, See Table of Contents; classification of, $253^{-256}$; reclassification of, $25^{6-}$ 262 ; evolution of, 262,263 .

Reactions, to shadows, $247-250$; to sudden increase of light intensity, $250,25 \mathrm{I}$; to continued illumination, 252, 253, 257; to change of intensity, 257; of questionable cause, 258 ; caused by direct effect of light, 258; caused by indirect effect, 258-260; caused by what light represents, 260 ; fundamental cause of, $258-260,278,279,298$, $300,320,363,366$; reversal in, $264-267,355$; cause of reversal in, $267-287,299$; extent of reversal in, $27 \mathrm{I}$; effect of light on reversal in, 265-272, 299; effect of temperature on reversal in, $272-279$, 300 ; effect of chemicals on reversal in, 279-283, 300; effect of concentration of medium and mechanical stimuli on reversal in, $283,284,300$; effect of internal changes on reversal in, 284-287; variability and modifiability in: general, 288-297, 361, 362, in ants, $35 \mathrm{I}$, in bees, $35^{2-354}$, in higher crustacea, $355^{-}-35^{8}$, in fishes, $35^{8-}$ 360 ; effect of mixed colors on, 310 , $316,335,340,362,363$.

Regulation, in behavior, 50, 377; Chapters I3, I4, and 20. See Jennings. 
Reighard, color vision in fishes, 359 , 360.

Reinke, chlorophyll-absorption band, 3I 2.

Reptiles, 343 .

Rhizopods, 74; 79; 229; 233; aggregation of, $242 ; 258$.

Romanes, 10; 24; 21 I ; 235; 25 I.

Roots. See Plants.

Root-tip, function of, in reactions, I9, 20.

Rothert, I2; 2I; 72.

Ryder, 247.

Sabella microphthalmia, 247 .

Sachs, J. von, ray-direction theory of orientation in plants (heliotropism, geotropism), I3-I6; aggregation of organisms due to currents, 15; criticism of Darwin's idea of function of root-tip in movement of roots, $2 \mathrm{I} ; 24 ; 25-30$; $33 ; 34 ; 38 ; 39 ; 40 ; 42$; definition of tropism, 53, 54; 57;60; 70; 80; 86; ray-direction theory criticized, 87; II 2 ; ray-direction theory applied to Volvox, I37, I44; I49; 233; 314; effect of different colors on reactions of seedlings, 3I 7; 3I9; See Ray Direction and Criticism. Sagartia, 48.

Sand fleas, adaptation, 237, 238.

Sarsia, 25 I.

Scapholeberis armata, 214; 27I; 277; 280; 300 .

Schäfer, cause of invisibility of infrared and ultra-violet, 362 .

Schreckbewegung, origin and meaning of term, 17 ; in Euglena, 82; IIO; I6I; 233; 240; 246; 257; 259; in bacteria, 325 .

Scystosiphon lomentarium, 274.

Sea anemone, 258; 299.

Sea squirt, 250 .
Sea urchin. See Echinoderms.

Seedlings, orientation in light, 5973; change in sense of orientation, 265; reactions in spectrum, $3 \mathrm{I} 4$. See Plants.

Semotilus atromaculatus, 358 .

Sensation. See Psychic phenomena.

Sensibilité différentielle, compared with motor reflex, I7; 243.

Sensitiveness, with different surfaces exposed: in Euglena, 104-106, in Stentor, II4, 115, II9; variation in, 288-297, 30r; in plants, 288 , 313, 3 I9.

Serpula, 247; 254; 258.

Serpula uncinata, 247 .

Setaria italica, 2 I.

Shadows, reactions to, $247^{-250}$.

Sharroc, 7 .

Shock-movement. See Schreckbewegung.

Shrimps, 249; 257; 260.

Sigesbeckia, 286.

Sign, reaction to, $243 ; 250 ; 259^{-263}$; 286; 292-295; 298.

Simocephalus sima, 265; reactions in spectrum, $337,341-343,362$.

Sinapis alba, reactions in spectrum, 316, 317 .

Smith, orientation in earthworms, I98; 201 .

Spaulding, modification in reactions of hermit crabs, 296.

Spectrum, energy distribution in, 304, 305; brightness distribution in, 305-308; actinic effect, distribution in, 308-312, 360; reactions: of plants in, $3{ }^{1} 3-320$, of unicellular forms in, $32 \mathrm{I}-332$, of Amoeba in, 327-332; distribution of stimulating efficiency in: plants, 314-320; swarm-spores, 32I, 322; diatoms and Oscillaria, 323,326 , 327 , ciliates, 323 , flagellates, 324 , 
bacteria, 325, Amoeba, 327, 330332, Hydra, 334, 335, Daphnia, 337-34I, Simocephalus, 34I-343, worms, spiders, insects, mollusks, fishes, amphibia, reptiles, birds, mammals, $343-346$, ants, $348-35^{2}$, bees, $35^{2-}-355$, higher crustacea, $355^{-}-35^{8}$, fishes, $35^{8}-360$, birds and mammals, 360 , general, 361, 362, 367 ; for fishes and dancing mouse, 359,360 .

Sphinx, 346.

Spider, water, reversal in reactions, 277,300 ; 343 ; 354 ; color vision in, 364 .

Spirographis spallanzani, 33; 247; $254 ; 255 ; 258$.

Stahl, 74; light reactions in Euglena, 82; 265 .

Starfish. See Echinoderms.

Stenorynchus, $355 ; 358$.

Stentor coeruleus, 42 ; orientation in light from two sources, $87, \mathrm{II}_{5}$, I 16; distribution of sensitive tissue in, II4, II9-I2I; mechanics of orientation, II4-II9, I22; reactions when attached, II 5 ; aggregation of, I2I, 24I; activity in different intensities of light, I23; I24; I26; I27; I32; I37; I56; orientation compared with that in Musca larvae; 195; 215; 229; 230; adaptation, 237; 250; 257; 259 ; 26 I; 263 ; 270; 277 ; 280 ; variation in sensitiveness, 29I, 301,$368 ; 297 ; 300$; variation in reactions, 374 .

Stentor viridis, aggregation of, 240 ; effect of oxygen on reaction, 279.

Stimulation, differential response to localized, in: Euglena, 83, гог, Stentor, I 21, Oedogonium swarmspores, I28, Volvox, I37, Hydra, I58, Eudendrium, I62, medusae,
I64, I65, Arenicola larvae, I74, fly larvae, I95, earthworms, 200, 201, 205, Planaria, 206, 210, various species, 214, Caprella, 225, arthropods, 226; general, 48; Summary of, 230-235.

Stimulus, transmission of, in plants, I2, 2I; fundamental cause of (Jennings), 5०; 59; orienting, cause of in: Euglena, 94, 98, Stentor, II 8, Oedogonium swarmspores, I 27, Paramecium, I34, I35, Volvox, I44, Hydra, I57, Eudendrium, I63, Arenicola larvae, I $7 \mathrm{I}^{-1} 74$, Musca larvae, I94, I95, earthworms, 204, 206, Planaria, 208, 210, Echinoderms, 21 2, Ranatra, 218, frogs and toads, 219 , 223, gramineae, myxomycetes, rhizopods, and various other organisms, 229-235; a sign as a cause of, 243 ; cause of, in reactions to shadows, 250; cause of (constant intensity), 252, 253; cause of, in reactions to light (Davenport), 254-256; character of, $25^{6-258 .}$

Stobbe, on reversible photochemical reactions, 308-31 2; 336 .

Strasburger, reactions of swarmspores to light, I5, I23; 16; 27 ; 40 ; effect of light intensity on rate of movement, IOC; I 24; reversal in reactions of swarmspores, etc., 265, 272-274; change in optimum, 288; 290; reactions of swarm-spores in spectrum, $22 \mathrm{I}$, 222.

Swarm-spores, 87 ; rate of movement in different intensities of light, I00; aggregation of, 24I; 257; 259; change in sense of reaction, 265 ; 272 ; 274 ; reactions of, in spectrum, 32I, 322, 36I. 
Sylvius, founder of iatrochemical school, 6.

System, harmonious equipotential, 375 .

Talorchestia, $27 \mathrm{I}$.

Temora longicornis, 284; 300 .

Temperature, effect of, on reversal in reactions, 272-279, 300; effect of, compared with that of light, 276,367 ; extent of effect of, on reversal in reactions, 277 .

Tenebrio, 346 .

Theory, of orientation in plants: De Candolle, I2, Sachs, I3-I6, Darwin, I8-2I; Loeb: first theory of orientation (ray direction), 24, 25,34 , second theory (angle of rays), 28, 29, 35, third theory (intensity difference), 29-3I, 35; of orientation in animals (Davenport), 40-42; Rádl's, 42, 43; Jennings' (trial and error), 46-49; Torrey's, 84, 85; Holmes', 218; Graber's, 218; of local response to local stimulation, 86. See Criticism.

Threshold, in Euglena, 104-106; in Stentor, II4, II5, II9; in plants, 288; in Volvox, 289-29I.

Thyone briareus, 21 2 ; reactions to shadows, 247.

Tissue, sensitive, distribution of: as a factor in orientation, 3 , in plants, 21, 59, 7I, in Hydra, I56, 157, in Arenicola larvae, 172 , in Musca larvae, I83, I84, I88, I97, in earthworm, 20I, 205; effect of, in reactions, $26 \mathrm{I}, 262$.

Toads. See Bufo and Frogs.

Torelle, 214; reactions of frogs to light and shadow, 218, 219; 222; 223 ; 244; reversal in reactions (frog), 273 .
Torrey, definition of tropism, 56; 57; criticism of Jennings on Euglena, 84,85 ; 89; 100; IOI; I04; II 2; 205. Towle, effect of mechanical stimulation on reaction, 284 .

Trachelomonas, orientation in light from two sources, 87 ; function of eye-spot, I09, I30; description of, I 28; structure of eye-spot, 128 , I 29; accuracy of orientation, I29; mechanics of orientation, I29, I30; I46; 229; 230; aggregation of, 24I; 257; 259 .

Trembley, 33, 34; observations on movements of Hydra, I48, I49.

Trial and error, orientation by, 46; in Euglena, 99; in Stentor, I23; in Volvox, I42, I45; in Eudendrium, I62; in Musca larvae, I96; in earthworms, 198, 199, 203, 206; 214; defined by Jennings, 215; Engelmann on, 240.

Titicum vulgare, 66 .

Trochophores, Hydroides, 87.

Tropaeolum, 59; 68; 72 .

Tropism, introduction of term and original meaning, II 23,52 ; defined, $53-57 ; 83$.

Uca pugnax. See Fiddler Crab.

Uexküll, von, 2I 2; 247; 248.

Ulothrix, 274 .

Ultra-violet, effect of, on: Paramecia, I 34, I 35, Daphnia, 339, 343, chemical reactions, $310,311,360$, ants, 349, seedlings, 3I4, 3I5, 3I9, Lumbricus, 345 ; cause of invisibility of, $362 ; 368$.

Ulva lactua, 274 .

Unterschiedsempfindlichkeit, compared with motor reflex, I7; 27 ; 33 ; 85 ; 94; II 4 ; II5；24I；243; compared with heliotropism, $254^{-}$ $256 ; 258$. 
Vanessa antiopa, 216; reactions to light, 227; aggregation of, 244; 260.

Variability, in reactions, 264-30I; 367 ; chemical regulation of, 370 . See Modifiability.

Vaucheria, 31; 265.

Vermes, aggregation, 242. See Earthworm.

Vertebrates, 233.

Verworn, II; 35; theory of orientation (tropism), 36-38; same compared with Loeb's theory, 38,39 ; general application of theory, 39; $42 ; 52 ; 53$; definition of tropism, $55 ; 56 ; 57 ; 70 ; 80 ;$ IO4; II $2 ;$ II 3 ; I22; I68; I7I; theory of orientation applied to: Arenicola larvae, I 73, earthworms, 205; 229; 234; 265 ; on effect of different colors on reactions, 303; reactions of unicellular forms in spectrum, 326 , 327. See Criticism.

Vicia sativa, 3 I5, 3 I6.

Vierordt, brightness in spectrum, 305-307.

Vision, as a factor in orientation, 218, 219, 223, 224, 233; color: in Daphnia, 339, in ants, 350 , in bees, 354 , in fishes, $35^{8-360}$, in birds, 360 , in monkeys, 360 , in raccoon, 360 , in dancing mouse, 360 , in general, 364,365 .

Visual purple, 307 .

Vitalism, origin and early ideas on, 8 ; 52 ; theory of (Driesch), 374378.

Vitis, 265 .

Voechting, 7I.

Volvox, Oltmann's experiments on, 39 ; orientation in light from two sources, 87 ; rate of movement in different intensities of light, Ioo, Ior; function of eye-spots, rog; structure of, I36; locomotion, I36; distribution of sensitive tissue, 137 ; mechanics of orientation, $\mathrm{I} 37-\mathrm{I} 44$, 23I; orientation of segments, $\mathrm{I}_{42}$, I43; orientation in negative colonies, 143 ; change in sense of orientation, $145,267-270,280,287$, 299,300 ; orientation in light compared with orientation in a galvanic current, I45, I46; I48; orientation compared with that in Arenicola larvae, I69, I7 I; adaptation, 236; aggregation of, 242; $255 ; 257 ; 259 ; 263 ; 265$; change in sensitiveness and optimum, 289-292, 301; 367; 370; 374 .

Wager, eye-spot in Euglena, 81, 82, Io6.

Walter, definition of tropism, 55; reactions of Planaria, 207, 245 .

Washburn, definition of tropism, 56; on movement in Hydra, I5\%; 2 II.

Washburn and Bentley, color vision in fishes, $35^{8}, 359$.

Wasps, modification in reactions of, 296, 297.

Watson, 360.

Weber, 9; law of, 363 .

Wheeler, definition of tropism, 56 .

Whitman, reactions of Clepsine to shadows, 249.

Wiesner, I9; 60; 265; effect of different rays on reactions of plants, 310, 314-317, 322, 362.

Willow borer, adaptation in caterpillar of, 238.

Wilson, reactions of Hydra to light, I 50 ; 265 ; effect of different rays on reactions of Hydra, 310, 362; reactions of Hydra in spectrum, 333-335.

Wöhler, 9 . 
Yerkes, Ada W., reactions of $\mathrm{Hy}-$ droides and modification in, 249, 292, 293.

Yerkes, R. M., definition of tropism (phototaxis, photopathy), 55; 63; reactions of Gonionemus, I64; 214 ; $25 \mathrm{I}$; classification of reactions to light, 255, 256; 266; 274; reactions of Simocephalus in spectrum, $34 \mathrm{I}-$ $343 ; 360$.

Zea mays, orientation of plumules, $59-73,229$.

Zoeae, orientation in light from two sources, $87 ; 226 ; 243 ; 277$; 28 o. 




\title{
Short-Title Catalogue \\ OF THE
}

\section{PUBLICATIONS}

\author{
$\mathrm{OF}$ \\ JOHN WILEY \& SONS \\ NEW YORK
}

LONDON: CHAPMAN \& HAL.L, LIMITED

\section{ARRANGED UNDER SUBJECTS}

Descriptive circulars sent on application. Books marked with an asterisk $\left(^{*}\right)$ are sold at net prices only. All books are bound in cloth unless otherwise stated.

\section{AGRICULTURE-HORTICULTURE-FORESTRY.}

Armsby's Principles of Animal Nutrition.................... $\$ 40$ vo 00

Budd and Hansen's American Horticultural Manual:

Part I. Propagation, Culture, and Improvement........... 150

Part II. Systematic Pomology.................... 150

Elliott's Engineering for Land Drainage..................... 150

Practical Farm Drainage. (Second Edition, Rewritten.).......12mo, 150

Graves's Forest Mensuration........................... 400

Green's Principles of American Forestry................... 150

Grotenfelt's Principles of Modern Dairy Practice. (Woll.).........12mo, 200

* Herrick's Denatured or Industrial Alcohol .................. 400

Kemp and Waugh's Landscape Gardening. (New Edition, Rewritten. In Press.)

* McKay and Larsen's Principles and Practice of Butter-making . . . .8vo, 150

Maynard's Landscape Gardening as Applied to Home Decoration.....12mo, 150

Sanderson's Insects Injurious to Staple Crops............... 150

Sanderson and Headlee's Insects Injurious to Garden Crops. (In Preparation.)

* Schwarz's Longleaf Pine in Virgin Forest. ................ 125

Stockbridge's Rocks and Soils................................. 250

Winton's Microscopy of Vegetable Foods.................. 7 vo, 750

Woll's Handbook for Farmers and Dairymen.................... 150

\section{ARCHITECTURE.}

Baldwin's Steam Heating for Buildings..................... 250

Berg's Buildings and Structures of American Railroads............... to, 500

Birkmire's Architectural Iron and Steel................... 3 vo, 30

Compound Riveted Girders as Applied in Buildings.............. 8 vo, 200

Planning and Construction of American Theatres............... 8 vo, 300

Planning and Construction of High Office Buildings........... 8 vo, 350

Skeleton Construction in Buildings........................... 300 
Briggs's Modern American School Buildings................ 8vo, $\$ 400$ Byrne's Inspection of Materials and Wormanship Employed in Construction.

Carpenter's Heating and Ventilating of Buildings. $6 \mathrm{mo}, 300$

Carpenter's Heating and Ventilating of Buildings..................

* Corthell's Allowable Pressure on Deep Foundations............... 12mo,

F1eitag's Architectural Engineering.........................

Fireproofing of Steel Buildings....................

Gerhard's Guide to Sanitary Inspections. (Fourth Edition, Entirely Re-

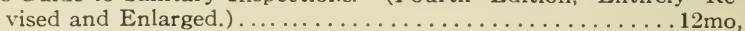

* Modern Baths and Bath Houses. . . . . . . . . Sanitation of Public Buildings.....................

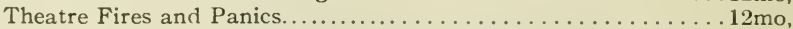

* The Water Supply, Sewerage and Plumbing of Modern City Buildings.

8vo, 400

Johnson's Statics by Algebraic and Graphic Methods............ 8vo, 200

Kellaway's How to Lay Out Suburban Home Grounds........... 8vo, 200

Kidder's Architects' and Builders' Pocket-book..................... mor., 500

Merrill's Stones for Building and Decoration................ 8 vo, 500

Monckton's Stair-building............................... 400

Patton's Practical Treatise on Foundations................ 5 vo, 500

Peabody's Naval Architecture............................... 750

Rice's Concrete-block Manufacture........................... 200

Richey's Handbook for Superintendents of Construction ...... 16mo, mor. 400

Building Foreman's Pocket Book and Ready Reference. 16mo, mor. 500

* Building Mechanics' Ready Reference Series:

* Carpenters' and Woodworkers' Edition...........16mo, mor. 150

* Cement Workers' and Plasterers' Edition............16mo, mor. 150

* Plumbers', Steam-Fitters', and Tinners' Edition. . .16mo, mor. 150

* Stone- and Brick-masons' Edition............... $16 \mathrm{mo}$, mor. 150

Sabin's House Painting................................ 100

Siebert and Biggin's Modern Stone-cutting and Masonry...........8vo, 150

Snow's Principal Species of Wood.......................... 350

Towne's Locks and Builders' Hardware................... 16mo, mor. 300

Wait's Engineering and Architectural Jurisprudence............. 8vo, 600

Law of Contracts................................. 300

Law of Operations Preliminary to Construction in Engineering and

Architecture............................. 8vo,

Sheep,

Wilson's Air Conditioning...........................

Worcester and Atkinson's Small Hospitals, Establishment and Maintenance,

Suggestions for Hospital Architecture, with Plans for a Small

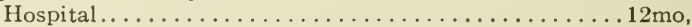

\section{ARMY AND NAVY.}

Bernadou's Smokeless Powder, Nitro-cellulose, and the Theory of the Cellu-

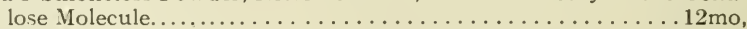

Chase's Art of Pattern Making.........................

Screw Propellers and Marine Propulsion .................

* Cloke's Enlisted Specialists' Examiner..................... . . vo,

* Gunner's Examiner............................. . . . . . .

Craig's Azimuth...............................

Crehore and Squier's Polarizing Photo-chronograph............... 8 vo,

* Davis's Elements of Law.............................. 8 vo,

* Treatise on the Military Law of United States............ 8vo,

* Dudley's Military Law and the Procedure of Courts-martial . . Large 12mo,

Durand's Resistance and Propulsion of Ships....................

* Dyer's Handbook of Light Artillery.......................

Eissler's Modern High Explosives......................

* Fiebeger's Text-book on Field Fortification............... Large 12mo,

Hamilton and Bond's The Gunner's Catechism..................

* Hoff's Elementary Naval Tactics........................ 
Ingalls's Handbook of Problems in Direct Fire.............. 8 vo, \$4 00

* Lissak's Ordnance and Gunnery............................ 8vo, 600

* Ludlow's Logarithmic and Trigonometric Tables.................8vo, 100

* Lyons's Treatise on Electromagnetic Phenomena. Vols. I. and II..8vo,each, 600

* Mahan's Permanent Fortifications. (Mercur.)........... . vo, half mor. 750

Manual for Courts-martial............................. 16 mo,mor. 150

* Mercur's Attack of Fortified Places......................mo, 200

* Elements of the Art of War. . . . . . . . . . . . . . . . . 8 vo, \& 00

Nixon's Adjutants' Manual..........................24mo, 100

Peabody's Naval Architecture........................ 8 vo, 750

* Phelps's Practical Marine Surveying.................... . 250

Putnam's Nautical Charts........................... 8vo, 200

Rust's Ex-meridian Altitude, Azimuth and Star-Finding Tables......8vo, 500

* Selkirk's Catechism of Manual of Guard Duty..............24mo, 50

Sharpe's Art of Subsisting Armies in War......................... mor. 150

Taylor's Speed and Power of Ships. (In Press.)

* Tupes and Poole's Manual of Bayonet Exercises and Musketry Fencing. 24 mo, leather,

* Weaver's Military Explosives......................... . . . . . .

* Woodhull's Military Hygiene for Officers of the Line......... Large 12mo,

\section{ASSAYING.}

Betts's Lead Refining by Electrolysis................... Fletcher's Practical Instructions in Quantitative Assaying with the Blowpipe. $16 \mathrm{mo}$, mor. Furman and Pardoe's Manual of Practical Assaying. (Sixth Edition, Revised and Enlarged. $). \ldots \ldots \ldots \ldots \ldots \ldots \ldots \ldots \ldots \ldots \ldots \ldots \ldots$ vo

Lodge's Notes on Assaying and Metallurgical Laboratory Experiments..8vo, Low's Technical Methods of Ore Analysis.................. Miller's Cyanide Process................................... . . . . Manual of Assaying.................................. Minet's Production of Aluminum and its Industrial Use. (Waldo.)...12mo, Ricketts and Miller's Notes on Assaying....................

Robine and Lenglen's Cyanide Industry. (Le Clerc.)........... 8vo,

* Seamon's Manual for Assayers and Chemists............ Large 12mo, Ulke's Modern Electrolytic Copper Refining................... . . vo, Wilson's Chlorination Process................................

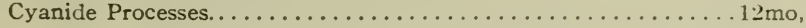

\section{ASTRONOMY.}

Comstock's Field Astronomy for Engineers................. . . Craig's Azimuth.................................. Crandall's Text-book on Geodesy and Least Squares............. 8 vo, Doolittle's Treatise on Practical Astronomy.................... . Hayford's Text-book of Geodetic Astronomy................. . . . . . Hosmer's Azimuth. Practical Astronomy. (In Press.)

Merriman's Elements of Precise Surveying and Geodesy...........8vo, 250

* Michie and Harlow's Practical Astronomy..................8vo, 300

Rust's Ex-meridian Altitude, Azimuth and Star-Finding Tables.......8vo, 500

*White's Elements of Theoretical and Descriptive Astronomy.......12mo, 200

\section{CHEMISTRY.}

* Abderhalden's Physiological Chemistry in Thirty Lectures. (Iíall and

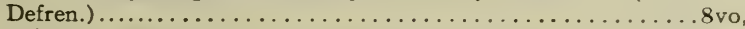
* Abegg's Theory of Electrolytic Dissociation. (von Ende.).......... Alexeyeff's General Principles of Organic Syntheses. (Matthews.).......8vo, Allen's Tables for Iron Analysis............. Armsby's Principles of Animal Nutrition................. Arnold's Compendium of Chemistry. (Mandel.).................... 
Association of State and National Food and Dairy Departments, Hartford Meeting, 1906..................................... $\$ 300$

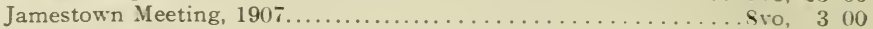

Austen's Notes for Chemical Students...................... . . 150

Baskerville's Chemical Elements. (In Preparation.)

Bernadou's Smokeless Powder.-Nitro-cellulose, and Theory of the Cellulose

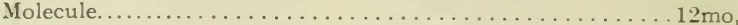

Biltz's Introduction to Inorganic Chemistry. (Hall and Phelan.). . . 12mo, Laboratory Methods of Inorganic Chemistry. (Hall and Blanchard.)

* Blanchard's Synthetic Inorganic Chemistry............... . . . 12 mo,

* Browning's Introduction to the Rarer Elements..................... Svo,

* Claassen's Beet-sugar Manufacture. (Hall and Rolfe.)........... 8vo, Classen's Quantitative Chemical Ana'ysis by Electrolysis. (Boltwood.).8vo, Cohn's Indicators and Test-papers.........................

Tests and Reagents.. ........................

* Danneel's Electrochemistry. (Merriam.) .................. .

Dannerth's Methods of Textile Chemistry....................

Duhem's Thermodynamics and Chemistry. (Burgess.)........... . svo,

Effront's Enzymes and their Applications. (Prescott.)................

Eissler's Modern High Explosives............................ . . . . . .

Erdmann's Introduction to Chemical Prefarations. (Dunlap.)....... 12mo,

Fischer's Oedema. (In Press.)

* Physiology of Alimentation. . ..................... $12 \mathrm{mo}$,

Fletcher's Practical Instructions in Quantitative Assaying with the Blowpipe.

Fowler's Sewage Works Analyses...... 16mo, mor. 150

Fresenius's Manual of Qualitative Chemical Analysis. (Wells.)........ Manual of Qualitative Chemical Analysis. Part I. Descriptive. (Wells. $\$$ svo, 300 Quantitative Chemical Analysis. (Cohn.) 2 vols................ 1250 When Sold Separately, Vol. I, \$6. Vol. II, \$\$.

Fuertes's Water and Public Health...........................

Furman and Pardoe's Manual of Practical Assaying. (Sixth Edition, Revised and En larged.)........................

* Getman's Exercises in Physical Chemistry.......................

Gill's Gas and Fuel Analysis for Engineers.....................

* Gooch and Browning's Outlines of Qualitative Chemical Analysis.

Grotenfelt's Principles of Modern Dairy Practice (Woll) Large $12 \mathrm{mo}$, Groth's Introduction to Chemical Crystallography (Marshall). .......... Hammarsten's Text-book of Physiological Chemistry. (Mandel.).....8vo, Hanausek's Microscopy of Technical Products. (Winton.)............ 8 vo,

* Haskins and Macleod's Organic Chemistry.................. 12mo,

* Herrick's Denatured or Industrial Alcohol...................... . 8vo,

Hinds's Inorganic Chemistry......................... . . . .

* Laboratory Manual for Students....................... 12mo,

* Holleman's Laboratory Manual of Organic Chemistry for Beginners.

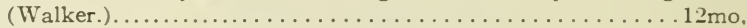

Text-book of Inorganic Chemistry. (Cooper.)...............

Text-book of Organic Chemistry. (Walker and Mott.).......... 8vo, * Holley's Lead and Zinc Pigments........................... 12mo, Holley and Ladd's Analysis of Mixed Paints, Color Pigments, and Varnishes. Large $12 \mathrm{mo}$, Hopkins's Oil-chemists' Handbook.. . . . . . . . . . . . . . . . . . vvo, Jackson's Directions for Laboratory Work in Physiological Chemistry. . 8vo, Johnson's Rapid Methods for the Chemical Analysis of Special Steels. Steelmaking Alloys and Graphite........................... $12 \mathrm{mo}$, Landauer's Spectrum Analysis. (Tingle.)................... 8vo, Lassar-Cohn's Application of Some General Reactions to Investigations in Organic Chemistry. (Tingle.).................... Leach's Inspection and Analysis of Food with Special Reference to State

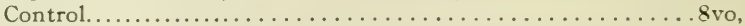
Löb's Electrochemistry of Organic Compounds. (Lorenz.)........... . vo, Lodge's Notes on Assaying and Metallurgical Laboratory Experiments. 8vo, Low's Technical Method of Ore Analysis..................... 8 vo, Lowe's Paint for Steel Structures.. . . . . . . . . . . . . . . . 12mo,

Lunge's Techno-chemical Analysis. (Cohn.)....................... 100 
* McKay and Larsen's Principles and Practice of Butter-making...... 8vo, \$1 50

Maire's Modern Pigments and their Vehicles..................12mo, 200

Mandel's Handbook for Bio-chemical Laboratory................12mo, 159

* Martin's Laboratory Guide to Qualitative Analysis with the Blowpipe

$12 \mathrm{mo}, 06$ ?

Mason's Examination of Water. (Chemical and Bacteriological.).....12mo, 125

Water-supply. (Considered Principally from a Sanitary Standpoint.)

* Mathewson's First Principles of Chemical Theory............... .

Matthews's Laboratory Manual of Dyeing and Textile Chemistry . . . 8vo, 3 5.

Textile Fibres. 2d Edition, Rewritten................ 8 vo, 400

* Meyer's Determination of Radicles in Carbon Compounds. (Tingle.)

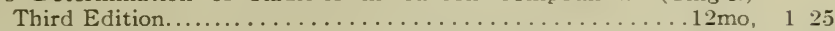

Miller's Cyanide Process...............................12mo, 100

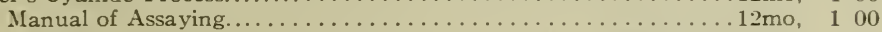

Minet's Production of Aluminum and its Industrial Use. (Waldo.)..12mo, 250

* Mittelstaedt's Technical Calculations for Sugar Works. (Bourbakis.) $12 \mathrm{mo}, 150$

Mixter's Elementary Text-book of Chemistry... . . . . . . . . . . 12mo, 150

Morgan's Elements of Physical Chemistry.................12mo, 300

Outline of the Theory of Solutions and its Results.......... 12mo, 100

* Physical Chemistry for Electrical Engineers............. $12 \mathrm{mo}, \quad 1$ j0

* Moore's Outlines of Organic Chemistry. . . . . . . . . . . . . 12mo, 150

Morse's Calculations used in Cane-sugar Factories............ 16mo, mor. 150

* Muir's History of Chemical Theories and Laws. . . . . . . . . . . . . . . vo, 400

Mulliken's General Method for the Identification of Pure Organic Compounds.

Vol. I. Compounds of Carbon with Hydrogen and Oxygen. Large 8vo,

Vol. II. Nitrogenous Compounds. (In Preparation.)

Vol. III. The Commercial Dyestuffs. . . . . . . . . . . . . . . . Large 8vo,

* Nelson's Analysis of Drugs and Medicines. . . . . . . . . . . . . . . 12mo,

Ostwald's Conversations on Chemistry. Part One. (Ramsey.).....12mo,

" " " $"$ Part Two. (Turnbull.)....12mo,

Introduction to Chemistry. (Hall and Williams.) (In Preparation.)

Owen and Standage's Dyeing and Cleaning of Textile Fabrics........ 12mo,

* Palmer's Practical Test Book of Chemistry. ................. $12 \mathrm{mo}$,

* Pauli's Physical Chemistry in the Service of Medicine. (Fischer.). . 12mo,

Penfield's Tables of Minerals, Including the Use of Minerals and Statistics of Domestic Production......................... . . . .

Pictet's Alkaloids and their Chemical Constitution. (Biddle.)......... . . . . . .

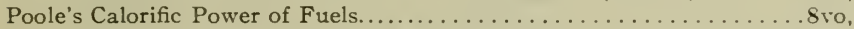

Prescott and Winslow's Elements of Water Bacteriology, with Special Refer-

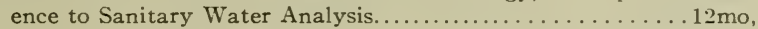

* Reisig's Guide to Piece-Dyeing......................... . . . . 2500

Richards and Woodman's Air, Water, and Food from a Sanitary Stand-

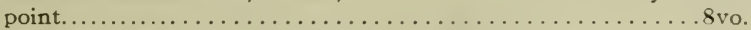

Ricketts and Miller's Notes on Assaying. . . . . . . . . . . . . . . . .

Rideal's Disinfection and the Preservation of Food................. . . .

Sewage and the Bacterial Purification of Sewage.............. 8 vo,

Riggs's Elementary Manual for the Chemical Laboratory............ . . . . 8vo,

Robine and Lenglen's Cyanide Industry. (Le Clerc.) . . . . . . . . . . . . . . . . . .

Ruddiman's Incompatibilities in Prescriptions. . . . . . . . . . . . vo,

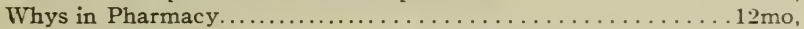

* Ruer's Elements of Metallography. (Mathewson.) ... . . . . . . . . . 8vo,

Sabin's Industrial and Artistic Technology of Paint and Varnish. ....8vo,

Salkowski's Physiological and Pathological Chemistry. (Orndorff.)....8vo,

Schimpf's Essentials of Volumetric Analysis.............. $\ldots \ldots$ 12mo,

Manual of Volumetric Analysis. (Fifth Edition, Rewritten) ... . 8vo,

* Qualitative Chemical Analysis . . . . . . . . . . . . . . . . . . . . .

* Seamon's Manual for Assayers and Chemists. . . . . . . . . . . . Large 12mo,

Smith's Lecture Notes on Chemistry for Dental Students. . . . . . . . . .8vo,

Spencer's Handbook for Cane Sugar Manufacturers.............

Handbook for Chemists of Beet-sugar Houses. ................

Stockbridge's Rocks and Soils........................... . . . . .

Stone's Practical Testing of Gas and Gas Meters..... . . . . . . . . . . . . . . . . . . . .

* Tillman's Descriptive General Chemistry............ . . . . . . . . vo,

* Elementary Lessons in Heat . . . . . . . . . . . . . . . . . . . . . . . . .

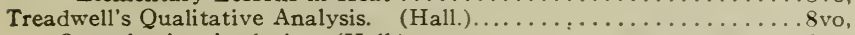

Quantitative Analysis. (Hall.).............................. 
Van Deventer's Physical Chemistry for Beginners. (Boltwood.)..... 12mo, 150

Venable's Methods and Devices for Bacterial Treatment of Sewage.....8vo, 300

Ward and Whipple's Freshwater Biology. (In Press.)

Ware's Beet-sugar Manufacture and Refining. Vol. I............ 8vo, 400

" " " " " " Vol. II...........

Washington's Manual of the Chemical Analysis of Rocks...............

* Weaver's Military Explosives.................................... 300

Wells's Laboratory Guide in Qualitative Chemical Analysis......... 8vo, 150

Short Course in Inorganic Qualitative Chemical Analysis for Engineering

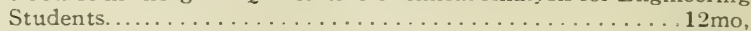

Text-book of Chemical Arithmetic .................... 150

Whipple's Microscopy of Drinking-water................................ 350

Wilson's Chlorination Process................................ 150

Cyanide Processes................................ 150

Winton's Microscopy of Vegetable Foods................. 8vo, 750

Zsigmondy's Colloids and the Ultramicroscope. (Alexander.)..Large 12mo, 300

\section{CIVIL ENGINEERING.}

\section{BRIDGES AND ROOFS. HYDRAULICS. MATERIALS OF ENGINEER-}

\section{ING. RAILWAY ENGINEERING.}

Baker's Engineers' Surveying Instruments................... Bixby's Graphical Computing Table............. Paper $19 \frac{1}{2} \times 24 \frac{1}{4}$ inches. Breed and Hosmer's Principles and Practice of Surveying. Vol. I. Elemen-

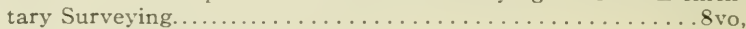

Vol. II. Higher Surveying......................

* Burr's Ancient and Modern Engineering and the Isthmian Canal. . . . . . 8vo,

Comstock's Field Astronomy for Engineers..................... . vo,

* Corthell's Allowable Pressure on Deep Foundations ........... . 12mo,

Crandall's Text-book on Geodesy and Least Squares............... . . . .

Davis's Elevation and Stadia Tables.................... . . .

Elliott's Engineering for Land Drainage................... .

* Fiebeger's Treatise on Civil Engineering......................

Flemer's Photographic Methods and Instruments............... . .

Folwell's Sewerage. (Designing and Maintenance.)............... . .

Freitag's Architectural Engineering. ......................

French and Ives's Stereotomy......................

Goodhue's Municipal Improvements.....................

* Hauch and Rice's Tables of Quantities for Preliminary Estimates. . 12mo,

Hayford's Text-book of Geodetic Astronomy.................. 8 vo,

Hering's Ready Reference Tables (Conversion Factors.) .........16mo, mor.

Hosmer's Azimuth.............................. mor.

Howe's Retaining Walls for Earth.......................

* Ives's Adjustments of the Engineer's Transit and Level....... 16mo, bds.

Ives and Hilts's Problems in Surveying, Railroad Surveying and Geod-

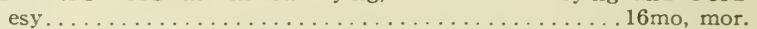

Johnson's (J. B.) Theory and Practice of Surveying............ Large 12mo, 400

Johnson's (L. J.) Statics by Algebraic and Graphic Methods............ . 8vo, 200

Kinnicutt, Winslow and Pratt's Sewage Disposal. (In Press.)

* Mahan's Descriptive Geometry.......................... 150

Merriman's Elements of Precise Surveying and Geodesy...........8vo, 250

Merriman and Brooks's Handbook for Surveyors................. mor. 200

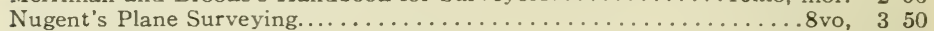

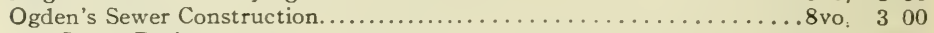

Sewer Design....................................... 200

Parsons's Disposal of Municipal Refuse.......................... 200

Patton's Treatise on Civil Engineering.............

Reed's Topographical Drawing and Sketching.................. 500

Rideal's Sewage and the Bacterial Purification of Sewrage............ 8vo, 400

Riemer's Shaft-sinking under Difficult Conditions. (Corning and Peele.).8vo, 300

Siebert and Biggin's Modern Stone-cutting and Masonry............8vo, 150

Smith's Manual of Topographical Drawing. (McMillan.).............8vo, 250 
Soper's Air and Ventilation of Subways........................ \$2 50

*'Tracy's Exercises in Surveying..................... 12mo, mor. 100

Tracy's Plane Surveying............................... mor. 300

* Trautwine's Civil Engineer's Pocket-book...............16mo, mor. 500

Venable's Garbage Crematories in America.................... 8vo, 200

Methods and Devices for Bacterial Treatment of Sewage.......... 8vo, 300

Wait's Engineering and Architectural Jurisprudence............. 8vo, 600

Law of Operations Preliminary to Construction in Engineering and

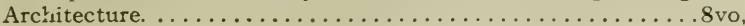

Sheep, 550

Warren's Stereotomy-Problems in Stone-cutting............... 8vo, 250

* Waterbury's Vest-Pocket Hand-book of Mathematics for Engineers.

$2 \frac{7}{8} \times 5 \frac{3}{8}$ inches. mor. 100

* Enlarged Edition, Including Tables................... 150

Webb's Proulems in the Use and Adjustment of Engineering Instruments.

$16 \mathrm{mo}$, mor. 125

Wilson's Topographic Surveying..................... 350

\section{BRIDGES AND ROOFS.}

Boller's Practical Treatise on the Construction of Iron Highway Bridges..8vo,

* Thames River Bridge.................... Oblong paper,

Burr and Falk's Design and Construction of Metallic Bridges. . . . . . . . . \&vo,

Influence Lines for Bridge and Roof Computations.............. 8vo, 300

Du Bois's Mechanics of Engineering. Vol. II....................... 4 to, 1000

Foster's Treatise on Wooden Trestle Bridges.................4to, 500

Fowler's Ordinary Foundations........................... 350

Greene's Arches in Wood, Iron, and Stone.................... 2 vo, 5 )

Bridge Trusses................................ 250

Roof Trusses......................................... 125

Grimm's Secondary Stresses in Bridge Trusses................. 8vo, 250

Heller's Stresses in Structures and the Accompanying Deformations. . . 8vo, 300

Howe's Design of Simple Roof-trusses in Wood and Steel............8vo. 200

Symmetrical Masonry Arches........................ 8 vo, 250

Treatise on Arches................................ 400

* Jacoby's Struc tural Details, or Elements of Design in Heavy Framing, 8vo, 225

Johnson, Bryan and Turneaure's Theory and Practice in the Designing of

Modern Framed Structures............................ 4 to, 100

* Johnson, Bryan and Turneaure's Theory and Practice in the Designing of

Modern Framed Structures. New Edition. Part I. ...... 8vo, 300

Merriman and Jacoby's Text-book on Roofs and Bridges:

Part I. Stresses in Simple Trusses..................... 8vo, 250

Part II. Graphic Statics............................ 250

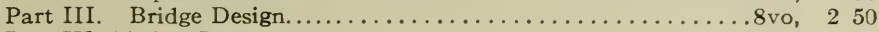

Part IV. Higher Structures........................... 250

Morison's Memphis Bridge................................... 4to, 1000

Sondericker's Graphic Statics, with Applications to. Trusses, Beams, and

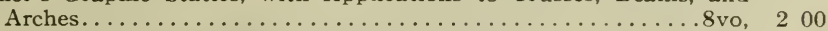

Waddell's De Pontibus, Pocket-book for Bridge Engineers......16mo, mor.

* Specifications for Steel Bridges........................

Waddell and Harrington's Bridge Engineering. (In Preparation.)

\section{HYDRAULICS.}

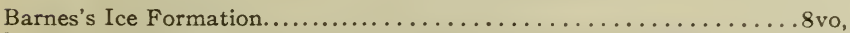
Bazin's Experiments upon the Contraction of the Liquid Vein Issuing from an Orifice. (Trautwine.)..........................

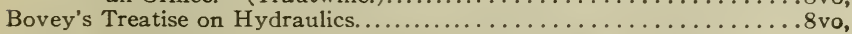
Church's Diagrams of Mean Velocity of Water in Open Channels. 
Coffin's Graphical Solution of Hydraulic Problems.

$.16 \mathrm{mo}$, mor. $\$ 250$

Flather's Dynamometers, and the Measurement of Power.........12mo, 300

Folwell's Water-supply Engineering.................... 8 vo, 400

Frizell's Water-power................................... 500

Fuertes's Water and Public Health........................ 150

Water-filtration Works............................. 250

Ganguillet and Kutter's General Formula for the Uniform Flow of Water in

Rivers and Other Channels. (Hering and Trautwine.).....8vo, 400

Hazen's Clean Water and How to Get It........................ 12mo, 150

Filtration of Public Water-supplies.................. 8 vo, 300

Hazelhurst's Towers and Tanks for Water-works.................... 250

Herschel's 115 Experiments on the Carrying Capacity of Large, Riveted, Metal

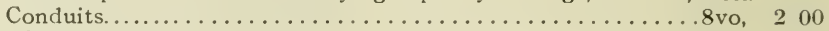

Hoyt and Grover's River Discharge......................... 200

Hubbard and Kiersted's Water-works Management and Maintenance.

* Lyndon's Development and Electrical Distribution of Water Power.

8vo, 400

Mason's Water-supply. (Considered Principally from a Sanitary Stand-

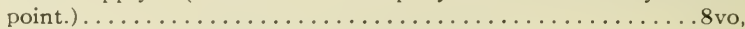

Merriman's Treatise on Hydraulics........................ 8 vo,

* Molitor's Hydraulics of Rivers, Weirs and Sluices............ . . .

* Morrison and Brodie's High Masonry Dam Design............ 8vo,

* Richards's Laboratory Notes on Industrial Water Analysis...... . . . 8vo,

Schuyler's Reservoirs for Irrigation, Water-power, and Domestic Watersupply. Second Edition, Revised and Enlarged........ Large 8vo,

* Thomas and Watt's Improvement of Rivers.................. to to

Turneaure and Russell's Public Water-supplies....................

Wegmann's Design and Construction of Dams. 5th Ed., enlarged.....4 to,

Water-Supply of the City of New York from 1658 to $1895 \ldots \ldots \ldots .4$,

Whipple's Value of Pure Water.............................

Williams and Hazen's Hydraulic Tables..................

Wilson's Irrigation Engineering. ..................

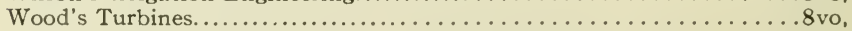

\section{MATERIALS OF ENGINEERING.}

Baker's Roads and Pavements........................

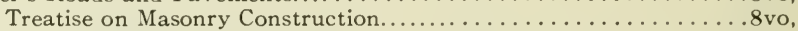

Black's United States Public Works.........................

Blanchard's Bituminous Roads. (In Preparation.)

Bleininger's Manufacture of Hydraulic Cement. (In Preparation.)

* Bovey's Strength of Materials and Theory of Structures............. 8vo,

Burr's Elasticity and Resistance of the Materials of Engineering....... . 8vo,

Byrne's Highway Construction..............................

Inspection of the Materials an 1 Workmanship Employed in Construction.

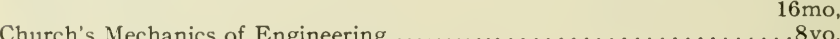

Du Bois's Mechanics of Engineering.

Vol. I. Kinematics, Statics, Kinetics.....................

Vol. II. The Stresses in Framed Structures, Strength of Materials and Theory of Flexures............................

* Eckel's Cements, Limes, and Plasters............................

Stone and Clay Products used in Engineering. (In Preparation.)

Fowler's Ordinary Foundations......................

* Greene's Structural Mechanics....................

* Holley's Lead and Zinc Pigments.............................. $12 \mathrm{mo}$, Holley and Ladd's Analysis of Mixed Paints, Color Pigments and Varnishes.

* Hubbard's Dust Preventives and Road Binders Large 12mo.

Johnson's (C. M.) Rapid Methods for the Chemical Analysis of Special Steels, Steel-making Alloys and Graphite...................

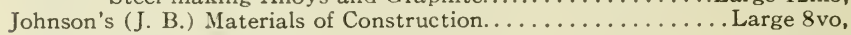
Keep's Cast Iron.................................

Lanza's Applied Mechanics............................

Lowe's Paints for Steel Structures....................... 
Maire's Modern Pigments and their Vehicles................. 12mo, \$2 00

Maurer's Technical Mechanics........................8vo, 400

Merrill's Stones for Building and Decoration................ 8vo, 500

Merriman's Mechanics of Materials..................... 8vo, 500

* Strength of Materials............................. 12mo, 100

Metcalf's Steel. A Manual for Steel-users................. 12mo, 200

Morrison's Highway Engineering.......................... 250

Patton's Practical Treatise on Foundations.................

Rice's Concrete Block Manufacture.......................... 200

Richardson's Modern Asphalt Pavement..................... 8vo, 300

Richey's Building Foreman's Pocket Book and Ready Reference.16mo,mor. 500

* Cement Workers' and Plasterers' Edition (Building Mechanics' Ready

Reference Series)......................

Handbook for Superintendents of Construction..............

* Stone and Brick Masons' Edition (Building Mechanics' Ready Reference Series) .......................

* Ries's Clays: Their Occurrence, Properties, and Uses.............. . vo,

* Ries and Leighton's History of the Clay-working Industry of the United

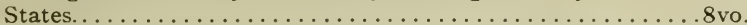

Sabin's Industrial and Artistic Technology of Paint and Varnish......8vo,

* Smith's Strength of Material........................

Snow's Principal Species of Wood.......................

Spalding's Hydraulic Cement............................

Text-book on Roads and Pavements.....................

*'Taylor and Thompson's Extracts on Reinforced Concrete Designs. . . 8vo, Treatise on Concrete, Plain and Reinforced...............8vo,

Thurston's Materials of Engineering. In Three Parts.............. 8 vo, Part I. Non-metallic Materials of Engineering and Metallurgy....8vo, Part II. Iron and Steel..........................

Part III. A Treatise on Brasses, Bronzes, and Other Alloys and their

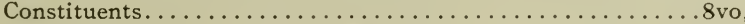
Tillson's Street Pavements and Paving Materials............... * Trautwine's Concrete, Plain and Reinforced ................. Turneaure and Maurer's Principles of Reinforced Concrete Construction. Second Edition, Revised and Enlarged............. 8 vo, Waterbury's Cement Laboratory Manual......................... Wood's (De V.) Treatise on the Resistance of Materials, and an Appendix on the Preservation of Timber................... Wood's (M. P.) Rustless Coatings: Corrosion and Electrolysis of Iron and

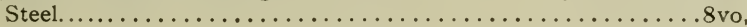

\section{RAILWAY ENGINEERING.}

Andrews's Handbook for Street Railway Engineers.......3 $3 \times 5$ inches, mor.

Berg's Buildings and Structures of American Railroads............ Brooks's Handbook of Street Railroad Location.............. $16 \mathrm{mo}$, mor.

Butts's Civil Engineer's Field-book....................

Crandall's Railway and Other Earthwork Tables.................8vo,

Transition Curve................................. mor.

* Crockett's Methods for Earthwork Computations................. . . . .

Dredge's History of the Pennsylvania Railroad. (1879).............. Paper,

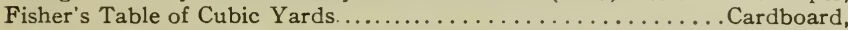
Godwin's Railroad Engineers' Field-book and Explorers' Guide.. 16mo, mor. Hudson's Tables for Calculating the Cubic Contents of Excavations and Fm-

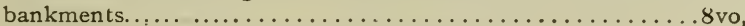
Ives and Hilts's Problems in Surveying, Railroad Surveying anci Geodesy

$16 \mathrm{mo}$, mor. Molitor and Beard's Manual for Resident Engineers......... . . . 16mo, Nagle's Field Manual for Railroad Engineers..............

* Orrock's Railroad Structures and Estimates................. . 8vo, Philbrick's Field Manual for Engineers................... Raymond's Railroad Engineering. 3 volumes.

Vol. I. Railroad Field Geometry. (In Press.)

Vol. II. Elements of Railroad Engineering. . . . . . . . . . . 8vo,

Vol. III. Railroad Engineer's Field Book. (In Preparation.) 
Roberts' Track Formulæ and Tables. (In Press.)

Searles's Field Engineering..................... 1\&mo, mor. \$3 00

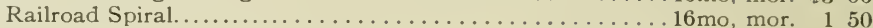

Taylor's Prismoidal Formulæ and Earthwork................

* Trautwine's Field Practice of Laying Out Circular Curves for Railroads.

* Method of Calculating the Cubic Contents of Excavations and Embankments by the Aid of Diagrams................. 8 vo, 200

Webb's Economics of Railroad Construction................ Large 12mo, 250

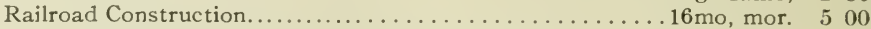

Wellington's Economic Theory of the Location of Railways......... .arge $12 \mathrm{mo}, 500$

Wilson's Elements of Railroad-Track and Construction..........12mo, 200

\section{DRAWING.}

Barr's Kinematics of Machinery............................. 250

* Bartlett's Mechanical Drawing....................... 300

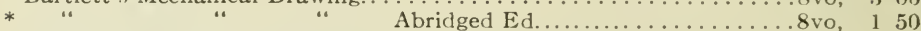

Bartlett and Johnson's Engineering Descriptive Geometry. (In Press.)

Coolidge's Manual of Drawing.................... 8vo, paper,

Coolidge and Freeman's Elements of General Drafting for Mechanical Engi-

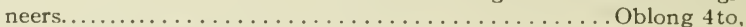

Durley's Kinematics of Machines. . . . . . . . . . . . . . . . . . . 8vo,

Emch's Introduction to Projective Geometry and its Application... . . 8vo,

Hill's Text-book on Shades and Shadows, and Perspective ..........8vo,

Jamison's Advanced Mechanical Drawing. . . . . . . . . . . . . . 8vo,

Elements of Mechanical Drawing...................

Jones's Machine Design:

Part I. Kinematics of Machinery...................... . . . . .

Part II. Form, Strength, and Proportions of Parts............ .

* Kimball and Barr's Machine Design . . . . . . . . . . . . . . . . 8vo,

MacCord's Elements of Descriptive Geometry . . . . . . . . . . . . . . 8vo,

Kinematics; or, Practical Mechanism................... . . . . .

Mechanical Drawing.............................. 4 to,

Velocity Diagrams.............................. . . . . . . . . . . .

McLeod's Descriptive Geometry....................... Large 12mo,

$\therefore$ Mahan's Descriptive Geometry and Stone-cutting. . . . . . . . . . . . . . . . . . .

Industrial Drawing. (Thompson.)...................

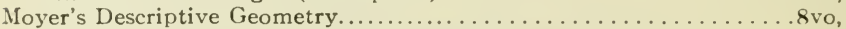

Reed's Topographical Drawing and Sketching.................4to,

Reid's Course in Mechanical Drawing...................... . . . .

Text-book of Mechanical Drawing and Elementary Machine Design..8vo,

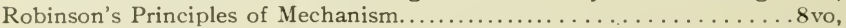

Schwamb and Merrill's Elements of Mechanism.................. . . .

Smith (A. W.) and Marx's Machine Design....................... . . . .

Smith's (R. S.) Manual of Topographical Drawing. (McMillan.)......8vo,

* Titsworth's Elements of Mechanical Drawing. . . . . . . . . . Oblong 8vo,

Warren's Drafting Instruments and Operations. . . . . . . . . . . 12mo,

Elements of Descriptive Geometry, Shadows, and Perspective:....8vo,

Elements of Machine Construction and Drawing............. 8vo,

Elements of Plane and Solid Free-hand Geometrical Drawing. . . 12mo,

General Problems of Shades and Shadows.................. . . . . .

Manual of Elementary Problems in the Linear Perspective of Forms and

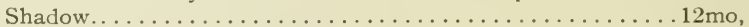

Manual of Elementary Projection Drawing. . . . . . . . . . . . 12mo,

Plane Problems in Elementary Geometry................ $12 \mathrm{mo}$,

Weisbach's Kinematics and Power of Transmission. (Hermann and Klein.)............................... . . . . . . .

Wilson's (H. M.) Topographic Surveying. . . . . . . . . . . . . . . 8vo,

* Wilson's (V. T.) Descriptive Geometry...................... . . . . .

Free-hand Lettering. . . . . . . . . . . . . . . . . . . . 8vo,

Free-hand Perspective............................ . . . . . . .

WVolf's Elementary Course in Descriptive Geometry... . . . . . . Large 8vo, 


\section{ELECTRICITY AND PHYSICJ.}

*Abegg's Theory of Electrolytic Dissociation. (von Ende.)......12mo, \$1 25 Andrews's Hand-book for Street Railway Engineering......3 $3 \times 5$ inches, mor. 125

Anthony and Ball's Lecture-notes on the Theory of Electrical Measurements..................................... 100 Anthony and Brackett's Text-book of Physics. (Magie.)....Large 12mo, 303

Benjamin's History of Electricity........................ 300

Betts's Lead Refining and Electrolysis.................... 8vo, 400

Classen's Quantitative Chemical Analysis by Electrolysis. (Boltwood.).8vo, 300

* Collins's Manual of Wireless Telegraphy and Telephony...........12mo, 150

Crehore and Squier's Polarizing Photo-chronograph............... 8vo, 300

* Danneel's Electrochemistry. (Merriam.)......................... 125

Dawson's "Engineering" and Electric Traction Pocket-book...16mo, mor. 500

Dolezalek's Theory of the Lead Accumulator (Storage Battery). (von Ende.)

Duhem's Thermodynamics and Chemistry. (Burgess.)........... 12mo,

Flather's Dynamometers, and the Measurement of Power..........12mo,

* Getman's Introduction to Physical Science. . . . . . . . . . . . 12mo,

Gilbert's De Magnete. (Mottelay) .......................... . . . . . .

* Hanchett's Alternating Currents........................

Hering's Ready Reference Tables (Conversion Factors)....... 15mo, mor.

* Hobart and Ellis's High-speed Dynamo Electric Machinery. . . . . . . . 8vo,

Holman's Precision of Measurements........................ . . . .

Telescopic Mirror-scale Method, Adjustments, and Tests... . Large 8vo,

* Karapetoff's Experimental Electrical Engineering................. .

Kinzbrunner's Testing of Continuous-current Machines. . . . . . . . . . 8vo,

Landauer's Spectrum Analysis. (Tingle.)................

Le Chatelier's High-temperature Measurements. (Boudouard-Burgess.) 12mo, 300

Löb's Electrochemistry of Organic Compounds. (Lorenz.).......... 8vo, 300

* Lyndon's Development and Electrical Distribution of Water Power. .8vo, 300

* Lyons's Treatise on Electromagnetic Phenomena. Vols, I and II. 8vo, each, 600

* Michie's Elements of Wave Motion Relating to Sound and Light. . . .8vo, 4 OU

Morgan's Outline of the Theory of Solution and its Results.........12mo, 100

* Physical Chemistry for Electrical Engineers............. 12mo, 150

* Norris's Introduction to the Study of Electrical Engineering.......8vo, 250

Norris and Dennison's Course of Problems on the Electrical Characteristics of

Circuits and Machines. (In Press.)

* Parshall and Hobart's Electric Machine Design.........4to, half mor, 1250

Reagan's Locomotives: Simple, Compound, and Electric. New Edition.

Large $12 \mathrm{mo}, \quad 350$

* Rosenberg's Electrical Engineering. (Haldane Gee-Kinzbrunner.). . 8vo,

Ryan, Norris, and Hoxie's Electrical Machinery. Vol. I............. 8vo, Schapper's Laboratory Guide for Students in Physical Chemistry.... 12mo,

* Tillman's Elementary Lessons in Heat.. . . . . . . . . . . . . . . . . . 8vo,

Tory and Pitcher's Manual of Laboratory Physics........... Large 12mo,

Ulke's Modern Electrolytic Copper Refining.................. 8vo,

\section{LAW.}

* Brennan's Hand-book of Useful Legal Information for Business Men. $16 \mathrm{mo}$, mor.

* Davis's Elements of Law.............................. . . . .

* Treatise on the Military Law of United States............ . . vo,

* Dudley's Military Law and the Procedure of Courts-martial. Large 12mo, Manual for Courts-martial.........................

Wait's Engineering and Architectural Jurisprudence............. 8vo,

Sheep,

Law of Contracts...........................

Law of Operations Preliminary to Construction in Engineering and Architecture ......................... 
Briggs's Elements of Plane Analytic Geometry. (Bôcher.) .......12mo, \$1 00

* Buchanan's Plane and Spherical Trigonometry...............8vo, 100

Byerly's Harmonic Functions.........................8vo, 100

Chandler's Elements of the Infinitesimal Calculus............. 12mo, 200

* Coffin's Vector Analysis. ........................12mo, 250

Compton's Manual of Logarithmic Computations..............12mo, 150

* Dickson's College Algebra................................... 12mo, 150

* Introduction to the Theory of Algebraic Equations........ Large 12mo, 125

Emch's Introduction to Projective Geometry and its Application.....8vo, 25

Fiske's Functions of a Complex Variable....................8vo, 100

Halsted's Elementary Synthetic Geometry..... . . . . . . . . . . .8vo, 150

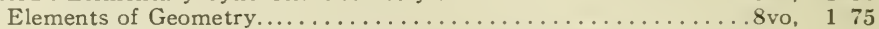

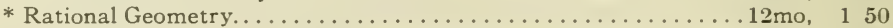

Synthetic Projective Geometry.....................8vo, 100

* Hancock's Lectures on the Theory of Elliptic Functions........... 8vo, 500

Hyde's Grassmann's Space Analysis........................8vo, 100

* Johnson's (J. B.) Three-place Logarithmic Tables: Vest-pocket size, paper, 15

* 100 copies, 500

* Mounted on heavy cardboard, $8 \times 10$ inches, 25

* 10 copies, 200

Johnson's (W. W.) Abridged Editions of Differential and Integral Calculus.

Large $12 \mathrm{mo}, 1$ vol. 250

100

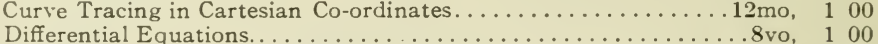

Elementary Treatise on Differential Calculus............. Large 12mo, 150

Elementary Treatise on the Integral Calculus..................... 12mo, 150

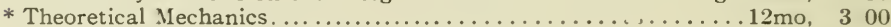

Theory of Errors and the Method of Least Squares...........12mo, 150

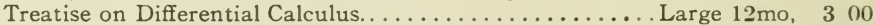

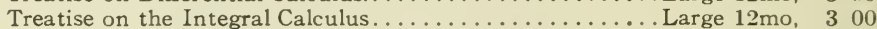

Treatise on Ordinary and Partial Differential Equations... Large 12mo, 350

Karapetoff's Engineering Applications of Higher Mathematics. (In Preparation.)

Laplace's Philosophical Essay on Probabilities. (Truscott and Emory.). 12mo, 200

* Ludlow's Logarithmic and Trigonometric Tables. . . . . . . . . . . 8vo, 100

* Ludlow and Bass's Elements of Trigonometry and Logarithmic and Other

Tables. . . . . . . . . . . . . . . . . . . . . . . . . . . . .

* Trigonometry and Tables published separately. . . . . . . . . . Each,

Macfarlane's Vector Analysis and Quaternions. . . . . . . . . . . . . .8vo,

Mc.Mahon's Hyperbolic Functions. . . . . . . . . . . . . . . . . . . 8vo.

Manning's Irrational Numbers and their Representation by Sequences and Series. . . . . . . . . . . . . . . . . . . . Mathematical Monographs. Edited by Mansfield Merriman and Robert

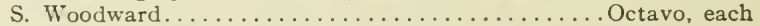

No. 1. History of Modern Mathematics, by David Eugene Smith.

No. 2. Synthetic Projective Geometry, by George Bruce Halsted.

No. 3. Determinants, by Laenas Gifford Weld. No. 4. Hyperbolic Functions, by James McMahon. No. 5. Harmonic Functions, by William E. Byerly. No. 6. Grassmann's Space Analysis, by Edward W. Hyde. No. 7. Probability and Theory of Errors, by Robert S. Woodward. No. 8. Vector Analysis and Quaternions, by Alexander Macfarlane. No. 9. Differential Equations, by William Woolsey Johnson. No. 10. The Solution of Equations, by Mansfield Merriman. No. 11. Functions of a Complex Variable, by Thomas S. Fiske.

Maurer's Technical Mechanics. ........................8vo, 400

Merriman's Method of Least Squares. .....................8vo, 200

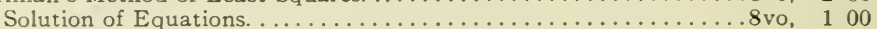

Moritz's Elements of Plane Trigonometry. (In Press.)

Rice and Johnson's Differential and Integral Calculus. 2 vols. in one.

Elementary Treatise on the Differential Calculus. Variable. ............................... 
* Waterbury's Vest Pocket Hand-book of Mathematics for Engineers

$2 \frac{5}{5} \times \frac{3}{3}$ inches, mor. $\$ 100$

* Enlarged Edition, Including Tables ...................mor. 150

Vield's Determinants................................... 100

Wood's Elements of Co-ordinate Geometry. . . . . . . . . . . . 8vo, 290

Woodward's Probability and Theory of Errors................ 8vo, 100

\section{HECHANICAL ENGINEERING.}

\section{MATERIALS OF ENGINEERING. STEAM-ENGINES AND BOILERS.}

Bacon's Forge Practice. ............................. 150

Baldwin's Steam Heating for Buildings...................... 250

Barr's Kinematics of Machinery. ............................. 250

* Bartlett's Mechanical Drawing................................. 300

* " " "Abridged Ed. ............... 8vo, 150

Bartlett and Johnson's Engineering Descriptive Geometry. (In Press.)

* Burr's Ancient and Modern Engineering and the Isthmian Canal. ...8vo, 350

Carpenter's Experimental Engineering. . . .................. 8vo, 600

Heating and Ventilating Buildings.................. 4 vo, 400

* Clerk's The Gas, Petrol and Oil Engine........................ 4 vo, 400

Compton's First Lessons in Metal Working. .................. 12 mo, 50

Compton and De Groodt's Speed Lathe...................... 150

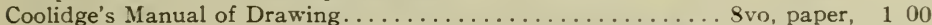

Coolidge and Freeman's Elements of General Drafting for Mechanical Engineers. . . . . . . . .

Cromwell's Treatise on Belts and Pulleys.................

Treatise on Toothed Gearing. . . . . . . . . . . . . . . . . . 12mo,

Dingey's Machinery Pattern Making....................

Durley's Kinematics of Machines..................... . . .

Flanders's Gear-cutting Machinery. .... .................... 12 mo,

Flather's Dynamometers and the Measurement of Power. .........12mo,

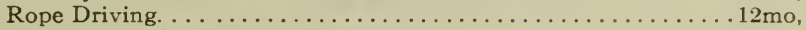

Gill's Gas and Fuel Analysis for Engineers. . . . . . . . . . . .

Goss's Locomotive Sparks. . . . . . . . . . . . . . . . . . . . 8vo,

Greene's Pumping Machinery. (In Preparation.)

Hering's Ready Reference Tables (Conversion Factors). . . . . . . 16mo; mor.

* Hobart and Ellis's High Speed Dynamo Electric Machinery. . . . . . . 8vo,

Hutton's Gas Engine. . . . . . . . . . . . . . . . . . .

Jamison's Advanced Mechanical Drawing. .................. . . . . .

Elements of Mechanical Drawing. . . . . . . . . . . . .

Jones's Gas Engine. ............................ Machine Design:

Part I. Kinematics of Machinery. .................. 8vo, 150

Part II. Form, Strength, and Proportions of Yarts. . . . . . . . 8vo, 300

* Kent's Mechanical Engineer's Pocket-Book...................... mor. 500

Kerr's Power and Power Transmission. . ..................... 200

* Kimball and Barr's Machine Design.................... 8vo, 300

Leonard's Machine Shop Tools and Methods. ................ 8vo, 400

* Levin's Gas Engine................................ 8vo, 400

* Lorenz's Modern Refrigerating Machinery. (Pope, Haven, and Dean)..8vo, 400

MacCord's Kinematics; or, Practical Mechanism............... 8vo, 500

Mechanical Drawing. ............................. 400

Velocity Diagrams............................. 150

MacFarland's Standard Reduction Factors for Gases. ........... 8vo, 150

Mahan's Industrial Drawing. (Thompson.). ............... 3 vo, 350

Mehrtens's Gas Engine Theory and Design........................ 12mo, 250

Oberg's Handbook of Small Tools. .......................... 12mo, 300

* Parshall and Hobart's Electric Machine Design. Small 4to, half leather, 1250

Peele's Compressed Air Plant for Mines. . . . . . . . . . . . . . . 8vo, 300

Poole's Calorific Power of Fuels. . ..................... . vo, 300

* Porter's Engineering Reminiscences, 1855 to $1882 \ldots \ldots \ldots \ldots \ldots$. . . . . 300

Reid's Course in Mechanical Drawing. ..................... 200 Text-book of Mechanical Drawing and Elementary Machine Design.8vo, 300 
Richards's Compressed Air.

$.12 \mathrm{mo}, \$ 150$

Robinson's Principles of Mechanism. . . . . . . . . . . . . . . . .8vo, 300

Schwamb and Merrill's Elements of Mechanism. . . . . . . . . . . . 8vo, 300

Smith (A. W.) and Marx's Machine Design. . . . . . . . . . . . . . 8vo, 300

Smith's (O.) Press-working of Metals.....................8vo, 300

Sorel's Carbureting and Combustion in Alcohol Engines. (Woodward and

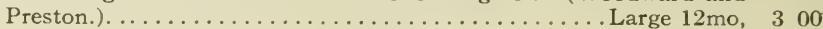

Stone's Practical Testing of Gas and Gas Meters. ...............8vo, 350

Thurston's Animal as a Machine and Prime Motor, and the Laws of Energetics.

$12 \mathrm{mo}, \quad 100$

Treatise on Friction and Lost Work in Machinery and Mill Work. . 8vo, 300

* Tillson's Complete Automobile Instructor. . . . . . . . . . . . . 16mo, 150

* Titsworth's Elements of Mechanical Drawing. . . . . . . . . . Oblong 8vo, 125

Warren's Elements of Machine Construction and Drawing. . . . . . . .8vo, 750

* Waterbury's Vest Pocket Hand-book of Mathematics for Engineers.

$2 \frac{7}{8} \times 5 \frac{3}{8}$ inches, mor. 100

* Enlarged Edition, Including Tables................. mor. 150

Weisbach's Kinematics and the Power of Transmission. (HerrmannKlein. . ..........................

Machinery of Transmission and Governors. (Fermann-Klein.).8vo, 500

Wood's Turbines. .............................8vo, 250

\section{MATERIALS OF ENGINEERING.}

* Bovey's Strength of Materials and Theory of Structures. . . . . . . 8vo, 750

Burr's Elasticity and Resistance of the Materials of Engineering. .....8vo, 750

Church's Mechanics of Engineering. . . . . . . . . . . . . . . 8vo, 600

* Greene's Structural Mechanics. . . . . . . . . . . . . . . . . . . .8vo, 250

* Holley's Lead and Zinc Pigments.................... Large 12 mo 300

Holley and Ladd's Analysis of Mixed Paints, Color Pigments, and Varnishes.

Large $12 \mathrm{mo}$,

Johnson's (C. M.) Rapid Methods for the Chemical Analysis of Special Steels, Steel-Making Alloys and Graphite. . . . . . . . Large 12mo, Johnson's (J. B.) Materials of Construction. . . . . . . . . . . . . . . . . vo, Keep's Cast Iron. . . . . . . . . . . . . . . . . . . . . . . . . . . . . .

Lanza's Applied Mechanics. . . . . . . . . . . . . . . . . . . . . 8vo,

Lowe's Paints for Steel Structures. . . . . . . . . . . . . . . . . . 12mo,

Maire's Modern Pigments and their Vehicles. ............... 12mo,

Maurer's Technical Mechanics. . . . . . . . . . . . . . . . . . 8vo,

Merriman's Mechanics of Materials. . . . . . . . . . . . . . . . 8vo,

* Strength of Materials. . . . . . . . . . . . . . . . . . . 12mo,

Metcalf's Steel. A Manual for Steel-users. . . . . . . . . . . . . . . 12mo,

Sabin's Industrial and Artistic Technology of Paint and Varnish. . . . .8vo,

Smith's ((A. W.) Materials of Machines. . . . . . . . . . . . . . 12mo,

* Smith's (H. E.) Strength of Material... . . . . . . . . . . . . . . . 12mo,

Thurston's Materials of Engineering...............

Part I. Non-metallic Materials of Engineering, . . . . . . . . . . 8 vo,

Part II. Iron and Steel. . . . . . . . . . . . . . . . . . . . . . .

Part III. A Treatise on Brasses, Bronzes, and Other Alloys and their

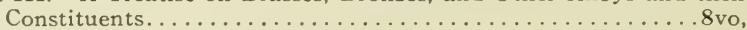

Wood's (De V.) Elements of Analytical Mechanics. . . . . . . . . . . . 8vo,

Treatise on the Resistance of Materials and an Appendix on the Preservation of Timber............................

Wood's (M. P.) Rustless Coatings: Corrosion and Electrolysis of Iron and Steel. . . . . . . . . . . . . . . . . . . . . . . . 8vo,

\section{STEAM-ENGINES AND BOILERS.}

Berry's Temperature-entropy Diagram. . . . . . . . . . . . . . . 12mo, Carnot's Reflections on the Motive Power of Heat. (Thurston.). ...12mo, 
Creighton's Steam-engine and other Heat Motors.............. 8 vo, $\$ 500$

Dawson's "Engineering" and Electric Traction Pocket-book. ...16mo, mor. 500

* Gebhardt's Steam Power Plant Engineering............... 8vo, 600

Goss's Locomotive Performance.......................... 8vo, 500

Hemenway's Indicator Practice and Steam-engine Economy.......12mo, 200

Hutton's Heat and Heat-engines. . . . . . . . . . . . . . . . 8vo, 500

Mechanical Engineering of Power Plants................ 8 vo, 500

Kent's Steam Boiler Economy ........................ 8vo, 400

Kneass's Practice and Theory of the Injector. . . . . . . . . . . . 150

MacCord's Slide-valves. ................................ 200

Meyer's Modern Locomotive Construction. ....................4to, 1000

Moyer's Steam Turbine. ......................... 8vo, 400

Peabody's Manual of the Steam-engine Indicator. ........... 150

Tables of the Properties of Steam and Other Vapors and Temperature-

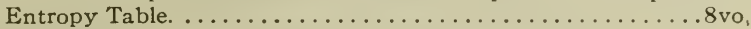

Thermodynamics of the Steam-engine and Other Heat-engines. . . 8vo,

Valve-gears for Steam-engines.................

Peabody and Miller's Steam-boilers ..................

Pupin's Thermodynamics of Reversible Cycles in Gases and Saturated Vapors.

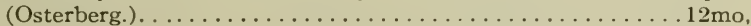

Reagan's Locomotives: Simple, Compound, and Electric. New Edition.

Large $12 \mathrm{mo}$,

Sinclair's Locomotive Engine Running and Management. . . . . . . . . 12mo,

Smart's Handbook of Engineering Laboratory Practice. . . . . . . . . . 12mo,

Snow's Steam-boiler Practice. . . . . . . . . . . . . . . . . . . 8vo,

Spangler's Notes on Thermodynamics. . . . . . . . . . . . . 12mo,

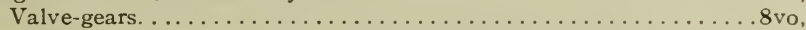

Spangler, Greene, and Marshall's Elements of Steam-engineering. . . . . 8vo,

Thomas's Steam-turbines. . . . . . . . . . . . . . . . . . .

Thurston's Handbook of Engine and Boiler Trials, and the Use of the Indi-

cator and the Prony Brake..........................

Handy Tables. ................................

Manual of Steam-boilers, their Designs, Construction, and Operation 8vo,

Manual of the Steam-engine.................... 8 vols.,

Part I. History, Structure, and Theory ............ 8 vo,

Part II. Design, Construction, and Operation.............

Wehrenfennig's Analysis and Softening of Boiler Feed-water. (Patterson.)

8vo,

Weisbach's Heat, Steam, and Steam-engines. (Du Bois.). . . . . . . 8vo,

Whitham's Steam-engine Design. . . . . . . . . .

Wood's Thermodynamics, Heat Motors, and Refrigerating Machines. . 8vo,

\section{MECHANICS PURE AND APPLIED.}

Church's Mechanics of Engineering. . . . . . . . . . . . . .

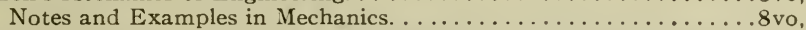

Dana's Text-book of Elementary Mechanics for Colleges and Schools .12mo, Du Bois's Elementary Principles of Mechanics:

Vol. I. Kinematics. .....................

Vol. II. Statics. . . .

Mechanics of Engineering. Vol. I. . . . . .

600

200

150

350

400

750

1000

* Greene's Structural Mechanics. ....................... 250

Hortmann's Elementary Mechanics for Engineering Students. (In Press.)

James's Kinematics of a Point and the Rational Mechanics of a Particle.

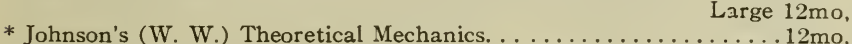

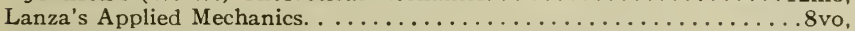

* Martin's Text Book on Mechanics, Vol. I, Statics.............. 12mo,

* Vol. II, Kinematics and Kinetics. $12 \mathrm{mo}$,

Maurer's Technical Mechanics..........................

* Merriman's Elements of Mechanics. . . . . . . . . .

Mechanics of Materials..............................

* Michie's Elements of Analytical Mechanics................ . . .

Robinson's Principles of Mechanism.................... 
Sanborn's Mechanics Problems. Large $12 \mathrm{mo}$, \$1 50

Schwamb and Merrill's Elements of Mechanism. . . . . . . . . . . 8vo, 300

Wood's Elements of Analytical Mechanics. .................. 8 vo, 300

Principles of Elementary Mechanics.................. 125

\section{MEDICAL.}

* Abderhalden's Physiological Chemistry in Thirty Lectures. (Hall and Defren.)............................... von Behring's Suppression of Tuberculosis. (Bolduan.). . . . . . . . 12mo, Bolduan's Immune Sera. . . . . . . . . . . . . . . . . . . . 12mo, Bordet's Studies in Immunity. (Gay.) ..................... Chapin's The Sources and Modes of Infection. (In Press.)

Davenport's Statistical Methods with Special Reference to Biological Varia-

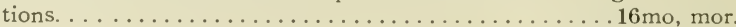

Ehrlich's Collected Studies on Immunity. (Bolduan.). . . . . . . . . 8vo, Fischer's Oedema. (In Press.)

* Physiology of Alimentation............................. 12mo, de Fursac's Manual of Psychiatry. (Rosanoff and Collins.)... Large 12mo, Hammarsten's Text-book on Physiological Chemistry. (Mandel.). . . .8vo, Jackson's Directions for Laboratory Work in Physiological Chemistry. . 8vo, Lassar-Cohn's Praxis of Urinary Analysis. (Lorenz.)............ . . Mandel's Hand-book for the Bio-Chemical Laboratory........... $12 \mathrm{mo}$.

* Nelson's Analysis of Drugs and Medicines................. . .

* Pauli's Physical Chemistry in the Service of Medicine. (Fischer.)..12mo,

* Pozzi-Escot's Toxins and Venoms and their Antibodies. (Cohn.). . 12mo, Rostoski's Serum Diagnosis. (Bolduan.). ................. 12mo, Ruddiman's Incompatibilities in Prescriptions..............

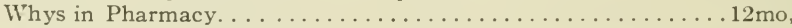
Salkow'ski's Physiological and Pathological Chemistry. (Orndorff.) ....8vo, * Satterlee's Outlines of Human Embryology. . . . . . . . . . . . . 12mo, Smith's Lecture Notes on Chemistry for Dental Students. . . . . . . . . 8vo, * Whipple's Tyhpoid Fever. ............................ 12mo,

* Woodhull's Military Hygiene for Officers of the Line . . . . . . Large 12mo,

* Personal Hygiene. . . . . . . . . . . . . . . . . . 12mo,

Worcester and Atkinson's Small Hospitals Establishment and Maintenance, and Suggestions for Hospital Architecture, with Plans for a Small

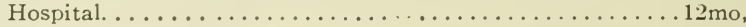

\section{METALLURGY.}

Betts's Lead Refining by Electrolysis. ................... 8 vo, Bolland's Encyclopedia of Founding and Dictionary of Foundry Terms used in the Practice of Moulding. . . . . .

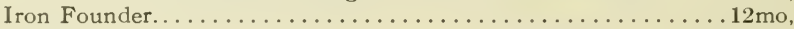
Supplement. .....................

Douglas's Untechnical Addresses on Technical Subjects. . . .........12mo, Goesel's Minerals and Metals: A Reference Book............16mo, mor.

* Iles's Lead-smelting. . . . . . . . . . . . . . . . . . . . 12mo, Johnson's Rapid Methods for the Chemical Analysis of Special Steels, Steel-making Alloys and Graphite. ................... 12mo,

Keep's Cast Iron. . . . . . . . . . . Le Chatelier's High-temperature Neasurements. (Boudouard-Burgess.)

Metcalf's Steel. A Manual for Steel-users................... 12mo, Minet's Production of Aluminum and its Industrial Use. (Waldo.). 12mo, * Ruer's Elements of Metallography. (Mathewson.)............. 8 vo, Smith's Materials of Machines. ......................... Tate and Stone's Foundry Practice................... Thurston's Materials of Engineering. In Three Parts. . . . . . . . . 8vo, Part I. Non-metallic Materials of Engineering, see Civil Engineering, page 9 .

Part II. Iron and Steel. . ......................

Part III. A Treatise on Brasses, Bronzes, and Other Alloys and their

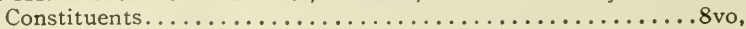


Uike's Modern Electrolytic Copper Refining. . . . . . . . . . . . . . . . \$ro, \$3 0:)

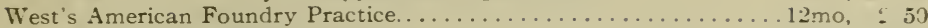

Moulders' Text Book. . . . . . . . . . . . . . . . . . . . 12nı. 250

\section{MINERALOGY.}

Baskerville's Chemical Elements. (In Preparation.)

* Browning's Introduction to the Rarer Elements. . . . . . . . . . Svo, 150

Brush's Manual of Determinative Mineralogy. (Penfield.)......... svo, 400

Butler's Pocket Hand-book of Minerals. . . . . . . . . . . . 16. no, mor. 300

Chester's Catalogue of Minerals....................... paper, 100

Cloth, 125

* Crane's Gold and Silver. .......................... 5 ro, 00

Dana's First Appendix to Dana's New "System of Mineralogy". Large Svo, 100

Dana's Second Appendix to Dana's New "System of Mineralogy."

Large Svo, 150

Manual of Mineralogy and Petrography..................... 200

Minerals and How to Study Them. . . . . . . . . . . . . . . $12 \mathrm{mo}, 150$

System of Mineralogy..................... 8 vo, half leather, 1250

Text-book of Mineralogy. ....................... 4 vo, 00

Douglas's Untechnical Addresses on Technical Subjects. . ........12mo, 100

Eakle's Mineral Tables............................... 125

Eckel's Stone and Clay Products Used in Engineering. (In Preparation.)

Goesel's Minerals and Metals: A Reference Book.............. 16mo, mor.

Groth's The Optical Properties of Crystals. (Jackson.) (in Press.)

Groth's Introduction to Chemical Crystallography (Marshall).......12mo, 125

* Hayes's Handbook for Field Geologists................. 16mo, mor. 150

Iddings's Igneous Rocks. . . . . . . . . . . . . . . . . . . $5 \ldots$

Rock Minerals. . . . . . . . . . . . . . . . $5 \ldots \ldots \ldots \ldots$ vo, 50

Johannsen's Determination of Rock-forming Minerals in Thin Sections. 8vo,

With Thumb Index

* Martin's Laboratory Guide to Qualitative Analysis with the Blow-

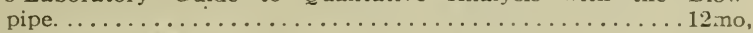

Merrill's Non-metallic Minerals: Their Occurrence and Uses. ........ . . . . .

Stones for Building and Decoration. ..................

* Penfield's Notes on Determinative Mineraiogy and Record of Mineral Tests.

8 vo, paper,

Tables of Minerals, Including the Use of Minerals and Statistics of

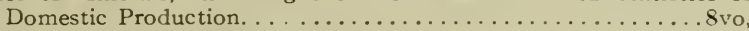

* Pirsson's Rocks and Rock Minerals..................... 12mo,

* Richards's Synopsis of Mineral Characters. . . . . . . . . . $12 \mathrm{mo}$, mor.

* Ries's Clays: Their Occurrence, Properties and Uses.............. . . . . .

* Ries and Leighton's History of the Clay-working Industry of the United

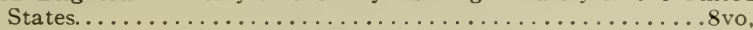

* Tillman's Text-book of Important Minerals and Rocks. . . . . . . . . . . . . vo,

Washington's Manual of the Chemical Analysis of Rocks. . . . . . . . . . 8vo,

\section{MINING.}

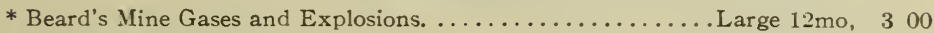

* Crane's Gold and Silver. ................................. 500

* Index of Mining Engineering Literature................... 400

*8vo, mor. 500

* Ore Mining Methods............................ 300

Douglas's Untechnical Addresses on Technical Subjects................... 100

Eissler's Modern High Explosives........................... 400

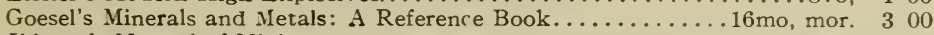

Ihlseng's Manual of Mining. ........................ j 00

* Iles's Lead Smelting. ........................................ 200

Peele's Compressed Air Plant for Mines............................. 300

Riemer's Shaft Sinking Under Difficult Conditions. (Corning and Peele.)8vo, 300

* Weaver's Military Explosivé ......................... 300

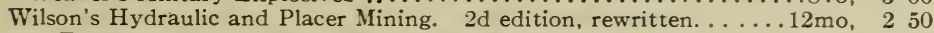

Treatise on Practical and Theoretical Mine Ventilation......... $12 \mathrm{mo}, 125$ 
Association of State and National Food and Dairy Departments, Hartford Meeting, 1906................................. \$3 00

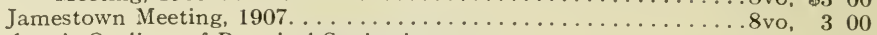

* Bashore's Outlines of Practical Sanitation. .................. 12 mo, 125

Sanitation of a Country House. ..................... 100

Sanitation of Recreation Camps and Parks.................. 100

Chapin's The Sources and Modes of Infection. (In Press.)
Folwell's Sewerage. (Designing, Construction, and Maintenance.). . . 8vo, 300

Water-supply Engineering. . ......................... 400

Fowler's Sewage Works Analyses. . . . . . . . . . . . . . . .

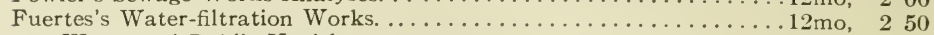

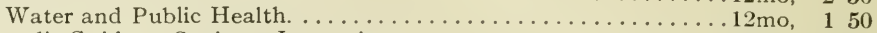

Gerhard's Guide to Sanitary Inspections.................. 150

* Modern Baths and Bath Houses........................ 300

Sanitation of Public Buildings. ............................. 150

* The Water Supply, Sewerage, and Plumbing of Modern City Buildings.

Hazen's Clean Water and How to Get It. . . . . . . . . . Large 12.no, 150

Filtration of Public Water-supplies. .................. 8 vo, 300

Kinnicut, Winslow and Pratt's Sewage Disposal. (In Press.)

Leach's Inspection and Analysis of Food with Special Reference to State

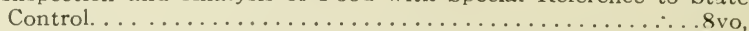

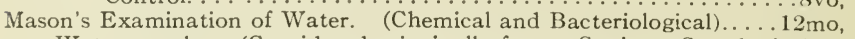

Water-supply. (Considered principally from a Sanitary Standpoint).

Mast's Light and the Behavior of Organisms. (In Press.)

* Merriman's Elements of Sanitary Engineering. . . . . . . . . . . 00

Ogden's Sewer Construction ................................ 300

Sewer Design...................................... 200

Parsons's Disposal of Municipal Refuse............................... 200

Prescott and Winslow's Elements of Water Bacteriology, with Special Refer-

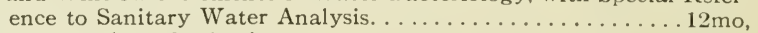

* Price's Handbook on Sanitation. . . . . . . . . . . . . . . . 12mo,

Richards's Cost of Cleanness. . . . . . . . . . . . . . . . .

Cost of Food. A Study in Dietaries. . . . . . . . . .

Cost of Living as Modified by Sanitary Science. . . . . . . . . . 12mo,

Cost of Shelter. . . . . . . . . . . . . . . .

* Richards and Williams's Dietary Computer. . . . . . . . . . . . . . .

Richards and Woodman's Air, Water, and Food from a Sanitary Standpoint. . . . . . . . . . . . . . .

* Richey's Plumbers', Steam-fitters', and Tinners' Edition (Building Mechanics' Ready Reference Series)............. 16mo, mor.

Rideal's Disinfection and the Preservation of Food. . . . . . . . . . . .

Sewage and Bacterial Purification of Sewage..............

Soper's Air and Ventilation of Subways. ..................

Turneaure and Russell's Public Water-supplies. . . . . . . . . . . 8vo,

Venable's Garbage Crematories in America. . . . . . . . . . . . . . . . 8vo,

Method and Devices for Bacterial Treatment of Sewage. . . . . . . . 8vo,

Ward and Whipple's Freshwater Biology. (In Press.)

Whipple's Microscopy of Drinking-water. . . . . . . . . . . . 350

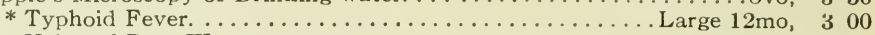

Value of Pure Water. ................................. 12mo, 100

Winslow's Svstematic Relationship of the Coccacex................ $12 \mathrm{mo}, 250$

\section{MISCELLANEOUS.}

Emmons's Geological Guide-book of the Rocky Mountain Excursion of the

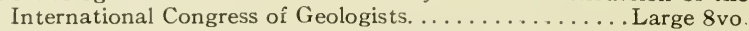

Ferrel's Pooular Treatise on the Winds.................

Fitzgerald's Boston Machinist. . . . . . . . . .

Gannett's Statistical Abstract of the World. . . . . . . . . . . .

Haines's American Railway Management. . . . . . . . . . . . . 12mo,

Hanausek's The Microscopy of Technical Products. (Winton) .......8vo, 
Jacobs's Betterment Briefs. A Collection of Published Papers on Organized Industrial Efficier.cy...................... \$ $\$ 30$

Metcalfe's Cost of Manufactures, and the Administration of Workshops..8vo. 500

Putnam's Nautical Charts. .............................. 200

Ricketts's History of Rensselaer Polytechnic Institute 1824-1894.

Large $12 \mathrm{mo}, 300$

Rotherham's Emphasised New Testament. . . .............. Large 8vo, 200

Rust's Ex-Meridian Altitude, Azimuth and Star-finding Tables. ....8vo 500

Standage's Decoration of Wood, Glass, Metal, etc................ . 200

Thome's Structural and Physiological Botany, (Bennett)........16mo, 225

Westermaier's Compendium of General Botany. (Schneider). . . . . . 8vo, 200

Winslow's Elements of Applied Microscopy.................. 150

\section{HEBREW AND CHALDEE TEXT-BOOOKS.}

Gesenius's Hebrew and Chaldee Lexicon to the Old Testament Scriptures.

(Tregelles.)....................... Small 4to, half mor, 500

Green's Elementary Hebrew Grammar............................. 125 






\section{DATE DUE}

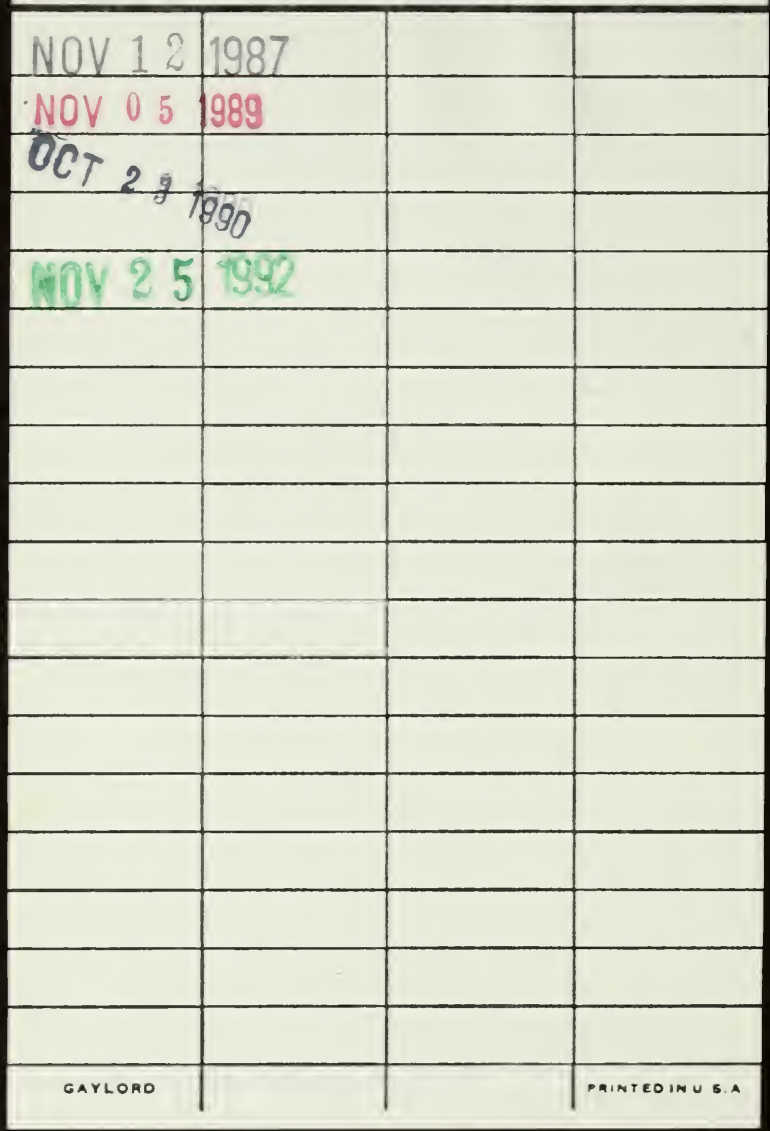



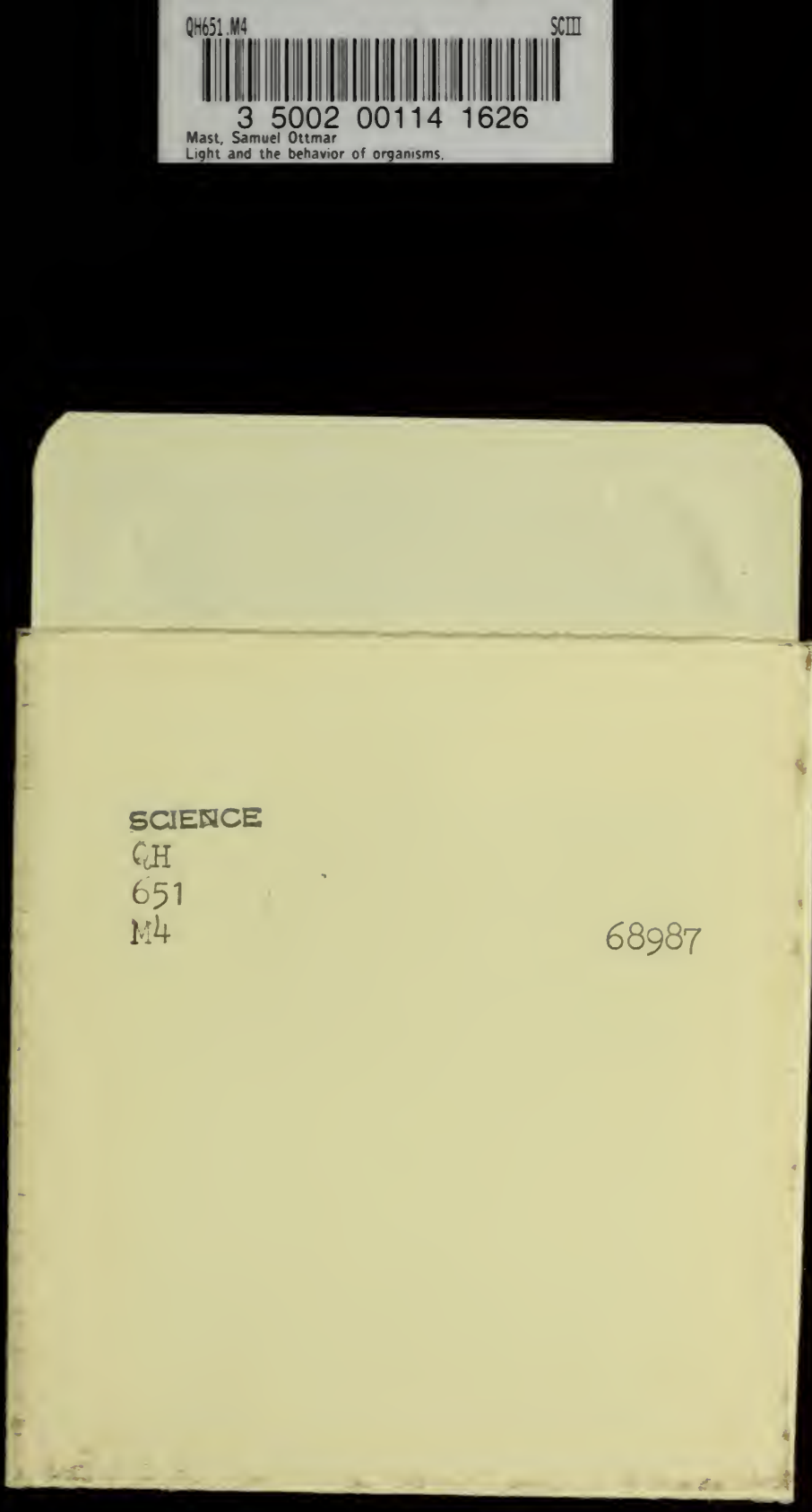
